\title{
OPTIMIZACIÓN DEL CONFORT TÉRMICO EN CLIMA ECUATORIAL CON TECNOLOGÍAS PASIVAS EN FACHADAS. EL CASO DE LAS VIVIENDAS DE INTERÉS SOCIAL DE CALI
}

Tesis doctoral presentada por WALTER GIRALDO CASTAÑEDA

ante la

Facultad de Arquitectura y Urbanismo de la Universidad Nacional de La Plata para acceder al grado académico de DOCTOR EN ARQUITECTURA Y URBANISMO

Dirección de tesis:

Director: Arq. Analía Fernanda Gómez

Codirector: Dr. Ing. Arq. Jorge Daniel Czajkowski

La Plata, Argentina 12 de julio de 2018 
No conozco el futuro, pero creo que en la actualidad tenemos diversos materiales y técnicas que no están siendo utilizadas. Quizás mañana aparezcan nuevos materiales, pero con lo que tenemos ahora podemos construir mejores casas y ciudades. Entonces, el problema no es descubrir la rueda, sino ocuparla correctamente. (Givoni, 2002). 


\section{AGRADECIMIENTOS}

Agradezco primero a Dios, por quien se fraguó este logro y por quien en este proceso nunca faltó nada, por el contrario, sobró ánimo y gusto. La gratitud es ese sentimiento que aflora por quien te ha tendido la mano y quieres corresponderle de alguna forma, aunque no tengas como. Así que yo aprovecho este pequeño apartado, no como mera formalidad sino para ofrecer un sincero "Dios le pague" al mejor estilo colombiano a todos quienes han abierto la mano para que esta investigación se materializara.

A mis directores Analía Fernanda Gómez y Jorge Daniel Czajkowski por la paciencia y confianza puesta en mí, por los aportes y observaciones a mi trabajo, por abrir las puertas de su laboratorio LAyHS en estos dos años y propiciar un ambiente científico, pero a la vez familiar.

A la Universidad del Valle, ya que por medio del programa "semilleros docentes" tuve acceso a esta comisión de estudios que me brindó auxilio económico, tiempo y una estabilidad laboral para poderme concentrar. A la Universidad Nacional de la Plata, sus directivas, funcionarios y profesores de quienes recibí siempre un buen trato y una excelente formación académica.

A mis colegas de laboratorio David Basualdo, Gabriela Reus, Roberto Berardi, Patricia Camporeale y María de la Paz Diulio que me acogieron como amigo haciendo que el día a día fuera más llevadero. A Paz un agradecimiento inmenso por haberse echado al hombro el papel de anfitriona que terminó en una especie de madrinazgo.

A toda mi familia que me contuvo de muchas maneras y fue partícipe de este enorme esfuerzo, especialmente a mi hermano Armando y su esposa Zoraida. Finalmente, a mi esposa Viviana Cáceres por su valentía, sacrificio y el más amoroso apoyo. 


\section{RESUMEN}

Las viviendas de interés social (VIS) que se han venido construyendo en Cali desde 1990 a la actualidad, presentan un deficiente nivel de confort térmico debido a características como el sistema constructivo, la materialidad y las pequeñas dimensiones espaciales. Problemas como ventilación deficiente y altas temperaturas superficiales en las fachadas de este tipo de edificaciones han sido identificados aquí y en trabajos anteriores.

La insatisfacción térmica incentiva el uso de climatización mecánica, la cual consume energía eléctrica y empeora el calentamiento global y la situación económica de los usuarios VIS.

La temperatura superficial o temperatura radiante $\left(T_{r}\right)$ de las envolventes es el factor más influyente en el confort térmico, este puede reducirse mediante tecnologías de enfriamiento pasivo como: aislamientos térmicos, protección solar, baja absortividad, muros vegetales y muros ventilados. Sin embargo, son poco utilizados en las VIS, bien sea por falta de recursos o por falta de estudios que demuestren su efectividad y factibilidad bajo el clima ecuatorial cálido-húmedo como el de Cali. En el estado del arte son pocos los trabajos que reportan el confort térmico logrado por estas tecnologías cuando son implementadas individual o conjuntamente en fachadas, sobre todo para tecnologías como el aislamiento reflectivo y la baja absortividad.

Debido a los ajustados presupuestos de obra de las VIS, y los bajos recursos de sus propietarios, este estudio propone algunas soluciones constructivas de bajo costo que combinan las estrategias pasivas mencionadas anteriormente.

Se planteó como hipótesis que es posible optimizar el confort térmico de un ambiente VIS en Cali mediante la implementación de estrategias pasivas, las cuales pueden reducir la $T_{r}$ de las envolventes en más de un $60 \%$. Y en mismo porcentaje la cantidad de personas insatisfechas. Adicionalmente, el costo inicial de implementar estas soluciones no es más costoso que la instalación de un equipo de aire acondicionado. 
El objetivo principal fue evaluar la reducción de la $T_{r}$ en las envolventes verticales opacas y la optimización del confort térmico que pueden alcanzar en las VIS de Cali algunas soluciones constructivas, inspiradas en las estrategias de enfriamiento pasivo.

La metodología fue experimental y tuvo cinco etapas: la primera evaluó la $T_{r}$ de la envolvente y el confort térmico de un ambiente VIS. Aquí se encontraron $T_{r}$ de hasta $47,27^{\circ} \mathrm{C}$ y alta insatisfacción térmica. También se plantearon y analizaron soluciones constructivas de mejora, las cuales fueron evaluadas en las siguientes etapas.

En la segunda etapa, se experimentó para conocer la capacidad de reducción de $T_{r}$ de cada alternativa en un laboratorio a cielo abierto bajo radiación solar; mientras que, en la tercera se determinó la transmitancia térmica.

En la cuarta etapa se realizó una simulación computacional que evaluó el nivel de optimización de confort térmico logrado por la solución con mejor desempeño en las pruebas anteriores usando el índice de Fanger. Por último, en la quinta etapa se evaluó la relación costobeneficio.

La metodología permitió cumplir el objetivo principal y confirmar la hipótesis con dos de las soluciones. Además, esta constituye una herramienta para la toma de decisiones arquitectónicas, pues es un modelo para diseñar, evaluar y comparar el desempeño de tratamientos térmicos para fachadas, su impacto en la optimización del confort y su relación costo beneficio antes de abordar la etapa constructiva.

Los resultados demostraron que dos de las combinaciones disminuyeron cerca del $74 \%$ la $T_{r}$ de las envolventes y el $60 \%$ de insatisfechos de una habitación VIS en el momento más inconfortable. Su implementación resultó más económica que la instalación de un aire acondicionado, el cual ha sido la solución típica a este problema.

Se recomiendan próximas investigaciones que apliquen esta metodología en otro tipo de edificios y evalúen el ciclo de vida de estas soluciones y su porcentaje de ahorro energético.

Palabras clave: Confort térmico, Vivienda Social, Arquitectura Bioclimática, climatización pasiva. 


\section{ABSTRACT}

Since 1990 to present, social housing (SH) in Cali have frequently shown low thermal comfort level due to certain characteristics as building system and materials and limited space dimensions. Issues like deficient natural ventilation y high surface temperatures in façades have been identified in this work as well as in previous research.

Thermal discomfort encourages air conditioning, which consumes electricity, increasing global warming and expenses.

Envelope surface temperature or radiant temperature $\left(T_{r}\right)$ is the most determining factor to achieve thermal comfort. Passive cooling strategies like thermal insulation, solar protection, low absorptance materials, green and ventilated walls can reduce radiant temperature. However, they are seldom employed in SH maybe because of low financial resources or lack of scientific evidence to demonstrate its effectiveness and feasibility in equatorial warm humid climate like Cali. Concerning to the state of the art, there are few research that study thermal comfort achievement through one or more strategies applied to façades, mainly reflective insulation and low absorptance.

Due to SH budget constraints and owner's low income, this work proposes some low-cost solutions that combine the strategies mentioned above.

The hypothesis poses that it is possible to optimize thermal comfort applying passive strategies, which can reduce more than $60 \%$ of building envelope $T_{r}$ in a SH typical room in Cali. The percentage of unsatisfied people is reduced in the same amount. Besides, these passive solutions are as expensive as an air-conditioned equipment.

As a result, the main objective of this thesis is the $T_{r}$ reduction assessment on vertical opaque building envelope elements through thermal comfort optimization by means of passive cooling strategies applied to SH blocks. 
To achieve this objective, it was deployed an experimental methodology divided into five stages: In the first stage, the $T_{r}$ of the envelope and thermal comfort of a typical SH room is evaluated. Here, $T_{r}$ of $47,27^{\circ} \mathrm{C}$ and high thermal dissatisfaction were found. Different construction solutions were proposed to improve these issues, which were evaluated in the next stages.

During the second stage, an experiment was done to know the $T_{r}$ reduction percentages in an open-air laboratory under solar radiation, while in the third U-values were measured.

In the fourth stage, a computational simulation evaluated the level of thermal comfort optimization achieved by the solutions in a typical room utilizing, Fanger's index. The fifth and last stage was assessed the cost-benefit ratio.

This methodology accomplished the main objective after testing two of the proposed solutions that confirmed the hypothesis. It also constitutes a decision-making tool because it is a model to design, assess and compare the performance of façade thermal treatments, its impact on comfort optimization and the cost-benefit issue before beginning the construction stage.

The results demonstrate that two of the proposed combined solutions can reduce approximately $74 \%$ of the envelope $T_{r}$ and $60 \%$ of the PPD for a typical $\mathrm{SH}$ room at the most uncomfortable time. Its implementation turned out to be less expensive than air-conditioned equipment installation, which have been the typical adopted solution for this issue.

Future research could add the life cycle assessment and energy savings of the successful solutions. It is also desirable that new studies develop the application of this model to other building typologies.

Keywords: thermal comfort, social housing, bioclimatic architecture, passive cooling. 


\section{CONTENIDO}

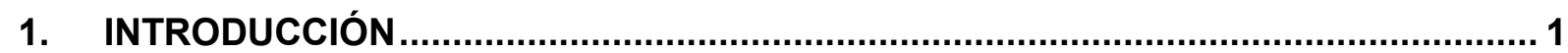

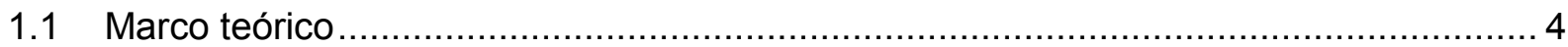

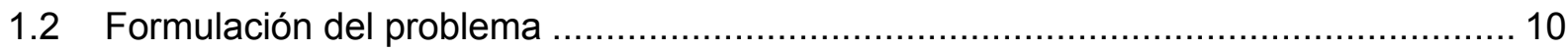

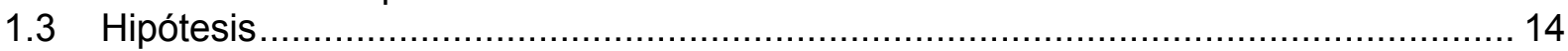

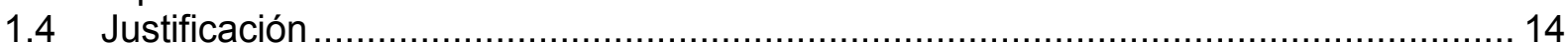

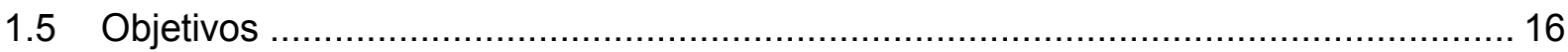

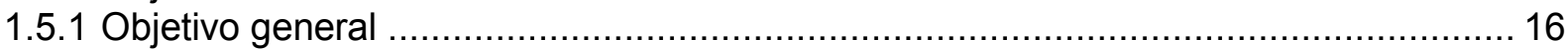

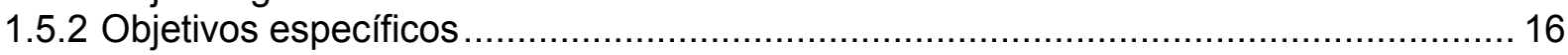

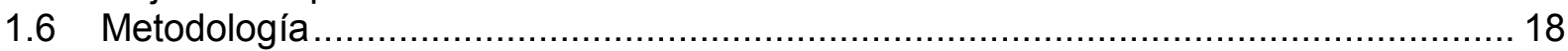

\section{SECCIÓN 1}

2. LA VIVIENDA DE INTERÉS SOCIAL EN CALI Y COLOMBIA ................................ 26

2.1 Concepto de la Vivienda de Interés Social en la historia.......................................... 26

2.2 Definición de Vivienda de Interés Social en Colombia ........................................... 27

2.3 Evolución de las políticas estatales frente a la VIS colombiana ................................ 28

2.4 Impacto de la VIS en el territorio nacional y de Cali ............................................... 34

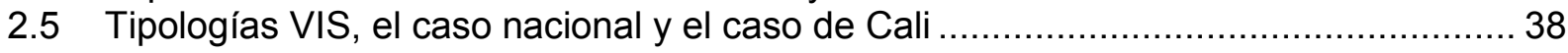

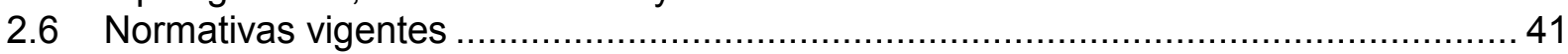

2.6.1 Norma NSR-10, Norma Sismorresistente ..................................................... 42

2.6.2 Reglamento Técnico para el Sector de Agua Potable y Saneamiento Básico .............. 43

2.6.3 RETIE, Reglamento Técnico de Instalaciones Eléctricas....................................... 43

2.6.4 RETILAP, Reglamento Técnico de Instalaciones Eléctricas ................................ 43

2.6.5 Normas Urbanísticas de cada municipio ......................................................... 44

2.6.6 Guías de asistencia técnica para vivienda de interés social: Valor, área, altura y frente de vivienda mínimos, área y lados mínimos de los espacios ......................................... 45

2.6.7 Reglamento técnico de construcción sostenible, Resolución 0549 de $2015 \ldots \ldots \ldots \ldots \ldots . . . .46$

2.7 Sistemas constructivos característicos de las VIS en Colombia................................ 48

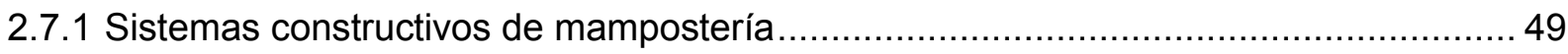

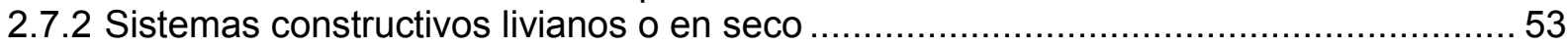

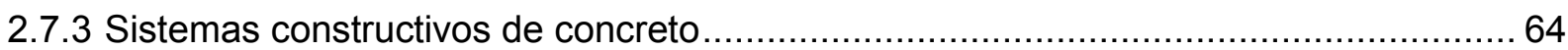

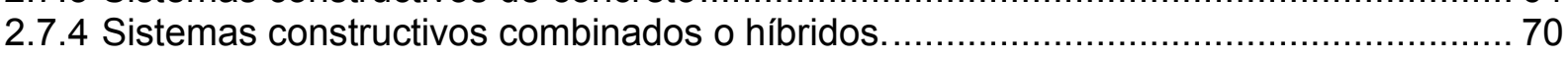

2.8 El confort térmico en la VIS bajo climas cálidos en Colombia. ................................ 72

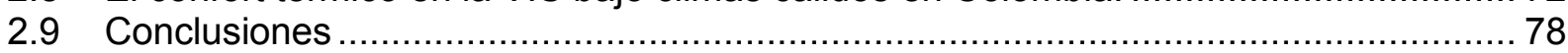

3. ESTRATEGIAS DE ENFRIAMIENTO PASIVO EN ENVOLVENTES .........................80

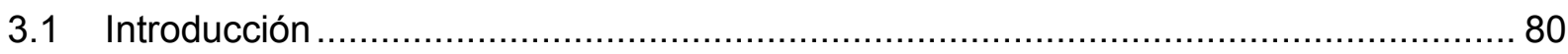




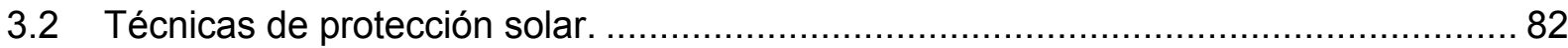

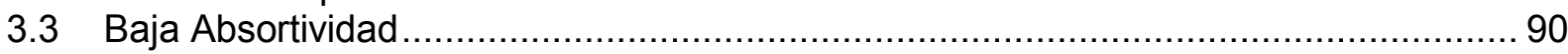

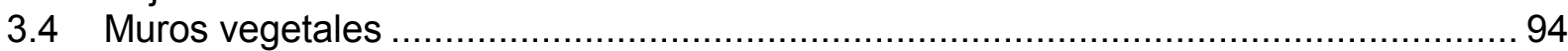

3.5 Aislamiento con materiales de alta resistencia térmica ....................................... 97

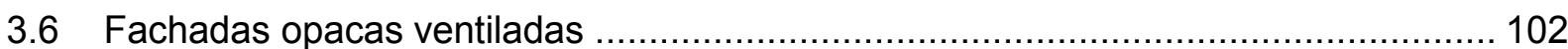

3.7 Aislamiento reflectivo o barreras radiantes ......................................................... 104

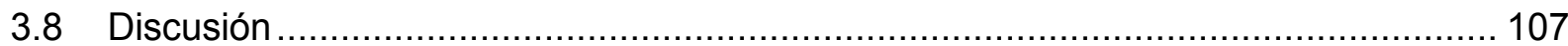

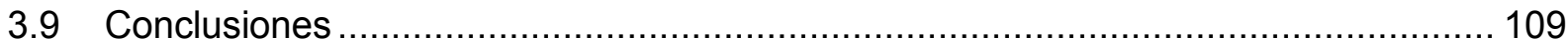

\section{SECCIÓN 2}

4. EVALUACIÓN DE CONFORT TÉRMICO A UN MODELO VIS DE CALI...................111

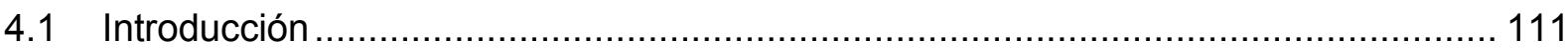

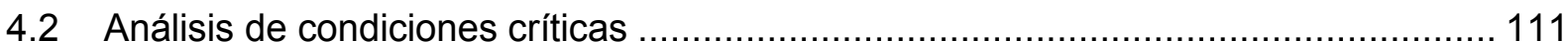

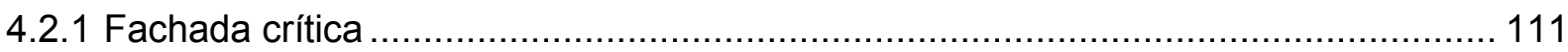

4.2.2 Condiciones climáticas críticas ( $T_{\text {air }}$ y radiación solar máximos) ............................... 112

4.2.3 Análisis de propiedades térmicas de los modelos VIS ....................................... 114

4.2.4 Cuantificación teórica de la $T_{r}$ en envolventes típicas de la VIS en el caso crítico .... 115

4.3 Definición de modelo VIS con rasgos críticos ....................................................... 118

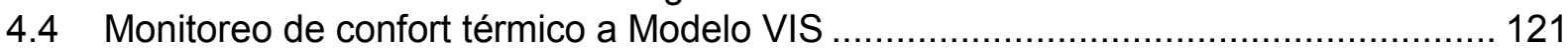

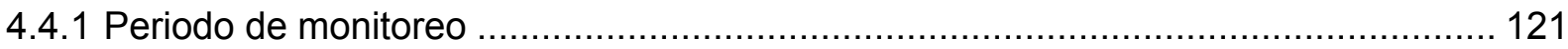

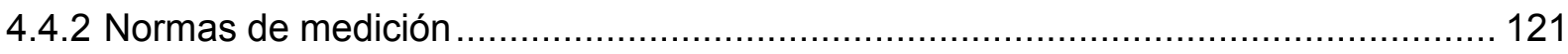

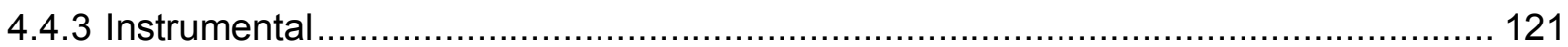

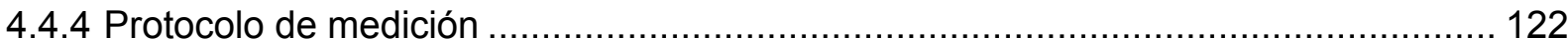

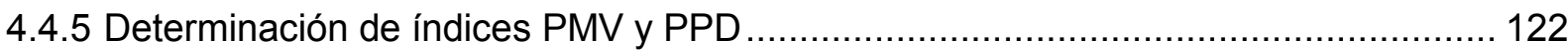

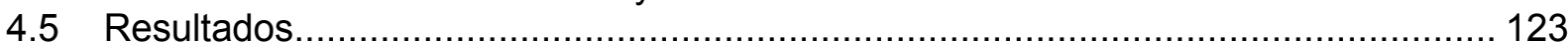

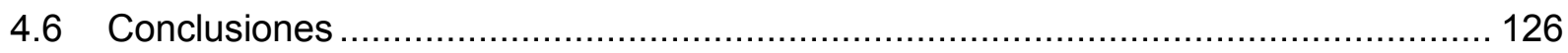

5. MODELIZADO DE SOLUCIONES CONSTRUCTIVAS …........................................ 127

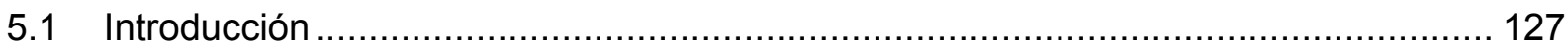

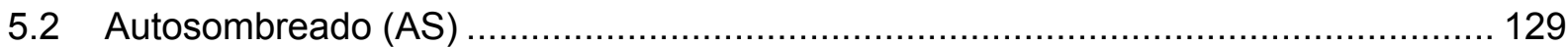

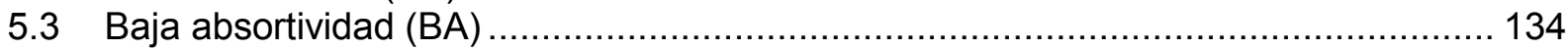

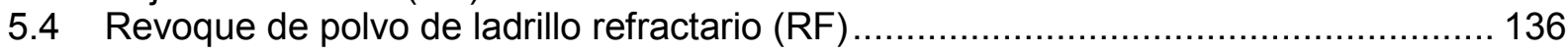

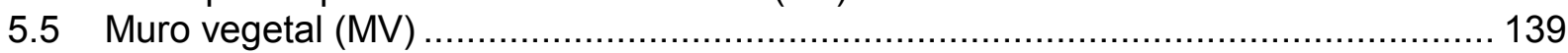

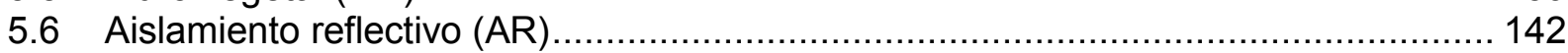

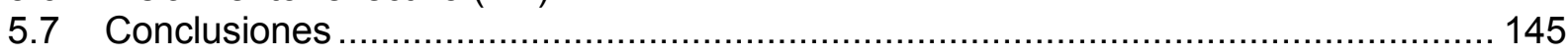

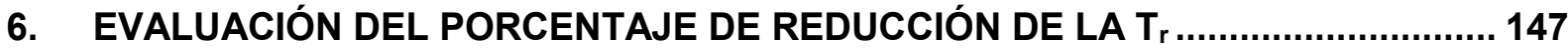

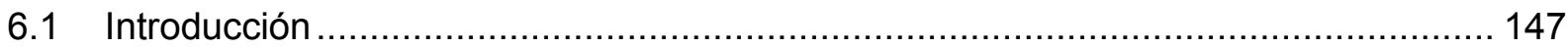

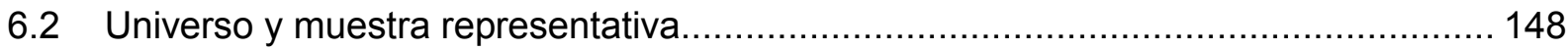

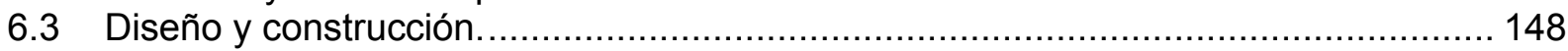

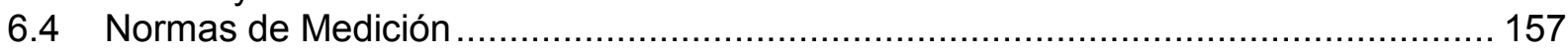

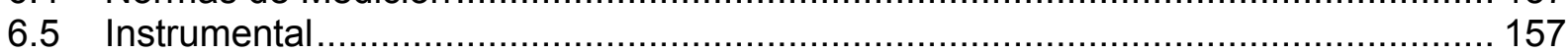

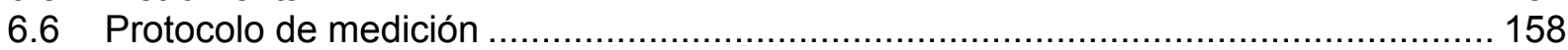

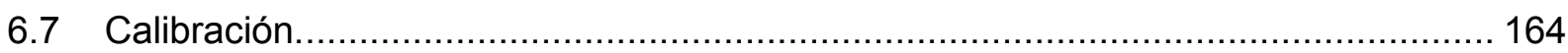

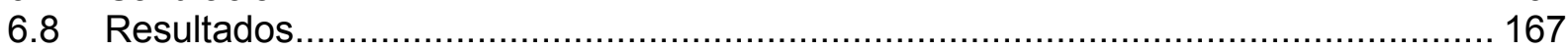

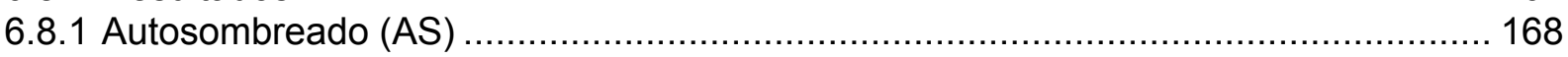

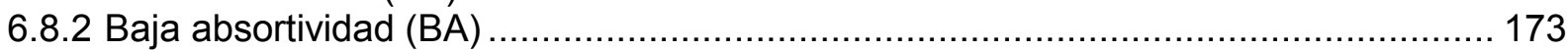

6.8.3 Revoque de polvo de ladrillo refractario (RF) ............................................... 179

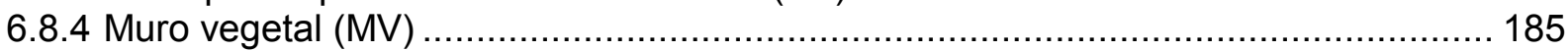

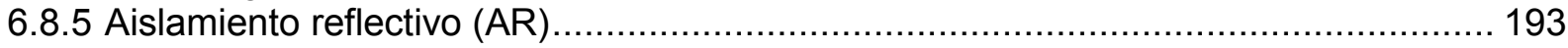

6.9 Discusión sobre diferencias entre los cálculos teóricos en régimen estacionario vs datos

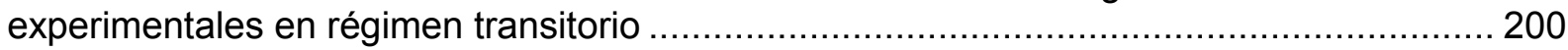


6.10 Discusión del porcentaje de reducción de la $T_{r}$ y los controles a la $T_{\text {air }}$ y la HR ......... 201

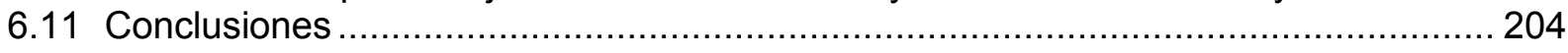

7. DETERMINACIÓN DE LA TRANSMITANCIA TÉRMICA (U) .............................. 205

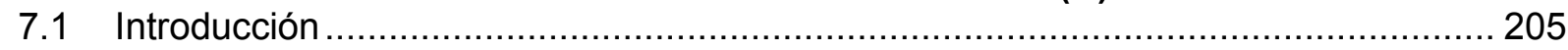

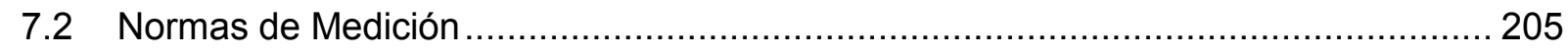

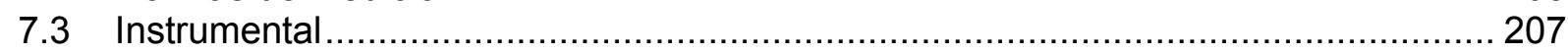

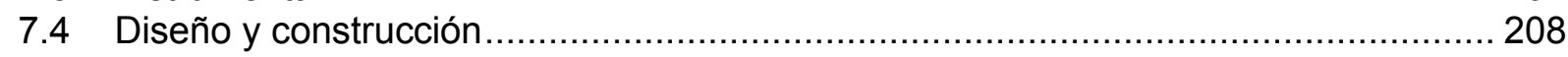

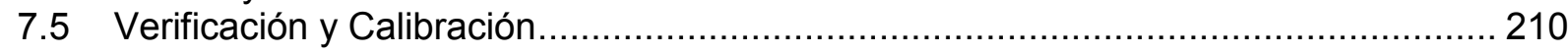

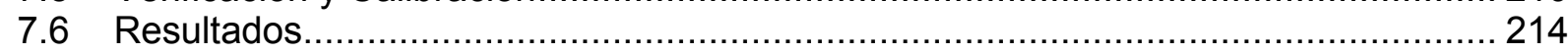

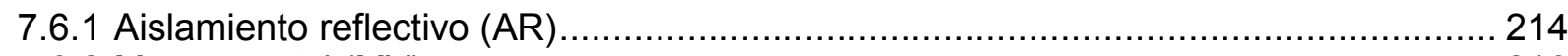

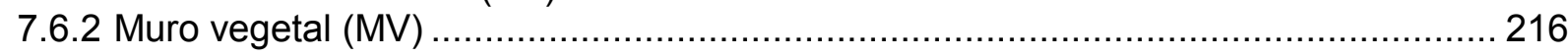

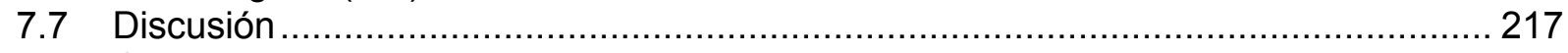

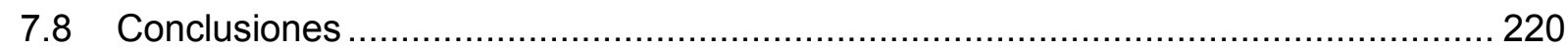

8. EVALUACIÓN DE CONFORT TÉRMICO DEL MODELO VIS MEJORADO ............. 221

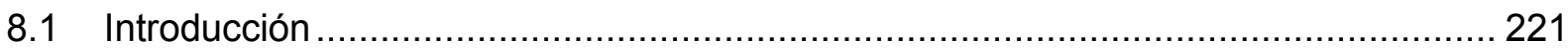

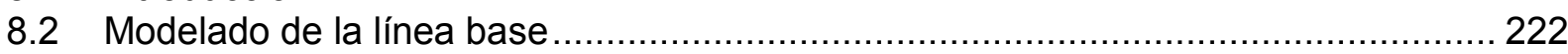

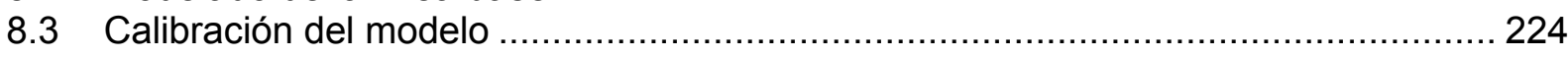

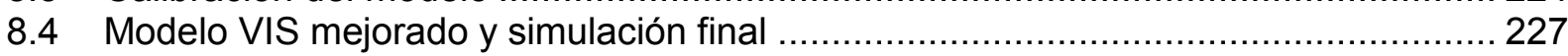

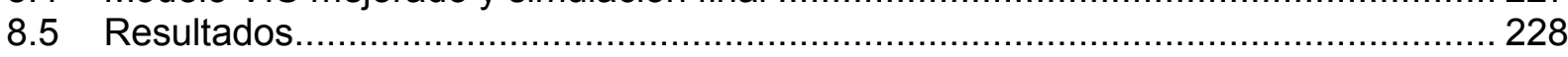

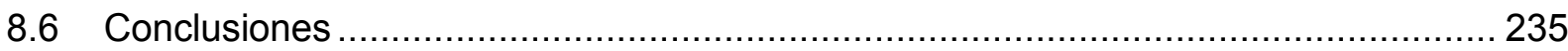

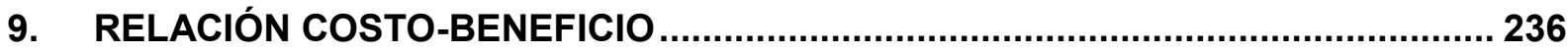

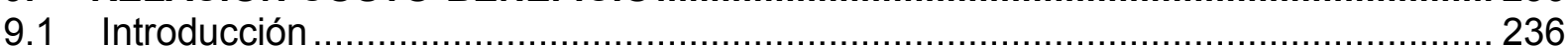

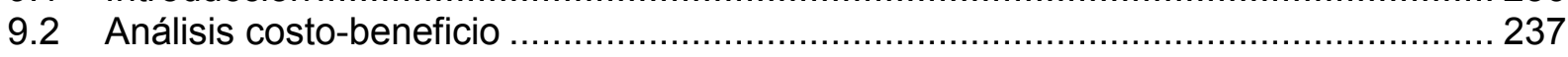

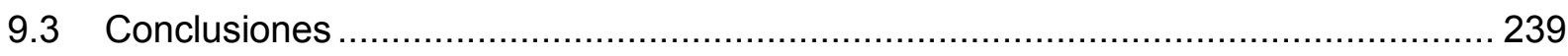

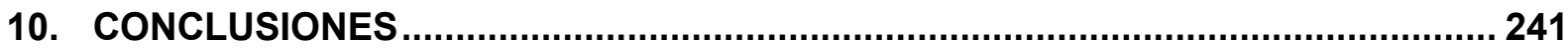

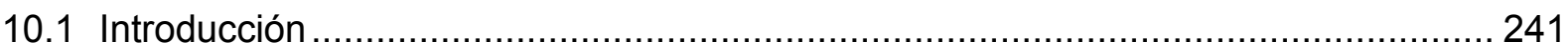

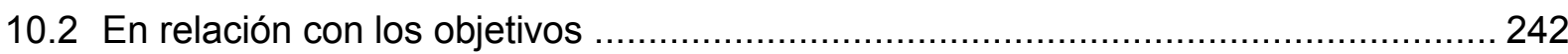

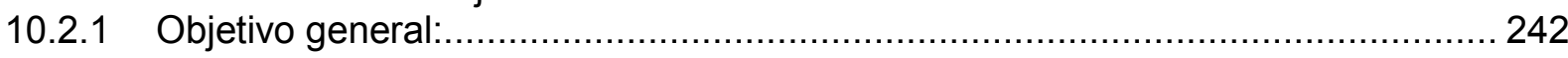

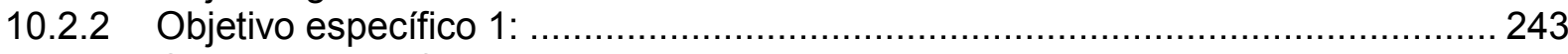

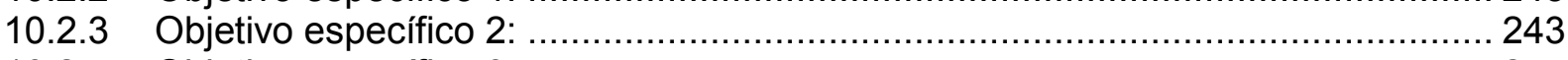

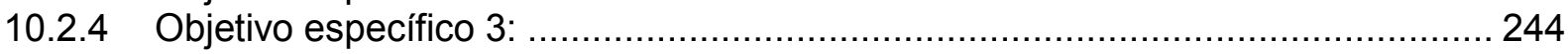

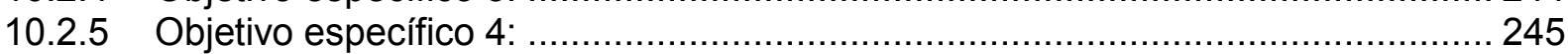

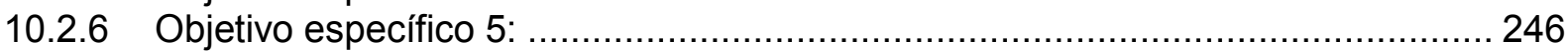

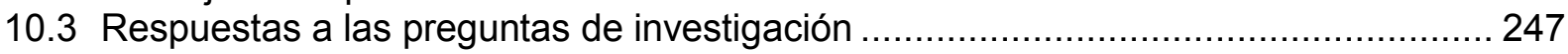

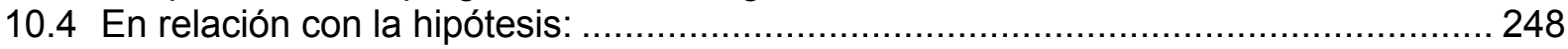

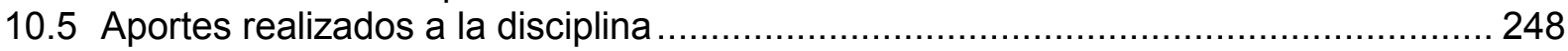

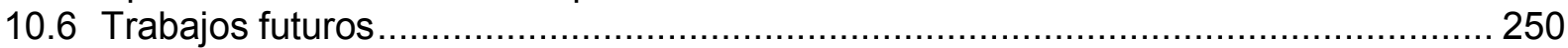

\section{APÉNDICES}

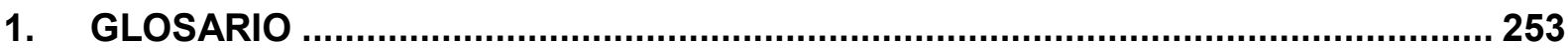

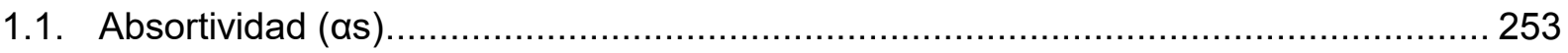

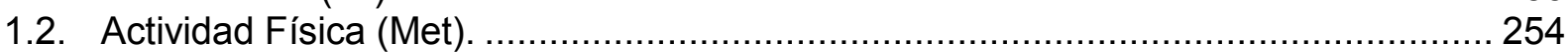

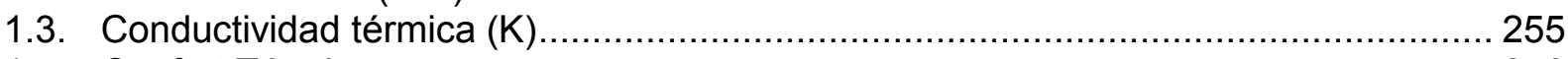

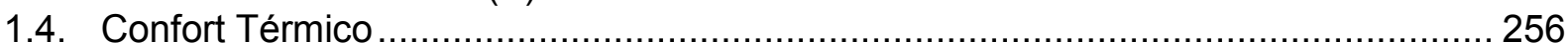

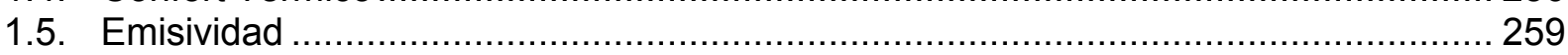

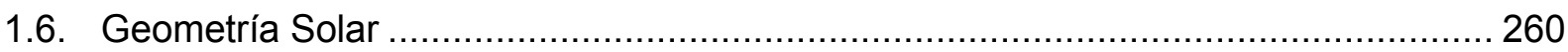

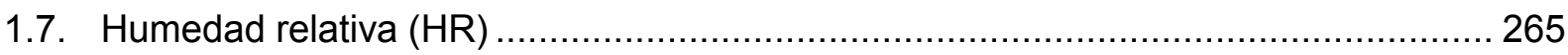

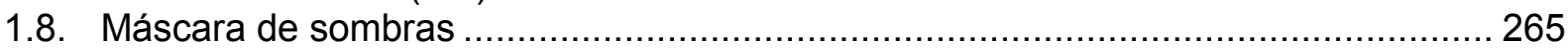

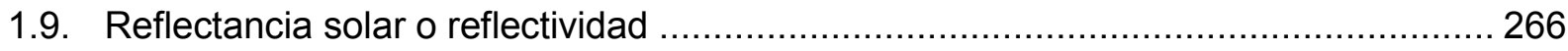




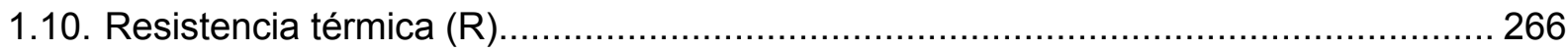

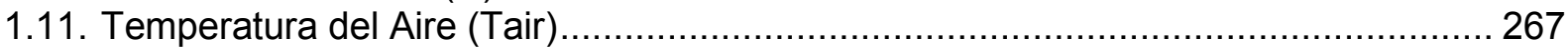

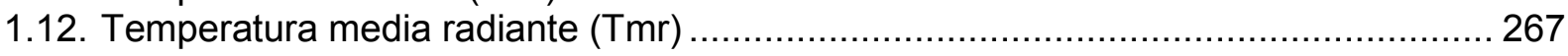

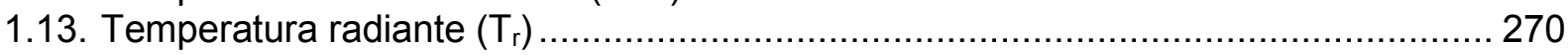

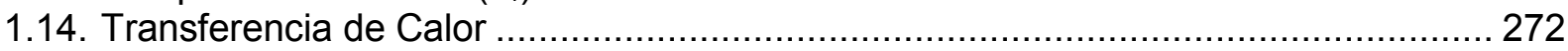

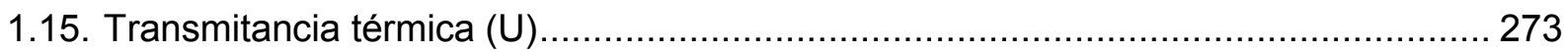

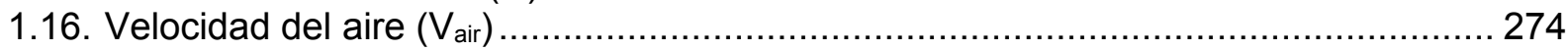

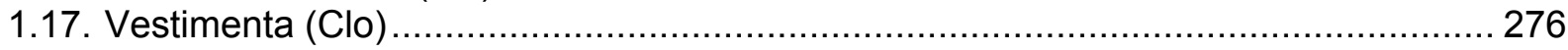

2. ANÁLISIS CLIMATOLÓGICO COMPARATIVO ENTRE CALI Y LA PLATA............. 277

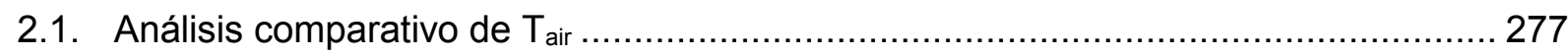

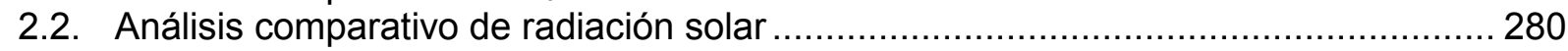

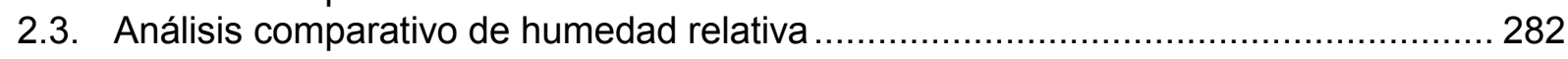

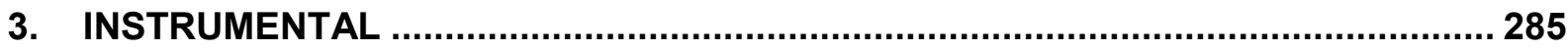

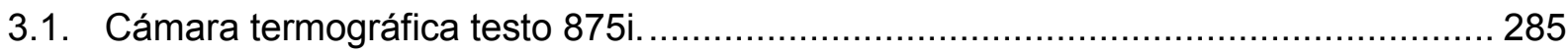

3.2. Termohigrómetro digital Datalogger de $T_{\text {air }}$ y HR marca Extech (modelo RHT30).... 287

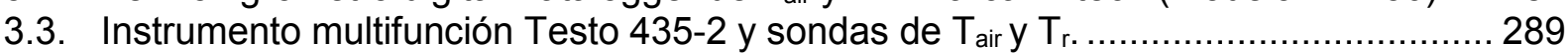

3.4. Termoanemometro digital de hilo caliente marca CEM (Modelo DT-8880) ................290

3.5. Termómetro infrarrojo marca Extech modelo IR 42500 ........................................ 291

4. ANÁLISIS DE PRECIOS UNITARIOS Y COSTO DE IMPLEMENTACIÓN TOTAL POR HABITACIÓN DE LAS SOLUCIONES CONSTRUCTIVAS........................................... 292

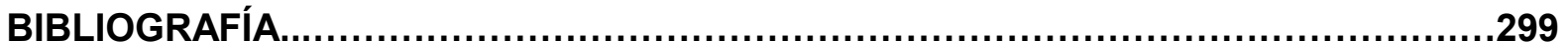

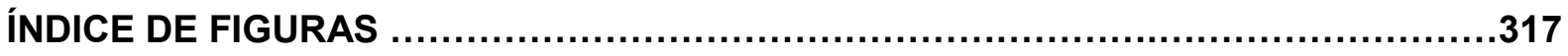

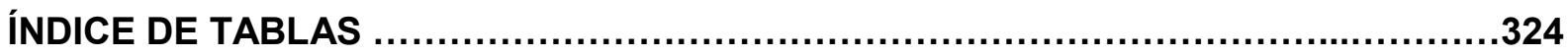




\section{INTRODUCCIÓN}

La presente tesis se desarrolla en el marco de la línea de investigación sobre eficiencia energética del Laboratorio de Arquitectura y Hábitat Sustentable LAyHS de la Facultad de Arquitectura y Urbanismo de la Universidad Nacional de La Plata en Argentina. Es producto de dos años de labor y formación en el programa de Doctorado de la misma facultad. Además, esta línea de conocimiento es también uno de los ejes investigativos centrales del Departamento de Tecnología de la Construcción de la Escuela de Arquitectura de la Universidad del Valle de Cali, Colombia, del cual soy docente y financió mi formación como Doctor mediante una comisión de estudios del programa "Semilleros Docentes" dedicado a profesores jóvenes vinculados en el año 2015

Los intereses por trabajar con temas de sustentabilidad nacen de la preocupación de que, en Cali, las viviendas construidas para las clases populares, obreras o bajo la política de Vivienda de Interés Social (VIS), son el $49 \%$ de las viviendas construidas y en cuyo funcionamiento se encontraron notorias deficiencias de confort térmico, lo cual repercute gravemente en el consumo energético y el bienestar de esta población que cuenta con pocos recursos económicos.

De la relación entre estos dos entramados: VIS y sustentabilidad, he desarrollado anteriormente mi tesis de maestría titulada: Diagnóstico y mejoramiento del comportamiento térmico y la ventilación en Viviendas de Interés Social en Cali con medios pasivos (Giraldo, 2013), en la cual se trabajó principalmente con la disminución de la carga térmica ganada por la cubierta mediante tratamientos bioclimáticos como la baja absortividad y la ventilación por diferencial térmico. El vínculo entre estos dos temas persiste en el presente trabajo que ahonda en la problemática de las altas temperaturas radiantes encontradas en las envolventes verticales opacas y la insatisfacción térmica en los espacios internos de este tipo de edificaciones. 
Por esta razón, en el desarrollo de este estudio se abarcarán temas de estos dos campos teóricos: el primero dedicado a la VIS en Cali y Colombia y el segundo concerniente a la arquitectura sustentable.

En esta introducción se podrá encontrar inicialmente un índice comentado, luego una descripción del tema analizado, arrancando desde una contextualización general e histórica de la relación entre arquitectura y sustentabilidad hasta situarse en el tema central y actual de la vivienda social de Cali y la problemática del deficiente confort térmico que proveen, con lo cual se plantean los objetivos y la hipótesis. También se explica la importancia del estudio desde varios ámbitos y se describe la metodología, el marco teórico y el estado del arte, este último a grandes rasgos, ya que posee dos capítulos independientes dedicados a la VIS en Colombia y a las estrategias de enfriamiento pasivo.

Esta tesis se encuentra dividida en dos secciones, la primera es conceptual y argumentativa mientras que la segunda es experimental. En la sección conceptual se contextualiza sobre la VIS en Colombia tocando temas políticos, urbanos, tecnológicos, legales, económicos y sociales; y se describe el estado del arte de las estrategias de enfriamiento pasivo; mientras que en la experimental se describen y ejecutan los procedimientos para cumplir con el objetivo general y se exponen los resultados.

En la sección conceptual encontramos dos capítulos: el primero dedicado a la VIS en Colombia y en Cali; y el segundo orientado a revisar las estrategias de enfriamiento pasivo. El tema de la VIS se aborda en el capítulo 2, allí se tratan temas como las políticas de desarrollo, las tipologías edificatorias, los sistemas constructivos, las normativas, lo urbano, lo económico, lo térmico y se concluye con algunas discusiones. Por otro lado, en el capítulo 3 , se tratan los conceptos y las tecnologías de enfriamiento pasivo aplicables a envolventes edilicias. Con base en la bibliografía revisada, este capítulo determina cuales de estas tecnologías han demostrado un mejor desempeño, cuales están bien documentadas y cuales poseen aún algunos vacíos. Esta sección es predominantemente técnica y es clave para el entendimiento y desarrollo del corpus.

Por otra parte, la sección experimental está dedicada al desarrollo de la metodología y va del Capítulo 4 al 10, en esta sección se van teniendo resultados y conclusiones parciales en cada capítulo que son producto de cada experimento. Esta sección se remata con las conclusiones que abarcan y conectan toda la tesis.

En el capítulo 4 se modelizan los rasgos y situaciones climáticas críticos de las VIS y de Cali; y se escoge un modelo real que los presenta. A este modelo VIS se le monitorea y evalúa el confort térmico. 
De acuerdo con esta evaluación, en el Capítulo 5 se identifican los requerimientos de calidad térmica que deben cumplir las intervenciones en las envolventes VIS para brindar confort térmico. Posteriormente se diseñan, describen y evalúan numéricamente algunos modelos que en la práctica serán soluciones constructivas. Los resultados de este capítulo son preparatorios y son evaluados empíricamente en el siguiente capítulo.

En el capítulo 6 se describe, se lleva a cabo y se discuten los resultados de un experimento que obtuvo el porcentaje de reducción de la temperatura radiante de las soluciones constructivas diseñadas. Posteriormente a los modelos de mejor desempeño se les determina el valor de transmitancia térmica en el Capítulo 7.

En el capítulo 8, se retoma el modelo VIS evaluado en el Capítulo 4 para llevar a cabo una simulación computacional que tiene como objetivo conocer el nivel de optimización de confort térmico que las mejores soluciones constructivas pueden lograr. Esta simulación es alimentada con los datos obtenidos en las experimentaciones de los Capítulos 6 y 7.

En el Capítulo 9 se expone y discute el tema costo-beneficio realizando inicialmente el análisis unitario de cada solución constructiva y el costo de implementación por habitación. Con ello se elaboran comparaciones tanto entre los modelos aquí evaluados como con otras soluciones tratadas en el estado del arte.

El cuerpo de la tesis finaliza con el capítulo 10 que presenta las conclusiones, en este se sintetiza y reelabora el trabajo, se debaten los logros alcanzados a la luz de los objetivos propuestos. También, se hace una reflexión sobre las limitaciones y se motivan y recomiendan futuros trabajos.

Después de las Conclusiones se encuentra la sección de Apéndices separada en cuatro partes. La primera es un glosario que puede consultarse para tener una definición más amplia de los conceptos principales a los que se referirá constantemente el corpus. La segunda es un análisis climatológico en el que se apoya el Capítulo 6, la tercera contiene descripciones y temas técnicos relacionados con el instrumental utilizado en las experimentaciones, y la cuarta y última contiene los análisis de precios unitarios en los que se apoya el Capítulo 9 de costobeneficio.

Finalmente, la tesis termina con la bibliografía consultada. 


\subsection{Marco teórico}

Las preocupaciones por la degradación del medio ambiente a causa de las actividades humanas y la degradación natural que amenaza la supervivencia de la vida, no solo han generado crisis en el orden político, social y económico del mundo, sino que también han motivado el surgimiento de la arquitectura bioclimática y la teoría del desarrollo sostenible a mediados del siglo XX.

El término desarrollo sostenible, establecido como aquel que satisface las necesidades del presente sin comprometer las necesidades de las futuras generaciones es una reflexión crítica al modelo de desarrollo económico llevado por la humanidad. Este término fue usado por primera vez en el Informe Brundtland de la ONU en 1987 (Organización de las Naciones Unidas, 1987), que además advierte la crisis ambiental ocasionada por las acciones nocivas del ser humano sobre la naturaleza, al igual que hace un llamado de atención a cambiar el modo de vida, para no poner en riesgo los sistemas naturales que sostienen la vida en la Tierra.

Posteriores informes de este mismo organismo revelan los riesgos del cambio climático: un planeta más caliente, desastres naturales a causa de tormentas, sequías, deslizamientos de tierra y aumento de los niveles del mar son algunos de ellos (United Nations Commission on Human Settlements, ONU, 2004 y 2011). Estos documentos orientan a los gobiernos a generar políticas para enfrentar los riesgos, y hacen hincapié en el control de la calidad de las edificaciones, pues de acuerdo con sus indicadores, las edificaciones aportan el mayor impacto a nivel mundial en cuanto a contaminación y consumo energético.

De acuerdo con estos informes, las construcciones consumen a nivel global el $46 \%$ de la energía, y son las productoras del $50 \%$ del CO2. Además, consideran preocupante que, de la energía total utilizada por las construcciones en su funcionamiento, el $42 \%$ se usa para dar confort térmico a los usuarios.

Aunque la responsabilidad de Colombia frente al cambio climático es pequeña, el inventario nacional de gases de efecto invernadero (IDEAM, 2015), muestra un incremento del $15 \%$ en este tipo de emisiones entre 1995 y 2015. De acuerdo con el SIN (Sistema Intercomunicado Nacional, 2018) ${ }^{1}$, en el país se consume energía eléctrica producida mediante hidroeléctricas

\footnotetext{
${ }^{1}$ http://informesanuales.xm.com.co/2015/SitePages/operacion/2-4-Generaci\%C3\%B3n-del-SIN.aspx
} 
de gran escala y termoeléctricas a partir de la quema de combustibles fósiles, las cuales aportan gases de efecto invernadero en grandes cantidades a la atmósfera. La proporción de la producción eléctrica nacional correspondiente a hidroeléctricas equivale al $63,8 \%$, mientras que el $31 \%$ es de termoeléctricas.

Por tal razón, es importante que Colombia invierta en formas de producción de energía renovables y sostenibles, pero sobre todo debe ser prioridad aplicar medidas de eficiencia energética desde el accionar de la arquitectura para disminuir el consumo en aparatos de acondicionamiento térmico, para lo cual existen tecnologías maduras y bien reconocidas mundialmente.

El Estado Colombiano en 2016 ordenó el cumplimiento obligatorio del Reglamento de Construcción Sostenible: Resolución 0549 de $2015^{2}$ (Ministerio de Vivienda, Ciudad y Territorio, 2015), para construcciones nuevas que se enfoca en reducir el consumo de agua y la emisión de gases de efecto invernadero aportadas por las construcciones mediante medidas de eficiencia energética y estrategias de climatización pasiva. Aunque el cumplimiento es optativo para las construcciones VIS, este reglamento recomienda que se debe ahorrar el $15 \%$ de energía en comparación con una línea base creada con estadísticas de consumo por tipo de clima.

Desde mediados del siglo pasado aumentaron considerablemente los estudios acerca de estos temas, como por ejemplo los llevados a cabo por Olgyay (1998.), quien creó el concepto de Arquitectura Bioclimática, que consiste en interrelacionar conocimientos entre Clima, Biología y Tecnología, aplicados en la Arquitectura para disminuir los impactos ambientales negativos y reducir el consumo energético de las construcciones, pero satisfaciendo a la vez las necesidades de confort de los ocupantes.

Lograr confort térmico para los pioneros de estos temas como Olgyay y Givoni (1976) dependía principalmente de la interrelación entre la temperatura del aire $\left(T_{\text {air }}\right)$ y la humedad relativa (HR). Sin embargo, otros índices como el de Fanger (1970), establecen que se requiere poner en equilibrio más variables como la tasa metabólica (Met), la vestimenta (Clo), la velocidad del aire $\left(\mathrm{V}_{\text {air }}\right)$ y la temperatura media radiante $\left(\mathrm{T}_{\mathrm{mr}}\right)$.

\footnotetext{
${ }^{2}$ http://www.minvivienda.gov.co/ResolucionesVivienda/0549\%20-\%202015.pdf
} 
Tanto Olgyay con su Gráfica Bioclimática de la Figura 1, como Givoni con el diagrama psicométrico de la Figura 2, muestran los niveles ideales de $T_{\text {air }}$ (eje $Y$ para Olgyay y eje $X$ para Givoni) y HR ( eje X para Olgyay y curvas para Givoni) con los cuales el ser humano se siente en confort térmico mediante las zonas sombreadas de cada gráfica. Además, ambos autores proponen las estrategias que se requieren usar para alcanzar el confort térmico dentro de un edificio en diferentes tipos de clima mediante las zonificaciones de sus respectivas gráficas.

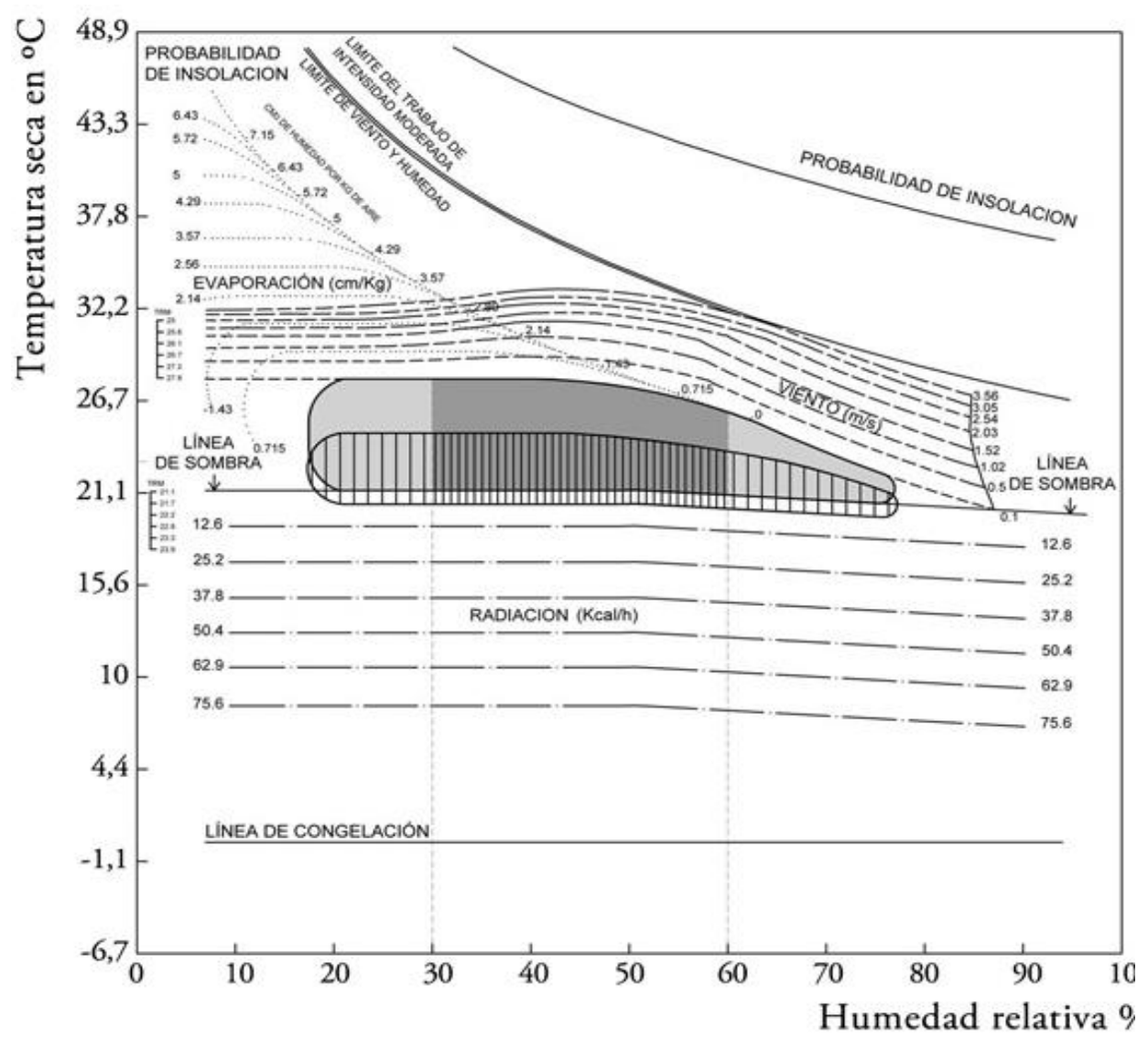

Leyenda

\begin{tabular}{|c|c|}
\hline & ZONA DE CONFORT VERANO \\
\hline & ZONA DE CONFORT TEMPORAL VERANO \\
\hline & ZONA DE CONFORT INVIERNO \\
\hline ПШ & ZONA DE CONFORT TEMPORAL INVIERNO \\
\hline 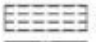 & CORRECCION POR MOVIMIENTO DE AIRE \\
\hline & CORRECCIÓN POR RADIACIÓN SOLAR \\
\hline & CORRECCION POR EVAPORACION \\
\hline
\end{tabular}

Figura 1. Gráfica Bioclimática de Olgyay. Fuente: (Olgyay, 1998.) 


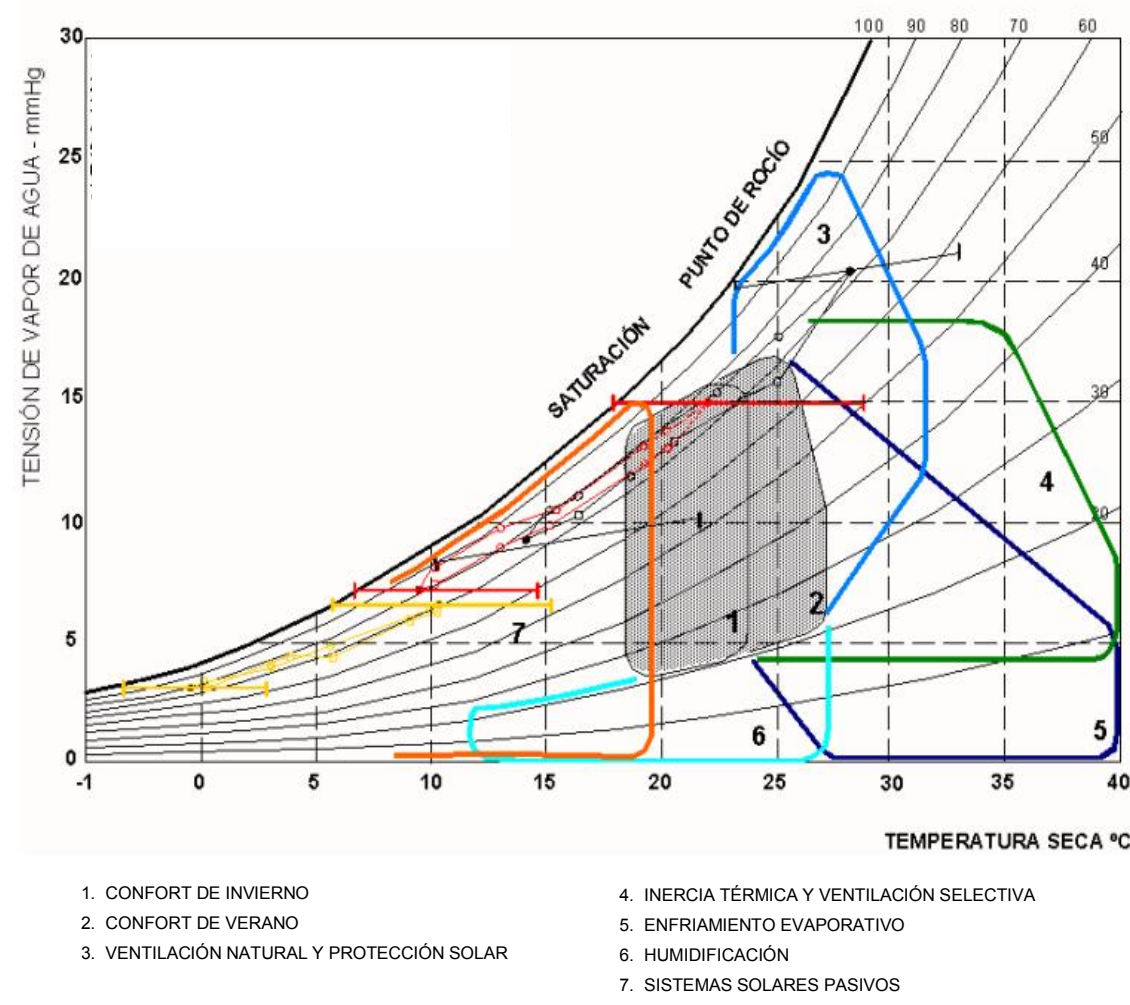

Figura 2. Diagrama Psicométrico de Givoni. Fuente: (Czajkowski \& Gómez, 1994)

De acuerdo con estos diagramas, para la evaluación del confort térmico solamente se utilizan la $T_{\text {air }}$ y la HR, y no se toman en cuenta todas las variables incluidas por Fanger.

Fanger, derivó una ecuación general de confort incluyendo las variables antes mencionadas, y propuso dos índices para evaluar la situación térmica de los espacios, el primero es el índice de sensación térmica denominado Voto Medio Estimado o $\mathrm{PMV}^{3}$ que tiene 7 escalas de calificación; y el segundo es el Porcentaje de Personas Insatisfechas llamado PPD. ${ }^{4}$ Instituciones como ISO en Europa mediante la Norma ISO 7730 (International Organization for Standardization [ISO], 2005) y ASHRAE en Estados Unidos mediante el Manual de Fundamentos (ASHRAE, 2013) , han adoptado este método como el más idóneo y completo

\footnotetext{
${ }^{3}$ Por las siglas en inglés de Predicted Mean Vote.

${ }^{4}$ Por las siglas en inglés de Predicted Percentage of Dissatisfied.
} 
para evaluar el confort térmico y sugieren que un PMV ideal está entre -0.5 a +0.5 , lo cual se traduce en un PPD menor a $10 \%$.

Sin embargo, Givoni (1992) en un trabajo posterior, demuestra que a pesar de la completitud del trabajo hecho por Fanger, los rangos de confort difieren entre los habitantes de zonas templadas y frías como el caso de Europa o Norteamérica y los de países con climas cálidos, quienes están acostumbrados a vivir en edificios ventilados naturalmente. Asimismo, demuestra que los pobladores de zonas cálidas están aclimatados a dichas condiciones y consideran agradables un rango más amplio de $\mathrm{T}_{\text {air }} \mathrm{y} \mathrm{V}_{\text {air. }}$ Por tal razón, Givoni adapta su diagrama psicrométrico para países como México, Brasil y Venezuela, ubicados en zonas tropicales, intertropicales y ecuatoriales.

Además, los trabajos de Olgyay y Givoni siguen siendo aceptados, muy útiles y eficaces a la hora de indicar las estrategias que se deben usar para lograr el confort térmico. Por ejemplo, para el caso de Cali, caracterizada por un clima cálido-húmedo de $\mathrm{T}_{\text {air }}$ media de $23,9^{\circ} \mathrm{C}$ y $\mathrm{HR}$ media de $70 \%$, ambos diagramas coinciden en sugerir la implementación de las estrategias de control solar y ventilación natural.

La ventilación natural se logra mediante la ubicación de aberturas que le permitan al viento fluir a través de la edificación, con el objetivo de llevarse el calor de los espacios interiores. Para ventilar naturalmente, se utilizan estrategias como la ventilación cruzada o la ventilación por diferencial térmico. Mientras que, la protección solar es la estrategia que excluye selectivamente la radiación solar utilizando elementos que den sombra y en ello es importante: la orientación y la geometría de las aberturas; los dispositivos de sombreado; y las propiedades térmicas de las partes opacas y transparentes de la edificación (Santamouris \& Asimakopoulos, 2001).

Apoyando lo establecido por Fanger, Dittmar (1995) encontró que, de todas las variables, la $T_{\mathrm{mr}}$, entendida de manera burda como el promedio de las temperaturas radiantes $\left(T_{r}\right)$ de los elementos que rodean a las personas y que les transfieren calor por radiación a través de ondas electromagnéticas, es el factor más influyente en el confort térmico. ${ }^{5}$

A pesar de que los niveles de bienestar óptimos para la $T_{m r}$ no están estrictamente definidos, Fanger y la ASHRAE recomiendan que no difieran de lo establecido para la $T_{\text {air. }}$ Por lo tanto,

\footnotetext{
${ }^{5}$ Puede consultarse el Glosario para ampliación y detalle de este concepto.
} 
para estos, el rango está entre $22^{\circ} \mathrm{C}$ y $28^{\circ} \mathrm{C}$; en contraste, para Olgyay, Givoni y otros autores como Coch \& Serrá (1995) y Blender (2015), el rango para condiciones de verano o climas cálidos se encuentra entre los $22^{\circ} \mathrm{C}$ y $29,5^{\circ} \mathrm{C}$.

Para dimensionar cuán influyente es la variable de $T_{\mathrm{mr}}$ en el confort térmico, Dittmar et al, evaluaron lo experimentado por personas al interior de un ambiente con condiciones controladas. Paradójicamente, los ocupantes experimentaron sensación de frío cuando la $T_{\text {air }}$ estaba a $48^{\circ} \mathrm{C}$ y los muros tenían temperaturas radiantes $\left(T_{r}\right)$ cercanas a los $10^{\circ} \mathrm{C}$. Mientras que, en un ambiente con $\mathrm{T}_{\text {air }}$ a $10^{\circ} \mathrm{C}$ se sintieron sofocadas a causa de que las $\mathrm{T}_{\mathrm{r}}$ de los muros estaban cercanas a los $40^{\circ} \mathrm{C}$.

En las edificaciones, la envolvente arquitectónica, es decir la capa del edificio en contacto con el ambiente exterior es la encargada de recibir, reflejar y transferir el calor de la radiación solar. Cengel (2003) expone que, si se toman decisiones acertadas en la geometría y propiedades físicas de esta parte del edificio, esta puede ser utilizada para controlar pasivamente el ambiente térmico interior. Entonces se entiende que envolvente, control solar, $\mathrm{T}_{\mathrm{mr}}$, confort térmico humano y gasto energético constituyen un vínculo intrínseco e inseparable.

Debido a que los vanos o elementos transparentes son necesarios para ventilar e iluminar naturalmente y a través de ellos penetra de manera directa la radiación solar, gozan de mayor jerarquía, y en la mayoría de los casos el control solar se concentra en ellos. Por el contrario, los elementos opacos a menudo se encuentran descuidados, sin tratamiento, sin protección solar, ganando calor y afectando el confort térmico interno.

Algunos ejemplos críticos de este tipo de descuidos en las VIS de la ciudad de Cali son encontrados por Gamboa, Rosillo, Herrera, López \& Iglesias (2011) en la Figura 3, que muestra una fotografía y su respectiva termografía de la fachada oeste del conjunto residencial Calicanto, cuya envolvente no sombreada, ni tratada alcanza una $T_{r}$ de $49^{\circ} \mathrm{C}$.

Es muy recomendable entonces cuidar la $T_{r}$, y al igual que los vanos, los elementos opacos también deberían tratarse con estrategias de enfriamiento pasivo. 


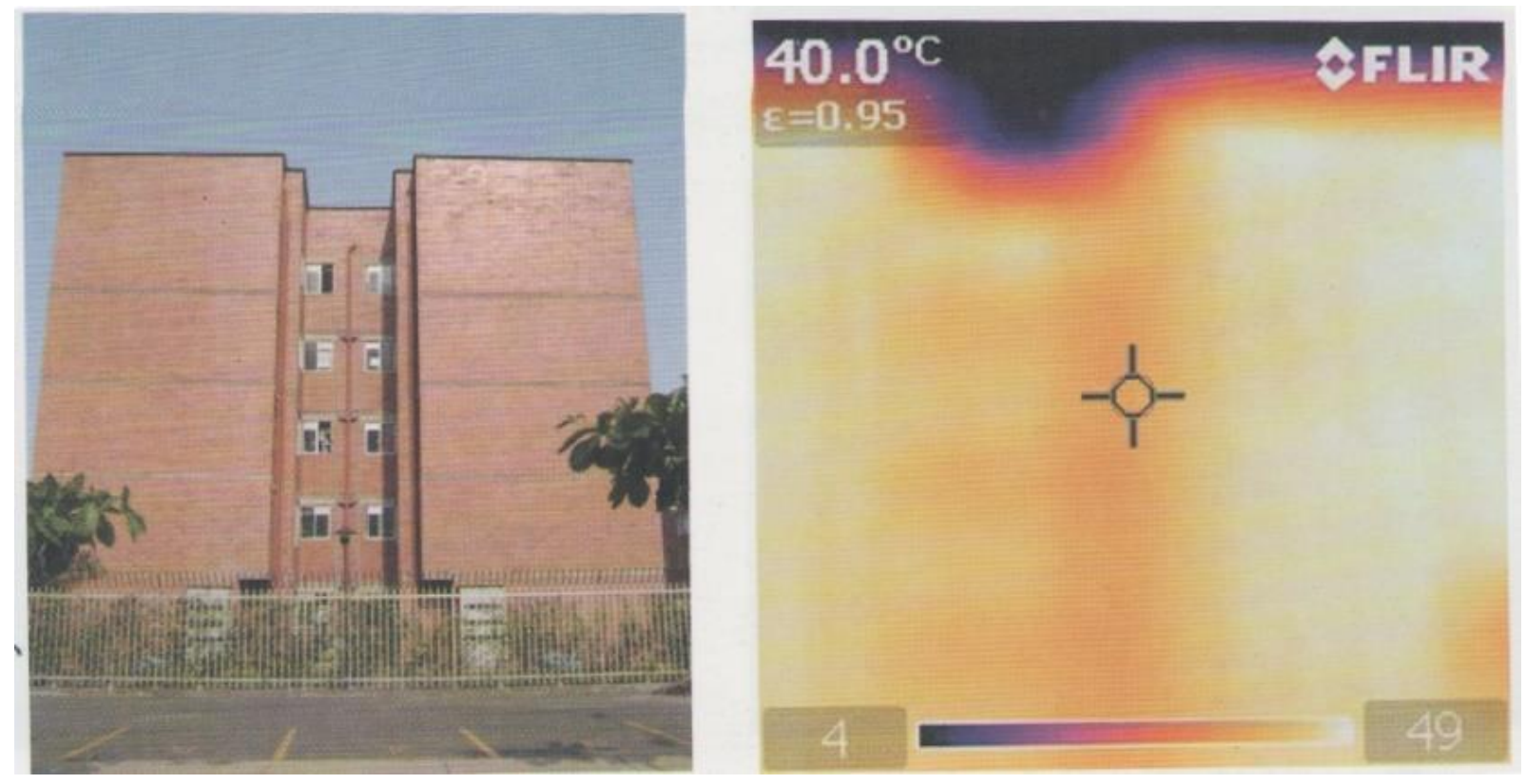

Figura 3. Fotografía vs Termografía de la fachada oeste del conjunto residencial Calicanto en Cali, hora $2 \mathrm{pm}$. Fuente: Gamboa, Rosillo, Herrera, López \& Iglesias (2011).

\subsection{Formulación del problema}

En la ciudad de Cali, caracterizada por un clima ecuatorial cálido-húmedo ( $T_{\text {air }}$ media $=23,9$ ${ }^{\circ} \mathrm{C}, \mathrm{T}_{\text {air }}$ máxima-media $=30,5^{\circ} \mathrm{C}, \mathrm{T}_{\text {air }}$ mínima-media $=20^{\circ} \mathrm{C}, \mathrm{HR}$ media $=70 \%$ y precipitación anual de 1484 mm (IDEAM, 2016)), es muy común ver que las VIS no brinden confort térmico a sus ocupantes y que esta deficiencia no se deba a la falta de recursos económicos de sus promotores o propietarios, sino más bien al descuido de la calidad ambiental en el diseño arquitectónico y a la ausencia de normativas que regulen este parámetro.

Estos descuidos hacen que habitualmente se encuentren altos niveles de $T_{\mathrm{mr}}$ en las VIS de Cali, este problema obedece a que la temperatura radiante $\left(T_{r}\right)$ o temperatura de la superficie interna de la envolvente alcanza valores entre $40{ }^{\circ} \mathrm{C}$ y $50{ }^{\circ} \mathrm{C}$ como los mostrados anteriormente en la Figura 3, lo cual se traduce en una alta insatisfacción térmica para sus ocupantes.

Esto se agrava aún más para las VIS porque sus espacios son de áreas pequeñas, construidas con las medidas mínimas para generar más rentabilidad los constructores, pero a 
la vez cumplir con el reglamento de Calidad de la Vivienda de Interés Social ${ }^{6}$ (Ministerio de Ambiente, Vivienda y Desarrollo Territorial, República de Colombia, 2011). Por ejemplo, las alcobas deben tener al menos $7,3 \mathrm{~m}^{2}(2,7 \mathrm{~m} \times 2,7 \mathrm{~m})$ lo cual hace que estas $T_{r}$ vistas en la Figura 3 tengan influencia directa sobre el confort de los usuarios debido a la proximidad de sus cuerpos con la envolvente.

Mantener la $\mathrm{T}_{\mathrm{mr}}$ en los niveles óptimos es difícil de lograr en Cali, debido a que, en esta latitud, $3^{\circ} 26^{\prime} 13^{\prime \prime} \mathrm{N}$, la radiación solar que puede llegar hasta los $1235 \mathrm{~W} / \mathrm{m}^{2} 7$ y se recibe tanto en la cubierta como en todas las fachadas alternadamente durante el año, lo cual implica tener tratamientos para cada fachada, que no son realizados ni por promotores ni propietarios.

Estos tratamientos requieren inversiones que no son llamativas para los propietarios, ni para las empresas constructoras y que pueden ser poco factibles en relación con el presupuesto de este tipo de proyectos, que solamente cuentan con $\$ 105^{\prime} 467.670$ pesos colombianos (COP) (equivalentes a \$549.703,95 ARS o \$36.646,93 USD -TRM 22 de febrero de 2018), por unidad (Ministerio de Vivienda, Ciudad y Territorio de Colombia, 2018)

Lo anterior, se contrasta con que las empresas constructoras invierten el presupuesto en componentes menos necesarios como materiales de piso lujosos o que los propietarios generalmente resuelvan su insatisfacción térmica implementando ventilación mecánica o incluso, sistemas de aire acondicionado bastante costosos, señalan Gamboa et al, Op. cit. Además, estas respuestas tienen gastos de funcionamiento y mantenimiento, producen enfermedades según lo expuesto por Hedge (2004) y afectan gravemente la sostenibilidad debido al consumo energético y la contaminación de sus refrigerantes.

Hay estrategias pasivas para reducir la $T_{r}$, y optimizar el confort térmico, por ejemplo: elementos de protección solar, materiales aislantes, recubrimientos de baja absortividad, muros vegetales, etc. Incluso en trabajos hechos en Cali como el de Gamboa et al, Op. cit, Iturre Campiño (2013), Osuna Motta (2017) y Giraldo \& Herrera (2017) exploraron soluciones como barreras radiantes, reducción de la absortividad, vegetación y chimeneas solares respectivamente para reducir la $T_{r}$ en cubiertas principalmente, lo cual mejoró ampliamente

\footnotetext{
${ }^{6}$ http://www.minvivienda.gov.co/Documents/guia asis tec vis 1.pdf

7 Valor tomado de las mediciones de radiación solar realizadas por la estación meteorológica de la Escuela de Arquitectura de la Universidad del Valle durante los dos últimos años (2015-2016)

8 http://www.minvivienda.gov.co/viceministerios/viceministerio-de-vivienda/vis-y-vip
} 
los índices de satisfacción en VIS de tipología independiente ${ }^{9}$. Estos positivos resultados se deben a que al mejorar el desempeño térmico de la cubierta también se reduce la entrada de calor por la parte de la envolvente que más recibe radiación, especialmente en latitudes cercanas al ecuador. A pesar de esto, la envolvente vertical sigue sin indagarse, lo cual es muy necesario sobre todo para las VIS multifamiliares ${ }^{9}$ que poseen fachadas de gran área y gran captación de radiación solar.

Ahora bien, en el ámbito industrial y comercial de la construcción de Cali es posible conseguir sistemas de aislamiento para fachadas basados en materiales aislantes tradicionales como el poliestireno expandido o la lana mineral, que además de ser bastante $\operatorname{costosos}^{10}$, ocupan un área considerable en fachada y elevan el peso de la envolvente; razones por las cuales no son muy aceptados, ni redituables.

Es preciso hacer hincapié en que además, la implementación del sistema tradicional de aislamiento basado en materiales de baja conductividad térmica requiere de estructuras de soporte independientes, impermeabilización, protección de la superficie ante agentes mecánicos o fuego mediante sustratos o paneles adicionales, e incluso mejorar el aspecto estético, ya que no posee una presentable terminación para poderse vincular en los sistemas constructivos más utilizados en las envolventes VIS tales como la mampostería o sistemas industrializados como el Outinord y el Contech.

A continuación, en el árbol de problemas ilustrado en la Figura 4, se jerarquiza en la parte central la dificultad a estudiar en la presente investigación, que corresponde a los altos niveles de temperatura radiante en la envolvente vertical opaca de las VIS de Cali.

Mientras que, en la parte superior se indican las causas que conjuntamente lo generan: los altos niveles de radiación solar sumados a la baja calidad térmica de las envolventes. En la parte inferior, se indica inicialmente el principal efecto negativo provocado por el problema, es decir, la insatisfacción térmica. A su vez, esta incentiva el uso de climatización mecánica, lo cual genera gran cantidad de agravantes que desembocan en la crisis ambiental, energética

\footnotetext{
${ }^{9}$ Solo existen 2 tipologías arquitectónicas de VIS: la tipología de multifamiliares que es la más numerosa con el $68 \%$, y la de casas independientes que solo representa el $32 \%$ del total. El tema de tipologías se explica detalladamente más adelante.

$10 \$ 102.254$ COP ( $\$ 657,57$ ARS o $\$ 35,26$ USD) por cada $\mathrm{m}^{2}$, según el análisis costo-beneficio realizado más adelante en el Apéndice 4, que toma como base el listado de precios de la gobernación del valle del cauca (Gobernación del Valle del Cauca, Colombia, 2017)
} 
y gastos económicos para los usuarios VIS, quienes precisamente constituyen la población con menos recursos.

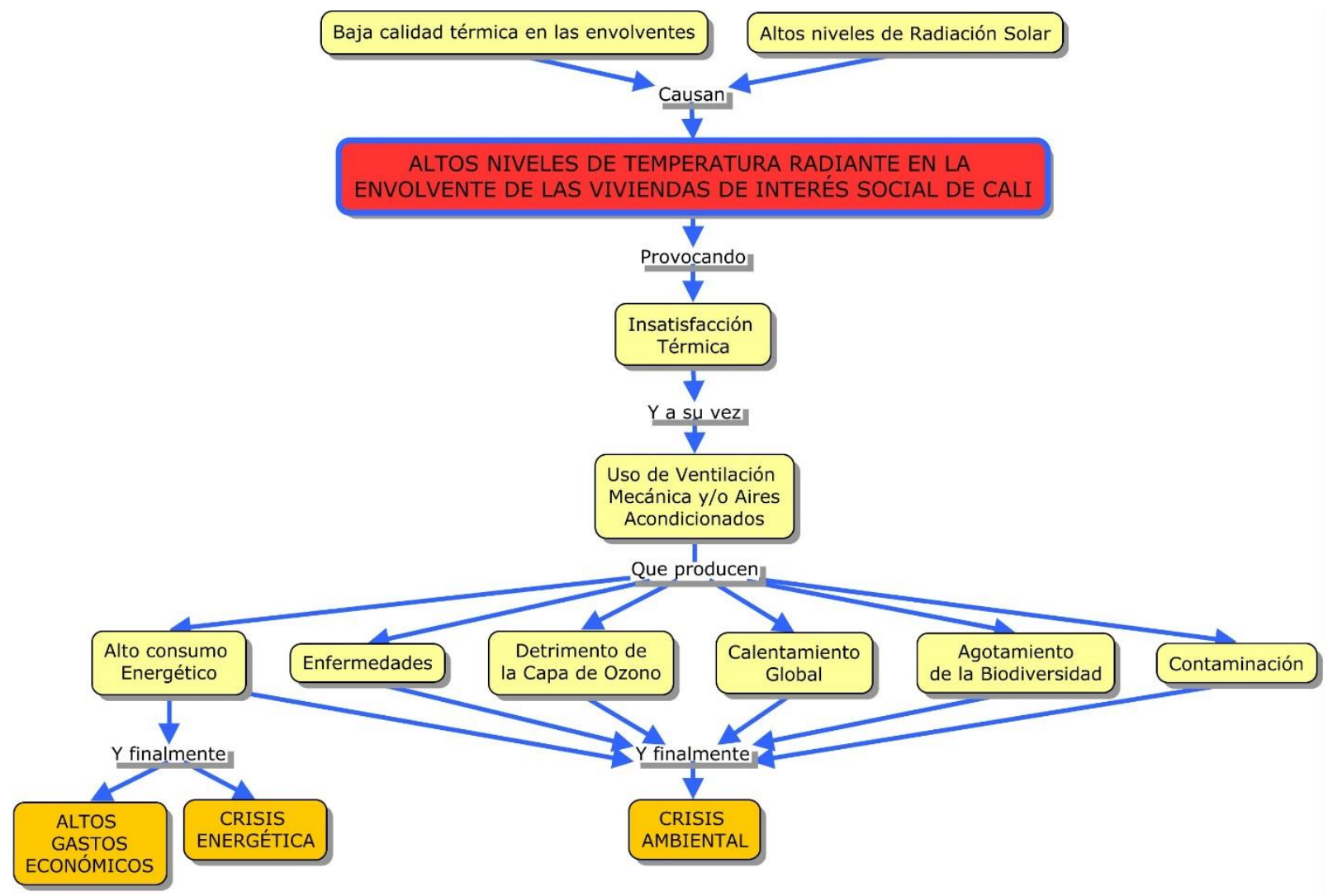

Figura 4. Árbol de Problemas. Fuente: Elaboración propia

Estos problemas evidencian la necesidad de explorar y evaluar alternativas distintas, con las que se pueda mejorar el confort térmico, pero a la vez tener en cuenta el contexto socioeconómico y tecnológico de las VIS.

Frente a este contexto de teorías, tecnologías y problemas surgen las siguientes preguntas:

- ¿Cuál es el desempeño térmico de algunas estrategias de enfriamiento pasivo o combinación de ellas si se implementan en las envolventes verticales opacas de las VIS de Cali en cuanto a reducción de la Tr?, ¿Cuál o cuáles poseen un mejor desempeño y que tanto influyen en la optimización del confort térmico?

- Entendiendo que a este nivel socioeconómico el costo de la solución constructiva es muy importante ¿Cuál o cuáles estrategias de enfriamiento pasivo o combinación de ellas son más convenientes desde el punto de vista costo-beneficio?, ¿Cómo es este en comparación al costo de instalación de un aparato de aire acondicionado que ha sido la solución típica a este problema? 
Las respuestas a estas preguntas requieren un proceso cognitivo, que será avanzado en el corpus de esta tesis, este incluye cálculos teóricos, verificaciones experimentales y simulaciones computacionales que aseguran la fidelidad de las respuestas.

\subsection{Hipótesis}

De otro lado, tomando como base lo visto anteriormente en el marco teórico y en el siguiente estado del arte de los Capítulos 2 y 3 , se plantea como hipótesis que:

Es posible optimizar el confort térmico de un ambiente típico de VIS de Cali mediante la implementación de estrategias de enfriamiento pasivo, ya sean individuales o unidas en soluciones constructivas, tales como: autosombreado (AS), baja absortividad (BA), revoque refractario + baja absortividad (RF), aislamiento reflectivo + baja absortividad (AR) y muro vegetal + baja absortividad + cámara de aire $(\mathrm{MV})$; ya que tienen la capacidad de reducir la $T_{r}$ de las envolventes en más de un $60 \%$. Con lo cual, se puede disminuir también en un $60 \%$ su PPD (porcentaje de personas insatisfechas). Adicionalmente, el costo inicial de implementar estas soluciones constructivas no es más costoso que la instalación de un equipo de aire acondicionado acorde con las necesidades de refrigeración.

\subsection{Justificación}

Reducir la $T_{r}$ y mejorar el confort térmico disminuye el consumo energético y por ende impacta positivamente en el fenómeno de calentamiento global. Pero además mejora la calidad de vida de los usuarios porque representa una optimización en la habitabilidad y salubridad. Con el ahorro energético hay implícito un positivo impacto económico porque se requieren menos recursos para vivir, que pueden ser utilizados en alimentación, educación, etc.

El abordar este tema tanto a nivel académico como profesional impulsa la masificación de estos conocimientos, la puesta en práctica de ellos y la creación de conciencia y responsabilidad ambiental. Esta investigación es conveniente porque constructores y diseñadores de edificaciones VIS y no VIS obtienen argumentos científicos y prácticos con evaluación de desempeño, para mejorar el confort térmico, lo cual es útil no solo a nivel local, sino en todas las zonas geográficas que presenten climas calurosos durante todo el año o parte de él. Incluso, trabajar con este tema puede apoyar o impulsar a emprendedores en el desarrollo de nuevas tecnologías constructivas o productos.

Desde el campo académico son pocos los estudios que han puesto a prueba o han comparado experimentalmente varias estrategias de enfriamiento pasivo en simultaneo, tales como el sombreado, la baja absortividad, el aislamiento reflectivo y los muros vegetales. Además, aquí 
se introdujeron innovaciones, con lo cual los resultados de las mediciones realizadas son claramente conocimiento nuevo que será útil para tener edificaciones más eficientes y más sostenibles.

Los datos obtenidos en esta investigación, tales como el porcentaje de reducción de la $T_{r}$, la máxima cantidad de grados Celsius de $T_{r}$ reducidos, la transmitancia térmica y el porcentaje de personas insatisfechas (PPD) disminuido las soluciones constructivas, son insumo necesario para los estudios sobre confort térmico y eficiencia energética, facilitando los cálculos y la simulación dinámica computarizada.

También resulta útil para el actual proceso de perfeccionamiento y complementación del Reglamento de Construcción Sostenible (Resolución 0549 de 2015) en el que avanza Colombia, ya que esta información enriquece el abanico de tecnologías pasivas para mejorar el confort térmico (Ministerio de Vivienda, Ciudad y Territorio, 2015). Incluso motiva la inclusión de las VIS de manera obligatoria dentro de esta norma ya que se demuestra que con un bajo presupuesto pueden lograrse buenos niveles de confort.

Una vez expuesto el tema, el marco teórico, la generalidad del estado del arte y toda la problemática e importancia del presente estudio, se plantean a continuación los siguientes objetivos: 


\subsection{Objetivos}

\subsubsection{Objetivo general}

Evaluar la reducción de la $T_{r}$ en las envolventes verticales opacas y la optimización del confort térmico que pueden alcanzar en las VIS de Cali algunas soluciones constructivas, desarrolladas a partir de la combinación estratégica de tecnologías de enfriamiento pasivo tales como el sombreado, la baja absortividad, el aislamiento, los muros vegetales y la ventilación.

\subsubsection{Objetivos específicos}

1. Evaluar el nivel de confort térmico de un ambiente de VIS de Cali y la relación con el comportamiento térmico de su envolvente vertical opaca.

2. Analizar teóricamente el comportamiento térmico de diferentes soluciones constructivas que puedan ser útiles en la reducción de la $T_{r}$ de las envolventes verticales opacas y la optimización del confort térmico, combinando las estrategias de enfriamiento pasivo.

3. Evaluar experimentalmente el comportamiento térmico de las soluciones constructivas desarrolladas y analizadas teóricamente.

4. Estudiar la optimización de confort térmico que las soluciones constructivas con mejor comportamiento térmico pueden alcanzar en un ambiente de VIS de Cali.

5. Evaluar la relación costo-beneficio de las soluciones pasivas propuestas, frente a otras similares en el estado del arte y frente a soluciones activas como la implementación de un equipo de aire acondicionado. 
La Figura 5, correspondiente al Árbol de objetivos, muestra en la parte central el objetivo principal de la tesis, mientras que en la parte superior se indica con que fines y en la parte inferior los medios para lograrlo.

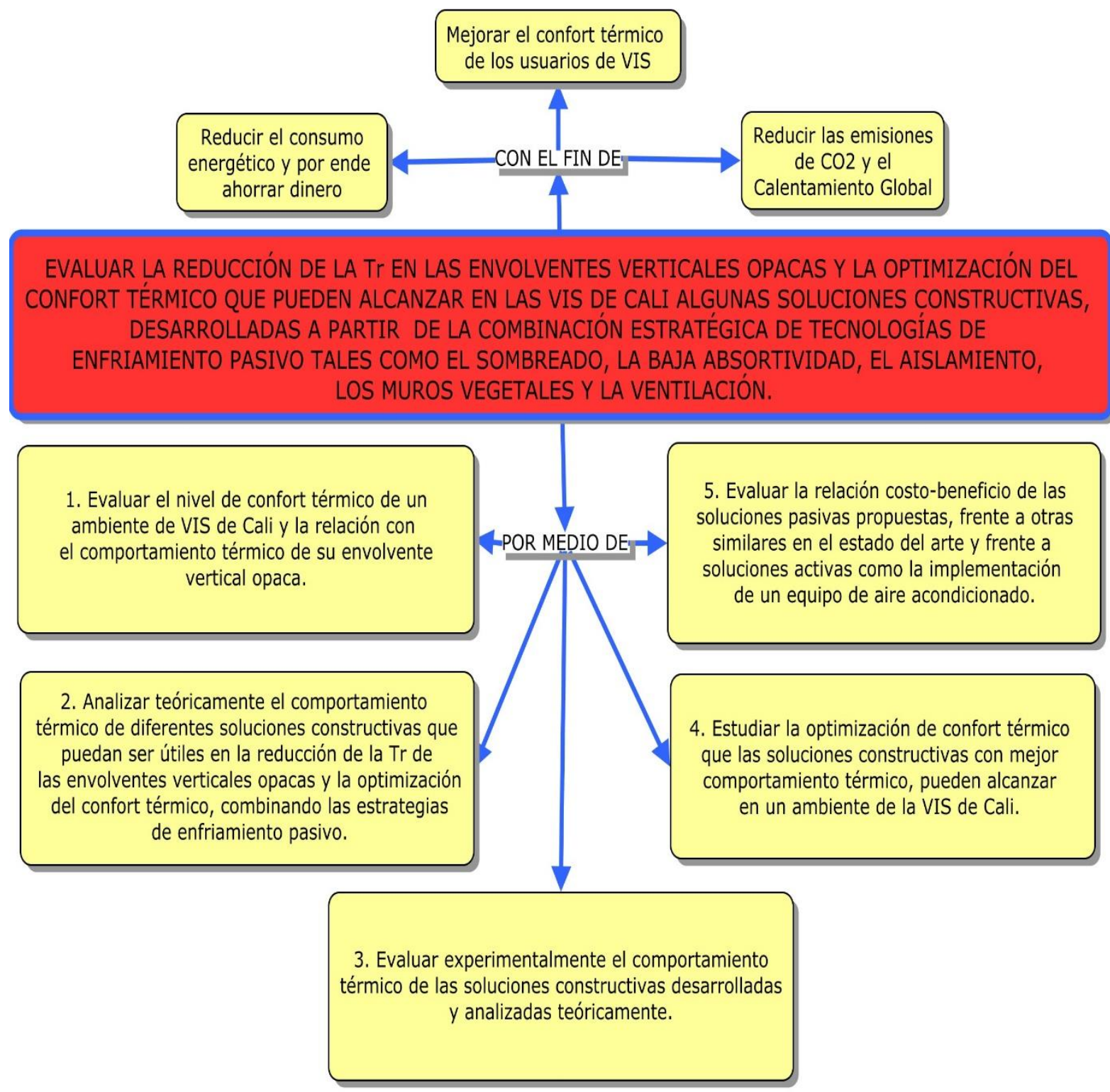

Figura 5. Árbol de Objetivos. Fuente: Elaboración propia. 


\subsection{Metodología}

La metodología de esta investigación tiene un enfoque descriptivo y explorativo logrado con procedimientos experimentales. Los contenidos explorativos se obtienen de algunas soluciones constructivas con innovaciones tecnológicas no evaluadas previamente.

La unidad de análisis central es la VIS de Cali construida desde 1990 a la actualidad (2016); las soluciones constructivas desarrolladas, que a su vez incorporaron varias estrategias de enfriamiento pasivo constituyen las variables independientes, y las variables dependientes son la $T_{a i r}$, la $T_{r}$, la HR y por supuesto, el confort térmico, el cual posee algunos índices para su evaluación como el PMV y el PPD.

Sin embargo, en el camino nos concentramos en la envolvente vertical opaca de esa unidad de análisis, ya que como se ha expuesto es bastante influyente en el desempeño térmico interno de las VIS. En esta etapa nos interesamos en la $T_{r}$, una variable que influye en el confort térmico, pero que también depende del tipo de solución constructiva aplicada a la envolvente.

Con cada alternativa constructiva se experimentó y se tomaron datos como la $T_{r}, T_{\text {air, }}$ HR y la transmitancia térmica o valor $U$, los cuales también sirvieron como indicadores de desempeño.

Para alcanzar el objetivo se estableció una metodología estructurada en seis etapas que están relacionadas directamente con los objetivos específicos. Estas son:

1. Evaluación de confort térmico a un modelo VIS.

2. Modelizado de soluciones constructivas.

3. Evaluación del porcentaje de reducción de $T_{r}$.

4. Determinación de la transmitancia térmica.

5. Evaluación de confort térmico de un modelo VIS mejorado.

6. Relación costo-beneficio.

Estas etapas conforman la Sección 2 o sección experimental del trabajo y cada uno de ellos corresponde a un capítulo, en los cuales se van obteniendo resultados y tomando decisiones con base en ellos. A continuación, se explica en más detalle cada una de estas etapas: 


\section{Evaluación de confort térmico a un modelo VIS}

La finalidad de esta etapa es revisar el desempeño térmico de las envolventes y el nivel de confort térmico de una unidad de VIS real. Asimismo, cuantificar en cuanto deben mejorarse algunos parámetros de la envolvente como la resistencia térmica para alcanzar el confort térmico en el caso más desfavorable.

Inicialmente, se trabajó con los datos climatológicos de Cali en busca de encontrar la fachada y los periodos calurosos críticos, esto se hizo determinando valores máximos de $\mathrm{T}_{\text {air }} \mathrm{y}$ radiación solar en las envolventes verticales.

Posteriormente, se calculó numéricamente la $T_{r}$ que alcanzan los modelos más comunes de envolventes típicas VIS en la fachada, durante un día crítico, para lo cual fue necesario seguir el método matemático explicado por Cengel Op. cit., y que a la vez sigue ASHRAE (2001).

Después de identificar estos rasgos críticos, se buscó una VIS que los tuviera y se seleccionó una alcoba principal de un apartamento del Conjunto Residencial Calicanto mostrado anteriormente en la Figura 3 de la introducción. Este ambiente fue monitoreado durante el periodo de una semana en la fecha crítica identificada con anterioridad. Con los registros se evaluó el confort térmico utilizando los índices PMV y PPD propuestos por Fanger Op. cit., y que también es utilizado en la norma ISO 7730 (2005).

Esta valoración del modelo VIS sirvió también para determinar una línea base con la cual comparar el desempeño del Modelo VIS mejorado que se desarrolló en la última etapa y que tiene implementada una de las alternativas constructivas desarrolladas durante el trabajo.

\section{Modelizado de soluciones constructivas}

Teniendo en cuenta los resultados de la etapa anterior, aquí se desarrollan y evalúan teóricamente varios modelos de soluciones constructivas, para reducir la $T_{r}$ y mejorar el confort térmico.

La metodología seguida aquí es creativa e integradora, pues se unen los conocimientos adquiridos en el estado del arte para crear soluciones constructivas que combinen estrategias de prevención, modulación y disipación del calor. Asimismo, se tuvieron en cuenta los aspectos: económico y técnico constructivo. El proceso se inició estimativamente con los modelos más sencillos y menos costosos y terminó con los más complejos.

La evaluación teórica se realizó con el mismo método propuesto por Cengel y ASHRAE utilizado en el punto anterior. Los resultados de esta etapa muestran cinco alternativas 
constructivas con su expectativa de desempeño durante el caso crítico. Evidentemente, este es un paso preparatorio que será continuado en las siguientes dos etapas experimentales.

\section{Evaluación del porcentaje de reducción de $T_{r}$.}

Este experimento se destinó a conocer el porcentaje de reducción de $T_{r}$, y se controló simultáneamente el comportamiento de la $\mathrm{T}_{\text {air }}$ y la HR.

Las mediciones se realizaron en un laboratorio a cielo abierto con radiación solar directa a través de un aparato experimental conformado por dos módulos calibrados, en los que fueron materializadas y analizadas las soluciones constructivas. Con esto se obtuvieron registros de comportamiento de $T_{r}, T_{\text {air }}$ y HR de cada solución.

Inicialmente se elaboró un plan de mediciones debido a que la ciudad de interés (Cali, Colombia), difiere de la ciudad donde se realizó la experimentación (La Plata, Argentina). El objetivo de este plan fue encontrar el mes o los meses del año en La Plata, más parecidos a los días típicos de Cali. Para elaborarlo, se realizó un análisis climatológico comparativo entre un día típico de Cali y los promedios mensuales de radiación solar, $\mathrm{T}_{\text {air }} \mathrm{y} \mathrm{HR}$ de la Plata. Además, el plan incluyó un dispositivo para lograr las condiciones de asoleamiento de Cali desde La Plata. La razón de esto obedeció a la imposibilidad de desplazamiento de un lugar a otro establecida en la beca doctoral.

El aparato experimental se fundamentó en modelos de investigación anteriores como las de Guo, Qiao, Huang, Fang, \& Han (2012) y Kang \& Yang (2013) quienes evaluaron el desempeño de aislamientos y recubrimientos externos para edificaciones mediante dos pequeños módulos cúbicos de $30 \times 30 \times 30 \mathrm{~cm}$, elaborados en poliestireno expandido de alta densidad. Guo et al, experimentaron el desempeño térmico de un recubrimiento reflectivo, mientras que Kang \& Yang examinaron el potencial aislante de un Aerogel combinado con perlita expandida.

El aparato experimental fue calibrado para asegurar su similitud de desempeño térmico mediante el monitoreo de la $T_{r}, T_{\text {air }}$ y HR. Después de la calibración, se destinó uno de los módulos como testigo, mientras que el otro fue intervenido continuamente con cada solución constructiva.

El cálculo de porcentaje de reducción de la $T_{r}$ (al igual que con $T_{\text {air }}$ y el aumento de la HR) se realizó con base en el método de eficiencia relativa establecido por Sánchez (1993) y utilizado también por Fajardo (2005) y Osuna (2017) para determinar la capacidad de enfriamiento de distintos modelos de cubiertas. Estos estudios compararon el desempeño experimental de modelos a escala. Este concepto es la fracción de temperatura reducida lograda por el módulo 
intervenido en relación con el módulo testigo y se establece relacionando el área bajo la curva de la variable analizada en el tiempo.

Los resultados obtenidos en esta experimentación son discutidos y contrastados con los cálculos desarrollados en la etapa de modelizado. El análisis de estos resultados identifica el modelo con mejor desempeño para continuar el proceso en la siguiente etapa.

\section{Determinación de la transmitancia térmica.}

Este experimento se orientó en conocer el valor $U$ de las soluciones constructivas que mejor desempeño tuvieron en la etapa anterior. El método usado para este fin fue el de la caja caliente calibrada descrito en la norma ISO 8990:1994, en el cual, una probeta de la solución constructiva es rodeada de dos ambientes: uno frío y uno caliente. En ambos ambientes la $T_{\text {air }}$ es controlada y constante para lograr un régimen estacionario.

Métodos similares han sido utilizados en algunas investigaciones orientadas a conocer este valor para elementos comunes de la construcción tales como paneles, ladrillos, pisos y tejas. Entre estas investigaciones está la desarrollada por Viegas, Walsh, \& Barros (2016), quienes utilizaron una heladera doméstica y una resistencia eléctrica para evaluar materiales alternativos de aislamiento; por otro lado, un método similar es utilizado por Chávez y Quinayás (2008), quienes probaron la conductividad térmica de varios materiales de la VIS de Cali.

\section{Evaluación de confort térmico de un modelo VIS mejorado}

Los datos obtenidos en las dos experimentaciones anteriores sirvieron para contrastar los desarrollos de la fase teórica y como inputs para alimentar la simulación computacional que es el siguiente paso del trabajo.

La simulación computacional cuantificó la optimización del confort térmico aportado por la solución constructiva con mejor desempeño durante las experimentaciones, se efectuó con el software Energy Plus, utilizando un modelado virtual del ambiente VIS elegido como línea base y los archivos climáticos de Cali. Esta simulación tuvo dos modelados: el primero que se calibró con las condiciones medidas en campo del ambiente VIS y el segundo con la implementación de la solución constructiva.

\section{Relación Costo-beneficio}

Aquí se calcula el costo de las soluciones constructivas tomando como base la información empírica del proceso de construcción del aparato experimental y los conocimientos del 
ejercicio profesional en la construcción. El costo de los modelos acá analizados y el de otras alternativas revisadas en el estado del arte ( $y$ también disponibles en el mercado) se contrastan a la luz del desempeño térmico. Se incluye también en el análisis y discusión el suministro e instalación de un aparato de aire acondicionado, el cual ha sido la solución típica a este problema.

Para valorar el costo inicial se utilizó la metodología explicada por Casas (2002), que inicia con la realización del análisis de precios unitarios (APU) de cada solución constructiva tomando como base las cantidades de materiales usados durante la construcción del aparato experimental.

Posteriormente, este precio unitario se multiplicó por el área en la que se aplicó dicho tratamiento para la simulación computacional. En este proceso también nos apoyamos de la base de datos de precios oficiales para la construcción de la Gobernación del Valle del Cauca, disponible en internet ${ }^{11}$ (Gobernación del Valle del Cauca, Colombia, 2017).

A continuación, la Tabla 1, resume esquemáticamente la estructura de la metodología, en la que se explica brevemente las etapas y actividades vinculadas a cada objetivo específico.

Mas abajo, la Tabla 2 muestra un resumen esquemático de las relaciones entre Objetivos Metodología - Resultados y Organización de Capítulos de la investigación. Esta tabla menciona los objetivos propuestos el número y título del Capítulo donde se desarrolla, y brevemente explica la metodología utilizada para lograrlos y los resultados obtenidos. Las flechas además de indicar el sentido del desarrollo de la investigación muestran las conexiones de los resultados que se van obteniendo en las primeras etapas metodológicas con las posteriores.

\footnotetext{
${ }^{11}$ http://www.valledelcauca.gov.co/vivienda/documentos.php?id=1018
} 


\begin{tabular}{|c|c|c|c|}
\hline ACTIVIDAD & ETAPA & OBJETIVO ESPECÍFICO & OBJETIVO GENERAL \\
\hline Análisis climático de Cali. & \multirow{6}{*}{$\begin{array}{l}\text { 1. Evaluación de } \\
\text { confort a un } \\
\text { modelo VIS. }\end{array}$} & \multirow{6}{*}{$\begin{array}{l}\text { 1. Evaluar el nivel de confort térmico de un } \\
\text { ambiente VIS de Cali y la relación con el } \\
\text { comportamiento térmico de su envolvente } \\
\text { vertical opaca. }\end{array}$} & \multirow{19}{*}{$\begin{array}{c}\text { Evaluar la reducción de } \\
\text { la Tr en las envolventes } \\
\text { verticales opacas y la } \\
\text { optimización del confort } \\
\text { térmico que pueden } \\
\text { alcanzar en las VIS de } \\
\text { Cali algunas soluciones } \\
\text { constructivas, } \\
\text { desarrolladas a partir } \\
\text { de la combinación } \\
\text { estratégica de } \\
\text { tecnologías de } \\
\text { enfriamiento pasivo } \\
\text { tales como el } \\
\text { sombreado, la baja } \\
\text { absortividad, el } \\
\text { aislamiento, los muros } \\
\text { vegetales y la } \\
\text { ventilación. }\end{array}$} \\
\hline Modelizar caso crítico VIS. & & & \\
\hline Seleccionar un modelo VIS real. & & & \\
\hline Monitorear modelo VIS. & & & \\
\hline $\begin{array}{l}\text { Evaluar el confort térmico del } \\
\text { modelo VIS. }\end{array}$ & & & \\
\hline Analizar y discutir resultados. & & & \\
\hline $\begin{array}{l}\text { Desarrollar modelos de } \\
\text { soluciones constructivas } \\
\text { inspiradas en las estrategias de } \\
\text { enfriamiento pasivo. }\end{array}$ & \multirow{3}{*}{$\begin{array}{l}\text { 2. Modelizado } \\
\text { de soluciones } \\
\text { constructivas. }\end{array}$} & \multirow{3}{*}{$\begin{array}{l}\text { 2. Analizar teóricamente el comportamiento } \\
\text { térmico de diferentes soluciones } \\
\text { constructivas que puedan ser útiles en la } \\
\text { reducción de la Tr de las envolventes } \\
\text { verticales opacas y la optimización del } \\
\text { confort térmico, combinando las estrategias } \\
\text { de enfriamiento pasivo. }\end{array}$} & \\
\hline $\begin{array}{l}\text { Evaluar de numéricamente la } \\
\text { reducción de la Tr durante el } \\
\text { caso crítico. }\end{array}$ & & & \\
\hline Analizar y discutir resultados. & & & \\
\hline $\begin{array}{l}\text { Medir experimentalmente el } \\
\text { porcentaje de reducción de Tr, } \\
\text { Tair y HR que aporta cada } \\
\text { solución constructiva. }\end{array}$ & \multirow{2}{*}{$\begin{array}{l}\text { 3. Evaluación } \\
\text { del porcentaje } \\
\text { de reducción de } \\
\text { la } \mathrm{T}_{\mathrm{r}}\end{array}$} & \multirow{4}{*}{$\begin{array}{c}\text { 3.Evaluar experimentalmente el } \\
\text { comportamiento térmico de las soluciones } \\
\text { constructivas desarrolladas y analizadas } \\
\text { teóricamente. }\end{array}$} & \\
\hline $\begin{array}{l}\text { Analizar y discutir resultados } \\
\text { para seleccionar el modelo de } \\
\text { mejor desempeño. } \\
\end{array}$ & & & \\
\hline $\begin{array}{l}\text { Medir mediante el método de la } \\
\text { caja caliente el valor U de la } \\
\text { solución constructiva con mejor } \\
\text { desempeño. }\end{array}$ & \multirow[t]{2}{*}{$\begin{array}{l}4 . \\
\text { Determinación } \\
\text { de la } \\
\text { transmitancia } \\
\text { térmica }\end{array}$} & & \\
\hline Analizar y discutir resultados. & & & \\
\hline $\begin{array}{l}\text { Modelado virtual del ambiente } \\
\text { VIS en EnergyPlus y calibración } \\
\text { con datos obtenidos en el } \\
\text { monitoreo de la Etapa } 1 . \\
\end{array}$ & \multirow{3}{*}{$\begin{array}{l}\text { 5. Evaluación de } \\
\text { confort térmico } \\
\text { de un modelo } \\
\text { VIS mejorado. }\end{array}$} & \multirow{3}{*}{$\begin{array}{l}\text { 4. Estudiar la optimización del confort } \\
\text { térmico que las soluciones constructivas } \\
\text { con mejor comportamiento térmico } \\
\text { analizadas anteriormente pueden alcanzar } \\
\text { en un ambiente de la VIS de Cali. }\end{array}$} & \\
\hline $\begin{array}{l}\text { Modelado y evaluación virtual } \\
\text { mediante EnergyPlus del } \\
\text { desempeño y confort térmico del } \\
\text { ambiente VIS mejorado }\end{array}$ & & & \\
\hline Analizar y discutir resultados. & & & \\
\hline $\begin{array}{c}\text { Cuantificar costo de } \\
\text { implementación de: } \\
\text { - Las soluciones pasivas } \\
\text { evaluadas aquí. } \\
\text { - Otras soluciones pasivas } \\
\text { disponibles en el mercado } \\
\text { - Una solución activa (aire } \\
\text { acondicionado) } \\
\end{array}$ & \multirow[t]{2}{*}{$\begin{array}{l}\text { 6. Relación } \\
\text { costo beneficio. }\end{array}$} & \multirow[t]{2}{*}{$\begin{array}{l}\text { 5. Evaluar la relación costo-beneficio de las } \\
\text { soluciones pasivas propuestas frente a } \\
\text { otras similares en el estado del arte y frente } \\
\text { a soluciones activas como la } \\
\text { implementación de un equipo de aire } \\
\text { acondicionado. }\end{array}$} & \\
\hline Analizar y discutir resultados. & & & \\
\hline \multicolumn{3}{|c|}{ CONCLUSIONES } & \\
\hline
\end{tabular}

Tabla 1. Resumen esquemático de la estructura metodológica. Fuente: Elaboración propia 


\section{OBJETIVO GENERAL}

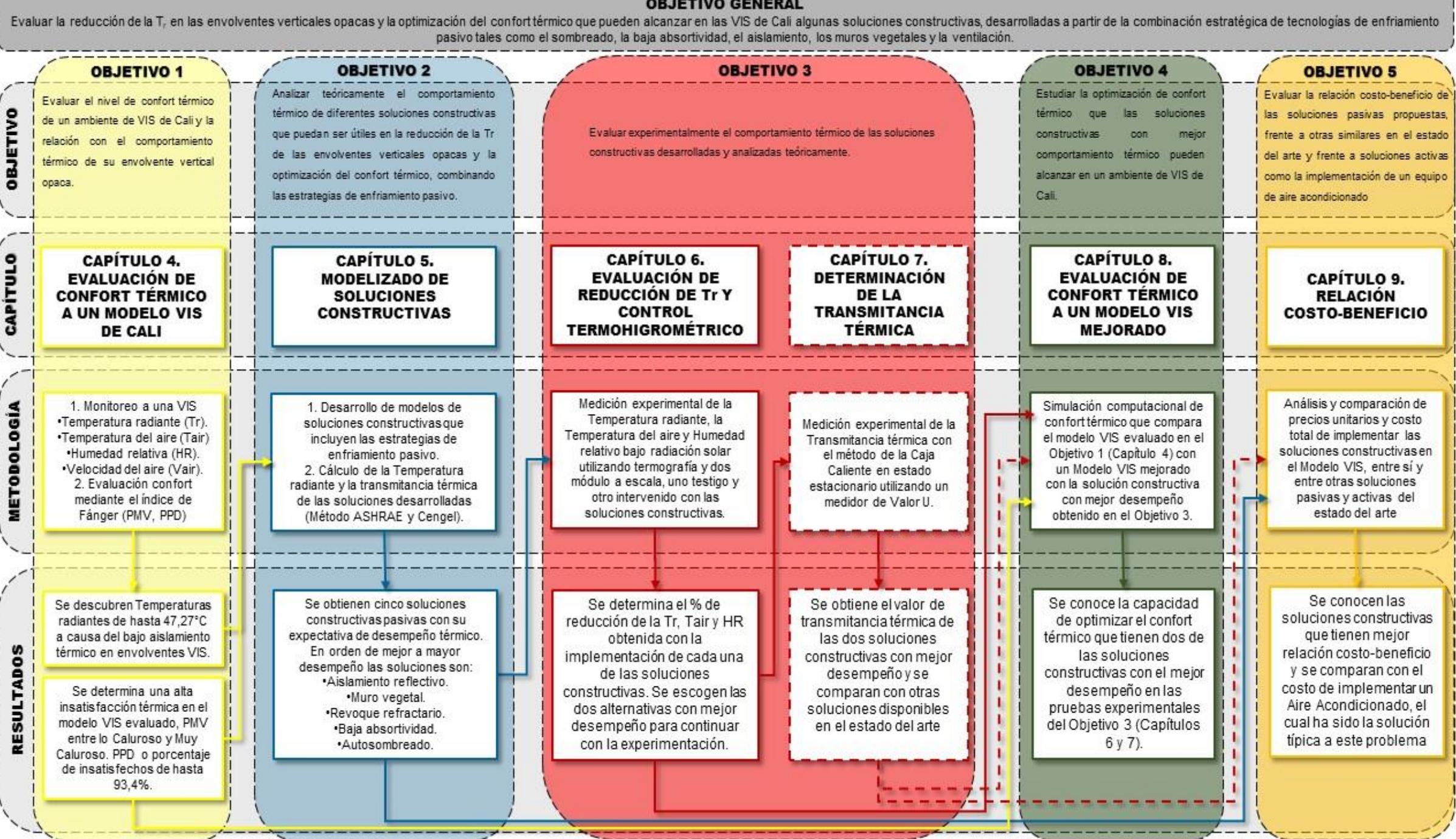

Tabla 2. Resumen esquemático de las relaciones entre Objetivos - Metodología - Resultados y Organización de Capítulos de la investigación. Fuente: Elaboración propia. 


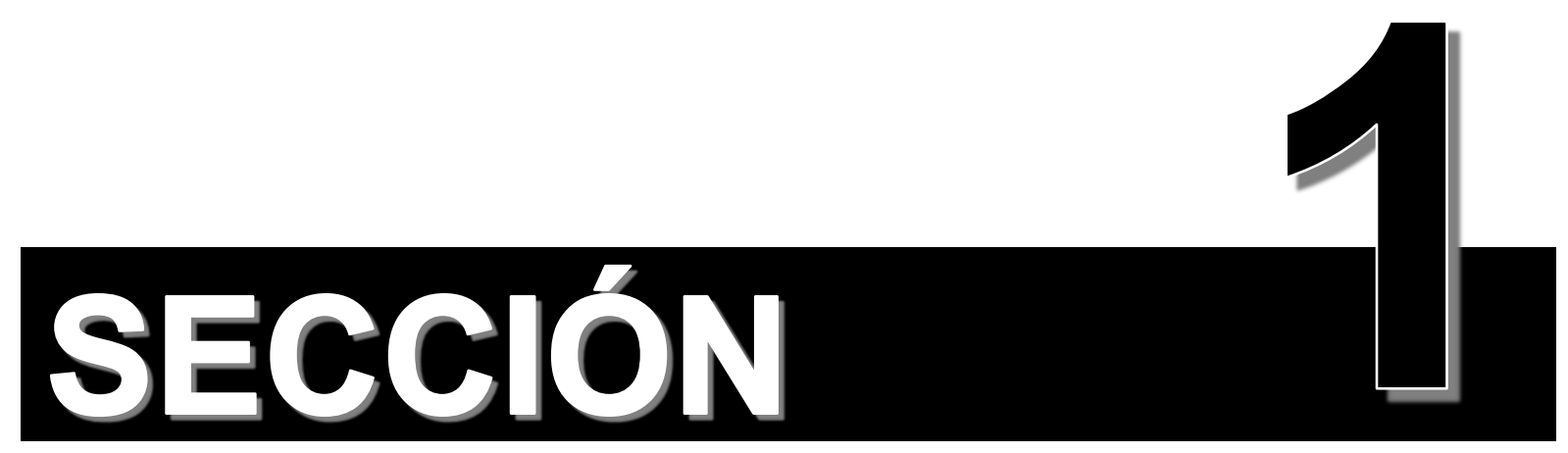




\section{LA VIVIENDA DE INTERÉS SOCIAL EN CALI Y COLOMBIA}

\subsection{Concepto de la Vivienda de Interés Social en la historia.}

El término "Vivienda de Interés Social" es relativamente nuevo, sin embargo, en la historia contemporánea la noción se remonta a principios del siglo XIX, cuando los países industrializados necesitaron alojar las grandes masas obreras requeridas para el proceso productivo.

Algunos planteamientos pioneros como las casas suburbanas aglomeradas de Robert Owen, los falansterios de desarrollo en altura de Charles Fourier o las ciudades jardín de Ebenezer Howard, son iniciativas cuyo ideal humanístico se basaba en la convivencia pacífica de las clases trabajadoras, el trabajo digno, el cooperativismo, los valores familiares y el cuidado del medio ambiente.

Hoy en día, el término o incluso el concepto de Vivienda Social puede variar de un país a otro, sin embargo, se conserva esa esencia acerca de que este tipo de viviendas van dirigidas para la comunidad trabajadora con menores recursos económicos.

Desde los inicios y aún hoy, son vigentes las discusiones sobre la higiene, la estandarización, el tamaño, el confort térmico, los servicios complementarios, la tecnología constructiva, entre otros. 


\subsection{Definición de Vivienda de Interés Social en Colombia}

De acuerdo con el artículo 91 de la Ley 388 de $1997^{12}$ (Congreso de Colombia, 1997), se señala:

Se entiende por viviendas de interés social aquellas que se desarrollen para garantizar el derecho a la vivienda de los hogares de menores ingresos. En cada Plan Nacional de Desarrollo el Gobierno Nacional establecerá el tipo y precio máximo de las soluciones destinadas a estos hogares teniendo en cuenta, entre otros aspectos, las características del déficit habitacional, las posibilidades de acceso al crédito de los hogares, las condiciones de la oferta, el monto de recursos de crédito disponibles por parte del sector financiero y la suma de fondos del Estado destinados a los programas de vivienda. (Congreso de Colombia, 1997)

Por su parte, el artículo 117 de la Ley 1450 de $2011^{13}$ (Congreso de Colombia, 2011), señala:

De conformidad con el artículo 91 de la Ley 388 de 1997, la vivienda de interés social es la unidad habitacional que cumple con los estándares de calidad en diseño urbanístico, arquitectónico y de construcción y cuyo valor no exceda ciento treinta y cinco salarios mínimos mensuales legales vigentes (135 smlmv). (Congreso de Colombia, 2011).

Además de la VIS, también existe otro tipo de vivienda con menor valor denominada por el Gobierno Nacional como Vivienda de Interés Prioritario (VIP), dedicada solo para cierto tipo de municipios. De acuerdo con la misma ley, el Parágrafo 1 define lo siguiente:

Se establecerá un tipo de vivienda denominada Vivienda de Interés Social Prioritaria, cuyo valor máximo será de setenta salarios mínimos legales mensuales vigentes (70 smlmv). Las entidades territoriales que financien vivienda en los municipios de categorías 3, 4, 5 y 6 de la Ley 617 de 2000, sólo podrán hacerlo en Vivienda de Interés Social Prioritaria. (Congreso de Colombia, 2011)

En el caso de la VIS para el año 2017, los 135 smlmv, corresponden a \$99'591.795 pesos colombianos y a $\$ 33.624$ USD mientras que, para las VIP, los $70 \mathrm{smlmv}$ corresponderían a $\$ 52 ` 340.190$ pesos colombianos y a $\$ 17.687$ USD, (TMR 9 de mayo de 2017).

Además, las VIS deben cumplir con todas las normativas vigentes en cuanto a determinantes urbanísticas y de habitabilidad arquitectónica, estructura, electricidad, fontanería, etc.

\footnotetext{
12 http://recursos.ccb.org.co/ccb/pot/PC/files/ley388.html

13 https://www.procuraduria.gov.co/portal/media/file/docs/ddr/CompiladoNormativo Parte3.pdf
} 


\subsection{Evolución de las políticas estatales frente a la VIS colombiana}

El papel que el Estado Colombiano ha jugado en el desarrollo de la vivienda social ha sido preponderante y cambiante políticamente. Inicialmente desempeñaba el rol protagónico que la administraba, promovía y producía, mientras que en la actualidad se muestra como un actor desinteresado que delegó la mayoría de sus funciones.

De acuerdo con Ceballos, Saldarriaga, \& Tarcópulos (2008), las etapas más notorias son: la higienista, la institucional, la transicional, la de creador de corporaciones y por último la de subsidios que es la actual y en la que se enfoca este estudio que abarca los desarrollos VIS desde 1990 hasta la fecha.

En la etapa higienista comprendida entre 1919 y 1942, el Estado Colombiano desarrolló el servicio de agua potable y alcantarillado en las ciudades del país con mayor crecimiento. Hubo una política de desarrollo preocupada por la salud pública. También se encara el tema de las Viviendas para la clase obrera y se crean algunas instituciones dedicadas a la financiación y promoción de estas, como el Banco Central Hipotecario, el Instituto de Crédito territorial y la Caja de Vivienda Popular.

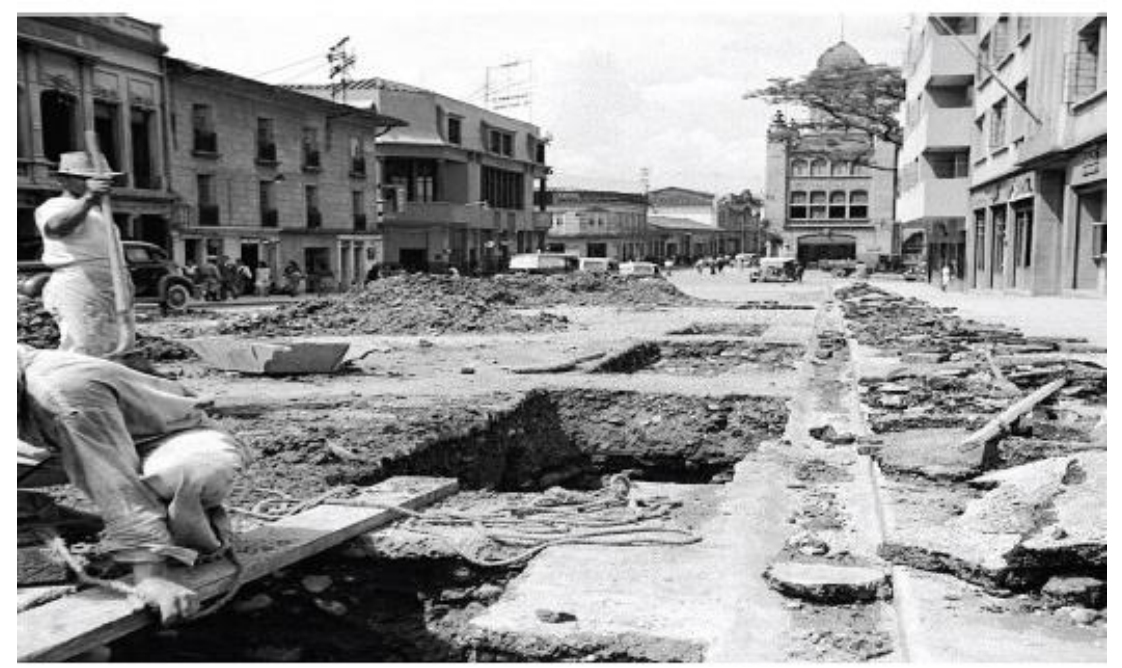

Figura 6. Construcción del alcantarillado de Medellín en la década de 1940. Fuente: (Inicios del alcantarillado de Medellín 1920-1955, 21)

Más delante en la etapa de 1942 a 1965 denominada Institucional por la fortaleza de los organismos que se encargaron del tema de la Vivienda, hubo un rápido crecimiento demográfico en las ciudades. En esta etapa se robustecieron las instituciones existentes y se crearon otras como la Caja de Vivienda Militar y las Juntas Departamentales de Vivienda Popular. El estado impulsó el crédito y otorgó subsidios a cooperativas y familias obreras. Por 
medio de los consejos municipales se compraron o expropiaron los ejidos para la construcción de barrios completos de viviendas obreras que redujeran los déficits habitacionales.

En este mismo periodo, también se acoge el Código Sanitario Nacional, se impulsa sobre todo la construcción de Vivienda Económica no mayor a $150 \mathrm{~m}^{2}$ y hay una preocupación por evitar la especulación en los costos del suelo y los inmuebles.

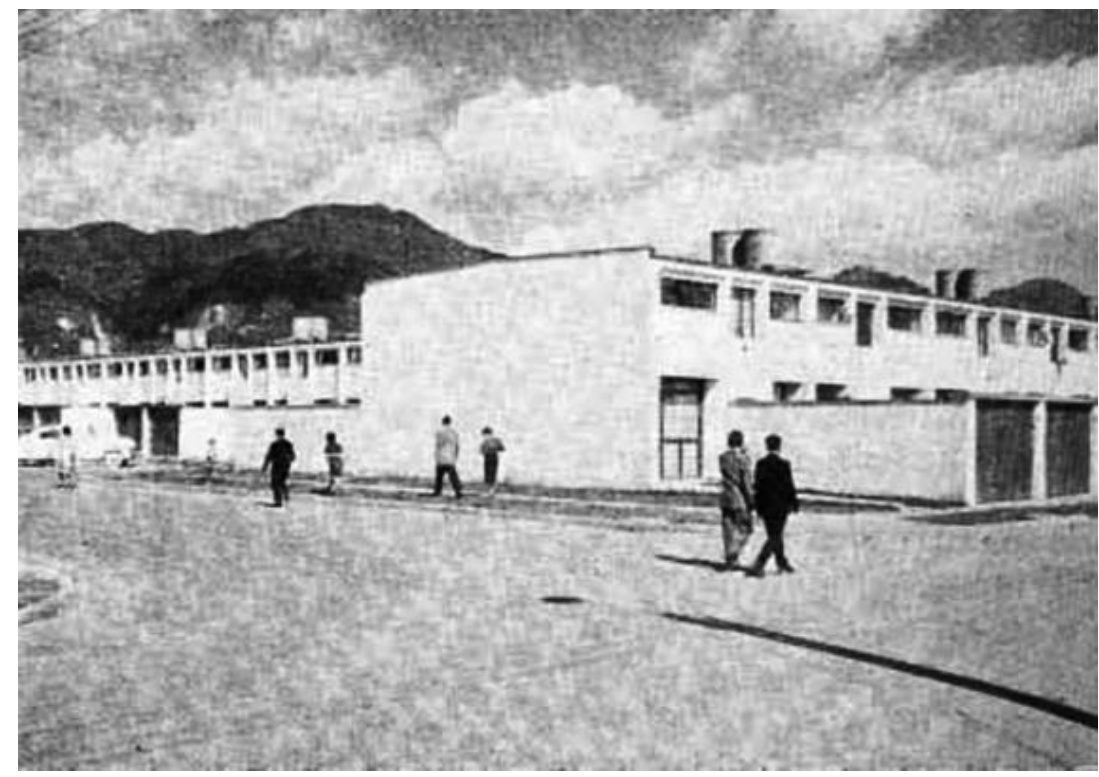

Figura 7. Vista del barrio Quinta Mutis en Bogotá, desarrollado por el Banco Central Hipotecario. Fuente: http://www.a57.org/articulos/cr-nica/habitar-moderno-sobre-las-pol-ticas-estatales-y-la-construcci-n-de-lavivienda-soc

Luego, en la etapa Transicional, entre 1965 y 1972, el Estado Colombiano empieza un periodo de cambio donde delega algunas responsabilidades y utiliza la construcción de vivienda como mecanismo para incentivar el desarrollo económico privado. En esta etapa los constructores y bancos privados empiezan a involucrarse con el tema.

Este periodo está caracterizado por el fuerte impacto de la migración de población campesina a la ciudad, se produjeron urbanizaciones ilegales con condiciones precarias, por lo cual se decide proteger los límites de las ciudades, desincentivar el crecimiento, promover la autoconstrucción, incluir planes de mejoramiento para vivienda informal, impulsar urbanizaciones en altura, disminuir los costos de mano de obra y vincular a los constructores privados con la generación de vivienda de bajo costo. 


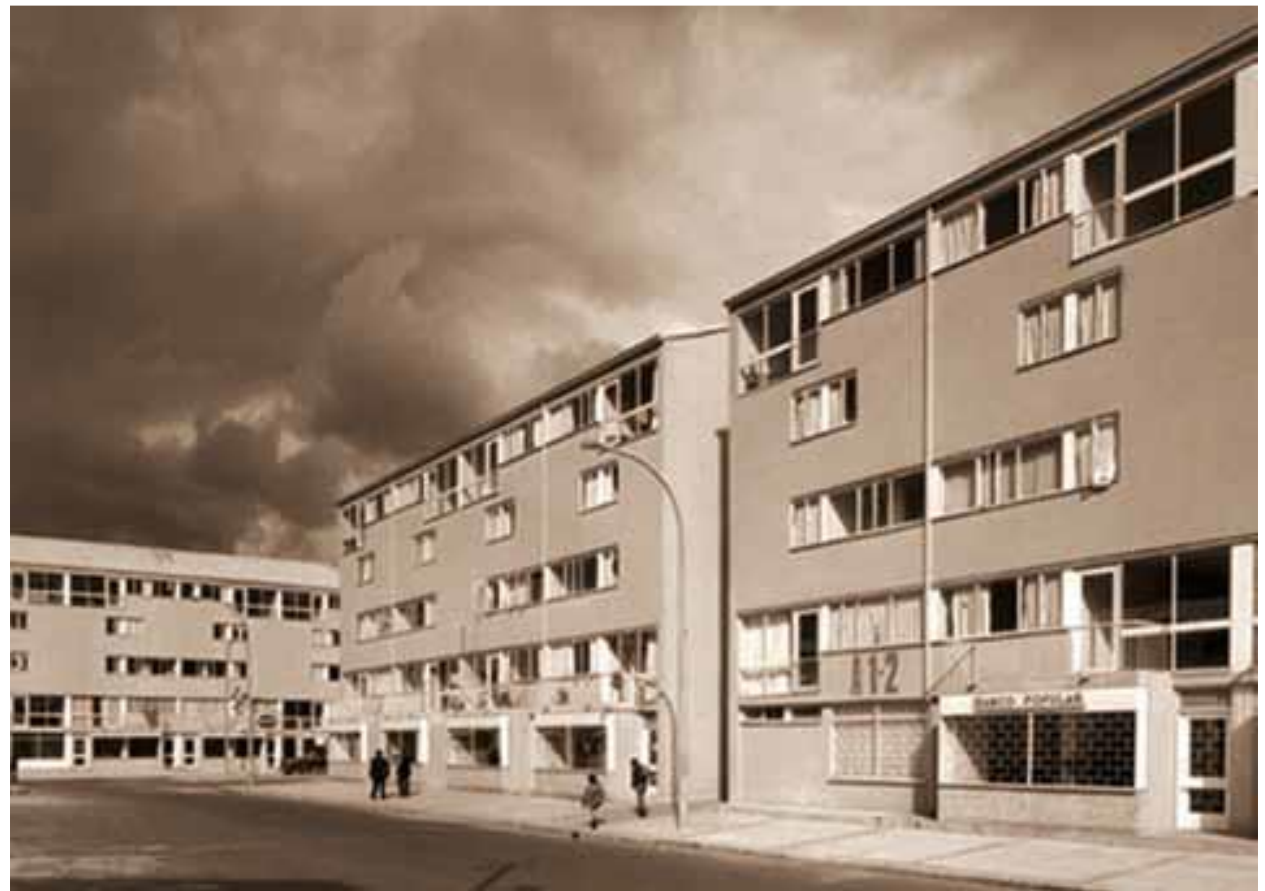

Figura 8. Barrio Pablo VI, Bogotá Colombia 1966. Fuente: VIS en Bogotá: Lecciones de Gestión Estatal, Guillermo Mejía correa.

Posteriormente, entre 1972 y 1990 el Gobierno Colombiano aplica una política de creación de corporaciones. Durante esta etapa las corporaciones de ahorro y vivienda convierten a las grandes empresas constructoras en las protagonistas del tema residencial. Estas empresas se centraron en la construcción de inmuebles para clases medias y altas e indirectamente a la generación de empleos para que las clases obreras pudiesen acceder a una solución de vivienda con sus respectivos salarios, provocándose así un déficit de vivienda de bajo costo y un ambiente propicio para la urbanización espontánea.

En contraste, la vivienda producida por las constructoras llegó a una sobreoferta, pero las poblaciones demandantes no tenían los recursos para acceder a ella. Frente a estos problemas el gobierno tomó acciones en los barrios subnormales, incentivando el desarrollo progresivo en lotes con servicios básicos de $41 \mathrm{~m}^{2}, 60 \mathrm{~m}^{2}, 90 \mathrm{~m}^{2}$ y $120 \mathrm{~m}^{2}$, e impulsó el desarrollo barrial-comunal.

Las consecuencias de la política de desarrollo habitacional de este periodo fueron: un retroceso en la calidad de la VIS y un caos especulativo acerca del costo de las edificaciones y el suelo. Frente al tema del suelo las discusiones se habían iniciado desde la década de los sesenta y se culmina en este periodo con la Ley 9 de 1989 de planeamiento urbano, con la cual cada municipio debe determinar su plan de desarrollo, en los cuales aparecen normas urbanísticas, áreas de expansión y mecanismos de adquisición y expropiación de suelo. 


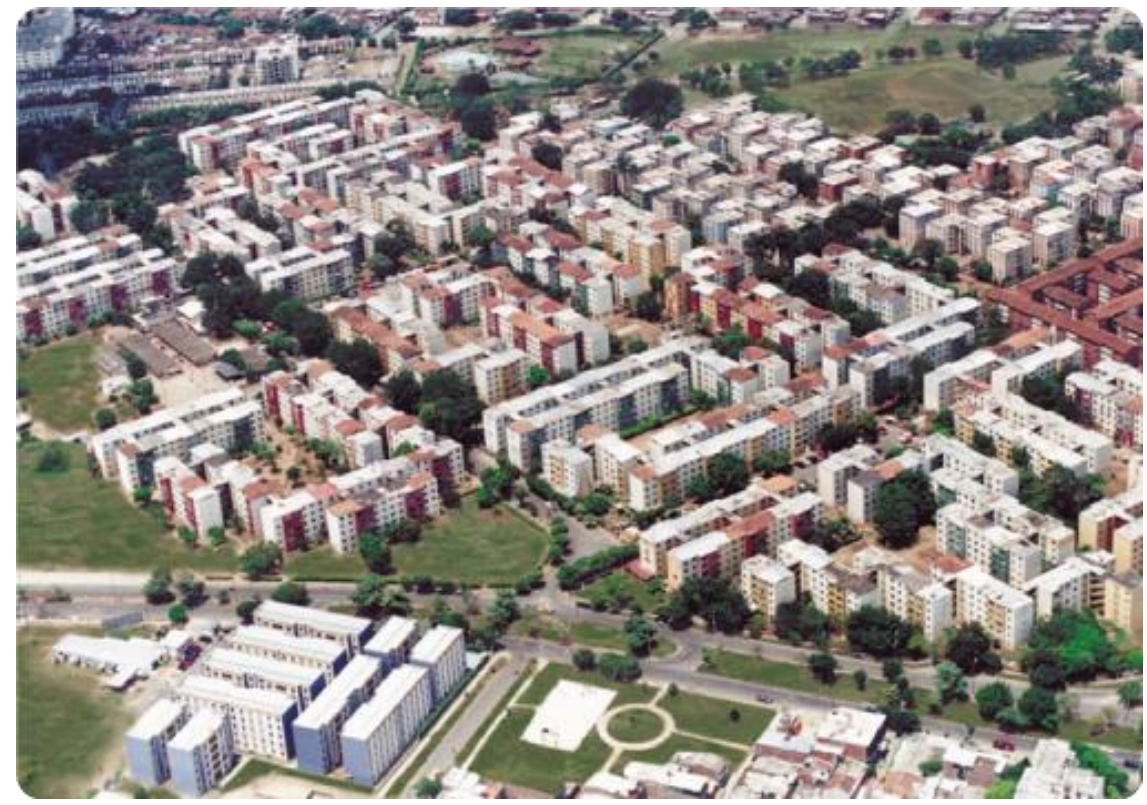

Figura 9. Urbanización Chiminangos en Cali, Década del 80. Fuente: Constructora IC Prefabricados

Por último, al periodo desde 1990 hasta la fecha, podría denominarse la etapa de los subsidios, porque la política estatal actual para VIS gira solamente en torno a la adjudicación de subsidios familiares. Este sistema se enmarcó legalmente con la Ley 3 de 1991 o Sistema Nacional de Vivienda de Interés Social ${ }^{14}$ (Congreso de Colombia, 1991), que describe la forma de aplicar y otorgar los subsidios.

El mecanismo para entregar los subsidios tiene muchos requisitos entre los cuales están: estar bancarizado, la pertenencia a una caja de compensación ${ }^{15}$, tener conformado un hogar legalmente ${ }^{16}$ y tener un certificado de ingresos o certificado laboral.

Estas condiciones dejan por fuera de concurso a muchas personas, lo cual no se dice metafóricamente sino literalmente, porque el sistema de adjudicación funciona como un

14 https://camacol.co/sites/default/files/base datos juridico/LEY CONGRESO NACION 0003 1991.pdf

15 Son entidades privadas, sin ánimo de lucro, de redistribución económica y naturaleza solidaria, creadas para mejorar la calidad de vida de las familias de los trabajadores colombianos, mediante la gestión y entrega, en subsidios y servicios, de parte de los aportes de seguridad social que hacen los empleadores. Las cajas de compensación reciben para su funcionamiento el $4 \%$ de los aportes de seguridad social que pagan los empleadores.

${ }^{16}$ Es decir que debe tener un documento legal, como el registro civil de matrimonio o acta de unión marital de hecho. En este sentido, se entiende por hogar el conformado por conyugues, las uniones maritales de hecho, incluyendo las parejas del mismo sexo y/o grupo de personas unidas por algún vínculo de parentesco hasta tercer grado de consanguinidad, segundo de afinidad y primero de civil, que compartan un mismo espacio habitacional. 
concurso en el que se compite por puntos, estos puntos se van ganando de acuerdo con otras características del hogar, tales como la capacidad de pago de cada solicitante, su capacidad de endeudamiento, tener un crédito aprobado, un ahorro existente o programado ya sea materializado en un lote o en una cuenta bancaria, entre otros.

Desde que esta ley entró en vigencia, la política estatal recortó su accionar para dinamizar la economía, favoreció el sector privado y depositó la confianza en el sistema de subsidio familiar como mecanismo de funcionamiento y financiación. Algunas instituciones estatales sobrevivientes como el Fondo Nacional del Ahorro y la Caja de Vivienda Militar se ajustaron a este nuevo sistema. Y las cajas de compensación familiar han desempeñado el papel de administradoras de los subsidios y en algunos casos de promotoras y constructoras a la vez.

Esta política de subsidios no ha garantizado que se satisfagan las cantidades ni las calidades de la comunidad en materia de déficit habitacional, incluso ni se ha logrado que el sector de la industria de la construcción dinamice la economía lo suficiente como para que todos los colombianos tengan un empleo y puedan pagarse una vivienda digna.

Según Escallón (2011), son pruebas fehacientes de lo anterior, los copiosos asentamientos precarios al margen de las principales ciudades como Bogotá, Cali o Medellín, y el persistente déficit de vivienda que según el DANE 17 (Departamento Administrativo Nacional de Estadística - DANE, 2018) , a 2017 es de 3’300.000 viviendas, de las cuales 1'300.000 es cuantitativo y $2^{\prime} 000.000$ es cualitativo, lo cual representa el $9,5 \%$ y el $15,3 \%$ de la población respectivamente.

Escallón afirma que este panorama de estancamiento o incluso retroceso en la política de desarrollo de VIS es atribuible a factores bastante debatibles como el desmantelamiento o debilitamiento de las instituciones que administraban, coordinaban, planeaban, ejecutaban, revisaban y evaluaban la construcción de VIS.

El marco técnico, por un tiempo limitó las opciones de subsidio solamente a la oferta de viviendas nuevas, posteriormente se tuvieron en cuenta otras dinámicas y modalidades de vivienda, como por ejemplo la construcción en lote o terraza propia, compra de vivienda usada y mejoramiento de vivienda y entorno. Esto permitió a las familias escoger la mejor opción que

\footnotetext{
17 https://www.dane.gov.co/index.php/estadisticas-por-tema/pobreza-y-condiciones-de-vida/deficit-de-vivienda
} 
se les acomodara, lamentablemente, estas opciones diferentes a las de vivienda nueva solo aplican para casos especiales y son muy exclusivas.

Otro de estos factores es la poca variedad, la baja calidad y los altos costos de las ofertas de vivienda nueva, que parecen pensadas siempre para un modelo de familia nuclear ${ }^{18}$ idealizado. Además, las constructoras han venido produciendo viviendas con un enfoque en la rentabilidad económica propia más que en ofrecer viviendas de alta calidad que continúen acoplándose, consolidando y conformando la ciudad.

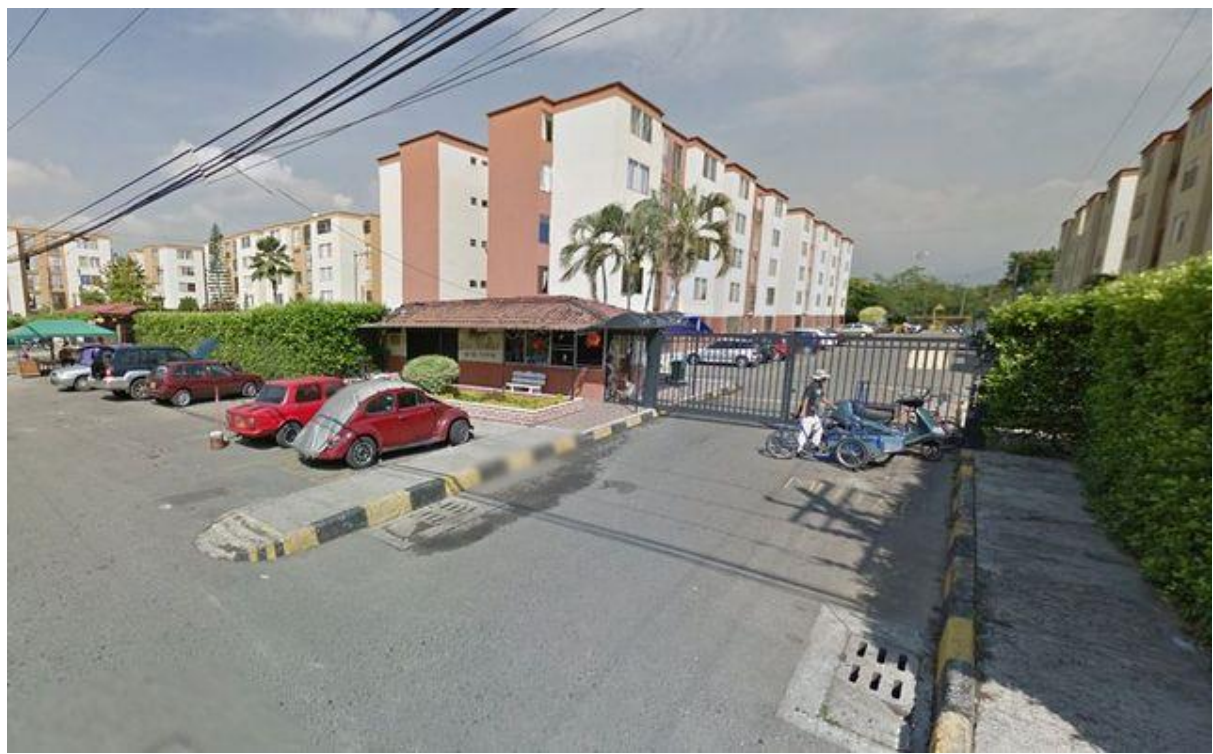

Figura 10. Unidad residencial brisas de los álamos, Cali, década de los 90. Fuente: http://co.clasificados.com/apartamento-en-venta-en-brisas-de-los-alamos-cali-1309190.

La revisión de las políticas del Estado frente a la VIS durante casi un siglo deja en evidencia su débil interés por planear, promover y controlar este tema que es de gran impacto en el territorio y el bienestar de todo el país. Por ahora, estos últimos lineamientos expuestos continuarán hasta mediados del 2018.

\footnotetext{
${ }^{18}$ Aquella formada por padre, madre e hijos (Hakim, 2005).
} 


\subsection{Impacto de la VIS en el territorio nacional y de Cali}

El verdadero impacto de este tipo de vivienda en Colombia es difícil de dimensionar debido al fenómeno de la construcción ilegal. Algunos reportes hechos por las secretarías de control físico o planeación municipal en ciudades como Cali19 (Periódico El País, 2015) y Villavicencio ${ }^{20}$ (Periódico El Tiempo, 2013) señalan que entre el $80 \%$ y el $60 \%$ de las construcciones del área urbana y el 100\% del área rural se erigen sin licencia de construcción, por esta razón, se considera que las cantidades de unidades o áreas construidas de VIS mostradas por las estadísticas son mucho mayores.

Precisamente las estadísticas de cantidad de VIS y No VIS de la Figura 11, provenientes del DANE (Departamento Nacional de Estadística DANE, 2017), muestran que la demanda y desarrollo de este tipo de vivienda en el país es casi la mitad del total, es decir, de la cantidad total de viviendas culminadas legalmente entre 2013 y 2016 , la VIS ocupa el $49 \%$ y la No VIS el $51 \%$.

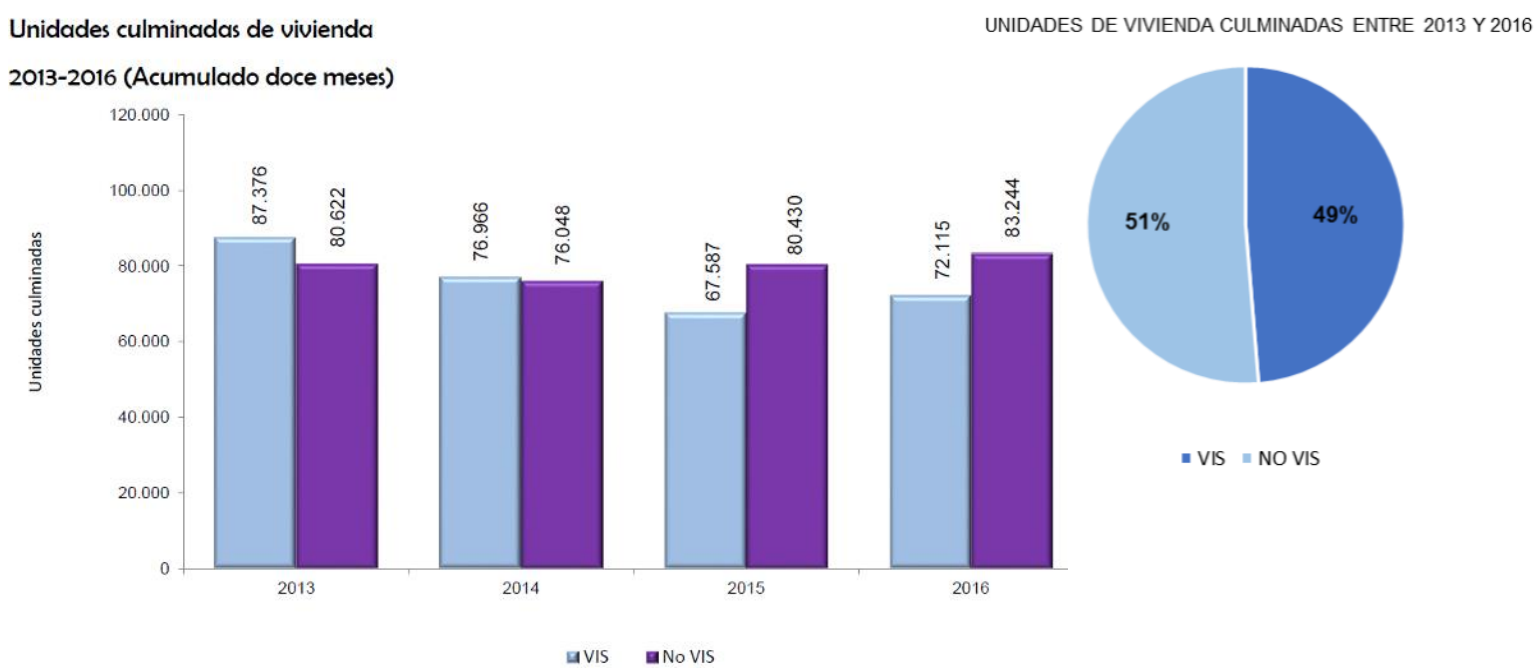

Figura 11. Gráfica comparativa de cantidades y porcentajes de viviendas culminadas VIS o No VIS durante 2013 y 2016. Fuente: (Departamento Nacional de Estadística DANE, 2017)

Con el objetivo de dimensionar el impacto que las VIS tienen sobre Santiago de Cali, se elaboró un plano que muestra los desarrollos de este tipo de vivienda que se han venido dando desde la década del cuarenta hasta la actualidad teniendo como base los registros

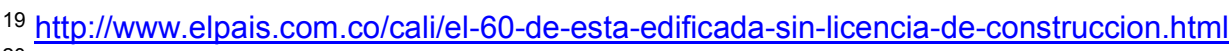

20 http://www.eltiempo.com/archivo/documento/CMS-12562830 
expuestos por el INURBE ${ }^{21}$ (Instituto Nacional de Vivienda de Interés Social y Reforma Urbana INURBE, 1996). Este plano, que se muestra en la Figura 12, se organizó por colores para llevar un registro cronológico década a década de los avances de la ciudad en materia de VIS y su ocupación de territorio.

Debe aclararse que, en la década del cuarenta, para denominar a este tipo de vivienda no se usaba el término de vivienda de interés social, sino que se le denominaba "vivienda para pobres", "vivienda popular" o "vivienda obrera". Estos desarrollos incluyen materializaciones urbanas como loteos, programas de autoconstrucción, barrios, proyectos independientes o privados, invasiones y asentamientos subnormales.

Década del cuarenta: Es un tiempo caracterizado por el crecimiento espontáneo, pero controlado, en este periodo aparecen barrios planeados por el municipio, como el Barrio Obrero, Benjamín Herrera, Popular, Jorge Isaacs y El porvenir. Sin embargo, también aparece el asentamiento de Siloé como invasión en la ladera al suroccidente de la ciudad.

Década del cincuenta: Durante este periodo marcado por las migraciones masivas de campesinos a la ciudad aparecen más invasiones en la ladera, se trata de los barrios Terrón Colorado y Meléndez, con ellos también surgen otros barrios de vivienda popular como el barrio Joaquín Borrero, Villanueva y Primitivo Crespo.

Década del sesenta: En esta década se impulsa la creación y ampliación de la ciudad mediante desarrollos de barrios obreros hacia el oriente, donde la tierra era más económica. Por medio del ICT (instituto de crédito territorial), aparecen barrios como El Guabal, La Floresta, La Fortaleza, La Merced, Vipasa, Periquillo, Aguablanca, Calima y Santa Mónica.

Década del Setenta: Durante este tiempo se estanca la actividad de solucionar el problema habitacional de los más pobres y se le dio prioridad a la creación de viviendas para las clases medias y altas, también por medio del ICT.

Década del Ochenta: En este tiempo se presenta una gran explosión de urbanización clandestina al oriente de la ciudad, incontrolable por el municipio, surgen grandes asentamientos en el Distrito de Aguablanca, Petecuy, El Vallado, Mojica. Mientras que, los

${ }^{21}$ Se trata del Instituto Nacional de Vivienda de Interés Social y Reforma Urbana, creado en 1997. Se encargó de coordinar actividades con las entidades del Sistema Nacional de Vivienda de Interés Social para el desarrollo de las políticas respectivas y la aplicación de la Reforma Urbana. 
esfuerzos del estado se concentraron en promover la VIS en altura, entre estas soluciones están la Urbanización Santiago de Cali, Chiminangos, Los Álamos, Cañaverales y Floralia

Década del Noventa: Caracterizada por la creación del Sistema VIS y los subsidios para la adquisición de vivienda. Hubo un boom de soluciones ofrecidas por constructoras privadas, tanto barrios de casas independientes como multifamiliares en altura, algunos de ellos son: Ciudad Córdoba, Puerta del sol, El Pondaje, Alto Meléndez, Ciudad 2000, Desepaz, Remanso de Fonoviemcali, Gomovas, Ciudadela Arquidiocesana, Rincón de Comfandi, Sorrento I y II, El Laguito, El Vergel, El poblado II, Mojica, San Miguel, La base, Urbanización golondrinas, Brisas de los Álamos, Lares de Comfenalco, Oasis de Comfandi, Puente del Comercio, Torremolinos, Puente Palma, Villa cristina, Mario Uribe, Los Álamos y Urbanización Barranquilla.

Del año 2000 al presente, se presentaron grandes cantidades de desarrollos VIS, concentrados principalmente en la zona sur y oriental de la ciudad, en barrios como El Caney, Brisas del Limonar y Valle del Lili y algunos pocos en el suroccidente, en zonas como Santa Elena y Alto Meléndez. El POT ${ }^{22}$ de Cali (Planeación Municipal, Alcaldía de Santiago de Cali, 2014) prevé zonas de desarrollo futuro para este tipo de viviendas extendiendo aún más el límite horizontal de la ciudad hacia los límites del Municipio de Puerto Tejada y Jamundí.

22 Plan de Ordenamiento Territorial: La Ley 388 de 1997 lo define como el conjunto de objetivos, directrices, políticas, estrategias, metas, programas, actuaciones y normas, destinadas a orientar y administrar el desarrollo físico del territorio y la utilización del suelo. http://www.cali.gov.co/planeacion/publicaciones/106497/pot 2014 idesc/ 


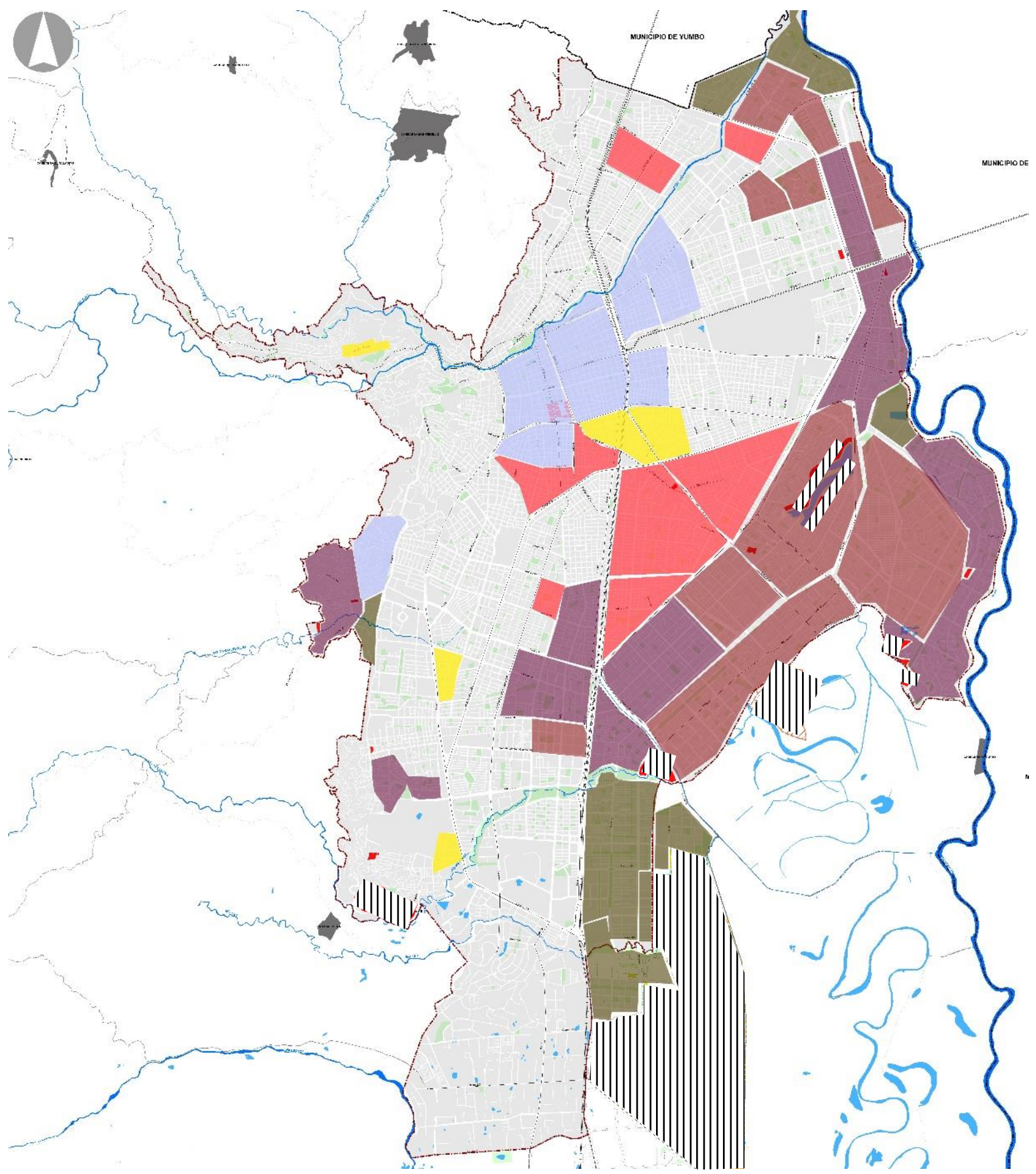

Década del cuarenta

Década del cincuenta

Década del sesenta

Décadas del setenta y ochenta

Década del noventa

Año 2000 a la actualidad

IIIIIIIII Zonas de desarrollo futuro para VIS

Figura 12. Plano de Cali con indicación de desarrollos de VIS desde 1940 a la actualidad y proyección al futuro. Fuente: Elaboración propia a partir de bibliografía, (Instituto Nacional de Vivienda de Interés Social y Reforma Urbana INURBE, 1996) 
Como lo muestran las manchas de colores en el plano de Cali de la Figura 12, cerca del $50 \%$ del desarrollo urbano se ha llevado a cabo bajo fenómenos relacionados con la VIS y se seguirá expandiendo de esta manera. Sólo de esta forma se alcanza a dimensionar el masivo impacto y la importancia de las decisiones que se han tomado o se tomarán frente a este tipo de edificaciones.

\subsection{Tipologías VIS, el caso nacional y el caso de Cali}

De acuerdo con el informe de vivienda tipo VIS y No VIS realizado por el DANE Op. cit. en 2017, en las principales ciudades del país es común encontrar dos tipologías de VIS diferenciables a simple vista, la tipología de casas individuales y la de multifamiliares o apartamentos.

Entre las principales ciudades del país, el promedio de área para apartamentos tipo VIS oscila entre $44 m^{2}$ y $67 m^{2}$, mientras que el área de las casas varía entre $58 m^{2}$ y $83 m^{2}$, esto depende de factores culturales y económicos como el costo del suelo y de los materiales de construcción en cada ciudad.

Para Cali, entre el año 2012 y el 2016 el área promedio estos apartamentos para estratos ${ }^{23}$ Bajo-Bajo y Bajo, se encuentra en $49 \mathrm{~m}^{2}$, mientras que los de estrato Medio-Bajo y Medio tienen $56 \mathrm{~m}^{2}$. Por su parte, las casas VIS, para estrato Bajo-Bajo y Bajo se encuentra en $72 \mathrm{~m}^{2}$ y para estratos Medio-Bajo y Medio llegan a $80 \mathrm{~m}^{2}$.

De acuerdo con estas cifras, Cali, la tercera ciudad con mayor cantidad de habitantes en Colombia, presenta un comportamiento promedio en cantidad de área, ya que las unidades de vivienda sean apartamentos o casas no tienen los valores más altos ni tampoco los más bajos $^{24}$. Este fenómeno puede apreciarse en las siguientes gráficas de la Figura 13 y la Figura

\footnotetext{
${ }^{23}$ Es una clasificación socioeconómica que tiene en cuenta las características de la vivienda y el entorno utilizada por el DANE como metodología de recolección y análisis de datos. Estos estratos son 6: 1. Bajo-bajo 2 . Bajo 3. Medio-bajo 4. Medio 5. Medio-alto 6. Alto. Los estratos 1, 2 y 3 corresponden a los usuarios con menores recursos, los cuales reciben subsidios en los servicios públicos domiciliarios; los estratos 5 y 6 corresponden a usuarios con mayores recursos económicos, quienes pagan sobrecostos sobre el valor de los servicios públicos domiciliarios. El estrato 4 no es beneficiario de subsidios, ni debe pagar sobrecostos.

${ }^{24}$ Solamente en el caso de la tipología de casas para estrato Medio-Bajo y Medio se encontró que el área en Cali era superior.
} 
14, en las que se realiza una comparación con Bogotá y Pasto, ciudades caracterizadas por los altos y bajos costos del suelo y la construcción respectivamente.

Área por unidad de vivienda VIS tipología de apartamentos en $\mathrm{m}^{2}$

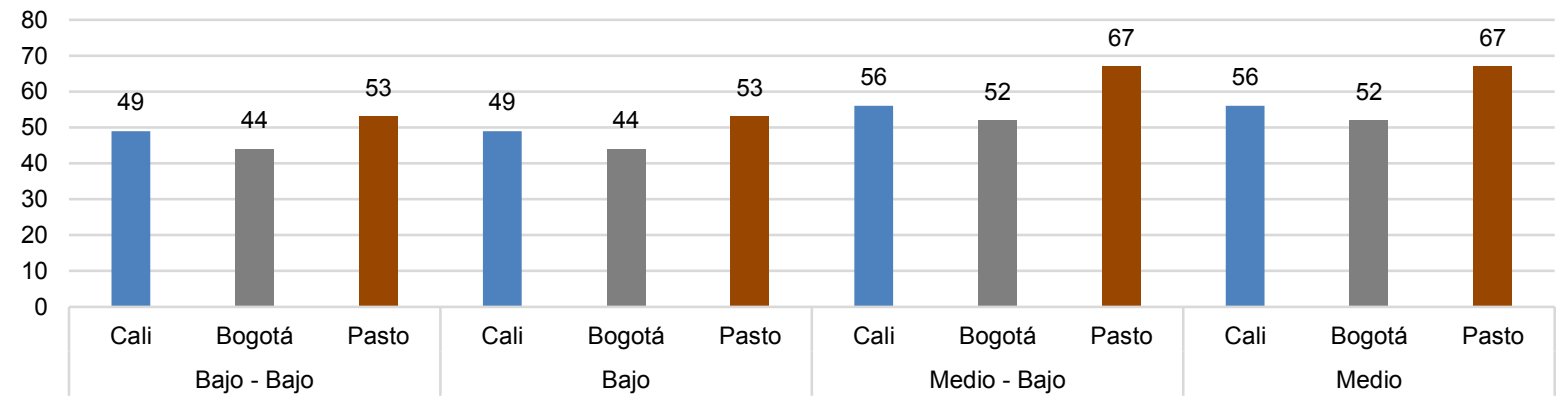

Figura 13. Gráfica comparativa de área por unidad de vivienda VIS tipo apartamento en m2. Fuente: Elaboración propia con datos del informe de Vivienda VIS y No VIS del DANE.

Área por unidad de vivienda VIS tipología de casas en $\mathrm{m}^{2}$

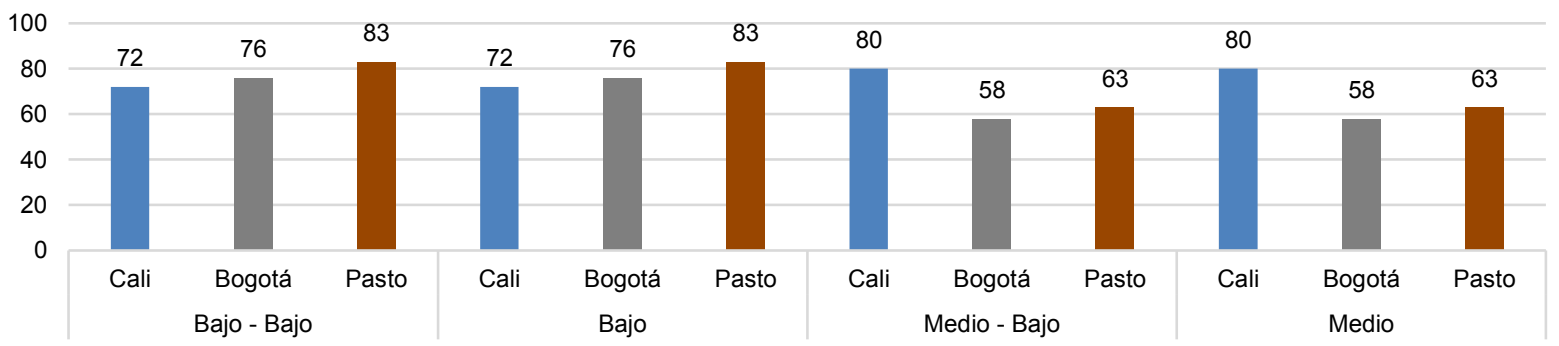

Figura 14. Gráfica comparativa de área por unidad de vivienda VIS, tipología de casas en m2. Fuente: Elaboración propia con datos del informe de Vivienda VIS y No VIS del DANE.

Para ejemplificar la tipología de casas individuales se tomó el conjunto residencial Rosedal de Comfandi con $60 \mathrm{~m}^{2}$, ubicado al sur oriente de la ciudad mostrado en la Figura 15, que contiene la planta del primer y segundo piso de un módulo constructivo conformado por dos viviendas, un corte longitudinal y una vista exterior.

Para la tipología de apartamentos, se utilizó como ejemplo el proyecto Sotorela de la firma IC Prefabricados de $47 \mathrm{~m}^{2}$ mostrado en la Figura 16 , donde se puede apreciar una vista exterior de los bloques y la planta de un apartamento típico del multifamiliar. 


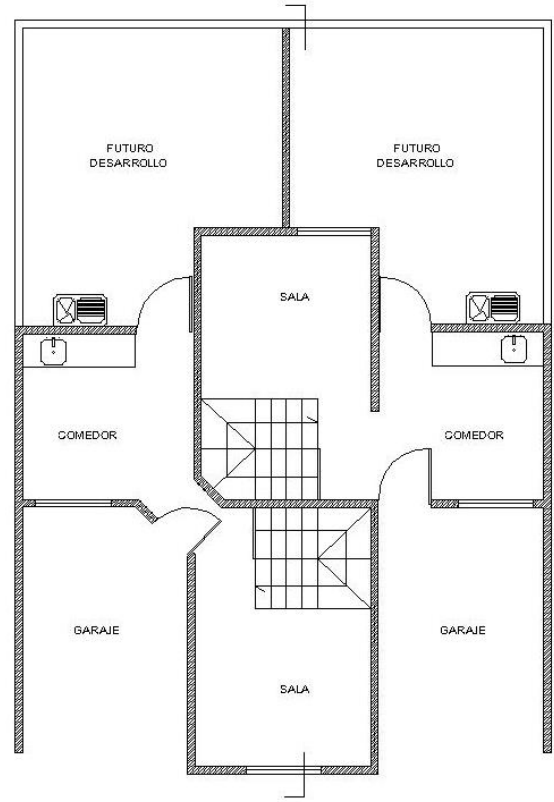

PLANTA PRIMER PISO

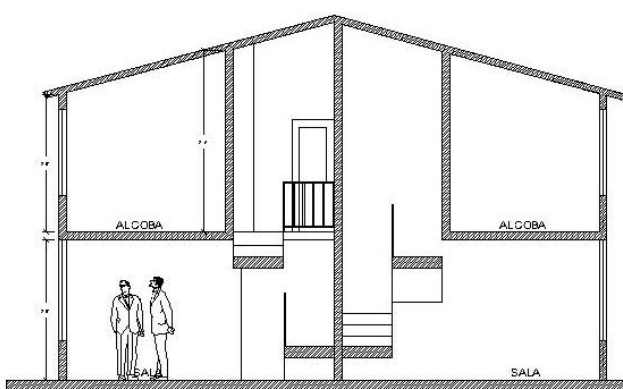

CORTE LONGITUDINAL

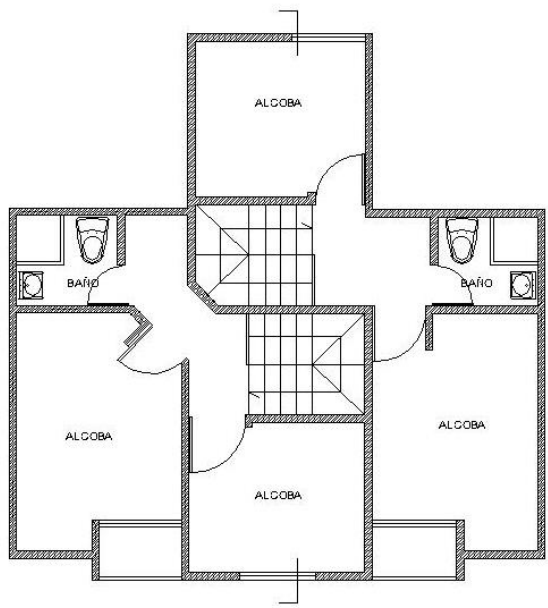

PLANTA SEGUNDO PISO

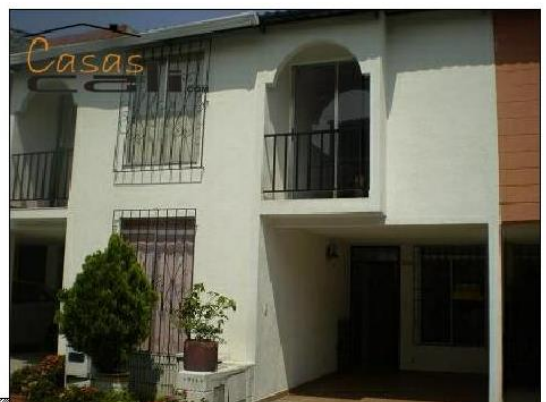

FOTOGRAFÍA EXTERIOR

Figura 15. Planimetrías y Fotografía del Conjunto Residencial Rosedales de Comfandi. Tipología de casas Individuales. Fuente: Departamento de Vivienda Comfandi.
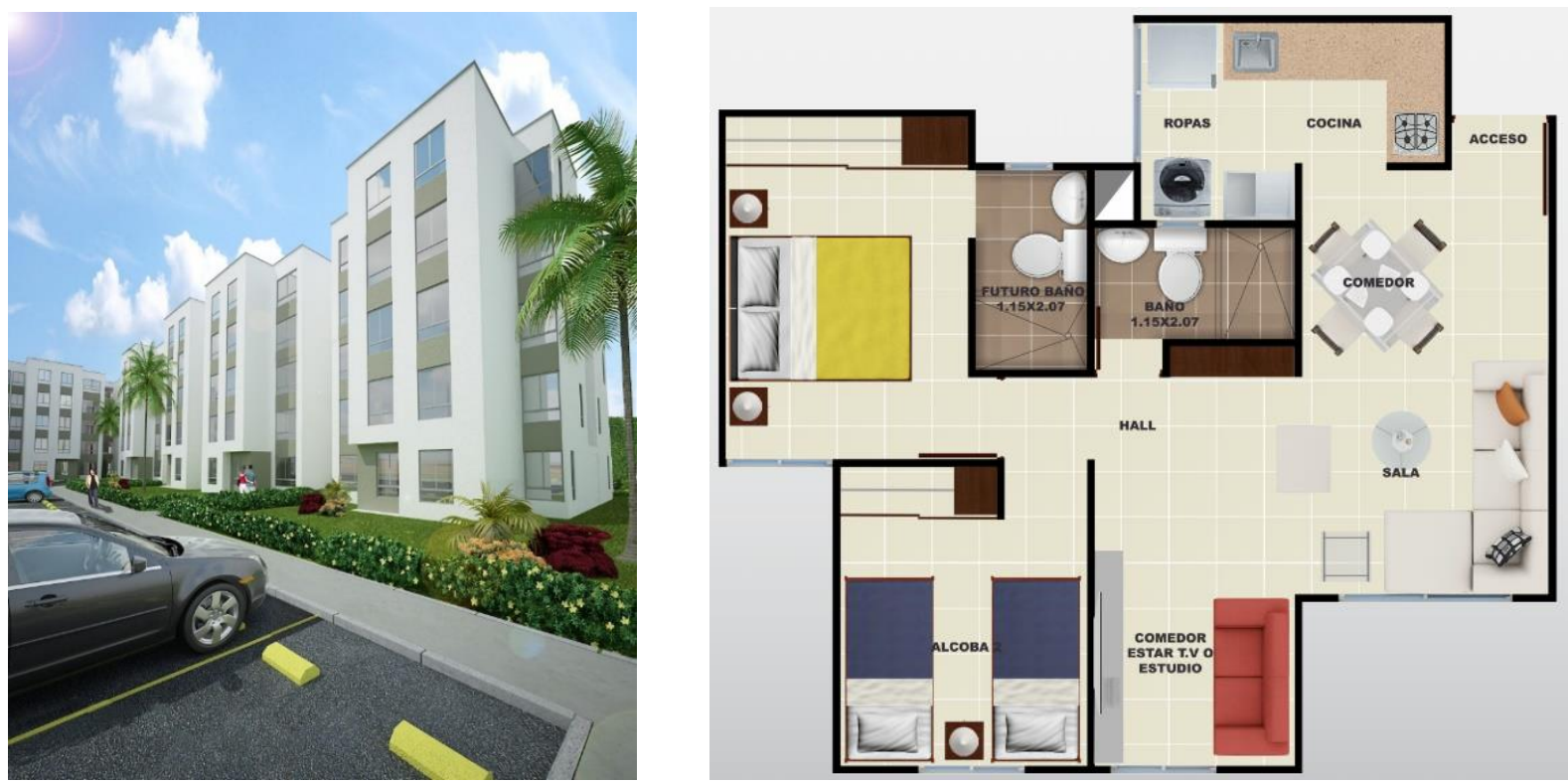

Figura 16. Vista exterior y planta tipo de uno de los apartamentos Sotorela de IC prefabricados. Tipología multifamiliar Fuente: IC Prefabricados (http://icprefabricados.com/). 
Si se centra la mirada en la distribución porcentual de tipologías VIS dentro del país, graficada en la Figura 17 , se encuentra que el $68 \%$ de las soluciones se resuelven con la tipología de apartamentos y tan solo el $32 \%$ con la tipología de casas.

Distribución de porcentaje de tipologías VIS a nivel nacional

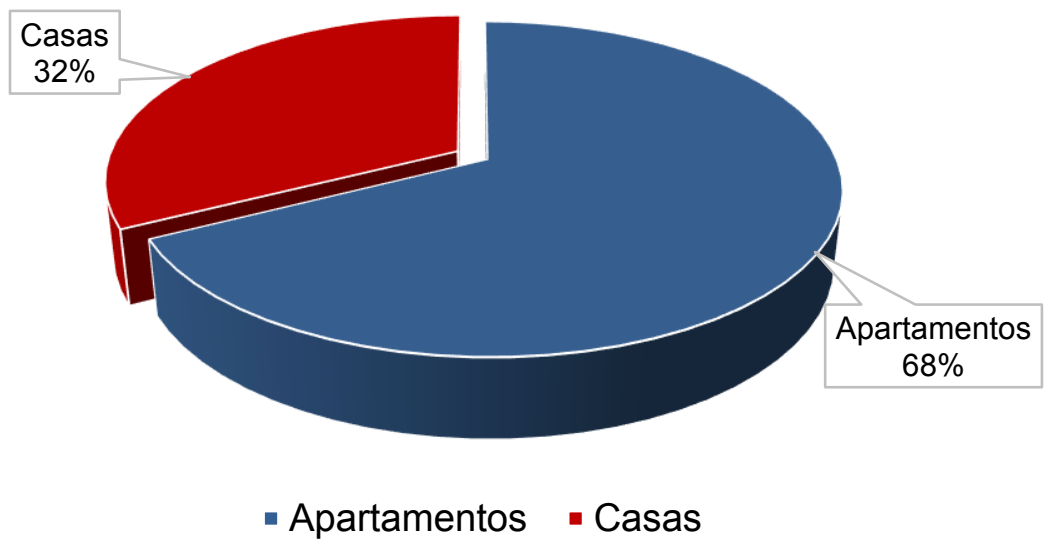

Figura 17. Distribución de porcentaje de tipologías de VIS a nivel nacional. Fuente: Elaboración propia con datos del informe de Vivienda VIS y No VIS del DANE. Fuente: (Departamento Nacional de Estadística DANE, 2017).

Este comportamiento nacional concuerda muy cerca con el obtenido en la ciudad de Cali, ya que, en esta ciudad, la tipología de apartamentos tiene un $69 \%$ mientras que la tipología de casas sólo el 31\%. Estos porcentajes concuerdan con lo reportado por Gamboa et al Op. cit entre 2004 y 2007, quienes encontraron que durante ese periodo el porcentaje más alto lo tienen los multifamiliares con $67,14 \%$ y la tipología de casas tiene $32,86 \%$.

\subsection{Normativas vigentes}

Dando cumplimiento a lo estipulado en los parámetros de calidad del folleto informativo No. 21 para garantizar el derecho a una vivienda digna de la Oficina del Alto Comisionado para los Derechos Humanos de la ONU (Alto Comisionado para los Derechos Humanos, Organización de las Naciones Unidas, 2009), en todo el territorio colombiano, las edificaciones de VIS deben cumplir una serie de normativas que se han venido adoptando para mejorar la seguridad y la calidad habitacional.

A continuación, se presenta la Tabla 3, que compila dichas normativas para luego entrar en detalle con cada una. 


\begin{tabular}{|c|c|c|c|c|}
\hline CARACTERÍSTICA & DESCRIPCIÓN & DISCIPLINA & NORMATIVA & CUMPLIMIENTO \\
\hline & Construcción Sismorresistente & Ingeniería Civil & NSR-10 (AIS,2010) & Obligatorio \\
\hline & Uso adecuado del Agua & Ingeniería Sanitaria & $\begin{array}{c}\text { RAS } 2000 \\
\text { (Minvivienda,2000) }\end{array}$ & Obligatorio \\
\hline & $\begin{array}{c}\text { Adecuadas instalaciones } \\
\text { eléctricas }\end{array}$ & Ingeniería Eléctrica & RETIE (Minminas,2004) & Obligatorio \\
\hline $\begin{array}{c}\text { Vivienda segura y } \\
\text { eficiente }\end{array}$ & $\begin{array}{c}\text { Apropiadas instalaciones de } \\
\text { iluminación y alumbrado } \\
\text { público }\end{array}$ & 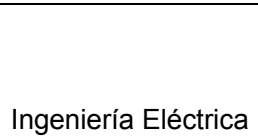 & RETILAP (Miniminas,2009) & Obligatorio \\
\hline Normativa Urbana & $\begin{array}{l}\text { Normas urbanísticas propias de } \\
\text { cada Municipio }\end{array}$ & Arquitectura & $\begin{array}{l}\text { POT o Normas urbanas de } \\
\text { cada municipio }\end{array}$ & Obligatorio \\
\hline Sustentabilidad & $\begin{array}{l}\text { Reglamento Técnico de } \\
\text { Construcción Sostenible }\end{array}$ & Arquitectura & $\begin{array}{c}\text { Resolución } 0549 \text { de } 2015 \\
\text { (Ministerio de vivienda, } \\
\text { Ciudad y Territorio) }\end{array}$ & Optativo \\
\hline $\begin{array}{l}\text { Guías de asistencia } \\
\text { técnica para vivienda } \\
\text { de interés social: } \\
\text { espacios). }\end{array}$ & $\begin{array}{c}\text { Valor, área, altura y frente de } \\
\text { vivienda mínimos, área y lados } \\
\text { mínimos de los }\end{array}$ & Arquitectura & $\begin{array}{c}\text { Ministerio de vivienda, } \\
\text { Ciudad y Territorio }\end{array}$ & Obligatorio \\
\hline
\end{tabular}

Tabla 3. Compilación de Normativas para la VIS en Colombia. Fuente: Elaboración propia.

\subsubsection{Norma NSR-10, Norma Sismorresistente ${ }^{25}$ (Asociación Colombiana de Ingeniería Sísmica, 2010)}

En 1975, se fundó la Asociación Colombiana de Ingeniería Sísmica, y desde esa fecha se ha venido trabajando en el tema de la reglamentación estructural a las construcciones, ya que el territorio colombiano posee actividad sísmica y ha tenido que sufrir varias tragedias de este tipo, como la de Popayán en 1983 y el eje cafetero en 1999.

La versión actual NSR-10 es la tercera versión, después de la de 1984 y 1998.

Todos los proyectos a construir deben cumplir con los requisitos que para este apliquen, en los cuales figura el dimensionamiento y resistencia de los elementos estructurales, el diseño de evacuación y medidas contra incendio. Obligatoriamente, todos los proyectos VIS deberán cumplir con lo estipulado en ella.

\footnotetext{
${ }^{25}$ https://www.idrd.gov.co/sitio/idrd/sites/default/files/imagenes/titulo-a-nsr-100.pdf
} 


\subsubsection{RAS 2000, Reglamento Técnico para el Sector de Agua Potable y Saneamiento Básico ${ }^{26}$ (MINVIVIENDA, 2000)}

Con la intención de estandarizar el diseño, el proceso constructivo y todos los procedimientos relacionados con el agua potable y saneamiento, en el año 2000 el Ministerio de Desarrollo económico publicó la resolución 1096 del 17 de noviembre, que contiene el Reglamento Técnico para el sector de Agua Potable y Saneamiento Básico RAS 2000.

\subsubsection{RETIE, Reglamento Técnico de Instalaciones Eléctricas ${ }^{27}$ (Ministerio de Minas y Energía, 2013)}

Mediante la resolución 180466 del 2 de abril de 2007, el Ministerio de Minas y energía emitió el Reglamento Técnico de Instalaciones Eléctricas, con el objetivo de reducir los riesgos eléctricos en los procesos de generación, transformación, distribución y utilización de la energía.

También reglamenta la calidad de elementos e insumos de mayor uso en el sector. Esta norma aplica para obras nuevas, remodelaciones o ampliaciones. Es de obligatorio cumplimiento en todo el país de lo contrario no se tendrá conexión eléctrica en el proyecto. Se expide mediante empresas privadas debidamente calificadas y aplica en todo el país.

\subsubsection{RETILAP, Reglamento Técnico de Instalaciones Eléctricas ${ }^{28}$ (Ministerio de Minas y Energía, 2009)}

Desde el 1 de abril de 2010, rige el reglamento Técnico de lluminación y Alumbrado PúblicoRETILAP para los sectores involucrados en el sector de la iluminación y el alumbrado público.

Este reglamento normaliza los requisitos y medidas que deben cumplir los sistemas de iluminación y alumbrado público para garantizar adecuados niveles y calidades de la luz.

Igualmente, para garantizar seguridad en el abastecimiento energético, la protección del consumidor y la preservación del medio ambiente.

\footnotetext{
${ }^{26} \mathrm{http}$ ://www.minvivienda.gov.co/viceministerios/viceministerio-de-agua/reglamento-tecnico-delsector/reglamento-tecnico-del-sector-de-agua-potable

${ }^{27}$ https://www.minminas.gov.co/retie

28 https://www.minminas.gov.co/retilap
} 
El reglamento técnico se aplica a toda instalación de iluminación o alumbrado público y privada nueva, ampliada o remodelada a partir de su entrada en vigencia, dentro de todo el territorio nacional.

\subsubsection{Normas Urbanísticas de cada municipio}

Dependiendo de la cantidad de habitantes en cada municipio, estos deberán o no, crear un Plan de Ordenamiento Territorial, sin embargo, cada municipio debe tener normas urbanas que dictan los lineamientos mediante los cuales se rigen las construcciones, tales como los paramentos, aislamientos, zonas patrimoniales, alturas permitidas, usos del suelo entre otros.

En el caso de Santiago de Cali, el suelo urbano dedicado para desarrollo de VIS sistemáticamente ha ampliado los límites de la ciudad, con lo cual, su suelo urbano creció aproximadamente quince veces en setenta y cuatro años (1940 -2014), (Alcaldía de Santiago de Cali, 2014). Estos crecimientos han sido dramáticos, por su magnitud y velocidad no han admitido una adecuada planificación. Las consecuencias de este crecimiento a lo ancho han ocasionado el agotamiento del suelo en la mayoría de los casos fértil, eliminación de varios ecosistemas, desbalance en la regulación de las aguas o inundaciones, contaminación de los afluentes hídricos entre otros.

Para los usuarios VIS, cuyas viviendas se encuentran en los límites de la ciudad existe la dificultad del incremento en los tiempos de transporte ida y regreso a sus sitios de trabajo, lo cual requiere más gasto de combustible, mayor contaminación por combustión y la creación de nuevas rutas o recorridos del servicio de transporte público. De la misma forma, la infraestructura de transporte no es solamente la que requiere una ampliación, sino también el servicio de electricidad, acueducto, alcantarillado, gas domiciliario, etc.

Por tal razón, la política de expansión de los límites urbanos de la Cali con fines de construcción de VIS es bastante debatible, aún más cuando la misma alcaldía mediante el documento: Cali en Cifras 2014 Op. cit., informó que existen más de 30000 lotes disponibles dentro del territorio urbano. Así mismo, existen zonas de urgente renovación urbana donde pueden plantearse viviendas de este tipo como por ejemplo los barrios San Nicolás y Obrero donde actualmente proliferan bodegas vacías.

Es también controversial que, en Cali las normas urbanísticas limiten la construcción en altura en las comunas de baja densidad habitacional del núcleo de la ciudad, cuya consolidación a nivel de infraestructura es total, mientras que permite grandes alturas a proyectos en zonas declaradas urbanas recientemente cuyos servicios son precarios. 
2.6.6 Guías de asistencia técnica para vivienda de interés social: Valor, área, altura y frente de vivienda mínimos, área y lados mínimos de los espacios $^{29}$ (Ministerio de Ambiente, Vivienda y Desarrollo Territorial, República de Colombia, 2011)

Esta guía tiene el objeto de entregar una herramienta metodológica para la formulación, ejecución y puesta en marcha de proyectos de VIS, como apoyo a los entes territoriales. Además de las condiciones mínimas de habitabilidad, también contiene recomendaciones como la selección del terreno, detalles de diseño arquitectónico e instalaciones eléctricas e hidrosanitarias. Aunque la mayoría del documento es una guía, si debe cumplirse al menos con las condiciones mínimas.

A continuación, se presenta la Tabla 4, resumiendo los principales y mínimos requisitos de habitabilidad en estas construcciones.

\begin{tabular}{|c|c|c|c|c|}
\hline CARACTERÍSTICA & DESCRIPCIÓN & DISCIPLINA & NORMATIVA & CUMPLIMIENTO \\
\hline Valor máximo & 135 SMMLV & \multirow{17}{*}{ Arquitectura } & \multirow{17}{*}{$\begin{array}{l}\text { Guías de asistencia técnica } \\
\text { para vivienda de interés } \\
\text { social (Minvivienda 2011) }\end{array}$} & Obligatorio \\
\hline Área mínima de Lote & $35 \mathrm{~m} 2$ & & & Obligatorio \\
\hline Frente Mínimo & $3,5 \mathrm{~m}$ & & & Obligatorio \\
\hline \multirow[b]{2}{*}{ Altura mínima } & $2,5 \mathrm{~m}$ para clima frío y templado & & & Obligatorio \\
\hline & $\begin{array}{l}\text { 2,7 para clima cálido seco y } \\
\text { húmedo }\end{array}$ & & & Obligatorio \\
\hline \multirow{6}{*}{ Áreas mínimas } & Dormitorio $7,3 \mathrm{~m} 2$ & & & Obligatorio \\
\hline & Cocina $3,6 \mathrm{~m} 2$ & & & Obligatorio \\
\hline & Baño 2,8m2 & & & Obligatorio \\
\hline & Cuarto de ropas $1,1 \mathrm{~m} 2$ & & & Obligatorio \\
\hline & Salón comedor $15,6 \mathrm{~m} 2$ & & & Obligatorio \\
\hline & Área Múltiple 14,6m2 & & & Obligatorio \\
\hline \multirow{6}{*}{ Lado mínimo } & Dormitorio $2,7 \mathrm{~m}$ & & & Obligatorio \\
\hline & Cocina $1,5 \mathrm{~m}$ & & & Obligatorio \\
\hline & Baño 1,2m & & & Obligatorio \\
\hline & Cuarto de ropas $0,8 \mathrm{~m}$ & & & Obligatorio \\
\hline & Salón comedor 2,8m & & & Obligatorio \\
\hline & Área Múltiple 2,7m & & & Obligatorio \\
\hline
\end{tabular}

Tabla 4. Requisitos mínimos de habitabilidad espacial para VIS. Fuente: Elaboración propia a partir de referencias (Ministerio de Ambiente, Vivienda y Desarrollo Territorial, República de Colombia, 2011)

${ }^{29}$ http://www.minvivienda.gov.co/viceministerios/viceministerio-de-vivienda/vis-y-vip/gu\%C3\%ADas-de-asistencia 


\subsubsection{Reglamento técnico de construcción sostenible, Resolución 0549 de 2015 (Ministerio de Vivienda, Ciudad y Territorio, 2015)}

El Ministerio de Vivienda Ciudad y Territorio, emitió este reglamento en el 2015 con el objetivo de cumplir con los compromisos hechos por Colombia en la COP 21, enfocándose en reducir la emisión de gases de efecto invernadero aportadas por las construcciones, mejorar la calidad de vida de los habitantes, reducir los consumos de recursos naturales y fomentar la sustentabilidad de las construcciones.

Aunque es un reglamento obligatorio para todas las edificaciones nuevas, es optativo para las construcciones VIS. Esta norma establece unos porcentajes de ahorro de agua y energía de acuerdo con una línea base creada con estadísticas de consumo suministradas por las empresas prestadoras de servicios públicos.

A pesar de su carácter optativo para VIS, esta norma sugiere que frente a la línea base se obtenga un ahorro de energía entre el $15 \%$ y el $20 \%$; mientras que propone una disminución del consumo de agua entre el $10 \%$ y el 15.

Dejar como optativa la decisión de adoptar este reglamento para las VIS es controversial desde el punto de vista sostenible, pues como se trató en el anterior título 2.4, la mitad de las unidades de vivienda que se construyen en el territorio colombiano corresponden a este tipo de edificaciones caracterizadas por sus deficientes prestaciones de confort térmico (como se demostrará más adelante en el título 2.8 y el Capítulo 4 ), lo cual causa un gran consumo en equipos de acondicionamiento y así mismo provocando un alto consumo energético.

Según el Ministerio de Minas y Energía (MME) (Unidad de Planeación Minero Energética, Ministerio de Minas y energía, República de Colombia, 2006), se ha identificado que la suma de la energía consumida por los estratos 1,2 y 3 a los cuales van dirigidas las VIS, supera lo consumido por los estratos 4,5 y 6 de No VIS.

Dado que la intención del gobierno nacional es disminuir las emisiones de $\mathrm{CO}_{2}$ con menos consumo energético, es totalmente contradictorio que no se obligue la aplicación del reglamento de construcción sostenible en las VIS cuando precisamente el MME señala que el $40 \%$ de la energía eléctrica consumida en el país es destinada al abastecimiento del sector residencial, y además, en este sector los mayores consumos corresponden a los estratos a los cuales pertenecen las VIS. 
Hasta la fecha, este reglamento contiene 2 anexos, el primero es la Guía de construcción Sostenible para el ahorro de agua y energía en edificaciones ${ }^{30}$ y el segundo es un Mapa de clasificación de clima en Colombia según la Temperatura y la Humedad relativa y lista de municipios.

En el primer anexo se explica el mecanismo con el cual se estableció la Línea Base, y partiendo de esta se muestran varias estrategias pasivas y activas con su porcentaje de ahorro energético o de agua y la relación costo-beneficio de llegar a ser implementadas.

De otro lado, el segundo anexo es un mapa y listado de municipios de Colombia donde se pueden consultar las características climáticas de los municipios que conforman el territorio colombiano.

Evidentemente, el cuerpo total de la norma aporta solamente generalidades y carece de profundidad a la hora de especificar los procedimientos a seguir para llevarla a la práctica en el diseño arquitectónico. Por ejemplo, en el caso energético hace falta un manual que indique con cuales de los parámetros de consumo deben darse los ahorros en orden jerárquico (confort térmico, iluminación artificial, equipos electrodomésticos), al igual que el procedimiento de cálculo a utilizar.

Además de lo anterior el reglamento no posee información relacionada con las propiedades físicas de los sistemas constructivos utilizados a nivel nacional como si se hace en las normas de otros países, como por ejemplo Argentina con la norma IRAM 11601 (Instituto Argentino de Normalización IRAM, 2002) o en Estados Unidos con la ASHRAE (2013).

Por último, vale destacar que para solicitar una licencia de construcción de un proyecto arquitectónico, se debe cumplir con la aplicación de este reglamento, pero como certificación de su aplicación en el diseño arquitectónico solamente se pide la firma del arquitecto, lo cual es insuficiente para determinar la veracidad.

Claramente, todas estas críticas pueden relacionarse con el poco tiempo que lleva la norma en vigencia, sin embargo, se espera que por beneficio del medio ambiente haya varios perfeccionamientos posteriores.

${ }^{30}$ http://www.minvivienda.gov.co/Documents/ViceministerioVivienda/ANEXO\%201\%200549\%20-\%202015.pdf 


\subsection{Sistemas constructivos característicos de las VIS en Colombia}

Un sistema constructivo es un conjunto de elementos, materiales, técnicas, herramientas, procedimientos y equipos que, combinados racionalmente y enmarcados en un método, generan un tipo de edificación en particular.

En Colombia, se han usado y siguen usándose sistemas constructivos tradicionales e industrializados para construir VIS. Según las estadísticas de la Cámara Colombiana de la Construcción (CAMACOL, 2016), solo tres sistemas constructivos acapararon el área de construcción de VIS iniciada durante el segundo trimestre del 2012 y el cuarto trimestre del año 2015 en las 16 principales ciudades colombianas. Estos fueron: los sistemas industrializados ${ }^{31}$ con un $40,37 \%$, la mampostería confinada con un $30,99 \%$ y la mampostería estructural con $27,58 \%$. El 1,01\% restante se lo llevaron otros sistemas como la construcción liviana o los sistemas híbridos. Una gráfica construida con estos datos se muestra en la
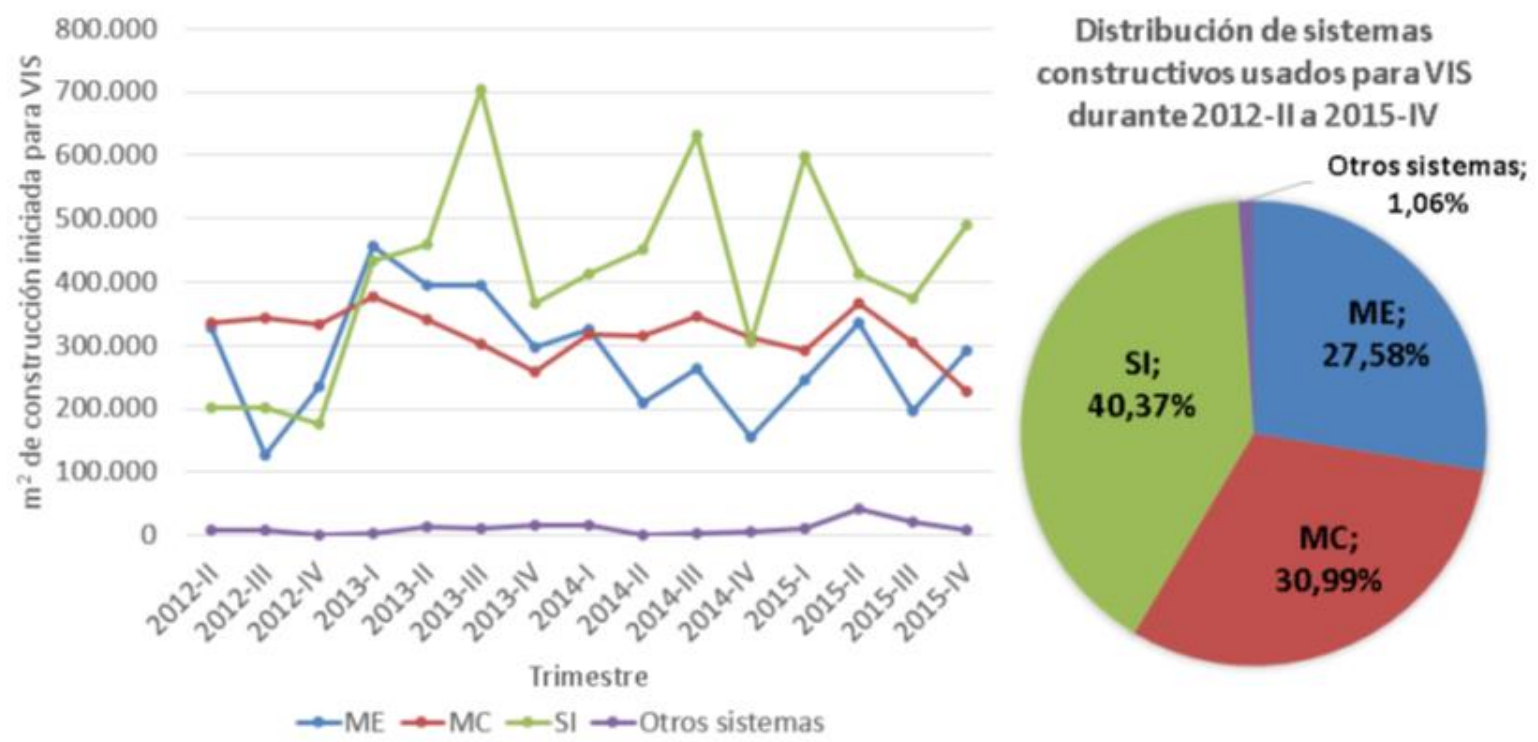

Figura 18. Distribución de sistemas constructivos usados para VIS desde el segundo trimestre de 2012 hasta el cuarto trimestre de 2015, según cifras de CAMACOL (2016). Fuente: García López, Stand Villareal, Gómez Cabrera, \& Nuñez Moreno (2016).

31 De acuerdo con las definiciones del estudio de CAMACOL, los sistemas industrializados incluyen los sistemas Con-tech, Outinord y grandes paneles, sin incluir a los sistemas de construcción liviana o en seco, como por ejemplo el Steel Frame. 
Echeverry \& Metrovivienda (2000), documentan y clasifican cada sistema de acuerdo con los métodos productivos, separando cuatro grandes grupos: mampostería, construcción liviana o en seco, concreto y combinados o híbridos.

A continuación, se presenta una a una la caracterización de estos cuatro grupos con una descripción condensada de cada sistema encontrado.

\subsubsection{Sistemas constructivos de mampostería}

En el grupo de Mampostería se encuentran dos de los sistemas más utilizados para VIS en Colombia: Mampostería reforzada que se hace con bloques de arcilla o de concreto de perforación vertical y la mampostería confinada que donde además pueden usarse ladrillos comunes de arcilla o bloques de perforación horizontal. Tradicionalmente se hace in situ, pero también existe la modalidad de utilizar paneles prefabricados de mampostería para lo cual se requieren equipos de izaje.

Su comportamiento estructural está estudiado y reglamentado por el Título D de la NSR 10.A continuación, se presenta la Tabla 5 que resume las características principales de este grupo.

\begin{tabular}{|c|c|c|c|c|}
\hline $\begin{array}{c}\text { SISTEMA } \\
\text { CONSTRUCTIVO }\end{array}$ & CLASIFICACIÓN & ELEMENTOS & $\begin{array}{l}\text { CONSIDERACIONES } \\
\text { ESTRUCTURALES }\end{array}$ & $\begin{array}{l}\text { CONSIDERACIONES } \\
\text { ARQUITECTÓNICAS }\end{array}$ \\
\hline \multirow{12}{*}{ Mampostería } & \multirow{12}{*}{ Artesanal } & $\begin{array}{l}\text { Unidades de } \\
\text { mampostería }\end{array}$ & \multirow{12}{*}{$\begin{array}{l}\text { Para ser estructural debe ser } \\
\text { continuo y sin aberturas. Se } \\
\text { busca simetría en planta entre } \\
\text { la cantidad de muros en } \\
\text { sentido vertical y horizontal } \\
\text { para evitar fenómenos de } \\
\text { torsión. Debe haber } \\
\text { coincidencia entre vanos. }\end{array}$} & \multirow{12}{*}{$\begin{array}{l}\text { Modulación de los muros según } \\
\text { tamaño de la unidad de } \\
\text { mampostería. Aprovechar las } \\
\text { unidades de mampostería como } \\
\text { acabado final evitando } \\
\text { recubrimientos. Vanos múltiplos } \\
\text { el tamaño de las unidades de } \\
\text { mampostería. Presenta } \\
\text { restricciones, dado que el diseño } \\
\text { se debe adecuar a las } \\
\text { dimensiones de los módulos. No } \\
\text { es necesario poner acabados en } \\
\text { los } \\
\text { muros, con una laca podría ser } \\
\text { suficiente }\end{array}$} \\
\hline & & Mortero de pega & & \\
\hline & & Grouting & & \\
\hline & & Refuerzo & & \\
\hline & & $\begin{array}{l}\text { Concreto (vigas y } \\
\text { columnetas de } \\
\text { confinamiento) }\end{array}$ & & \\
\hline & & Acero de Refuerzo & & \\
\hline & & $\begin{array}{c}\text { Vigas de } \\
\text { Cimentación }\end{array}$ & & \\
\hline & & Contrapiso & & \\
\hline & & Entrepiso & & \\
\hline & & Paneles en Ladrillo & & \\
\hline & & Cubierta & & \\
\hline & & Escaleras & & \\
\hline
\end{tabular}

Tabla 5. Características generales de los sistemas constructivos de mampostería. Fuente: Echeverry Campos \& MetroVivienda (2000). 


\section{Mampostería confinada}

Los muros de mampostería confinada están conformados por ladrillos pegados con mortero y se confinan con columnetas y vigas de amarre en concreto reforzado que se vacían posteriormente a la construcción del muro como lo indica la Figura 19, con esto se conforman láminas que funcionan como monolitos. Este sistema es portante y hace las veces de cerramiento, división y estructura a la vez, sin embargo, las instalaciones eléctricas, hidráulicas, entre otras, requieren la apertura de regatas para su colocación.

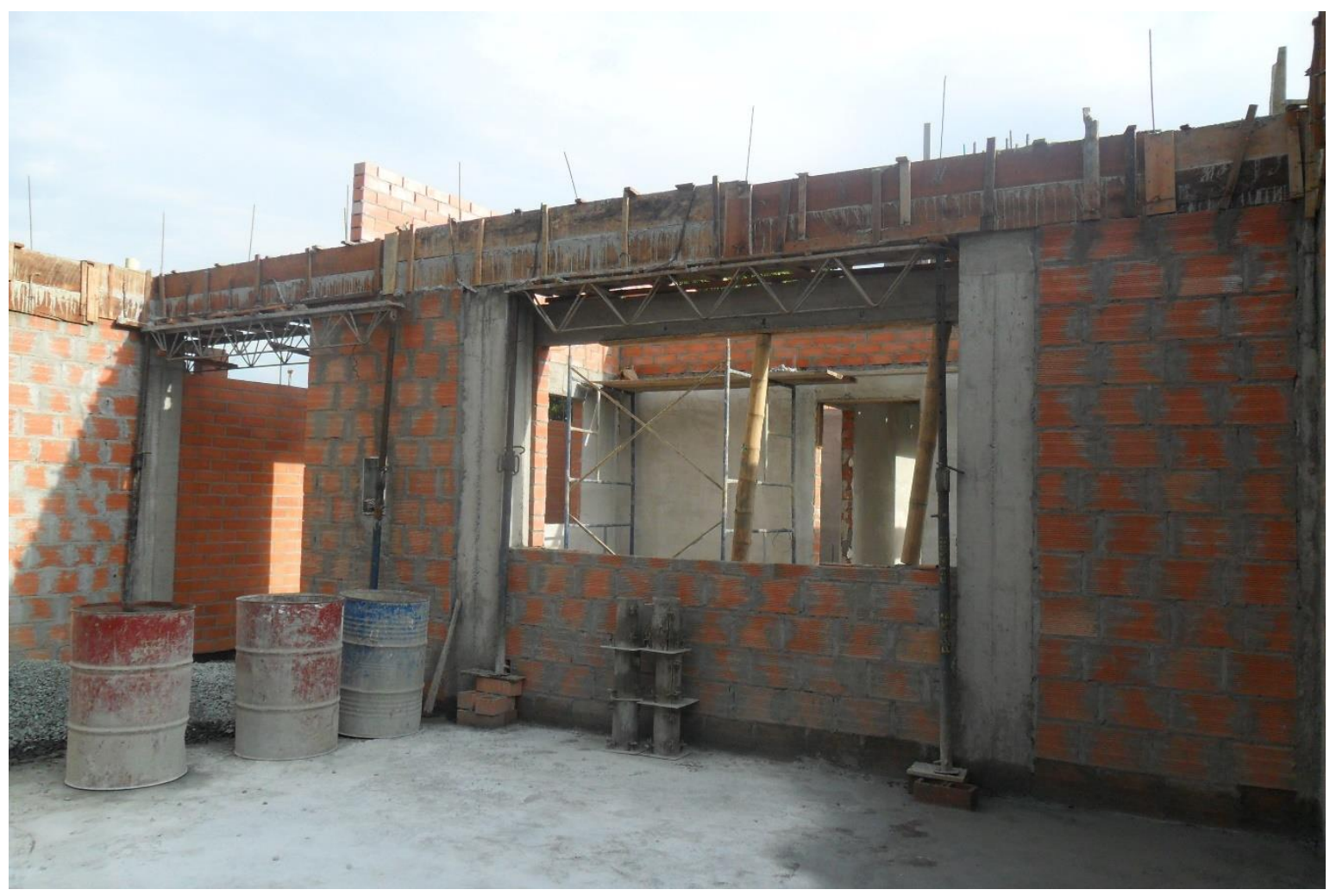

Figura 19. Muro de mampostería confinada con bloques de arcilla. Fuente: Elaboración propia.

Ventajas

- Goza de gran popularidad y aceptación en la comunidad.

- Los muros cumplen la función de cerramiento y estructura simultáneamente.

- Por las características físicas de los ladrillos brinda un mejor aislamiento térmico y acústico que otros sistemas.

- Es un método ampliamente conocido por los obreros y es fácil la consecución de mano de obra.

- No requiere modulación y permite cierto grado de flexibilidad arquitectónica. 
Desventajas

- El peso de la edificación es mayor en comparación con otros tipos de estructura.

- El acabado requiere revoques debido a las imperfecciones de los ladrillos y pegas.

- Aunque en poca cantidad, requiere encofrado y tiempo de curado en los elementos verticales y horizontales de concreto.

- Debido a que no es necesaria la modulación genera más desperdicio en los cortes de ladrillo.

- Se requieren muros en ambos sentidos para el tema estructural, lo cual brinda poca libertad arquitectónica y genera espacios compartimentados.

\section{Mampostería reforzada}

La mampostería reforzada se fundamenta en la construcción de muros portantes hechos con bloques de perforación vertical que se unen por medio de mortero y alambrones de acero en el sentido horizontal. Las perforaciones verticales permiten también reforzar verticalmente con varillas de acero y concreto fluido.

La cantidad de celdas que se inyectan de concreto dependen de la capacidad de disipación de energía en el rango inelástico definida en el diseño sismorresistente de la edificación. Estructuralmente es un sistema de gran rigidez lograda por el ensamble monolítico de los bloques.

Ya que este método conforma la estructura vertical y divisoria a la vez, los subsistemas de electricidad, hidrosanitarios y demás, deben integrarse a los muros y considerarse desde la etapa de diseño. 
El proceso constructivo, al igual que la mampostería confinada se hace por procesos artesanales, aunque también es posible adquirir paneles prefabricados. Una imagen típica de un conjunto residencial VIS construida con mampostería reforzada en bloque de concreto se ve en la Figura 20.

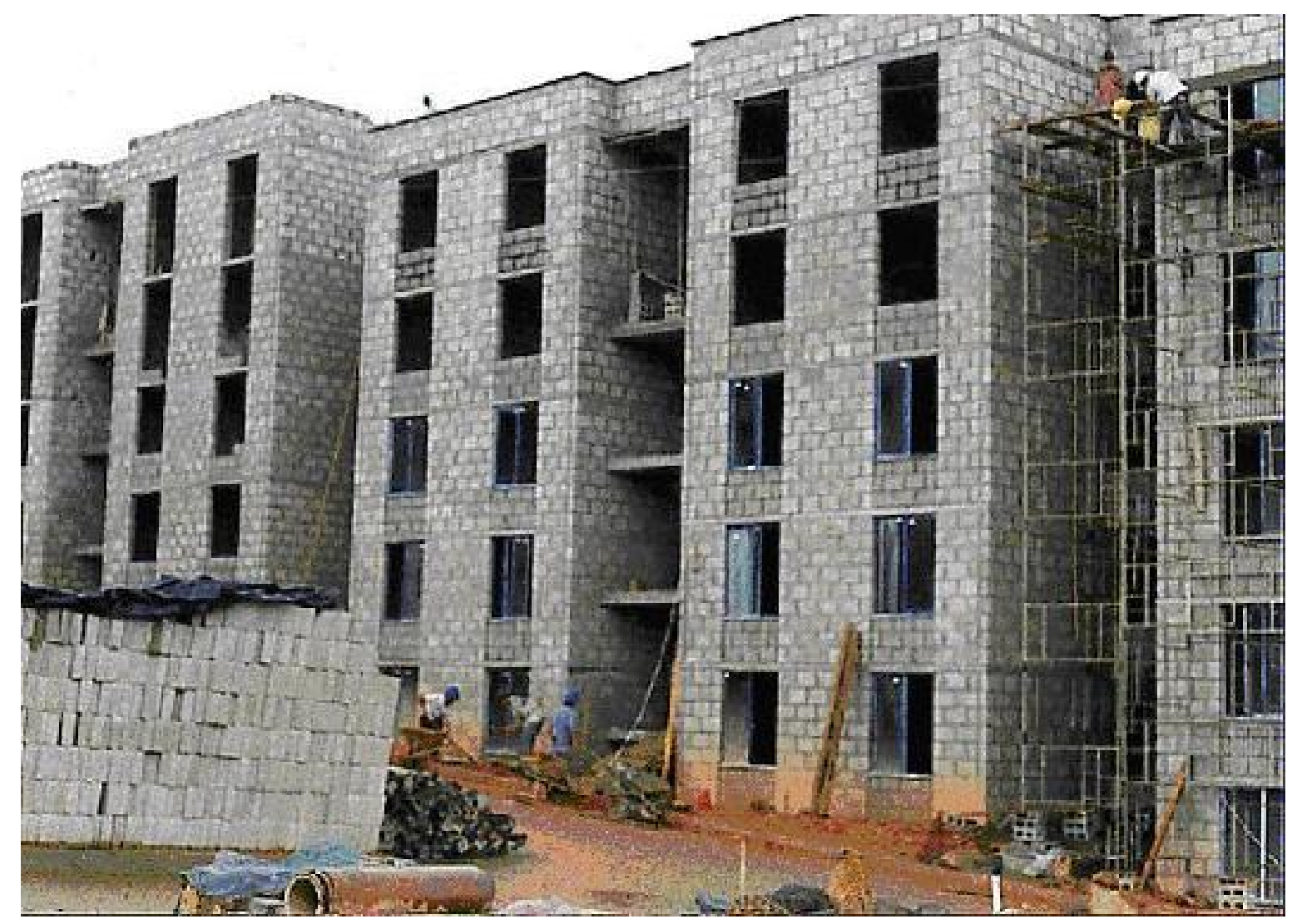

Figura 20. Conjunto habitacional VIS desarrollado con mampostería reforzada en bloque de concreto. Fuente: http://materialesdeconstruccio.blogspot.com.ar/2012/10/mamposteria-estructural.html

Ventajas

- Debido a la estricta modulación se disminuyen los desperdicios en cortes de los bloques.

- Su pulcritud estética permite dejar el muro a la vista, o aplicar estucos delgados o pinturas directamente sin necesidad de revoques gruesos.

- Los muros cumplen la función de cerramiento y estructura simultáneamente.

- Permite alojar las instalaciones eléctricas, hidrosanitarias y demás en el interior de las celdas de los bloques.

- No requiere formaletas, ya que el refuerzo y el vaciado de las dovelas se hacen dentro de los mampuestos.

- Por las características físicas de los ladrillos brinda un mejor aislamiento térmico y acústico que otros sistemas. 
Desventajas

- Es indispensable una mano de obra calificada, al igual que un estricto control de obra para que se cumplan las modulaciones y especificaciones de diseño.

- Requiere un diseño arquitectónico riguroso en cuanto a la modulación vertical y horizontal.

- Debido a que la mampostería es estructural, no se pueden hacer cambios posteriores.

\subsubsection{Sistemas constructivos livianos o en seco}

Los sistemas de construcción livianos, también conocidos como sistemas de construcción en seco, son prefabricados e industrializados, ya que el trabajo en obra solo implica el ensamble de partes que vienen listas de fábrica.

Por lo general las láminas que conforman los muros vienen en módulos de $1,22 m \times 2,44 m$, por lo que se procura que el diseño arquitectónico se ajuste a estas dimensiones para ahorrar en desperdicios.

La mayoría requieren un tratamiento superficial y sello de juntas, el alma estructural está constituida por perfiles metálicos livianos o estructurales, permiten construcción en altura hasta dos pisos, pero si se requieren alturas mayores se debe complementar con otro tipo de estructura.

Actualmente, la norma NSR-10 no especifica el manejo que se le debe dar a estas construcciones, sin embargo, pueden ser homologadas mediante regímenes de excepción por parte de la Asociación Colombiana de Ingeniería Sísmica.

Este método constructivo es poco utilizado en el país, ya que tan solo el 1,06\% de las VIS se fabrican de esta forma. La causa de esto se debe a la poca aceptación en la comunidad, cuya percepción de calidad y durabilidad está asociada con la robustez y el gran peso de los sistemas constructivos tradicionales, (García López, Stand Villareal, Gómez Cabrera, \& Nuñez Moreno, 2016).

Hay una gran variedad de modalidades en este tipo de sistema, entre ellos están: Vivienda Celular Eternit, Plycem, Royalco, 3D Panel, Speed Co, Colditec, Servivienda y Metecno. Un resumen de las características de estos sistemas constructivos se presenta en la Tabla 6, (Echeverry Campos \& MetroVivienda, 2000). 


\begin{tabular}{|c|c|c|c|c|}
\hline $\begin{array}{l}\text { SISTEMA } \\
\text { CONSTRUCTIVO }\end{array}$ & CLASIFICACIÓN & ELEMENTOS & $\begin{array}{l}\text { CONSIDERACIONES } \\
\text { ESTRUCTURALES }\end{array}$ & $\begin{array}{l}\text { CONSIDERACIONES } \\
\text { ARQUITECTÓNICAS }\end{array}$ \\
\hline \multirow{7}{*}{$\begin{array}{c}\text { Sistema de } \\
\text { construcción en } \\
\text { liviana o en seco }\end{array}$} & \multirow{7}{*}{$\begin{array}{l}\text { Industrializado y } \\
\text { prefabricado }\end{array}$} & $\begin{array}{l}\text { Paneles de } \\
\text { fibrocemento }\end{array}$ & \multirow{7}{*}{$\begin{array}{l}\text { Comportamiento favorable de } \\
\text { las láminas a compresión. Su } \\
\text { bajo peso lo favorece en el tema } \\
\text { de sismos. } \\
\text { Disposición ortogonal de muros } \\
\text { en planta, simetría en planta } \\
\text { para evitar torsiones. Liviana y } \\
\text { flexible. Necesita la estructura } \\
\text { metálica para edificaciones de } \\
\text { más de } 2 \text { pisos. No admite luces } \\
\text { mayores a } 6 \mathrm{~m} \text {. }\end{array}$} & \multirow{7}{*}{$\begin{array}{l}\text { Diseño limitado por el tamaño } \\
\text { de las láminas. Sin restricción } \\
\text { para el diseño. Los perfiles y } \\
\text { láminas pueden ser cortados en } \\
\text { fábrica según diseño. }\end{array}$} \\
\hline & & Perfiles metálicos & & \\
\hline & & $\begin{array}{c}\text { Tejas de } \\
\text { Fibrocemento }\end{array}$ & & \\
\hline & & Anclajes & & \\
\hline & & Pegantes & & \\
\hline & & Selladores & & \\
\hline & & $\begin{array}{l}\text { Paneles tipo } \\
\text { sándwich con caras } \\
\text { metálicas y relleno } \\
\text { de poliuretano }\end{array}$ & & \\
\hline
\end{tabular}

Tabla 6.Características generales de los sistemas constructivos livianos o en seco. Fuente: Echeverry Campos \& MetroVivienda (2000).

\section{Vivienda Celular Eternit}

El sistema utiliza elementos laminares planos, ondulados y esquineros curvos de fibrocemento reforzado que se ensamblan unos a otros mediante uniones mecánicas como: tornillos, remaches y pegantes epóxicos; y cintas de amarre vertical y horizontal, (ETERNIT, 2017).

El módulo básico o célula, tiene una dimensión en planta de $3,0 \mathrm{~m} \times 3,0 \mathrm{~m}$, por su parte, los paneles de muro de son de $1,22 \mathrm{~m} \times 2,44 \mathrm{~m} \times 33 \mathrm{~mm}$; los esquineros tienen un radio de $28 \mathrm{~cm}$ de longitud y una altura de $2,60 \mathrm{~m}$ a $4,50 \mathrm{~m}$.

El método cumple con la Norma NSR-10 su peso liviano genera muy pocas cargas inerciales frente a los sismos, debe hacerse simétrico para evitar torsiones, es decir que debe haber muros dispuestos en los dos sentidos ortogonales de la planta. Adicionalmente, los esquineros rigidizan y aportan al comportamiento monolítico de la unidad. En caso de requerirse un segundo nivel, se recurre a estructuras metálicas independientes.

Una vista exterior de la urbanización Santiago, en Puerto Triunfo, Antioquia, desarrollada con este sistema se aprecia en la Figura 21. 


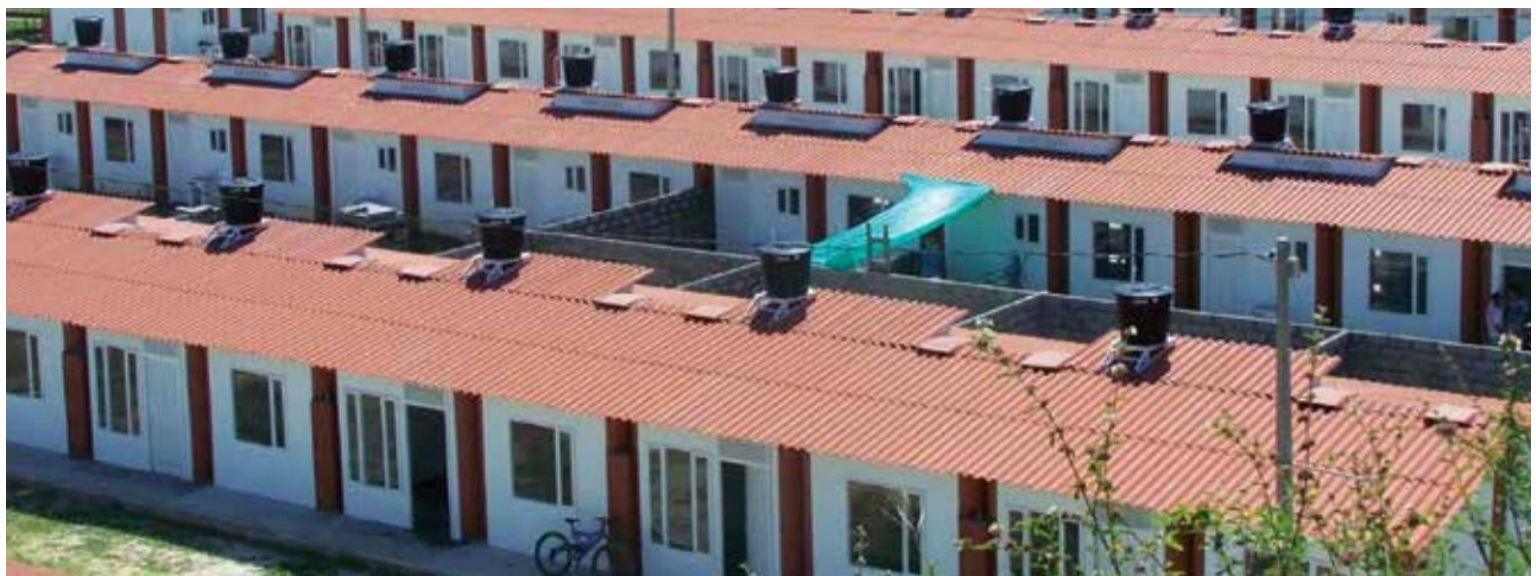

Figura 21. Urbanización desarrollada con el sistema constructivo Vivienda Celular Eternit. Fuente: Eternit (ETERNIT, 2017).

Ventajas

- Su tiempo de construcción es ágil debido a su sencillez

- No requiere revoques gruesos, pero sí permite la aplicación de todo tipo de acabados finos.

- Al área ocupada en estructura y muros es tan solo del $2 \%$ de su área.

- No requiere equipos ni herramientas especializadas.

Desventajas

- La distribución arquitectónica está sujeta a los kits que vende la empresa.

- Debido a su baja resistencia térmica presenta condensación en climas fríos, al igual que muy bajo comportamiento frente al confort térmico en todos los climas.

- La cubierta está limitada a tipos livianos.

\section{Plycem}

El sistema constructivo PLYCEM está conformado por una estructura de perfiles livianos de acero formados en frío y unidos entre sí, a los cuales se les fijan las láminas de fibrocemento de 1,22m x 2,44m en espesores desde $5 \mathrm{~mm}$ hasta $30 \mathrm{~mm}$. Estas láminas están hechas de una mezcla de cemento portland y fibras de celulosa mineralizada, además llevan un proceso de hidrofugado para resistir la humedad de la intemperie.

Este sistema constructivo ofrece dos alternativas para construcción: el sistema 1000, que utiliza solo láminas portantes como elementos estructurales unidas con una sección tubular de acero; y el sistema 2000 cuyas láminas no son portantes y utiliza dos tableros apoyados y separados por perfiles de acero. La primera alternativa es la más usada para VIS. 
La apariencia exterior del sistema 1000 con sus paneles portantes y uniones metálica se aprecia en la constructivo de un muro con el sistema 2000 se muestra en la Figura 22.

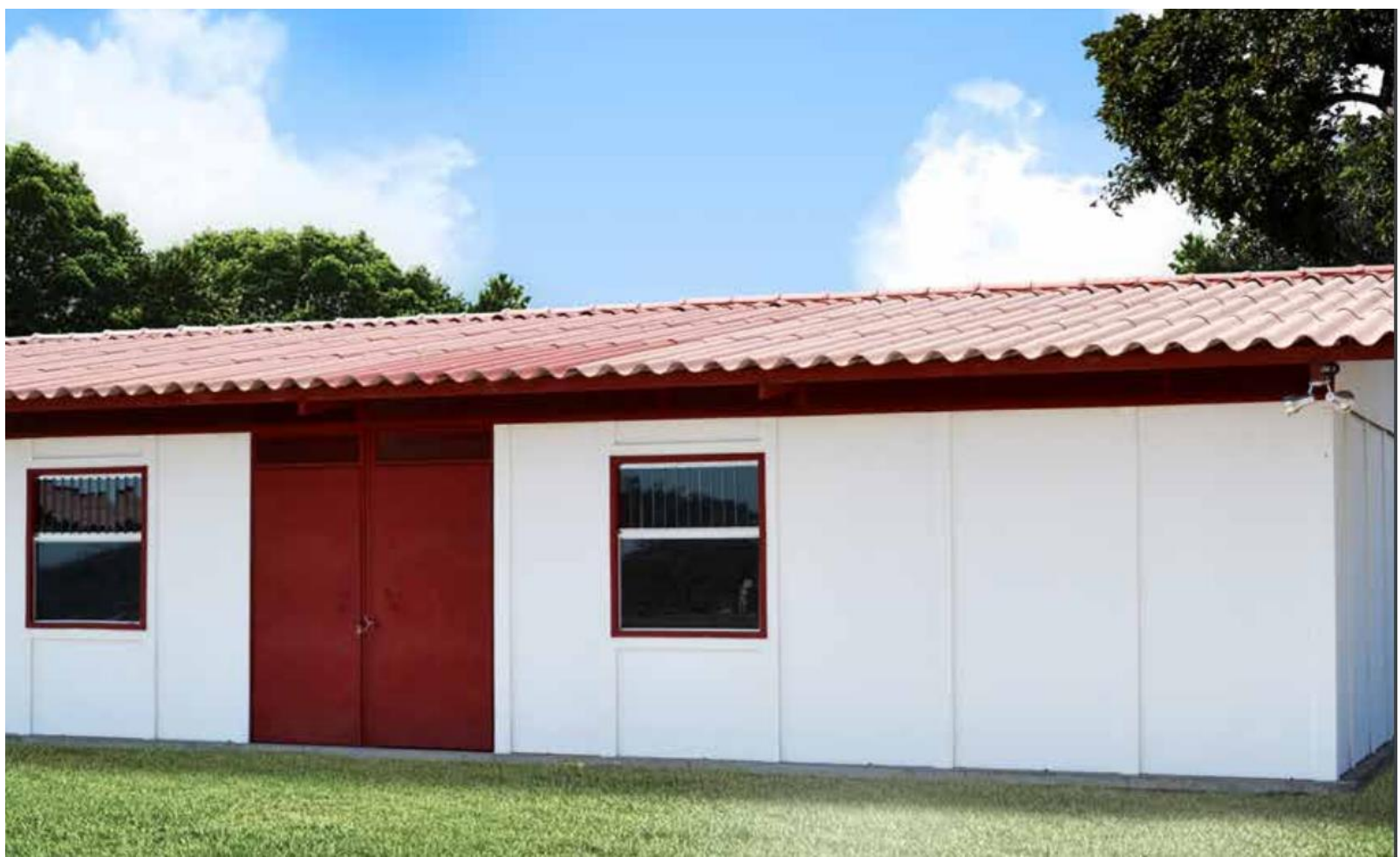

Figura 22. Vista exterior de una VIS con sistema constructivo Plycem $1000 . \quad$ Fuente: https://www.plycem.com/contenido/wp-content/uploads/2016/01/Manual-Sistemas-1000-25-enero-2016.pdf

PLYCEM es un sistema importado de Estados Unidos que cumple las normas técnicas de construcción liviana en ese país, pero en Colombia la NSR-10 hay muy poca literatura sobre este tipo de edificaciones. A pesar de esto, se han desarrollado tablas de cálculo estructural basadas en la normativa local para asegurar un buen comportamiento sismo resistente.

Ventajas

- Su tiempo de construcción es ágil debido a su sencillez

- $\quad$ No requiere revoques, pero sí permite la aplicación de todo tipo de acabados finos.

- Por su bajo peso, puede llevarse a lugares remotos y de difícil acceso.

- Si se mezcla con aislamientos térmicos llega a proveer un buen nivel de confort térmico y acústico.

Desventajas

- No se produce en el país y se debe importar.

- Requiere gran cantidad de productos complementarios. 


\section{Royalco}

Esta técnica no es prefabricada completamente, más bien, es una formaleta hecha en módulos de $\mathrm{PVC}^{32}$ rígido que se ensamblan entre sí y posteriormente se vacían de concreto en su interior para conformar los muros estructurales de la edificación, como se explica en la Figura 23. Así pues, los perfiles de PVC actúan como un encofrado perdido.

Los muros pueden reforzarse con acero dispuesto vertical y horizontalmente, además el concreto puede variar de resistencia, todo esto, de acuerdo con las necesidades estructurales.

Los entrepisos se resuelven con perfiles metálicos apoyados en los muros, más una lámina colaborante metálica que actúa como encofrado perdido, sobre la que se funde una losa de hormigón armado.

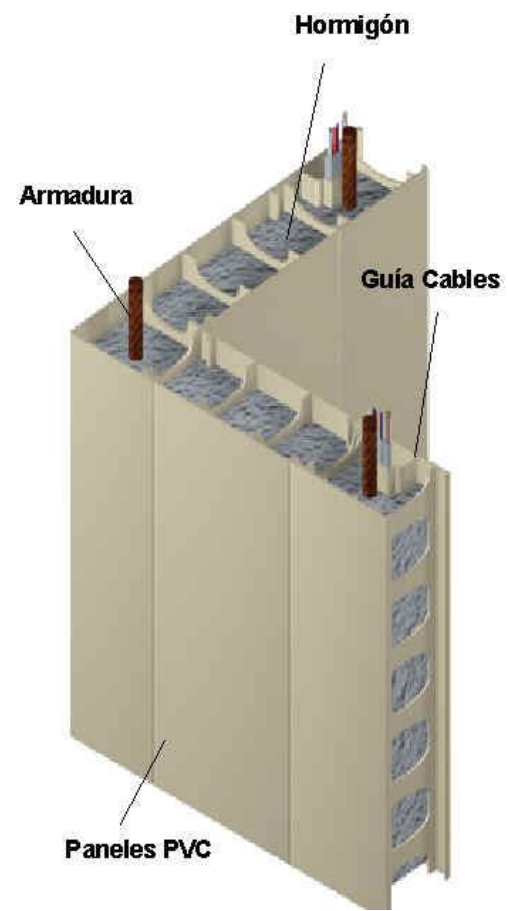

Figura 23. Detalle constructivo del sistema Royalco. Fuente: http://royaluruguay.com

El sistema de muros portantes asegura un comportamiento monolítico avalado por la NSR-10.

Además de las formaletas en PVC es posible adquirir elementos complementarios de obra como carpintería, tuberías eléctricas e hidrosanitarias y siding para aislamiento térmico.

Ventajas

- Tiempo de construcción ágil debido a su sencillez y poco equipo requerido.

- Acabado muy pulcro que elimina la necesidad de tratamientos posteriores.

Desventajas

- Es más costoso que las otras alternativas del mercado.

- Hay restricciones de tipo arquitectónico y dificultad de reparación para instalaciones que se encuentran embebidas en concreto.

\footnotetext{
32 Policloruro de Vinilo. Es el producto de la polimerización del monómero de cloruro de vinilo a policloruro de vinilo. Es derivado del plástico y es empleado más versátilmente en tuberías, envases, chapas y demás.
} 


\section{D Panel}

Esta alternativa constructiva está basada en la utilización de paneles constituidos por un núcleo de poliestireno expandido y una malla electrosoldada en ambas caras, que se unen entre sí mediante conectores de acero que atraviesan el núcleo. Posteriormente a su colocación, cada cara es recubierta por concreto lanzado, constituyendo así un muro portante que será la estructura edilicia.

3D panel no solo posibilita la construcción de estructuras verticales, sino que también es posible realizar estructuras horizontales como entrepisos y cubiertas.

Aunque el sistema no sea nombrado explícitamente en la norma NSR-10, su comportamiento aplica y cumple la modalidad en sistema de muros portantes.

Una típica situación de obra con esta tecnología se aprecia en la Figura 24.

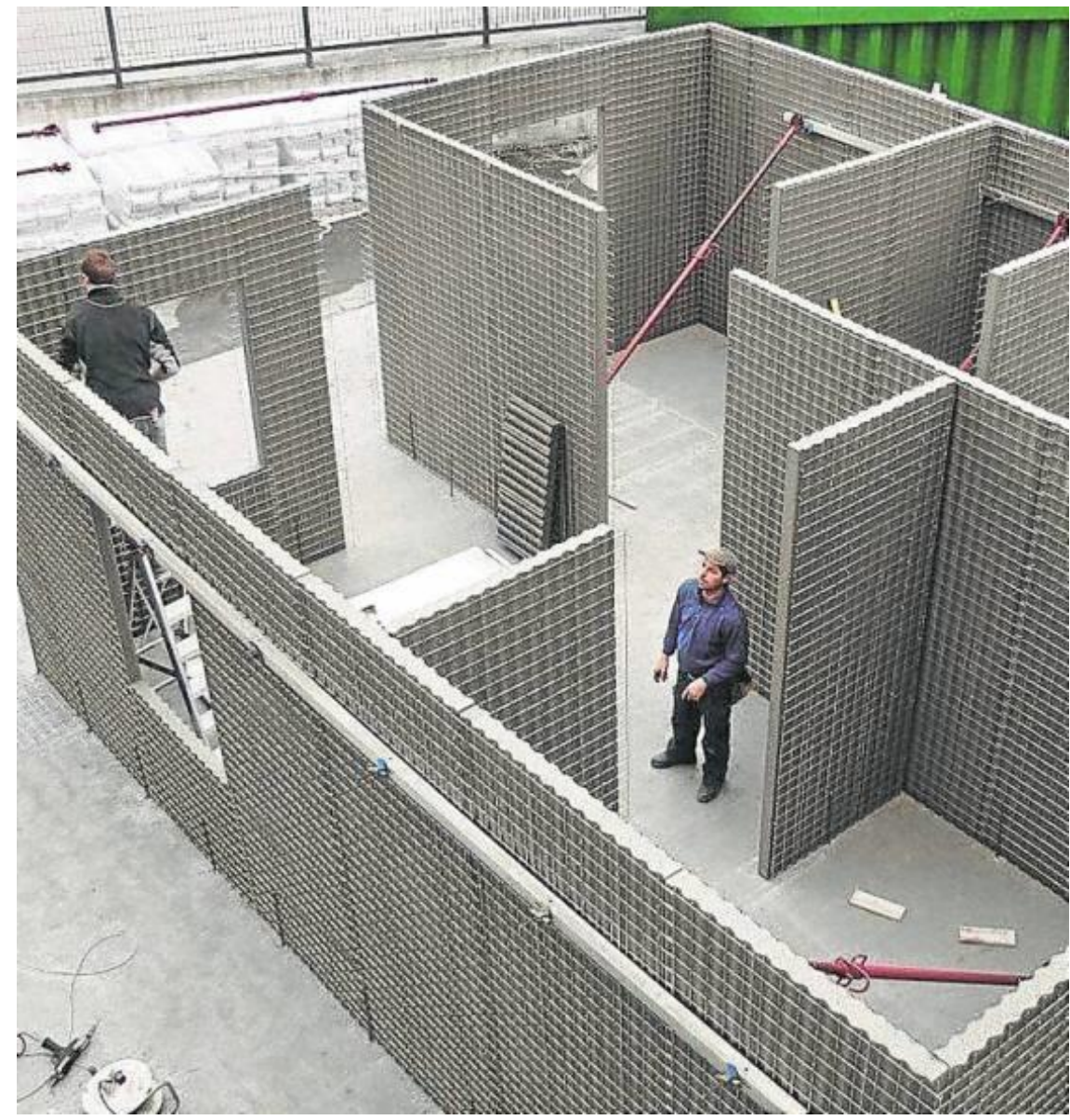

Figura 24. Proceso constructivo de una vivienda utilizando el sistema constructivo 3D panel. Fuente: http://noticias.arq.com.mx/Detalles/17370.html\#.WR9T1Wg1-M8 
Ventajas

- Brinda buen nivel de aislamiento térmico y acústico

- Gran rapidez constructiva.

Desventajas

- Requiere capacitación en la mano de obra.

- Debe tenerse un riguroso control y cuidado en el manejo del concreto proyectado para evitar desperdicios.

- Hay pocas plantas de producción del sistema, por lo que debe tenerse en cuenta el impacto de los fletes en el costo de las viviendas.

\section{Speedco}

La tecnología SpeedCo se basa en la producción de paneles prefabricados de fibrocemento rellenos de poliuretano expandido bautizadas como Thermowall. La estructura está compuesta por perfiles de aluminio que se fijan a la cimentación mediante herrajes de rápida instalación. Sobre la perfilería se fijan los paneles que constituyen las paredes de la construcción.

Los materiales de construcción son entregados en las cantidades y medidas precisas sin generar escombros ni materia de desperdicio y permitiendo la planeación estricta de la obra.

Los muros no deben superar luces máximas de $6 \mathrm{~m}$ y no se deben utilizar para soportar un segundo nivel o de apoyo de techos con altas pendientes. Por lo tanto, las edificaciones de dos niveles deben tener una estructura metálica adicional que cargue la losa.

El sistema tiene estudios de sismo resistencia, que acompañan las memorias de los diseños estructurales, y sobre él se han realizado pruebas y ensayos, por parte de la empresa, avalados por la Asociación de Ingeniería Sísmica AIS.
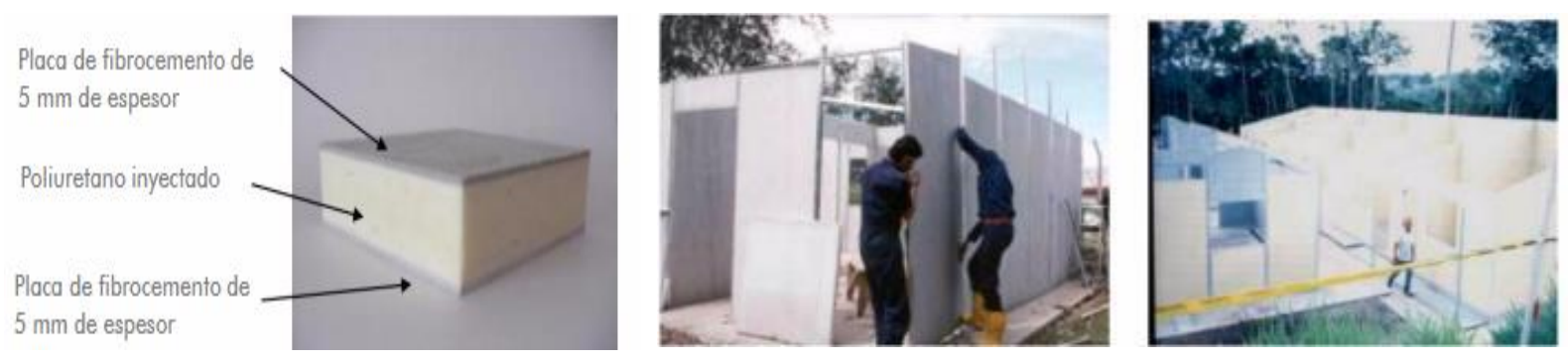

Figura 25. Detalle de las láminas Thermowall (izquierda) y proceso constructivo de las viviendas con sistema constructivo Speedco (centro y derecha). Fuente: https://issuu.com/koespacios/docs/viviendas_modulares 
Ventajas

- No genera desperdicios y la obra es muy limpia y seca.

- El proceso constructivo es ágil.

- Los requerimientos de cimentación son bajos, debido a su bajo peso.

Desventajas

- Las instalaciones deben dejarse a la vista ya que no permiten alojarse dentro de los paneles.

- Las edificaciones de dos pisos requieren una estructura adicional.

- Hay limitaciones debido a las características estructurales de la tecnología.

\section{Colditec (Drywall)}

Este método constructivo sigue los mismos principios del sistema Drywall de Estados Unidos, fue introducido en los años noventa a Colombia. Es una alternativa que usa una estructura de perfiles de acero galvanizado revestida con paneles de fibrocemento y paneles de yeso. Esta combinación conforma un diafragma que se comporta homogéneamente frente a eventos sísmicos. Los paneles de fibrocemento resistentes a la humedad son especialmente colocados en las fachadas y zonas húmedas, por su parte, los paneles de yeso solo se emplean como tabiques en lugares secos o interiores.

Las placas de entrepiso se apoyan en viguetas descolgadas que se revisten con placas de fibrocemento formando un diafragma al igual que los muros.

El espacio en el interior de muros y losas permite que se alojen aislamientos térmicos y toda clase de instalaciones. Una explicación gráfica del sistema y su proceso de obra se indica en la Figura 26. 


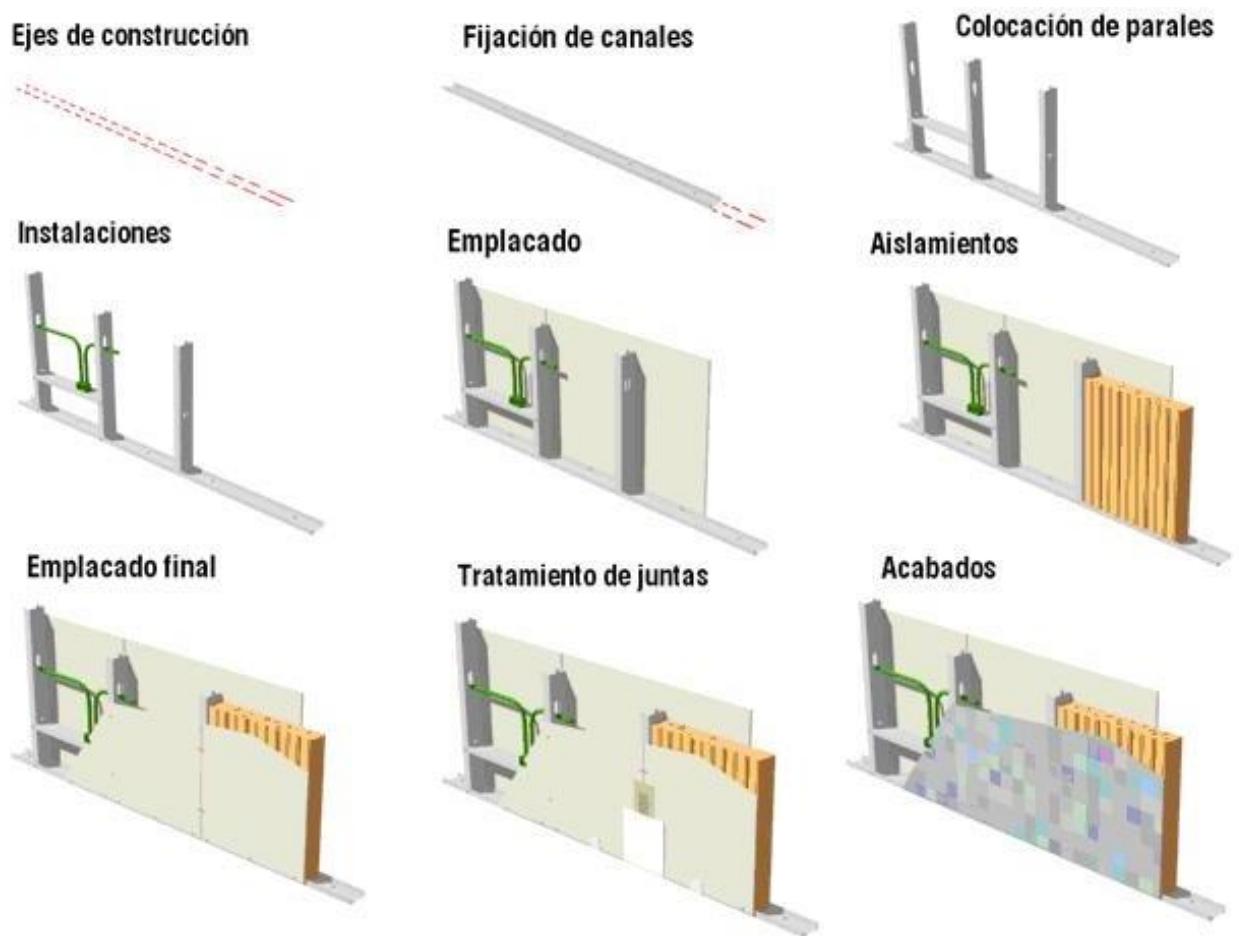

Figura 26. Sistema constructivo Colditec (Drywall). Proceso constructivo de muros. Fuente: http://www.arquitectiando.com/2007/10/construccion-de-muros-o-tabiques/

\section{Ventajas}

- La estética de las fachadas de las viviendas elaboradas es agradable.

- El montaje es rápido y sencillo

- No se requiere personal con mucho entrenamiento.

Desventajas

- Para que el sistema sea competitivo requiere un alto volumen de unidades.

- La aceptación cultural del sistema es baja frente a otros basados en ladrillo o concreto. 


\section{Servivienda.}

En esta técnica se utiliza prefabricación tradicional para producir placas de concreto de 3000psi de 3,2cm de espesor moduladas en múltiplos de 0,97x0,97m.

Las placas que se ensamblan dentro de perfiles de lámina galvanizada constituyen muros estructurales que se apoyan en la cimentación, bien sea de vigas corridas o losa.

La estructura vertical conformada por los muros puede sostener hasta un nivel adicional o soportar la cubierta directamente como el ejemplo de la Figura 27. El sistema cumple con las normas NSR-10 para un nivel y deben presentarse cálculos para el caso de dos niveles.

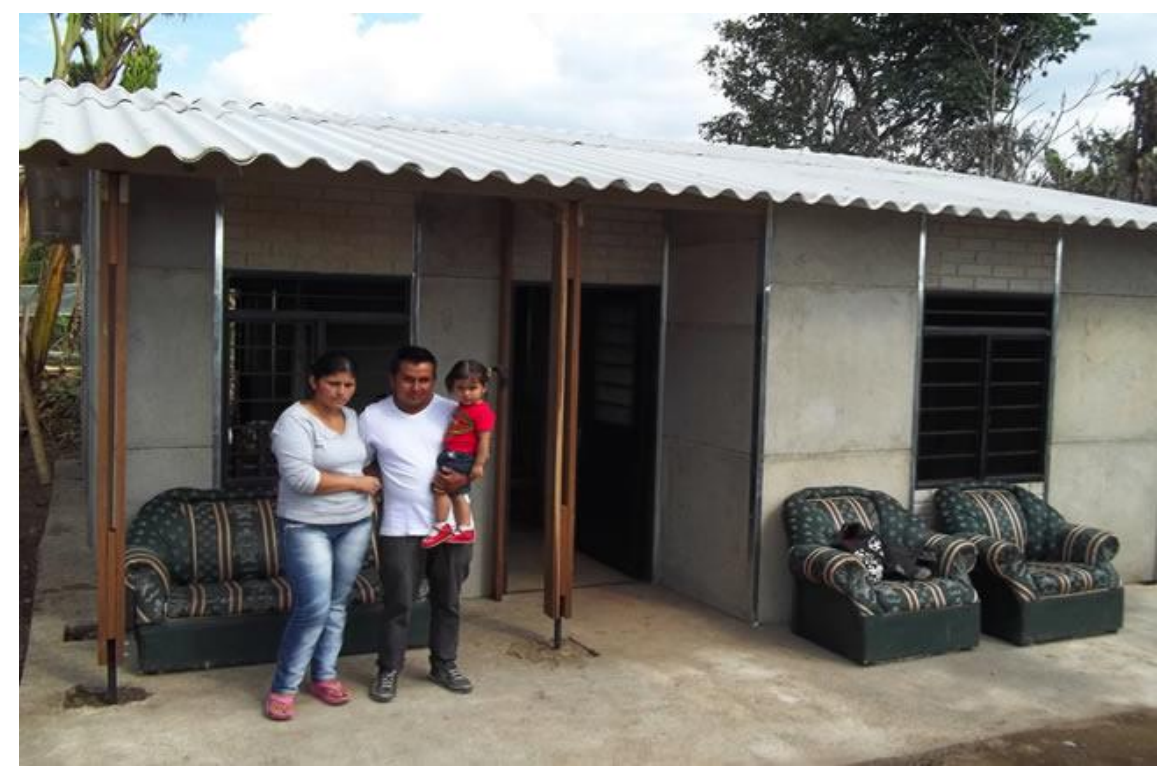

Figura 27. Aspecto exterior de una VIS construida con el sistema constructivo Servivienda. Fuente: http://www.jesuitas.org.co/noticia.html?noticia_id=479

Ventajas

- Posibilita la aplicación de gran variedad de acabados.

- La prefabricación con sistema tradicional permite realizar obras de grandes cantidades a muy bajo costo sin requerir mano de obra especializada.

- Es un sistema limpio que reduce desperdicios y escombros.

Desventajas

- Presenta bajo aislamiento térmico y acústico.

- Baja aceptación cultural debido al poco espesor de los paneles

- Es común la rotura de los módulos de concreto en el transporte, la ejecución y el funcionamiento de la vivienda. 


\section{Metecno}

La tecnología industrializada empleada por Metecno, consiste en la prefabricación de paneles aislantes y autoportantes hechos en poliuretano con caras metálicas pintadas. Estos se usan en muros, cerramientos y cubierta.

Para la elaboración de viviendas de un nivel, se utiliza una estructura de aluminio liviana, mientras que para más de un nivel se usa estructura metálica que depende del diseño estructural.

Su comportamiento estructural es muy bueno debido a su bajo peso, se encuentra normalizado por la Norma NSR-10 y como se muestra en la Figura 28, pueden encontrarse soluciones de $36 \mathrm{~m}^{2}$ y $56 \mathrm{~m}^{2}$ con posibilidad de ampliación.
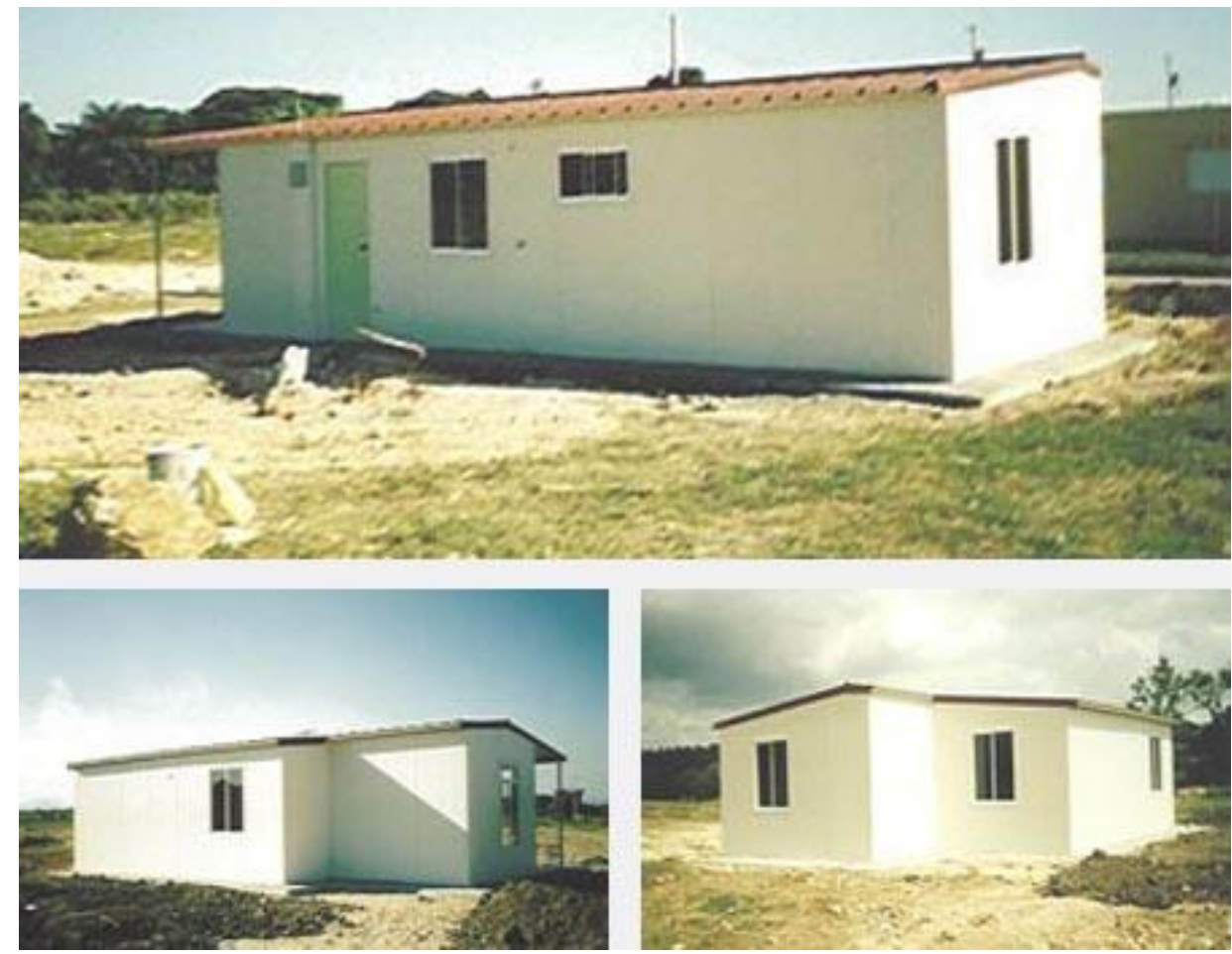

Figura 28. Soluciones de VIS de $36 \mathrm{~m}^{2}$ y $56 \mathrm{~m}^{2}$ desarrolladas con el sistema constructivo Metecno. Fuente: http://www.metecnocolombia.com/viviendas/montajecasa.html

Ventajas

- Tienen un buen comportamiento térmico tanto en climas fríos o calurosos. Con un muro de $8 \mathrm{~cm}$ de poliuretano y láminas metálicas se puede alcanzar una resistencia térmica de $4 \mathrm{~m}^{2 \circ} \mathrm{C} / \mathrm{W}$

- Contando con la placa de cimentación, una vivienda de un solo piso puede armarse en un solo día.

- Los diseños arquitectónicos pueden ser flexibles y variados. 
Desventajas

- Debido a que utiliza elementos prefabricados en planta, no es muy económico si el lugar del proyecto se encuentra alejado de ella.

- No es un sistema constructivo muy aceptado por la comunidad en general.

- Requiere un mantenimiento periódico para asegurar que los paneles no se deterioren.

\subsubsection{Sistemas constructivos de concreto}

La producción de cemento y concreto en el país, conjugada con la apropiación de conocimientos acerca del comportamiento estructural del material y un mercado que demanda y prefiere este tipo de construcciones ha hecho que la cantidad de VIS y no VIS materializadas con estos métodos sean superiores en cantidad a las de otras alternativas.

Aunque a simple vista, las tecnologías de concreto como Con-tech, Outinord o Grandes paneles no sean competitivas con otras ya nombradas en este trabajo, detrás de ellas se ha hecho un gran trabajo de optimización estructural, aprovechamiento del espacio y del suelo, investigación en resistencia de materiales, innovación en herramientas y equipos, planeación de tareas, análisis de costos y por supuesto inversiones económicas, que las han convertido en una competencia fuerte.

En la Norma NSR-10, el título C se encuentra dedicado a normalizar y documentar este tipo de edificaciones, que generalmente son multifamiliares de varios niveles, para sacar mayor rentabilidad, sin embargo, hay también casos de casas independientes de uno o dos niveles.

Esta alternativa, además de contar con el concreto como material protagonista tanto en la estructura vertical como horizontal, en las divisiones y hasta en los cerramientos, se caracteriza también por la utilización de grandes equipos para el vaciado y encofrados metálicos, durables y reutilizables.

A continuación, se presenta la Tabla 7, que resume las características generales de los sistemas constructivos de concreto. Más adelante, se documenta una a una cada tecnología. 


\begin{tabular}{|c|c|c|c|c|}
\hline $\begin{array}{c}\text { SISTEMA } \\
\text { CONSTRUCTIVO }\end{array}$ & CLASIFICACIÓN & ELEMENTOS & $\begin{array}{l}\text { CONSIDERACIONES } \\
\text { ESTRUCTURALES }\end{array}$ & $\begin{array}{l}\text { CONSIDERACIONES } \\
\text { ARQUITECTÓNICAS }\end{array}$ \\
\hline \multirow{9}{*}{$\begin{array}{l}\text { Sistema } \\
\text { concreto }\end{array}$} & \multirow{9}{*}{$\begin{array}{l}\text { Industrializado in } \\
\text { situ /prefabricado }\end{array}$} & $\begin{array}{l}\text { Paneles, vigas y losas } \\
\text { prefabricadas en concreto }\end{array}$ & \multirow{9}{*}{$\begin{array}{l}\text { Muros de carga y divisorios } \\
\text { con paneles prefabricados o } \\
\text { vaciados in situ. } \\
\text { Se pueden utilizar losas de } \\
\text { entrepiso prefabricadas. } \\
\text { Muros en ambas } \\
\text { direcciones para rigidizar } \\
\text { ante cargas sísmicas. } \\
\text { Resistencias del concreto: } \\
\text { superiores en los primeros } \\
\text { niveles e inferiores en los } \\
\text { superiores. }\end{array}$} & \multirow{5}{*}{$\begin{array}{l}\text { El acabado en los muros es } \\
\text { poco. El sistema modular y } \\
\text { ortogonal restringe el diseño. } \\
\text { Solo está disponible en los } \\
\text { principales municipios. }\end{array}$} \\
\hline & & Concreto & & \\
\hline & & Malla electrosoldada & & \\
\hline & & Piezas de anclaje & & \\
\hline & & Desmoldantes & & \\
\hline & & $\begin{array}{l}\text { Varillas de acero para } \\
\text { refuerzo }\end{array}$ & & Aunque requiere mano de \\
\hline & & Formaletas & & obra calificada \\
\hline & & $\begin{array}{l}\text { Equipo de mezcla } \\
\text { vaciado de concreto }\end{array}$ & & $\begin{array}{l}\text { rendimientos son muy } \\
\text { eficientes. }\end{array}$ \\
\hline & & Equipo de izaje & & \\
\hline
\end{tabular}

Tabla 7. Características generales de los sistemas constructivos de Concreto. Fuente: Echeverry Campos \& MetroVivienda (2000).

\section{Grandes paneles.}

Este método constructivo es industrializado y prefabricado. Se basa en la fundición de paneles para entrepisos y muros a los que solo les falta el acabado fino. Las instalaciones son colocadas internamente en la prefabricación de los paneles y conectadas en obra.

Las piezas, se fabrican en una planta fija o en obra bajo un estricto control de calidad, para finalmente trasladarse y colocarse en la edificación con ayuda de equipos de izaje.

El sistema no utiliza columnas ni vigas como estructura, sino que los muros, diseñados equitativamente en las dos direcciones ortogonales de la planta de la vivienda, garantizan la estabilidad. En la unión de piezas se emplean conexiones soldadas, con morteros de alta resistencia, concreto fluido y anclajes metálicos especiales.

Para el montaje de las piezas se requiere una torre grúa, de la capacidad de esta, depende el peso máximo de los paneles y por ende su dimensionamiento. En este proceso de dimensionamiento, se tiene en cuenta ser lo más modular posible para aprovechar al máximo las formaletas y disminuir los costos.

El proceso de diseño arquitectónico con esta técnica constructiva lleva implícitamente la comunión del diseño estructural y de instalaciones para evitar largos recorridos y debilitamiento de las piezas. Una secuencia de imágenes del proceso constructivo con grandes paneles se aprecia en la Figura 29. 
Ventajas

- Se reduce considerablemente el trabajo en obra y los desperdicios, alcanzando altos niveles de rendimiento, calidad y rentabilidad.

- Todos los muros construidos con esta tecnología son estructurales, lo cual garantiza una alta estabilidad edilicia.

- La tecnología está reglamentada y documentada ampliamente en la NSR-10.

Desventajas

- Se necesita una planta de producción para los paneles, lo cual se traduce en altos niveles de inversión.

- La factibilidad de construir VIS con este sistema depende de la demanda de grandes cantidades de unidades.

- El sistema no permite remodelaciones.

- Las juntas o uniones entre elementos son difíciles de ocultar o mejorar su apariencia.

- El diseño arquitectónico está restringido a las condiciones y posibilidades de la prefabricación y a facilitar el proceso de producción.

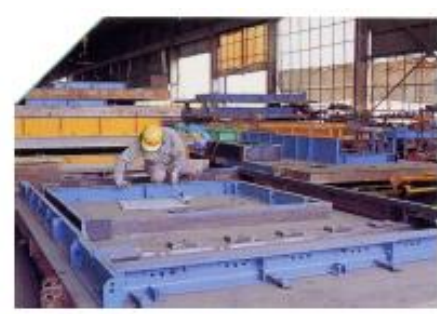

1. Adecuación de formaletas y colocación de refuerzo

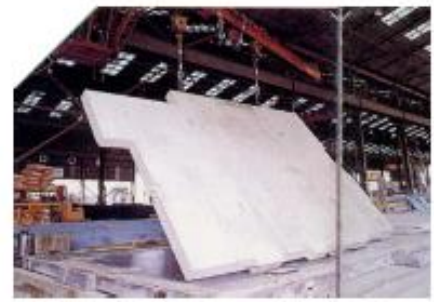

3. Desmoldey almacenaje de los pareles

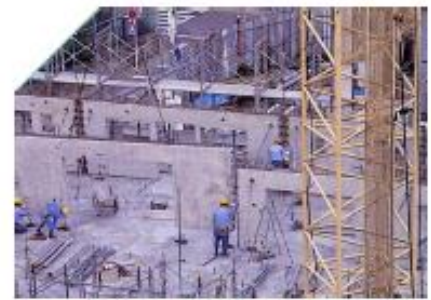

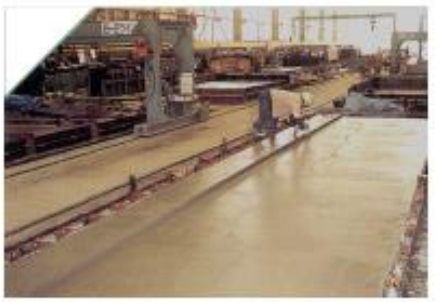

2. Colocación y afinado del concreto

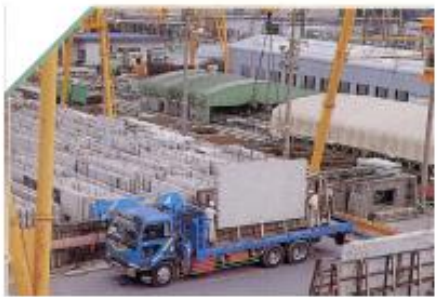

4. Transporte e zaje de los pareles

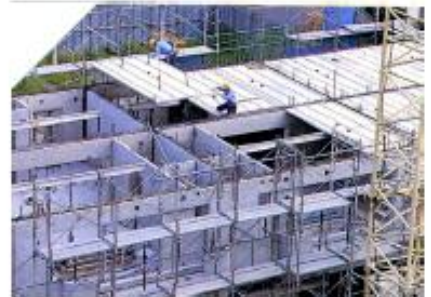

Figura 29. Proceso constructivo con el sistema de grandes paneles. Fuente: Echeverry Campos \& MetroVivienda, (2000). 


\section{Con-tech.}

Es una tecnología industrializada que usa placas modulares de aluminio fundido que se ensamblan para conformar la formaleta de los muros e incluso las losas de entrepiso de la edificación. Previamente al encofrado y fundición, se hacen los trabajos de colocación de refuerzo e instalaciones. Todo este proceso puede hacerse en un solo día contando con una mezcla de concreto acelerado.

Aunque es un proceso ordinario, es muy competitivo debido a su fácil repetición, con la cual la producción de viviendas en serie es bastante ágil y rentable. Algunos constructores reportan que el costo es 10 o $20 \%$ menor que el de los sistemas tradicionales.

La formaleta en sí posee módulos de varios tamaños, con lo cual pueden producirse muros de variadas dimensiones, además para las uniones y alineación perfecta entre módulos existen accesorios complementarios como las cuñas, pines, corbatas, tensores, tapamuros, alineadores, esquineros, tornillos y abrazaderas.

Además del clásico acabado liso de los muros, es posible encontrar formaletas con texturas simulando ladrillo, piedra u otros patrones agradables.

La formaleta requiere un cuidado básico como limpieza, aplicación de desencofrante y reducir los golpes para que su durabilidad alcance los 1000 o hasta 1400 usos documentados por algunos constructores en Colombia.

Al igual que varios sistemas ya mencionados, Con-tech utiliza los muros longitudinales y transversales en planta como estructura portante. Se diseña para que cada muro soporte los esfuerzos producidos por cargas paralelas a su eje principal.

Este método cumple con las especificaciones de las Normas Colombianas de Diseño y Construcción Sismo Resistente NSR - 10. 
Un detalle de la formaleta utilizada en esta tecnología constructiva se aprecia en las imágenes de la Figura 30.
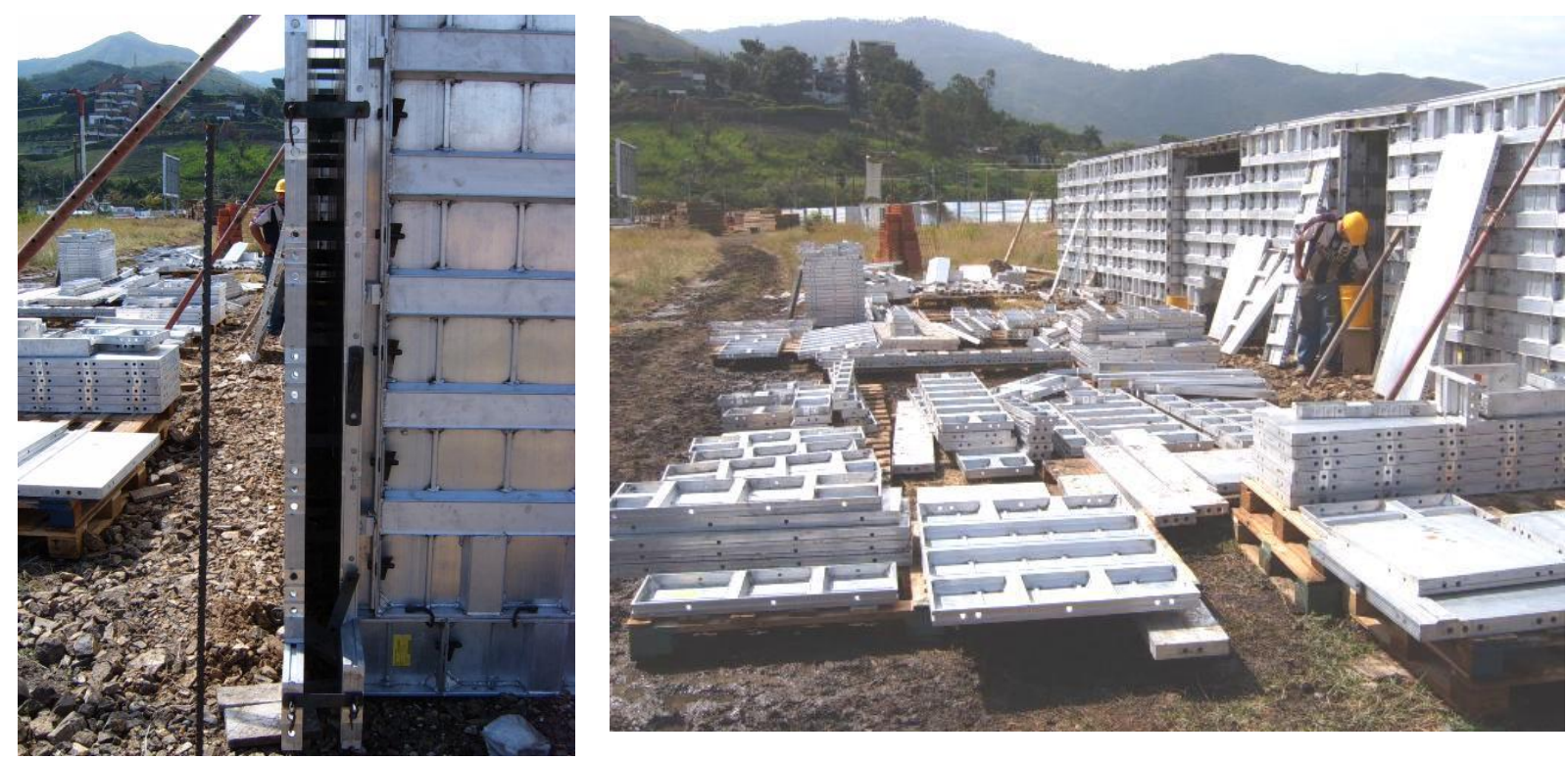

Figura 30.Detalle y vista exterior de la formaleta armada de un apartamento tipo VIS utilizando el sistema constructivo Con-tech. Fuente: Elaboración propia, proyecto Patios de la Flora, Cali-Colombia.

Ventajas

- Muy bajo desperdicio de concreto.

- Se pueden obtener acabados lisos o con cualquier textura.

- Arquitectónicamente, las dimensiones de los módulos de formaleta permiten materializar cualquier espacio.

- Es fácilmente transportable.

Desventajas

- Aunque goza de cierta libertad en el diseño arquitectónico, por lo general los diseños son casi siempre rígidos y monótonos.

- Como todos los muros son estructurales, cualquier daño afecta la estructura y no se pueden hacer remodelaciones.

- El costo de la formaleta es alto y requiere un análisis presupuestal que contemple la amortización en los tiempos del proyecto. 


\section{Outinord}

Esta tecnología tiene un procedimiento que permite fundir in-situ y en una misma operación muros longitudinales, transversales y placas de una unidad de vivienda en un día mediante el uso de un encofrado especial denominado Túnel. El encofrado túnel consta de dos planos verticales y uno horizontal, con elementos adecuados de unión, cuñas y rodachines para el desencofrado.

El proceso arranca con la fundición de un arranque de muros o talones de $10 \mathrm{~cm}$ de altura, en los cuales se posiciona la malla de refuerzo y las instalaciones. Este talón recibe la formaleta túnel que se nivela y ploma con un sistema de gatos propio del encofrado. Posteriormente se coloca la malla de refuerzo de la placa junto a sus respectivas instalaciones para que finalmente se realice el vaciado de concreto. Al siguiente día se realiza el desencofrado, facilitado por los rodachines que posee la base del túnel. Una vista del proceso de obra de este sistema constructivo se aprecia en la Figura 31.



Figura 31. Proyecto VIS materializado con el sistema constructivo Outinord en Bogotá Colombia. Fuente: http://www.bogota.gov.co/article/temas-de-ciudad/habitat/repunta-vivienda-de-interes-social-en-bogota

Ventajas

- Permite construir a un ritmo muy acelerado y a bajo costo.

- El fundido simultaneo de placas y muros asegura un excelente comportamiento estructural monolítico.

- Es muy bajo el desperdicio de concreto

- Ahorro en revoques entre un $85 \%$ y $90 \%$ gracias al excelente acabado logrado con la formaleta lisa. 
Desventajas

- Produce diseños arquitectónicos muy rígidos.

- Como todos los muros son estructurales, cualquier daño afecta la estructura y no se pueden hacer remodelaciones.

- El costo de la formaleta es alto y requiere un análisis presupuestal que contemple la amortización en los tiempos del proyecto.

- Los apartamentos tienen un bajo desempeño acústico.

\subsubsection{Sistemas constructivos combinados o híbridos.}

Este conjunto de sistemas constructivos en los que se encuentran Corpacasa y Casa Kit, son una mezcla entre estructura metálica prefabricada y cerramientos y divisiones hechas en sitio con mampostería o paneles prefabricados de fibrocemento, yeso, etc.

Se han tenido experiencias hasta de 3 pisos de altura y se adaptan con facilidad a cualquier tipo de distribución espacial. El sistema estructural debe cumplir los requisitos del Título $\mathrm{F}$ de NSR 10. Un resumen de sus características se indica en la siguiente Tabla 8 y posteriormente se detallan uno a uno.

\begin{tabular}{|c|c|c|c|c|}
\hline $\begin{array}{c}\text { SISTEMA } \\
\text { CONSTRUCTIVO }\end{array}$ & CLASIFICACIÓN & ELEMENTOS & $\begin{array}{l}\text { CONSIDERACIONES } \\
\text { ESTRUCTURALES }\end{array}$ & $\begin{array}{l}\text { CONSIDERACIONES } \\
\text { ARQUITECTÓNICAS }\end{array}$ \\
\hline \multirow{7}{*}{$\begin{array}{c}\text { Sistema } \\
\text { Combinado de } \\
\text { estructura } \\
\text { metálica y } \\
\text { mampostería }\end{array}$} & \multirow{7}{*}{ Híbrido } & Concreto & \multirow{7}{*}{$\begin{array}{c}\text { Pórticos estructurales } \\
\text { metálicos }\end{array}$} & \multirow{7}{*}{$\begin{array}{c}\text { Permite mucha } \\
\text { versatilidad y libertad } \\
\text { en el diseño debido a } \\
\text { la estructura puntual. } \\
\text { Máxima altura } 6 \\
\text { pisos. }\end{array}$} \\
\hline & & Varillas de acero para refuerzo & & \\
\hline & & $\begin{array}{l}\text { Ladrillo cerámico o bloque } \\
\text { estructural }\end{array}$ & & \\
\hline & & $\begin{array}{l}\text { Lámina colaborante metálica para } \\
\text { entrepiso }\end{array}$ & & \\
\hline & & $\begin{array}{l}\text { Paneles tipo sándwich con caras } \\
\text { metálicas y relleno de poliuretano }\end{array}$ & & \\
\hline & & Perfiles estructurales & & \\
\hline & & Cerramiento en ladrillo o paneles & & \\
\hline
\end{tabular}

Tabla 8. Características generales de los sistemas constructivos combinados. Fuente: Echeverry Campos \& MetroVivienda (2000). 


\section{Corpacasa}

Este método constructivo consiste en pórticos, losas y cubierta metálicos. Las vigas y columnas están elaboradas en perlines, la losa en steel deck y la cubierta en una lámina metálica ondulada. Por tal razón, la vivienda es liviana y requiere pocos requerimientos de cimentación. Cumple con todas las exigencias de la norma NSR-10.

Los elementos principales como columnas y vigas tienen incorporados elementos de encaje para que sea muy

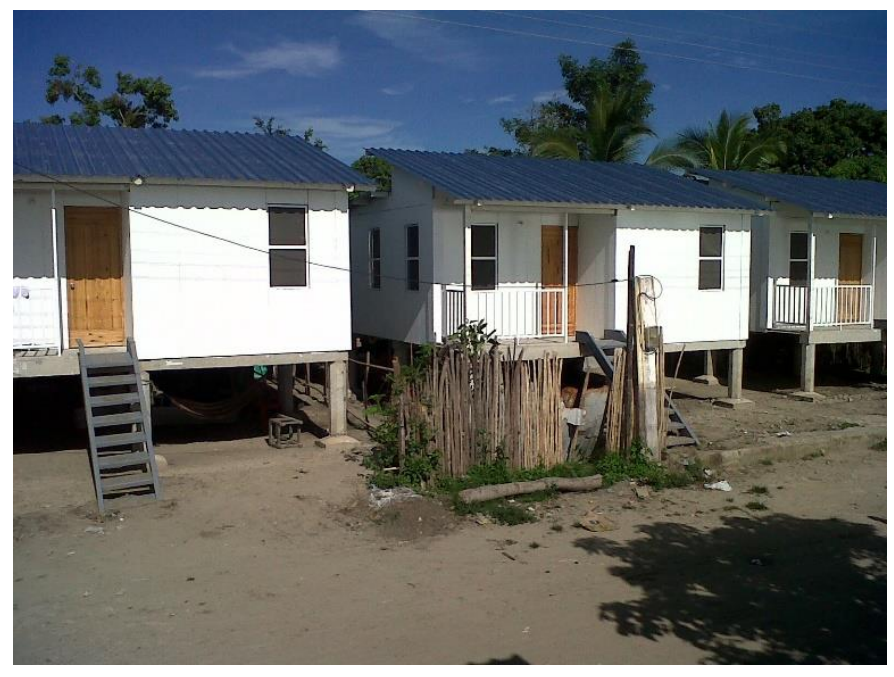

Figura 32. Conjunto de VIS desarrolladas con el sistema constructivo Corpacasa en la ciudad de Barranquilla. Fuente: http://www.corpacero.com/Productos/Paginas/Corpacasa.aspx

exacto, fácil y rápido el proceso de montaje, por esta razón no se requieren equipos especializados o de izaje.

La tecnología no proporciona los cerramientos o divisiones interiores, sin embargo, es compatible con elementos de construcción tradicional u otros sistemas. Actualmente es posible conseguir viviendas desde un nivel como se ve en la Figura 32 hasta 3, y a futuro se planean prototipos de 4 y 5 pisos.

Ventajas

- La mayoría de la edificación es hecha en taller lo cual asegura una buena calidad, precisión en las dimensiones de los elementos y además agilidad constructiva en sitio.

- No requiere mano de obra ni equipos especializados.

- Es muy versátil arquitectónicamente, permite flexibilidad y modificaciones posteriores.

Desventajas

- Para que el sistema sea competitivo requiere un alto volumen de unidades. 


\subsection{El confort térmico en la VIS bajo climas cálidos en Colombia.}

Algunas investigaciones dedicadas a estudiar el confort térmico en la VIS bajo climas cálidos en Colombia se han llevado a cabo recientemente desde el año 2011, la mayoría de ellas se centraron en disminuir la ganancia térmica por la cubierta ya que en esta latitud es la parte de la envolvente que más radiación solar recibe.

Gamboa, Rosillo, Herrera, López \& Iglesias (2011), fueron los pioneros en identificar la insatisfacción térmica brindada a los usuarios VIS. Abordaron inicialmente este problema en Cali desde una mirada macro haciendo un análisis climatológico y relacionándolo con fenómenos urbanos como la isla de calor urbana.

Posteriormente pasaron a identificar problemas en una VIS unifamiliar con mediciones de campo y evaluaciones de confort con los índices de Fanger y la carta psicrométrica. El análisis mostró que la mayoría de la carga térmica ganada y la insatisfacción térmica se atribuía al asoleamiento recibido por la cubierta, como lo muestra la termografía de la Figura 33.

Como consecuencia el ambiente presentaba un PMV "Muy caluroso" con insatisfacciones (PPD) del 100\%.
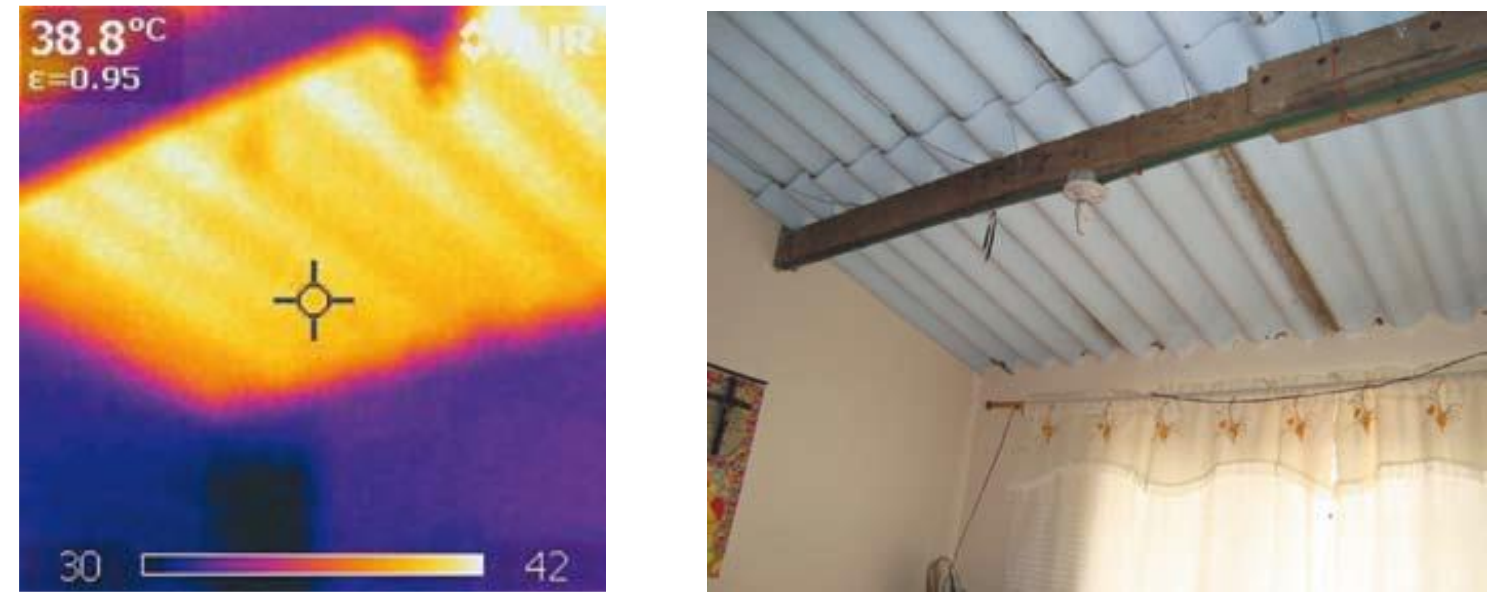

Figura 33. Temperaturas superficiales del interior de una cubierta perteneciente a una VIS de tipología unifamiliar. Fuente: (Gamboa, Rosillo, Herrera Cáceres, López Bernal, \& Iglesias, 2011).

Los autores instalaron una barrera radiante de aluminio paralela a la cubierta para formar una cámara de aire que posteriormente ventilaron en la cumbrera, como lo indica el esquema de la Figura 51. 

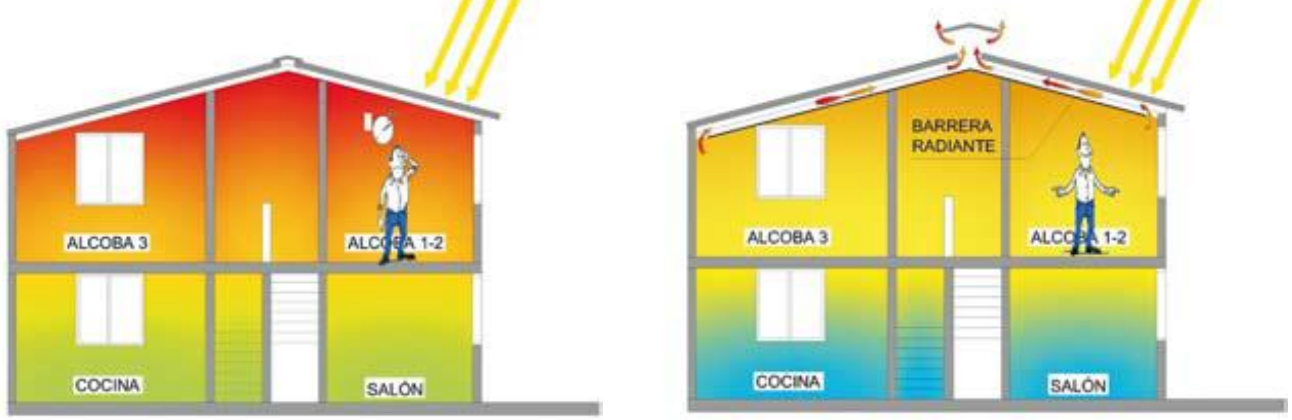

Figura 34. Esquema de intervención a cubierta hecho por Gamboa et al. Fuente: (Gamboa, Rosillo, Herrera Cáceres, López Bernal, \& Iglesias, 2011)

Con esta intervención se redujo notablemente la carga térmica ganada por la cubierta y el $100 \%$ de insatisfechos se redujo al $20 \%$. Una termografía que muestra la diferencia de las temperaturas superficiales de la cubierta se muestra en la
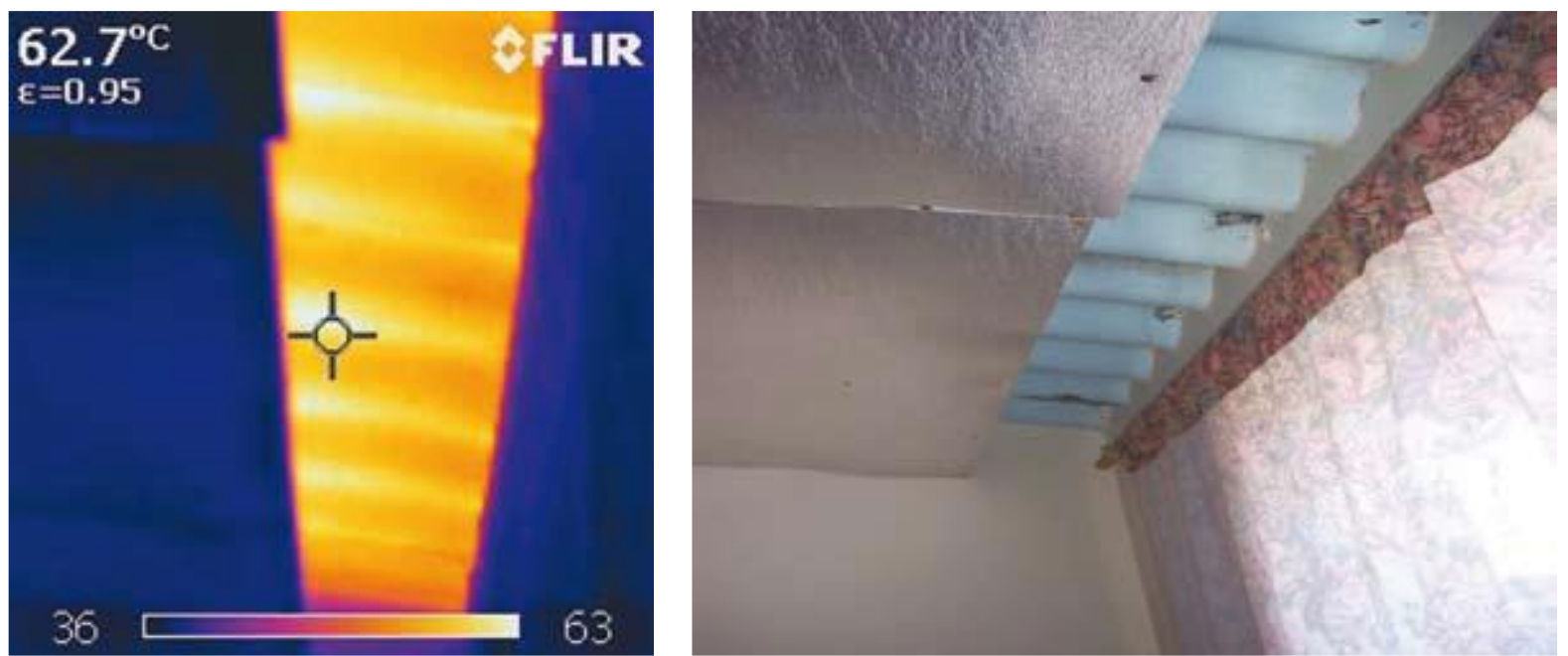

Figura 35. Termografías de la intervención a la cubierta de la VIS unifamiliar. Fuente: (Gamboa, Rosillo, Herrera Cáceres, López Bernal, \& Iglesias, 2011).

De otro lado, Giraldo \& Herrera (2017), también en Cali, evaluaron experimentalmente el confort térmico de tres módulos a escala real que simulan una habitación VIS de tipología unifamiliar. Allí, al igual que en la investigación anterior, encontraron una sensación térmica "Muy Calurosa" y el 100\% de ocupantes insatisfechos.

Para mejorar esta situación, también trabajaron sobre la cubierta con estrategias pasivas de ventilación natural (chimeneas solares), reducción de la absortividad y aislamientos reflectivos con cámaras de aire, como se ilustra en la Figura 36. 


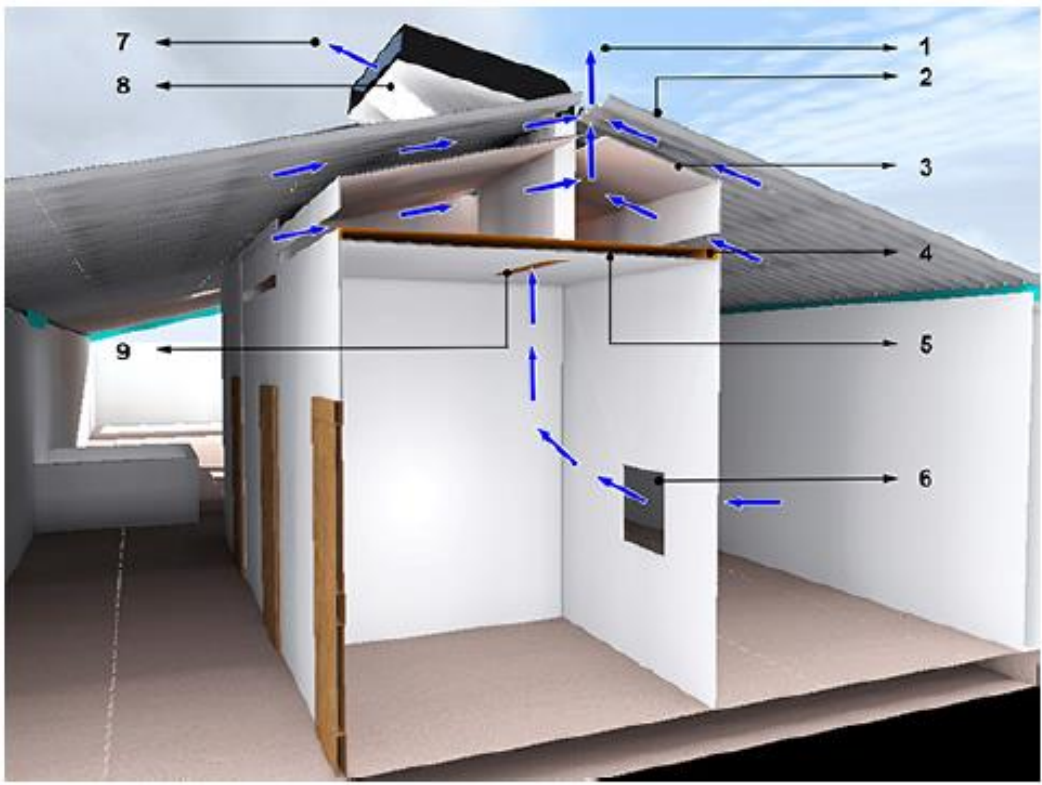

Figura 1: Disposición constructiva de los módulos de prueba [40] y patrones de flujo de aire. 1. Evacuación por cumbrera (no dibujada), 2. Cubierta blanca, 3. foil de aluminio, 4. Lana de vidrio, 5. Panel-yeso, 6. Ventana,

7. Evacuación chimenea, 8. Chimenea solar, 9. Succión chimenea.

Figura 36. Disposición constructiva de las mejoras de los módulos de prueba y las estrategias pasivas implementadas por Giraldo \& Herrera (2017). Fuente: Giraldo \& Herrera (2017).

Con la implementación de las medidas pasivas de baja absortividad y aislamiento pudo reducirse en primera instancia la ganancia solar, en cuanto a las chimeneas solares, se encontró que la de morfología plana logró un total de 34,5 cambios de aire por hora (ACH) $\left(514 \mathrm{~m}^{3} / \mathrm{h}\right)$, mientras que la de morfología tubular alcanzó $27,3 \mathrm{ACH}\left(408 \mathrm{~m}^{3} / \mathrm{h}\right)$. Lo anterior no solo significó garantizar una adecuada calidad del aire, (ya que lo mínimo requerido es $4 \mathrm{ACH}$, no alcanzado por el módulo testigo) sino que pudo evacuarse en el mejor de los casos cerca del $70 \%$ de la carga térmica. Con este conjunto de estrategias se alcanzó una satisfacción promedio del $30 \%$ de los ocupantes.

Osuna (2017), trabajó también en Cali con el objetivo de evaluar la capacidad de enfriamiento de un prototipo de techo plantado, el cual puede ser instalado sobre tejas onduladas de fibrocemento muy características de las VIS unifamiliares de Cali. En la experimentación se construyó un módulo testigo y dos experimentales en los que se plantaron dos especies diferentes como lo muestra la siguiente Figura 37. Con la evaluación de confort llevada a cabo en dos momentos se encontró que mientras el módulo testigo presentaba insatisfacción total, los módulos plantados lograron un porcentaje aceptable de $18,5 \%$.

Además, con una estimación matemática se logró conocer que la resistencia térmica del prototipo fue de $0,645 \mathrm{~m}^{2 \circ} \mathrm{K} / \mathrm{W}$. 


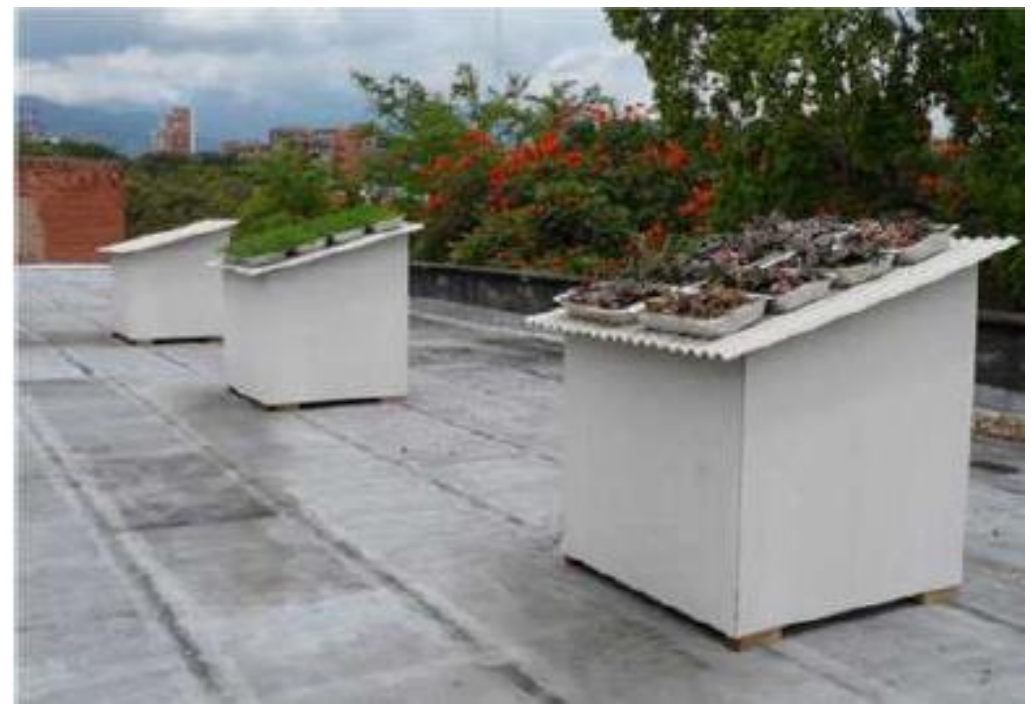

Figura 37. Experimentación con techos plantados en Cali. Fuente: (Osuna Motta, 2017)

Iturre (2013), quien trabajó en con la VIS de Buenaventura, logró identificar mediante sondeos de campo y encuestas a más de 200 casas, que en el 53\% de ellas, se utilizaba climatización mecánica constantemente. Según el autor esto se debe a que en el diseño arquitectónico y constructivo no se tuvo en cuenta la parte térmica y que el deficit de confort se atribuía principalmente al calor ganado por la cubierta y por su baja resistencia térmica. Sin embargo también encontró ausencia de ventilación cruzada y alta absortividad y baja resistencia térmica en los muros de fachada.

La propuesta del autor que consistió en mejorar la resistencia térmica de la cubierta, cambiar el color de los muros para reducir la absortividad y mejorar la ventilación natural, como se ve en la Tabla 9 , muestra que la $\mathrm{T}_{\mathrm{r}}$ de la cubierta pasó de $62,17^{\circ} \mathrm{C}$ a $30,28^{\circ} \mathrm{C}$ y la envolvente de $41,77^{\circ} \mathrm{C}$ a $36,19^{\circ} \mathrm{C}$.

\begin{tabular}{|c|c|c|c|c|c|c|c|}
\hline & ESPACIO & QWATT (OPCION INICIAL) & QWATT (OPCION MEJORAS) & $\begin{array}{l}\text { PORCENTAJE } \\
\text { (INICLAL) }\end{array}$ & $\begin{array}{l}\text { PORCENTANE } \\
\text { [MEORAS] }\end{array}$ & $\begin{array}{l}\text { TEMAPERATURA } \\
\text { RADIANTE("C) } \\
\text { (INICLAL) }\end{array}$ & $\begin{array}{l}\text { TEMAPERATURA } \\
\text { RADIANTE('C) } \\
\text { [MEORAS) }\end{array}$ \\
\hline 1 & Q TECHOS & 11848,25 & 339,53 & $56,43 \%$ & $3,99 \%$ & 62,17 & 30,28 \\
\hline 2 & Q PAREDES ASOLEADAS & 2479,01 & 154209 & $11,81 \%$ & 18,128 & 41,77 & 36,19 \\
\hline 3 & Q PAREDES NO ASOLEADAS & 3494,21 & 3454,90 & $16,64 \%$ & $40,59 \%$ & 33,97 & 33,89 \\
\hline 4 & QVENTANAS ASOLEADAS & 692,99 & 692,99 & $3,30 \%$ & $8,14 \%$ & 27,77 & 27,77 \\
\hline 6 & Q OCUPANTES & 520,00 & 520,00 & $2,48 \%$ & $6,11 \%$ & & \\
\hline 7 & QEQUIPOS & 1962,00 & 1962,00 & $9,34 \%$ & $23,66 \%$ & & \\
\hline 6 & TOTAL & 20996,45 & 8511,50 & $100,00 \%$ & $100,00 \%$ & & \\
\hline
\end{tabular}

Tabla 9. Cuadro comparativo de VIS de Buenaventura sin intervenir vs Modelo mejorado. Fuente: (Iturre Campiño, 2013). 
Recientemente, Barona (2016) llevó a cabo una investigación para determinar el comportamiento térmico de dos de las envolventes más utilizadas en las VIS de Cali, la Mampostería estructural con bloques de arcilla cocida y los Muros macisos de concreto reforzado. Este estudio se llevó a cabo en viviendas unifamiliares construidas en municipios aledaños a Cali como Candelaria y Jamundí, los cuales comparten las mismas características climáticas.

En este estudio se concluye que estos dos tipos de envolventes verticales no poseen la capacidad suficiente para aislar térmicamente el calor irradiado por el sol y brindar confort térmico a pesar de que el clima no presente fluctuaciones estacionales ni cambios extremos.

Para sustentar lo anterior el autor enseña los siguientes collages de termografías de la Figura 38 y Figura 39, en los cuales las temperaturas de las superficies interiores llegan hasta los $38^{\circ} \mathrm{C}$, sobrepasando así los rangos superiores de confort.

El autor menciona que especialmente la temperatura superficial interior de la cubierta (que como puede verse en la Figura 38 alcanza los $44,2^{\circ} \mathrm{C}$ ) genera insatisfacción térmica en los ocupantes debido a que incrementa la Temperatura media radiante de los recintos.
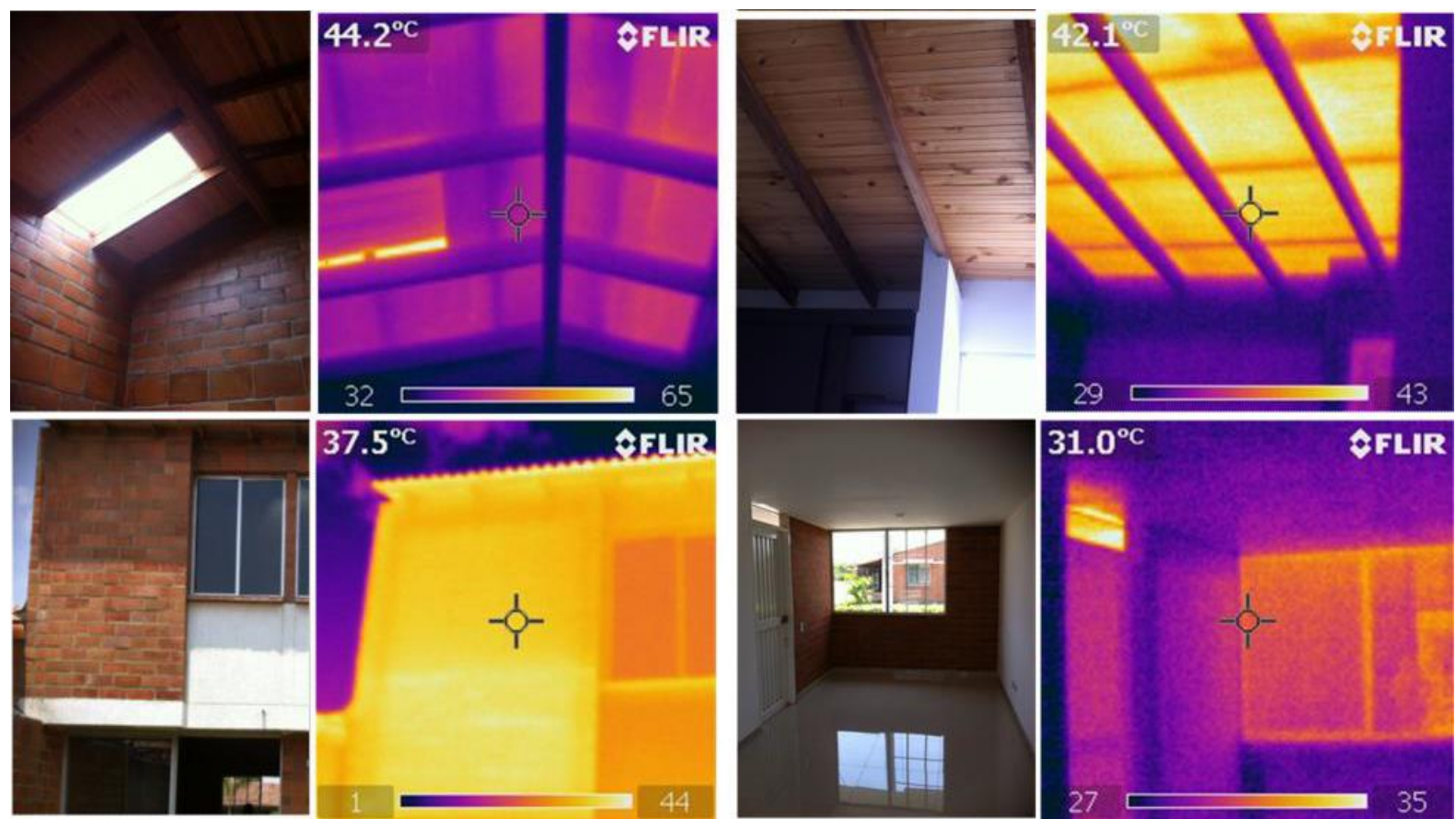

Figura 38. Termografías interiores de una VIS con envolvente de bloques de arcilla. Fuente: (Barona, 2016) 

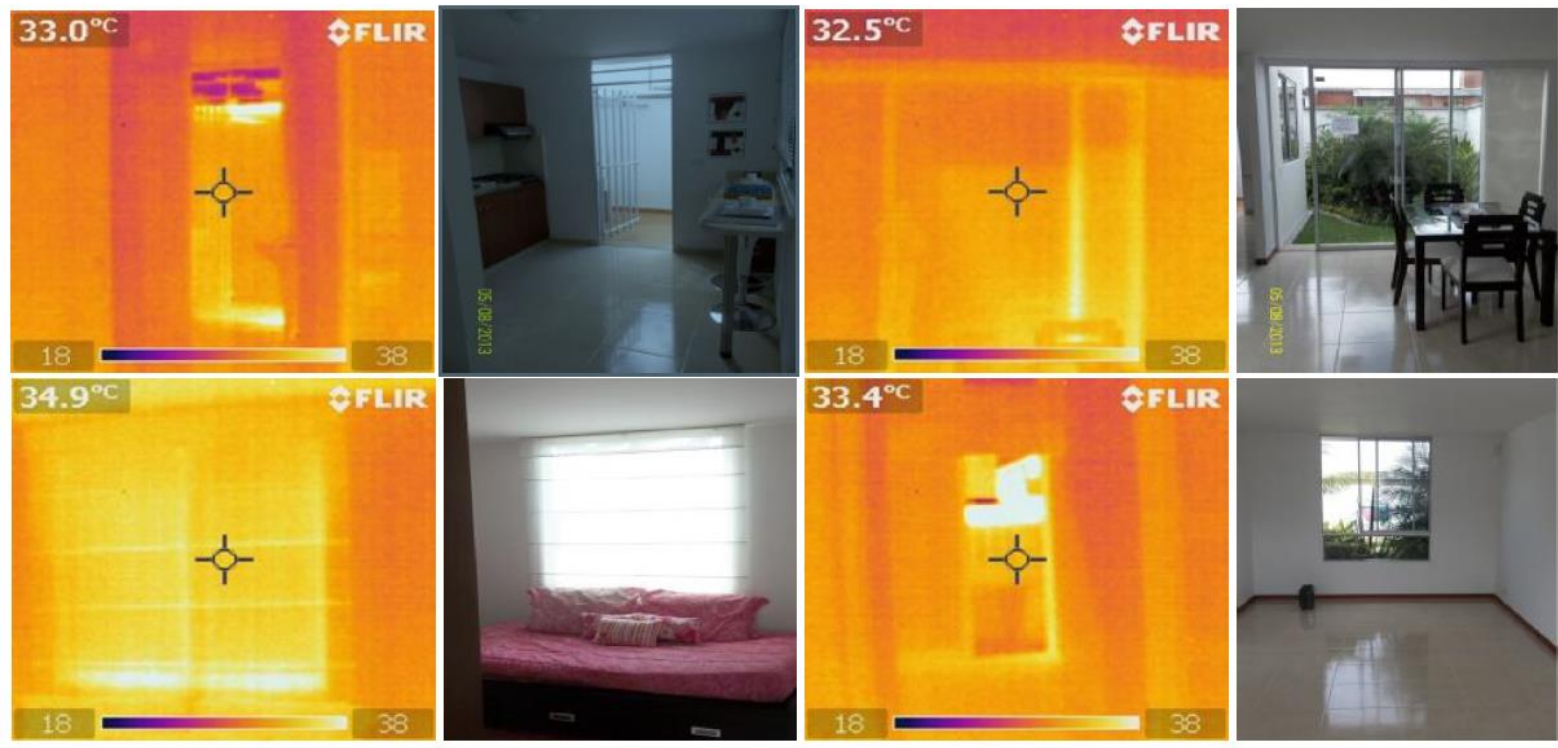

Figura 39. Termografías interiores de una VIS con envolvente de concreto reforzado. Fuente: (Barona, 2016).

Con datos recogidos en campo el 14 de agosto de 2013 a las 15:20, Barona evaluó el confort térmico de la VIS de mampostería de ladrillo de arcilla mediante el índice de Fanger, concluyendo que la sensación térmica al interior de esta vivienda es "Muy Calurosa" y el 95,3\% de los ocupantes se encuentra en insatisfacción térmica. Dicha evaluación puede observarse a continuación en la Figura 40.

\begin{tabular}{|c|c|}
\hline Parameter & Input \\
\hline Clothing (clo) & 1,00 \\
\hline Air temp. $\left({ }^{\circ} \mathrm{C}\right)$ & 36,2 \\
\hline Mean radiant temp. $\left({ }^{\circ} \mathrm{C}\right)$ & 30,0 \\
\hline Activity (met) & 1,2 \\
\hline Air speed $(\mathrm{m} / \mathrm{s})$ & 0,00 \\
\hline Relative humidity (\%) & 47,7 \\
\hline \multicolumn{2}{|c|}{ Calculate PMV } \\
\hline Parameter & Results \\
\hline Operative temp. $\left({ }^{\circ} \mathrm{C}\right)$ & 33,1 \\
\hline PMV & 2,6 \\
\hline PPD & 95,3 \\
\hline
\end{tabular}

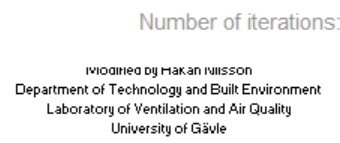

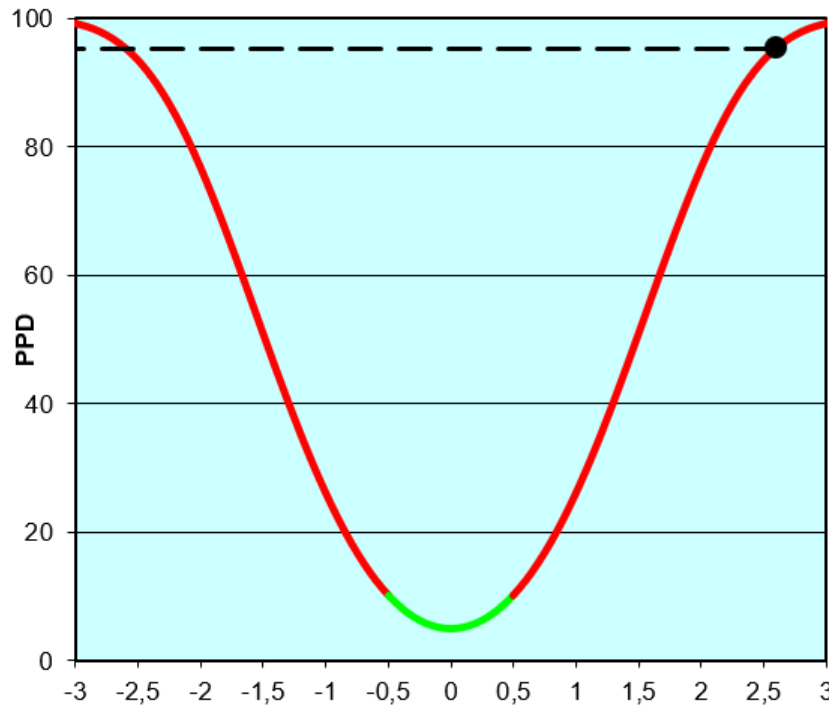

Figura 40. Evaluación de PMV y PPD de una VIS con envolvente de ladrillo de arcilla. Fuente: (Barona, 2016).

De la misma forma el autor evaluó el confort térmico para la VIS con envolvente en concreto reforzado, para lo cual se tomó como base un monitoreo hecho el 15 de septiembre de 2013 a las 11:45, obteniendo una sensación térmica "Muy Calurosa" y un porcentaje de insatisfechos de $97,8 \%$, lo cual puede verse en la Figura 41. 


\begin{tabular}{|c|c|c|}
\hline Parameter & Input & \\
\hline Clothing (clo) & 1,00 & [0 to $2 \mathrm{clo}]$ \\
\hline Air temp. $\left({ }^{\circ} \mathrm{C}\right)$ & 37,7 & {$\left[10\right.$ to $\left.30^{\circ} \mathrm{C}\right]$} \\
\hline Mean radiant temp. $\left({ }^{\circ} \mathrm{C}\right)$ & 30,0 & {$\left[10\right.$ to $\left.40^{\circ} \mathrm{C}\right]$} \\
\hline Activity (met) & 1,2 & {$[0.8$ to $4 \mathrm{met}]$} \\
\hline Air speed $(\mathrm{m} / \mathrm{s})$ & 0,00 & [0 to $1 \mathrm{~m} / \mathrm{s}]$ \\
\hline Relative humidity (\%) & 46,1 & {$[30$ to $70 \%]$} \\
\hline \multicolumn{2}{|l|}{ Calculate PMV } & \\
\hline Parameter & Results & \\
\hline Operative temp. $\left({ }^{\circ} \mathrm{C}\right)$ & 33,85 & \\
\hline PMV & 2,8 & \\
\hline PPD & 97,8 & \\
\hline Number of iterations: & 6 & \\
\hline $\begin{array}{l}\text { Modified by Häkan Nilsson } \\
\text { Department of Technology and Built Environment } \\
\text { Laboratory of Ventilation and Air Quality } \\
\text { University of Gäule }\end{array}$ & & \\
\hline
\end{tabular}

University of Gänle
Unte

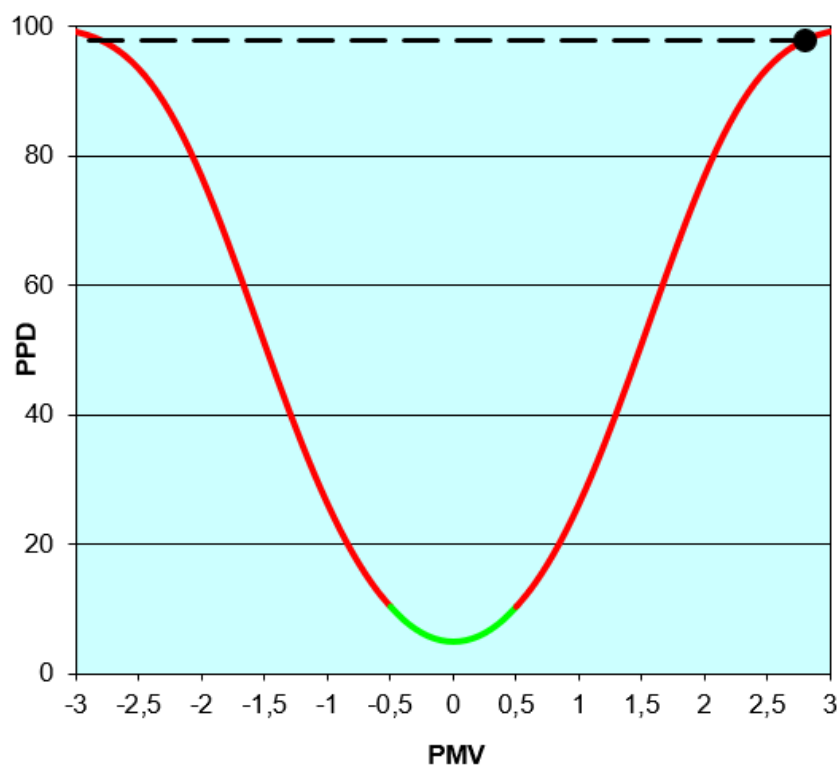

Figura 41. Evaluación de PMV y PPD de una VIS con envolvente de concreto reforzado. Fuente: (Barona, 2016).

Finalmente, aunque no en profundidad, Barona sugiere que estos problemas pueden solucionarse con decisiones que van desde la etapa del diseño arquitectónico como una correcta orientación respecto al sol hasta las decisiones constructivas como el aumento de la resistencia térmica en la envolvente con materiales aislantes y la reducción de la absortividad con la aplicación del color blanco en fachada, entre otros.

\subsection{Conclusiones}

A continuación, se presentan unas conclusiones derivadas de relacionar y analizar críticamente la información recopilada acerca del actual estado del arte en la VIS en Cali y Colombia:

- El concepto de Vivienda de Interés Social consignado en el título 2.1, al igual que las normativas estipuladas por el Estado Colombiano vistas en el título 2.6 son claras y completas. Sin embargo, como se relató en el título 2.3 y 2.8 , esto no ha garantizado el derecho fundamental a una vivienda a la totalidad de la población, ni ha asegurado que las condiciones de habitabilidad de este tipo de edificaciones sean de buena calidad.

- Dejar que el Reglamento de construcción sostenible (Decreto 0549-2015) sea de cumplimiento optativo para las VIS, les quita la posibilidad a las personas con menos recursos económicos de obtener viviendas con mejor calidad y disminuir su costo de vida. Al igual que se pierde la oportunidad de reducir el gasto energético e impacto 
ambiental de este tipo de edificaciones, que como se vio en los títulos 2.4 y 2.6 .7 constituyen el $49 \%$ de las viviendas construidas y consumen más energía que las viviendas no VIS.

- Con lo revisado en el título 2.7 acerca de los sistemas constructivos y materiales disponibles se concluye que hay gran diversidad. Estos sistemas se pueden adaptar a diferentes situaciones geográficas, económicas, climáticas, culturales, y tecnológicas, lo cual podría aprovecharse mucho más para que los usuarios VIS tengan mayores prestaciones de habitabilidad en sus viviendas.

- En las estadísticas de uso de sistemas constructivos y materialidad para las VIS en Colombia, sintetizadas en la gráfica de la Figura 18 se identificó que al menos el $97 \%$ este tipo de construcciones están constituidas por materiales de altos niveles de absortancia solar y conductividad térmica como el concreto y la arcilla. Estos materiales bajo una alta radiación solar y clima cálido como el de Cali producen altos niveles de $T_{r}$ en las envolventes como las vistas en las imágenes de la Figura 3, Figura 33 y Figura 35.

Estas altas $T_{r}$ influyen de forma directa sobre los cuerpos de los usuarios debido a las áreas reducidas de las VIS (vistas en la Tabla 4) generando así insatisfacción térmica. Se infiere que como la mayoría de las VIS comparten estos mismos rasgos, también compartan el deficiente nivel de confort térmico en los climas cálidos.

- El estado del arte sobre el confort térmico en VIS bajo climas cálidos tratado en el numeral 2.8 demuestra avances que se concentran en disminuir la ganancia térmica por la cubierta, debido a que es la parte de la envolvente que más absorbe radiación solar en esta latitud. Estas investigaciones son muy útiles especialmente para las VIS de tipología multifamiliar o para los últimos pisos de la tipología multifamiliar donde la influencia de la cubierta es directa. Sin embargo, se nota un vacío de evaluaciones de confort y exploración de mejoras para las VIS de tipología multifamiliar donde el calor ganado por las envolventes verticales es más influyente. 


\section{ESTRATEGIAS DE ENFRIAMIENTO PASIVO EN ENVOLVENTES}

\subsection{Introducción}

El término estrategias de enfriamiento pasivo según el Departamento de Energía de los Estados Unidos ((DOE), 2016), está asociado a aquellas medidas utilizadas en el diseño arquitectónico para enfriar las edificaciones y cuyo funcionamiento no requiere un consumo de energías disímiles a las naturales. Las estrategias de enfriamiento pasivo como por ejemplo la ventilación natural, la protección solar y el aislamiento térmico no consumen energía eléctrica a diferencia de las estrategias de enfriamiento activo como los aires acondicionados o la ventilación mecánica. Estas estrategias son especialmente utilizadas en la arquitectura bioclimática y tienen la capacidad de mejorar el confort térmico en las edificaciones y por ende reducir la demanda interna de energía.

Paralelamente, Harvey (2009) las define como conceptos de diseño sustentable, las cuales usan cero o muy baja energía para enfriar los espacios, lo cual aporta grandes ahorros energéticos.

En cuanto a las estrategias dedicadas solamente para enfriamiento, existen gran variedad, pero pueden clasificarse en tres clases principales, enuncian Geetha \& Velraj (2012): las de prevención del calentamiento que trabajan eliminando la posibilidad de ganar calor, bloqueando los rayos del sol. Las estrategias de modulación del calor que intentan modificar el calor ganado mediante su almacenamiento durante el día y la liberación paulatina durante la noche. Y por último las estrategias de disipación, cuyo objetivo es remover el calor de la edificación mediante fuerzas naturales del sitio. Un esquema clasificatorio de estas estrategias de enfriamiento pasivo se encuentra en el esquema de la Figura 42. 


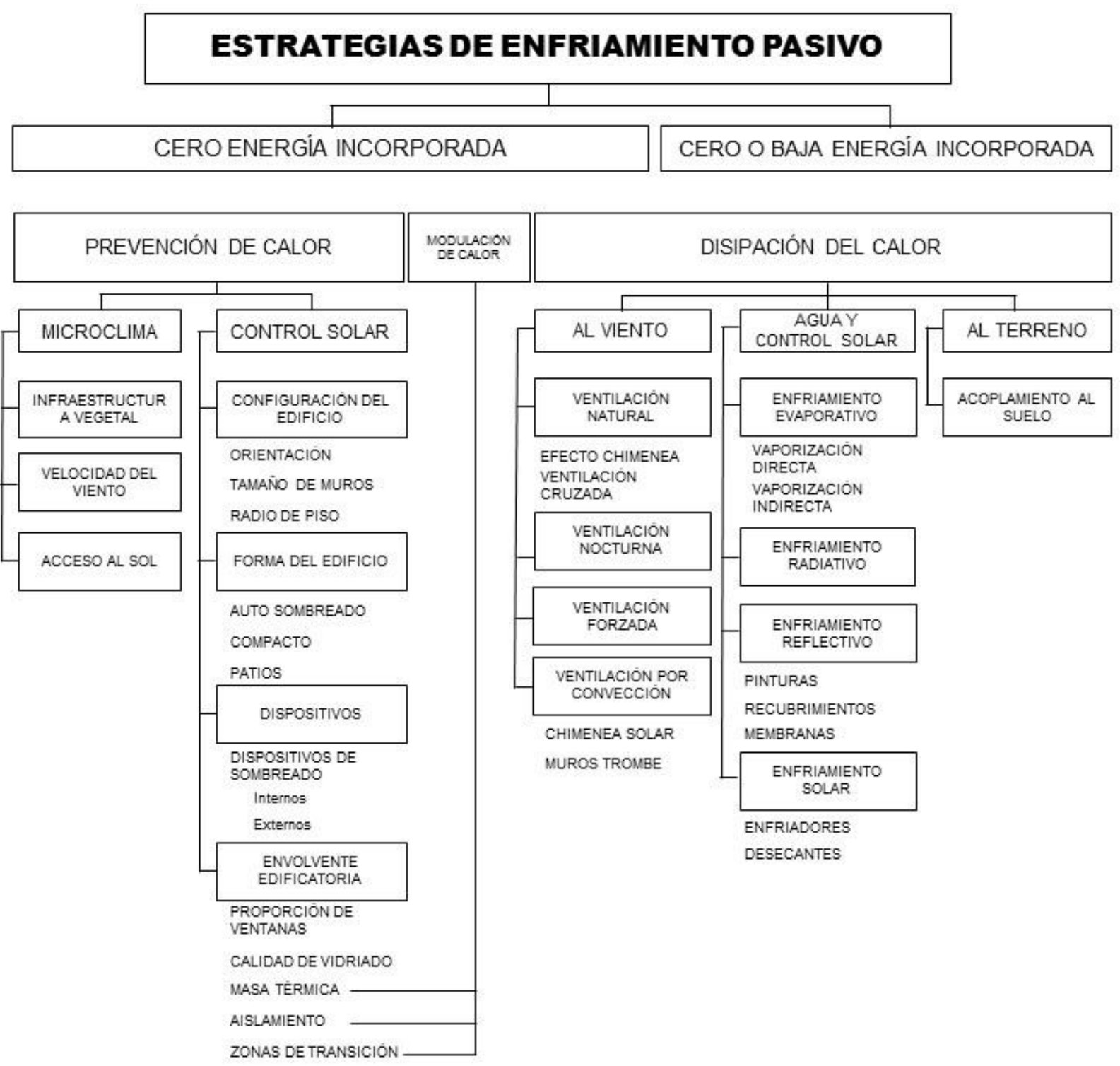

Figura 42. Clasificación de estrategias de enfriamiento pasivo. Fuente: Geetha \& Velraj (2012).

Con el fin de encontrar las tecnologías más eficientes para reducir la $T_{\mathrm{mr}}$ se consultó el estado actual del conocimiento y se han identificado 6 grandes grupos de estrategias de tipo pasivo aplicables a las envolventes arquitectónicas a saber:

- Técnicas de protección solar.

- Baja absortividad o Muros fríos.

- Muros vegetales.

- Materiales de alta resistencia térmica.

- Fachadas opacas ventiladas.

- Aislamiento reflectivo o barreras radiantes.

A continuación, se describen detalladamente cada una de las estrategias y los trabajos de investigación que conforman su estado del conocimiento actual. 


\subsection{Técnicas de protección solar.}

Conforme a lo enunciado por Santamouris \& Asimakopoulos (2001), esta estrategia es la exclusión selectiva de la radiación solar utilizando elementos que den sombra como aleros, quiebrasoles, árboles, etc.

Bermúdez (1987), explica que este es un extenso tema que inicia con la comprensión de la geometría solar (ver explicación en el título 1.6), su intensidad de radiación y el concepto de transferencia de calor por radiación aplicado en las edificaciones. Con la aplicación de esta estrategia es posible controlar el sobrecalentamiento de las fachadas e incluso los niveles de iluminación requeridos de los espacios.

Las técnicas de control solar abarcan gran cantidad de estrategias que pueden ser aplicadas en el diseño arquitectónico para reducir el impacto de la radiación solar en la envolvente edificatoria y en el interior de los espacios para reducir la demanda de energía destinada al enfriamiento. Las cuatro principales clases de estas técnicas son: la orientación del edificio, las fachadas auto-sombreadas, los dispositivos de sombreado y la relación vidriado opaco (RVO). Sin embargo, la aplicación de esta estrategia debe ser cuidadosa porque otros temas relacionados como la iluminación natural y la visibilidad al exterior pueden verse afectados (Mingzhe, Wittchen, \& Heisel, 2015).

Las fachadas auto-sombreadas son consideradas como una piel para el edificio, que además de aportar un contenido estético cumplen la función principal de reducir la insolación a los elementos opacos y transparentes que conforman el exterior (Nikpour, Zin Kandar, Ghasemi, \& Ghomeshi, 2012).

La efectividad de esta estrategia fue evaluada en unas oficinas ubicadas en la parte superior de un edificio en la cálida y seca ciudad de Jerusalén, Israel. A la envolvente de estos espacios se le adicionó una segunda piel inclinada de vidrio con persianas. Una de las oficinas ubicada

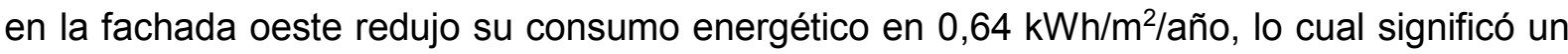
ahorro del $43 \%$ anual. Esta estrategia pudo ahorrar más energía que las fachadas vidriadas verticales tratadas con tecnología de baja emisividad (Capeluto, 2003).

También, el trabajo realizado por Chan \& Chow (2014), en un edificio de fachada inclinada

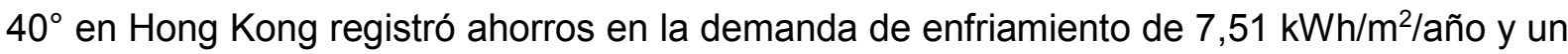
$10,95 \%$ de ahorro energético anual. Adicionalmente, se encontró que inclinar aún más el ángulo, a $30^{\circ}$, produjo un consumo energético adicional al caso base porque mucha cantidad de radiación reflejada por el suelo afectó negativamente el comportamiento térmico. 
Blanco (2014), comparó el desempeño térmico de una fachada simple frente a un sistema doble, obteniendo al interior del espacio una reducción de $\mathrm{T}_{\text {air }}$ entre $4^{\circ} \mathrm{C}$ y 5 ${ }^{\circ} \mathrm{C}$. En cuanto a materialidad, se encontró que el aluminio se calienta entre 2 o 3 grados menos que la lámina de acero galvanizado. Además, se pudo dar como válido el modelo matemático con el que fue diseñada, el cual tuvo en cuenta no solo la transferencia de calor por radiación, sino también por convección y conducción.

El edificio de la Plaza de la Libertad en Medellín, Colombia, sirve como ejemplo para ilustrar esta tecnología en la Figura 43.

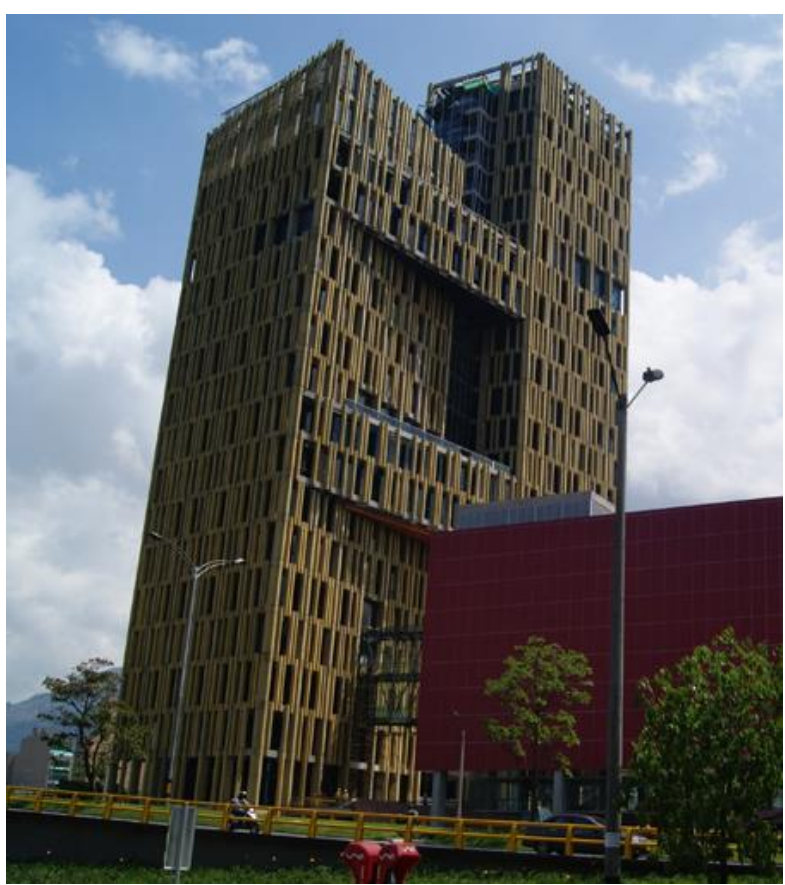

Figura 43. Edificio de la Plaza de la Libertad, MedellínColombia.

Además, varias secciones esquemáticas en 2D y 3D de fachadas auto-sombreadas simples y complejas pueden verse en la Figura 44.

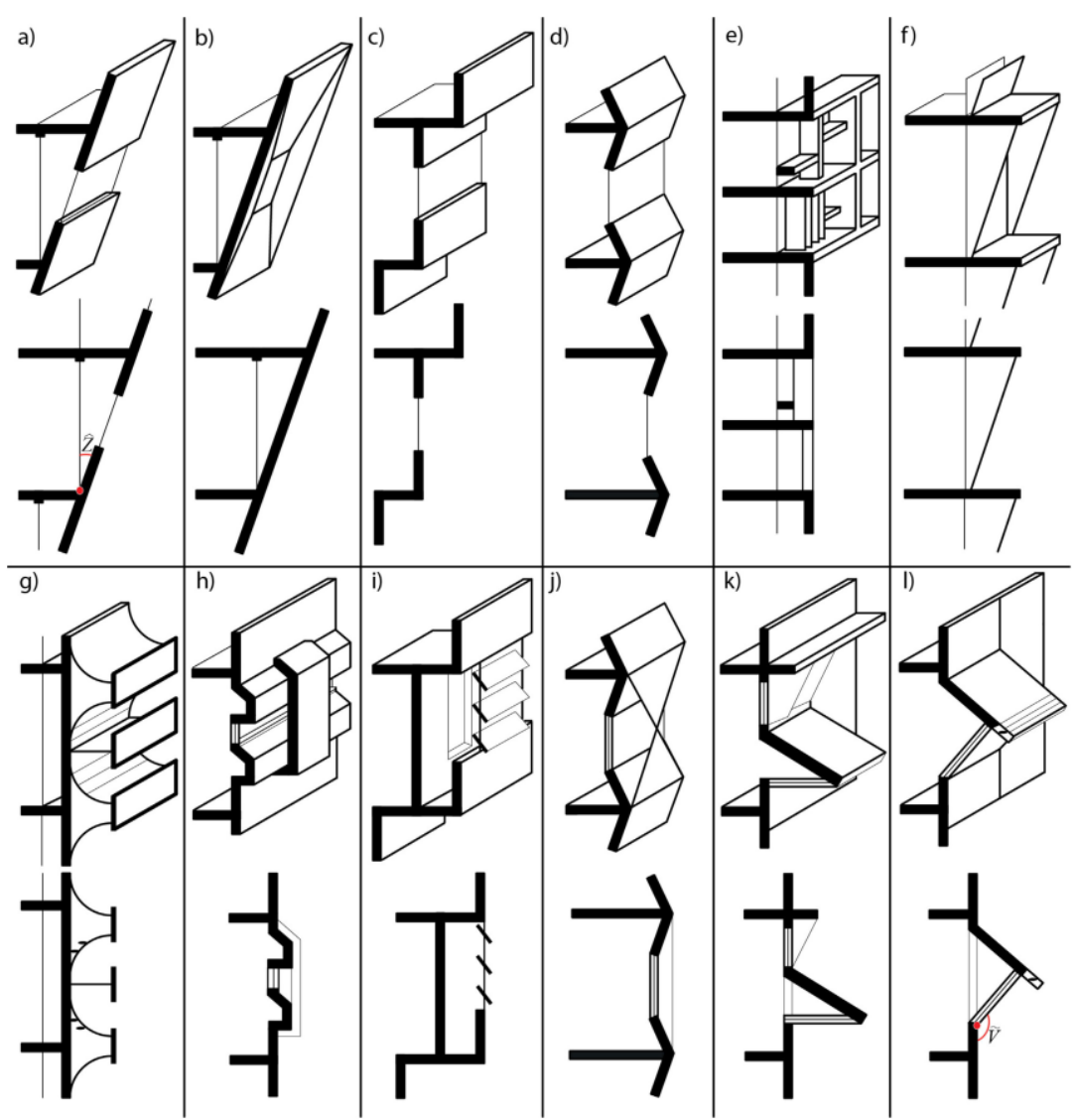

Figura 44. Secciones esquemáticas en $2 D$ y 3D de diseños simples $(a-f)$ y complejos $(g-l)$ de fachadas autosombreadas. Fuente: Valladares-Rendón, Schmid, \& Lo (2017). 
Los dispositivos de sombreado cumplen las funciones de arrojar sombra a la edificación para evitar su calentamiento, proteger la entrada directa del sol a los espacios interiores a través de los vanos y aumentar o reducir la cantidad de luz que entra a los espacios. Además, algunas veces, estos elementos también cumplen funciones estructurales. Estos elementos no requieren mucho mantenimiento, son económicos y poseen un alto desempeño térmico (Olgyay, 1998.).

Los dispositivos de control solar deben variar según la latitud y el tipo de clima. Asimismo, deben ser diseñados con exactitud y equilibrio para cada fachada mediante el método de la máscara de sombras (explicado en el título 1.8 del presente trabajo), porque debe equilibrarse el control solar, la iluminación y la visibilidad señalan De la Peña y Quintero ( 2011).

Valladares y Lo (2014), trabajaron en Taipéi, caracterizada por tener un clima con invierno seco y verano caliente mediante modelos computacionales. Los resultados indicaron que los dispositivos de sombreado solamente horizontales disminuyeron la insolación en toda la envolvente de un edificio y al mismo tiempo mejoraron el microclima externo. Esto produjo

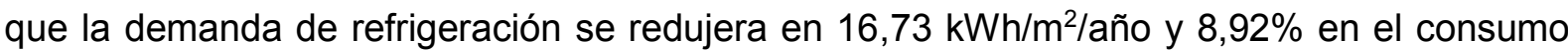
anual neto.

En Seúl, Corea, llevaron a cabo un estudio para evaluar la aplicabilidad de los dispositivos de sombreado para edificaciones residenciales de varios pisos en busca de minimizar la ganancia solar y reducir el consumo energético en enfriamiento. Los resultados mostraron que los elementos horizontales y verticales lograron reducir el $19,7 \%$ y $17,3 \%$ de la energía anual respectivamente. Teniendo en cuenta que el análisis se realizó a los $37^{\circ}$ de latitud Norte, se encontraron mejoras representativas en las fachadas Sur, Este y Oeste, el análisis de factibilidad económica indicó que la inversión puede amortiguarse en un lapso promedio de cinco años (Cho, Yoo, \& Kim, 2014).

Gon, Hong Soo, Tae Sub, Schaefer, \& Jeong Tai(2012), observaron que un dispositivo de persianas inclinado como el indicado en la Figura 45 literal $\mathrm{L}$, a $60^{\circ}$, ubicado en las ventanas

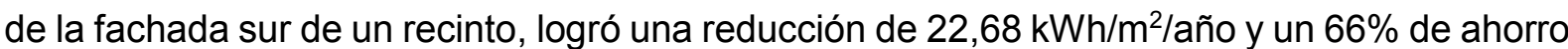
energético anual.

Un estudio experimental y analítico fue llevado a cabo por Freewan (2014), para examinar el efecto de los dispositivos de sombreado sobre la $T_{\text {air }}$, el confort visual y la interacción de los usuarios en la fachada suroeste de un edificio de oficinas de la Universidad de Jordán, en Jordania a $31,9^{\circ}$ de latitud Norte. Tres tipos de elementos de protección solar fueron examinados por el autor durante el periodo de verano (junio-agosto): lamas verticales, lamas 
diagonales y una retícula con la combinación de lamas verticales y horizontales. Estos dispositivos fueron instalados en tres oficinas idénticas y se dispuso una cuarta como testigo.

Los resultados mostraron que las lamas verticales redujeron la $T_{\text {air }}$ interna entre un $5 \%$ y $6 \%$. En la mañana se redujo alrededor de $0,5^{\circ} \mathrm{C}$, pero en el periodo de $13: 00$ a $16: 00$ las diferencias promedio se incrementaron de $1,7^{\circ} \mathrm{C}$ a $2,15^{\circ} \mathrm{C}$, llegando a máximos de $2,15^{\circ} \mathrm{C}$ y $2,75^{\circ} \mathrm{C}$ en julio y agosto respectivamente.

Por su parte, las lamas diagonales redujeron la $\mathrm{T}_{\text {air }}$ entre $19 \%$ y $16 \%$ comparado con el caso base, la diferencia en la mañana fue superior a $1,5^{\circ} \mathrm{C}$ y desde las $12: 00$ a las $16: 00$ se produjeron disminuciones de hasta $5,75^{\circ} \mathrm{C}$ y $6,65^{\circ} \mathrm{C}$ en julio y agosto respectivamente.

Por último, la retícula disminuyó la $\mathrm{T}_{\text {air }}$ en un $10 \%$. También hubo mermas entre $3,25^{\circ} \mathrm{C}$ y $3,5^{\circ} \mathrm{C}$ en el periodo de julio y agosto respectivamente. La disminución máxima fue alrededor de las $15: 00$ con $5,35^{\circ} \mathrm{C}$ y $6,3^{\circ} \mathrm{C}$ en julio y agosto respectivamente.

Freewan concluyó que los casos de lamas diagonales y reticuladas se comportaron mejor en comparación al de lamas verticales y al caso base. Además, el confort visual fue mejorado por el control de la iluminancia, la uniformidad y la eliminación del resplandor.

Con simulaciones, Bekkouche et al (2011), encontraron que en un clima desértico como el de Ghardaïa - Algeria, la inclusión de aleros en el diseño arquitectónico redujo ligeramente la temperatura interior en $1^{\circ} \mathrm{C}$, aunque no fue suficiente para alcanzar la temperatura de confort situada en $27^{\circ} \mathrm{C}$. Asimismo, Hashemi \& Khatami (2017), simularon mediante el software Energy Plus los efectos de esta estrategia en el confort térmico de viviendas de bajos ingresos en Uganda. La muestra representativa consistió en viviendas aisladas de un solo nivel con muros de ladrillo visto y techo de lámina metálica. Como elementos de protección solar se utilizaron cortinas, galerías, aleros y árboles en diferentes combinaciones. Al igual que el estudio anterior, ninguna de las combinaciones fue capaz de alcanzar los rangos de confort térmico, sin embargo, la mejor condición, lograda con una galería cubierta de 2 metros fue capaz de reducir la carga térmica en un $52 \%$.

A manera de ilustrar esta tecnología, en la Figura 45 se presentan varias secciones esquemáticas en 2D y 3D de fachadas con dispositivos de sombreado simples y complejos. 


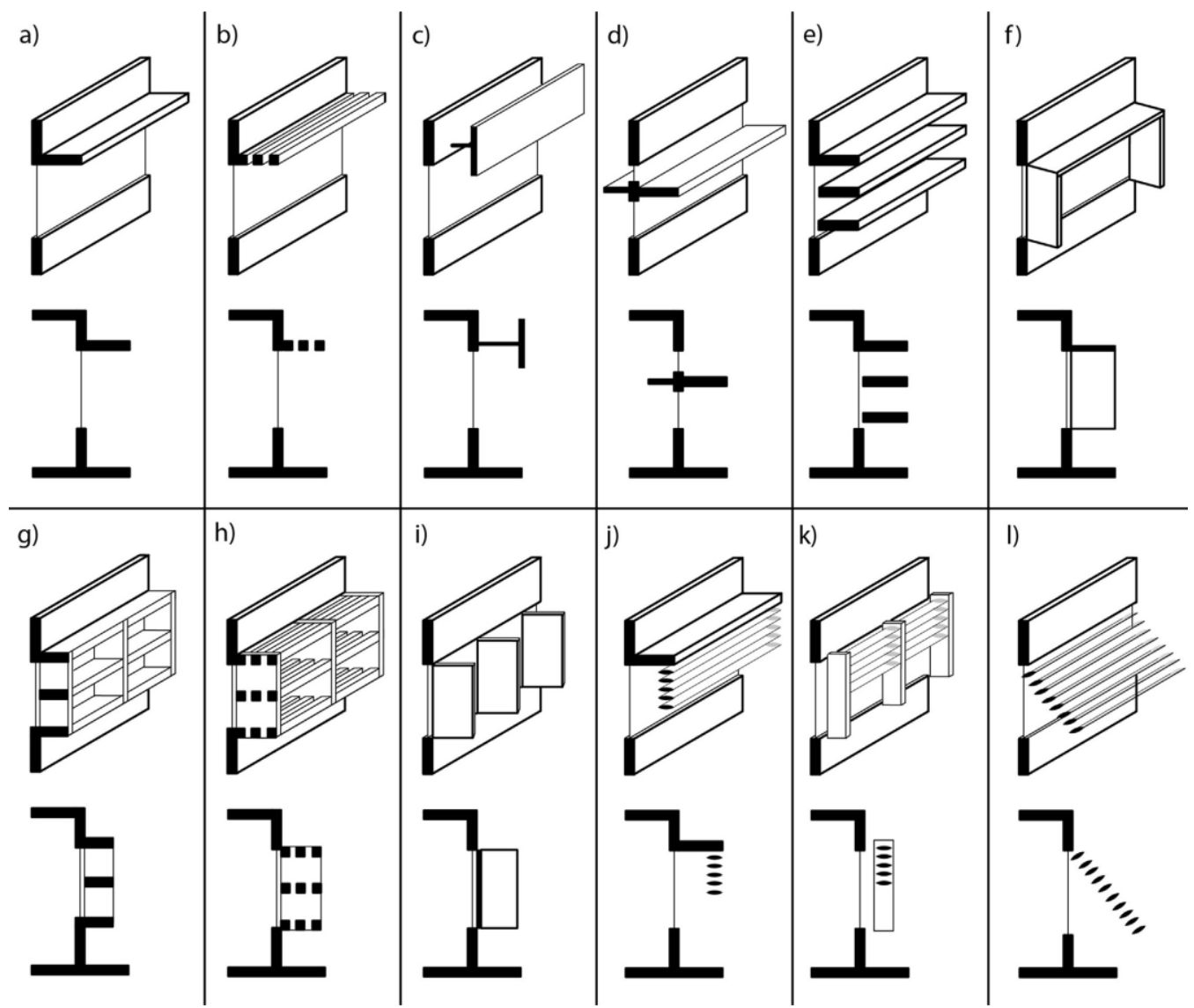

Figura 45. Secciones esquemáticas en $2 \mathrm{D}$ y $3 \mathrm{D}$ de diseños simples $(\mathrm{a}-\mathrm{f})$ y complejos $(\mathrm{g}-\mathrm{I})$ de fachadas dispositivos de sombreado. Fuente: Valladares-Rendón, Schmid, \& Lo (2017).

La relación vidriado opaco (RVO) es un importante indicador que compara el área total de ventanas en la envolvente frente al área total de la envolvente del edificio. Provee una evaluación previa para determinar si hay mucha o poca cantidad de superficie de ventanas por las que se pueda ganar demasiado calor.

Este valor, se expresa en porcentajes donde $0 \%$ equivale a que no hay ventanas y $100 \%$ a que la totalidad del muro está conformado por vidrio. Ambos extremos son generalmente negativos en términos de eficiencia energética, iluminación natural o visibilidad. La Figura 46 tomada de Valladares, Schmid, \& Lo (2017), ilustra cómo pueden verse los diferentes porcentajes de RVO.

Hay valores recomendados de RVO para cada tipo de clima. Algunos códigos de construcción sostenible como los desarrollados por ASHRAE (2013), incorporan estos estándares en su contenido. Este parámetro es muy importante porque las ventanas suelen ser los elementos constructivos con menos resistencia térmica, aunque debe ir acompañado del análisis de la orientación, el tipo de ventana, la función que cumple entre otras. 

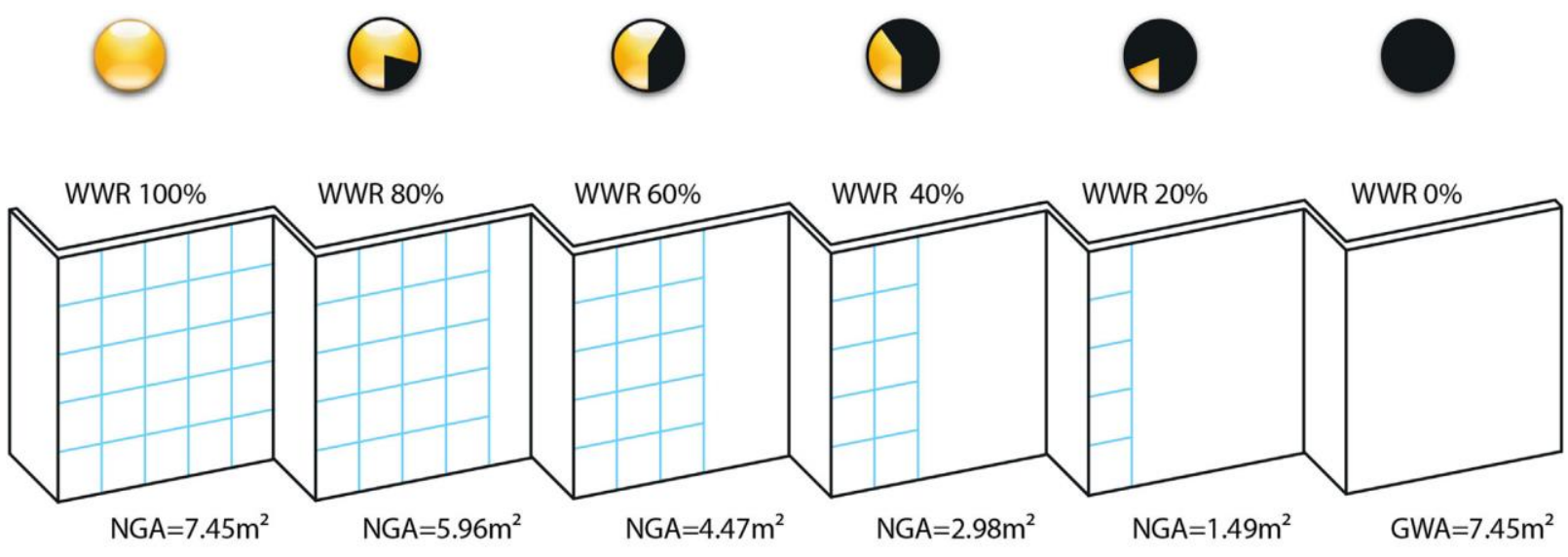

(O)

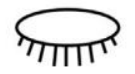

Figura 46. Esquema tridimensional de proporción de ventanas en fachada exterior en relación con la visibilidad y la iluminación natural. Fuente: Valladares-Rendón, Schmid, \& Lo (2017).

La efectividad del RVO diseñado para disminuir la insolación y el ahorro energético fue investigada por estos autores en Antalya Turquía, mediante simulaciones en un edificio residencial de planta cuadrada con $200 \mathrm{~m}^{2}$ de área y 2 unidades de vivienda por piso. El cambio de este parámetro de $90 \%$ a $25 \%$ produjo una reducción notoria en la carga térmica por insolación, de esta manera se redujo el consumo energético por enfriamiento en $36,11 \mathrm{kWh} / \mathrm{m}^{2}$ equivalentes al $54,17 \%$.

Para Santiago de Chile, Pino, Bustamante \& Escobar (2012), estudiaron mediante simulaciones la influencia de esta estrategia en el desempeño energético y la iluminación natural con un caso hipotético de RVO de $100 \%$ y una reducción posterior a $20 \%$. Con las simulaciones se encontró que la energía necesaria para mantener el confort con toda la fachada acristalada era de $155 \mathrm{kWh} / \mathrm{m}^{2}$, mientras que con el $20 \%$ solo fueron necesarios 25 $\mathrm{kWh} / \mathrm{m}^{2}$. Asimismo, se detectó que un $37 \%$ de ahorro adicional se logró con la aplicación de la estrategia de ventilación nocturna. Finalmente, con la aplicación de todas las estrategias se obtuvo un ahorro del $76,57 \%$ energético anual, además se hizo notorio que, con estas estrategias combinadas, también la iluminación natural fue totalmente funcional y se evitó el deslumbramiento.

Por su parte, Valladares-Rendón, Schmid, \& Lo (2017), con estudios realizados en China y Noruega, encontraron que el RVO es una medida que reduce eficazmente la demanda de energía y los impactos del asoleamiento, sin embargo, es limitada en este último punto, porque en las tempranas horas de la mañana o en las últimas horas de la tarde, cuando el ángulo de 
altura solar es bajo puede penetrar a los espacios interiores causando incomodidad visual y sobrecalentamiento. Así que la combinación con otras estrategias es recomendable.

Por su lado, la estrategia de orientación del edificio se refiere a la disposición de la edificación sobre el plano horizontal o el ángulo azimut hacia donde el edificio apunta. Los ángulos azimut en el marco de la arquitectura Bioclimática se identifican con $0^{\circ}$ para Norte, $90^{\circ}$ para Este, $180^{\circ}$ para Sur y $270^{\circ}$ para Este. Esta estrategia es mucho más notoria cuando el edificio es de planta rectangular, ya que los lados cortos suelen orientarse hacia los puntos cardinales con mayor carga de radiación solar. Esto es debido a que entre más pequeña es el área expuesta a la radiación solar, más se incrementan los ahorros energéticos para enfriamiento. Cabe mencionar que estas condiciones varían para cada latitud y cada tipo de clima.

Un ejemplo de reducción del consumo energético con esta estrategia se logró en lbadan, Nigeria caracterizada por presentar un clima de sabana tropical de verano cálido húmedo. Odunfa K., Odunfa V., Ojo, \& Ohunakin (2015), encontraron que las ganancias térmicas se incrementaron principalmente por los vanos de las fachadas del Este y el Oeste. Después de haber alargado las fachadas con vista al Norte y al Sur, el consumo energético total fue reducido en $7,96 \mathrm{kWh} / \mathrm{año}$, equivalente al 4,87\%. De la misma manera, se mejoró la iluminación y la ventilación natural, lo cual aportó a acrecentar el confort interno en general.

También Al-Anzi \& Khattab (2010), investigaron esta estrategia con una casa existente de grandes fachadas vidriadas orientadas al Sureste y Suroeste en Kuwait. Mediante un cambio de dirección de las fachadas, orientándolas al Norte y al Sur sumado a la implementación de dispositivos de sombreado y zonas de amortiguamiento, lograron un ahorro energético del $43 \%$ anual.

Koranteng \& Abaitey (2009), presentaron otro trabajo similar, realizado en la ciudad de Kumasi, Ghana, clasificada como clima de sabana tropical. En éste, un edificio de planta rectangular fue orientado mostrando su fachada más amplia hacia el Oeste, Norte y Sur. Cuando este fue orientado hacia el Norte o Sur se obtuvieron ahorros energéticos de 1,57

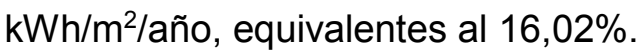

También esta estrategia fue puesta a prueba con un edificio residencial en medio de un entorno altamente densificado de la ciudad de Hong Kong, China, singularizada por su clima templado, de invierno seco y verano caliente. En esta ocasión, se simuló el comportamiento térmico de los pisos superiores con sus grandes fachadas orientadas al Este y Oeste. Con esta configuración se tuvo gran cantidad de consumo por enfriamiento para obtener el confort, principalmente por la gran cantidad de insolación recibida en estas fachadas. Por el contrario, 
cuando las grandes fachadas se orientaron hacia el Norte y Sur, la carga sensible anual de refrigeración decreció en 11,15 kWh/m²/año, equivalentes al 19,76\% (Chan A. S., 2012).

En síntesis, los ahorros más sustanciales logrados mediante la estrategia de control solar fueron: El 76,57\% obtenidos por Pino, Bustamante, \& Escobar (2012), a partir de un óptimo porcentaje de ventanas y unas estrategias adicionales. El $66 \%$ logrado por un sistema complejo de dispositivos de sombreado por Gon, Hong Soo, Tae Sub, Schaefer, \& Jeong Tai (2012), y finalmente un $43 \%$ alcanzado mediante un cambio de orientación edilicia sumado a dispositivos de sombreado llevado a cabo por Al-Anzi \& Khattab (2010). 


\subsection{Baja Absortividad}

Esta estrategia pasiva se caracteriza por evitar la ganancia térmica proveniente del sol mediante la aplicación de materiales naturales, pinturas, membranas, recubrimientos y enchapes especiales, que poseen muy baja absortividad (ver definición en el título 1.1).

Las superficies con baja absortividad absorben menos calor y permanecen más frescas. Son caracterizadas por presentar un gran albedo o reflectividad, lo cual quiere decir que gran parte de la radiación solar es reflejada.

Generalmente los colores claros poseen esta característica, sin embargo, algunos trabajos han logrado obtener recubrimientos de colores oscuros con pigmentos que reflejan las ondas infrarrojas del espectro solar, llegando a obtener paredes $10,2^{\circ} \mathrm{C}$ más frías y diferencias de absortividad entre 0,06 y 0,22 (Synnefa \& Santamouris, 2007).

Pisello (2017), también encuentra disminuciones de temperatura superficial en cubiertas de baja absortividad de hasta $28^{\circ} \mathrm{C}$ y promedios de ahorro energético del $20 \%$ en edificaciones con esta tecnología. Incluso, destaca la utilidad de esta estrategia para reducir la isla de calor urbana si se aplica a techos y pavimentos que sumados pueden representar entre el $40 \%$ y el $84 \%$ de la superficie horizontal urbana.

En un clima cálido húmedo como el de Hong Kong, mediante un método experimental realizado con dos recintos construidos en sistema liviano, uno con pintura blanca y otro con pintura negra en su envolvente, se descubrió que, durante el día, el recinto tratado con pintura blanca mantuvo $12^{\circ} \mathrm{C}$ más bajo el pico de $T_{\text {air }}$ máxima interna, tanto en verano como en otoño (Cheng, Ng, \& Givoni, 2005). En condiciones de radiación solar de $800 \mathrm{~W} / \mathrm{m}^{2}$ la $\mathrm{T}_{\text {air }}$ máxima en el interior del recinto blanco estuvo $3^{\circ} \mathrm{C}$ por encima de la $\mathrm{T}_{\text {air }}$ exterior, mientras que la diferencia con el recinto negro fueron $15^{\circ} \mathrm{C}$. Por otro lado, cuando la radiación solar presentó $300 \mathrm{~W} / \mathrm{m}^{2}$, la diferencia fue de $1^{\circ} \mathrm{C}$ y $5^{\circ} \mathrm{C}$ respectivamente. Los autores demostraron que entre más oscuro es el color, la envolvente es más sensitiva a la radiación solar. Las superficies oscuras absorben la mayoría de los rayos con que impacta el sol. De acuerdo con los autores, la aplicación de colores claros en la superficie externa de las edificaciones es en efecto la manera más simple, efectiva y económica de reducir la temperatura interior en un clima cálidohúmedo.

Del mismo modo, Al-Sanea, Zedan, \& Al-Hussain (2013), mediante simulaciones computarizadas combinaron la estrategia de masa térmica con baja absortividad, encontrando dos ventajas de esta combinación. La primera razón se refiere a la reducción de la transmisión de carga térmica total anual recibida por el sol en climas en los que la demanda de refrigeración domina sobre el calentamiento durante todo el año. Y la segunda razón se refiere 
al hallazgo de que una menor absortividad de la superficie produce un mayor porcentaje de ahorro de energía para una masa térmica dada, en el caso simulado, la disminución de la absortividad en 0,2 puntos significó también un ahorro de energía anual del $20 \%$ en enfriamiento.

Synnefa, Santamouris, \& Akbari (2007), realizaron simulaciones reduciendo la absortividad en los techos para latitudes entre $20^{\circ}$ y $43^{\circ}$ cuyos resultados mostraron que esta estrategia reduce el consumo energético por enfriamiento entre 18\% y 93\%. Asimismo, esta implementación fue capaz de reducir entre el 9\% y 100\% las horas de insatisfacción térmica y la $\mathrm{T}_{\text {air }}$ interior entre 1,2 y $3,3^{\circ} \mathrm{C}$ en edificaciones residenciales sin aire acondicionado. Para las locaciones estudiadas, se encontró que las desventajas que una cubierta de baja absortividad puede tener en el invierno al aumentar el consumo por calefacción entre 0,2 y $17 \mathrm{kWh} / \mathrm{m}^{2}$ al año, fueron menores a las ventajas de reducción de la carga de enfriamiento en verano, estimada entre 9 y $48 \mathrm{kWh} / \mathrm{m}^{2}$ anual.

Ahora bien, Pisello, Castaldo, Piselli, Fabiani, \& Cotana (2017), critican que, aunque el efecto de la absortividad en cubiertas ha sido bastante estudiado, no se ha hecho igual con los efectos de la aplicación de esta estrategia en los muros de fachada y mucho menos los efectos de la combinación de estos. Para mejorar lo anterior realizaron un estudio analítico y experimental que cuantificó por separado y combinado los beneficios derivados de aplicar revestimientos fríos sobre las superficies envolventes de un módulo de pruebas.

Uno de los experimentos realizados en esta investigación llevada a cabo en Perugia, Italia (Latitud $43^{\circ} \mathrm{Norte}$ ) fue comparar la reflectancia solar de una membrana de baja absortividad frente a una membrana bituminosa de color negro, encontrándose una diferencia del $80 \%$. Con esta misma configuración se encontró que el tratamiento de cubierta fue capaz de reducir la temperatura operativa interior en $2,6{ }^{\circ} \mathrm{C}$ durante los días cálidos. Además, la temperatura superficial de la cubierta disminuyó $19,8^{\circ} \mathrm{C}$ y $3,4^{\circ} \mathrm{C}$ en el interior y el exterior respectivamente, lo cual fue atribuido a la aplicación de este tratamiento.

Con estas mismas instalaciones se adicionó pintura de baja absortividad a la fachada sur del módulo de pruebas, lo cual produjo una pequeña reducción adicional de $0,5{ }^{\circ} \mathrm{C}$ en la temperatura operativa, obteniendo un efecto combinado de $3,1^{\circ} \mathrm{C}$ de reducción total entre el techo y la fachada sur tratados. La temperatura superficial del interior y el exterior de la fachada sur se redujo en $9,9^{\circ} \mathrm{C}$ y $4,4^{\circ} \mathrm{C}$ respectivamente.

Posteriormente, todas las fachadas fueron pintadas con la pintura de baja absortividad obteniendo reducciones en la temperatura superficial exterior de $9,9^{\circ} \mathrm{C}, 8,7^{\circ} \mathrm{C}, 13,8^{\circ} \mathrm{C}$ y $11,4^{\circ} \mathrm{C}$ en las fachadas Sur, Norte, Este y Oeste respectivamente. Con este último escenario, 
la temperatura operativa obtuvo una reducción de $4,4^{\circ} \mathrm{C}$, lo cual significó un gran beneficio para el confort térmico interior.

Zinzi (2016), con el objetivo de presentar las potencialidades de aplicar tratamientos de baja absortividad en las fachadas realizó simulaciones paramétricas con el software Energy Plus, en tres ubicaciones de la región mediterránea: Marsella, Atenas y El Cairo. El trabajo se concentró en dos tipologías de edificios residenciales: una casa aislada y un bloque de apartamentos de 12 unidades en 3 pisos con y sin sistemas de acondicionamiento mecánico. Se tuvo en cuenta indicadores para los beneficios y penalidades de la implementación de la estrategia, por esta razón el desempeño se expresó en usos de energía anual. Para edificaciones con sistemas de acondicionamiento, los resultados mostraron un ahorro del $60 \%$ en energía usada para enfriamiento en Marsella lo cual representó un ahorro del $6 \%$ en el consumo anual. Del mismo modo, en Atenas el ahorro en enfriamiento fue superior al $60 \%$, pero en este caso, el impacto en el ahorro energético fue del $11 \%$ en el consumo anual. Por su parte, en el Cairo el ahorro en la demanda de enfriamiento es un poco superior al $43 \%$, cuya representación en el consumo anual es de $25 \%$ debido a la favorabilidad climática para técnicas de enfriamiento pasivo.

De otro lado, el desempeño de edificaciones sin enfriamiento activo fue evaluado mediante la cuantificación de la temperatura operativa. Con la implementación de esta estrategia en Marsella, se eliminó el $100 \%$ de las temperaturas operativas superiores $30^{\circ} \mathrm{C}$ y el $64 \%$ de las superiores a $27^{\circ} \mathrm{C}$ en el mejor de los casos. En Atenas, la cantidad de horas por encima de $30^{\circ} \mathrm{C}$ se redujo en $62 \%$ y en un $22 \%$ las superiores a $27^{\circ} \mathrm{C}$. Finalmente en El Cairo la cantidad de horas por encima de $27^{\circ} \mathrm{C}$ se redujo al $12 \%$ y en $47 \%$ las superiores a $30^{\circ} \mathrm{C}$.

En el clima árido y seco de Emiratos Árabes Unidos se comparó un módulo de $3 \mathrm{~m} \times 3 \mathrm{~m} \times 3 \mathrm{~m}$ con paredes de concreto de $15 \mathrm{~cm}$ de espesor frente a otro igual, pero con tratamiento de pintura de baja absortividad de 0,16 en la fachada sur. Los resultados de esta prueba indicaron que, en comparación con el módulo de referencia, el porcentaje de reducción del flujo de calor usando la pintura de baja absortividad fue de $22 \%$. Para mantener el aire en una temperatura de confort previamente establecida de $24^{\circ} \mathrm{C}$, en el módulo de referencia se consumieron 103,3 $\mathrm{kWh}$, mientras que con el tratamiento de baja absortividad se utilizaron 95,4kWh, lo cual resultó en un ahorro energético de 7,6\%. Finalmente, cuando se utilizó una absortividad de 0,25 , la temperatura superficial de las fachadas solo estuvo pocas horas por encima de los $40^{\circ} \mathrm{C}$ en todos los casos. Como promedio general en los edificios se obtuvo que la aplicación de esta estrategia disminuyó $7,5^{\circ} \mathrm{C}$ la temperatura de los muros exteriores y $25^{\circ} \mathrm{C}$ en el pico. En promedio se redujo $1,1^{\circ} \mathrm{C}$ la temperatura operativa y se ahorraron $2,9 \mathrm{Kwh} / \mathrm{m}^{2}$ por cada 0,1 puntos de absortividad reducidos (Rehman, 2015). 
Estos estudios en su totalidad demuestran que los tratamientos de baja absortividad son una tecnología que además puede ser combinada con otras estrategias para mejorar el confort térmico y consecuentemente es totalmente válida como estrategia de enfriamiento pasivo y eficiencia energética. 


\subsection{Muros vegetales}

Un muro vegetal es un sistema de fachada en el que las plantas de hoja perenne o caduca crecen directamente en las paredes, en contenedores colgantes o en estructuras de soporte especiales de manera controlada con mantenimiento regular. Una fachada vegetal puede mejorarles a las edificaciones la calidad de aire interior, la sensación del ruido y la eficiencia energética debido al incremento del confort térmico. Asimismo, esta estrategia es capaz de captar dióxido de carbono y proteger la envolvente de agentes externos, proveer un hábitat para la biodiversidad, dar una apariencia estética psicológicamente positiva e incrementar el valor de la propiedad (Perini K. , Ottelé, Fraaij, Haas, \& Raiteri, 2011).

Una cuidadosa selección de las plantas adaptadas al clima del lugar de implementación es vital para tener un exitoso desempeño. Para climas cálidos húmedos como el de Santiago de Cali, los muros vegetales son una buena alternativa porque las plantas tienen la habilidad de disipar la radiación solar absorbida tanto en calor sensible como en calor latente mediante el proceso de evapotranspiración.

De acuerdo con Wong \& Baldwing (2016), la evapotranspiración es la pérdida de agua de una planta durante su proceso de respiración y evaporación. El agua es absorbida por las plantas a través de las raíces y transportada al follaje donde es vaporizada a través de los estomas. El calor es absorbido durante la evaporación del agua de las plantas, lo cual genera un enfriamiento evaporativo que refresca la temperatura de las fachadas. Este proceso puede convertir el $60 \%$ de la radiación solar absorbida en calor (Stec, Van Passsen, \& Maziarz, 2005).

Manso \& Castro-gomes (2015), identifican tres tipos de muros vegetales: el primer tipo es el tradicional, en los que las plantas trepan y usan la propia fachada como estructura de soporte. El segundo es la doble fachada vegetal cuyas plantas trepan por una estructura separada de la envolvente que da lugar a un espacio de aire en medio de las dos. Por último, el tercer tipo son los muros vivos que incluyen pequeños contenedores de sustrato donde se plantan y crecen las plantas alrededor del edificio.

Una investigación experimental acerca del potencial de ahorro energético conseguido con esta estrategia fue hecha por Coma et al (2017) en Lleida, España. El informe da cuenta de que se pueden lograr reducciones en consumo para enfriamiento entre el $34 \%$ y $59 \%$ durante la temporada de verano, los porcentajes corresponden a un muro de doble fachada y a un muro vivo respectivamente. También, Pérez, Coma, Sol, \& Cabeza (2017) reportaron un ahorro similar del $34 \%$ mediante el empleo de un sistema de doble fachada con Hedera Hélix. 
Ahora bien, establecer una comparación apropiada entre los diferentes estudios sobre esta tecnología es bastante difícil, porque entre ellos difieren muchos factores tales como el sistema constructivo, el clima, el tipo de plantas usadas, la orientación, etc. No obstante, un indicador común que puede unificar y facilitar la comparación fue hallado en la mayoría de las investigaciones, este indicador es el valor de la reducción de temperatura superficial exterior o $T_{r}$ exterior.

Teniendo como base este indicador, a continuación, se enseña la Tabla 10, donde se resumen las características principales de cada trabajo en orden cronológico y se organizan de acuerdo con la clase de muros vegetales propuesta por Manso \& Castro-gomes (2015). Aquí se identifica que las más altas reducciones son logradas por el sistema de muros vivos, cuyos valores oscilan entre $1^{\circ} \mathrm{C}$ y $39^{\circ} \mathrm{C}$; seguido por los sistemas de doble fachada con variaciones entre $1^{\circ} \mathrm{C}$ a $18^{\circ} \mathrm{C}$ y finalmente los tradicionales entre $1,2^{\circ} \mathrm{C}$ y $13^{\circ} \mathrm{C}$ 


\begin{tabular}{|c|c|c|c|c|c|c|c|c|}
\hline AUTORES & AÑo & UBICACIÓN & CLIMA SEGÚN Köppen & $\begin{array}{l}\text { PERIODO } \\
\text { DE } \\
\text { ESTUDIO }\end{array}$ & $\begin{array}{l}\text { ESPECIES } \\
\text { PLANTADAS }\end{array}$ & ORIENTACIÓN & $\begin{array}{c}\text { GROSOR DEL } \\
\text { FOLLAJE Y CAPA } \\
\text { DE AIRE(cm) O (\%) }\end{array}$ & $\begin{array}{c}\text { REDUCCIÓN } \\
\text { TEMP MURO } \\
\text { EXTERIOR EN } \\
{ }^{\circ} \mathrm{C} \\
\end{array}$ \\
\hline \multicolumn{9}{|l|}{ Muro vegetal tradicional } \\
\hline (Hoyano, 1988) & 1998 & Tokio, Japón & $\begin{array}{l}\text { Cfa Templado-Cálido, } \\
\text { húmedo, verano caliente }\end{array}$ & Verano & $\begin{array}{c}\text { Parthenocissus } \\
\text { tricuspidata }\end{array}$ & Oeste & & 13 \\
\hline (Köhler, 2008) & 2008 & Berlín, Alemania & $\begin{array}{l}\text { Cfb Templado-cálido, } \\
\text { húmedo, verano cálido }\end{array}$ & $\begin{array}{l}\text { Verano e } \\
\text { invierno }\end{array}$ & $\begin{array}{c}\text { Parthenocissus } \\
\text { tricuspidata }\end{array}$ & & & $\begin{array}{l}3 \text { en verano y } \\
3 \text { en invierno } \\
\end{array}$ \\
\hline $\begin{array}{c}\text { (Eumorfopoulou \& Kontoleon, } \\
2009 \text { ) }\end{array}$ & 2009 & $\begin{array}{l}\text { Thessaloniki, } \\
\text { Grecia }\end{array}$ & $\begin{array}{l}\text { Cfb Templado-cálido, } \\
\text { húmedo, verano cálido }\end{array}$ & Verano & $\begin{array}{l}\text { Parthenocissus } \\
\text { tricuspidata }\end{array}$ & Este & 25 & 5,7 \\
\hline $\begin{array}{l}\text { (Sternberg, Viles, \& } \\
\text { Cathersides, 2011) }\end{array}$ & 2011 & $\begin{array}{c}\text { Byland Abbey, } \\
\text { Ramsey, Oxford, } \\
\text { Nailsea, Dover. } \\
\text { Inglaterra }\end{array}$ & $\begin{array}{l}\text { Cfb Templado-cálido, } \\
\text { húmedo, verano cálido }\end{array}$ & $\begin{array}{l}\text { Todo el } \\
\text { año }\end{array}$ & Hedera Hélix & Suroeste & 10 a 45 & $\begin{array}{l}1,7-9,5 \text { en } \\
\text { verano }\end{array}$ \\
\hline $\begin{array}{c}\text { (Perini K., Ottelé, Fraaij, Haas, } \\
\text { \& Rossana, 2011) }\end{array}$ & 2011 & Delft, Holanda & $\begin{array}{l}\text { Cfb Templado-cálido, } \\
\text { húmedo, verano cálido }\end{array}$ & Otoño & Hedera Hélix & Noroeste & 20 & 1,2 \\
\hline $\begin{array}{c}\text { (Cameron, Taylor, \& Emmett, } \\
\text { 2014) }\end{array}$ & 2014 & $\begin{array}{l}\text { Reading, } \\
\text { Inglaterra } \\
\end{array}$ & $\begin{array}{l}\text { Cfb Templado-cálido, } \\
\text { húmedo, verano cálido }\end{array}$ & Verano & $\begin{array}{l}\text { Hereda Hélix, } \\
\text { Stachys } \\
\text { byzantina } \\
\end{array}$ & Norte y sur & & 7 y 7,3 \\
\hline $\begin{array}{c}\text { (Bolton, Rahman, Armson, \& } \\
\text { Ennos, 2014) }\end{array}$ & 2014 & $\begin{array}{l}\text { Manchester, } \\
\text { Inglaterra }\end{array}$ & $\begin{array}{l}\text { Cfb Templado-cálido, } \\
\text { húmedo, verano cálido }\end{array}$ & Invierno & Hedera Hélix & Norte & & $(+) 0,5$ \\
\hline $\begin{array}{c}\text { (Susorova, Azimi, \& Stephens, } \\
\text { 2014) }\end{array}$ & 2014 & Chicago, USA & $\begin{array}{c}\text { Dfa. Nieve, alta humedad } \\
\text { y verano caliente }\end{array}$ & Verano & $\begin{array}{l}\text { Parthenocissus } \\
\text { tricuspidata }\end{array}$ & $\begin{array}{l}\text { Este, Sur, } \\
\text { Oeste y Norte }\end{array}$ & 20 & 12,6 \\
\hline $\begin{array}{l}\text { (Haggag, Hassan, \& Elmasry, } \\
\text { 2014) }\end{array}$ & 2014 & $\begin{array}{l}\text { Al Ain, Emiratos } \\
\text { Árabes Unidos }\end{array}$ & $\begin{array}{c}\text { BWh, árido y desértico, } \\
\text { con verano caliente y } \\
\text { seco }\end{array}$ & Verano & & & & 6 \\
\hline \multicolumn{9}{|l|}{ Doble Fachada Vegetal } \\
\hline (Hoyano, 1988) & 1988 & Kyushu, Japón & $\begin{array}{c}\text { Cfa Templado-Cálido, } \\
\text { húmedo, verano caliente }\end{array}$ & Verano & Dishcloth gourd & Suroeste & $55 \%$ & 1 a 3 \\
\hline $\begin{array}{l}\text { (Koyama, Yoshinaga, Hayashi, } \\
\text { Maeda, \& Yamauchi, 2013) }\end{array}$ & 2013 & Chikusa, Japón & $\begin{array}{l}\text { Cfa Templado-Cálido, } \\
\text { húmedo, verano caliente }\end{array}$ & Verano & $\begin{array}{l}\text { Bitter melon, } \\
\text { Morning glory, } \\
\text { Sword bean, } \\
\text { Kudzu, Apios }\end{array}$ & Sur & $54-52-29-52$ Y $15 \%$ & $\begin{array}{c}4,1-11,3- \\
7,9-6,6 \text { Y } 3,7\end{array}$ \\
\hline $\begin{array}{l}\text { (Wong, Kwang Tan, Yok Tan, } \\
\text { Chiang, \& Chung Wong, 2010) }\end{array}$ & 2010 & Singapur & $\begin{array}{l}\text { Af Clima ecuatorial - } \\
\text { húmedo }\end{array}$ & & $\begin{array}{l}\text { Plantas } \\
\text { trepadoras }\end{array}$ & & & 4,36 \\
\hline $\begin{array}{c}\text { (Pérez, Rincón, González, \& } \\
\text { Cabeza, 2011) } \\
\end{array}$ & 2011 & Lleida, España & $\begin{array}{l}\text { Csa Templado-Cálido de } \\
\text { verano seco y caliente }\end{array}$ & $\begin{array}{c}\text { Todo el } \\
\text { año }\end{array}$ & Wisteria sinensis & Sur y Este & $20 \mathrm{~cm}$ & $\begin{array}{c}15,18 \text { en } \\
\text { verano }\end{array}$ \\
\hline $\begin{array}{l}\text { (Perini K., Ottelé, Fraaij, Haas, } \\
\text { \& Rossana, 2011) }\end{array}$ & 2011 & $\begin{array}{l}\text { Rotterdam, } \\
\text { Holanda }\end{array}$ & $\begin{array}{l}\text { Cfb Templado-cálido, } \\
\text { húmedo, verano cálido }\end{array}$ & Otoño & $\begin{array}{c}\text { Hereda hélix, } \\
\text { Vitis, Clematis, } \\
\text { Jasminum, } \\
\text { Pyracantha }\end{array}$ & & $10 \mathrm{~cm}$ & 2,7 \\
\hline $\begin{array}{l}\text { (Šuklje, Medved, \& Arkar, } \\
\text { 2013) }\end{array}$ & 2013 & $\begin{array}{l}\text { Ljubljana, } \\
\text { Eslovenia }\end{array}$ & $\begin{array}{l}\text { Cfa Templado-Cálido, } \\
\text { húmedo, verano caliente }\end{array}$ & Verano & $\begin{array}{c}\text { Phaseolus } \\
\text { vulgaris "Anellino } \\
\text { verde" }\end{array}$ & & & 4 \\
\hline (Jim, 2015) & 2015 & $\begin{array}{l}\text { Hong Kong, } \\
\text { China }\end{array}$ & $\begin{array}{l}\text { Cwa Templado cálido, } \\
\text { con invierno seco y } \\
\text { verano caliente }\end{array}$ & Verano & $\begin{array}{c}\text { Ficus pumila, } \\
\text { Campsis } \\
\text { grandiflora, } \\
\text { Bauhinia } \\
\text { corymbosa, } \\
\text { Pyrostegia } \\
\text { venusta }\end{array}$ & $\begin{array}{l}\text { Este, Sur, } \\
\text { Oeste y Norte }\end{array}$ & & 5 \\
\hline \multicolumn{9}{|l|}{ Muros vivos } \\
\hline (Cheng, Cheung, \& Chu, 2010) & 2010 & Wuhan, China & $\begin{array}{l}\text { Cfa Templado-Cálido, } \\
\text { húmedo, verano caliente }\end{array}$ & Verano & $\begin{array}{c}\text { Combinación de } \\
6 \text { diferentes } \\
\text { especies }\end{array}$ & Oeste & $\begin{array}{c}\text { Sustrato liviano de } \\
10 \mathrm{~cm} \text {, capa de aire } \\
\text { ajustable entre } 3 \text { y } 7 \\
\mathrm{~cm}\end{array}$ & 20,8 \\
\hline $\begin{array}{l}\text { (Wong, Kwang Tan, Yok Tan, } \\
\text { Chiang, \& Chung Wong, 2010) }\end{array}$ & 2010 & $\begin{array}{l}\text { Singapur, } \\
\text { Singapur }\end{array}$ & $\begin{array}{l}\text { Af Clima ecuatorial - } \\
\text { húmedo }\end{array}$ & No aplica & $\begin{array}{c}\text { Hemigraphisrepa } \\
\text { nda, Phyllanthus } \\
\text { myrtifolius, } \\
\text { Tradescantia } \\
\text { spathacea, } \\
\text { moses } \\
\end{array}$ & & Varios sustratos & $\begin{array}{l}\text { Día } 1-10,94 \text { I } \\
\text { Noche } 2-9\end{array}$ \\
\hline $\begin{array}{c}\text { (Perini K. , Ottelé, Fraaij, Haas, } \\
\text { \& Rossana, 2011) }\end{array}$ & 2011 & $\begin{array}{l}\text { Benthnizen, } \\
\text { Holanda }\end{array}$ & $\begin{array}{l}\text { Cfb Templado-cálido, } \\
\text { húmedo, verano cálido }\end{array}$ & Otoño & Evergreen $\mathrm{sp}$ & Oeste & $\begin{array}{l}\text { Tierra de } 22 \mathrm{~cm} \mathrm{de} \\
\text { espesor, } 10 \mathrm{~cm} \mathrm{de} \\
\text { follaje y } 4 \mathrm{~cm} \text { de } \\
\text { cámara de aire }\end{array}$ & 5 \\
\hline $\begin{array}{l}\text { (Mazzali, Peron, Romagnoni, } \\
\text { Pulselli, \& Bastianoni, 2013) }\end{array}$ & 2013 & $\begin{array}{l}\text { A) Lonigo, B) } \\
\text { Venezia, Italia }\end{array}$ & $\begin{array}{l}\text { Cfa Templado-Cálido, } \\
\text { húmedo, verano caliente }\end{array}$ & Verano & Varios & $\begin{array}{l}\text { A) Suroeste, } \\
\text { B) Suroeste }\end{array}$ & $\begin{array}{c}\text { Fieltro de } 1 \mathrm{~cm} \text { capa } \\
\text { de aire A) } 5 \mathrm{~cm}, B) \\
3 \mathrm{~cm}\end{array}$ & $\begin{array}{l}\text { Día A)12-20, } \\
\text { B)16 / Noche } \\
\text { A)2-3, B)6 }\end{array}$ \\
\hline $\begin{array}{l}\text { (Mazzali, Peron, Romagnoni, } \\
\text { Pulselli, \& Bastianoni, 2013) }\end{array}$ & 2013 & Pisa, Italia & $\begin{array}{l}\text { Cfb Templado-cálido, } \\
\text { húmedo, verano cálido }\end{array}$ & Otoño & Varios & Este & $\begin{array}{c}\text { Tierra de } 5 \mathrm{~cm} \text {, } \\
\text { capa de aire abierta } \\
\text { de } 5 \mathrm{~cm}\end{array}$ & $\begin{array}{c}\text { Día 12, Noche } \\
3\end{array}$ \\
\hline (Olivieri, Olivieri, \& Neila, 2014) & 2014 & $\begin{array}{l}\text { Colmenar viejo, } \\
\text { España }\end{array}$ & $\begin{array}{l}\text { Csa Templado-Cálido de } \\
\text { verano seco y caliente }\end{array}$ & Verano & Sedum sp & Sur & $\begin{array}{c}8 \mathrm{~cm} \text { de sustrato }+ \\
7 \mathrm{~cm} \text { de poliestireno } \\
\text { expandido }\end{array}$ & $15,1-31,9$ \\
\hline $\begin{array}{c}\text { (Manso \& Castro-Gomes, } \\
\text { 2016) }\end{array}$ & 2016 & $\begin{array}{l}\text { Covilhã, } \\
\text { Portugal, }\end{array}$ & $\begin{array}{l}\text { Csa Templado-Cálido de } \\
\text { verano seco y caliente }\end{array}$ & $\begin{array}{l}\text { Invierno y } \\
\text { Verano }\end{array}$ & $\begin{array}{l}\text { Varias especies } \\
\text { de Sedum y } \\
\text { Thymus y } \\
\text { Archillea }\end{array}$ & Sur & $\begin{array}{l}\text { Sustrato de corcho } \\
\text { de } 13 \mathrm{~cm}\end{array}$ & De $7-15$ \\
\hline
\end{tabular}

Tabla 10. Relación de investigaciones sobre muros vegetales clasificadas según el tipo, descripción de la investigación y resultados obtenidos en reducción de la temperatura superficial exterior del muro. Fuente: Manso \& Castro-gomes (2015). 


\subsection{Aislamiento con materiales de alta resistencia térmica}

Tal vez pudiese denominarse a esta estrategia también aislamiento por masa o aislamiento por materiales de baja conductividad térmica. Esta estrategia es la más difundida y puede considerarse como la forma de aislamiento térmico tradicional, en ella se utilizan materiales o combinaciones de materiales que poseen una baja transmitancia térmica ${ }^{33}$ (o lo que es igual a una alta resistencia térmica total) para impedir que el flujo de calor proveniente del exterior se transfiera al interior por conducción.

El desempeño de esta estrategia está ligado a la propiedad física de la conductividad térmica $(K)^{34}$ de los materiales, es decir entre menor $K$ tengan las capas de materiales que conforman la envolvente, mejor se impedirá el ingreso del flujo de calor al interior.

Lo anterior es explicado matemáticamente por Cengel \& Ghajar (2015), con la ecuación de transferencia de calor en estado estacionario mostrada a continuación.

$$
Q=U A\left(T_{i}-T_{0}\right)
$$

Donde:

$\mathrm{Q}$ es la carga térmica o flujo de calor en W

$\mathrm{U}$ es la transmitancia térmica en $\mathrm{W} / \mathrm{m}^{2 \circ} \mathrm{K}$

A es el área en metros cuadrados

$\mathrm{T}_{\mathrm{i}}$ y $\mathrm{T}_{\mathrm{o}}$ son la temperatura interior y exterior en ${ }^{\circ} \mathrm{C}$ respectivamente.

En esta ecuación, U es una variable multiplicadora, con lo cual es notorio que la transmitancia térmica es inversamente proporcional al flujo de calor.

Actualmente existe gran variedad de materiales aislantes de alta resistencia térmica, que se pueden clasificar en dos clases: los orgánicos e inorgánicos. Entre los inorgánicos figuran los materiales como la lana de vidrio, la lana de roca, el silicato de calcio, perlita aglomerada, vermiculita y otros productos de origen cerámico. Por su parte, entre los materiales orgánicos se puede encontrar la celulosa, algodón, madera, pulpas, caña, fibras sintéticas, corcho, espuma de goma, poliestireno, polietileno, poliuretano y otros polímeros (Al-Homoud, 2005).

Estos materiales resisten el flujo de calor como resultado de las innumerables células microscópicas de aire atrapado, que suprimen (evitando que el aire se mueva) la transferencia

\footnotetext{
${ }^{33}$ Ver definición en el título 1.15.

34 Ver definición en el título 1.3.
} 
de calor convectiva. Para conseguir la alta R, es incluso mucho más influyente el aire atrapado dentro del aislamiento, que el mismo material.

La creación de pequeñas células (estructura de celdas cerradas) dentro del aislamiento térmico, a través del cual la diferencia de temperatura no es grande también reduce los efectos de la radiación. Esto hace que las trayectorias de radiación se rompan en pequeñas distancias donde la radiación infrarroja de onda larga es absorbida y dispersada por el material aislante. Sin embargo, la conducción suele aumentar a medida que disminuye el tamaño de la célula porque aumenta la densidad.

Típicamente, los materiales aislantes a base de aire no son capaces de superar el valor $\mathrm{R}$ del aire estancado. Sin embargo, los aislantes de espuma de plástico, como por ejemplo el poliestireno y el poliuretano, utilizan gas fluorocarbonado en lugar de aire convencional dentro de las células, lo que da un mayor valor $\mathrm{R}$. Otro de estos aislantes y quizás el más moderno es el Aerogel fabricado por nanotecnología, es un material altamente poroso que es $97 \%$ aire, pero, precisamente el pequeño tamaño de sus poros impide el paso del aire y a la vez la transferencia de calor por conducción y convección. El valor de conductividad térmica de este material, según sus productores como CABOT (Tectonica-online, 2018) ) $^{35}$ es de $0,018 \mathrm{~W} / \mathrm{m}^{\circ} \mathrm{C}$, mientras que el de los aislantes comunes se encuentran entre $0,027 \mathrm{~W} / \mathrm{m}^{\circ} \mathrm{C}$ y $0,040 \mathrm{~W} / \mathrm{m}^{\circ} \mathrm{C}$.

Por lo tanto, la eficacia del aislamiento o sea su resistencia térmica global, está sujeta a la interacción de los tres modos de transferencia de calor por convección, radiación y conducción.

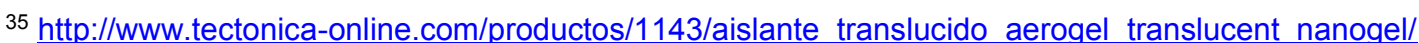


En la siguiente gráfica de la Figura 47 puede compararse la resistencia térmica de algunos de los materiales nombrados anteriormente tomada en muestras de $5 \mathrm{~cm}$ de espesor.

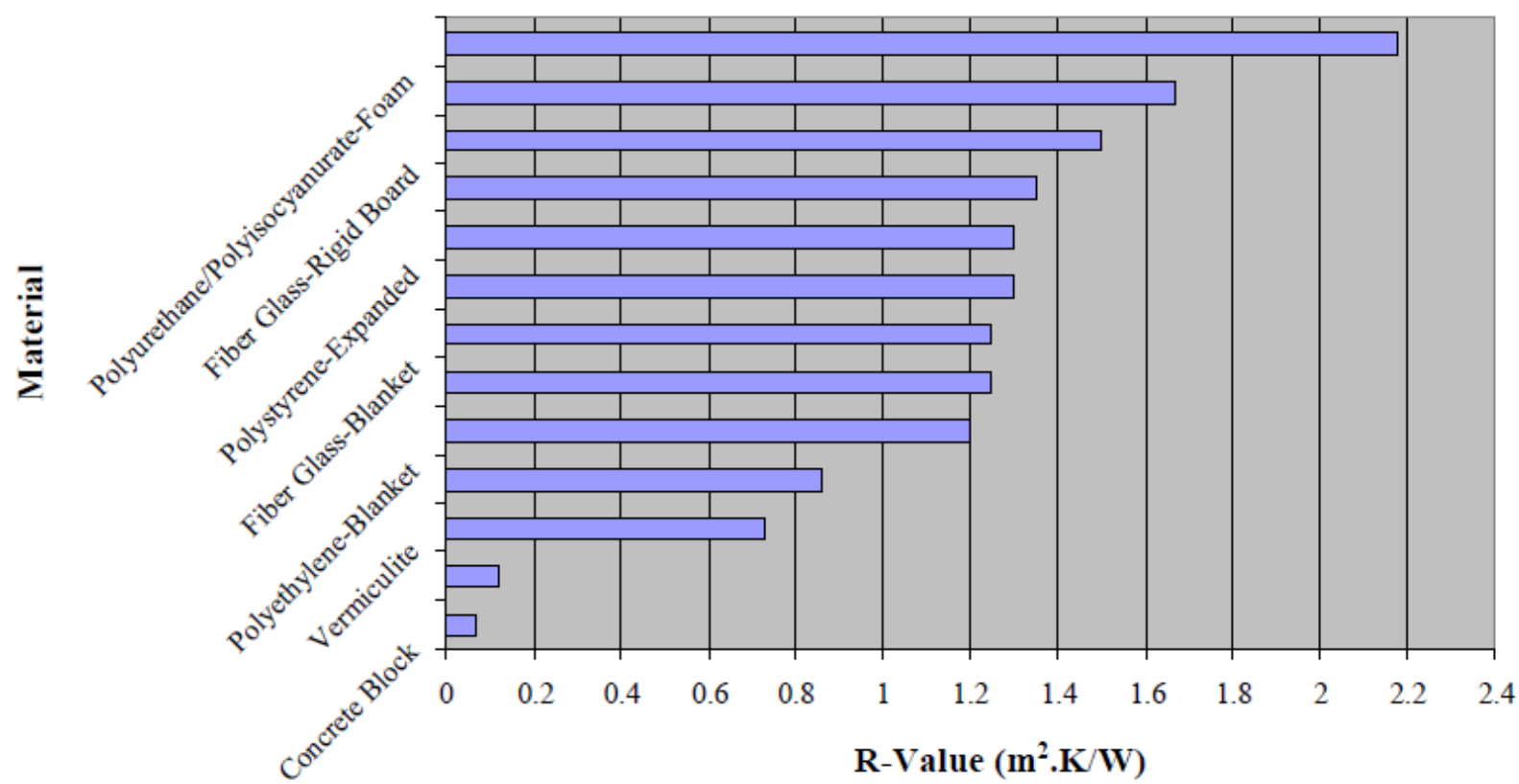

Figura 47. Grafica comparativa de resistencia térmica de algunos materiales de aislamiento térmico utilizados en la construcción, elaborada con muestras de 5cm de espesor. Fuente: Al-Homoud (2005).

Al-Homoud (2005), sostiene que los mejores resultados pueden lograrse ubicando el material de aislamiento cerca al flujo de calor, esto quiere decir que para climas donde es necesario refrigerar, es idóneo ubicarlo en los primeros centímetros de la envolvente desde el exterior al interior, sin embargo, por facilidades constructivas es común que se coloque en el medio o en el interior.

Rehman (2015), desde 2012 a 2014, en la ciudad de Al Jazeera Al Hamra de los Emiratos Árabes Unidos, a una latitud de $25^{\circ}$ Norte caracterizada por presentar un clima cálido y seco, utilizó cuatro módulos de pruebas cúbicos de $3 m \times 3 m \times 3 m$, construidos con concreto para comparar el desempeño térmico de algunas estrategias de enfriamiento pasivo, entre ellas dos tipos de materiales aislantes, el poliestireno expandido (EPS) y los paneles de espuma rígida de poliisocianurato (PIR). En la experimentación se modificaron los materiales de la fachada sur solamente. Tres de los módulos fueron construidos con una línea base que consta de un recubrimiento interior de $2 \mathrm{~cm}$ de mortero + concreto de $15 \mathrm{~cm}+$ recubrimiento de mortero de $15 \mathrm{~cm}$, un cuarto módulo fue construido sin la línea base, pero con placa de yeso de $2,4 \mathrm{~cm}$ + placa mineral de $0,9 \mathrm{~cm}+$ EPS de $10 \mathrm{~cm}$. Uno de los tres módulos base se lo dejó sin modificar como referencia, mientras que a los otros dos se les aplicaron los siguientes tratamientos: Al primero PIR de $5 \mathrm{~cm}$ y al segundo Pintura con absortividad de 0,16. 
Los resultados de estas pruebas indicaron que, en comparación con el módulo de referencia, el porcentaje de reducción del flujo de calor usando la pintura de baja absortividad fue de $22 \%$, el PIR alrededor del $69 \%$ y el EPS un $75 \%$.

Para mantener el aire en una temperatura de confort previamente establecida de $24^{\circ} \mathrm{C}$, en el módulo de referencia se consumieron 103,3 kWh, mientras que en el tratamiento de baja absortividad se utilizaron 95,4kWh, en el módulo con PIR 79,5kWh y en el módulo con EPS $77,1 \mathrm{kWh}$. Esto resulta en un ahorro energético de $7,6 \%, 23 \%$ y $25,3 \%$ respectivamente.

Chirarattananon, Hien, \& Tummu (2012), mediante simulaciones computarizadas y experimentaciones de campo, investigaron el desempeño del aislamiento térmico en tres diferentes tipos de edificaciones comerciales en muros con ventanas, sin ventanas y ubicando el aislamiento en la parte interior o exterior del edificio.

Para el caso de paredes sin ventanas, los resultados demostraron que, de la energía consumida anualmente para refrigeración en un espacio de referencia sin ningún aislamiento, se ahorró un $58 \%$ mediante la aplicación de un aislamiento térmico de EPS de $25 \mathrm{~mm}$ de espesor en el interior, mientras que, cuando se ubicó en el exterior se obtuvo un $2 \%$ de ahorro adicional. Cuando el grosor del EPS se aumentó a $50 \mathrm{~mm}$ en cada uno de los casos, se observó que con el caso exterior se obtenía un $2 \%$ más de ahorro, es decir, un $69 \%$ para la ubicación interior y $71 \%$ para la parte exterior.

Este mismo análisis realizado para muros con ventanas arrojó que los ahorros son muy poco representativos. Con una configuración de ventanas $\mathrm{RVO}^{36}$ de $30 \%$, el aislamiento de $25 \mathrm{~mm}$ de EPS sea interno o externo solamente obtuvo un ahorro energético del $10 \%$ mientras que los $50 \mathrm{~mm}$ tan solo obtuvieron $12 \%$ de ahorro. Cuando RVO subió al $60 \%$ con el aislamiento de $25 \mathrm{~mm}$ de grosor tan solo se lograron reducciones del $1 \%$.

Los autores concluyeron que la ganancia solar directa a través de las ventanas afecta mucho el desempeño del aislamiento y que en esos casos la inversión no es rentable. En contraste las envolventes expuestas directamente al sol sin ventanas tienen una rentabilidad comprobada. En este último caso, recomiendan ubicar el aislamiento en el interior del edificio

${ }^{36}$ Ver definición de este concepto más arriba en el título 3.2. 
a pesar de que el rendimiento sea menor, ya que los gastos para impermeabilizar el tratamiento exterior incrementan los costos.

De acuerdo con Aditya et al (2017), el potencial de ahorro energético de una construcción bien aislada con este método varía entre 50 y $90 \%$ en el entorno europeo. De otro lado, en Malasia, con un clima ecuatorial húmedo se han logrado ahorros energéticos anuales del $64 \%$ en comparación a las construcciones tradicionales que poseen aire acondicionado y se ha logrado reducir en $5^{\circ} \mathrm{C}$ la $\mathrm{T}_{\text {air }}$ interior en edificaciones ventiladas naturalmente con la instalación de aislamiento en la cubierta.

Según Lee, Lim, \& Salleh (2016), la tecnología de aislamiento basado en masa no es la más idónea ni la más efectiva para resistir la transferencia de calor radiativo. En contraste, el aislamiento térmico que adopta las técnicas reflectivas como los recubrimientos de baja absortividad y las barreras radiantes usan capas muy pequeñas de material, ocupan menos espacio, son livianas y por tanto no requieren estructuras de soporte complejas ni aportan peso considerable a la estructura propia del edificio. 


\subsection{Fachadas opacas ventiladas}

Ibañez, Vidaurre, Sacristán, \& Martín (2017), definen una fachada opaca ventilada (FOV), como una envolvente vertical multicapa, compuesta por dos capas opacas y un canal de ventilación en medio. La capa en contacto con el exterior funciona principalmente como un filtro de radiación solar, mientras que la capa interna y el canal de ventilación cumplen el papel de aislantes de calor.

En el canal de ventilación se pueden presentar dos formas de ventilación, la producida por la flotación del aire caliente hacia arriba por efecto de la diferencia de temperaturas entre la parte inferior y superior del canal; y por el efecto del viento.

Algunos autores como Aparicio, Vivancos, Ferrer, \& Royo (2014), encontraron que durante condiciones de radiación solar sobre la FOV suele presentarse una elevación de la temperatura en la capa exterior lo cual incrementa el flujo de aire al interior por convección natural, haciendo que la capa interna permanezca a menor temperatura. Por consiguiente, mientras más radiación solar influya sobre la capa exterior más ahorros energéticos se logran.

Asimismo, Gagliano, Nocera, \& Aneli (2016) y Labat, Woloszyn, Garnier, Rusaouen, \& Roux, (2012), señalan que el enfriamiento por acción del viento es mucho más notable en la ausencia de radiación solar, con lo cual esta estrategia asegura enfriamiento pasivo tanto en las horas del día como en la noche.

Respecto a la capa exterior, para climas cálidos los autores como Patania, Gagliano, Nocera, \& Galesi (2010) y Stazi, Veglió, \& Di Perna (2011), recomiendan usar colores claros de baja absortividad, porque los colores oscuros incrementan la temperatura de la piel exterior, lo cual aumenta el flujo de aire al interior, pero también incrementan la transferencia de calor por radiación a las otras capas.

En cuanto a las aberturas de la primera piel, autores como Labat et al, Op. cit. y Sanjuan, Sánchez, Heras, \& Blanco (2011), concuerdan en que, si existen perforaciones en ella, el flujo de aire se vuelve mucho más complejo y se reduce porque hay mayor cantidad de aberturas por las cuales puede ingresar o salir el aire, reduciéndose la capacidad de enfriamiento.

En general esta estrategia demuestra tener un desempeño notable en la reducción del flujo de calor, pues algunos trabajos experimentales reportan una reducción del $58 \%$ del flujo de calor con una fachada ventilada de bloques de arcilla en comparación a una fachada no ventilada (Fantucci, Marinosci, Serra, \& Carbonaro, 2017). 
De otro lado, investigaciones de simulación computacional como la desarrollada por Gagliano Op. cit. encuentran que un porcentaje entre el $47 \%$ y el $51 \%$ de energía en climatización puede ser ahorrada con esta estrategia, dependiendo del tipo de clima. Por su parte, la revisión bibliográfica hecha por Ibáñez Op. cit., en la cual se incluyen estudios teóricos y experimentales, da cuenta que estos porcentajes varían entre el $20 \%$ y el $41 \%$ para el tiempo y las condiciones de verano europeo si se comparan con envolventes no ventiladas. Estos mismos autores reportan además que en un día típico de verano, una FOV puede lograr una reducción máxima de $12^{\circ} \mathrm{C}$ en la $\mathrm{T}_{\text {air }}$ para condiciones de verano. 


\subsection{Aislamiento reflectivo o barreras radiantes}

El aislamiento térmico reflectivo no trabaja como los aislamientos convencionales basados en la resistencia térmica $(\mathrm{R})$ de los materiales, sino con las propiedades físicas de reflectividad y emisividad. Con base a lo expuesto por la American Society for Testing and Materials ASTM (Oak Ridge National Laboratory, 2018), un material es considerado apto para formar parte de una barrera radiante cuando posee un valor de reflectividad igual o mayor a 0,9; y un valor de emisividad igual o menor a 0,1. Esto quiere decir, que un material con estas condiciones reflejará el $90 \%$ del flujo de calor transferido por radiación y del calor ganado solo emitirá el $10 \%$.

Con valores de reflectividad y emisividad de 0,95 y 0,05 respectivamente, el Aluminio es el material más común y ampliamente utilizado, debido a su fácil asequibilidad y bajo costo. Este material es usado en una delgada capa o film que varía entre 6 y 80 micras.

Para que esa reflexión ocurra y se produzca el efecto barrera, la delgada capa reflectiva debe ir acompañada de un espacio de aire donde se produzca el intercambio directo de calor por radiación. Adicionalmente, en esta cavidad, también ocurrirá una transferencia de calor convectiva/conductiva/convectiva. Una explicación gráfica de estos componentes de la barrera radiante, al igual que el proceso de transferencia de calor a través de ella es explicado en la Figura 48 tomada de Escudero, Martin, Erkoreka, Flores, \& Sala (2013), donde $R_{c}$ hace referencia a la resistencia por convección y $R_{r}$ hace referencia a la resistencia por radiación.

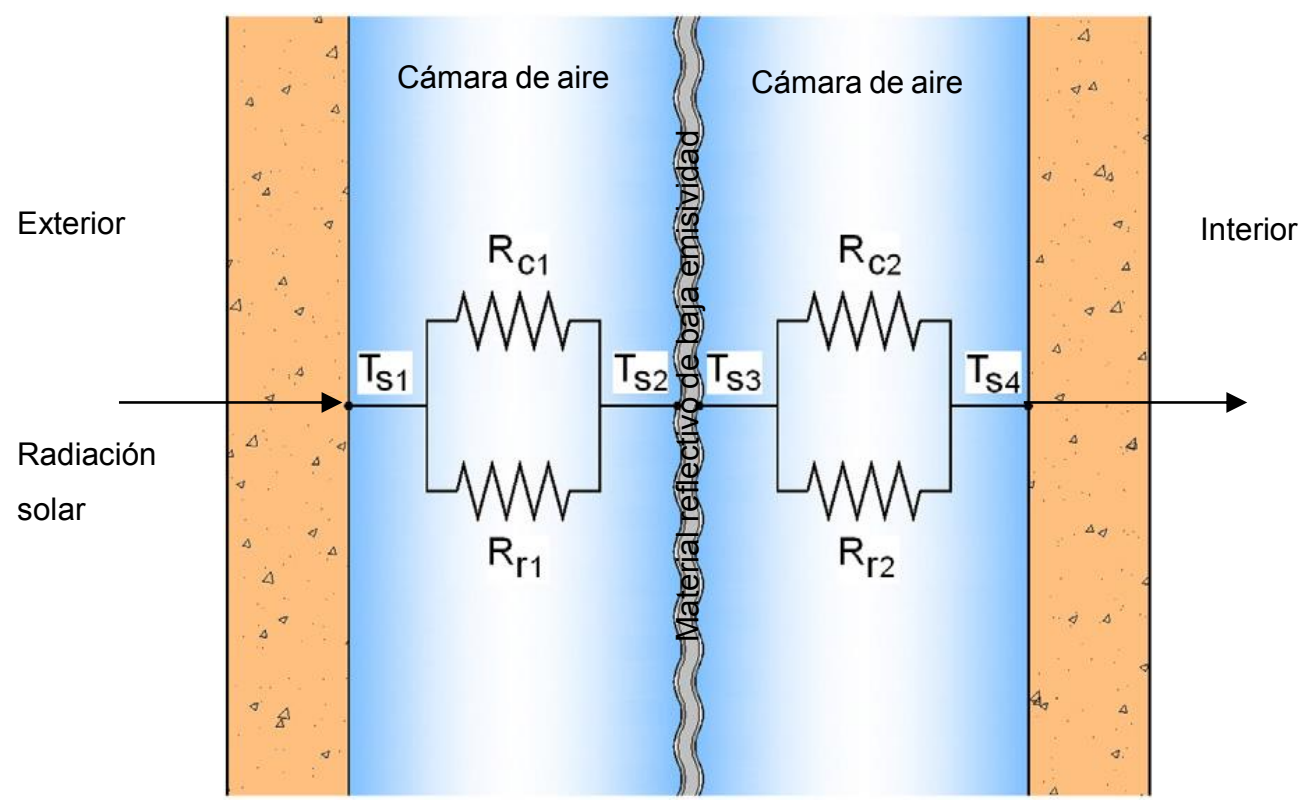

Figura 48. Corte transversal explicativo de los componentes de una barrera radiante y el proceso de transferencia de calor a través de ella. Fuente: Escudero, Martin, Erkoreka, Flores, \& Sala (2013). 
Usualmente, el film posee un lado brillante y otro opaco; el lado brillante es el poseedor de las propiedades mencionadas anteriormente y para fines de enfriamiento, este debe posicionarse hacia el lado de donde proviene el flujo de calor, es decir, hacia el exterior, debido a que a la radiación solar es a la que se le desea impedir el paso.

Como los materiales usados son una delgada capa, algunas fuentes como Rogers (2013) y ASTM (Oak Ridge National Laboratory, 2018), aseguran que es imposible conocer el valor R de ellos, incluso lo consideran despreciable frente al poder de aislamiento proporcionado por los atributos reflectivos de esta estrategia. Por su parte, el espacio de aire que bien puede estar cerrado o abierto tampoco aporta mucho valor $\mathrm{R}$ viéndolo separadamente, no obstante, la unión de los dos hace la diferencia. De hecho, el ancho de la capa de aire es un tema bastante influyente en el desempeño térmico de las barreras radiantes.

Si la distancia entre las superficies va de 1 a $2 \mathrm{~cm}$, se obtiene la mayor eficiencia, aunque pueden obtenerse buenos resultados con espesores de hasta $9 \mathrm{~cm}$. El valor R de algunas barreras radiantes con diversas emisividades, direcciones del flujo de calor y posición y anchos de cámaras de aire pueden consultarse en la siguiente Tabla 11 (ASHRAE, 2013).

(from ASHRAE Handbook of Fundamentals, Ref. 1, Chap. 2í, Table 2)

(a) SI units (in $\mathrm{m}^{2} \cdot{ }^{\circ} \mathrm{C} / \mathrm{W}$ )

\begin{tabular}{|c|c|c|c|c|c|c|c|c|c|c|c|c|c|c|c|}
\hline \multirow{3}{*}{$\begin{array}{l}\text { Position } \\
\text { of air } \\
\text { space }\end{array}$} & \multirow{3}{*}{$\begin{array}{l}\text { Direction } \\
\text { of heat } \\
\text { flow }\end{array}$} & \multirow{3}{*}{$\begin{array}{l}\text { Mean } \\
\text { temp., } \\
{ }^{\circ} \mathbf{C}\end{array}$} & \multirow{3}{*}{$\begin{array}{l}\text { Temp. } \\
\text { diff., } \\
{ }^{\circ} \mathbf{C}\end{array}$} & \multirow{2}{*}{\multicolumn{4}{|c|}{$\begin{array}{c}\text { 20-mm air space } \\
\text { Effective } \\
\text { emissivity, } \varepsilon_{\text {eff }}\end{array}$}} & \multirow{2}{*}{\multicolumn{4}{|c|}{$\begin{array}{c}\text { 40-mm air space } \\
\text { Effective } \\
\text { emissivity, } \varepsilon_{\text {eff }}\end{array}$}} & \multirow{2}{*}{\multicolumn{4}{|c|}{$\begin{array}{c}\text { 90-mm air space } \\
\text { Effective } \\
\text { emissivity, } \varepsilon_{\text {eff }}\end{array}$}} \\
\hline & & & & & & & & & & & & & & & \\
\hline & & & & 0.03 & 0.05 & 0.5 & 0.82 & 0.03 & 0.05 & 0.5 & 0.82 & 0.03 & 0.05 & 0.5 & 0.82 \\
\hline \multirow{4}{*}{ Horizontal } & \multirow{4}{*}{ Up $\uparrow$} & 32.2 & 5.6 & 0.41 & 0.39 & 0.18 & 0.13 & 0.45 & 0.42 & 0.19 & 0.14 & 0.50 & 0.47 & 0.20 & 0.14 \\
\hline & & 10.0 & 16.7 & 0.30 & 0.29 & 0.17 & 0.14 & 0.33 & 0.32 & 0.18 & 0.14 & 0.27 & 0.35 & 0.19 & 0.15 \\
\hline & & 10.0 & 5.6 & 0.40 & 0.39 & 0.20 & 0.15 & 0.44 & 0.42 & 0.21 & 0.16 & 0.49 & 0.47 & 0.23 & 0.16 \\
\hline & & -17.8 & 11.1 & 0.32 & 0.32 & 0.20 & 0.16 & 0.35 & 0.34 & 0.22 & 0.17 & 0.40 & 0.38 & 0.23 & 0.18 \\
\hline \multirow{4}{*}{$45^{\circ}$ slope } & \multirow{4}{*}{ Up $\uparrow$} & 32.2 & 5.6 & 0.52 & 0.49 & 0.20 & 0.14 & 0.51 & 0.48 & 0.20 & & 0.56 & 0.52 & 0.21 & \\
\hline & & 10.0 & 16.7 & 0.35 & 0.34 & 0.19 & 0.14 & 0.38 & 0.36 & 0.20 & 0.15 & 0.40 & 0.38 & 0.20 & 0.15 \\
\hline & & 10.0 & 5.6 & 0.51 & 0.48 & 0.23 & 0.17 & 0.51 & 0.48 & 0.23 & 0.17 & 0.55 & 0.52 & 0.24 & 0.17 \\
\hline & & -17.8 & 11.1 & 0.37 & 0.36 & 0.23 & 0.18 & 0.40 & 0.39 & 0.24 & 0.18 & 0.43 & 0.41 & 0.24 & 0.19 \\
\hline \multirow{4}{*}{ Vertical } & \multirow{4}{*}{ Horizontal $\rightarrow$} & 32.2 & 5.6 & 0.62 & 0.57 & 0.21 & 0.15 & 0.70 & 0.64 & 0.22 & 0.15 & 0.65 & 0.60 & 0.22 & \\
\hline & & 10.0 & 16.7 & 0.51 & 0.49 & 0.23 & 0.17 & 0.45 & 0.43 & 0.22 & 0.16 & 0.47 & 0.45 & 0.22 & 0.16 \\
\hline & & 10.0 & 5.6 & 0.65 & 0.61 & 0.25 & 0.18 & 0.67 & 0.62 & 0.26 & 0.18 & 0.64 & 0.60 & 0.25 & 0.18 \\
\hline & & -17.8 & 11.1 & 0.55 & 0.53 & 0.28 & 0.21 & 0.49 & 0.47 & 0.26 & 0.20 & 0.51 & 0.49 & 0.27 & 0.20 \\
\hline \multirow{4}{*}{$45^{\circ}$ slope } & \multirow{4}{*}{ Down $\downarrow$} & 32.2 & 5.6 & 0.62 & 0.58 & 0.21 & 0.15 & 0.89 & 0.80 & 0.24 & 0.16 & 0.85 & 0.76 & 0.24 & 0.16 \\
\hline & & 10.0 & 16.7 & 0.60 & 0.57 & 0.24 & 0.17 & 0.63 & 0.59 & 0.25 & 0.18 & 0.62 & 0.58 & 0.25 & 0.18 \\
\hline & & 10.0 & 5.6 & 0.67 & 0.63 & 0.26 & 0.18 & 0.90 & 0.82 & 0.28 & 0.19 & 0.83 & 0.77 & 0.28 & 0.19 \\
\hline & & -17.8 & 11.1 & 0.66 & 0.63 & 0.30 & 0.22 & 0.68 & 0.64 & 0.31 & 0.22 & 0.67 & 0.64 & 0.31 & 0.22 \\
\hline \multirow{4}{*}{ Horizontal } & \multirow{4}{*}{ Down $\downarrow$} & 32.2 & 5.6 & 0.62 & 0.58 & 0.21 & 0.15 & 1.07 & 0.94 & 0.25 & 0.17 & 1.77 & 1.44 & 0.28 & 0.18 \\
\hline & & 10.0 & 16.7 & 0.66 & 0.62 & 0.25 & 0.18 & 1.10 & 0.99 & 0.30 & 0.20 & 1.69 & 1.44 & 0.33 & 0.21 \\
\hline & & 10.0 & 5.6 & 0.68 & 0.63 & 0.26 & 0.18 & 1.16 & 1.04 & 0.30 & 0.20 & 1.96 & 1.63 & 0.34 & 0.22 \\
\hline & & -17.8 & 11.1 & 0.74 & 0.70 & 0.32 & 0.23 & 1.24 & 1.13 & 0.39 & 0.26 & 1.92 & 1.68 & 0.43 & 0.29 \\
\hline
\end{tabular}

Tabla 11. Tabla de valores $\mathrm{R}$ para barreras radiantes con diferentes configuraciones de emisividad, dirección del flujo de calor, posición y ancho de la cámara de aire. Fuente: (ASHRAE, 2013). 
De la anterior tabla puede notarse que una barrera radiante de posición vertical donde el flujo de calor es horizontal (como en una envolvente edilicia), con un espacio de aire de $20 \mathrm{~mm}$ y un material de emisividad 0,05 como el aluminio pueden tener valores de $\mathrm{R}$ muy similares a una barrera radiante de igual configuración, pero con una cavidad de aire de $90 \mathrm{~mm}$.

Esta tecnología, ha sido habitualmente estudiada para aislamientos térmicos de cubiertas en zonas cercanas al ecuador, donde la radiación solar recibida por la cubierta constituye una de las principales causas de insatisfacción térmica. Esta carga térmica en dichas latitudes incluso alcanza el 70\% del total. En Malasia, por ejemplo, Azraai, Ali, Salleh, \& Asaroon (2012), mediante dos módulos experimentales a escala real con cubierta a dos aguas, obtuvo una reducción cercana a los $15^{\circ} \mathrm{C}$ en las horas pico de radiación entre el módulo donde se implementó una barrera con foil de aluminio y el módulo testigo.

Lee, Lim, \& Salleh (2016), realizaron una revisión de trabajos de simulación, de campo y de laboratorio que se llevaron a cabo para descubrir el desempeño de las barreras radiantes en las cubiertas. En esta revisión se analizaron 59 trabajos durante la temporada de verano en varias latitudes. En cuanto a la reducción del flujo de calor, se logró un rango que va desde el $26 \%$ hasta el $50 \%$. En términos de reducción de la carga térmica total, estas mismas investigaciones dieron cuenta que las barreras radiantes pudieron reducir entre el $6 \%$ y el $16 \%$. Adicionalmente señalaron haber podido reducir la temperatura del interior de los áticos entre 4 y $10^{\circ} \mathrm{C}$.

Dentro de este conjunto de estudios se notó que las barreras radiantes posicionadas completamente horizontales tuvieron un mejor desempeño que aquellas localizadas diagonalmente. En promedio las barreras dispuestas horizontalmente obtuvieron una reducción del $35 \%$ del flujo de calor, mientras que las inclinadas tan solo llegaron al $22 \%$.

Como se ha visto, en el estado del arte se encuentran varias investigaciones sobre el comportamiento térmico de esta estrategia en cubiertas, sin embargo, algunos autores sostienen que son pocos los estudios que indagan sobre el comportamiento de las barreras radiantes en las envolventes verticales de los edificios y consideran necesario e importante indagar este tema para la eficiencia energética de las edificaciones. (Sarber. 2012; Escudero, Martin, Erkoreka, Flores, \& Sala. 2013; Lee, Lim, \& Salleh. 2016),

Una investigación en muros fue realizada por Vrachopoulos et al (2011), en ella se usó un módulo de pruebas a pequeña escala, expuesto directamente a las condiciones exteriores de invierno y de verano. El film de aluminio se insertó en medio de una cámara de aire de $2 \mathrm{~cm}$ dejando un espacio de $1 \mathrm{~cm}$ a cada lado. En invierno, la barrera radiante ayudó a retener el calor causando la estabilización de la temperatura de la cara interna del muro envolvente. La 
temperatura de la cara interna del muro permaneció entre $10^{\circ} \mathrm{C}$ y $12^{\circ} \mathrm{C}$, mientras que la condición exterior del muro fluctuó entre $4^{\circ} \mathrm{C}$ y $16{ }^{\circ} \mathrm{C}$. En el verano, el aislamiento reflectivo bloqueó la radiación solar, mientras que la temperatura de la superficie interior varió entre $23^{\circ} \mathrm{C}$ y $27^{\circ} \mathrm{C}$, la temperatura de la superficie exterior estuvo entre $17^{\circ} \mathrm{C}$ y $32^{\circ} \mathrm{C}$.

Baldinelli (2010), condujo una investigación para validar una metodología de evaluación de las propiedades de las barreras radiantes mediante mediciones de campo tomadas en un módulo de pruebas con un panel de baja emisividad insertado en los muros. Los resultados mostraron concordancia entre los modelos teóricos de la norma ISO 13786, los simuladores CFD y los experimentos. Finalmente, la implementación del panel reflectivo incrementó el valor $\mathrm{R}$ en $1,236 \mathrm{~m}^{2} \mathrm{~K} / \mathrm{W}$.

Juanicó \& González (2017), demuestran numéricamente el potencial de aislamiento térmico de combinar varias cámaras de aire con materiales aislantes. Los autores estudian varias opciones de cámaras de aire separadas por láminas de poliestireno expandido (EPS), en donde a medida que se aumenta la cantidad de cámaras, también va decreciendo la transmitancia térmica, pero, a la vez se aumenta el grosor de la configuración. Por ejemplo, sin utilizar aluminio, pero con 4 cámaras de aire y un grosor de $7,7 \mathrm{~cm}$ se logró un valor $U$ de $0,5 \mathrm{~W} / \mathrm{m}^{2 \circ} \mathrm{C}$, lo cual equivalió a un gran ahorro en material, pues este mismo valor $\mathrm{U}$ es logrado por $7 \mathrm{~cm}$ macizos de EPS. Esta configuración fue optimizada recubriendo las láminas de EPS con foil de aluminio. Con esta modificación, el valor $U$ se redujo en un $40 \%$ alcanzando 0,211 $\mathrm{W} / \mathrm{m}^{2 \circ} \mathrm{C}$. Los autores recomiendan más investigación experimental, para evaluar y crear más soluciones constructivas que involucren el concepto de las cámaras de aire combinadas con materiales de baja emisividad.

\subsection{Discusión}

A manera de síntesis se realizó una comparación de desempeño térmico con los máximos resultados alcanzados con cada estrategia reportados en la bibliografía. Estos resultados sirvieron como indicadores de desempeño, aunque no toda la bibliografía usó los mismos indicadores, este ejercicio permite visualizar cual o cuales estrategias poseen mayor poder de enfriamiento. Esta comparación se puede detallar a continuación en la Tabla 12. 


\begin{tabular}{|c|c|c|c|c|c|c|c|}
\hline & \multicolumn{6}{|c|}{$\begin{array}{l}\text { ESTRATEGIAS DE ENFRIAMIENTO PASIVO DESARROLLADAS PARA ENVOLVENTES } \\
\text { EDIFICATORIAS }\end{array}$} \\
\hline & & $\begin{array}{c}\text { Baja } \\
\text { absortividad }\end{array}$ & $\begin{array}{l}\text { Protección } \\
\text { solar }\end{array}$ & $\begin{array}{l}\text { Muros } \\
\text { vegetales }\end{array}$ & $\begin{array}{l}\text { Aislamiento } \\
\text { reflectivo }\end{array}$ & $\begin{array}{c}\text { Aislamiento con } \\
\text { materiales de } \\
\text { alta resistencia } \\
\text { térmica }\end{array}$ & $\begin{array}{l}\text { Fachadas } \\
\text { opacas } \\
\text { ventiladas }\end{array}$ \\
\hline \multirow{4}{*}{ 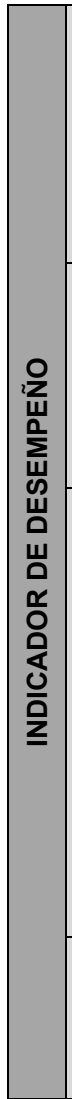 } & $\begin{array}{l}\text { Porcentaje } \\
\text { de } \\
\text { reducción } \\
\text { del flujo de } \\
\text { calor o } \mathrm{T}_{\mathrm{r}}\end{array}$ & $\begin{array}{l}22 \% \\
\text { (Rehman, } \\
\text { 2015) }\end{array}$ & $\begin{array}{c}52 \% \\
\text { (Hashemi \& } \\
\text { Khatami, } \\
\text { 2017) }\end{array}$ & $\begin{array}{c}\text { 34\% - 59\% } \\
\text { (Coma, y } \\
\text { otros, 2017) y } \\
\text { 34\% (Pérez, } \\
\text { Rincón, } \\
\text { González, \& } \\
\text { Cabeza, } \\
\text { 2011) } \\
\end{array}$ & $\begin{array}{c}\text { 26\%-50\% (Lee, } \\
\text { Lim, \& Salleh, } \\
\text { 2016) }\end{array}$ & $\begin{array}{c}69 \%-71 \% \\
\text { (Chirarattananon, } \\
\text { Hien, \& Tummu, } \\
\text { 2012) }\end{array}$ & $\begin{array}{c}20 \%-41 \% \\
\text { (Ibañez-Puy, } \\
\text { Vidaurre- } \\
\text { Arbizu, } \\
\text { Sacristán- } \\
\text { Fernandez, \& } \\
\text { Martín-Gómez, } \\
2017 \text { ) } \\
\end{array}$ \\
\hline & $\begin{array}{l}\text { Reducción } \\
\text { de } T_{\text {air }}\end{array}$ & $\begin{array}{l}12^{\circ} \mathrm{C}-15^{\circ} \\
\text { (Cheng, Ng, } \\
\text { \& Givoni, } \\
\text { 2005) }\end{array}$ & $\begin{array}{l}6,65^{\circ} \mathrm{C} \\
\text { (Freewan, } \\
\text { 2014) }\end{array}$ & & $\begin{array}{c}15^{\circ} \mathrm{C} \text { (Azraai, } \\
\text { Ali, Salleh, \& } \\
\text { Asaroon, 2012) } \\
\text { y } 4^{\circ} \mathrm{C}-10^{\circ} \mathrm{C} \\
\text { (Lee, Lim, \& } \\
\text { Salleh, 2016) }\end{array}$ & $\begin{array}{l}5^{\circ} \mathrm{C} \text { (Aditya, y } \\
\text { otros, 2017) }\end{array}$ & $\begin{array}{l}12^{\circ} \mathrm{C} \text { (Ibañez- } \\
\text { Puy, Vidaurre- } \\
\text { Arbizu, } \\
\text { Sacristán- } \\
\text { Fernandez, \& } \\
\text { Martín-Gómez, } \\
\text { 2017) }\end{array}$ \\
\hline & \begin{tabular}{|c|} 
\\
Ahorro en \\
energía \\
anual en \\
enfriamiento
\end{tabular} & $\begin{array}{l}20 \% \text { y } 7,6 \% \\
\text { (Rehman, } \\
\text { 2015) }\end{array}$ & $\begin{array}{c}8,92 \% \\
\text { (Valladares- } \\
\text { Rendón, } \\
\text { Schmid, \& Lo, } \\
2017 \text { ), 19\%- } \\
17 \% \text { (Cho, } \\
\text { Yoo, \& Kim, } \\
\text { 2014) y 66\% } \\
\text { (Gon, Hong } \\
\text { Soo, Tae } \\
\text { Sub, } \\
\text { Schaefer, \& } \\
\text { Jeong Tai, } \\
\text { 2012) }\end{array}$ & $\begin{array}{c}\text { 34\% - 59\% } \\
\text { (Coma, y } \\
\text { otros, 2017) y } \\
\text { 34\% (Pérez, } \\
\text { Rincón, } \\
\text { González, \& } \\
\text { Cabeza, } \\
\text { 2011) }\end{array}$ & & $\begin{array}{c}25,3 \% \text { (Rehman, } \\
2015 \text { ) y } 64 \% \\
\text { (Aditya, y otros, } \\
2017 \text { ) }\end{array}$ & $\begin{array}{c}47 \%-51 \% \\
\text { (Gagliano, } \\
\text { Nocera, \& } \\
\text { Aneli, 2016). } \\
20 \%-41 \% \\
\text { (Ibañez-Puy, } \\
\text { Vidaurre- } \\
\text { Arbizu, } \\
\text { Sacristán- } \\
\text { Fernandez, \& } \\
\text { Martín-Gómez, } \\
\text { 2017) }\end{array}$ \\
\hline & $\begin{array}{c}\text { Reducción } \\
\text { de } T_{r} \\
\text { exterior de } \\
\text { la } \\
\text { envolvente }\end{array}$ & $\begin{array}{l}25^{\circ} \mathrm{C} \text { en el } \\
\text { pico } \\
\text { (Rehman, } \\
2015)\end{array}$ & & $\begin{array}{c}31,9^{\circ} \mathrm{C} \\
\text { (Olivieri, } \\
\text { Olivieri, \& } \\
\text { Neila, 2014) }\end{array}$ & & & \\
\hline
\end{tabular}

Tabla 12. Síntesis y comparación del desempeño térmico máximo logrado por las estrategias de enfriamiento pasivo mediante los indicadores de reducción del flujo de calor, reducción de $T$ air, ahorro de energía anual en enfriamiento y reducción de $T_{r}$ exterior de la envolvente. Fuente: Elaboración propia. 


\subsection{Conclusiones}

- La bibliografía revisada señala primeramente la disponibilidad de estrategias de tipo pasivo para enfriamiento en edificaciones, las cuales se clasifican de acuerdo con su actuación frente al calor, ya sea previniéndolo, modulándolo o disipándolo. De estas alternativas se profundizó la búsqueda sobre aquellas desarrolladas específicamente para envolventes edificatorias, encontrando seis grupos en los que se encuentran: protección solar, la baja absortividad, muros vegetales, aislamiento reflectivo, aislamiento con materiales de alta resistencia térmica y fachadas opacas ventiladas.

- Para todas las estrategias se encontró bibliografía con diferentes tipos de estudio, tanto numéricos como experimentales. En ella se identificaron algunos vacíos como, por ejemplo:

- Se ha estudiado el desempeño térmico de las estrategias de baja absortividad y aislamiento reflectivo sobre todo en envolventes horizontales, pero es necesario revisar en más detalle su efecto en envolventes verticales.

- Las investigaciones recogidas dan prioridad al comportamiento térmico de cada tecnología, sin embargo, la mayoría no aborda el tema de costos.

- La mayoría de los estudios corresponden a zonas templadas, notándose pocos reportes en latitudes cercanas al ecuador en climas cálido-húmedos como el de Cali.

- Con base en la discusión anterior apoyada en la Tabla 12, si se comparan el desempeño de las estrategias de enfriamiento pasivo mediante el indicador de reducción del flujo de calor (en el cual se recogieron datos de todas las estrategias) el mejor desempeño lo tendría el aislamiento con materiales de alta resistencia térmica con un porcentaje máximo de $71 \%$; en segundo lugar las muros vegetales con el $59 \%$; en tercer lugar la protección solar con 52\%; en cuarto lugar el aislamiento reflectivo con un $50 \%$; en quinto lugar las fachadas ventiladas con $41 \%$ y en sexto y último lugar la baja absortividad con $22 \%$. 


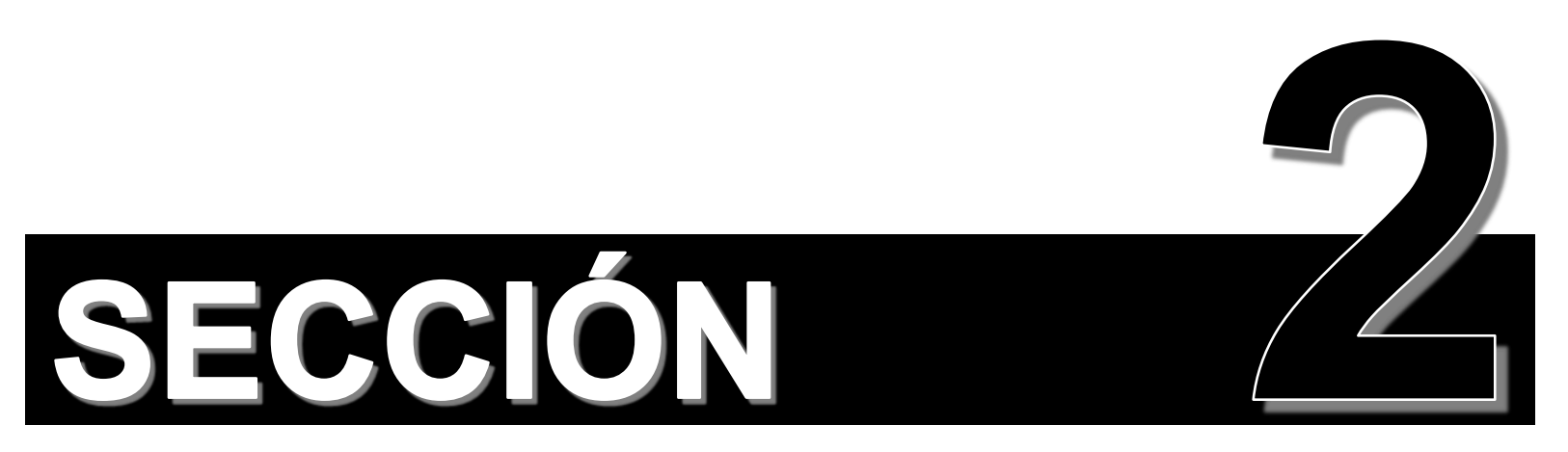




\section{EVALUACIÓN DE CONFORT TÉRMICO A UN MODELO VIS DE CALI}

\subsection{Introducción}

Este título está dedicado a conocer el desempeño térmico de las envolventes verticales opacas y el confort térmico de un ambiente VIS de manera experimental. Se modelizaron inicialmente las condiciones críticas, para lo cual se analizó el clima, las fachadas, las materialidades y el sistema constructivo de las envolventes con el objetivo de escoger el caso más desfavorable para el confort térmico. Luego, se encontró un caso VIS real con dichos rasgos, este fue monitoreado y evaluado mediante los índices PMV y PPD propuestos por Fanger.

\subsection{Análisis de condiciones críticas}

Son varios los parámetros que influencian el desempeño térmico de una VIS, pero, principalmente es afectado por los factores climático como la radiación solar y la $T_{\text {air, }}$, igualmente por las propiedades físicas de los materiales que constituyen la envolvente. A continuación, se revisarán estas variables en la ciudad de Cali.

\subsubsection{Fachada crítica}

El primer paso para identificar la que orientaciones son más críticas en Cali fue realizar un análisis acumulativo anual de radiación solar total (directa + difusa) mediante el software Autodesk Ecotect 2011 previamente cargado con los datos climatológicos de la ciudad de Cali, los cuales fueron tomados de la estación meteorológica de la escuela de arquitectura de la Universidad del Valle de Cali en la sede del barrio Meléndez (extensión epw). 
Los resultados señalaron que la cubierta es la cara que más recibe radiación con 1364300 $\mathrm{Wh} / \mathrm{m}^{2}$, seguida de la fachada Oeste con $604574 \mathrm{Wh} / \mathrm{m}^{2}$, luego la Este con $522253 \mathrm{Wh} / \mathrm{m}^{2}$, después la Sur con $485558 \mathrm{Wh} / \mathrm{m}^{2}$, y por último la Norte con $454430 \mathrm{Wh} / \mathrm{m}^{2}$.

A manera de porcentajes, el plano vertical con mayor radiación solar incidente en el año es el Oeste, con un $14 \%$ más el Este, $20 \%$ más que el Sur y $25 \%$ más que el Norte. De esta forma la fachada Oeste se identificó como la orientación crítica.

Estos resultados también pueden leerse gráficamente de la imagen obtenida con el software en la siguiente Figura 49.

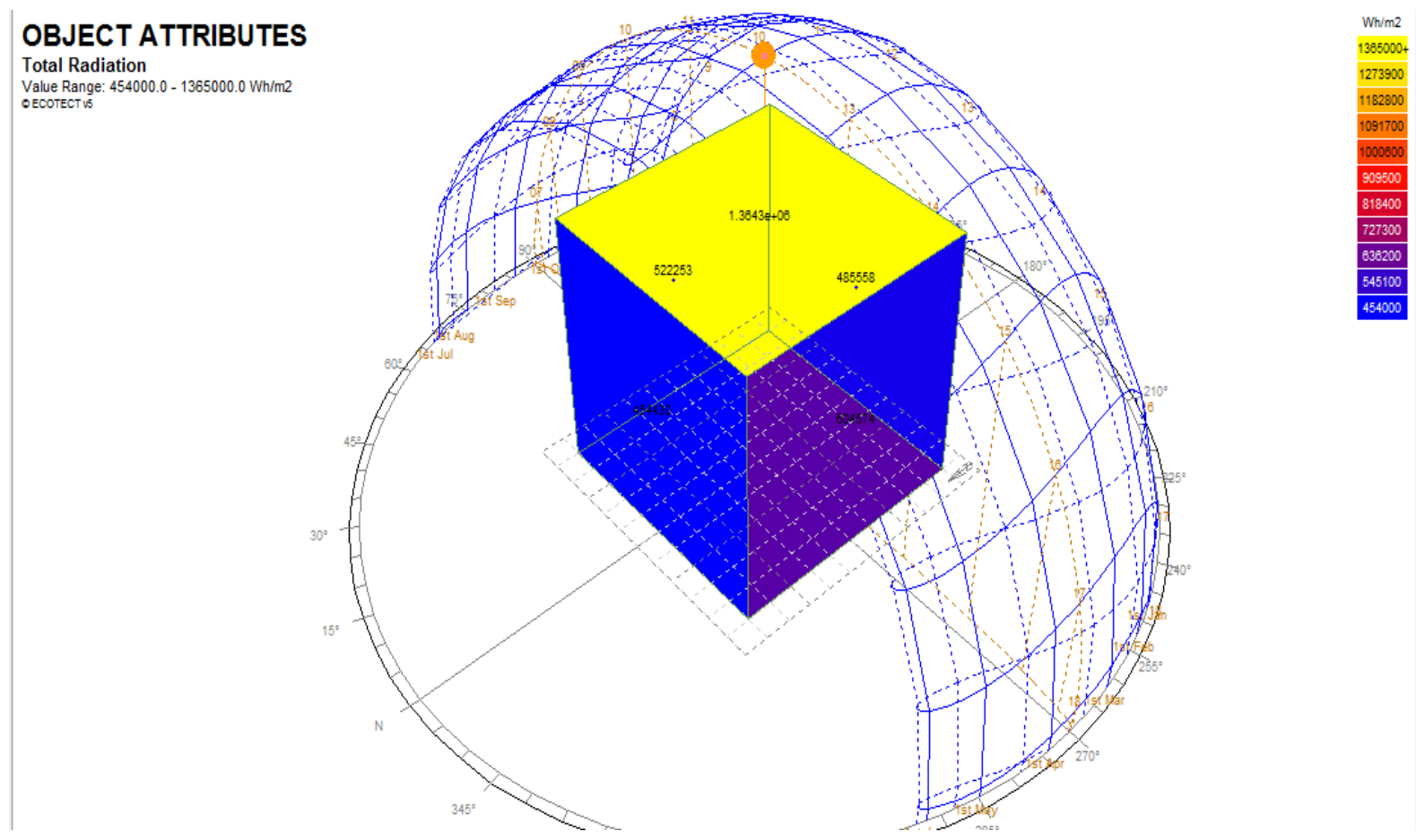

Figura 49. Radiación Solar Total (Directa + Difusa) acumulada en un año en Wh/m² de 8:00 a 18:00 h, en Fachadas y Cubierta. Fuente: Elaboración propia con software Autodesk Ecotect.

\subsubsection{Condiciones climáticas críticas ( $T_{a i r}$ y radiación solar máximos)}

Inicialmente, se efectuó un análisis en busca del día con mayor $\mathrm{T}_{\text {air }} \mathrm{y}$ mayor radiación solar incidente sobre la fachada crítica. Estas dos condiciones se dieron el 15 de enero a las 16:00 (hora solar), cuando se registró una radiación de $741 \mathrm{~W} / \mathrm{m}^{2}$ y una $\mathrm{T}_{\text {air }}$ máxima de $32^{\circ} \mathrm{C}$. Este análisis se realizó por medio de los programas Climate Consultant y Ecotect, ambos cargados previamente con los archivos climáticos de Cali. Una gráfica de la media de la radiación solar 
total sobre la fachada oeste (color naranja, tercera barra) se muestra en la Figura $50^{37}$, allí se aprecia que durante el mes de enero dicha superficie tiene un promedio de radiación mayor que el resto del año, mientras que en la gráfica de la Figura $51^{38}$, se relaciona la radiación solar incidente vs tiempo del 15 de enero, cuyos registros son los más altos de todo el año.

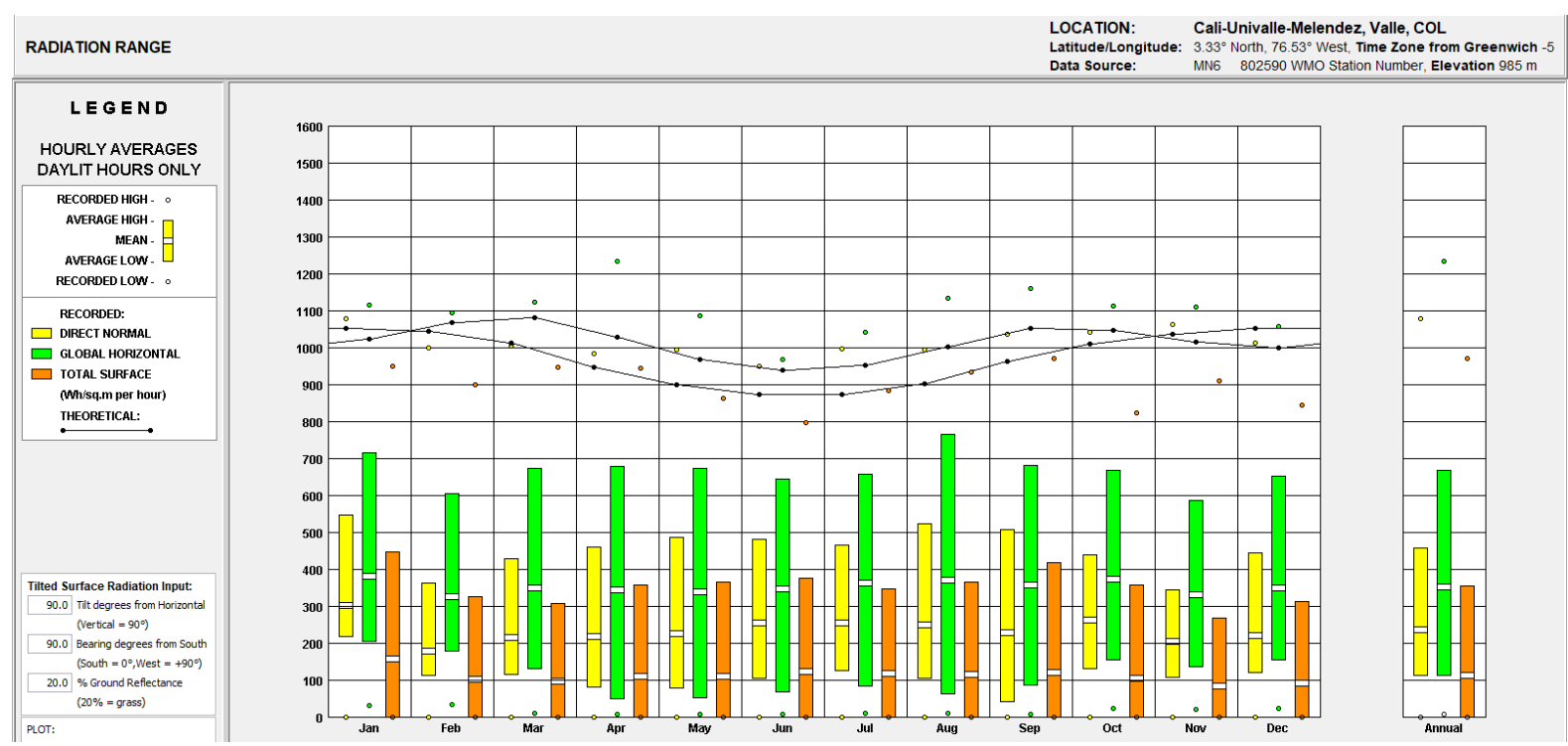

Figura 50. Gráfica de radiación solar total anual sobre la fachada oeste. Fuente: Elaboración propia a través del software Cimate Consultant.

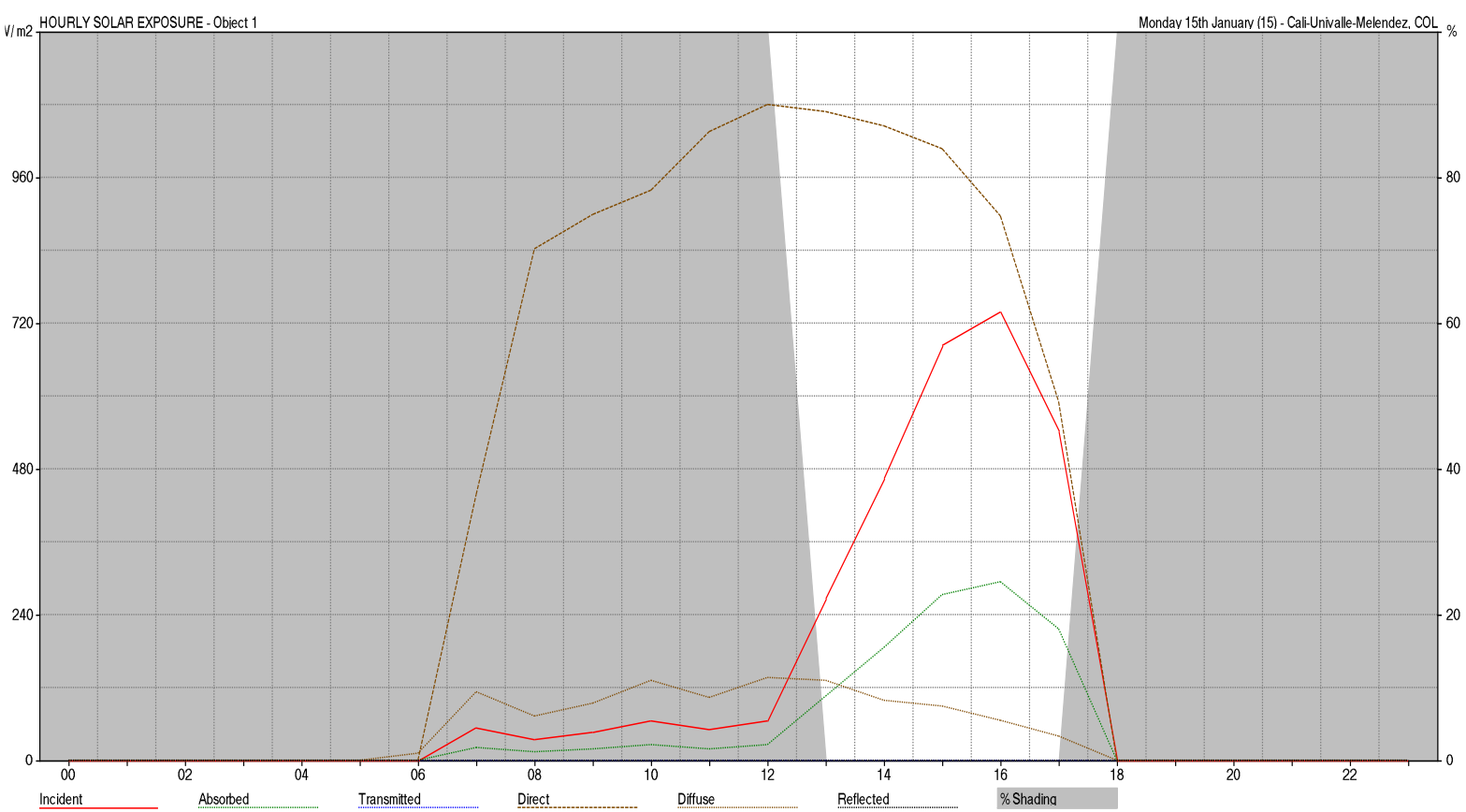

Figura 51. Gráfica de radiación solar (incidente, directa y difusa) en la fachada oeste perteneciente al día crítico en la ciudad de Cali. Fuente: Elaboración propia a través de software Ecotect.

37 Obtenida con el software Climate Consultant.

38 Obtenida mediante el software Autodesk Ecotect. 


\subsubsection{Análisis de propiedades térmicas de los modelos VIS}

Este análisis se realizó calculando teóricamente el valor U (o resistencia térmica) de las dos envolventes VIS más comunes revisadas en el título 2.7 del Capítulo 2 de la primera sección. Este análisis se realizó con el método descrito por Cengel (2003) que a su vez sigue a ASHRAE (2001) suponiendo un estado estacionario.

En la Tabla 13, se calculó este valor para la envolvente de los sistemas industrializados (Outinord y Con-tech), la cual se compone de un muro de concreto macizo de $10 \mathrm{~cm}$ de espesor con revoque interior, obteniendo un valor $U$ de $3,73 \mathrm{~m}^{2 \circ} \mathrm{K} / \mathrm{W}$. Mientras que en la Tabla 14 , se calculó una envolvente del sistema de mampostería estructural en bloque de concreto con revoque interior, con el cual se alcanzó un valor $U$ de $2,37 \mathrm{~m}^{2 \circ} \mathrm{K} / \mathrm{W}$.

Estos valores nos muestran que, por cada grado centígrado de diferencia entre el interior y el exterior, la envolvente está ganando entre $3,73 \mathrm{~W}$ y 2,37 W en cada metro cuadrado a causa de la radiación solar. Además, que el sistema de muros de mampostería posee un poco más de resistencia térmica que los muros de concreto macizo. Las cámaras de aire en el interior de los bloques mejoran su desempeño.

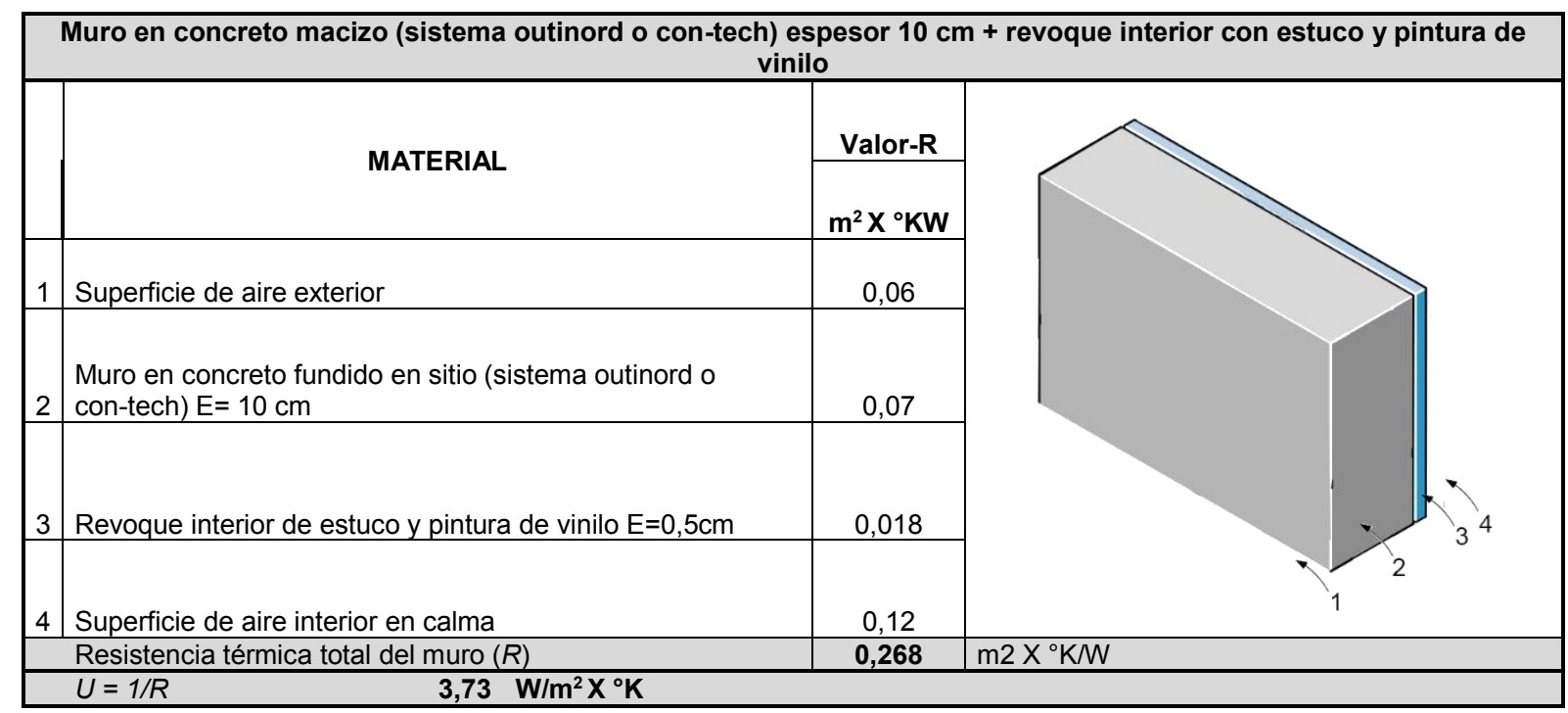

Tabla 13. Cálculo del valor U para un muro de concreto macizo típico de los sistemas Outinord o Con-tech de VIS de Cali. Fuente: Elaboración propia. 


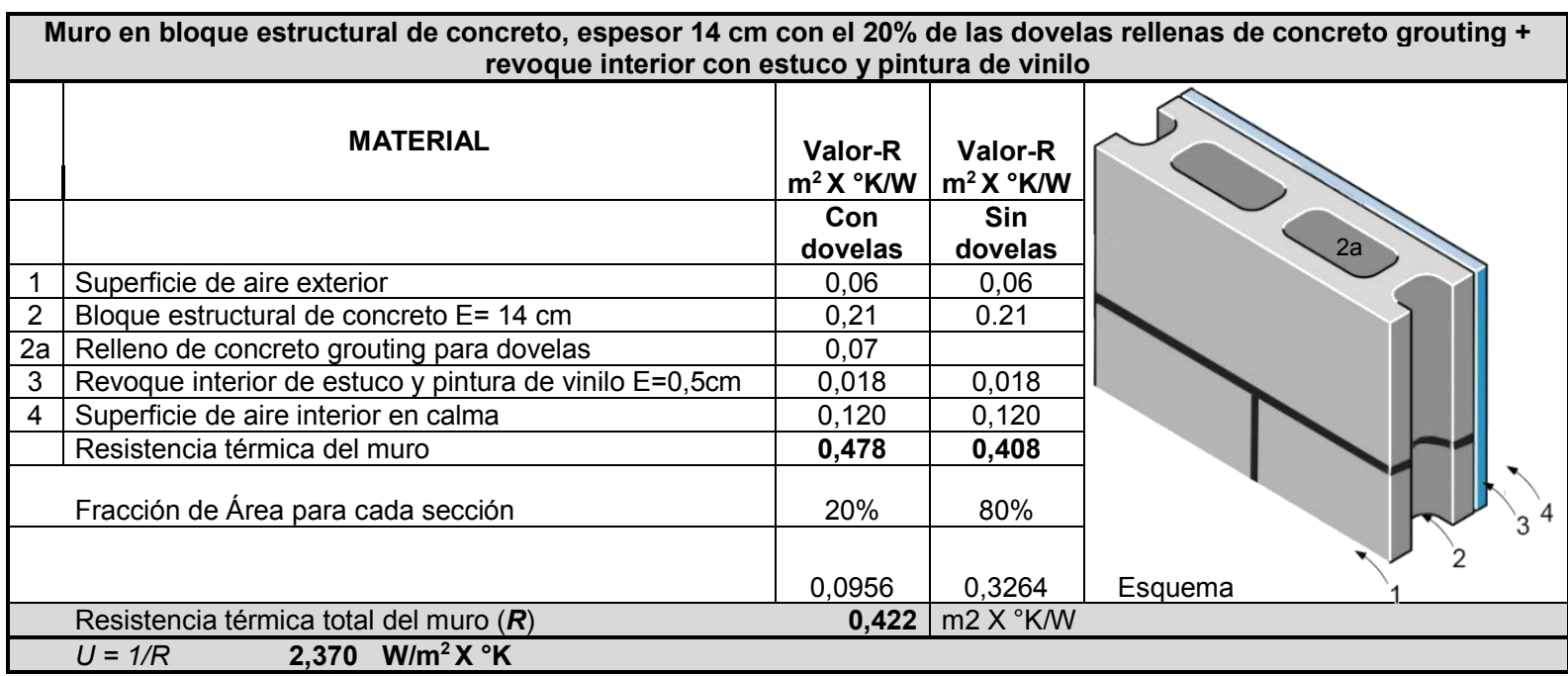

Tabla 14. Cálculo del valor U para un muro de concreto macizo típico de los sistemas de mampostería estructural de VIS de Cali. Fuente: Elaboración propia.

\subsubsection{Cuantificación teórica de la Tr de las envolventes típicas de la VIS en el caso crítico}

Este análisis permitió conocer cuán lejos se encuentran las $T_{r}$ de las envolventes VIS orientadas hacia el Oeste del rango máximo de confort $\left(29,5^{\circ} \mathrm{C}\right)$. Asimismo, sirvió como línea base teórica para proyectar soluciones constructivas y comparar su desempeño en la fase experimental. El cálculo se llevó a cabo solamente en el caso crítico de la fachada Oeste con las dos tipologías de envolventes analizadas en el punto anterior. Cabe aclarar que este método también es descrito por Cengel (2003) y la ASHRAE (2001).

En primer lugar, se calculó la Temperatura Sol-Aire ( $\left.T_{\text {sol-air }}\right)$, es decir la temperatura que posee la cara exterior del muro bajo las condiciones climáticas críticas seleccionadas en el título 0 anteriormente. La fórmula utilizada es:

$$
T_{\text {sol-air }}=T_{\text {amb }}+\frac{\alpha \mathrm{s} * q_{\text {solar }}}{h_{0}}-\frac{\varepsilon * \sigma *\left(\left(T_{\text {amb }+273}\right)^{4}-\left(T_{\text {surr }+273}\right)^{4}\right)}{h_{0}}
$$

Donde:

$T_{a m b}$ es la temperatura exterior del aire en el caso crítico en ${ }^{\circ} \mathrm{C}$.

$\alpha_{\text {s }}$ es la absortividad de la superficie en $\%$.

$q_{\text {solar }}$ es la radiación solar incidente sobre la superficie en el caso crítico en $\mathrm{W}$.

$\varepsilon$ es la emisividad de la superficie en $\%$.

$h_{0}$ es el coeficiente combinado de radiación y convección

$T_{\text {surr }}$ es la temperatura de los alrededores en ${ }^{\circ} \mathrm{C}$

Nótese bien que en esta ecuación la absortividad $\alpha_{\mathrm{s}}$ es multiplicador de la carga solar, con lo cual es muy importante tener valores bajos para ganar la menor carga térmica. Por el 
contrario, la $\alpha_{\mathrm{s}}$ típica de las envolventes VIS, fabricadas con bloques de arcilla cocida o concreto presentan valores de 0,70 , es decir que el $70 \%$ de la carga solar es absorbida por la envolvente. De esta forma, este análisis numérico devela una de las estrategias básicas para reducir la $T_{r}$ : mantener una absortividad baja o lo que es igual una reflectividad alta.

En el procedimiento para hallar $\mathrm{T}_{\text {sol-air }}$ se asignaron los siguientes valores señalados en la Tabla 15.

\begin{tabular}{|l|c|l|}
\hline VARIABLE & VALOR & \multicolumn{1}{c|}{ FUENTE } \\
\hline$T_{\text {amb }}$ & $32^{\circ} \mathrm{C}$ & $\begin{array}{l}\text { Pico de } T_{\text {air }} \text { en el mes de marzo de la base de datos climática de Cali de la } \\
\text { estación meteorológica de Univalle }\end{array}$ \\
\hline $\boldsymbol{\alpha}_{\mathrm{S}}$ & 0,70 & Tomado de Incropera (Incropera, Dewitt, Bergman, \& Lavine, 2007) \\
\hline qsolar & $741 \mathrm{~W} / \mathrm{m}^{2}$ & $\begin{array}{l}\text { Incidencia solar pico en la fachada oeste, hallada el 21 de marzo a las } \\
16: 00 \text { mediante Ecotect cargado con la base de datos climática de Cali de } \\
\text { la estación meteorológica de Univalle. }\end{array}$ \\
\hline $\boldsymbol{\varepsilon}$ & 0,90 & Tomado de ASHRAE (2013) \\
\hline $\mathrm{h}_{\mathrm{o}}$ & 17 & Cengel (2003) \\
\hline Tsurr & $32^{\circ} \mathrm{C}$ & $\begin{array}{l}\text { Promedio de Tr entre zonas de césped y zonas duras alrededor de la } \\
\text { edificación, tomado de las termografías de Gamboa, Rosillo, Herrera } \\
\text { Cáceres, López Bernal \& Iglesias (2011) }\end{array}$ \\
\hline
\end{tabular}

Tabla 15. Valores asignados para cálculo de $\mathrm{T}_{\text {sol-air. }}$ Fuente: Elaboración propia.

Reemplazando los valores consignados en la Tabla 15 en la fórmula de $T_{\text {sol-air, }}$ se obtuvo un resultado de $63^{\circ} \mathrm{C}$, lo cual es superior en $13^{\circ} \mathrm{C}$ a los valores mostrados por Gamboa et al Op. cit., en las termografías de envolventes VIS orientadas al Oeste.

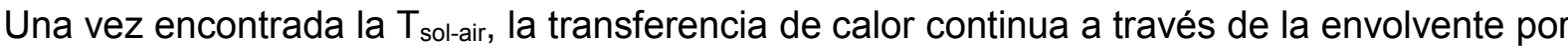
conducción, para esto se halló la carga térmica mediante la siguiente ecuación de transferencia de calor en estado estacionario:

$$
Q=U A(T i-T o)
$$

Donde:

$Q$ es la carga térmica o flujo de calor en $W$

$U$ es el coeficiente de transferencia de calor general del muro en $W / \mathrm{m}^{2 \circ} \mathrm{K}$ o el inverso de la $\mathrm{R}$ en $\mathrm{m}^{2 \circ} \mathrm{K}$ W.

$A$ es el área en $\mathrm{m}^{2}$

$T_{\mathrm{i}}$ y $T_{\mathrm{o}}$ son la temperatura interior y exterior en ${ }^{\circ} \mathrm{C}$ respectivamente, en este caso $\mathrm{T}_{\mathrm{o}}$ será reemplazada por la Temperatura Sol Aire $\left(T_{\text {sol-air }}\right)$ en el caso crítico y $T_{i}$ será reemplazada por la $T_{r}$ deseada.

Luego, se asignó un valor unitario a $\mathrm{A}\left(1 \mathrm{~m}^{2}\right)$ y $\mathrm{U}$ de $3,731 \mathrm{~W} / \mathrm{m}^{2 \circ} \mathrm{K}$ y $2,370 \mathrm{~W} / \mathrm{m}^{2 \circ} \mathrm{K}$ para sendos casos estudiados, resultando unas cargas térmicas $Q$ de $132,51 \mathrm{~W}$ y $84,15 \mathrm{~W}$ respectivamente. 
Por ende, despejando $T_{r}$ de la fórmula:

$$
Q=\frac{A *(T r-\text { Tdeseada })}{R \text { aire interior }}
$$

tenemos que la $T_{r}$ para el muro de concreto macizo es de $42.9^{\circ} \mathrm{C}$, mientras que para el muro de bloque de concreto es $37,1^{\circ} \mathrm{C}$.

Posteriormente, utilizando como herramienta una hoja de cálculo cargada con las anteriores ecuaciones, se realizaron algunas iteraciones para encontrar el valor $\mathrm{R}$ necesario para que la envolvente VIS alcanzara una $\mathrm{T}_{\mathrm{r}}$ de $28,0^{\circ} \mathrm{C}$ (límite máximo de confort térmico para ASHRAE y $1,5^{\circ} \mathrm{C}$ menor al mencionado por Olgyay, Givoni,).

Para el caso de la pared de concreto macizo es necesario sumar $3,73 \mathrm{~m}^{2 \circ} \mathrm{C} / \mathrm{W}$, mientras que para la opción de bloque hacen falta $3,58 \mathrm{~m} 2^{\circ} \mathrm{C} N$. Este incremento equivaldría a implementar un aislamiento similar a $13 \mathrm{~cm}$ de fibra de vidrio ${ }^{39}$ aproximadamente.

A través de esta hoja de cálculo también se elaboró el comportamiento de $T_{r}$ para cada tipología durante toda la tarde del 15 de enero, actualizando solamente la variable $\mathrm{q}_{\mathrm{solar}}{ }^{40} \mathrm{en}$

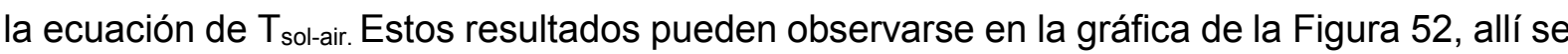
aprecian lo alejadas que se encuentran las $T_{r}$ del rango de confort señalado en la zona

39 Tomado de Cengel (Cengel \& Ghajar, 2015)

${ }^{40}$ Calculada hora a hora con el software Ecotect que sigue el método de cálculo de la radiación solar incidente de Duffie y Beckman (Duffie \& Beckman, 2013)) 
sombreada y se hace evidente que el muro de concreto macizo es la tipología que exige mayor tratamiento para mejorar la $\mathrm{T}_{\mathrm{r}}$.

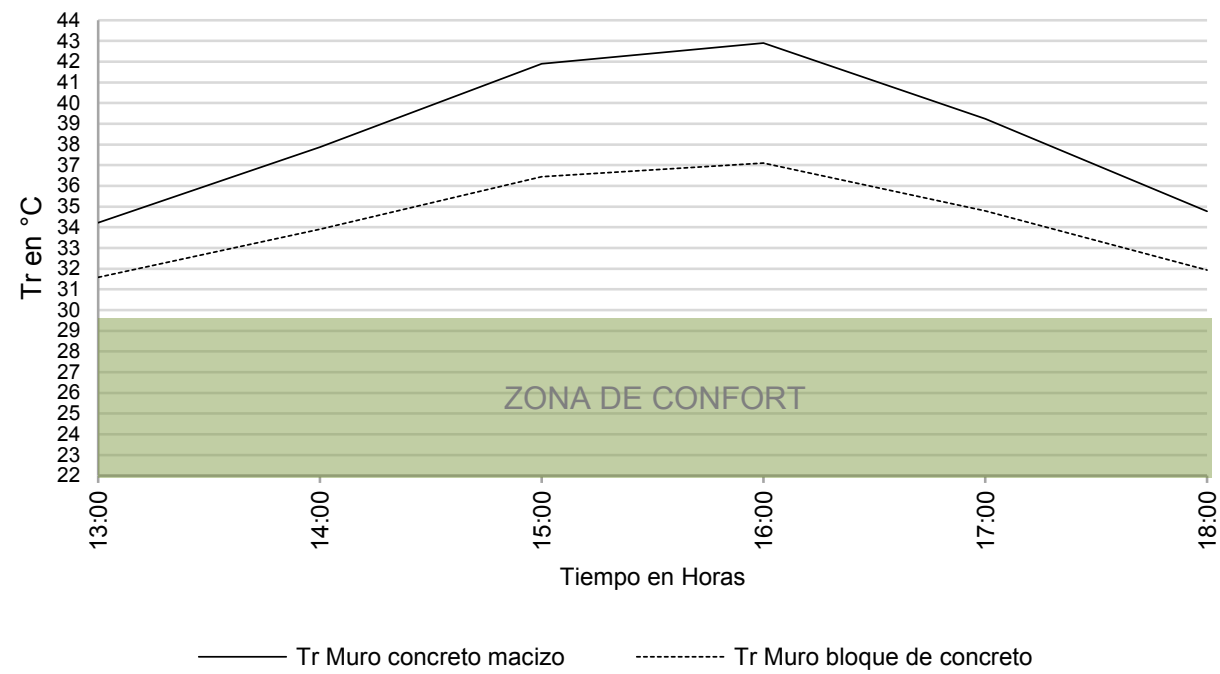

Figura 52. Gráfica comparativa de $T_{r}$ vs Tiempo entre las tipologías más comunes de envolventes VIS durante la tarde del caso crítico. Fuente: Elaboración propia.

\subsection{Definición de modelo VIS con rasgos críticos}

Luego de identificar los anteriores rasgos críticos de confort térmico en la VIS de Cali, se buscó un modelo de vivienda con similares características. La unidad de VIS escogida pertenece al conjunto residencial Calicanto, en el cual también trabajaron Gamboa et al Op. cit., del cual se han expuesto fotografías y termografías exteriores de su envolvente en el capítulo introductorio.

El conjunto residencial fue construido entre 2006 y 2007, se encuentra ubicado entre las Calles 42 y 45 y las Carreras 95 A y 96 A, en la periferia del sur de la ciudad en una zona destinada al desarrollo de proyectos VIS. La imagen la Figura 53, tomada de Google Maps indica gráficamente su localización en la ciudad. 


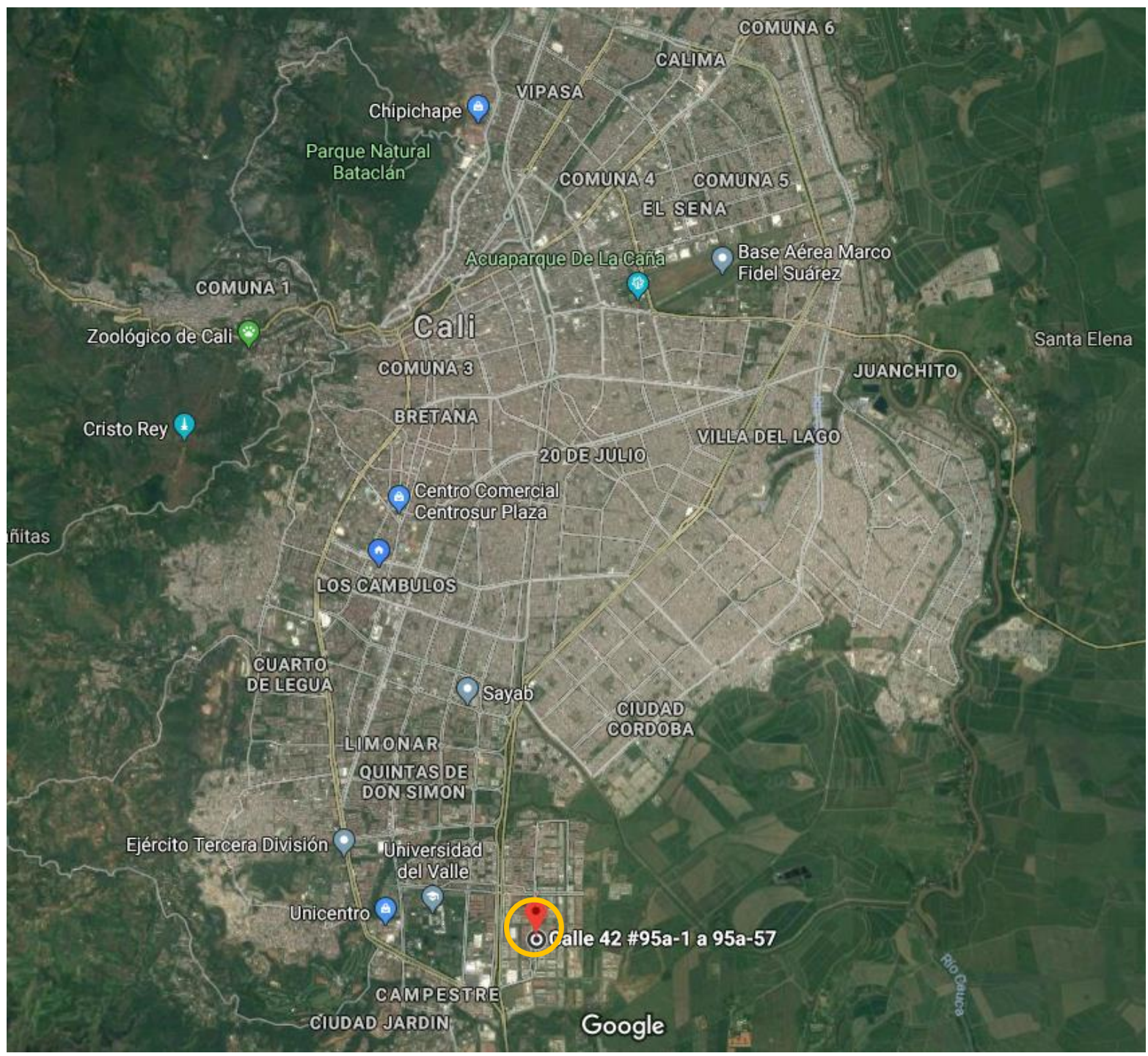

Figura 53. Localización conjunto residencial Calicanto. Fuente: Google Earth.

Como se observa en la fotografía de la Figura 54 , este conjunto hace parte de la tipología multifamiliar y está conformado por bloques de apartamentos de cinco niveles. El apartamento escogido como línea base se encuentra señalado también en la Figura 54 con una línea discontinua de color negro, se localiza en el cuarto piso y posee fachadas orientadas hacia el Oeste y Sur, con lo cual recibe radiación solar todo el año por su fachada Oeste y de septiembre 21 a marzo 21 en su fachada Sur. 
El sistema constructivo de estos bloques es de mampostería reforzada y su envolvente está constituida por bloques estructurales de arcilla cocida revocados y pintados solamente en el interior.

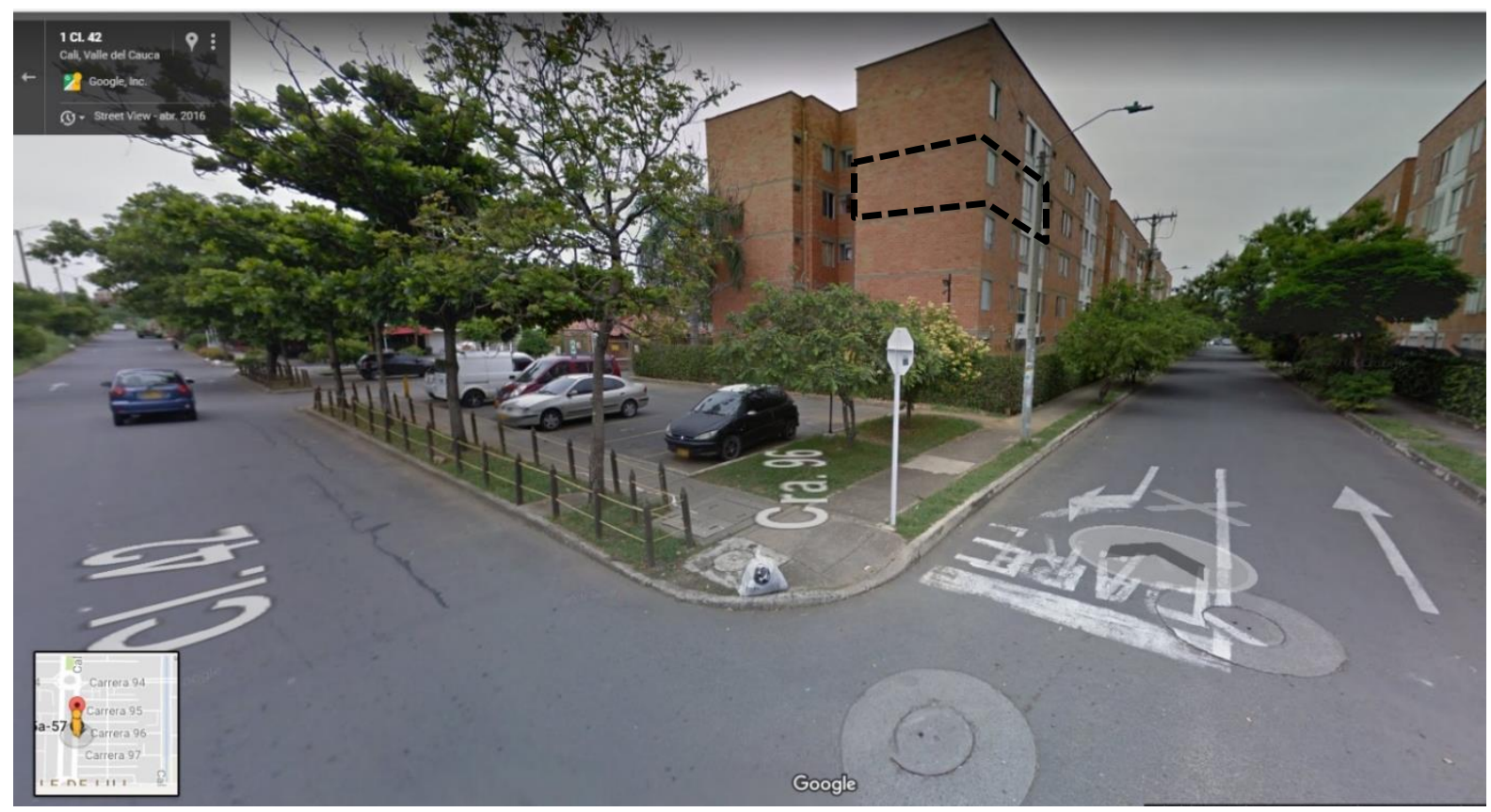

Figura 54. Fachada oeste del conjunto residencial Calicanto. Tomada de Google Earth.

La distribución arquitectónica de este apartamento que tiene $56 \mathrm{~m}^{2}$, se muestra a continuación en la Figura 55, consta de sala-comedor, cocina, zona de oficios, dos alcobas, dos baños y un estudio.

En entrevistas con los usuarios, estos mencionaron que en general el apartamento es caluroso, pero hacen hincapié en que esta sensación es más intensa en la alcoba principal desde el mediodía hasta el anochecer, lo cual es bastante lógico debido a que este ambiente, (como se ve también en el plano de la Figura 55), posee precisamente fachadas hacia el Oeste (que como se vio párrafos atrás es la fachada crítica) y el Sur. Este espacio fue escogido para realizar un monitoreo valorativo de confort térmico mediante el método de Fanger. 


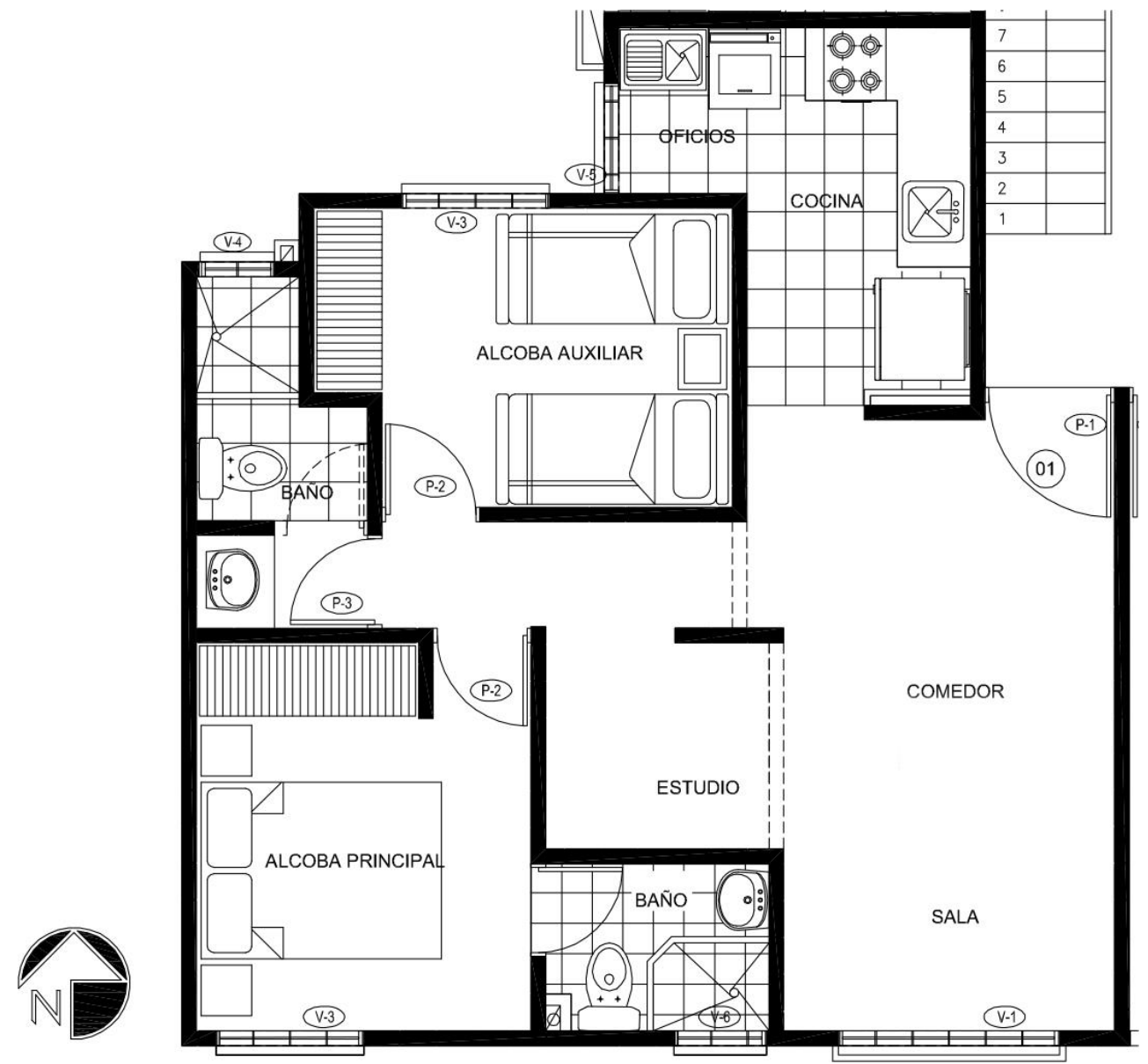

Figura 55. Distribución arquitectónica del apartamento establecido como línea base. Fuente: Elaboración propia.

\subsection{Monitoreo de confort térmico a Modelo VIS}

\subsubsection{Periodo de monitoreo}

El monitoreo se realizó durante la primera semana del 2016 del 2 al 8 de enero.

\subsubsection{Normas de medición}

ISO 7726-2002 que estipula los términos, protocolos e instrumentos (International Organization for Standardization, 2002).

\subsubsection{Instrumental}

El instrumental utilizado para el monitoreo de las distintas variables se relaciona a continuación en la Tabla 16, una descripción más amplia de estos puede consultarse en el Apéndice 3. 


\begin{tabular}{|c|c|c|}
\hline INSTRUMENTO & VARIABLE & DESCRIPCIÓN \\
\hline $\begin{array}{lr}\text { Termohigrómetro } & \text { digital } \\
\text { Datalogger marca } & \text { Extech } \\
\text { (modelo RHT30) } & \\
\end{array}$ & $\begin{array}{l}\text { - Temperatura del aire. } \\
\text { - Humedad relativa. }\end{array}$ & Consultar Apéndice del 3, título 3.2. \\
\hline $\begin{array}{ll}\text { Termómetro infrarrojo } & \text { marca } \\
\text { Extech modelo IR } 42500 & \end{array}$ & $\begin{array}{l}\text { - Temperatura superficial } \\
\text { temperatura radiante }(\mathrm{Tr}) .\end{array}$ & Consultar Apéndice 3, título 3.5 . \\
\hline $\begin{array}{l}\text { Termoanemómetro digital de hilo } \\
\text { caliente marca CEM (Modelo } \\
\text { DT-8880) }\end{array}$ & - Velocidad del aire. & Consultar Apéndice 3, título 3.4. \\
\hline
\end{tabular}

Tabla 16. Instrumental utilizado en el monitoreo al ambiente VIS. Fuente: Elaboración propia.

\subsubsection{Protocolo de medición}

Un termohigrómetro digital con almacenamiento de datos o Datalogger, registró cada hora los valores de $T_{\text {air }}$ y HR en la zona central de esta habitación a una altura de 1,4 $\mathrm{m}$.

Para calcular el valor de $T_{\mathrm{mr}}$ se registraron las temperaturas superficiales de los 6 planos que conforman la habitación con el termómetro infrarrojo cada hora y posteriormente se promediaron.

Por último, los valores de $\mathrm{V}_{\text {air }}$ fueron promedios de las mediciones registradas en sitio con el anemómetro de hilo caliente.

\subsubsection{Determinación de índices PMV y PPD}

El cálculo de PMV y PPD se produjo con el software PMV Calc v2 de la Universidad de Gävle (Department of Technology and Built Environment - Laboratory of Ventilation and Air Quality University of Gävle). Sin embargo, en este cálculo, también fueron requeridas las variables Clo y Met. Para determinar estos valores se utilizaron perfiles adaptativos dinámicos acordes al ASHRAE (2017). En cuanto al Clo se utilizó 0,6 para las horas diurnas y 1,2 para las nocturnas, mientras que en el Met se usó 1,2 para las horas diurnas y 0,8 para las nocturnas. 


\subsection{Resultados}

La siguiente Tabla 17 resume los valores horarios promedio de $T_{\text {air, }} T_{m r}, V_{\text {air, }} H R$, Met y Clo, con los que se elaboraron los índices PMV y PPD, además estos dos últimos también se adjuntan también al final de la tabla.

\begin{tabular}{|c|c|c|c|c|c|c|c|c|c|}
\hline FECHA & HORA & $\mathbf{T}_{\text {air }}$ & $\mathrm{T}_{\mathrm{mr}}$ & $V_{\text {air }}$ & HR & Met & Clo & PMV & PPD \\
\hline Ene 02 -Ene 08 & 0:00:00 & 24,70 & 27,00 & 0,05 & 71,01 & 0,8 & 1,2 & 0,40 & 8,30 \\
\hline Ene 02 -Ene 08 & 1:00:00 & 23,86 & 26,6 & 0,05 & 72,18 & 0,8 & 1,2 & 0,2 & 5,80 \\
\hline Ene 02 -Ene 08 & 2:00:00 & 23,47 & 25,9 & 0,05 & 73,40 & 0,8 & 1,2 & 0,1 & 5,20 \\
\hline Ene 02 -Ene 08 & 3:00:00 & 23,06 & 25,50 & 0,05 & 74,25 & 0,8 & 1,2 & $-0,10$ & 5,20 \\
\hline Ene 02 -Ene 08 & 4:00:00 & 22,30 & 24,94 & 0,05 & 75,44 & 0,8 & 1,2 & $-0,30$ & 6,90 \\
\hline Ene 02 -Ene 08 & 5:00:00 & 22,43 & 24,57 & 0,05 & 76,57 & 0,8 & 1,2 & $-0,30$ & 6,90 \\
\hline Ene 02 -Ene 08 & 6:00:00 & 22,52 & 25,19 & 0,05 & 76,28 & 0,8 & 1,2 & $-0,20$ & 5,80 \\
\hline Ene 02 -Ene 08 & 7:00:00 & 23,75 & 26,90 & 0,05 & 72,30 & 0,8 & 1,2 & 0,20 & 5,80 \\
\hline Ene 02 -Ene 08 & 8:00:00 & 25,20 & 28,55 & 0,10 & 68,00 & 1,2 & 0,6 & 0,90 & 22,10 \\
\hline Ene 02 -Ene 08 & 9:00:00 & 27,15 & 29,70 & 0,10 & 60,66 & 1,2 & 0,6 & 1,30 & 40,30 \\
\hline Ene 02 -Ene 08 & $10: 00: 00$ & 28,50 & 30,75 & 0,10 & 54,12 & 1,2 & 0,6 & 1,60 & 56,30 \\
\hline Ene 02 -Ene 08 & $11: 00: 00$ & 29,75 & 31,69 & 0,10 & 51,03 & 1,2 & 0,6 & 1,90 & 72,10 \\
\hline Ene 02 -Ene 08 & $12: 00: 00$ & 30,70 & 32,40 & 0,20 & 48,20 & 1,2 & 0,6 & 2,00 & 76,80 \\
\hline Ene 02 -Ene 08 & 13:00:00 & 31,50 & 33,40 & 0,20 & 47,60 & 1,2 & 0,6 & 2,30 & 88,30 \\
\hline Ene 02 -Ene 08 & $14: 00: 00$ & 32,02 & 34,40 & 0,20 & 48,25 & 1,2 & 0,6 & 2,50 & 93,40 \\
\hline Ene 02 -Ene 08 & $15: 00: 00$ & 31,80 & 34,60 & 0,20 & 48,40 & 1,2 & 0,6 & 2,50 & 93,40 \\
\hline Ene 02 -Ene 08 & $16: 00: 00$ & 31,32 & 34,20 & 0,20 & 49,00 & 1,2 & 0,6 & 2,40 & 91,10 \\
\hline Ene 02 -Ene 08 & $17: 00: 00$ & 29,83 & 32,70 & 0,20 & 52,20 & 1,2 & 0,6 & 1,90 & 72,10 \\
\hline Ene 02 -Ene 08 & 18:00:00 & 28,30 & 30,00 & 0,20 & 57,90 & 1,2 & 0,6 & 1,30 & 40,30 \\
\hline Ene 02 -Ene 08 & 19:00:00 & 27,50 & 29,10 & 0,20 & 61,60 & 1,2 & 0,6 & 1,10 & 30,50 \\
\hline Ene 02 -Ene 08 & 20:00:00 & 27,40 & 29,00 & 0,10 & 63,64 & 1,2 & 0,6 & 1,30 & 40,30 \\
\hline Ene 02 -Ene 08 & 21:00:00 & 26,94 & 28,30 & 0,10 & 64,80 & 1,2 & 0,6 & 1,10 & 30,50 \\
\hline Ene 02 -Ene 08 & $22: 00: 00$ & 26,17 & 27,80 & 0,10 & 66,90 & 0,8 & 1,2 & 0,70 & 15,30 \\
\hline Ene 02 -Ene 08 & 23:00:00 & 25,00 & 27,70 & 0,10 & 70,30 & 0,8 & 1,2 & 0,50 & 10,20 \\
\hline
\end{tabular}

Tabla 17. Resultados medios horarios de las mediciones de campo en la alcoba elegida como línea base. Fuente: Elaboración propia.

Nótese que las mediciones de campo de $T_{\text {air }}$ y $T_{m r}$ entre las 13:00 y 15:00 horas, son cercanas a las obtenidas teóricamente en el título anterior. La $\mathrm{T}_{\text {air }}$ tomada del archivo climático fue de $32^{\circ} \mathrm{C}$, la cual fue también el promedio de las temperaturas medidas en campo a las 14:00 horas. 
Por su parte la $\mathrm{T}_{\mathrm{r}}$ entre $42,9^{\circ} \mathrm{C}$ y $37,1^{\circ} \mathrm{C}$ que se calculó teóricamente en el ejercicio anterior del título 4.2.4 de la página 115; resultó ser más baja que la de campo, puesto que en el dormitorio se recogieron mediciones de hasta $47,27^{\circ} \mathrm{C}$ como se muestra en la gráfica de la Figura 56 (cuarto día de medición a las 16:00 horas). Además, en ella también se nota que la $T_{r}$ de este muro Oeste se aleja de la zona de confort desde la mitad de la mañana hasta el fin de la tarde con valores que llegan hasta $16^{\circ} \mathrm{C}$

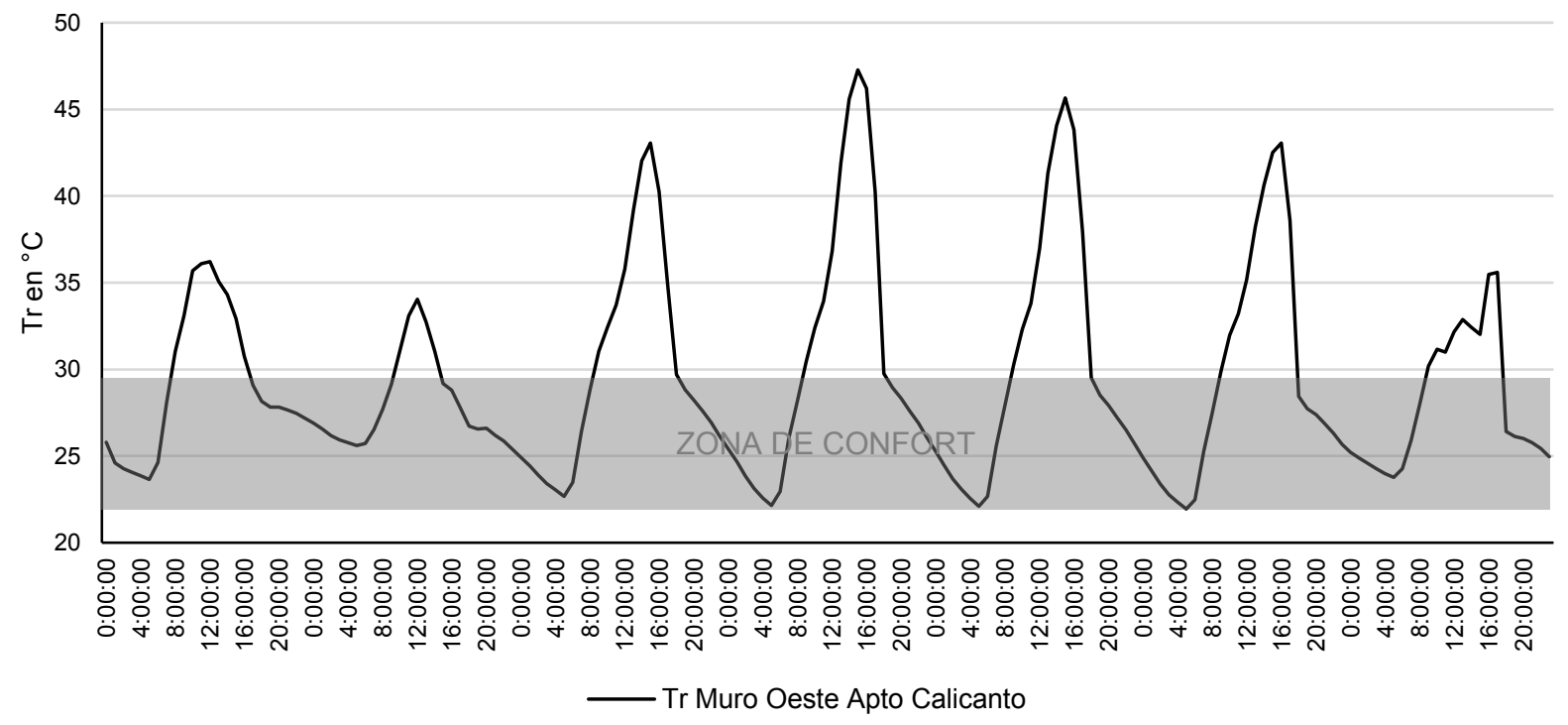

Figura 56. Gráfica de $T_{r}$ vs tiempo de la fachada oeste, durante el monitoreo de campo en la habitación modelo. Fuente: Elaboración propia.

Finalmente, para visualizar de manera gráfica el confort térmico de esta habitación se elaboraron las siguientes gráficas de la Figura 57 y Figura 58.

En la gráfica de la Figura 57, se puede leer el PMV, o sea, la sensación térmica presentada dentro de la habitación, esta solamente logra neutralidad en la madrugada, mientras que, desde las 9:00 hasta las 21:00 horas se sobrepasa el límite de lo "ligeramente caluroso", permaneciendo entre las sensaciones "calurosas" y "muy calurosas". Es notorio que entre las 13:00 hasta las 17:00 se alcanzan las mayores temperaturas con sensaciones "muy calurosas" durante este periodo. 


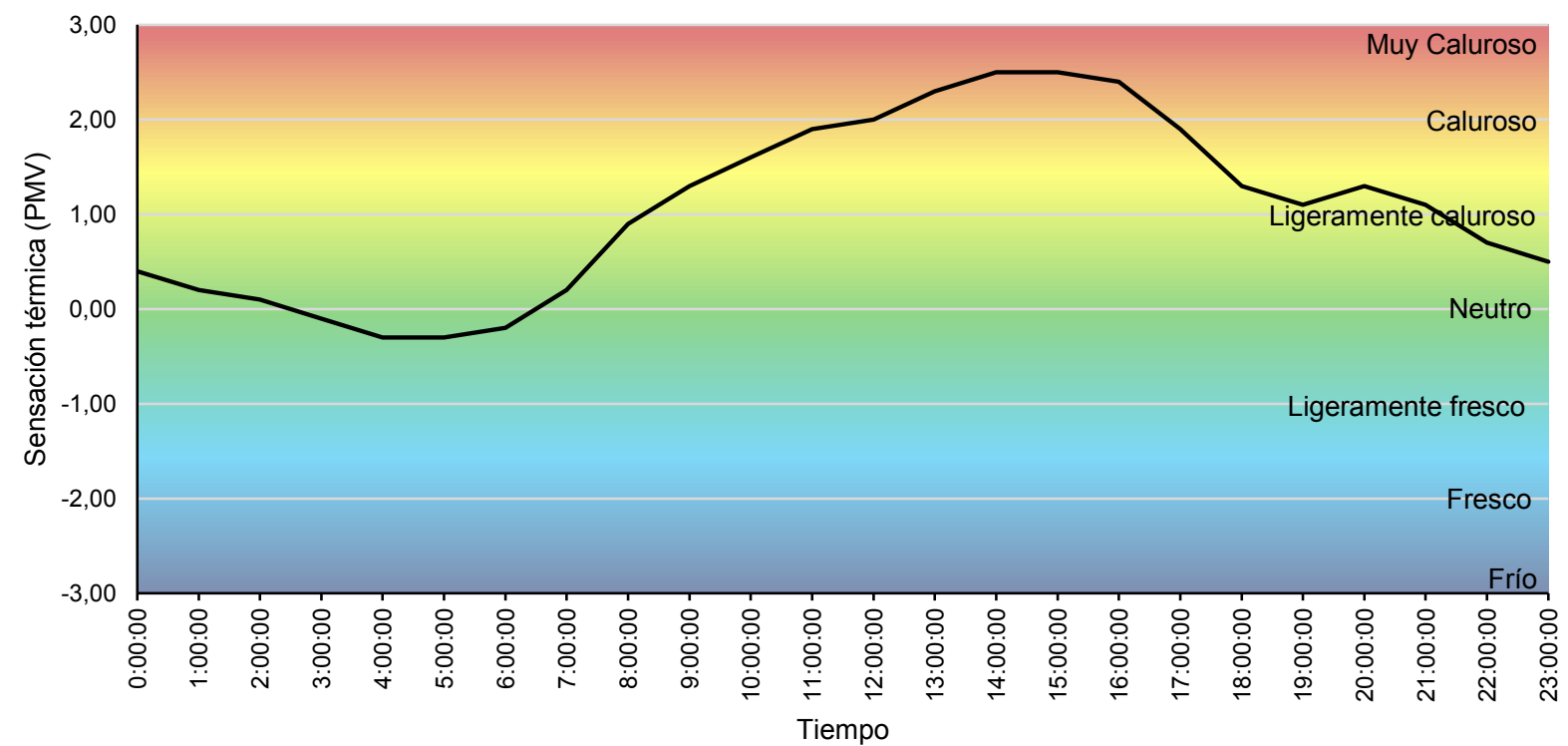

Figura 57. Gráfica de PMV (índice de sensación térmica) en la alcoba seleccionada como línea base. Fuente: Elaboración propia.

Complementariamente, la Figura 58 muestra el porcentaje de personas insatisfechas o PPD, donde puede verse que, en 14 de las 24 horas del día, este espacio permanece por fuera del rango aceptable de confort térmico marcado en el $20 \%$, llegando a cifras de insatisfechos hasta del $93,4 \%$ en las horas posteriores al mediodía.

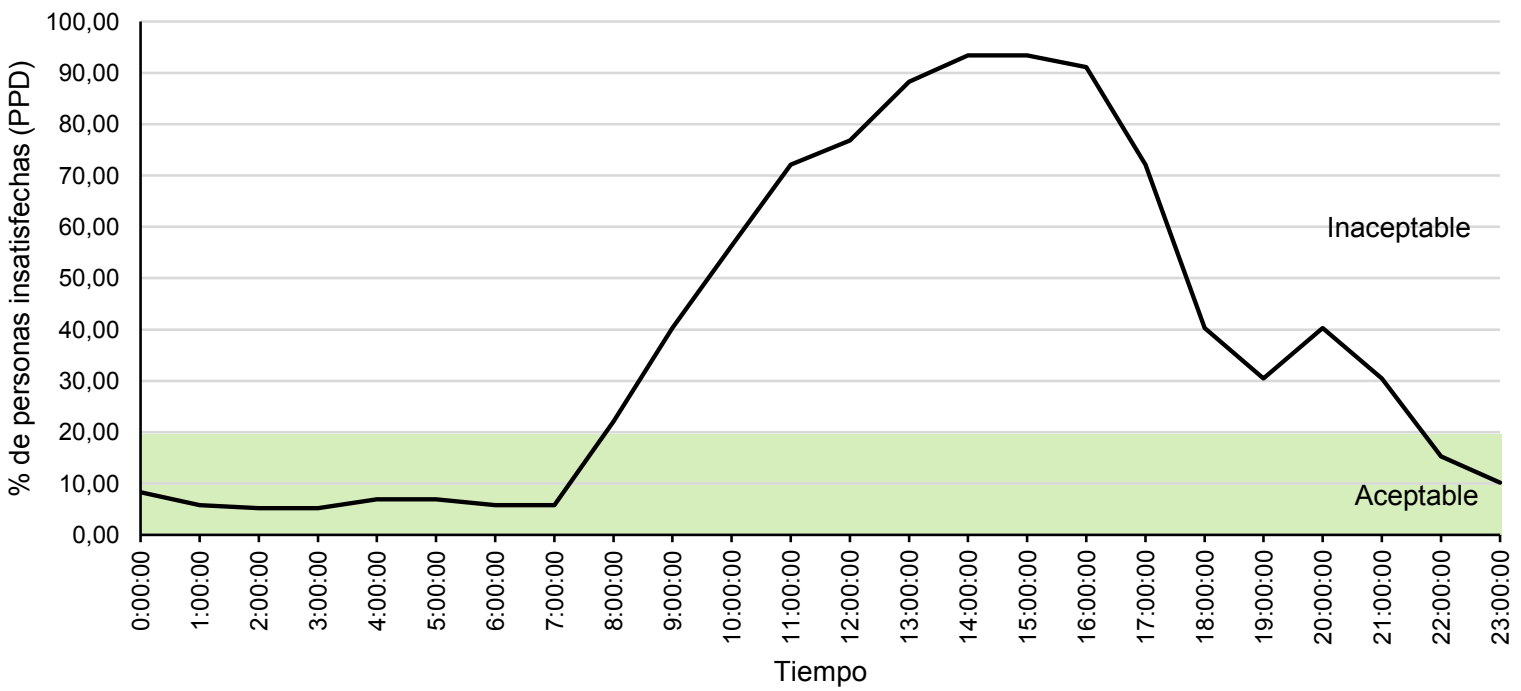

Figura 58. Gráfica de PPD (Porcentaje de personas insatisfechas) en la alcoba seleccionada como línea base. Fuente: Elaboración propia. 


\subsection{Conclusiones}

- En general, el análisis numérico hecho en el numeral 4.2 logró identificar los rasgos críticos de condiciones climáticas, orientación y materialidad con los cuales se encontró un modelo VIS que presentara condiciones de insatisfacción térmica.

- Con lo hecho en el numeral 4.2.4 se identificó que, entre los sistemas constructivos más comunes en la VIS de Cali, la envolvente de muro macizo de concreto (espesor $10 \mathrm{~cm}$ ), presenta el más bajo desempeño térmico, pues con su valor $U$ de $3,73 \mathrm{~W} / \mathrm{m}^{2}{ }^{\circ} \mathrm{K}$ la $T_{r}$ alcanzó teóricamente los $42,9^{\circ} \mathrm{C}$. Esta tipología de envolvente fue señalada como caso crítico y constituye un punto de partida para modelizar las soluciones constructivas.

- Mediante los cálculos del título 4.2.4, se obtuvo que para llevar la $T_{r}$ de la envolvente VIS con más bajo desempeño térmico a un nivel aceptable debería adicionarse 3,73 $\mathrm{m}^{2 \circ} \mathrm{K} / \mathrm{W}$, si solo se utiliza la estrategia de aumentar la resistencia térmica. Sin embargo, también se conoció que existe gran posibilidad de optimizar el desempeño térmico mediante la reducción de la absortividad y la emisividad, pues esta envolvente presenta valores altos de ambos parámetros: 0,7 y 0,9 respectivamente.

- De acuerdo con los resultados mostrados en la Figura 57 y Figura 58 que resumen el PMV y el PPD del ambiente VIS monitoreado, se demuestra que el nivel de aislamiento que poseen las envolventes más comunes de la VIS de Cali es insuficiente para proveer confort térmico. Según los cálculos realizados en el numeral 4.2.3, las envolventes VIS más comunes como los muros macizos o la mampostería estructural de concreto poseen valores: $\mathrm{R}$ de $0,42 \mathrm{~m}^{20} \mathrm{~K} / \mathrm{W}$ (como máximo), absortividad de 0,7 y emisividad 0,9. Con estas condiciones como se indica en la gráfica de la Figura 56, la $T_{r}$ sobrepasa los límites máximos de la zona de confort en la fachada Oeste de esta habitación, llegándose a presentar valores medidos de hasta $47,27^{\circ} \mathrm{C}$, lo cual hace que en el ambiente interior se presente un alto nivel de inconformidad térmica.

- El monitoreo a este dormitorio resumido en la Tabla 17 y las gráficas de la Figura 57 y Figura 58, muestran lo inconfortable que resulta la permanencia en estas viviendas y refuerza lo señalado por Gamboa et al, Giraldo \& Herrera, Barona e Iturre en el título 2.8, pues se encontró que la sensación térmica experimentada en este ambiente desde las 12:00 hasta las 17:00 horas oscila entre lo "caluroso" y "muy caluroso", con lo cual se alcanzan porcentajes de insatisfacción de hasta 93,4\%; y durante 14 de las 24 horas del día esta insatisfacción supera el $20 \%$ de los ocupantes. Con esto, se establece esta habitación como línea base con la cual pueden realizarse las simulaciones computacionales y realizar comparaciones más adelante. 


\section{MODELIZADO DE SOLUCIONES CONSTRUCTIVAS}

\subsection{Introducción}

Teniendo en cuenta los altos valores de $T_{r}$ y los bajos niveles de confort térmico encontrados en el modelo VIS de la etapa anterior, este capítulo se dedica al desarrollo y evaluación teórica de varios modelos constructivos, para solucionar estos problemas.

La metodología para diseñar estas soluciones parte de la integración creativa de los conocimientos adquiridos en el estado del arte. Como premisa en el aspecto térmico se buscó consolidar los tres tipos de estrategias de enfriamiento pasivo: de prevención, modulación y disipación del calor, en una solución constructiva. Sin embargo, en el proceso de diseño no solo se contempló el componente térmico, también se consideró que las soluciones constructivas:

- Tuviesen un bajo costo, el cual se fue analizando simultáneamente en hojas de cálculo que se muestran en el Apéndice 4.

- Pudiesen ser utilizadas tanto en VIS nuevas como construidas.

- No requieran intervenciones técnico-constructivas drásticas, con lo cual se privilegian aquellas que aporten poco peso y tengan mínimo espesor posible.

Cabe resaltar que, lograr buen desempeño térmico con poco peso y poco espesor no solamente es altamente valorado en el estado del arte debido a que las soluciones con estas características suelen tener menos impactos ambientales (Juanicó \& González, 2017), sino que también es muy importante por el aspecto económico, pues una solución pesada requerirá una estructura propia o un mejoramiento estructural de la infraestructura existente, mientras que soluciones livianas y de poco espesor como enlucidos o paneles livianos pueden aplicarse o sujetarse con estructuras menores. 
Además, se trató de incluir la mayor variedad de estrategias priorizando las menos documentadas en el estado del arte. El proceso se inició estimativamente con los modelos más sencillos y menos costosos hasta los más complejos.

A continuación, se explica cada modelo, las estrategias de enfriamiento pasivo incluidas en ellos y las razones teóricas por las cuales son útiles en la reducción de la $\mathrm{T}_{\mathrm{r}}$. Cada alternativa tiene un cálculo teórico de desempeño realizado con el mismo método propuesto por Cengel y ASHRAE utilizado en el capítulo anterior. El desempeño térmico de cada solución se contrasta con los niveles óptimos de $\mathrm{T}_{\mathrm{r}}\left(22^{\circ} \mathrm{C}-29,5^{\circ} \mathrm{C}\right)$ y con la $\mathrm{T}_{\mathrm{r}}$ calculada previamente para las envolventes típicas (Max: $42,9^{\circ} \mathrm{C}$ )

Los resultados de esta son cinco alternativas constructivas con su expectativa teórica de desempeño durante el caso crítico, evidentemente, este es un paso preparatorio que será continuado en las siguientes dos etapas experimentales. Las soluciones constructivas propuestas y analizadas fueron las siguientes: 


\subsection{Autosombreado (AS)}

En esta solución constructiva se planteó la posibilidad de aplicar la estrategia bioclimática del control solar que se hace a escala mayor mediante elementos verticales y horizontales como aleros o quiebrasoles, pero a pequeña escala, desde los mínimos componentes de la envolvente del edificio. Es decir que, los paneles, ladrillos o bloques sean tratados con texturas en su cara exterior con el objetivo de crear un sombreado automático e independiente en la envolvente.

En adición a la sombra que las texturas generan, es importante mencionar que, al crearse entrantes y salientes en la envolvente del edificio, se incrementa el área de contacto con el aire, lo cual mejora el intercambio de calor por convección, haciendo más eficiente el enfriamiento pasivo del muro.

En el modelo matemático utilizado con anterioridad, esta estrategia está enfocada en la disminución de la variable $q_{\text {solar, }}$ que a su vez hace parte de la ecuación de $\mathrm{T}_{\text {sol-air, }}$ por lo tanto, está orientada a reducir la captación de energía proveniente del sol en los primeros procesos de la transferencia de calor en la envolvente.

En esta ecuación, la variable $q_{\text {solar }}$ será acompañada por un coeficiente adicional al que llamaremos coeficiente de sombra $\mathrm{C}_{\mathrm{s}}$, este coeficiente se basa en el trabajo hecho por Esteves, De Rosa, Basso, Cortegosso, \& Atencio (1988), quienes utilizaron la cuantificación del área directamente asoleada de las fachadas para encontrar su potencial de captación solar. Este coeficiente multiplica el valor de $q_{\text {solar, }}$ haciendo que se tenga en cuenta la reducción de la radiación solar incidente por acción de las sombras que arrojan los elementos de protección solar.

De esta forma el $\mathrm{C}_{\mathrm{s}}$ puede ser escrito de la siguiente manera:

$$
\text { Cs }=\frac{\text { Area asoleada de la superficie }}{\text { Area total de la superficie }}
$$


Diseño de la textura: como nuestra caso de análisis es sobre la fachada oeste, se utilizó un patrón de elementos horizontales ya que es el más eficiente para esta orientación, nótese a modo comparativo en la Figura 59, que en el recorrido solar anual de Cali expresado con líneas de color azul, los elementos horizontales en la máscara de sombras del lado izquierdo producen más cantidad de área sombreada que la lograda por los elementos verticales en la máscara de sombras de la derecha. Este análisis comparativo se realizó mediante el método de la máscara de sombras explicado en el título 1.8, utilizando el software Autodesk Ecotect.
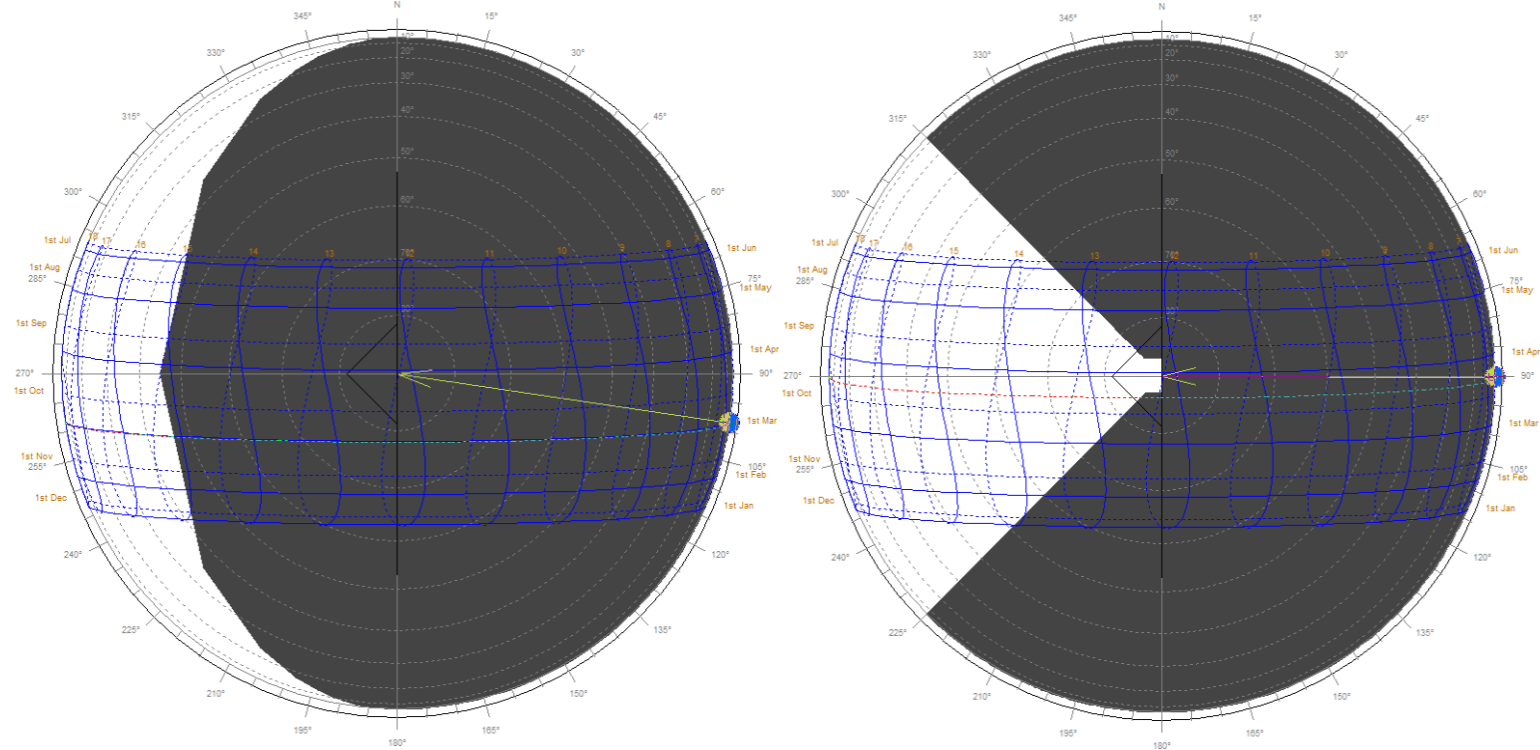

Figura 59. Máscaras de sombra logradas sobre la fachada oeste con elementos horizontales al lado izquierdo y elementos verticales al lado derecho. Fuente: Elaboración propia a partir del software Autodesk Ecotect.

Para diseñar la textura se revisó también la carta solar de la Figura 60, que incluye los valores anuales de radiación solar. En ella se observa que las horas del día que poseen las más altas intensidades de radiación están comprendidas entre las 9:00 y las 15:30 horas y van de 2976

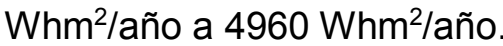

Debido a que es imposible proveer sombra el $100 \%$ del tiempo a esta fachada utilizando elementos horizontales porque la altura solar es muy baja en las últimas horas de la tarde, se consideró meritorio sombrearla durante el periodo de 12:00 a 15:30 cuando la qsolar es mayor.

Desde la perspectiva térmica, entre más profundas sean las lamas, más sombra proveen, pero también es cierto que esto las vuelve más frágiles y difíciles de construir con materiales como el concreto o la arcilla.

En la Figura 60, el analema correspondiente a las 15:30 es resaltado en línea continua gruesa de color negro y mediante el círculo concéntrico en línea discontinua de color negro se halla el ángulo de altura solar a de $40^{\circ}$, que sirvió para proyectar la textura. 


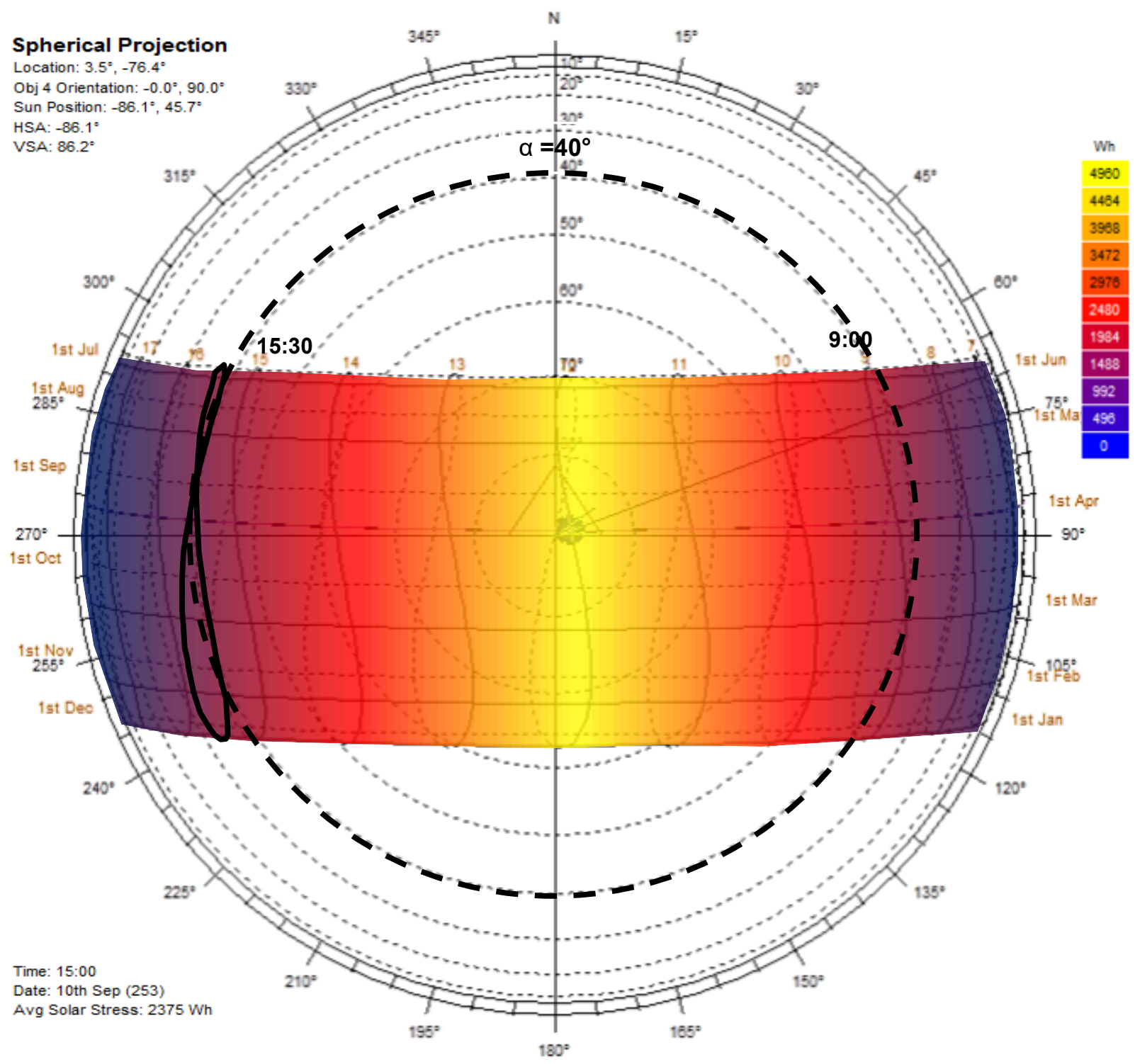

Figura 60. Carta Solar correspondiente a la ciudad de Cali indicando el periodo con mayor radiación solar (9:00 a 15:30 horas). Fuente: Elaboración propia a partir del software Autodesk Ecotect.

El ángulo de altura solar a de $40^{\circ}$, fue trasladado entonces a una vista de sección de la envolvente para calcular las dimensiones de la profundidad de los elementos horizontales. De esta manera se obtuvo que para unas lamas de $1 \mathrm{~cm}$ de espesor, su profundidad debía ser de $3 \mathrm{~cm}$. Este proceso se explica gráficamente en la Figura 61, que contiene una vista en sección del esquema con las dimensiones. 


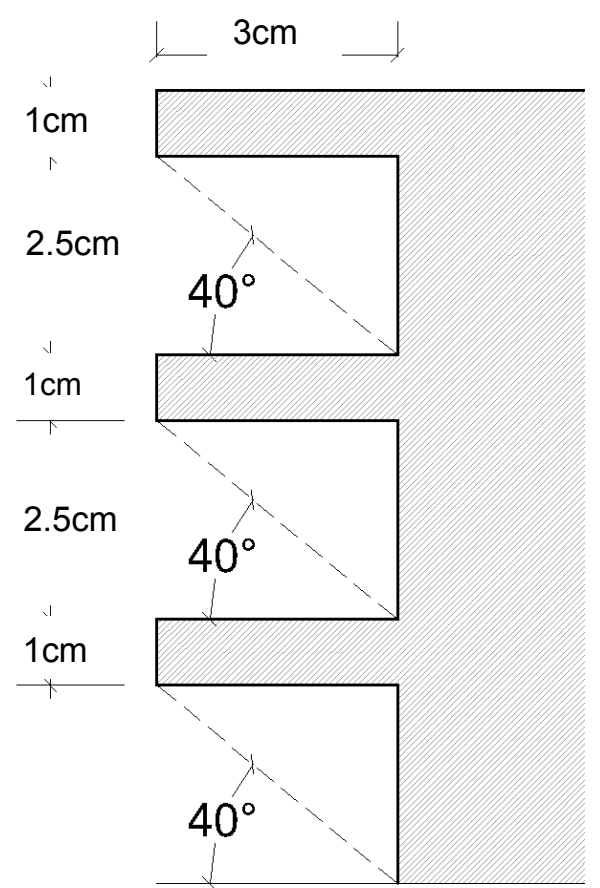

Figura 61. Sección transversal con dimensiones del diseño de lamas horizontales para generar el autosombreado. Fuente: Elaboración propia.

Posteriormente, se realizó el calculó de $\mathrm{C}_{\mathrm{s}}$ desde las 12:30 hasta las 17:30, para lo cual como área superficial total se estableció una unidad $\left(1 \mathrm{~m}^{2}\right)$, mientras que las áreas asoleadas fueron cuantificadas mediante simulaciones de asoleamiento hora a hora a través del software Ecotect. Los resultados que se enseñan en la Figura 62, permitieron esclarecer que en las horas de mayor radiación solar los valores de $C_{s}$ reducirán la qsolar, pero después de las 17:00 ocurrirá lo contrario ya que el valor es superior a 1,0 .

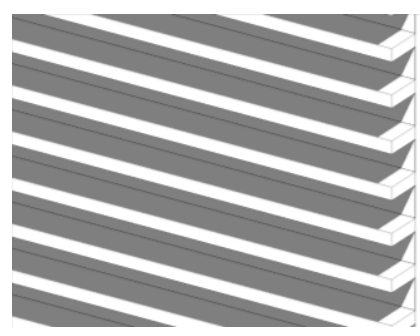

$13: 00-C_{s}=0.29$

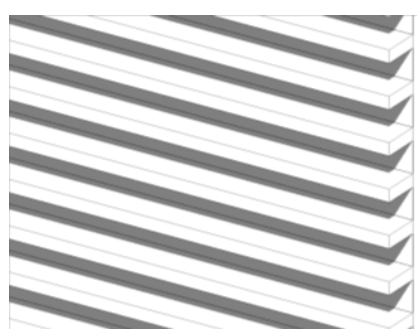

$16: 00-C_{s}=0.92$

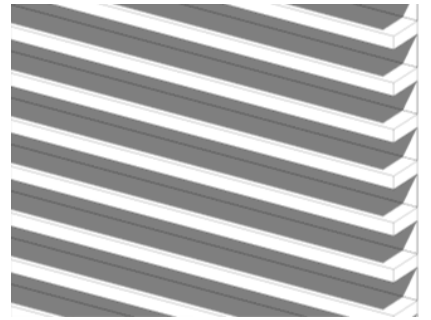

$14: 00-C_{s}=0.5$

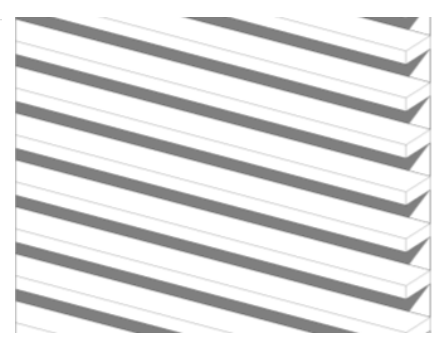

$17: 00-\mathrm{C}_{\mathrm{s}}=1.0$

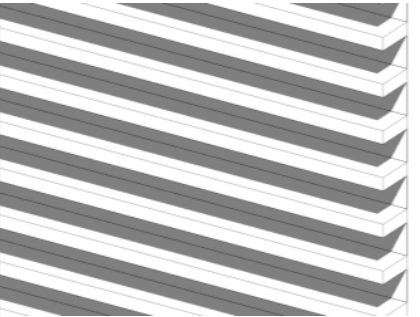

$15: 00-C_{s}=0.71$

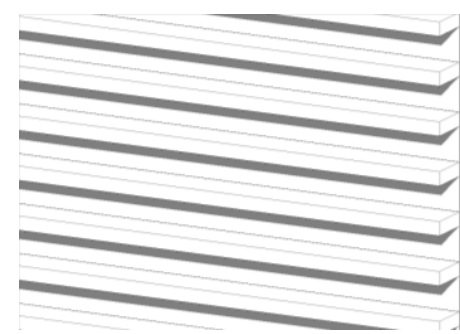

$18: 00-C_{s}=1.47$

Figura 62. Sombreado producido el diseño de las lamas horizontales en la fachada oeste de 12:30 a 17:30, con su respectivo coeficiente de sombra. Fuente: Elaboración propia. 
Después de calcular el $\mathrm{C}_{\mathrm{s}}$, se calculó el valor $\mathrm{U}$ mediante la siguiente Tabla 18.

\begin{tabular}{|c|c|c|c|c|}
\hline \multicolumn{5}{|c|}{$\begin{array}{c}\text { Sombreado con textura de lamas horizontales de } 3 \times 1 \mathrm{~cm} \text { a cada } 2,5 \mathrm{~cm}+\text { muro en concreto macizo E= } 10 \mathrm{~cm}+ \\
\text { revoque interior con estuco y pintura de vinilo }\end{array}$} \\
\hline \multirow{2}{*}{\multicolumn{2}{|c|}{ MATERIAL }} & $\begin{array}{l}\text { Valor-R } \\
\mathbf{m}^{2} \mathbf{X}^{\circ} \mathrm{C} / \mathrm{W}\end{array}$ & $\begin{array}{c}\text { Valor-R } \\
\mathrm{m}^{2} \mathbf{X}^{\circ} \mathbf{C} / \mathbf{W}\end{array}$ & \multirow{10}{*}{ ss } \\
\hline & & $\begin{array}{c}\text { Con } \\
\text { Lama } \\
\text { horizontal }\end{array}$ & $\begin{array}{l}\text { Sin lama } \\
\text { Horizontal }\end{array}$ & \\
\hline 1 & Superficie de aire exterior & 0,06 & 0,06 & \\
\hline 2 & $\begin{array}{l}\text { Lama horizontal de concreto de } 3 \mathrm{~cm} \text { de espesor } \times 1 \mathrm{~cm} \\
\text { de altura }\end{array}$ & 0,02 & & \\
\hline 3 & $\begin{array}{l}\text { Muro en concreto fundido en sitio (sistema outinord o } \\
\text { con-tech) } \mathrm{E}=10 \mathrm{~cm}\end{array}$ & 0,07 & 0,07 & \\
\hline 4 & Revoque interior de estuco y pintura de vinilo $E=0,5 \mathrm{~cm}$ & 0,018 & 0,018 & \\
\hline 5 & Superficie de aire interior en calma & 0,120 & 0,120 & \\
\hline & Resistencia térmica del muro & 0,288 & 0,268 & \\
\hline \multirow{2}{*}{\multicolumn{2}{|c|}{ Fracción de Área para cada sección }} & $30 \%$ & $70 \%$ & \\
\hline & & 0,0864 & 0,1876 & \\
\hline & Resistencia térmica total del muro $(\boldsymbol{R})$ & 0,274 & $\mathrm{~m} 2 \mathrm{X}^{\circ} \mathrm{C} / \mathrm{W}$ & Esquema \\
\hline
\end{tabular}

Tabla 18. Cálculo del valor U para la solución constructiva de autosombreado. Fuente: Elaboración propia.

Teniendo todas las variables necesarias para hallar la $T_{r}$ se inició por multiplicar el valor de $C_{s}$ por el qsolar en cada hora y luego se continuó con el proceso de ecuaciones, así, se obtuvieron los resultados mostrados en la gráfica de la Figura 63. Si se compara el área bajo la curva correspondiente a la $\mathrm{T}_{\mathrm{r}}$ del muro macizo de concreto sombreado y sin sombreado se nota que existe una reducción del $18 \%$ en la $T_{r}$.

Asimismo, si se revisan las reducciones de $T_{r}$ que estas lamas aportaron a lo largo de la tarde, se encuentran disminuciones cercana a los $5^{\circ} \mathrm{C}$ al inicio de la tarde. Por el contrario, al final de la tarde este tratamiento incrementó en $2,6^{\circ} \mathrm{C}$ la $\mathrm{T}_{\mathrm{r}}$.

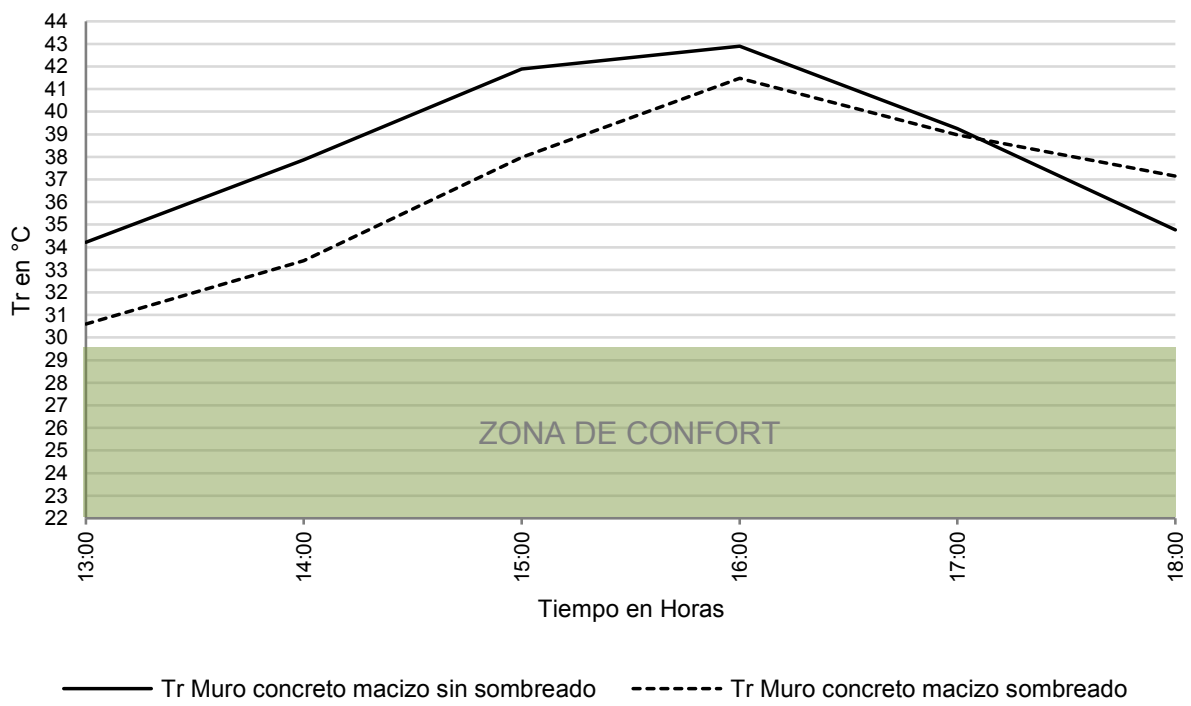

Figura 63. Gráfica comparativa de $T_{r}$ vs Tiempo entre un muro típico de VIS y con tratamiento de sombreado. Fuente: Elaboración propia. 


\subsection{Baja absortividad (BA)}

Se planteó una alternativa de enlucido exterior, enfocada en reducir la ganancia de radiación solar desde la capa más externa de la envolvente. Como se ha visto, esta variable determina en menos de $1 \mathrm{~mm}$ de espesor el porcentaje de energía que el muro absorbe y que posteriormente conduce e irradia al interior, es decir que en el modelo matemático la as actúa disminuyendo la $\mathrm{T}_{\text {sol-air. }}$

Se buscó entonces un enlucido de BA que cumpliera con los requerimientos comunes de un tratamiento externo para fachadas, por ejemplo, que fuese resistente a la intemperie, durable e impermeable. Estos requisitos fueron cumplidos por una pintura disponible en el mercado a base de agua, fabricada con polímeros acrílicos de color blanco y semi mate.

De acuerdo con las tablas encontradas en bibliografía como la desarrollada por Incropera, Dewitt, Bergman, \& Lavine (2007) y ASHRAE (2013), la as de este tipo de recubrimientos está entre un rango de 0,24 a 0,26 ; en contraste el concreto a la vista utilizado en el caso crítico posee un valor de 0,7 .

Al reemplazar el valor de 0,7 por 0,26 en la rutina de ecuaciones para hallar la $T_{r}$ se obtuvieron los resultados mostrados en la gráfica de la Figura 64. Si se compara el área bajo la curva correspondiente a la $T_{r}$ del muro macizo de concreto con $\alpha_{s}=0,7$ y $\alpha_{s}=0,25$ se nota que existe una reducción del $62,2 \%$.

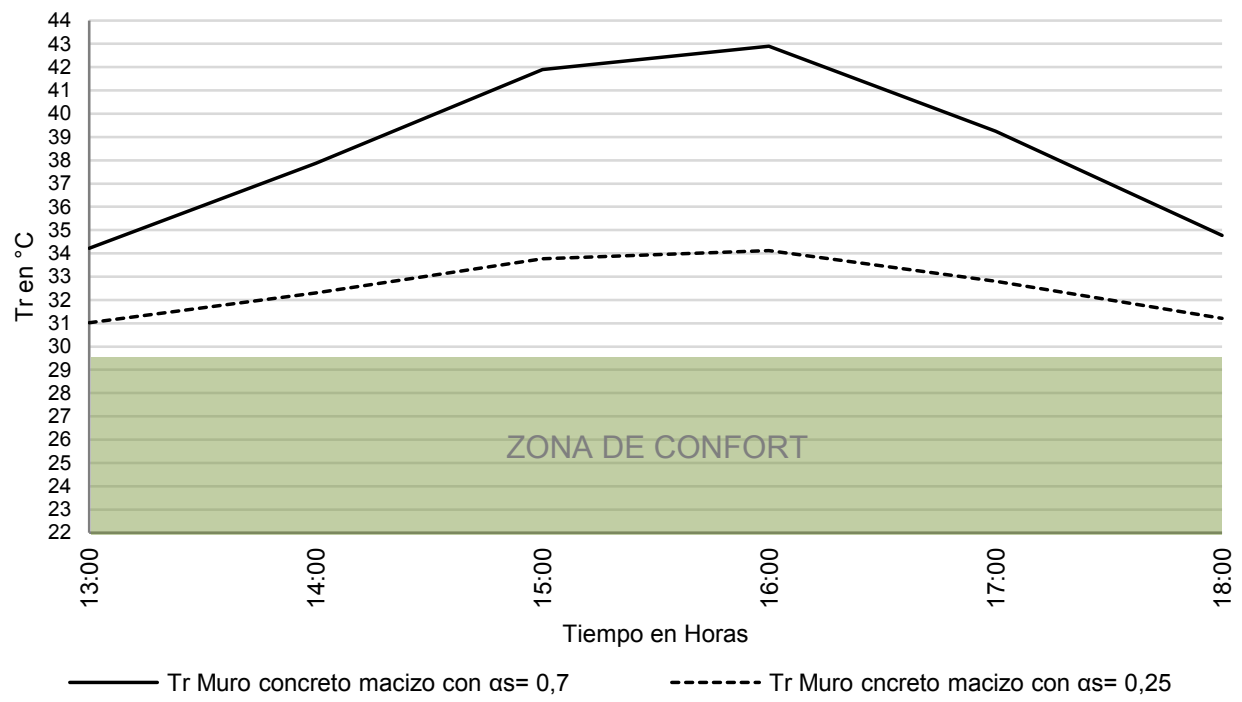

Figura 64. Gráfica comparativa de $T_{r}$ vs Tiempo entre un muro de concreto macizo sin y con tratamiento de baja absortividad. ( $\alpha_{s}=0,7$ vs $\left.\alpha_{s}=0,25\right)$. Fuente: Elaboración propia. 
Con este mismo cambio en la ecuación de $\mathrm{T}_{\text {sol air, }}$, se lograron $43^{\circ} \mathrm{C}$, lo cual son $20^{\circ} \mathrm{C}$ menos que con el concreto a la vista. Igualmente, al revisar la $T_{r}$ en el pico, es decir, a las 16:00, se encuentra una diferencia de $8,8^{\circ} \mathrm{C}$ en relación con el concreto a la vista. Sin embargo, en esta misma hora falta reducir $7^{\circ} \mathrm{C}$ adicionales para alcanzar el rango de confort.

Debe considerarse que, aunque esta sencilla estrategia no implique el aumento de la resistencia térmica, es capaz de reducir en un $62,2 \%$ la $T_{r}$, para lo cual se necesitaría aumentar aproximadamente $2,16 \mathrm{~m}^{2 \circ} \mathrm{C}$ W equivalentes a $6,5 \mathrm{~cm}$ de poliuretano. Además, esto es muy positivo presupuestalmente, pues en términos prácticos solo se ha pintado la cara exterior de la envolvente con una pintura de $\alpha_{\mathrm{s}}$ baja. 


\subsection{Revoque de polvo de ladrillo refractario (RF)}

En esta propuesta se unió la baja conductividad térmica ${ }^{41}$ del ladrillo refractario con la reducción de la absortividad. El ladrillo refractario posee un coeficiente de dilatación térmico bajo, con lo cual, puede soportar elevadas temperaturas sin ningún tipo de deformación, retiene el calor reduciendo el rápido calentamiento de la superficie que cubre, de manera que en función del espesor tiende a retrasar el flujo de calor al interior del muro y posteriormente a los espacios interiores.

La conductividad térmica de un ladrillo común es de $0,8 \mathrm{~W} / \mathrm{m}^{\circ} \mathrm{C}$, mientras que la de este tipo de ladrillo se reduce a $0,4 \mathrm{~W} / \mathrm{m}^{\circ} \mathrm{C}$.

El revoque con el que se trató la envolvente fue preparado a base de polvillo de ladrillo refractario con alto contenido de alúmina como el que se muestra en la Figura 65 y aglutinantes acrílicos a base de agua de color blanco.

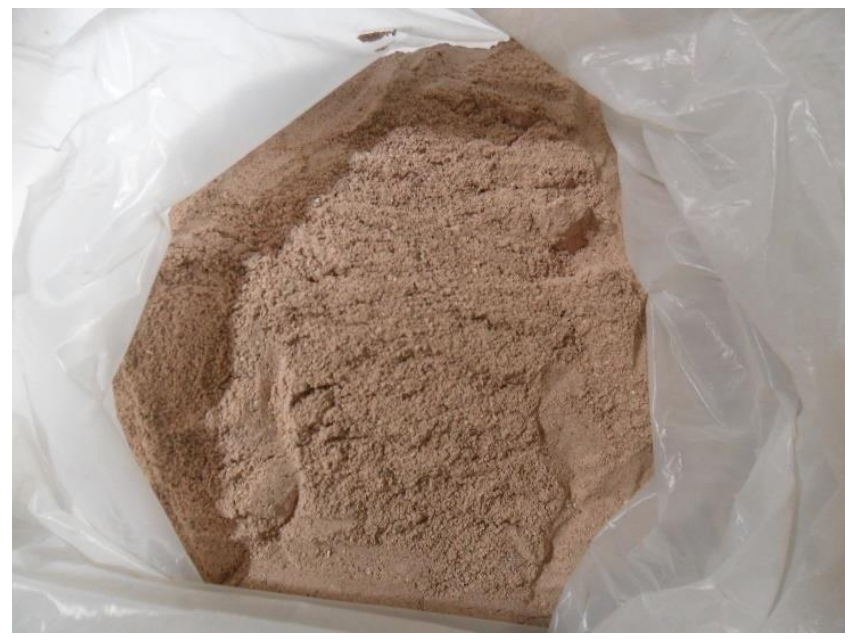

Figura 65. Polvillo de ladrillo refractario. Fuente: Elaboración propia.

Teóricamente, ni la absortividad ni la resistencia térmica de este revoque pudo establecerse con exactitud antes de la experimentación, ya que particularmente la mezcla realizada no se

${ }^{41}$ Lo que es igual a tener una alta resistencia térmica $\mathrm{R}$. 
encontró en ninguna bibliografía. Sin embargo, para poder prever los resultados de esta solución constructiva se usó por analogía la resistencia térmica de la arcilla refractaria y la $\alpha_{s}$ de 0,25 asignada previamente al color blanco, este cálculo se muestra a continuación en la Tabla 19.

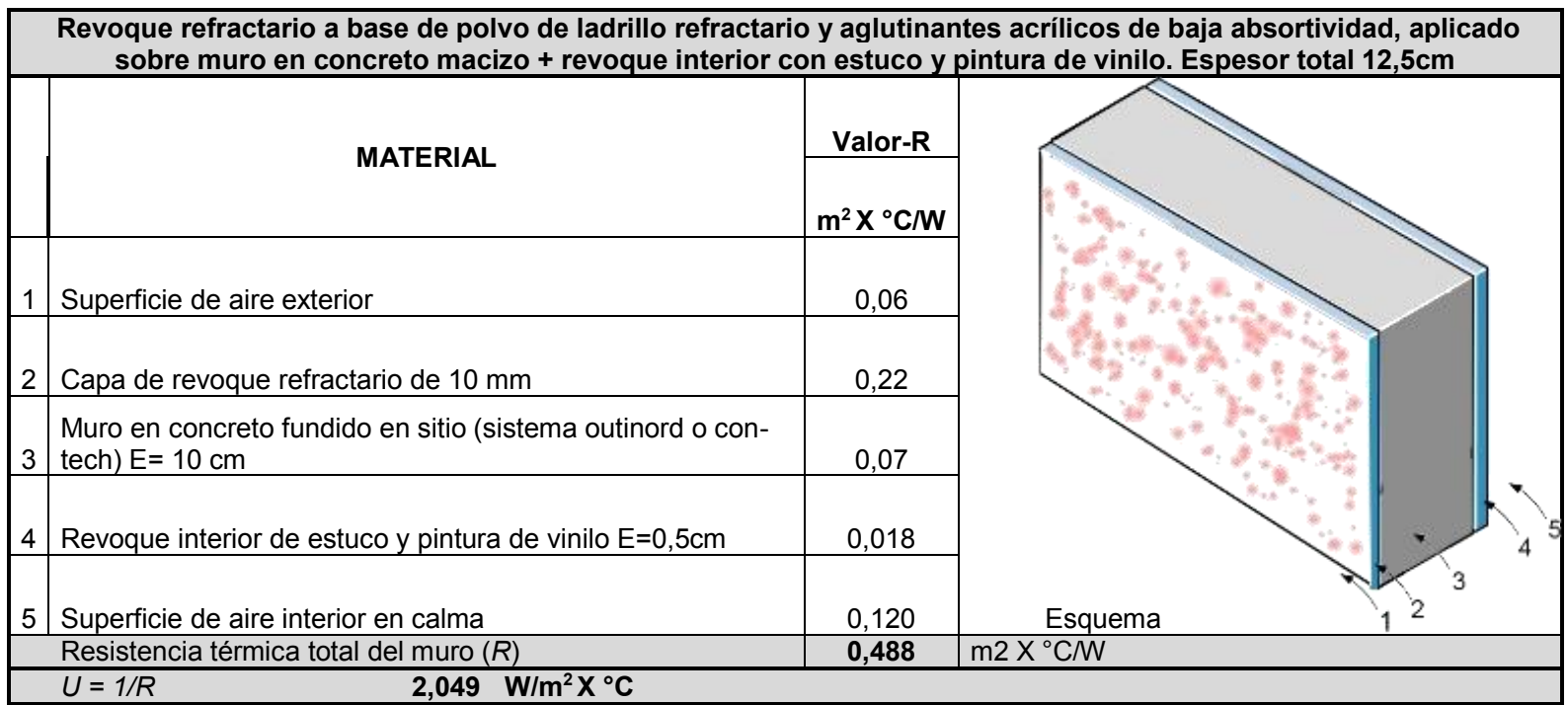

Tabla 19. Cálculo del valor U de la solución constructiva que incorpora revoque refractario. Fuente: Elaboración propia.

Una vez definido el valor teórico de $U$ y $\alpha_{s}$ se despejó hora a hora la $T_{\text {solair }} y$ luego la $T_{r}$ a través de las ecuaciones conocidas previamente. Los resultados de $T_{r}$ se muestran a continuación en la gráfica de la Figura 66 , de la cual se aprecia que con esta solución hay un notorio acercamiento a la zona de confort.

Si se compara el área bajo la curva de la $T_{r}$ perteneciente al muro de concreto macizo con y sin $\mathrm{RF}$, se encuentra que el revoque refractario disminuyó el $81,8 \%$ en el transcurso de la tarde. 
Asimismo, comparando los resultados del horario crítico de las 16:00, esta alternativa tuvo una $\mathrm{T}_{\mathrm{r}}$ de $30,91^{\circ} \mathrm{C}$; lo cual es $11,99^{\circ} \mathrm{C}$ inferior a la temperatura obtenida sin este tratamiento.

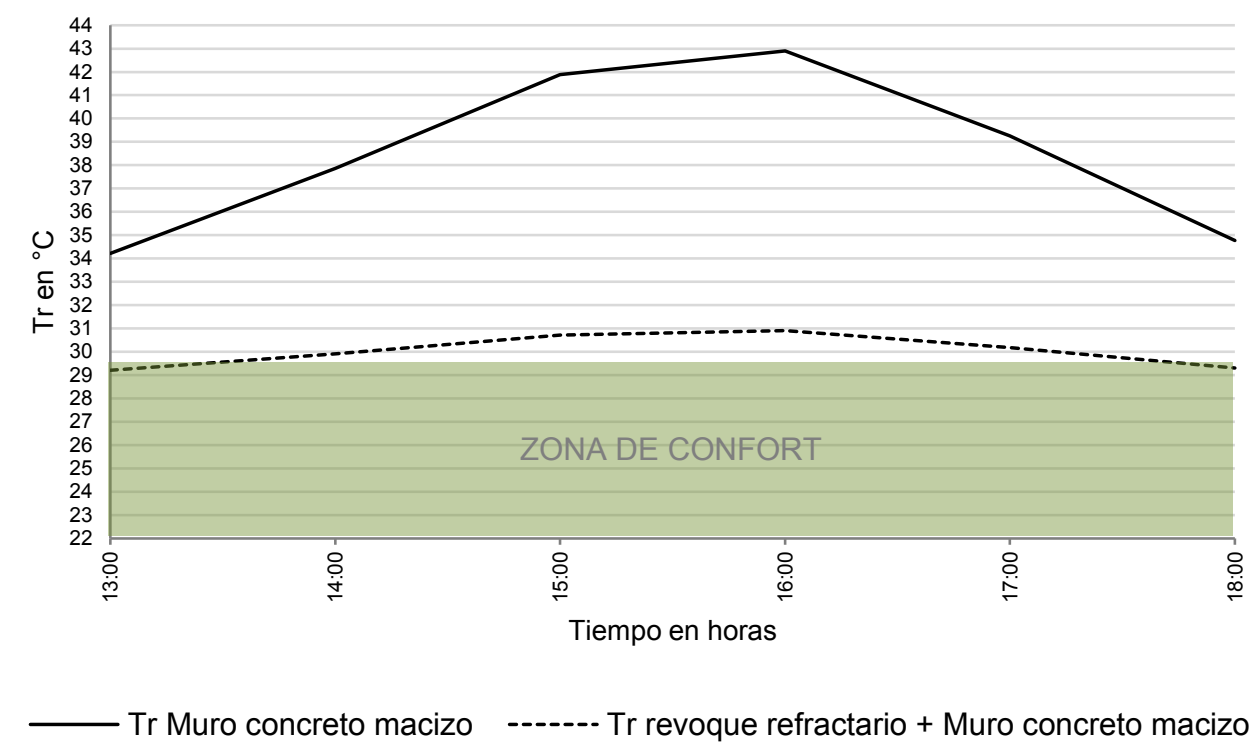

Figura 66. Gráfica comparativa de $T_{r}$ vs Tiempo entre un muro de concreto macizo con y sin revoque refractario. Fuente: Elaboración propia. 


\subsection{Muro vegetal (MV)}

Un MV, tienen la capacidad de crear sombreado y aumentar la $\mathrm{R}$ de la envolvente. El sombreado se crea a través de la cobertura que ofrecen las plantas e incluso los contenedores y estructura de soporte. Por su parte, la R se incrementa por la cantidad de masa agregada en el sustrato y la estructura.

En el diseño propuesto, dos componentes adicionales se incorporaron, el primero es el tratamiento de baja absortividad y el segundo es una cámara de aire formada entre la cara exterior de la fachada y la cara interior del contenedor.

Así pues, en la solución constructiva se reúnen las siguientes estrategias de enfriamiento pasivo: sombreado y enfriamiento evapotranspirativo de las plantas, tratamiento de baja absortividad aplicado en el contenedor, aislamiento térmico con masa aportado por el sustrato, y el aislamiento a través de una cámara de aire conformada entre el contenedor y la cara exterior de la envolvente.

El comportamiento térmico de esta estrategia es complejo de modelar matemáticamente, ya que al incluir cobertura vegetal se deben considerar sus complejas propiedades e interacciones con los factores del medio ambiente tales como temperatura, radiación solar, evapotranspiración, fotosíntesis, etc. Además, otros componentes como el sustrato y su grado de humedad pueden variar constantemente produciendo cambios notorios en la resistencia térmica total.

Por esta razón para determinar la $T_{r}$ de esta solución constructiva, a través del método numérico que se ha venido utilizando, se asumieron valores empíricos de la bibliografía revisada para las variables de $\mathrm{R}$ y coeficiente de sombreo pertenecientes a la capa de especies vegetales y sustrato.

La Tabla 20 contiene una descripción gráfica del diseño de esta solución con los valores $\mathrm{R}$ de cada componente que se suman para obtener finalmente el valor U. Cabe destacar que, de acuerdo con lo encontrado por Machado, Brito, \& Neila (2000), la resistencia térmica de la capa de vegetación es prácticamente nula debido a su alto contenido de agua, pero su efecto de sombreado se tiene en cuenta en el $C_{s}$. A pesar de que Cheng, Cheung, \& Chu (2010) y Mazzali, Peron, Romagnoni, Pulselli, \& Bastianoni (2013) indicaron que este valor puede estar entre el rango de $70 \%$ a $80 \%$, el $\mathrm{C}_{\mathrm{s}}$ fue estimado conservativamente en 0,5 ; lo cual significa que el $50 \%$ de la superficie exterior estará sombreada por las plantas. 
Por su parte, la resistencia de la estructura y la lona contenedora, ambas de PVC se tomaron de tablas suministradas por los fabricantes (SL, 2018) ${ }^{42}$. El valor correspondiente al sustrato fue estimado con los valores obtenidos experimentalmente por Canales (2014) e Incropera, Dewitt, Bergman, \& Lavine (2007), teniendo en cuenta una saturación de agua al 50\%. Finalmente, la cuantía asignada a la cámara de aire fue tomada de Cengel (2003).

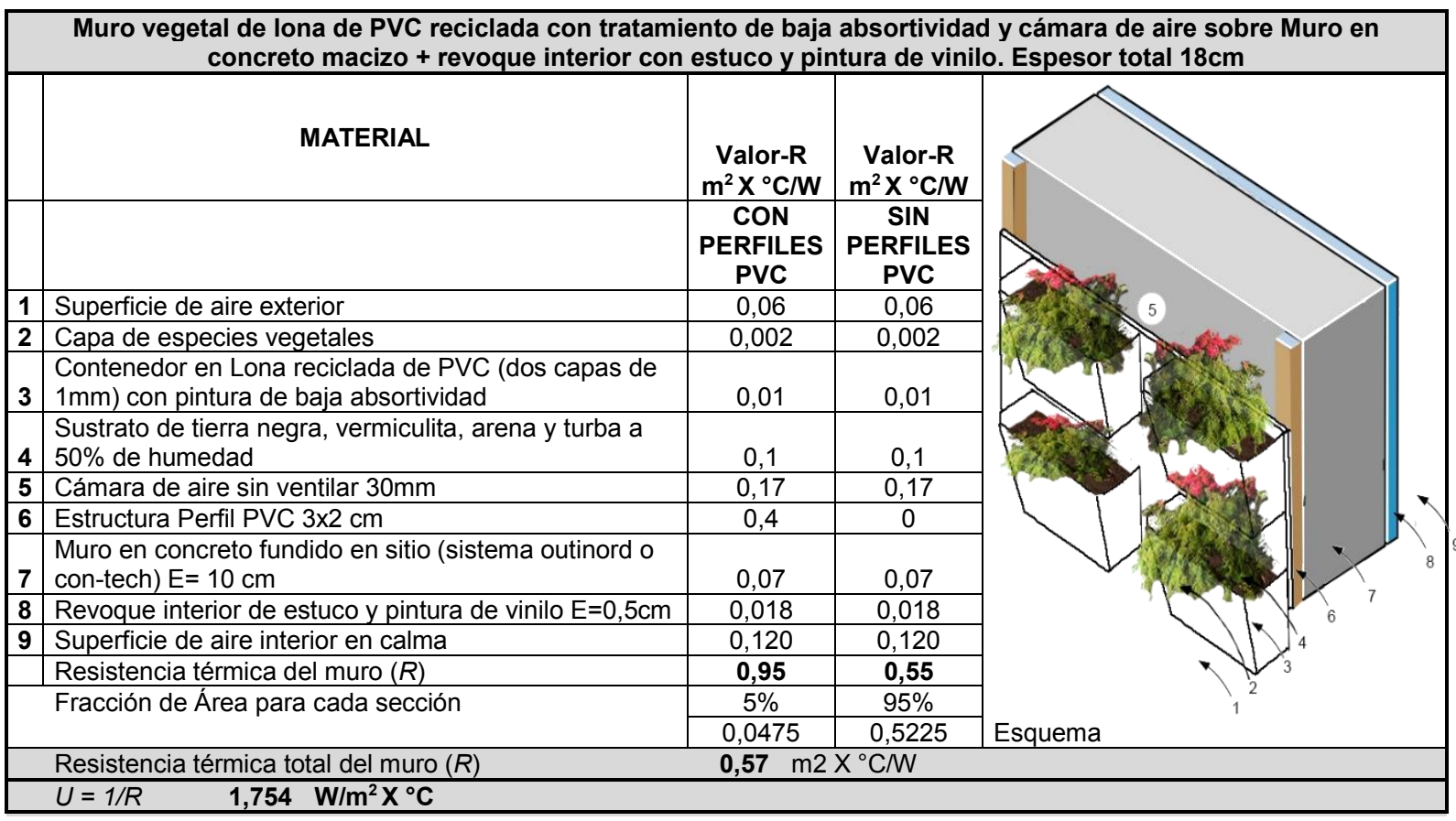

Tabla 20. Cálculo del valor U para la solución constructiva que incorpora muro vegetal. Fuente: Elaboración propia.

Entonces, al despejar $T_{\text {solair }}$ con los valores de $C_{s}=0,5$ y $\alpha_{s}=0,25$ en el horario crítico de las 16:00 se tuvo un resultado de $37^{\circ} \mathrm{C}$ lo cual es $26^{\circ} \mathrm{C}$ inferior a lo visto en la condición inicial del concreto a la vista.

Asimismo, al continuar el proceso de las ecuaciones, se obtuvieron los valores presentados en la gráfica de la Figura 67, en la cual se aprecia que esta solución constructiva alcanza la zona de confort y que la variación de $T_{r}$ es pequeña.

42 http://www.plasticbages.com/caracteristicaspvc.html 
De la misma forma, si se compara el área bajo la curva de la $T_{r}$ perteneciente al muro de concreto macizo con y sin tratamiento de MV, se encuentra que el MV disminuye el $90,73 \%$ de la $T_{r}$ en el transcurso de la tarde.

Por último, al contrastar el valor pico de ambas curvas, encontramos que mientras la envolvente común de concreto macizo se encuentra a $42,9^{\circ} \mathrm{C}$, la solución con $\mathrm{MV}$ tan solo llega a $28,97^{\circ} \mathrm{C}$; encontrándose así una diferencia de $13,93^{\circ} \mathrm{C}$ bastante notoria si se compara con las soluciones tratadas anteriormente.

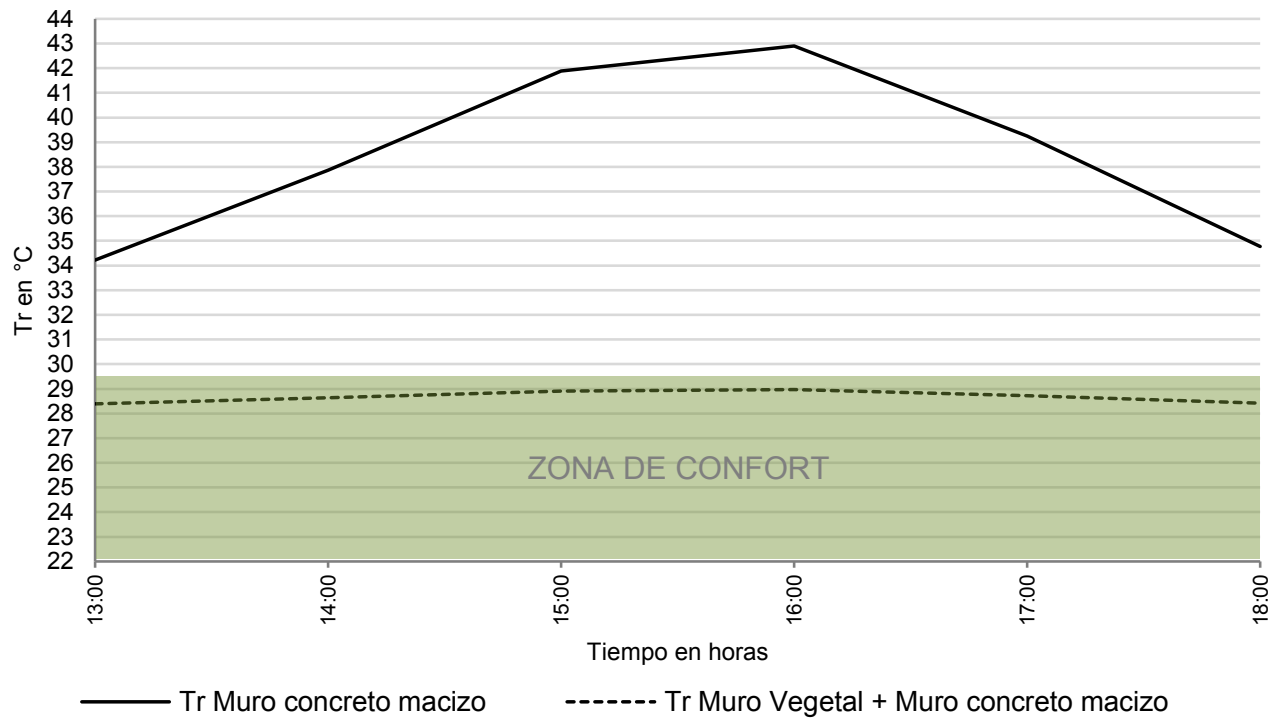

Figura 67. Gráfica comparativa de $\mathrm{T}_{\mathrm{r}}$ vs Tiempo del muro de concreto macizo con y sin la implementación del muro vegetal. Fuente: Elaboración propia. 


\subsection{Aislamiento reflectivo (AR)}

Como se conoció en título 3.7, el AR requiere un material de baja emisividad y un espacio de aire completamente libre entre 1 y $2 \mathrm{~cm}$ para que pueda actuar. Esta propuesta consiste en conformar dos cámaras de aire reflectivas que aportan resistencia térmica al conjunto. Además, esto se combina con el tratamiento de baja absortividad en la parte superficial. Para lograr esto, se tomó como inspiración la fabricación del cartón corrugado, incluso para que también pudiese ser fabricado de forma similar a nivel industrial.

El cartón corrugado común, está elaborado a partir de una lámina intermedia corrugada que aporta espesor al conjunto, a la que son adheridas dos láminas planas a cada lado. En este caso, la lámina corrugada intermedia es reemplazada por un foil de aluminio adherido a un respaldo plástico de $0,5 \mathrm{~mm}$ de espesor, con la cara brillante del foil de aluminio hacia el ambiente exterior.

Las láminas planas puestas a cada lado también son plásticas, pero de $2 \mathrm{~mm}$ de espesor y de color blanco. Un segundo foil de aluminio se ubicó en la cara interna de la lámina plástica contigua al interior para conformar otra cámara de aire reflectiva.

A continuación, una sección explicativa con especificaciones y dimensiones se puede detallar en la Figura 68.

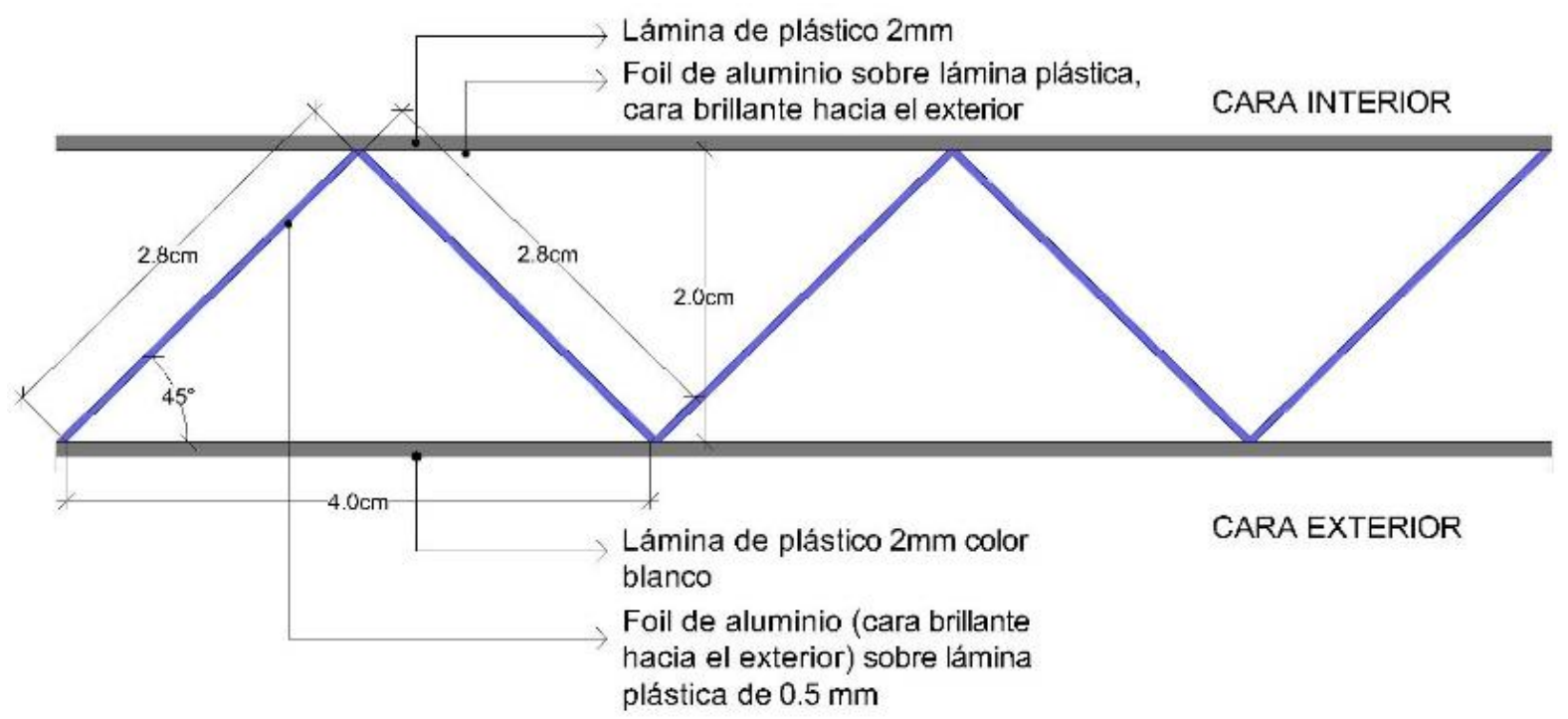

Figura 68. Planta de la solución constructiva de aislamiento reflectivo + baja absortividad. Fuente: Elaboración propia. 
Para el modelado matemático de esta solución constructiva primero se calculó el valor $U$ del conjunto como se indica en la Tabla 21.

Posteriormente, para cada hora de la tarde se despejó $T_{\text {solair }}$ utilizando $\alpha_{s}=0,25$ y luego $T_{r}$ usando $U=0,704$. Los resultados de $T_{r}$ consignados en la gráfica de la Figura 69 , muestran que con esta solución solo haría falta reducir $1^{\circ} \mathrm{C}$ para alcanzar la zona de confort. De igual forma, la variación de temperaturas lograda por este conjunto durante la tarde es pequeña.

Al contrastar el área bajo la curva de la $T_{r}$ de los muros de concreto macizo con y sin tratamiento de $A R$, se encontró que el muro tratado con $A R$ pudo reducir el $91,3 \%$ de la $T_{r}$ a lo largo de la tarde.

\begin{tabular}{|c|c|c|c|}
\hline \multicolumn{4}{|c|}{$\begin{array}{l}\text { Aislamiento reflectivo de dos cámaras de aire hechas con foil de aluminio + tratamiento de baja } \\
\text { absortividad sobre muro en concreto macizo } E=10 \mathrm{~cm}+\text { revoque interior con estuco y pintura de vinilo }\end{array}$} \\
\hline & MATERIAL & $\begin{array}{l}\text { Valor-R } \\
\mathrm{m}^{2} \mathrm{X}^{\circ} \mathrm{C} / \mathrm{W}\end{array}$ & \multirow{12}{*}{ Esquema } \\
\hline 1 & Superficie de aire exterior & 0,06 & \\
\hline 2 & Lámina opaca de plástico color blanco. Espesor 2mm & 0,004 & \\
\hline 3 & $\begin{array}{l}\text { Foil de Aluminio (adherido a lámina de PET reciclado) } \\
\text { para conformar la primera cámara de aire reflectivo sin } \\
\text { ventilación }\end{array}$ & 0,57 & \\
\hline 4 & $\begin{array}{l}\text { Foil de Aluminio (adherido a lámina plástica) para } \\
\text { conformar la segunda cámara de aire reflectivo sin } \\
\text { ventilación }\end{array}$ & 0,57 & \\
\hline 5 & Lámina opaca de plástico color blanco. Espesor $2 \mathrm{~mm}$ & 0,004 & \\
\hline 6 & $\begin{array}{l}\text { Muro en concreto fundido en sitio (sistema outinord o } \\
\text { con-tech) } E=10 \mathrm{~cm}\end{array}$ & 0,07 & \\
\hline 7 & Revoque interior de estuco y pintura de vinilo $E=0,5 \mathrm{~cm}$ & 0,018 & \\
\hline \multirow[t]{4}{*}{8} & Superficie de aire interior en calma & 0,120 & \\
\hline & Resistencia térmica del muro & 1,416 & \\
\hline & Resistencia térmica total del muro $(\boldsymbol{R})$ & 1,42 & \\
\hline & $U=1 / R \quad 0,704 \quad \mathrm{~W} / \mathrm{m}^{2} \mathrm{X}^{\circ} \mathrm{C}$ & & \\
\hline
\end{tabular}

Tabla 21. Cálculo del valor $U$ para la solución constructiva que incorpora aislamiento reflectivo. Fuente: Elaboración propia. 
Adicionalmente, al comparar el valor pico de las 16:00 horas en ambas curvas, encontramos que mientras la envolvente de concreto macizo se encuentra a $42,9^{\circ} \mathrm{C}$, la presente solución tan solo llega a $28,34^{\circ} \mathrm{C}$, lo cual significa una diferencia de $14,56{ }^{\circ} \mathrm{C}$ bastante notoria, similar a la solución con muro vegetal. ${ }^{43}$

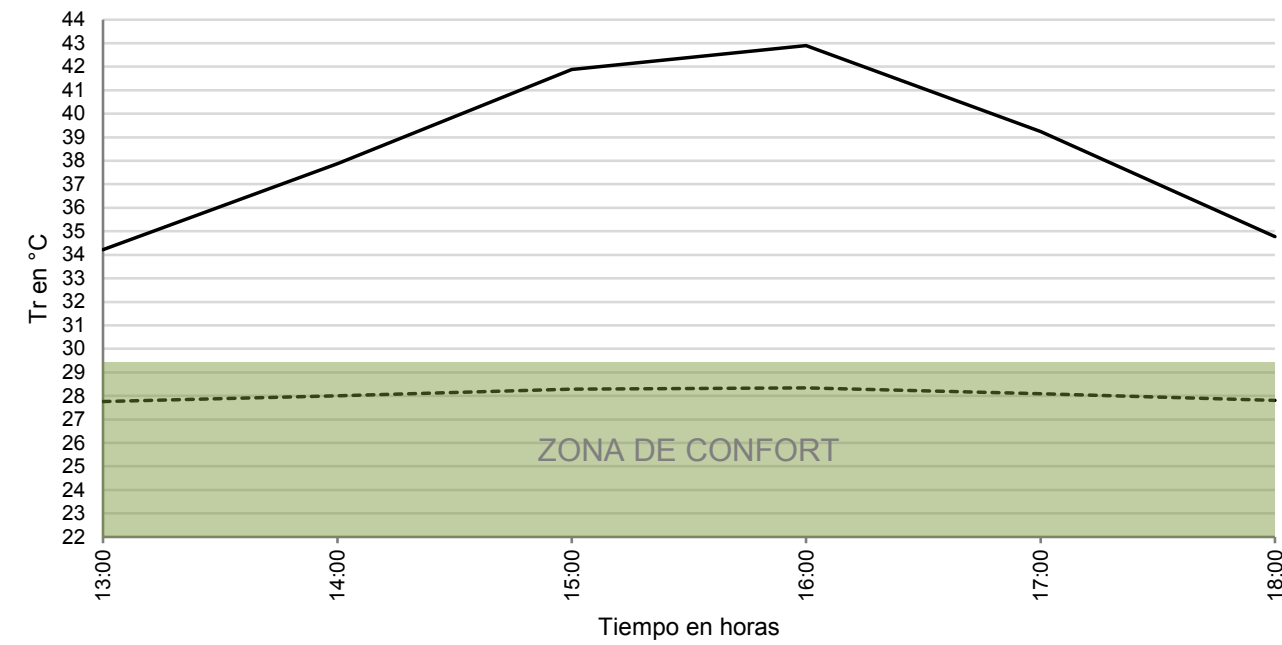

Tr Muro concreto macizo

Tr Aislamiento reflectivo + Muro concreto macizo

Figura 69. Gráfica comparativa de $T_{r}$ vs Tiempo del muro de concreto macizo con y sin implementación del aislamiento reflectivo. Fuente: Elaboración propia.

$4313.93{ }^{\circ} \mathrm{C}$ reducidos mediante el muro vegetal. 


\subsection{Conclusiones}

Como herramienta de síntesis de este apartado se elaboró la gráfica de la Figura 70, que compara el desempeño térmico de la tipología de envolvente VIS crítica ${ }^{44}$ (concreto macizo), con los resultados de cada solución constructiva.

En esta gráfica el primer elemento de la izquierda corresponde a la envolvente VIS crítica, con la barra se representa el $100 \%$ de la $T_{r}$ mientras que con el punto se señala la $T_{r}$ máxima alcanzada $\left(42,9^{\circ} \mathrm{C}\right)$; luego, hacia la derecha se presentan las soluciones constructivas de menor a mejor desempeño. Cada alternativa tiene su porcentaje de reducción de $\mathrm{T}_{\mathrm{r}}(\mathrm{en} \%)$ y reducción máxima de $\mathrm{T}_{\mathrm{r}}\left(\mathrm{en}^{\circ} \mathrm{C}\right)$. Además, se señaló la zona de confort para identificar fácilmente cuales soluciones logran estar dentro de este rango.

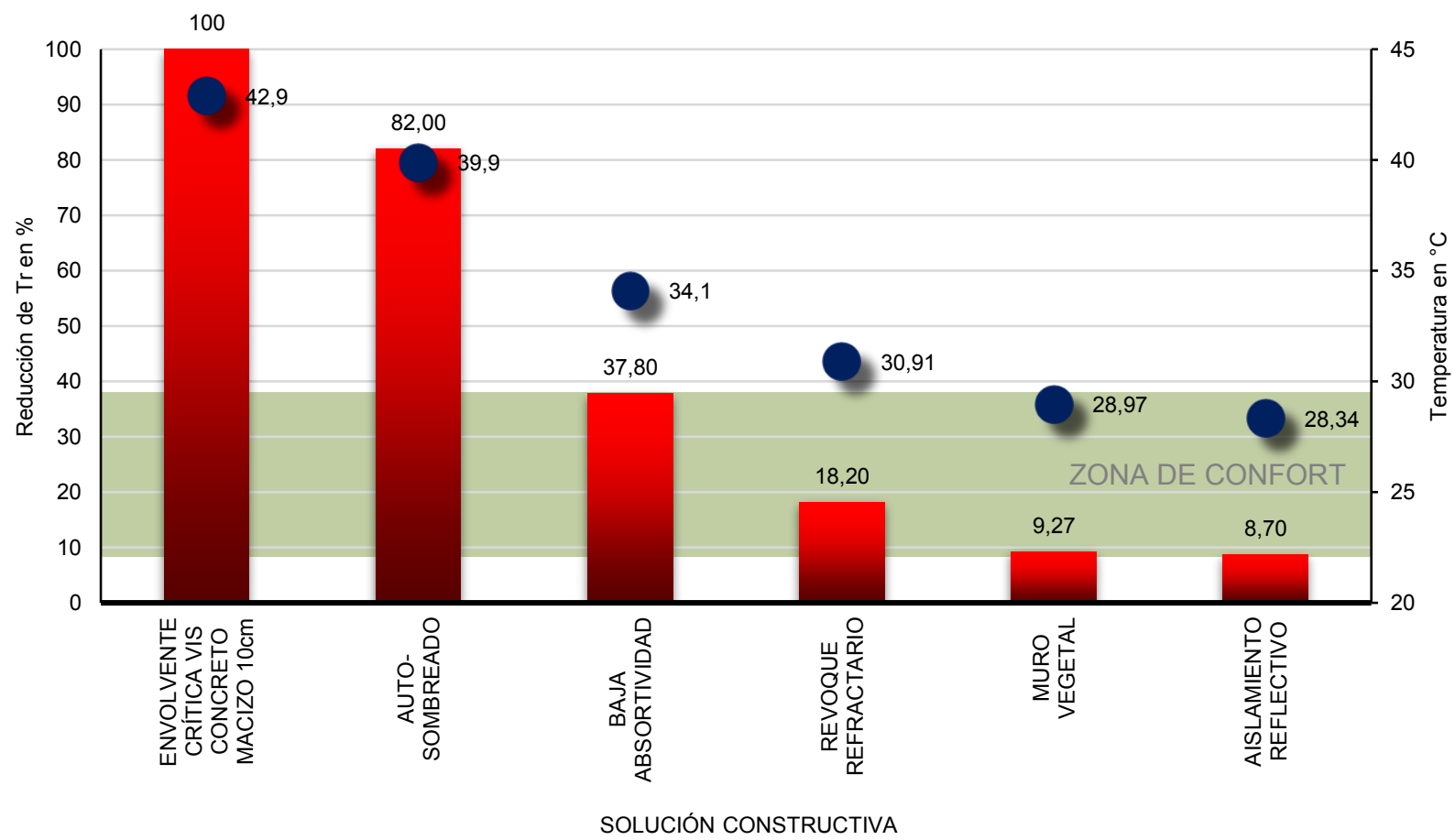

• \% de reducción de $\operatorname{Tr} \quad$ Reducción máxima de $\operatorname{Tr}$ en ${ }^{\circ} \mathrm{C}$

Figura 70. Gráfica comparativa de reducción de $\mathrm{T}_{\mathrm{r}}$ en $\%$ y máxima reducción de $\mathrm{T}_{\mathrm{r}}$ en ${ }^{\circ} \mathrm{C}$ entre un muro típico VIS y las soluciones constructivas. Fuente: Elaboración propia.

${ }^{44}$ Analizada en el numeral 4.2.4 del capítulo anterior 
- Como lo muestra la gráfica anterior, solo se alcanzó la zona de confort con las soluciones de Muro vegetal y Aislamiento reflectivo, las cuales lograron un valor máximo de $\mathrm{T}_{\mathrm{r}}$ de $28,97^{\circ} \mathrm{C}$ y $28,34^{\circ} \mathrm{C}$ respectivamente. Esto también significó haber reducido el porcentaje de la $T_{r}$ del $100 \%$ a $9,27 \%$ y $8,70 \%$ respectivamente; mientras que el desempeño más bajo fue el logrado por la opción de Autosombreado, que solo pudo reducir la $\mathrm{T}_{\mathrm{r}}$ del $100 \%$ al $82 \%$ y lograr una $\mathrm{T}_{\mathrm{r}}$ máxima de $39,9^{\circ} \mathrm{C}$.

- Las soluciones de baja absortividad y revoque refractario poseen desempeños intermedios que no alcanzaron la zona de confort, pero que vale la pena considerar porque de acuerdo con el análisis presupuestal (Apéndice 4), poseen unos de los costos más bajos. Por su parte, la solución de Baja absortividad permitió reducir la $T_{r}$ al $37,8 \%$ y consiguió llevarla de $42,9^{\circ} \mathrm{C}$ a $34,1^{\circ} \mathrm{C}$. Por su parte, la opción de Revoque refractario consiguió bajar a $18,2 \%$ la $T_{r}$, lo cual equivale a reducirla de $42,9^{\circ} \mathrm{C}$ a $30,91^{\circ} \mathrm{C}$, lo cual solo está a $1,4^{\circ} \mathrm{C}$ de la zona de confort.

- De acuerdo con la gráfica de la Figura 70, cuatro de las alternativas evaluadas aquí, demuestran tener una reducción de más del $50 \%$ de la $\mathrm{T}_{\mathrm{r}}$ lo cual significa tener una influencia positiva en el desempeño térmico de las envolventes. Sin embargo, estos datos fueron calculados teóricamente, considerando un estado estacionario sin contemplar otros aspectos termodinámicos como la acumulación de energía, por lo cual es conveniente verificar dicho desempeño de forma experimental. 


\section{EVALUACIÓN DEL PORCENTAJE DE REDUCCIÓN DE LA Tr (Y CONTROL TERMOHIGROMÉTRICO)}

\subsection{Introducción}

Con el fin de evaluar empíricamente el porcentaje de reducción de $\mathrm{T}_{\mathrm{r}}$ de las soluciones constructivas analizadas teóricamente en el punto anterior, se elaboró un experimento que materializa dichas condiciones críticas con las que se evaluaron, es decir: bajo radiación solar y orientación Oeste. A diferencia de la evaluación teórica esta experimentación se realizó en estado transitorio en el laboratorio a cielo abierto de la FAU -UNLP ${ }^{45}$ el cual es una terraza en un tercer nivel donde la radiación solar llega de forma directa, sin obstrucciones desde el mediodía hasta el final de la tarde, es decir en condiciones similares a las que enfrenta cualquier envolvente de VIS.

Aunque la investigación va dirigida especialmente a la variable $T_{r}$, se realizaron controles de la $T_{\text {air }}$ y la HR tanto en la calibración del aparato experimental como en la evaluación de cada solución constructiva. Esto permitió verificar la similitud del ambiente térmico del aparato experimental durante la calibración y complementar los efectos logrados por cada alternativa implementada.

A continuación, se describen las decisiones técnicas concernientes al desarrollo de esta prueba:

${ }^{45}$ Facultad de Arquitectura y Urbanismo de la Universidad Nacional de La Plata. 


\subsection{Universo y muestra representativa.}

Una de las cuestiones iniciales en el proceso de creación del aparato experimental fue acerca de qué se quiere o qué se necesita representar. Es claro que se quiere estudiar la envolvente VIS, pero sin duda es ideal que el aparato experimental represente el universo de esas edificaciones o al menos una buena parte.

Dado que los datos estadísticos expuestos en el numeral 2.7 señalaron que el $98,94 \%$ de este tipo de edificaciones están construidas con sistemas basados en arcilla cocida o concreto en sus envolventes, se entiende que deberían ser considerados como muestra representativa del universo VIS.

Del mismo modo, los registros señalan que el $40,37 \%$ de las viviendas son construidas con sistemas industrializados como con-tech y outinord, los cuales son de concreto. Además, que otro $58,57 \%$ correspondiente a los sistemas de mampostería se dividen entre bloques de concreto y de arcilla. Con lo cual se infiere que el uso del concreto como material de construcción en VIS es más común que la arcilla cocida en la actualidad. Incluso, de los 15 sistemas constructivos inventariados, 13 incluyen el concreto o el mortero en su envolvente.

En consecuencia, dentro del universo de materiales, el concreto fue seleccionado como material representativo en el presente estudio, además, la diferencia entre la arcilla cocida y el concreto no es muy notoria desde el punto de vista térmico, ya que ambos materiales poseen un comportamiento similar. Cuando se presentan en forma maciza, tanto su densidad como resistencia térmica varían en un rango de $1800-2200 \mathrm{Kg} / \mathrm{m}^{3}$ y $1,0-1,37 \mathrm{~m}^{2}{ }^{\circ} \mathrm{K} / \mathrm{W}$, respectivamente.

\subsection{Diseño y construcción.}

Antes de describir la construcción del aparato experimental es necesario explicar que la ciudad de interés del presente estudio es la ciudad de Cali, Colombia, ubicada a $3^{\circ} 26^{\prime} 13^{\prime \prime}$ de latitud norte, mientras que el lugar de estudio y experimentación es la ciudad de La Plata, Argentina, ubicada a $34^{\circ} 55^{\prime} 17^{\prime \prime}$ de latitud sur, con lo cual existen diferencias bastante notorias en asoleamiento y clima.

La razón de esta discrepancia obedeció a un tema logístico de las condiciones de la comisión de estudio con fines doctorales de la cual soy beneficiario actualmente. Sin embargo, este detalle se tomó en cuenta en la metodología, se tomaron medidas para lograr condiciones similares a la ciudad de Cali, con las cuales se pretende minimizar el margen de diferencia y conservar la validez del estudio aun experimentando en La Plata. 
Las medidas mencionadas consistieron en la elaboración de una plataforma inclinada para que el asoleamiento concordara con la latitud de Cali y un análisis climatológico previo de ambas ciudades, (el cual se puede consultar en el Apéndice 2) para programar las mediciones durante el periodo estacional que mejor se semejara a las condiciones climatológicas cálidohúmedas de la ciudad de interés. En este caso fue el periodo de verano Platense que corresponde a los meses de enero febrero y marzo.

Por consiguiente, se es consciente que persiste algún grado de disimilitud en los resultados, sin embargo, estas mismas, se han minimizado y metodología de evaluación de desempeño térmico sigue siendo aceptable tanto para Cali, como para cualquier otra localidad que presente un clima cálido-húmedo y altos niveles de radiación solar.

Dos módulos de pruebas fueron utilizados para esta experimentación con una medida interior de 50 × 50 × $50 \mathrm{~cm}$, uno de ellos fue destinado a servir como módulo testigo y el otro a recibir una a una las diferentes soluciones constructivas.

Cada módulo consiste en una caja de 5 caras apoyada sobre una base de aglomerado de madera de $18 \mathrm{~mm}$, las 5 caras coinciden perpendicularmente con las orientaciones Norte, Sur, Este, Oeste y Cenit. Todas a excepción de la cara ubicada perpendicularmente al oeste están conformadas con placas de poliestireno expandido (EPS) de $30 \mathrm{~mm}$ de espesor, cuya conductividad térmica es $0,027 \mathrm{~W} / \mathrm{m}^{\circ} \mathrm{K}$.

Tan solo la cara ubicada perpendicularmente al Oeste está fabricada con una placa de concreto $^{46}$ de $2 \mathrm{~cm}$ de espesor, con una dosificación 1:2:2 y una densidad aproximada de 2000 $\mathrm{kg} / \mathrm{m}^{3}$ (este material se eligió como muestra representativa de las envolvente VIS en el título anterior y además representa también el caso crítico analizado en el numeral 4.2.4).

En las caras Norte y Sur se abrieron unos vanos debidamente protegidos de la radiación solar directa mediante elementos horizontales y verticales construidos con Foam Board de $5 \mathrm{~mm}$. Estos fueron calculados con el método de la máscara de sombras explicado en el título 1.8. Los vanos se dispusieron con el fin de permitir la ventilación natural de los módulos y lograr una homogeneidad con la $\mathrm{T}_{\text {air }}$ exterior.

\footnotetext{
${ }^{46}$ Más adelante se explica detalladamente el proceso de fabricación y los controles que se tomaron para garantizar características térmicas homogéneas en estos elementos de concreto.
} 
Una planimetría explicativa de lo anterior que incluye planta y alzados con especificaciones y dimensiones se aprecia en la siguiente Figura 71.

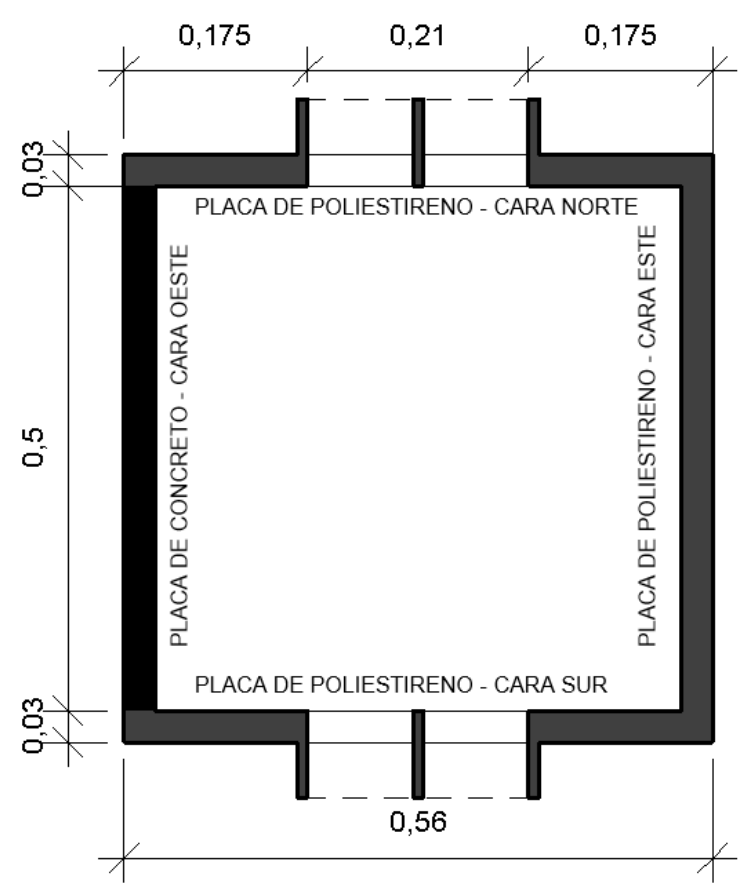

PLANTA

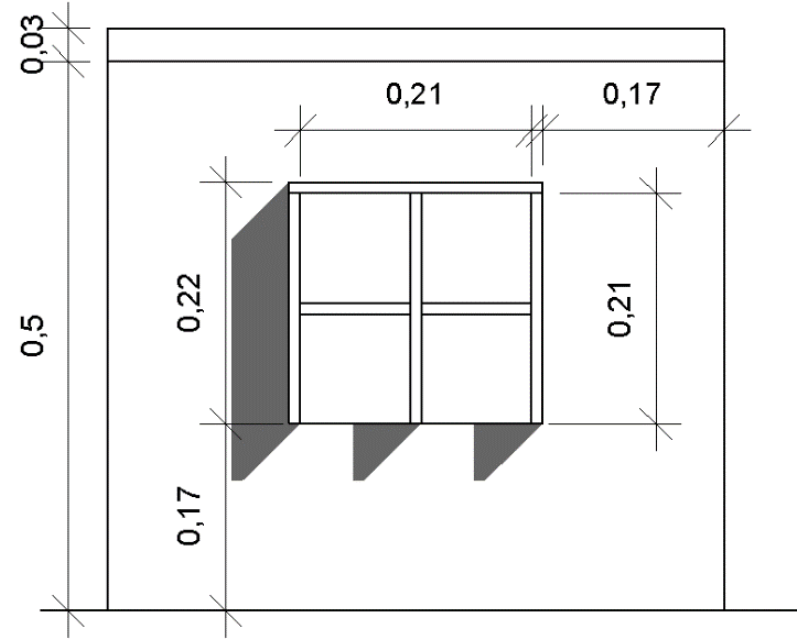

ALZADAS NORTE Y SUR

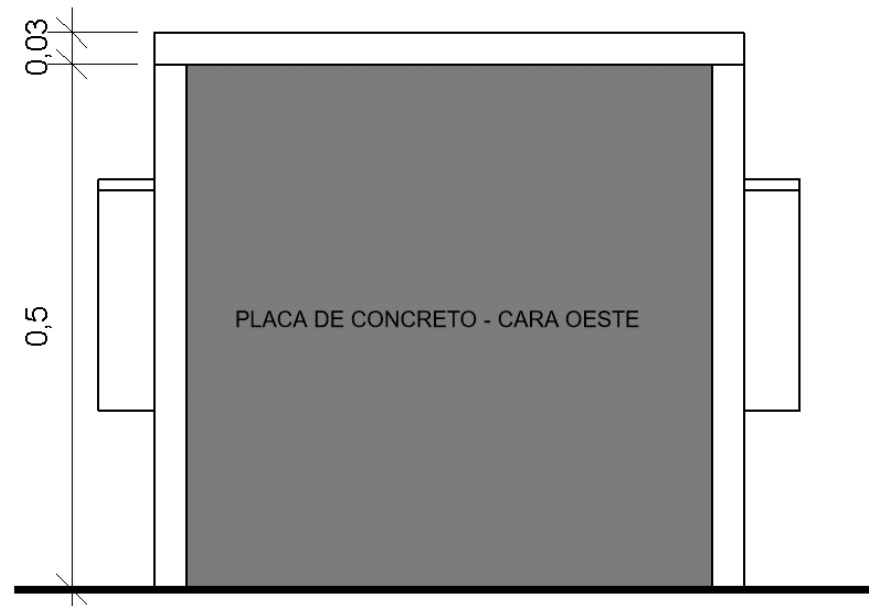

ALZADA

Figura 71. Planimetría de un módulo experimental: planta y alzados con especificaciones y dimensiones en metros. Fuente: Elaboración propia.

La base de los módulos se inclinó $38.35^{\circ}$ hacia el norte obedeciendo a la necesidad de alcanzar el asoleamiento de la ciudad de Cali, para esto se sumaron los valores angulares absolutos de las latitudes de la ciudad de La Plata (latitud sur) y de la ciudad de Cali (latitud norte) de la siguiente manera:

$34,92^{\circ}($ La Plata $)+3,43^{\circ}$ (Santiago de Cali $)=38,35^{\circ}$ 
Para corroborar y además explicar lo anterior nos apoyaremos de la Figura 72, obtenida mediante el software Autodesk Ecotect. Con esta herramienta se traslaparon las cartas solares de ambas ciudades desde una vista Este (Cali en color azul y La Plata en color amarillo).

Luego de esto, se escogió un día y hora para localizar el sol (círculo de color naranja) en ambas cartas solares. Se escogió el cenit (12:00 hora solar) del solsticio del 21 de junio, ya que es un punto fácilmente identificable y se ubica precisamente en el extremo superior Norte de la carta solar. Una vez situados los puntos del sol en ambas cartas, se trazó una línea desde el punto de análisis hasta ellos. De esta forma el ángulo formado entre ambas líneas corresponde a la inclinación que se debe dar a las bases de los módulos y lograr el asoleamiento de Cali en La Plata. Esta medida angular fue de $38,35^{\circ}$, la cual concuerda con el valor hallado mediante el método aritmético desarrollado antes.

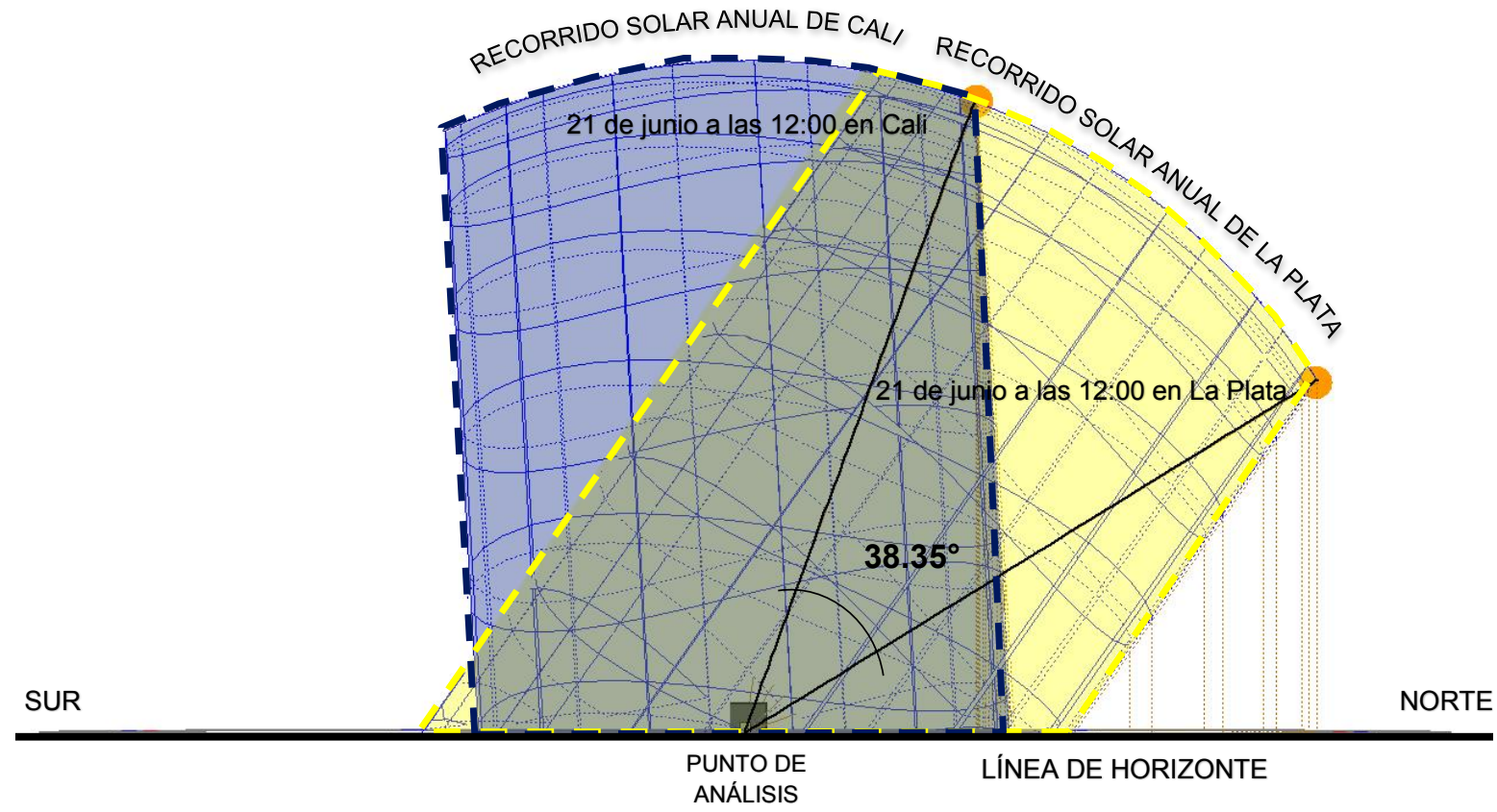

Figura 72. Análisis para determinar la inclinación de la plataforma de los módulos del aparato experimental, utilizando como método las cartas solares y el software Autodesk Ecotect. Fuente: Elaboración propia.

Nótese bien que el cuadrado gris situado en el punto de análisis representaría un módulo de pruebas en Cali visto en alzada lateral Este, el cual debe inclinarse $38,35^{\circ}$ hacia el norte para conservar el mismo asoleamiento en la ciudad de La Plata. 
Una vez obtenido el valor de este ángulo se elaboraron dos plataformas de aglomerado de madera de $18 \mathrm{~mm}$ con dicha inclinación, sobre estas, se realizó el montaje de los módulos. El resultado final se muestra a continuación en la Figura 73.

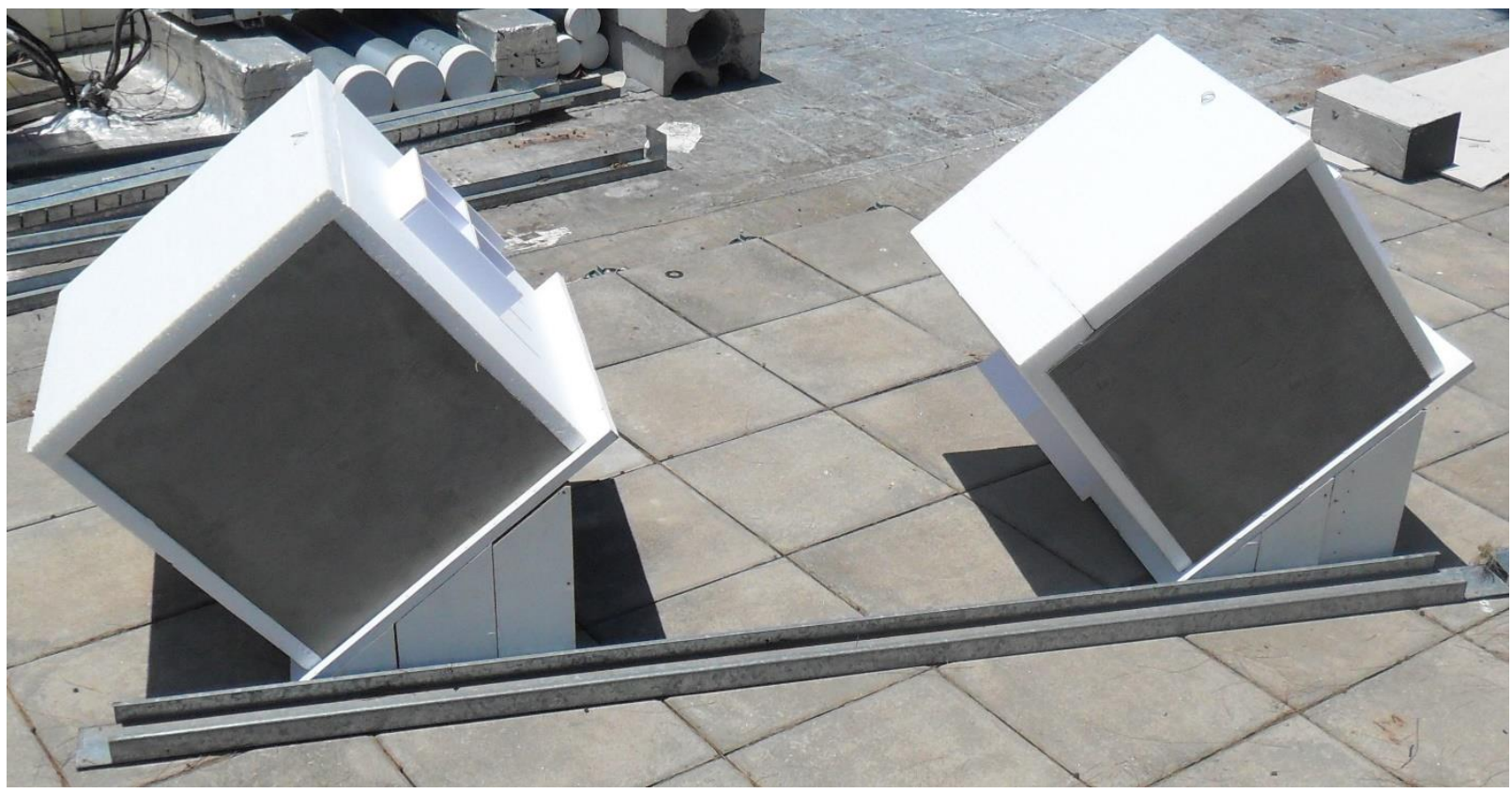

Figura 73. Disposición final del aparato experimental que consta de dos módulos idénticos de poliestireno expandido y concreto sobre una base inclinada $38.35^{\circ}$ hacia el norte. Fuente: Elaboración propia.

\section{Elementos de Concreto}

En total, durante toda la experimentación se utilizaron cuatro placas de concreto correspondientes a:

- Placa 1: acabado liso, dimensión total: $50 \times 50 \times 2 \mathrm{~cm}$.

- Placa 2: acabado liso, dimensión total: $50 \times 50 \times 2 \mathrm{~cm}$.

- Placa 3: acabado liso, dimensión total: $50 \times 50 \times 2 \mathrm{~cm}$.

- Placa 4: acabado con textura de lamas horizontales de $1 \mathrm{~cm}$ de espesor y $2,5 \mathrm{~cm}$ de profundidad, separadas cada $2,5 \mathrm{~cm}$, dimensión total: $50 \times 50 \times 4,5 \mathrm{~cm}$.

Estas placas de concreto se fundieron de forma simultánea para asegurar las mismas condiciones en cuanto a dosificación, mezclado y curado del concreto, ya que estos procedimientos modifican la densidad y por ende la resistencia térmica de cada elemento.

A pesar de que luego de la calibración, una de las caras exteriores de las placas de concreto deba ser cubierta con cada solución constructiva, se cuidó que el color de estas fuese muy 
similar, ya que la absortividad de las caras exteriores del concreto afectaría directamente el comportamiento de la $T_{r}$ en el módulo.

El concreto fabricado fue de una granulometría fina con el objetivo de tener una adecuada manejabilidad y amoldamiento a los encofrados que presentaban relieves o texturas. La dosificación de la mezcla implementada fue de 1:2:2, con lo cual se obtuvo un concreto de 3500psi aproximadamente ${ }^{47}$. Esta dosificación correspondió a una parte de cemento tipo portland tomado de una misma bolsa; dos partes de arena fina filtrada mediante un tamiz de $1 \mathrm{~mm} \times 1 \mathrm{~mm}$ sin contenido orgánico y dos partes de gravilla de $5 \mathrm{~mm}$ de espesor.

Para hidratar la composición se agregó agua potable en una proporción del $40 \%$ con relación al cemento. El proceso de mezclado fue realizado mecánicamente, empleando una paleta mezcladora acoplada a un taladro.

Se utilizaron láminas rígidas de poliestireno expandido de alta densidad tratadas con desmoldante para la elaboración del encofrado.

El vaciado, vibrado y allanado del concreto sobre el encofrado se realizó de forma manual, mediante el uso de herramientas menores como palustre, mazo de caucho y llana metálica respectivamente.

Después de un periodo de curado de 14 días en los que las placas permanecieron bajo sombra, humectadas y cubiertas por una capa plástica, se desmoldaron, obteniendo un resultado como el que se aprecia en las fotografías de la Figura 74.
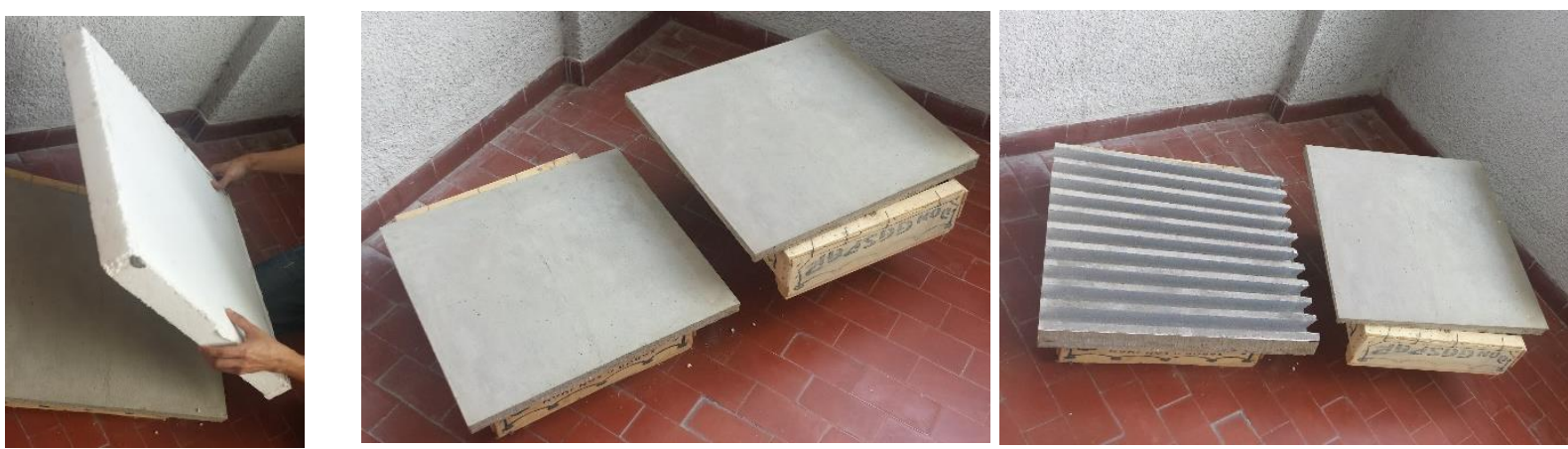

Figura 74. Desencofrado y resultado final de las placas de concreto. Fuente: Elaboración propia.

47 Esta resistencia es la más utilizada por las VIS construidas con sistema industrializado, aunque esta característica no se midió en esta investigación, se tomó como base lo indicado para esta dosificación en bibliografía (CEMEX (Cementos CEMEX, 2018)).

http://www.cemexmexico.com/Content/descargables/aplicaciones-manual-construccion-general.pdf 
Previamente a las pruebas de calibración de los módulos y la experimentación, se realizaron mediciones de reflectividad, densidad y transmitancia térmica en las diferentes placas de concreto con el objetivo de identificar cualquier discrepancia demasiado notoria que pudiese alterar los resultados. A continuación, se explican y detallan los controles tomados:

Control de reflectancia lumínica: La reflectancia es la relación entre el flujo luminoso reflejado por una superficie y el flujo recibido en la superficie. Esta medición de reflectancia lumínica no es igual a la medición de reflectividad térmica de la superficie, ya que, en esta última además de medirse el espectro visible, también se tiene en cuenta el espectro infrarrojo y el ultravioleta de la radiación solar. Sin embargo, en la mayoría de los materiales la reflectividad térmica y lumínica tienen idéntica proporción, así que este control permitió examinar si existen o no variaciones marcadas en las coloraciones de las probetas de concreto.

Este control se llevó a cabo en un ambiente iluminado naturalmente, pero protegido de la penetración de los rayos directos del sol. Para esto se utilizó: un luxómetro marca LMT modelo Pocket-2 con un rango de medición entre 0 y 120.000 luxes, y un luminancímetro marca Konica Minolta modelo LS-100 con un ángulo de lectura de $1 / 3^{\circ}$ y un rango de medición de 0,01 a $999.900 \mathrm{~cd} / \mathrm{m} 2$.

La reflectividad lumínica de cada muestra se halló mediante la fórmula:

$R=L^{*} \pi / E$

Donde:

$\mathrm{R}=$ Reflectancia en \%

$\mathrm{L}=$ Luminancia en Candelas $/ \mathrm{m}^{2}$

$\pi=3,1416$ (constante adimensional)

$\mathrm{E}=$ lluminancia en luxes

Las medidas de luminancia e iluminancia se registraron sobre la cara exterior de las muestras, es decir, por la cara que recibieron radiación solar durante las pruebas. Después de disponer verticalmente cada probeta, se enfocó con el luminancímetro y se localizó el sensor del luxómetro en el punto central de cada probeta. En el caso de las placas con textura, la luminancia fue tomada sobre la superficie más externa, es decir, en la cara vertical de las lamas.

En la siguiente Tabla 22, se indican los valores de luminancia e iluminancia registrados en la cara exterior de cada placa y su respectivo cálculo de reflectancia del espectro visible. Los resultados mostraron valores de reflectancia entre $46,8 \%$ y $48 \%$, con lo cual se entiende que 
el tono o coloración de las muestras es bastante similar, ya que las diferencias obtenidas son muy leves, pues no superaron el 1,2\%. Por lo tanto, en cuanto a esta variable las muestras se consideraron homogéneas y aptas para continuar su implementación en el aparato experimental.

\begin{tabular}{|c|c|c|c|c|}
\hline No. & PROBETA & $\begin{array}{l}\text { LUMINANCIA } \\
\text { (L) } \mathrm{Cd} / \mathrm{m}^{2}\end{array}$ & $\begin{array}{l}\text { ILUMINANCIA } \\
\text { (E) Luxes }\end{array}$ & $\begin{array}{c}\text { REFLECTANCIA (R) }= \\
L * \pi / E * 100\end{array}$ \\
\hline 1 & Placa Módulo 1: acabado liso 50 × 50 × $2 \mathrm{~cm}$. & 11,92 & 80 & $46.8 \%$ \\
\hline 2 & Placa Módulo 2: acabado liso 50 × 50 × 2cm. & 12,2 & 80 & $47.9 \%$ \\
\hline 3 & Placa Módulo 3: acabado liso 50 x 50 x 2cm. & 12,13 & 80 & $47.6 \%$ \\
\hline 4 & $\begin{array}{l}\text { Placa con textura de } 50 \times 50 \times 2 \mathrm{~cm}+\text { Textura } \\
\text { de lamas horizontales de } 1 \mathrm{~cm} \text { de espesor y } \\
2.5 \mathrm{~cm} \text { de profundidad, separadas cada } \\
2.5 \mathrm{~cm}\end{array}$ & 12,23 & 80 & $48.0 \%$ \\
\hline
\end{tabular}

Tabla 22. Valores de luminancia e iluminancia registrados en la cara exterior de cada muestra y su respectivo cálculo de reflectancia para el espectro visible. Fuente: Elaboración propia.

Control de densidad: Los datos de volumen y peso relacionados en esta variable se obtuvieron pesando directamente cada muestra con la ayuda de una balanza y calculando el volumen con las dimensiones teóricas de diseño.

Los datos de peso, volumen y densidad resultantes son expuestos en la Tabla 23, de ella se puede extraer que las placas de acabado liso tienen un peso entre los $12,52 \mathrm{Kg}$ y $12,56 \mathrm{Kg}$, por su parte la placa No. 4 con acabado de textura posee un peso de 12,86 Kg debido a su mayor volumen.

Los cálculos de densidad señalan unas leves diferencias entre las placas de concreto de acabado liso en un rango que va desde los $2003,2 \mathrm{Kg} / \mathrm{m}^{3}$ a los $2009,6 \mathrm{Kg} / \mathrm{m}^{3}$. Específicamente, esta máxima diferencia se presenta entre las placas 1 y 2 debido a que la probeta No. 1 pesa $30 \mathrm{~g}$ más que la probeta No. 2, sin embargo, esta máxima diferencia no supera el $0,32 \%$.

Por consiguiente, en referencia a la variable densidad, se entiende que estas leves variaciones no afectarán notoriamente el desempeño térmico de las probetas, así pues, se consideraron homogéneas y aptas para la experimentación.

\begin{tabular}{|c|c|c|c|c|}
\hline No. & PROBETA & VOLUMEN (m3) & PESO (Kg) & DENSIDAD (Kg/m3) \\
\hline 1 & Placa 1: acabado liso $50 \times 50 \times 2 \mathrm{~cm}$. & 0,00625 & 12,56 & 2009,600 \\
\hline 2 & Placa 2: acabado liso $50 \times 50 \times 2 \mathrm{~cm}$. & 0,00625 & 12,52 & 2003,200 \\
\hline 3 & Placa 3: acabado liso $50 \times 50 \times 2 \mathrm{~cm}$. & 0,00625 & 12.53 & 2004.800 \\
\hline 4 & $\begin{array}{l}\text { Placa con textura de } 50 \times 50 \times 2 \mathrm{~cm}+\text { Textura de } \\
\text { lamas horizontales de } 1 \mathrm{~cm} \text { de espesor y } 2.5 \mathrm{~cm} \\
\text { de profundidad, separadas cada } 2.5 \mathrm{~cm}\end{array}$ & 0.0064 & 12.85 & 2007.812 \\
\hline
\end{tabular}

Tabla 23. Valores de peso y volumen y densidad registrados y calculados para cada placa de concreto construida. Fuente: Elaboración propia. 
Control de transmitancia térmica o valor $\mathrm{U}$ : Utilizando el método de la caja caliente calibrada descrito más adelante en el título 7, se revisó esta variable en las probetas No. 1, 2 y $4^{48}$.

La Tabla 24 mostrada a continuación, resume los valores obtenidos de las mediciones, los cuales fueron muy semejantes. Entre las placas de acabado liso se encontró que la No.1 alcanzó un valor de $3,73 \mathrm{~W} / \mathrm{m}^{2 \circ} \mathrm{K}$, mientras que, la No. 2 tuvo un valor de $3,70 \mathrm{~W} / \mathrm{m}^{2 \circ} \mathrm{K}$, lo cual significa una diferencia de solo $0,03 \mathrm{~W} / \mathrm{m}^{2 \circ} \mathrm{K}$, que porcentualmente es el $0,80 \%$.

De otro lado la misma experimentación realizada con la placa de lamas horizontales arrojó un valor de $3,72 \mathrm{~W} / \mathrm{m}^{2 \circ} \mathrm{K}$, el cual es bastante cercano a los resultados obtenidos con las dos placas anteriores. Su diferencia máxima se presenta con la placa No. 2 y solo es el $0,54 \%$.

De esta forma, el control del valor $U$ permite ver que hay unas muy leves diferencias en la capacidad que posee cada placa para transferir el calor por conducción, pero estas mismas no superan el $0,80 \%$, así pues, en cuanto a este parámetro las placas de concreto también se consideran aptas para la experimentación.

\begin{tabular}{|c|c|c|}
\hline No. & PROBETA & Transmitancia térmica $(\mathrm{U})$ en $\mathrm{W} / \mathrm{m}^{2}{ }^{\circ} \mathrm{K}$ \\
\hline 1 & Placa 1: acabado liso $50 \times 50 \times 2 \mathrm{~cm}$. & 3,73 \\
\hline 2 & Placa 2: acabado liso $50 \times 50 \times 2 \mathrm{~cm}$ & 3,70 \\
\hline 4 & $\begin{array}{l}\text { Placa con textura de } 50 \times 50 \times 2 \mathrm{~cm}+\text { Textura de lamas } \\
\text { horizontales de } 1 \mathrm{~cm} \text { de espesor y } 2.5 \mathrm{~cm} \text { de profundidad, } \\
\text { separadas cada } 2.5 \mathrm{~cm}\end{array}$ & 3,72 \\
\hline
\end{tabular}

Tabla 24. Valores de transmitancia térmica registrados mediante el método de la caja caliente para las placas de concreto No. 1, 2 y 4 . Fuente: Elaboración propia.

48 Para simplificar, la probeta No. 3 se exoneró de este control debido a que presenta valores intermedios de Densidad y Reflectancia entre la No. 1 y 2 y se infiere que su valor $U$ no será ni mayor ni menor a los resultados obtenidos con estas dos placas. 


\subsection{Normas de Medición}

En el presente título se describen las normas acatadas en el proceso de medición para la obtención de los datos experimentales de la presente prueba.

Con el objetivo de normalizar los términos, los métodos y los dispositivos de medición en el estudio del ambiente térmico, algunas instituciones como ISO, ANSI o ASTM han creado normas internacionalmente reconocidas y aceptadas en el campo científico. El presente trabajo procuró seguir las siguientes tres normas en cuanto a la medición del ambiente térmico: ISO 7726-2002 (International Organization for Standardization, 2002), ASTM E193399a (American Society for Testing and Materials, 2000) e ISO 18434-1:2008 (International Organization for Standardization, 2008).

Las definiciones y descripciones de los términos, conceptos, instrumentos y metodología para la toma de mediciones con los que se ha realizado este trabajo responden a lo estipulado en la norma ISO 7726-2002. Las variables como $\mathrm{T}_{\text {air, }} \mathrm{T}_{\mathrm{r}}$ y $\mathrm{HR}$ se han registrado acatando las recomendaciones manifestadas allí.

En la recopilación de los datos mediante el uso de la cámara termográfica se tomó en cuenta la norma ASTM E1933-99a (American Society for Testing and Materials, 2000) y la norma ISO 18434-1:2008.

\subsection{Instrumental}

A continuación, para cada variable analizada en esta prueba se le indica el respectivo equipo utilizado y su correspondiente protocolo de medición:

\begin{tabular}{|l|l|l|}
\hline \multicolumn{1}{|c|}{ INSTRUMENTO } & \multicolumn{1}{|c|}{ VARIABLE } & \multicolumn{1}{c|}{ DESCRIPCIÓN } \\
\hline Cámara termográfica testo 875i & $\begin{array}{l}\text { - Temperatura radiante o } \\
\text { temperatura superficial. }\end{array}$ & Consultar Apéndice 3, título 3.1. \\
\hline $\begin{array}{l}\text { Termohigrómetro digital } \\
\begin{array}{l}\text { Datalogger marca Extech } \\
\text { (modelo RHT30) }\end{array}\end{array}$ & $\begin{array}{l}\text { - Temperatura del aire. } \\
\text { - Humedad relativa. }\end{array}$ & Consultar Apéndice 3, título 3.2. \\
\hline
\end{tabular}

Tabla 25. Instrumental utilizado en la experimentación de porcentaje de reducción de la $\mathrm{T}_{\mathrm{r}}$ y control de la $\mathrm{T}_{\text {air }} \mathrm{y}$ la HR. Fuente: Elaboración propia. 


\subsection{Protocolo de medición}

Cada rutina de medición consistió en los siguientes pasos:

\section{Verificación de similitud de $T_{r}$}

Dentro del sitio de acopio del aparato experimental descrito con anterioridad, la primera actividad que se realiza es una medición de $T_{r}$ en las superficies exteriores e interiores de las placas de concreto de ambos módulos para verificar que estas sean similares. La campaña no debería efectuarse si esta diferencia fuera notoria ya que esto afectaría los resultados.

Un ejemplo de esta verificación se muestra a continuación en Figura 75 (correspondiente a la calibración del aparato experimental).
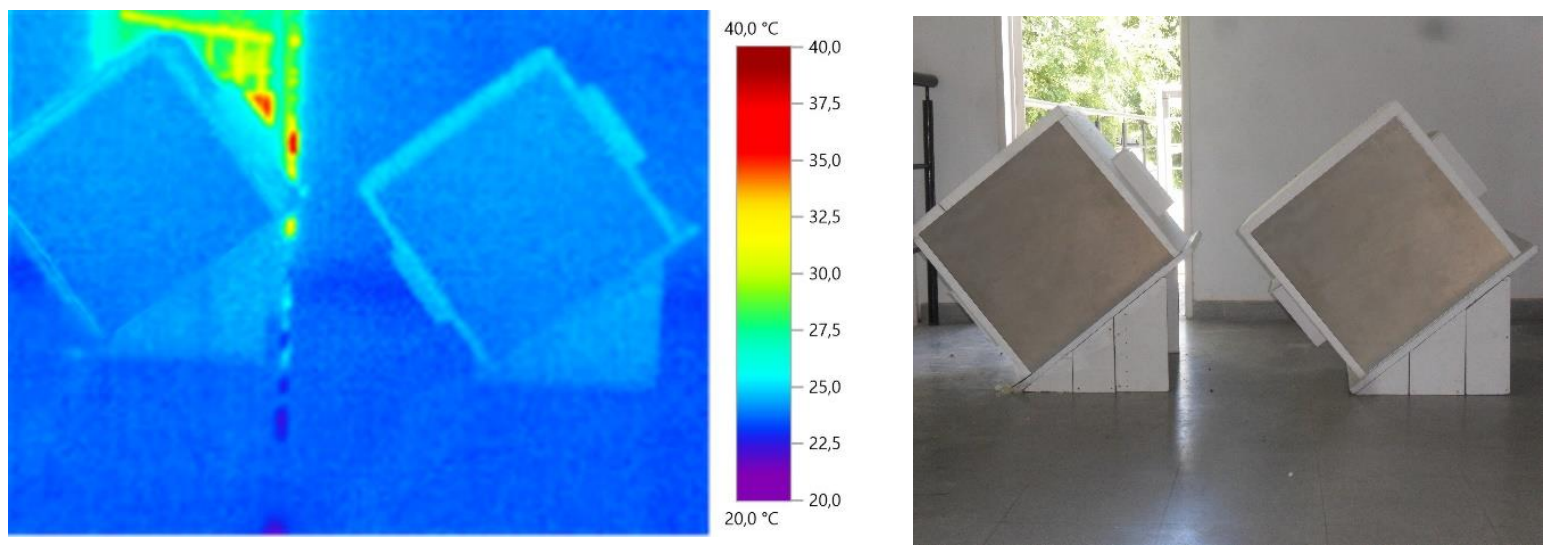

Figura 75. Verificación de condiciones similares de $T_{r}$ en el sitio de acopio. Fuente: Elaboración propia.

\section{Registro de $\mathrm{T}_{\text {air }}$ y HR: Programación y posicionamiento de termohigrómetros}

Una vez verificado el punto anterior se procede a programar los termohigrómetros dataloggers (DL), es importante mencionar que esta configuración se verificó antes de cada campaña, programando que el inicio y final de dichos registros fueran a las 12:00 y a las 18:00 horas respectivamente.

Los DL tienen gran capacidad de almacenamiento de datos, sin embargo, se consideró equilibrado configurar la frecuencia de medición cada 30 minutos para no saturarlos de demasiada información y a la vez no perder eventos importantes que comprometan el objetivo de la investigación. Como el periodo de medición fue de 12:00 a 18:00 se obtuvieron 13 registros diarios de $\mathrm{T}_{\text {air }} \mathrm{y} \mathrm{HR}$ por cada módulo de pruebas. 
Ya que en este caso el instrumental tenía igual apariencia, cada DL fue rotulado con el objetivo de prevenir el intercambio de resultados y su información fue descargada y ordenada en una computadora inmediatamente después de finalizar cada tarde.

Luego de tener programados los DL, estos se localizaron en el interior de cada módulo. La cajilla de aluminio que contiene el DL fue ubicada en el centroide del módulo ${ }^{49}$, suspendida mediante un soporte rígido de alambre anclado en las láminas de poliestireno, como se indica a continuación en la Figura 76.

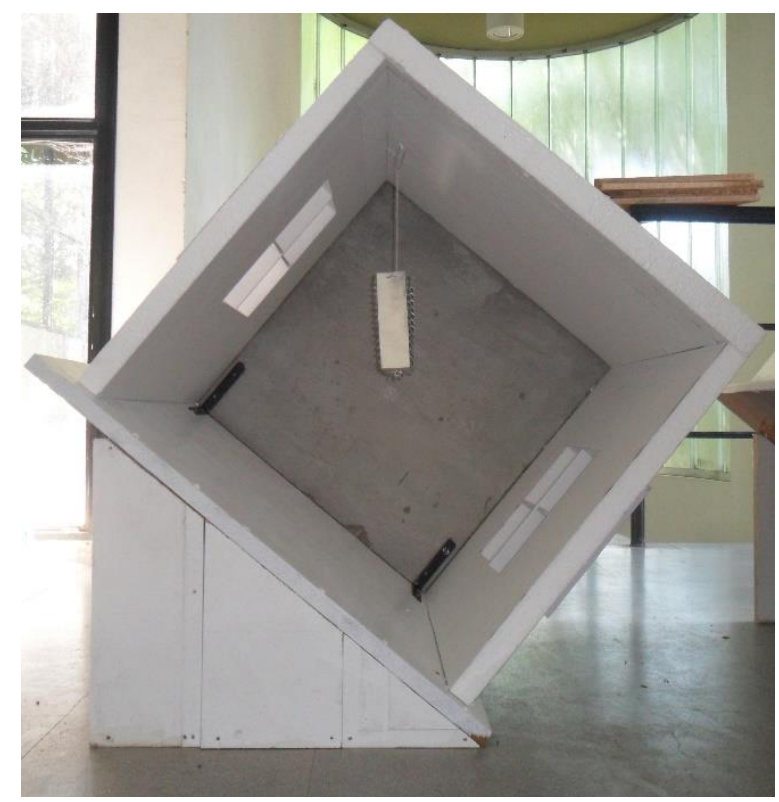

Figura 76. Posicionamiento de los dataloggers. Fuente: Elaboración propia.

\section{Posicionamiento del aparato experimental en la plataforma de medición}

Después de posicionar los DL en cada módulo, estos son trasladados a una plataforma de medición que facilita la captura de las termografías y evita el sobrecalentamiento que aporta la losa de concreto de la terraza.

${ }^{49}$ Centro en planta a una altura de $0,25 \mathrm{~m}$. 
La plataforma de medición es una estructura fija de perfiles metálicos que soportan una superficie horizontal de fibrocemento, su altura es de 1,20 m. En ella se trazó una línea en el sentido Norte-Sur con el objetivo de alinear y orientar los modelos más fácilmente.

Una vista de este posicionamiento se aprecia en la siguiente Figura 77.
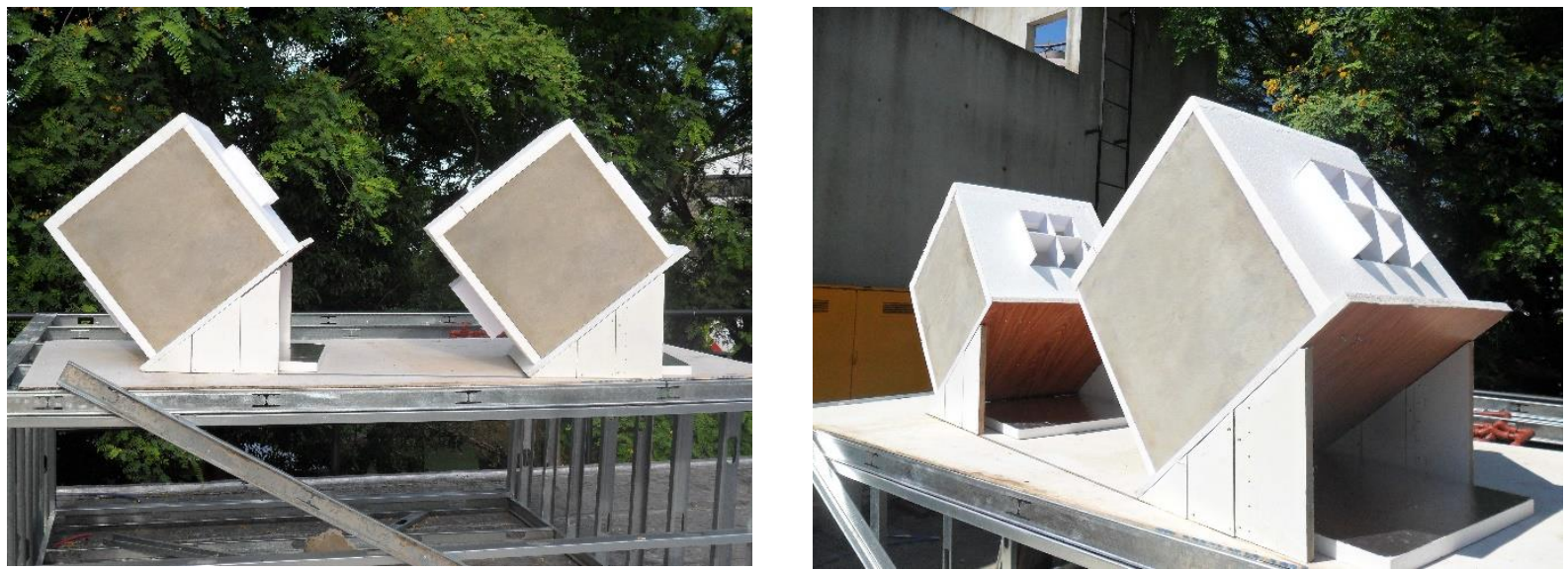

Figura 77. Posicionamiento y alineación del aparato experimental en la plataforma de medición. Fuente: Elaboración propia.

\section{Registro de Temperatura radiante:}

En cada tarde de medición de 12:00 a 18:00, se tomó una secuencia de termografías (con su respectiva fotografía) cada 30 minutos. Esa secuencia está integrada al menos por 5 vistas, con lo cual, en cada tarde de medición se obtuvieron como mínimo 65 imágenes térmicas. $\mathrm{A}$ continuación, se describe cada una de las imágenes de la secuencia:

1. Vista exterior de ambos módulos desde la fachada oeste.

2. Vista exterior individual del módulo testigo desde la fachada oeste.

3. Vista exterior individual del módulo intervenido desde la fachada oeste.

4. Vista interior individual del módulo testigo (interior de la fachada oeste).

5. Vista interior individual del módulo intervenido (interior de la fachada oeste).

El intervalo de muestreo de la $T_{r}$ cada 30 minutos fue sincronizado con la programación de los dataloggers de medición de la $\mathrm{T}_{\text {air }}$ y la $\mathrm{HR}$, con el fin de obtener datos de forma simultánea y en cantidades equilibradas sin perder eventos durante la tarde. Sin embargo, esto no fue del todo posible porque solo se contaba con una cámara termográfica (CT), con lo cual se advierte que existió una separación temporal entre imágenes de aproximadamente 10 a 15 segundos. 
Respetando las recomendaciones de las normas mencionadas en el anterior título 6.4 acerca de que cada captura debe ser tomada a la mínima distancia posible, se manejaron dos distancias: la primera para capturar ambos módulos y la segunda para tomarlos individualmente.

Para la primera opción, dicha distancia fue de $2,50 \mathrm{~m}$, mientras que para la segunda solo fue de 1,50 m. Una vista del segundo proceso de captura se observa a continuación en la Figura 78.

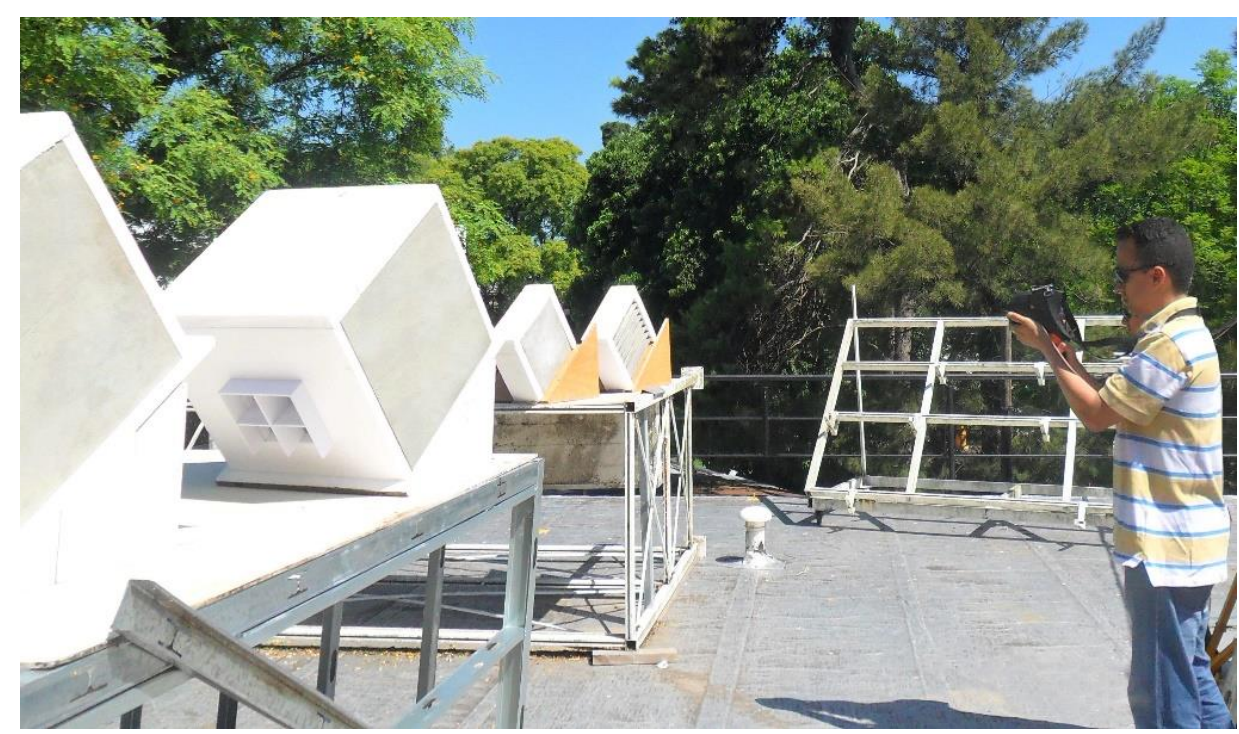

Figura 78. Captura de termografías. Fuente: Elaboración propia.

La CT posee una memoria suficiente para almacenar varios días de experimentación, sin embargo, para evitar pérdidas y confusiones en los archivos, los registros fueron descargados y ordenados cronológicamente al final de cada campaña en una computadora.

Luego de la descarga, las imágenes térmicas fueron abiertas con el software Testo IRsoft, que viene incluido con el equipo. El software posee la herramienta "promedio" que permite calcular la temperatura superficial media de cualquier área que se le indique en la pantalla.

La Figura 79 contiene una vista de pantalla del IRsoft, como ejemplo en ella se muestran tres termografías tomadas a las 16:00 durante la medición de la solución constructiva de aislamiento reflectivo + absortividad. A la izquierda se muestra una imagen de ambos módulos, mientras que en el centro y derecha se muestran individualmente el módulo intervenido y el módulo testigo. En estas dos últimas termografías se nota un marco que señala solamente el área de estudio, es decir la superficie interna de la placa de concreto. El programa promedia las temperaturas de estas áreas, determinando así la $T_{r}$. 
Finalmente, estos resultados fueron tabulados y graficados mediante hojas electrónicas para su posterior análisis.

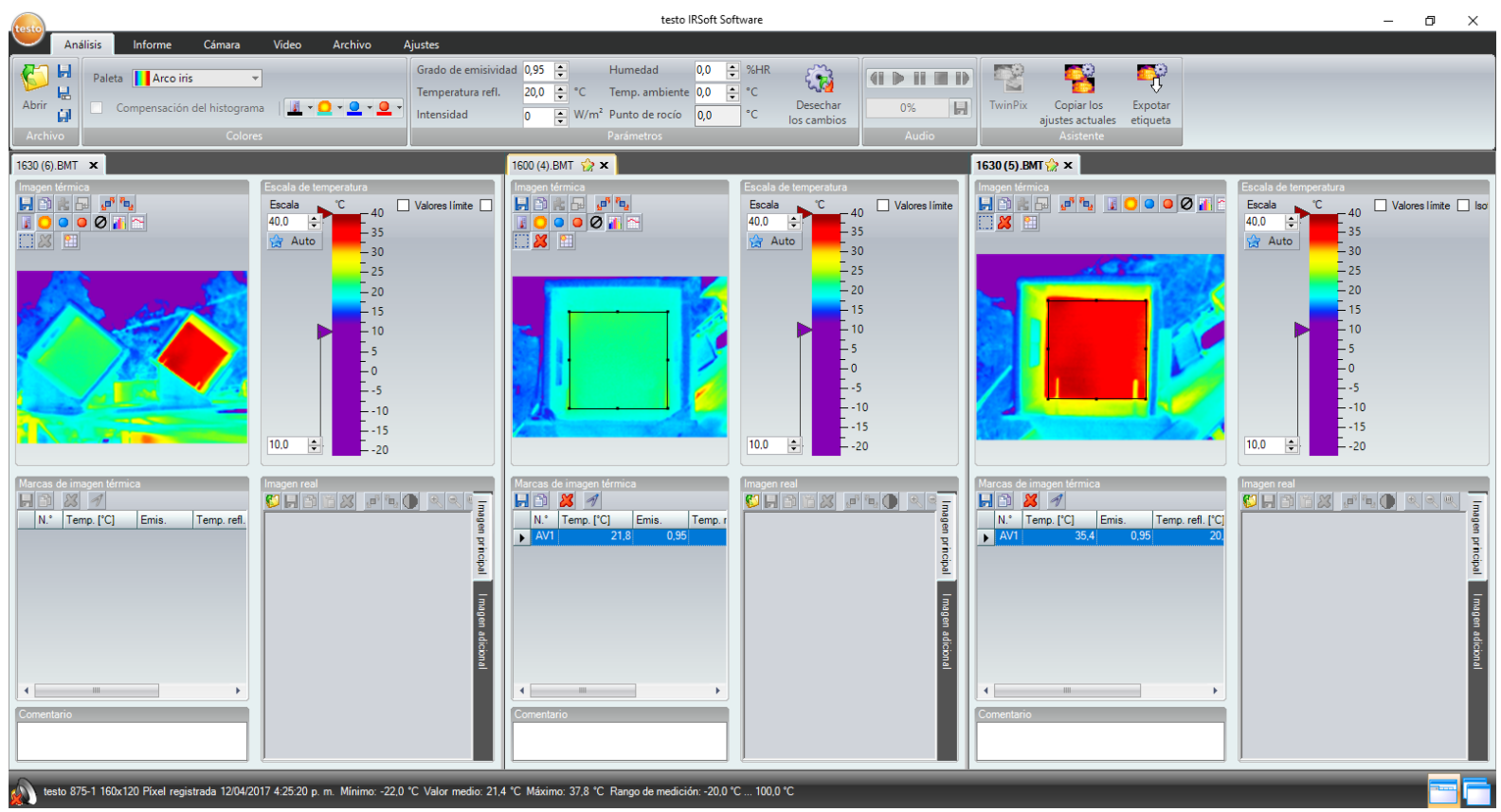

Figura 79. Vista de pantalla del procesamiento de las termografías para hallar la $T_{r}$, mediante el software Testo IRSoft. Fuente: Elaboración propia.

\section{Registro de Radiación solar}

Para la medición de la radiación solar se tuvo acceso a los datos recopilados por el piranómetro de la estación meteorológica automática del observatorio de la Universidad Nacional de La Plata ${ }^{50}$ (Departamento de Sismología e Información Meteorológica. Estación Meteorológica Automática. La Plata Observatorio., 2018), separada a una distancia de $880 \mathrm{~m}$ del sitio de experimentación.

Estos datos son cargados automáticamente a la red cada 5 minutos, intervalo en el que este equipo está programado para tomar una medición.

50 http://meteo.fcaglp.unlp.edu.ar/ 
Los datos fueron descargados mediante el software WeatherLink 6.0.3 que trabaja en red al final de cada campaña experimental. Aunque estos datos permanecen siempre en la web, se prefirió al final de cada jornada experimental descargarlos inmediatamente

\section{Desmonte y acopio del aparato experimental}

Concluida la jornada de mediciones durante las 19:00 y las 12:00 horas, el aparato experimental fue llevado al sitio de acopio con el objetivo de protegerlo de cualquier eventualidad, pero sobre todo con el fin de enfriarlo y obtener nuevamente la igualdad de $\mathrm{T}_{\mathrm{r}}$ en ambos módulos, necesaria para acometer otra campaña de evaluación.

El lugar de acopio es un recinto cubierto contiguo al laboratorio a cielo abierto. Este lugar no posee climatización mecánica, pero sí ventilación natural, dentro de este, los módulos estuvieron libres de goteras, radiación solar y corrientes de aire puntualizadas. Una vista de este lugar se muestra a continuación en la Figura 80.

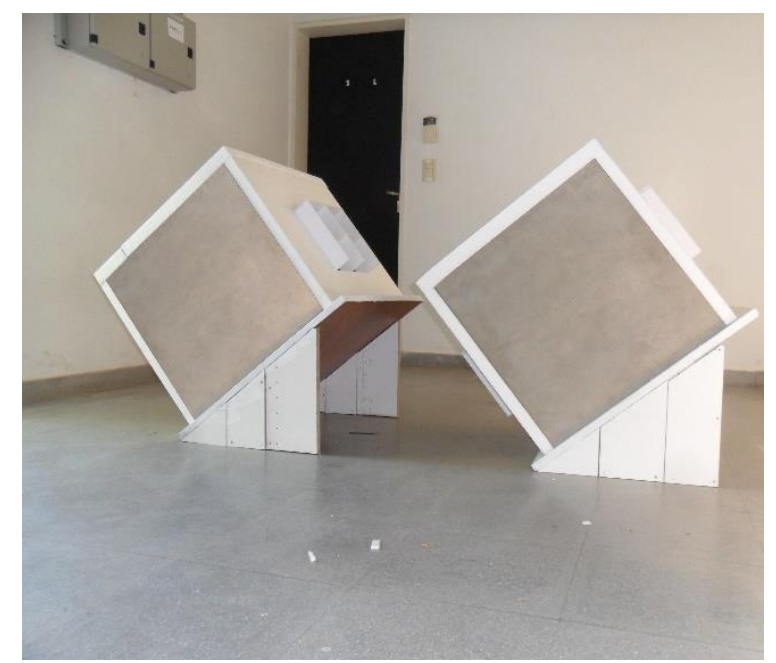

Figura 80. Lugar y condiciones de acopio del aparato experimental. Fuente: Elaboración propia. 


\subsection{Calibración.}

En concordancia con los trabajos desarrollados por Guo, Qiao, Huang, Fang, \& Han (2012) y Kang \& Yang (2013), este método es válido para realizar comparaciones de desempeño siempre y cuando se garantice un comportamiento térmico similar entre los módulos del aparato experimental. Debe tenerse en cuenta que este experimento es en escala reducida y pueden presentarse ligeras diferencias de comportamiento en aplicaciones a escala real.

Así que, antes de realizar las pruebas definitivas, los módulos experimentales fueron calibrados con el objetivo de comprobar que su comportamiento térmico tuviese condiciones similares. Durante la calibración se tuvo en cuenta que ambos módulos estuviesen libres de interferencias tales como, sombras, reflejos, goteras o corrientes de aire focalizadas que modificaran el desempeño térmico en alguno de ellos.

De forma estratégica las placas de concreto escogidas para ser probadas en la calibración fueron las No. 1 y No. 2, ya que son las que presentaron mayores diferencias en peso, reflectancia y transmitancia, mientras que la placa la No. 3 presentó valores intermedios entre la No. 1 y la No. 2, con lo cual se infiere que también tendrá un comportamiento térmico intermedio. Cabe recordar que la muestra No. 4 incluye el texturizado de lamas horizontales y por tal razón no se incluye en el proceso de calibración, pero será utilizada posteriormente en la evaluación de desempeño del sombreado.

De esta forma, el módulo de pruebas acoplado con la placa de concreto No. 1 fue denominado Módulo 1, y el módulo con la placa No. 2 fue denominado Módulo 2.

La similitud térmica en esta calibración está dada por la similitud en el comportamiento de la $T_{\text {air, }}$ HR y $T_{r}$, que se midieron cada 5 minutos durante la tarde del 5 de enero de 2017.

Las mediciones de $T_{\text {air }}$ y $H R$ fueron tomadas en el centroide de cada módulo mediante termohigrómetros dataloggers marca EXTECH, modelo RHT30 (ver descripción en el título 3.2 del Apéndice 3) previamente calibrados y protegidos de la radiación con una caja de aluminio pulido como se indicó en el anterior título.

Por su parte, la $T_{r}$ fue tomada de acuerdo con el protocolo indicado en el título anterior la cámara termográfica marca Testo, modelo 875 - 1 previamente calibrada y configurada como se describe en el Apéndice 3, título 3.1.

Los resultados de esta calibración pueden verse en la gráfica comparativa de la Figura 81, donde se aprecia el comportamiento de las variables $T_{a i r}, H R$ y $T_{r}$. 
De forma individual, las mediciones de $\mathrm{T}_{\text {air }}$ presentaron diferencias medias de $0,15^{\circ} \mathrm{C}$ y no superiores a $0,4^{\circ} \mathrm{C}$ entre módulo y módulo, con lo cual se obtuvieron diferencias promedio y máximas de $0,53 \%$ y $1,4 \%$ respectivamente. Aunque hubo excepciones, en la mayoría de los casos el Módulo 1 resultó ser el más caliente. Esto se atribuye a que la placa de concreto del Módulo 1 posee una menor reflectancia y una mayor densidad.

En lo que concierne a la HR, se presentaron diferencias medias de $0,30 \%$ y no superiores a 0,7\% entre módulos, con lo cual se obtuvo una disimilitud media de $0,75 \%$ y una máxima de 1,67\%. En la mayoría de los casos el Módulo 2 presentó un ambiente más húmedo, aunque hubo excepciones.

En cuanto a la $T_{r}$, se presentaron diferencias medias de $0,27^{\circ} \mathrm{C}$ y no superiores a $0,5^{\circ} \mathrm{C}$, con lo cual se obtuvieron diferencias medias de 0,53\% y máximas de 0,99 \%. En la mayoría de los casos el Módulo 2 presentó una $T_{r}$ en su cara interior más baja que el Módulo 1, aunque hubo excepciones. Esto es nuevamente atribuible a la mayor reflectancia y menor densidad presentada por el Módulo 2.

En resumen, aunque hubo excepciones, la tendencia es que el Módulo 1 presente mayores valores de $T_{\text {air }}$ y $T_{r}$ y el Módulo 2 presente mayores valores de HR a causa de las razones expuestas anteriormente. Sin embargo, la gráfica comparativa de la Figura 81 muestra un desempeño térmico bastante semejante en ambos módulos del aparato experimental y las disimilitudes numéricas son bastante pequeñas, ya que no superaron el $1,7 \%$, con lo cual no fueron consideradas relevantes y se espera que los resultados obtenidos de la experimentación con estos módulos sean confiables. 
CALIBRACIÓN: GRÁFICA COMPARATIVA DE T $T_{\text {air, }}$ HR y Tr vs TIEMPO, ENTRE LOS DOS MÓDULOS DEL APARATO EXPERIMENTAL

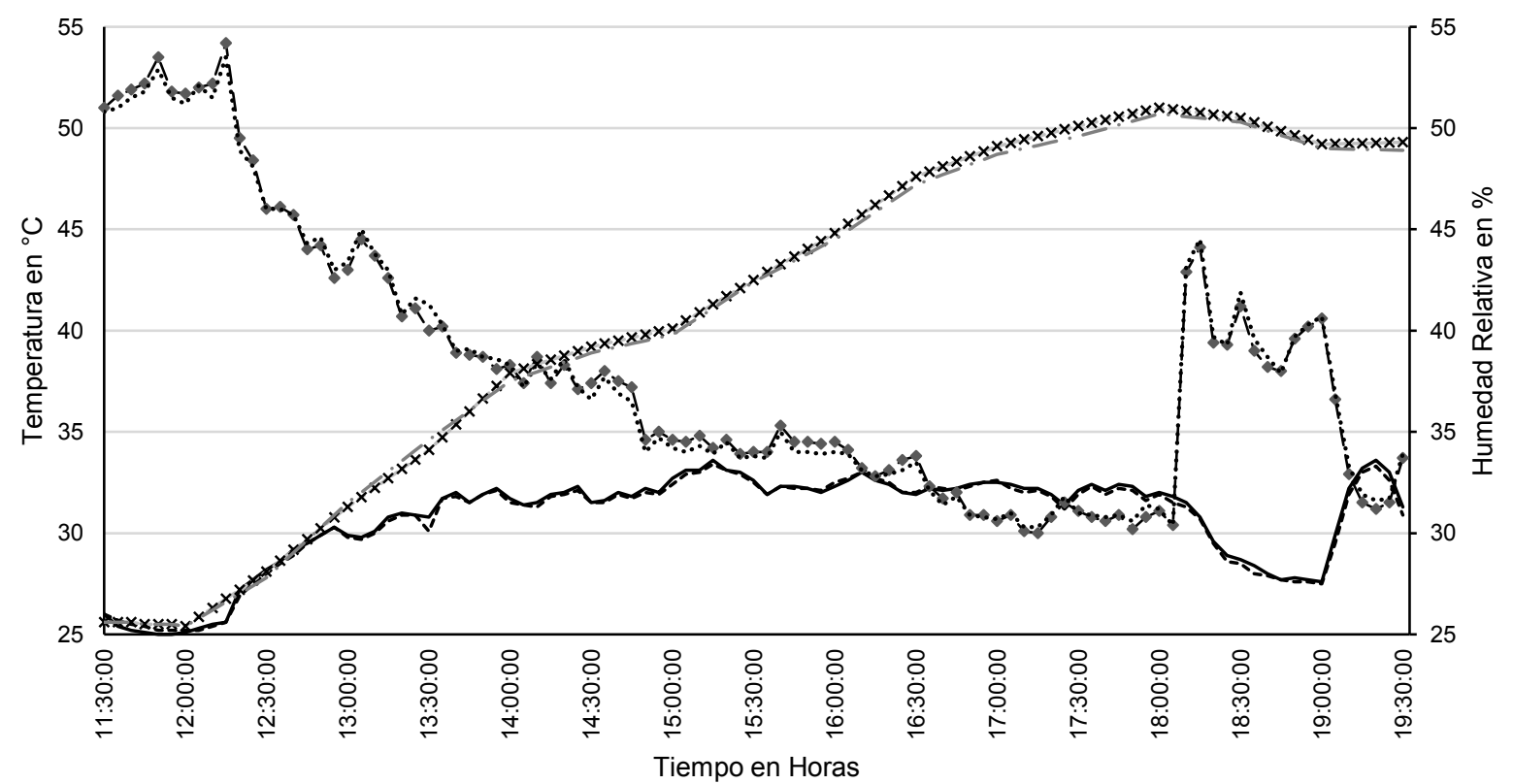

Tair Módulo 1 - ---- Tair Módulo $2-\rightarrow-\cdot$ HR Módulo 1 .

HR Módulo 2 ---x--- Tr Módulo $1-\cdots-\operatorname{Tr}$ Módulo 2

Figura 81. Gráfica comparativa de $\mathrm{T}_{\text {air, }} \mathrm{HR}$ y $\mathrm{T}_{\mathrm{r}}$ vs tiempo, entre los dos módulos del aparato experimental. Datos obtenidos durante la calibración. Fuente: Elaboración propia. 


\subsection{Resultados}

En este título se presentan los resultados obtenidos con este experimento. En la primera parte se describe poco a poco lo observado con cada opción, mientras que en la parte final se integra, compara y discute esta información, proceso en el cual se destaca o elige una de estas soluciones constructivas para continuar la investigación.

También se hacen comparaciones entre los datos acá obtenidos con los calculados teóricamente en el capítulo anterior.

El cálculo de porcentaje de reducción de la $T_{r}$ (al igual que con $T_{\text {air }}$ y el aumento de la HR) se realizó con base en el método de eficiencia relativa establecido por Sánchez (1993) y utilizado también por Fajardo (2005) y Osuna (2017) para determinar la capacidad de enfriamiento de distintos modelos de cubiertas. Estos estudios compararon el desempeño experimental de modelos a escala. Este concepto es la fracción de temperatura reducida lograda por el módulo intervenido en relación con el módulo testigo y se establece relacionando el área bajo la curva de la variable analizada en el tiempo. 


\subsubsection{Autosombreado (AS)}

La experimentación con la estrategia de autosombreado se llevó a cabo durante los días 14,16 y 17 de enero de 2017. En la siguiente Figura 82 se aprecia una fotografía de la instalación elaborada para esta propuesta constructiva, al lado derecho se ubicó el módulo intervenido (MI) con las lamas horizontales implementadas y a la izquierda puede verse el módulo testigo (MT).

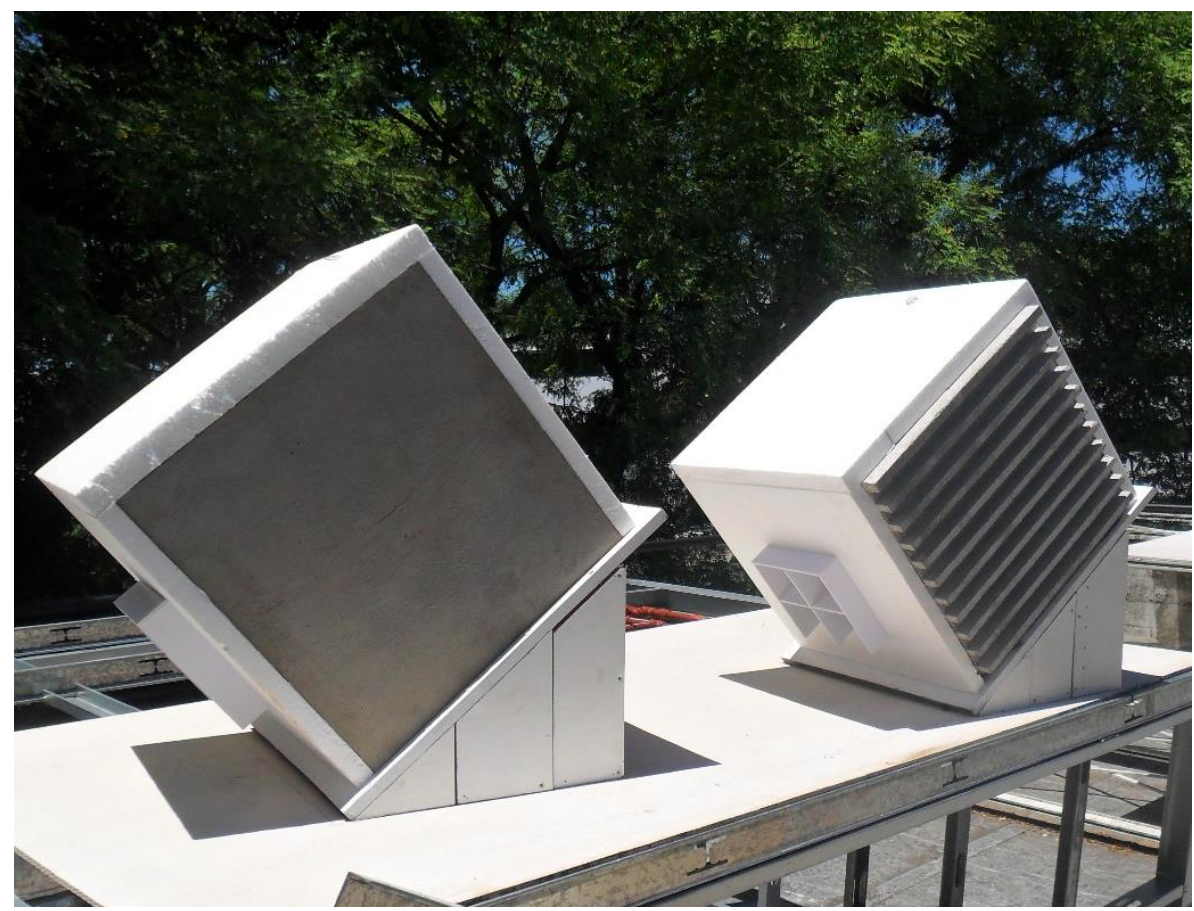

Figura 82. Configuración del aparato experimental para experimentación con la estrategia de autosombreado. Fuente: Elaboración propia.

\section{Temperatura radiante}

Algunas termografías y fotografías adquiridas en el registro de la $T_{r}$ durante esta campaña experimental se muestran en los tres collages correspondientes a las 13:00, 15:30 y 18:00 del 14 de enero de 2017. Estos collages corresponden a la Figura 83, Figura 84 y Figura 85 respectivamente. Estas, se elaboraron con el objetivo de sintetizar la tendencia general de desempeño térmico de esta solución constructiva durante los tres días de experimentación.

Las imágenes de la Figura 83 muestran que a las 13:00, la $\mathrm{T}_{\mathrm{r}}$ del $\mathrm{Ml}$ se encontró $3^{\circ} \mathrm{C}$ por debajo del MT, el MT presentó una $T_{r}$ casi homogénea en toda su superficie tanto exterior como interior. En contraste, en el interior y exterior del MI se notó un calentamiento focalizado en la primera lama superior, debido a que esta recibió en primera instancia la radiación solar y sombreó al resto de la superficie. 
La Figura 84, muestra la situación a las 15:30, allí las diferencias de $T_{r}$ entre el MT y el MI aumentaron a $4^{\circ} \mathrm{C}$, sin embargo, el Ml comenzó a mostrar calentamientos en todas las lamas.

Por último, en la Figura 85 correspondiente a las 18:00, la diferencia de $T_{r}$ entre los módulos se invirtió, pues se distingue el Ml con valores de $T_{r}$ un poco más elevados que el MT.
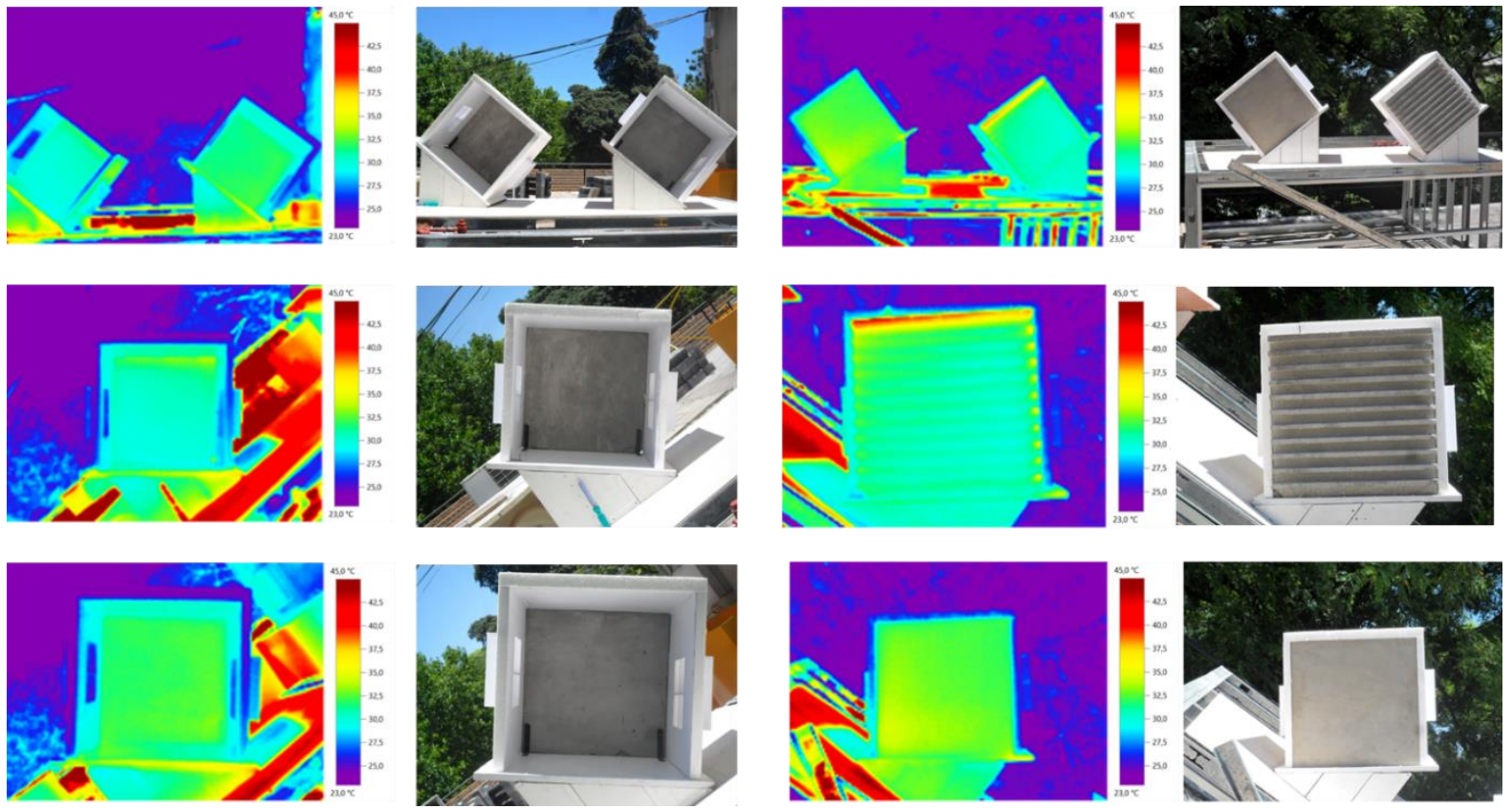

Figura 83. Collage de termografías y fotografías correspondientes al 14 de enero de 2017 a las 13:00. Fuente: Elaboración propia. 

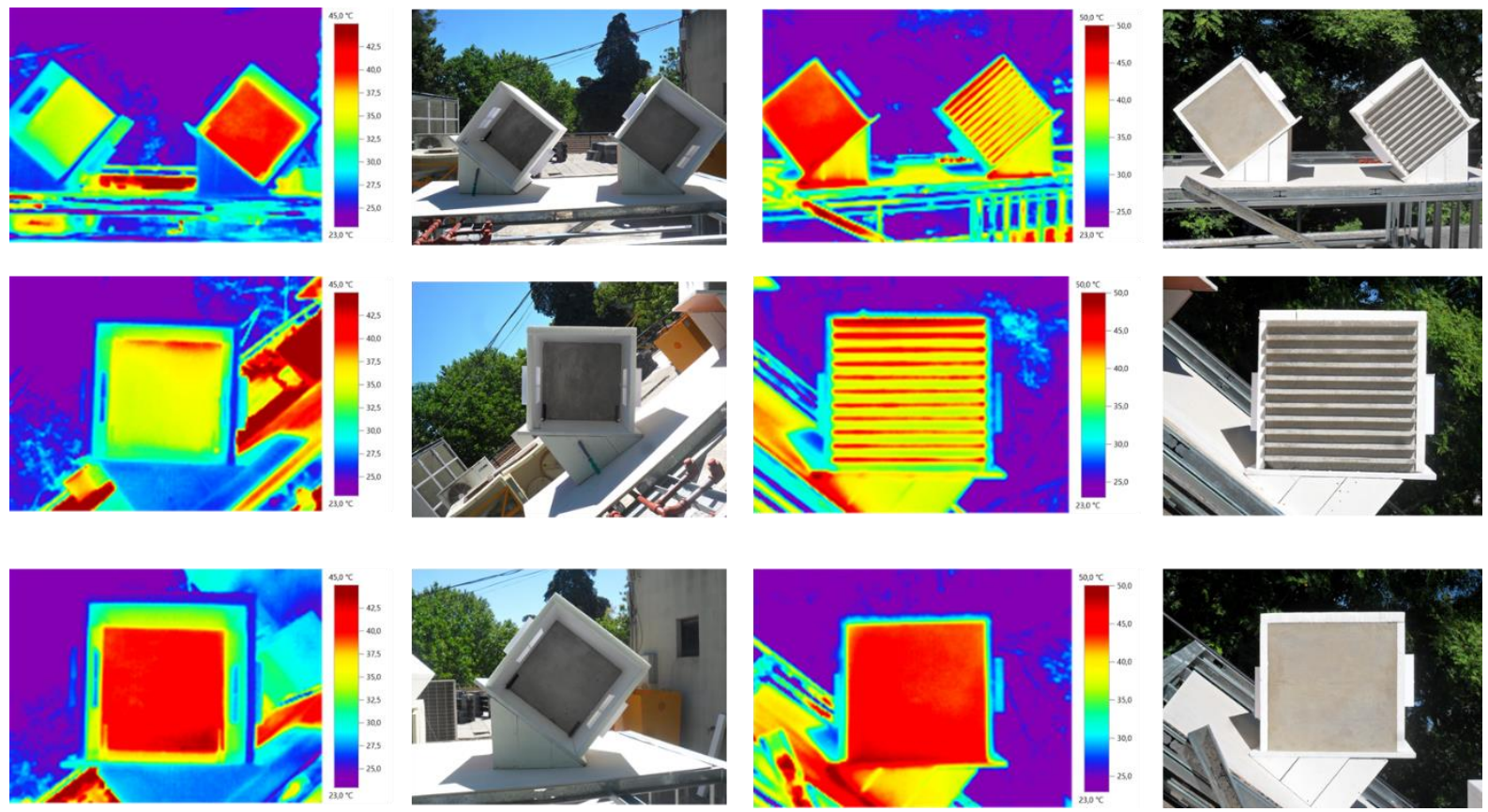

Figura 84. Collage de termografías y fotografías correspondientes al 14 de enero de 2017 a las 15:30. Fuente: Elaboración propia
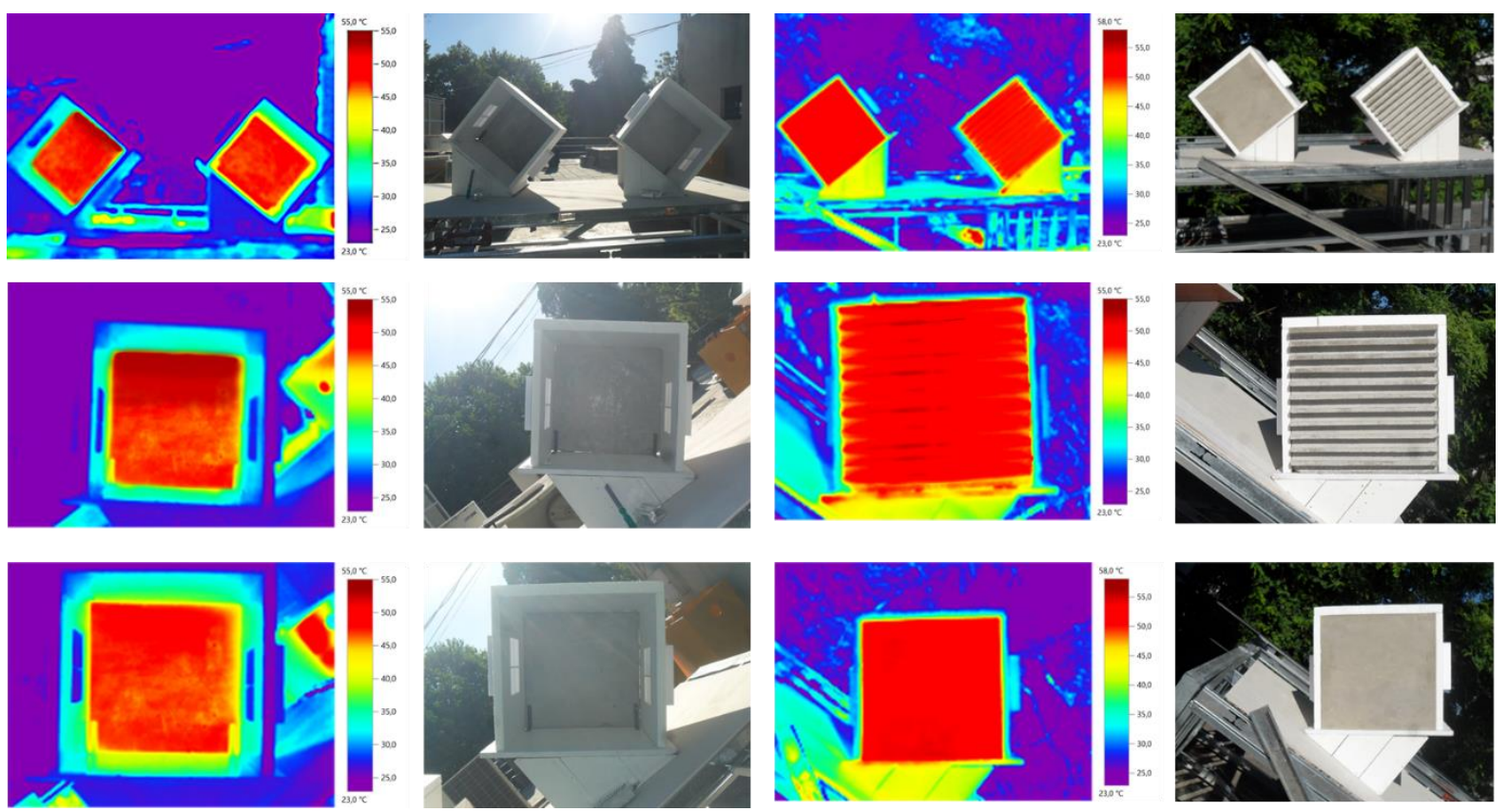

Figura 85. Collage de termografías y fotografías correspondientes al 14 de enero de 2017 a las 18:00. Fuente: Elaboración propia.

Como se indicó en el protocolo de medición (numeral 6.6), el cálculo de la Tr realizado a través del software IRSoft, se efectuó solamente con las termografías de la cara interna de cada módulo, es decir, con las dos imágenes inferiores de la columna izquierda.

Los resultados de dicho cálculo, cada 30 minutos pueden leerse a continuación en la gráfica de la Figura 86. En ella se nota que la reducción de la $\mathrm{T}_{\mathrm{r}}$ en el $\mathrm{Ml}$ es mayor en las primeras 
horas de la tarde, cuando las lamas proveen mayor porcentaje de sombreo, sin embargo, esta diferencia se disminuye gradualmente al finalizar la tarde.

Al calcular la reducción de $T_{r}$ de los tres días, mediante la comparación del área bajo las curvas, se obtuvieron valores de $17,83 \%, 18,32 \%$ y $17,11 \%$, para un promedio de $17,7 \%$, lo cual es un poco inferior al porcentaje de $18 \%$ obtenido en los procedimientos teóricos.

Asimismo, se encontró que la disminución media fue de $2,6^{\circ} \mathrm{C}$ y la máxima fue de $5,4{ }^{\circ} \mathrm{C}$ presentada el 14/01/2017 a las 14:30. El peor escenario, se presentó siempre al final de la tarde, cuando este tratamiento no redujo la $T_{r}$ sino que la elevó, el peor de estos casos fue registrado a las 18:00 del 17/01/2017 con un incremento en la $T_{r}$ de $0,8^{\circ} \mathrm{C}$.

Nótese además que, durante el tiempo evaluado, la estrategia solo pudo lograr niveles aceptables de confort en el inicio de la experimentación. En el tiempo restante se encontraron separaciones de más de $15^{\circ} \mathrm{C}$ respecto al límite máximo de confort.

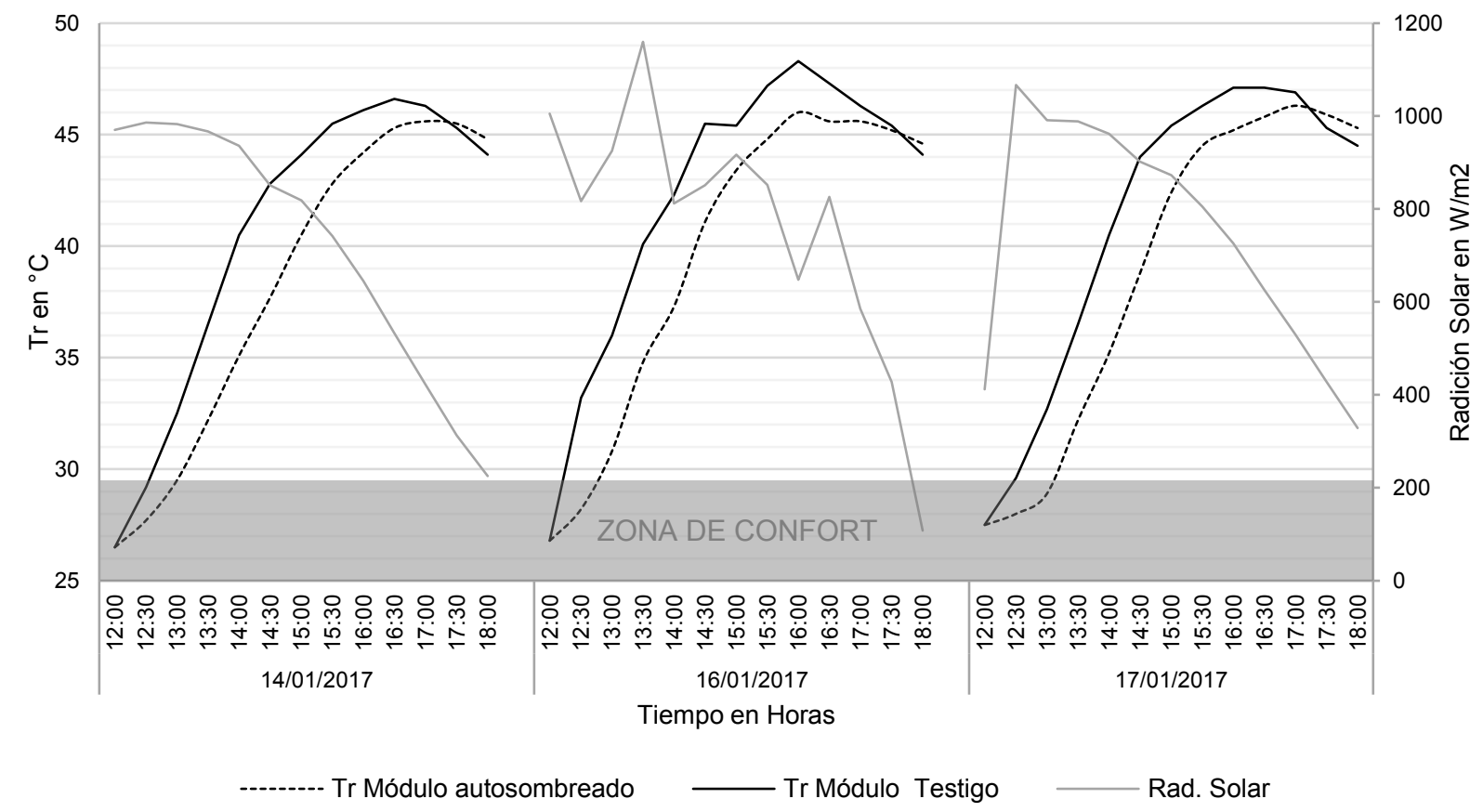

Figura 86. Gráfica comparativa de $T_{r}$ vs Tiempo entre el módulo experimental modificado con la estrategia de autosombreado y el módulo testigo. Fuente: Elaboración propia. 


\section{Temperatura del aire y humedad relativa}

Los valores de $T_{\text {air }}$ y HR registrados durante la experimentación con esta estrategia se muestran a continuación en la Figura 87 , en la cual se distinguen las diferencias de estas variables entre el MT y el MI.

En general, la $\mathrm{T}_{\text {air }}$ en el Ml fue menor que la del MT, el porcentaje medio de diferencia fue de $6,85 \%$. De otro lado, la HR permaneció más alta en el MI que en el MT en un porcentaje medio de $9,84 \%$.

La diferencia promedio de $\mathrm{T}_{\text {air }}$ entre el $\mathrm{MT}$ y $\mathrm{Ml}$ fue de $0,1^{\circ} \mathrm{C}$, con máxima de $0,5^{\circ} \mathrm{C}$. Por otra parte, la diferencia promedio de HR fue de $1 \%$, con una máxima de $1,7 \%$.

Aunque estas tendencias son continuas, los valores y porcentajes de diferencia son pequeños, y se encuentran dentro de la imprecisión del instrumental $\left( \pm 0,5^{\circ} \mathrm{C}\right.$ para $T_{\text {air }} \mathrm{y} \pm 3 \%$ para HR). Por esta razón, se considera que la implementación de esta solución constructiva no aportó cambios significativos en la $\mathrm{T}_{\text {air }}$ y la HR.

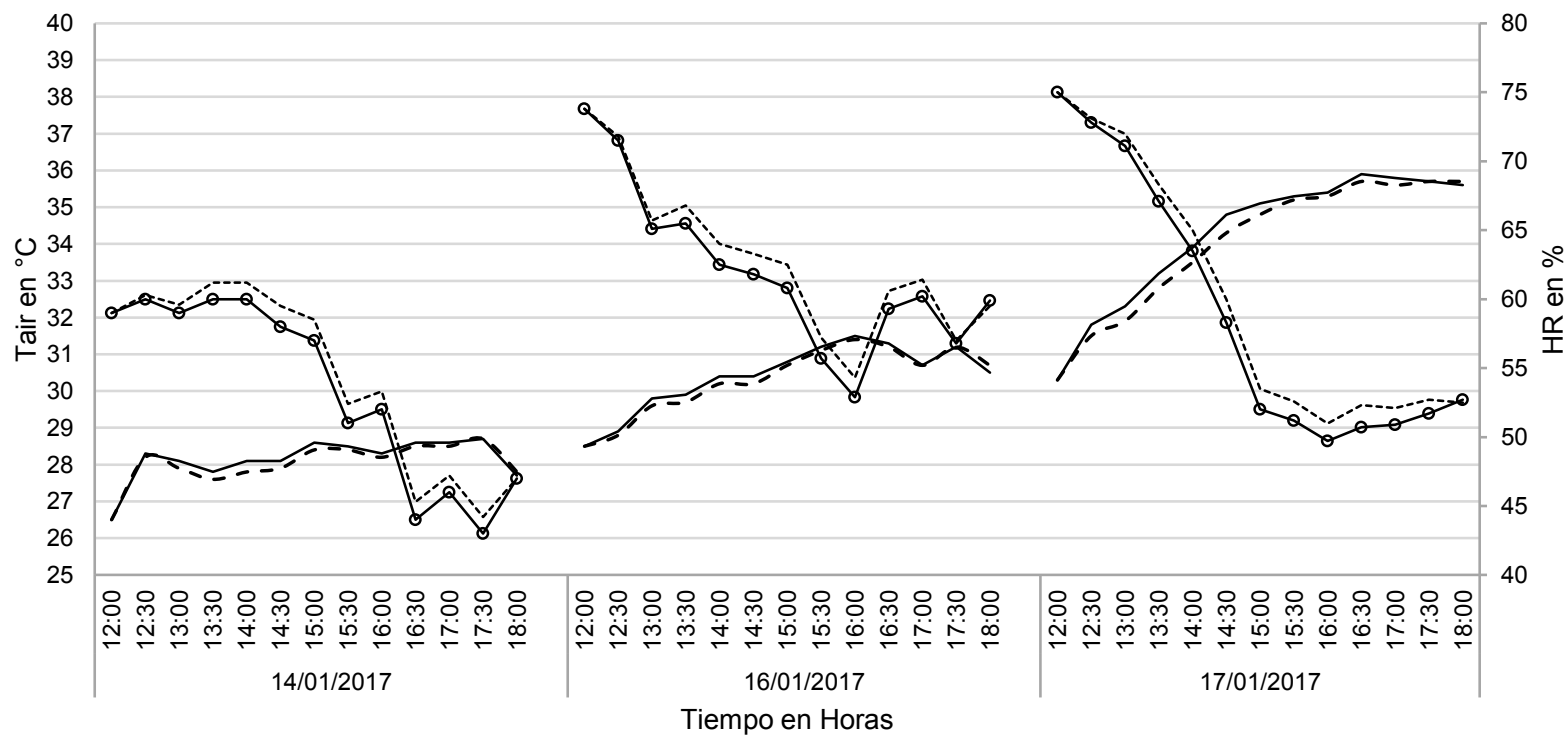

- - - - Tair Módulo sombreado de autosombreado y el módulo testigo. Fuente: Elaboración propia. 


\subsubsection{Baja absortividad (BA)}

La campaña experimental con esta estrategia se realizó durante las tardes del 18,19 y 21 de enero de 2017, una fotografía del aparato experimental configurado con esta alternativa se aprecia en la siguiente Figura 88, en este escenario al lado derecho se ubicó el Ml con el tratamiento de pintura de baja absortividad, mientras que a la izquierda se ubicó el MT.

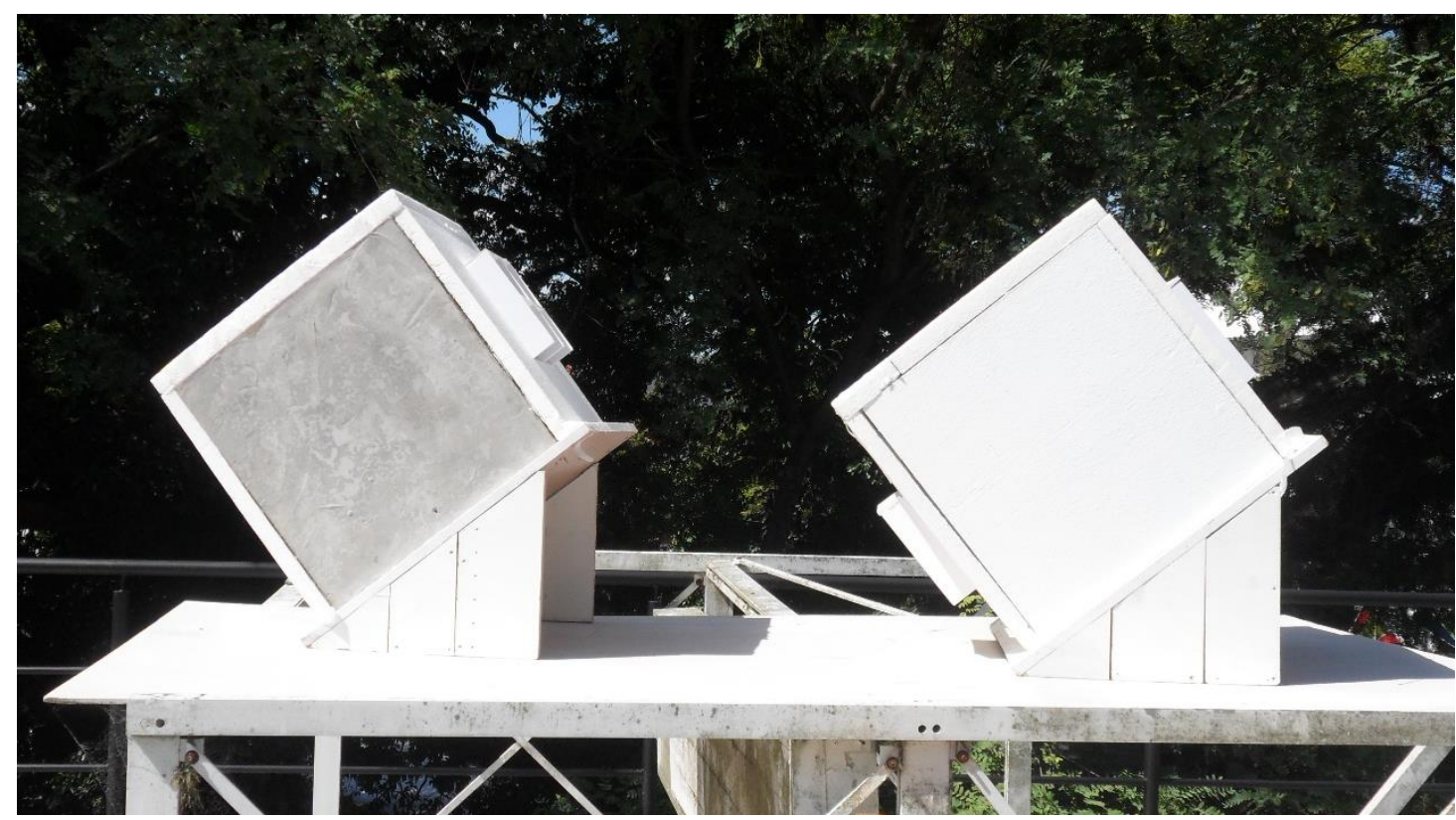

Figura 88. Configuración del aparato experimental con la estrategia de baja absortividad. Fuente: Elaboración propia.

\section{Temperatura radiante}

Algunas de las termografías y fotografías adquiridas durante esta campaña experimental, se muestran en los collages elaborados para las 13:00, 15:30 y 18:00 del 18 de enero de 2017. Estos collages corresponden a la Figura 89, Figura 90 y Figura 91 respectivamente. En esta secuencia, se observa y sintetiza la tendencia general de desempeño térmico de esta solución constructiva durante los tres días de experimentación.

Las imágenes de la Figura 89 muestran que a las $13: 00$, la $\mathrm{T}_{\mathrm{r}}$ del $\mathrm{Ml}$ se encontró $2,3^{\circ} \mathrm{C}$ por debajo del MT. Más adelante, en el collage de la Figura 90 correspondiente a las 15:30, esta diferencia se acrecentó a $7,4^{\circ} \mathrm{C}$. Por último, en la Figura 91 correspondiente a las 18:00 horas, la diferencia de $\mathrm{T}_{\mathrm{r}}$ llegó a $8,3^{\circ} \mathrm{C}$.

Las termografías mostraron una tendencia marcada y continua de que la $T_{r}$ del Ml se encontró siempre por debajo de la del MT, tanto desde el inicio como al final de la experimentación. 

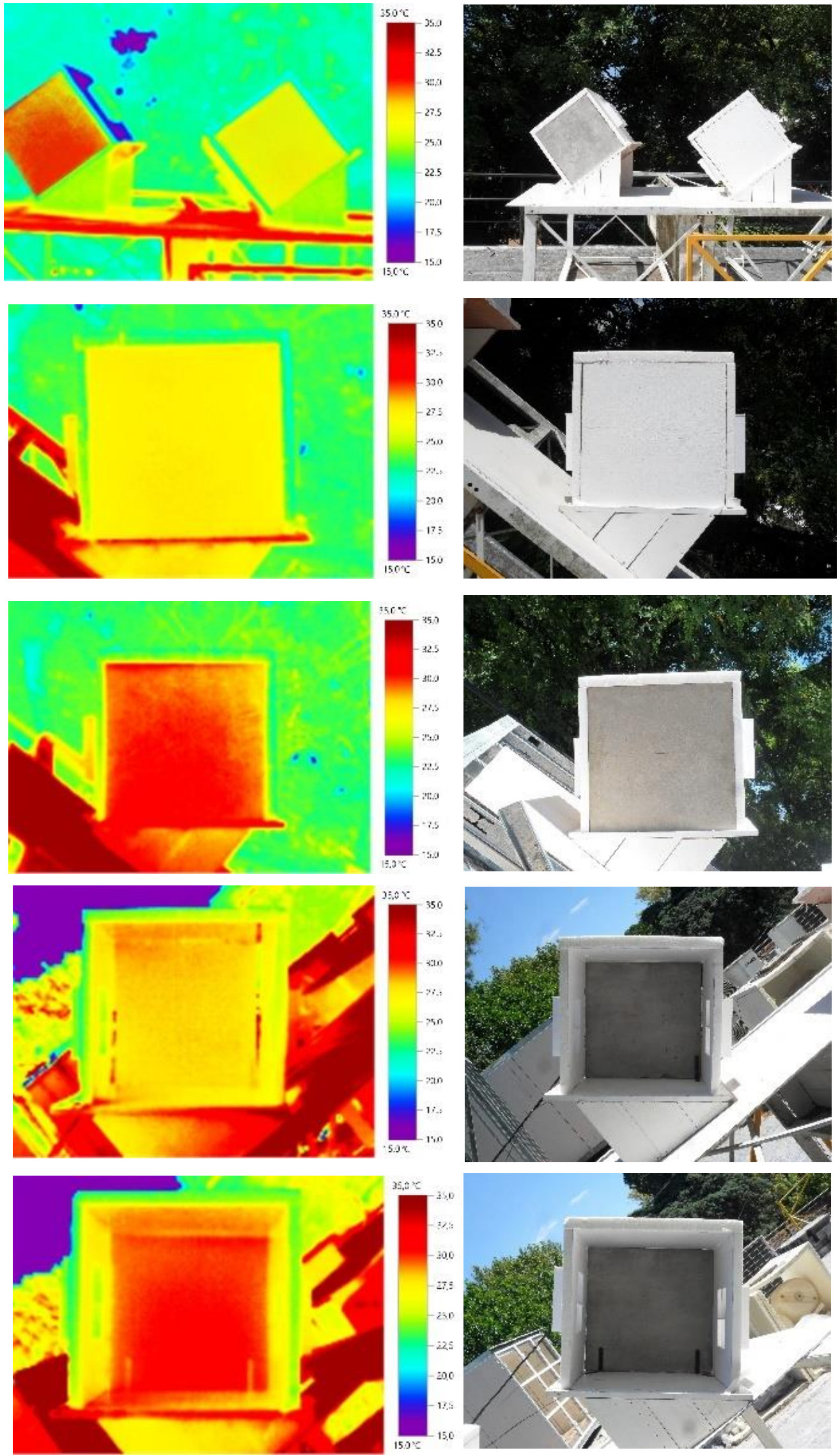

Figura 89. Collage de termografías y fotografías correspondientes al 17 de enero de 2017 a las 13:00. Fuente: Elaboración propia. 

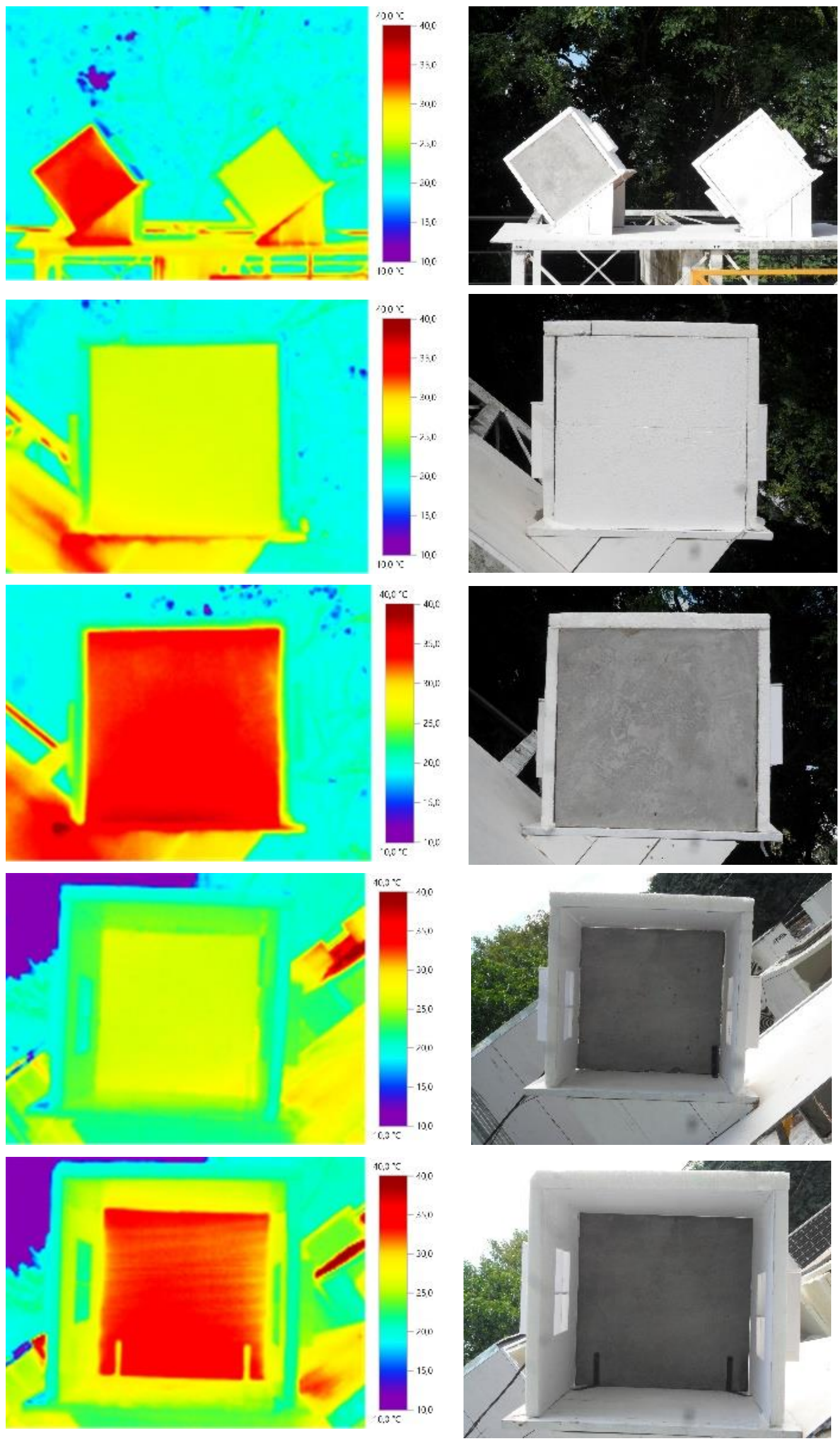

Figura 90. Collage de termografías y fotografías correspondientes al 17 de enero de 2017 a las 15:30. Fuente: Elaboración propia. 

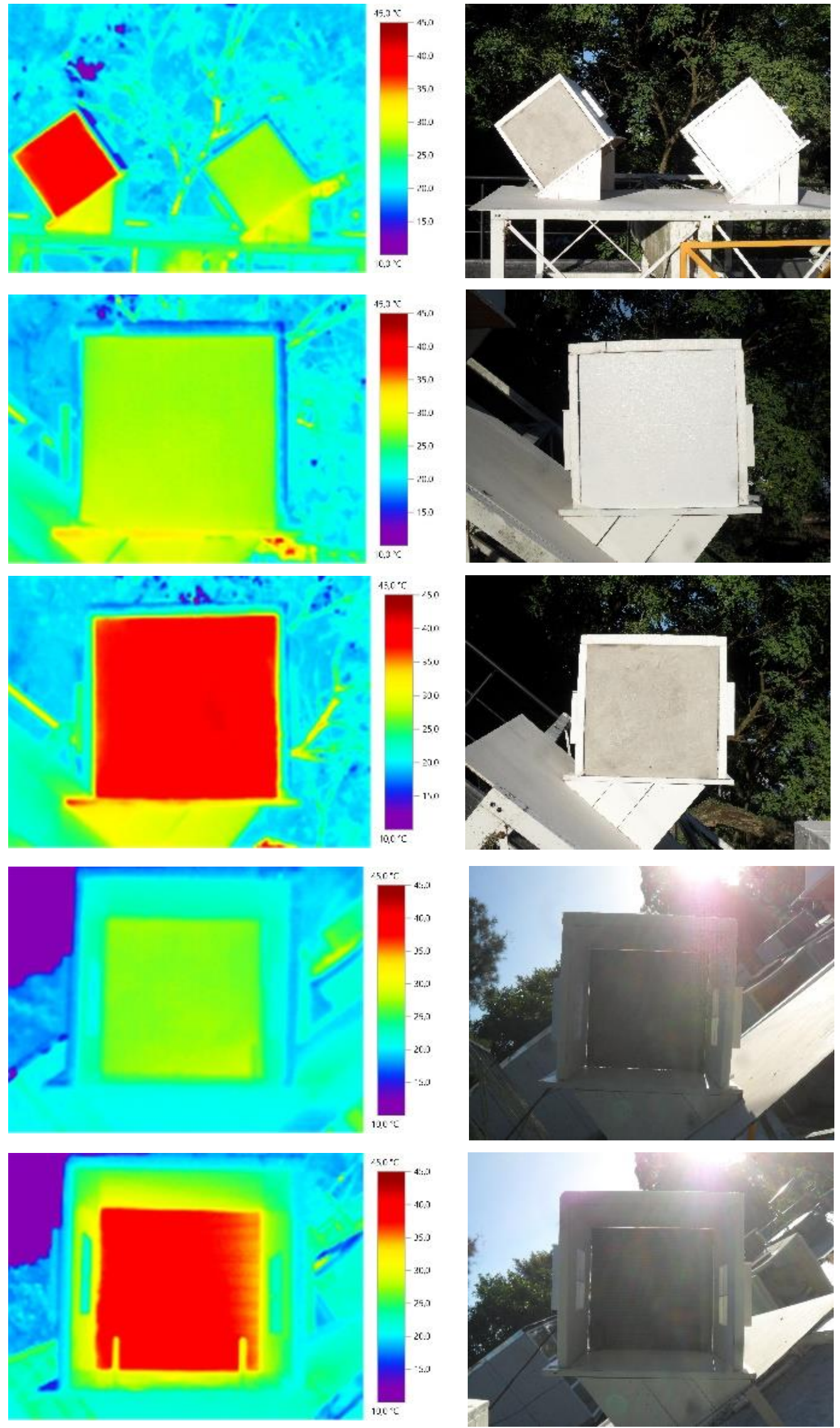

Figura 91. Collage de termografías y fotografías correspondientes al 17 de enero de 2017 a las 18:00. Fuente: Elaboración propia. 
Los resultados de $T_{r}$ a lo largo de los tres días de experimentación, extraídos de las anteriores termografías se muestran a continuación en la gráfica de la Figura 92. En esta gráfica puede leerse que la $T_{r}$ en el $\mathrm{Ml}$, representada con la línea discontinua fue notoriamente menor que la del MT desde las primeras horas de la tarde hasta el final.

Se distingue también que los altibajos de la $T_{\mathrm{r}}$ producidos por la variación de la radiación solar representada con la línea continua de tono gris afectaron por igual el desempeño del MT y del MI. A pesar de esto, el porcentaje de reducción de $T_{r}$ logrado por esta alternativa fue bastante similar durante las tres tardes experimentadas, pues mediante los cálculos se obtuvieron valores de $51,29 \%, 50,47 \%$ y $46,6 \%$, para un promedio de $49,4 \%$, lo cual es menor al porcentaje de $62,2 \%$ calculado teóricamente en el capítulo anterior, sin embargo, sigue siendo una reducción alta obtenida solamente con pintar de color blanco.

Asimismo, se encontró que la disminución media de $T_{\mathrm{r}}$ fue de $4,9^{\circ} \mathrm{C}$ y la máxima fue de 8,4 ${ }^{\circ} \mathrm{C}$ presentada durante todos los días de medición entre las 17:00 y las 17:30.

Nótese además que, durante el tiempo evaluado, la estrategia solo pudo lograr niveles aceptables de confort en el inicio de la experimentación. En el tiempo restante se encontraron separaciones de hasta de $10,3^{\circ} \mathrm{C}$, teniendo como referencia el límite superior de confort.

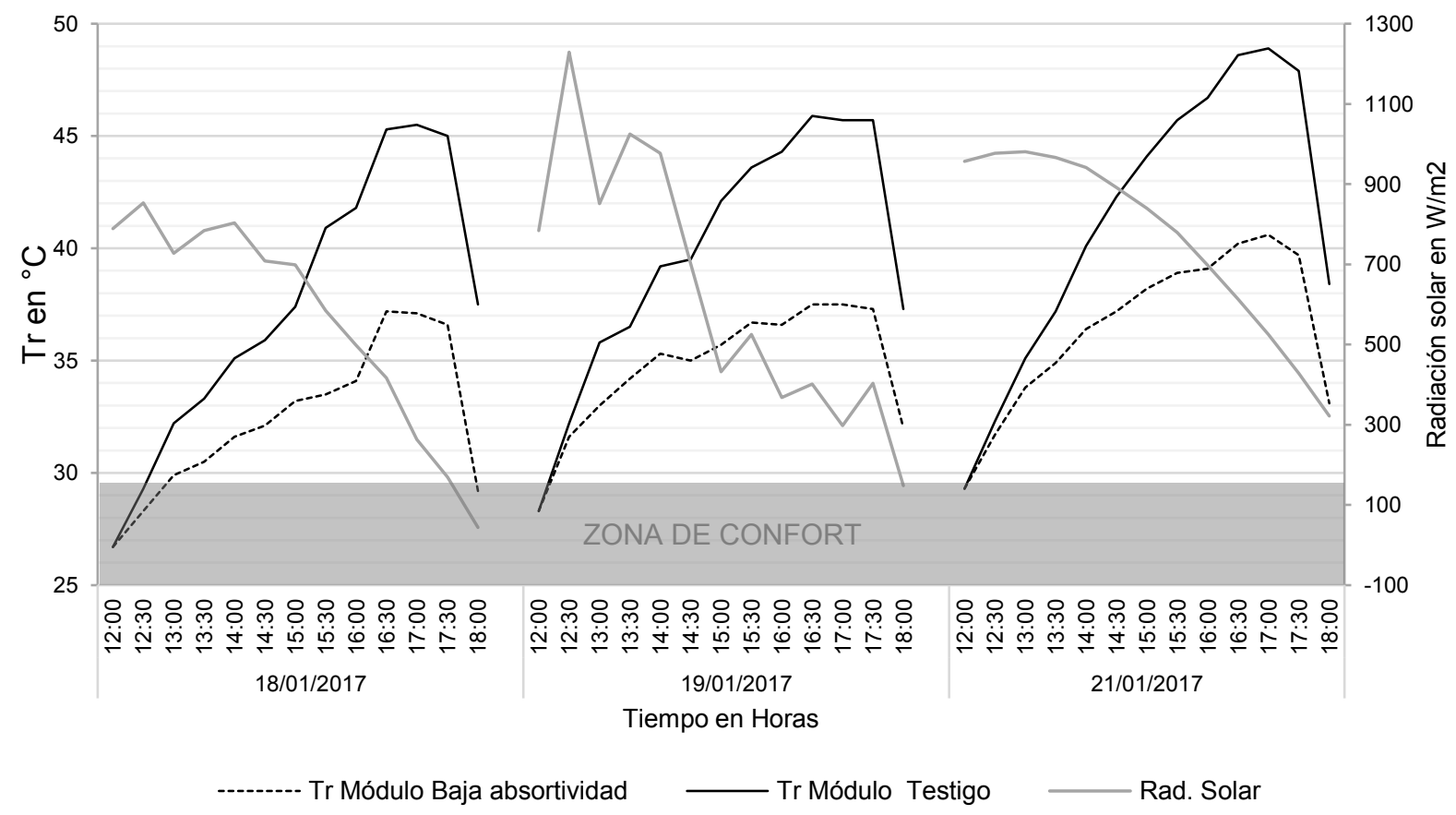

Figura 92. Gráfica comparativa de $\mathrm{T}_{\mathrm{r}}$ vs Tiempo entre el MI con la estrategia de baja absortividad y el MT. Fuente: Elaboración propia. 


\section{Temperatura del aire y humedad relativa}

Los valores de $T_{\text {air }}$ y HR registrados durante la experimentación con esta estrategia se muestran a continuación en la Figura 93, en la cual se distinguen las diferencias de estas variables entre el MT y el MI.

En todos los casos, la $\mathrm{T}_{\text {air }}$ en el MI fue menor que la del MT, el porcentaje medio de reducción fue del $20,33 \%$. Por otro lado, la HR permaneció en todos los casos más alta en el Ml que en el MT, en un porcentaje medio de $28,5 \%$.

En promedio la $\mathrm{T}_{\text {air }}$ del $\mathrm{Ml}$ estuvo $0,67{ }^{\circ} \mathrm{C}$ más baja que la del $\mathrm{MT}$ y el valor máximo de diferencia fue de $1,0^{\circ} \mathrm{C}$. De la misma forma, en promedio la HR estuvo $2,2 \%$ más alta que la del MT y el valor máximo de diferencia fue de $4 \%$.

Estas tendencias fueron continuas y los valores de diferencia superaron los de imprecisión del instrumental y el aparato experimental, con lo cual esta estrategia demuestra una influencia positiva en la $\mathrm{T}_{\text {air }} \mathrm{y} H \mathrm{HR}$.

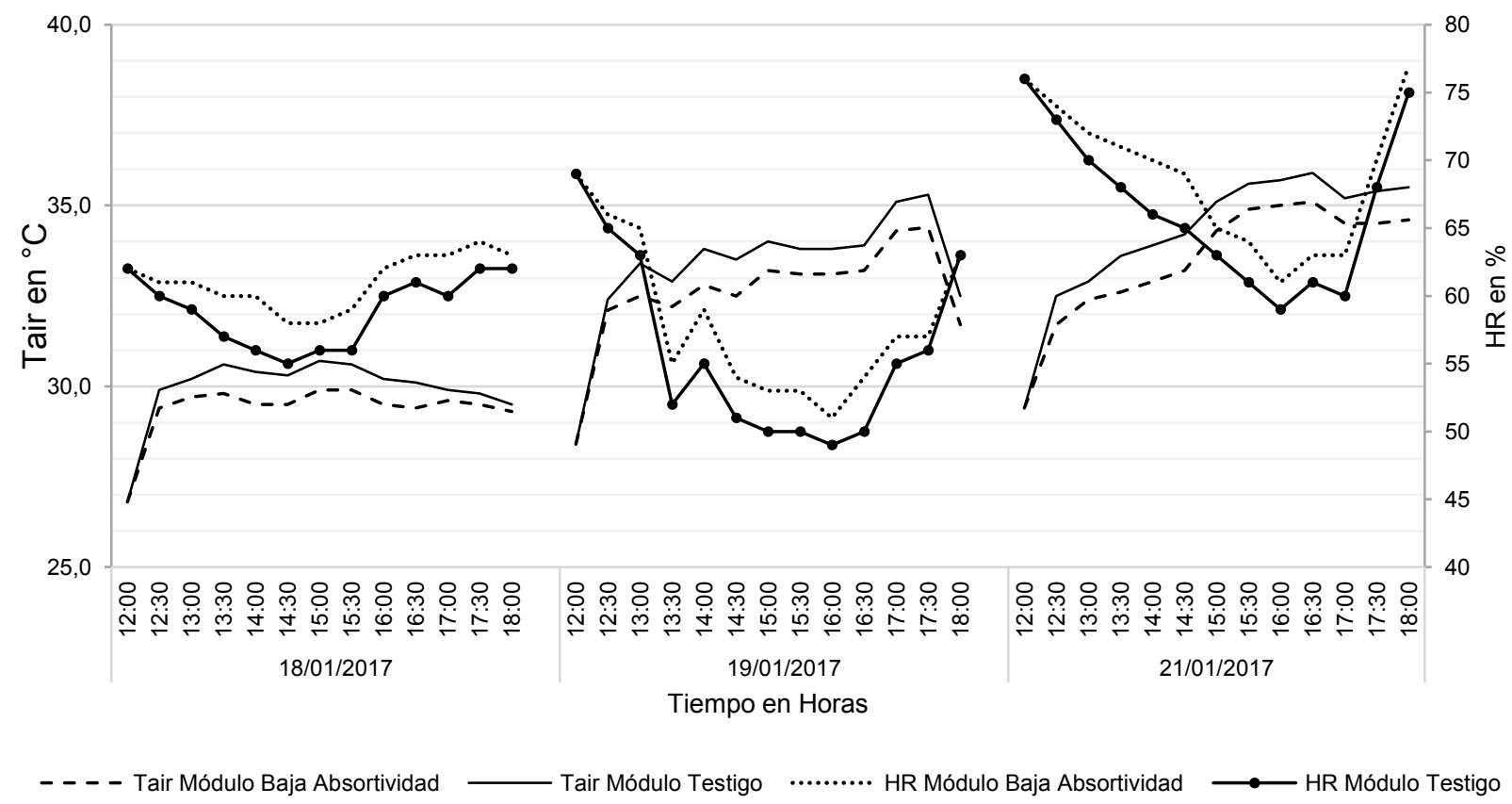

Figura 93. Gráfica comparativa de $\mathrm{T}_{\text {air }}$ y HR vs Tiempo entre el MI con la estrategia de baja absortividad y el MT. Fuente: Elaboración propia. 


\subsubsection{Revoque de polvo de ladrillo refractario (RF)}

Como resultado de la mezcla del polvo de ladrillo refractario y la base acrílica se produjo una pasta de tono rojizo pálido, que fue aplicada con llana metálica sobre la cara exterior de la envolvente formando un revoque de $10 \mathrm{~mm}$ de espesor como se muestra en la fotografía de la Figura 88 .

La campaña experimental con esta estrategia se realizó durante las tardes del 25, 26 y 27 de enero de 2017, una fotografía del aparato experimental configurado con esta alternativa se aprecia en la siguiente Figura 94, en este escenario al lado derecho se ubicó el Ml con el tratamiento de revoque refractario, mientras que a la izquierda se ubicó el MT de concreto a la vista.

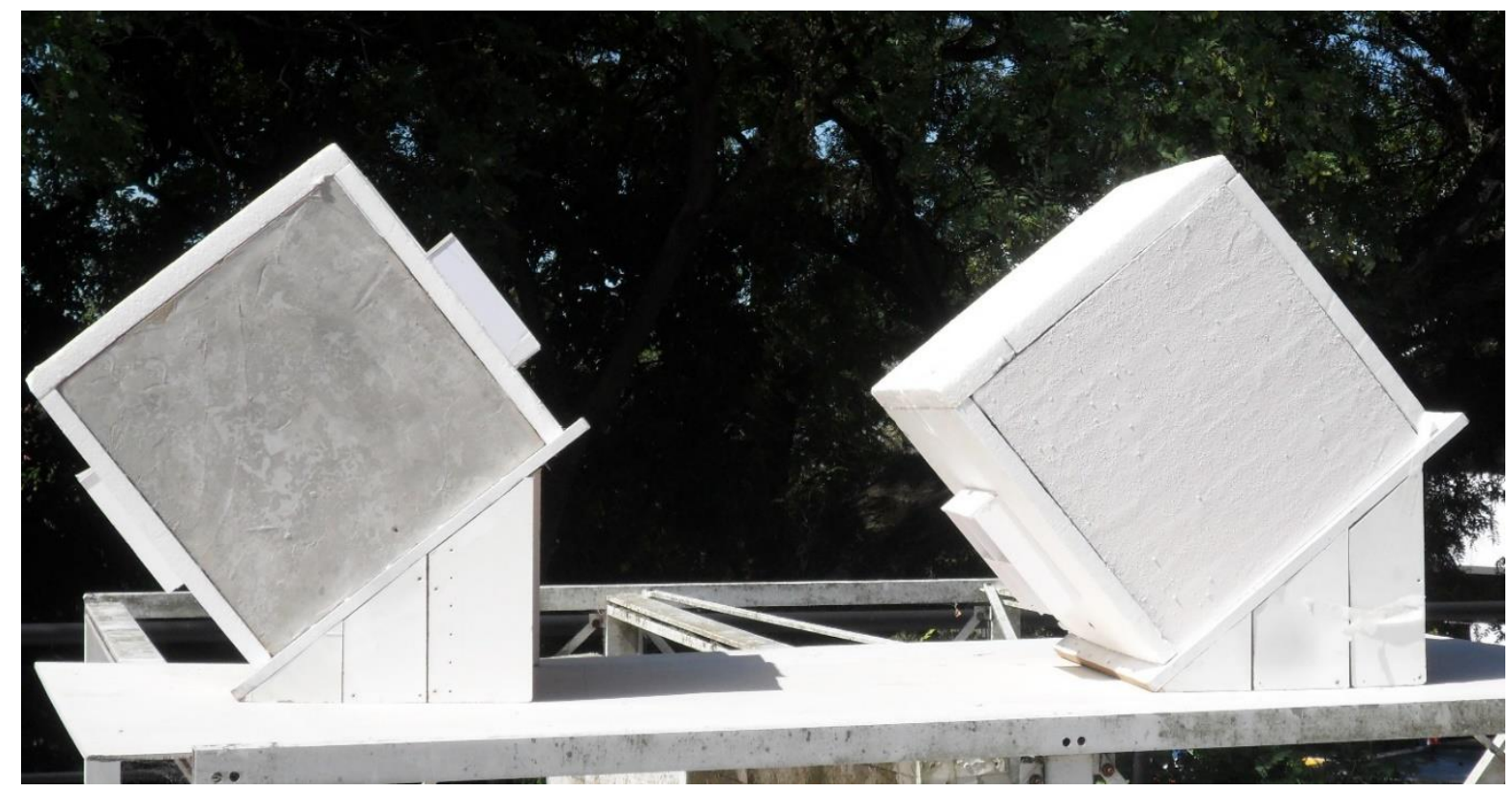

Figura 94. Configuración del aparato experimental para experimentación con la estrategia de revoque refractario. Fuente: Elaboración propia.

\section{Temperatura radiante}

Algunas de las termografías y fotografías adquiridas durante esta campaña experimental, se muestran en los collages elaborados para las 13:00, 15:30 y 18:00 del 25 de enero de 2017. Estos collages corresponden a la Figura 95, Figura 96 y Figura 97, respectivamente. En esta secuencia, se sintetiza en general, el desempeño térmico de esta solución constructiva durante los tres días de experimentación.

Las imágenes de la Figura 95 , muestran que a las $13: 00$, la $\mathrm{T}_{\mathrm{r}}$ del $\mathrm{Ml}$ se encontró $1,2^{\circ} \mathrm{C}$ por debajo del MT. Más adelante, en el collage de la Figura 96 perteneciente a las 15:30, la diferencia se acrecentó a $5,3^{\circ} \mathrm{C}$. Por último, en la Figura 97 de las 18:00, la diferencia de $\mathrm{T}_{\mathrm{r}}$ 
llegó a $4,0^{\circ} \mathrm{C}$. Las termografías mostraron una tendencia marcada y continua de que la $T_{r}$ del Ml se encontró siempre por debajo de la del MT, tanto desde el inicio como al final de la experimentación.
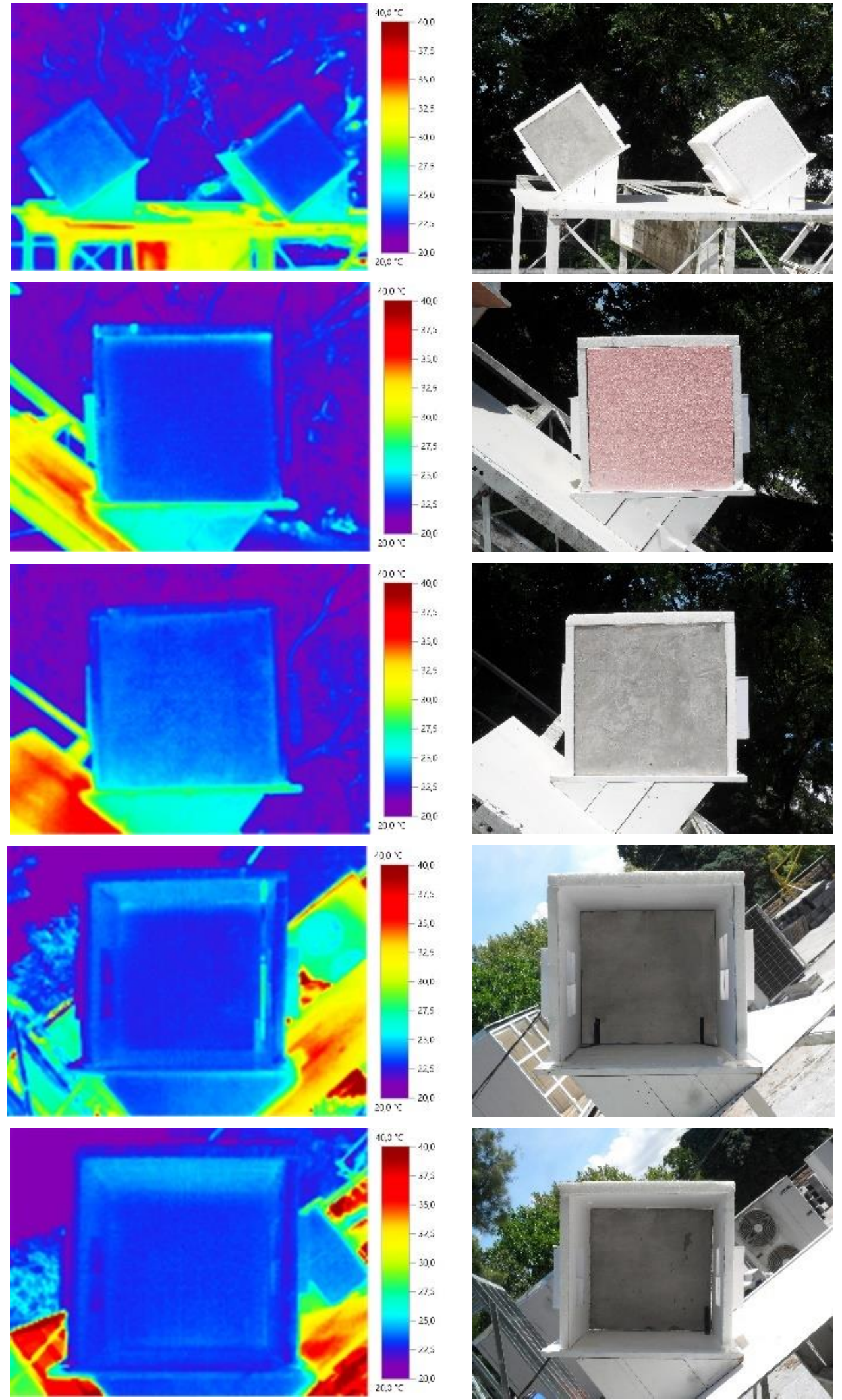

Figura 95. Collage de termografías y fotografías correspondientes al 25 de enero de 2017 a las 12:30. Fuente: Elaboración propia. 

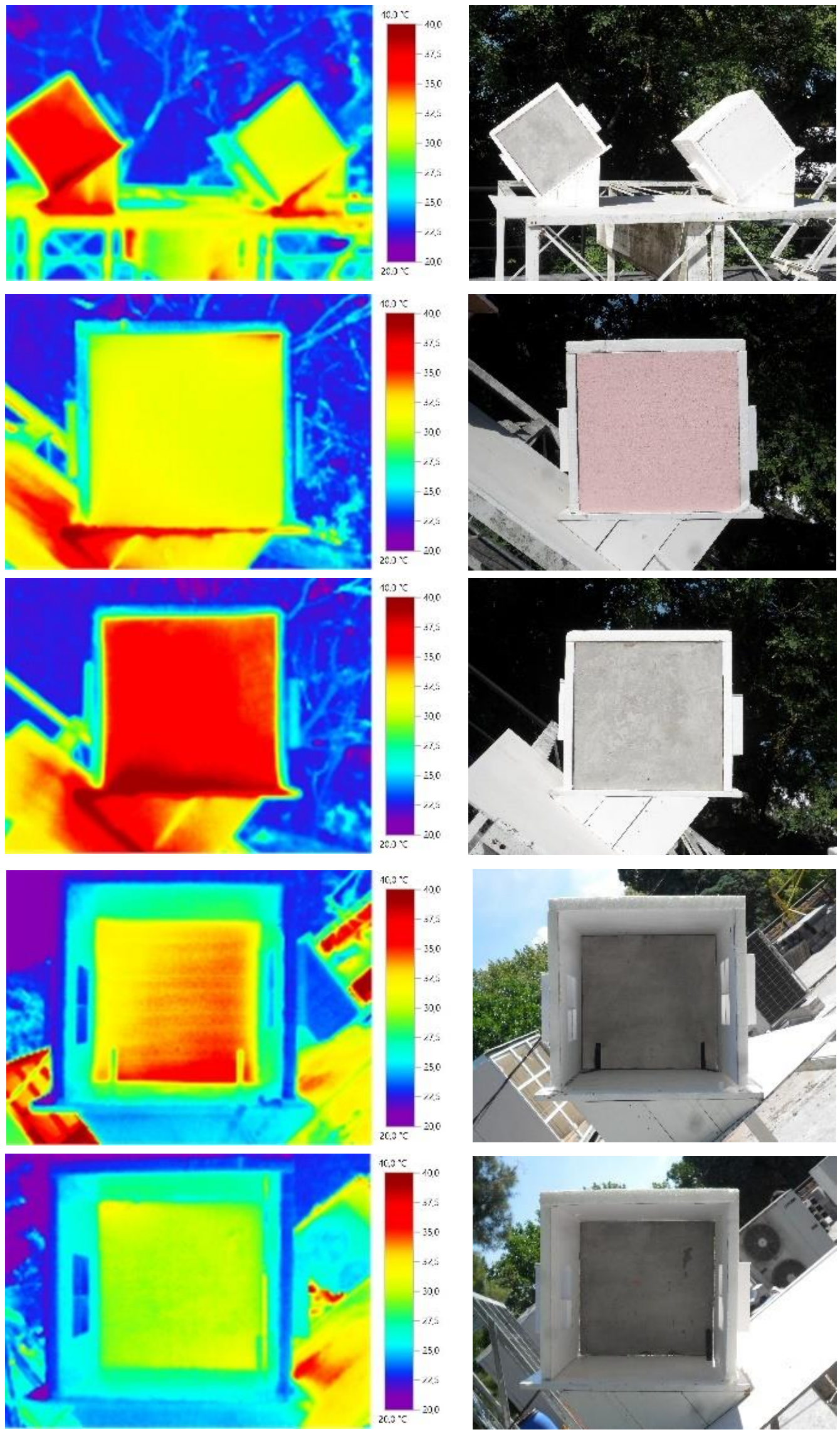

Figura 96. Collage de termografías y fotografías correspondientes al 25 de enero de 2017 a las 15:30. Fuente: Elaboración propia. 

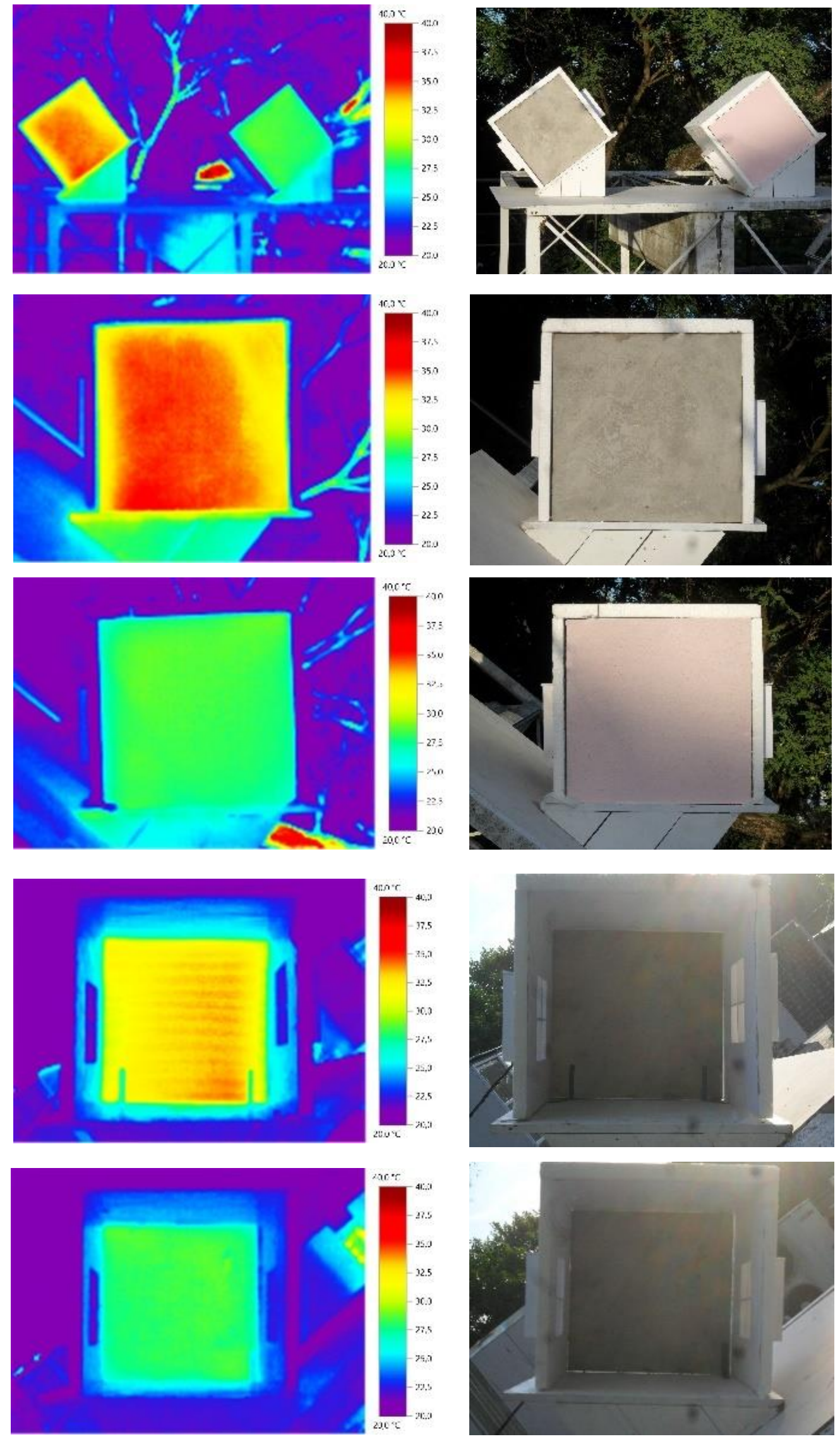

Figura 97. Collage de termografías y fotografías correspondientes al 25 de enero de 2017 a las 18:00. Fuente: Elaboración propia 
Los resultados de $T_{r}$ a lo largo de los tres días de experimentación, extraídos de las anteriores termografías se muestran a continuación en la gráfica de la Figura 98. En esta gráfica puede observarse que la $\mathrm{T}_{\mathrm{r}}$ en el $\mathrm{Ml}$, representada con la línea discontinua de color negro fue notoriamente menor que la del MT desde las primeras horas de la tarde hasta el final.

Se distingue también que los altibajos de la $T_{r}$ producidos por la variación de la radiación solar representada con la línea continua de tono gris afectaron por igual el desempeño del MT y del MI. A pesar de esto, el porcentaje de reducción de $T_{r}$ logrado por esta alternativa fue bastante similar durante las tres tardes experimentadas, pues mediante las comparaciones de las áreas bajo las curvas se obtuvieron valores de reducción de 30,8\%, 31,9\% y 31,8\%, para un promedio de $31,5 \%$, lo cual es notablemente menor que el porcentaje de $81,8 \%$ calculado teóricamente.

Esto es atribuible a que el color final del revoque no fue blanco completamente, sino que dicha mezcla tomó una coloración rojiza aumentando la variable $\alpha_{s}$. También puede atribuirse a que la resina acrílica con la que se mezcló disminuyó la $\mathrm{R}$ del polvillo de ladrillo refractario.

De otro lado, se encontró que la disminución media de $T_{r}$ fue de $3,42^{\circ} \mathrm{C}$ y la máxima fue de $6,4^{\circ} \mathrm{C}$ presentada durante a las 16: 30 del primer y tercer día de medición.

Nótese además que, durante el tiempo evaluado, la estrategia solo pudo lograr niveles aceptables de confort en el inicio de la experimentación. En el tiempo restante se encontraron separaciones de hasta de $6,7^{\circ} \mathrm{C}$, teniendo como referencia el límite superior del rango de confort.

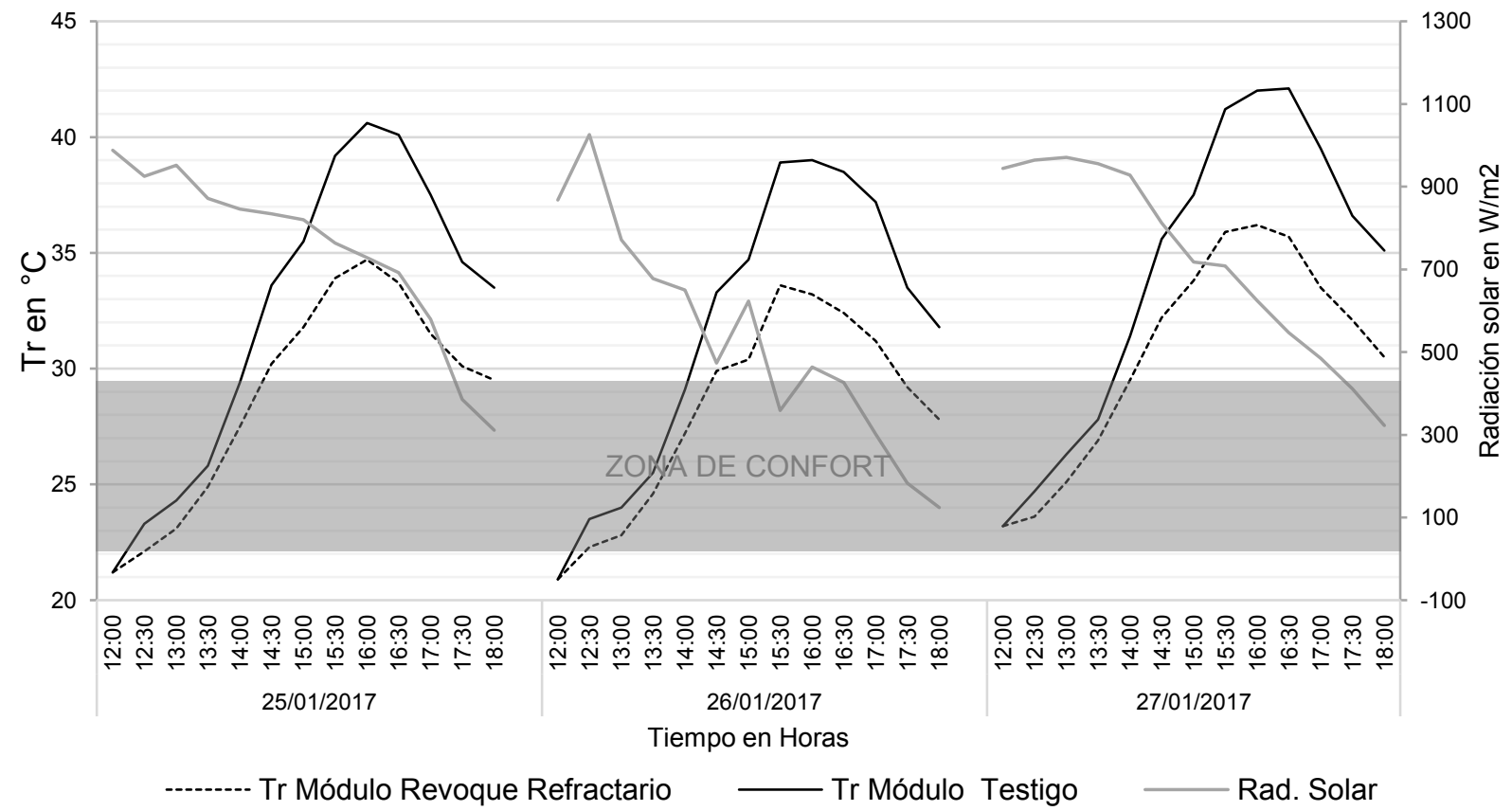

Figura 98. Gráfica comparativa de $\mathrm{T}_{\mathrm{r}}$ vs Tiempo entre el Ml con la estrategia de revoque refractario y el MT. Fuente: Elaboración propia 


\section{Temperatura del aire y humedad relativa}

Los valores de $T_{\text {air }}$ y HR registrados durante la experimentación con esta estrategia se muestran a continuación en la Figura 99, en la cual se distinguen las diferencias de estas variables entre el MT y el MI.

En todos los casos, la $\mathrm{T}_{\text {air }}$ en el MI fue menor que la del MT, el porcentaje medio de reducción fue del $12,5 \%$. Por otro lado, la HR permaneció en todos los casos más alta en el MI que en el MT, en un porcentaje medio de $18,12 \%$.

En promedio la $\mathrm{T}_{\text {air }}$ del $\mathrm{Ml}$ estuvo $0,30{ }^{\circ} \mathrm{C}$ más baja que la del $\mathrm{MT}$ y el valor máximo de diferencia fue de $0,8{ }^{\circ} \mathrm{C}$. De la misma forma, en promedio la HR en el Ml estuvo $1,3 \%$ más alta que la del MT y el valor máximo de diferencia fue de $3 \%$.

Estas tendencias son continuas y los valores de diferencia superan los de imprecisión del instrumental y el aparato experimental, con lo cual esta estrategia demostró una influencia positiva en la $\mathrm{T}_{\text {air }}$ y HR.

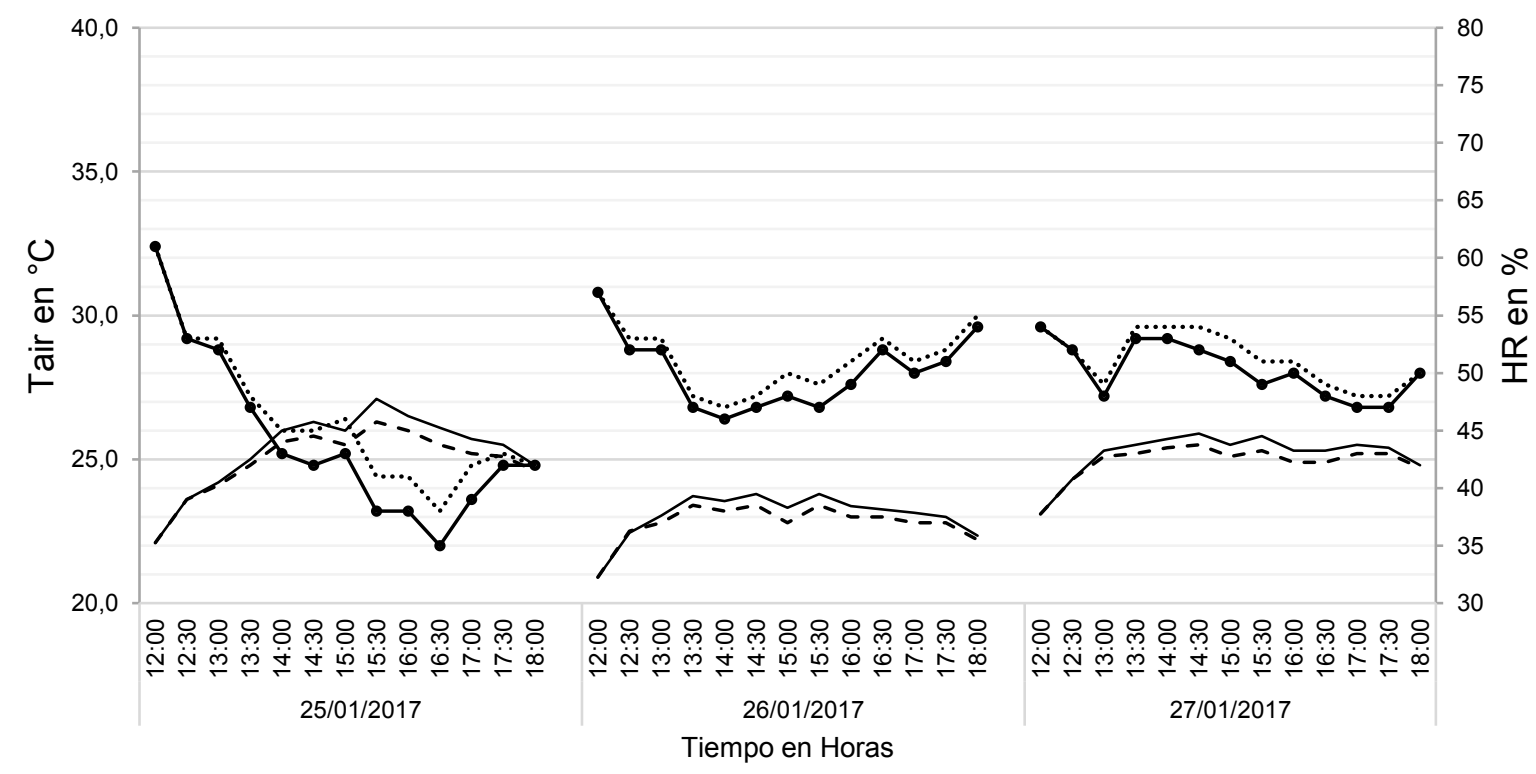




\subsubsection{Muro vegetal (MV)}

El proceso constructivo del MV se describe brevemente a continuación, como contenedor se usó una lona reciclada de material publicitario ${ }^{51}$ compuesta de poliéster y PVC. La cual constituye en sí misma una capa impermeable para la envolvente. Esta lona fue tratada con la pintura de baja absortividad descrita con anterioridad en el título 5.3. Con este material se conformó un fondo plano al cual se cosieron varios bolsillos para alojar el sustrato y las raíces de las especies vegetales.

Para la estructura se anclaron unos perfiles rectangulares de sección $4 \times 3 \mathrm{~cm}$ en PVC a la muestra de concreto, a los cuales se atornilló la lona posteriormente.

Una imagen de la configuración de los perfiles de PVC en la muestra de concreto y de la lona antes de recibir el sustrato y las especies vegetales se aprecia a continuación en la Figura 100.
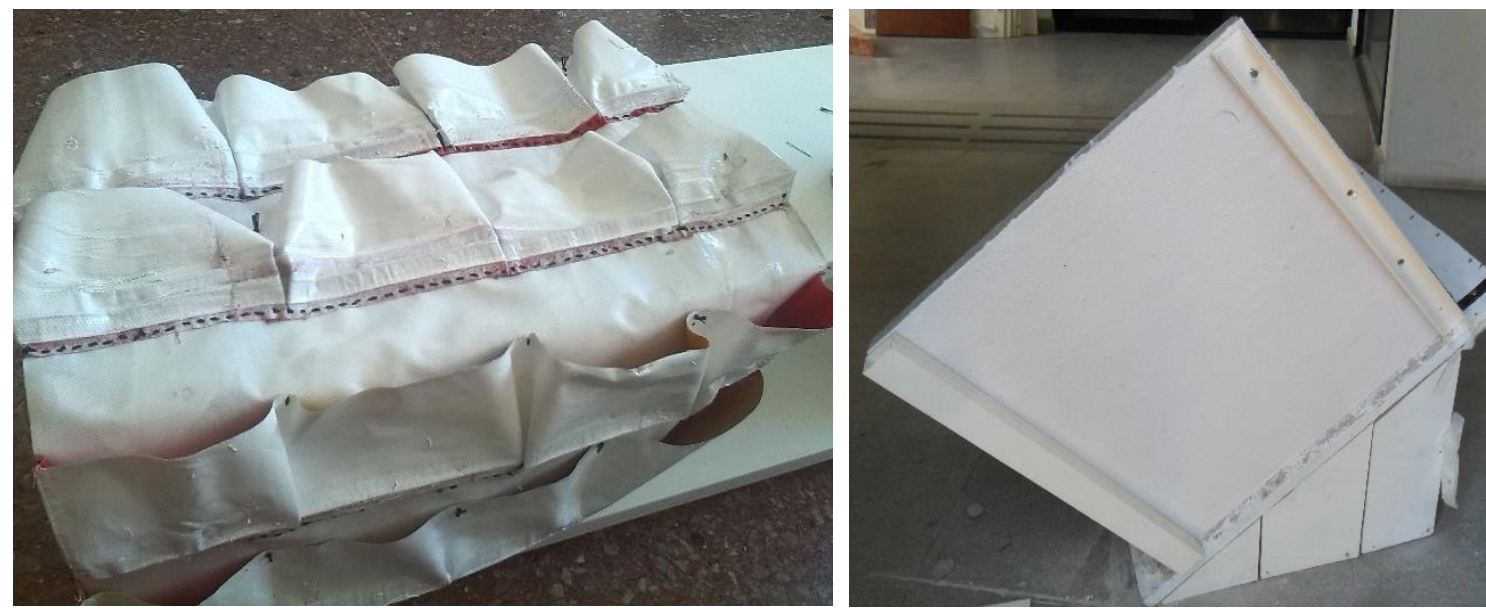

Figura 100. Configuración de la lona antes de recibir el sustrato y las especies vegetales (izquierda) y la estructura de perfiles de PVC (derecha). Fuente: Elaboración propia.

Dentro de los bolsillos se depositó un sustrato de tierra negra, arena y turba en la que posteriormente se sembraron dos especies vegetales: Portulaca grandiflora y Philodendron scandens.

${ }^{51}$ La cual es frecuentemente encontrada como material de desecho en la ciudad de Cali. Bien podría vincularse esta solución constructiva a una iniciativa de emprendimiento entre la comunidad VIS, que no solo se verá beneficiada por el confort térmico brindado sino también por ingresos económicos ligados al desarrollo sostenible. 
La Portulaca grandiflora es una planta anual seleccionada por su rápido crecimiento, por su buena adaptación a la radiación directa del sol y las altas temperaturas. Es una planta suculenta que almacena una buena cantidad de agua en sus hojas y tallos, por lo tanto, no requiere mucho riego ni mantenimiento. Estéticamente es valorada por su colorida y numerosa floración. Crece entre 15 y $20 \mathrm{~cm}$, por lo cual se adaptó muy bien a los espacios intersticiales de los bolsillos.

Por otro lado, se plantó Philodendron scandens o Cordatum, esta es una planta trepadora muy resistente que prefiere los ambientes a media luz, pero fue escogida porque trepa y cuelga cubriendo las superficies verticales a las que se aferra mediante delgadas raíces. Además, requiere poco riego y mantenimiento.

Estas plantas fueron sembradas con cinco meses de anterioridad (septiembre 2016) a la fecha de las mediciones bajo condiciones exteriores, con lo cual se obtuvieron ejemplares medianamente adaptados tanto a la superficie vertical como a la intemperie.

Una fotografía del aspecto de esta configuración al cuarto mes de ser plantado puede apreciarse en la Figura 101.

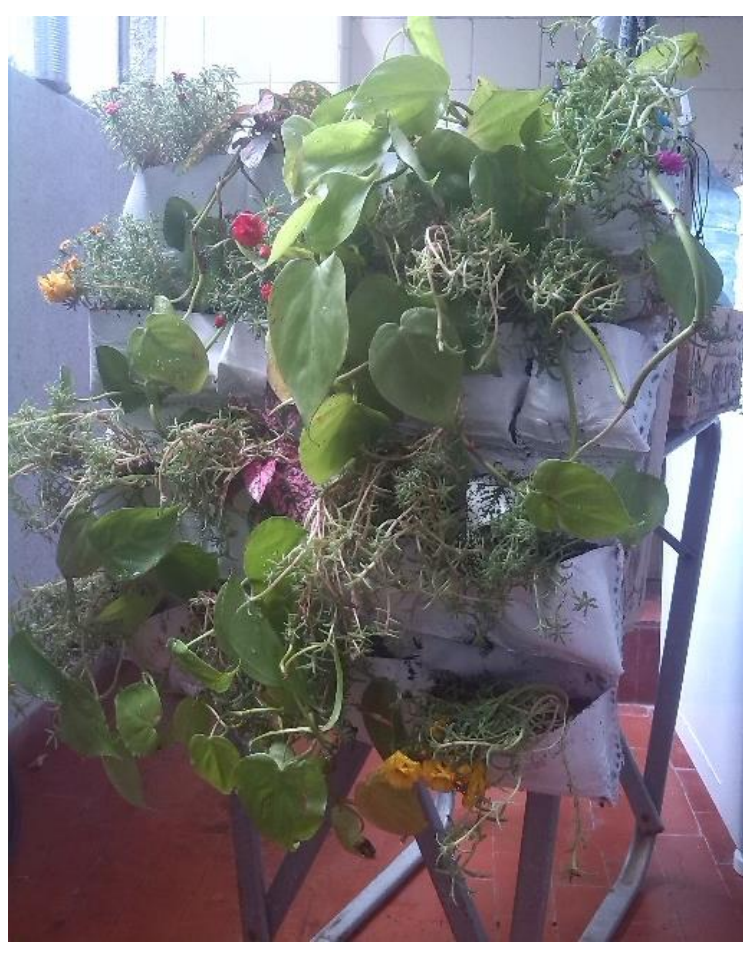

Figura 101. Fotografía de la configuración del muro vegetal al cuarto mes de ser plantado. Fuente: Elaboración propia.

El resultado final del aparato experimental configurado con esta alternativa se aprecia en la siguiente Figura 102, en este escenario al lado derecho se ubicó el MI con el muro vegetal, mientras que a la izquierda se ubicó el MT de concreto a la vista. La campaña experimental con esta estrategia se realizó durante las tardes del 15,16 y 17 de febrero de 2017. 


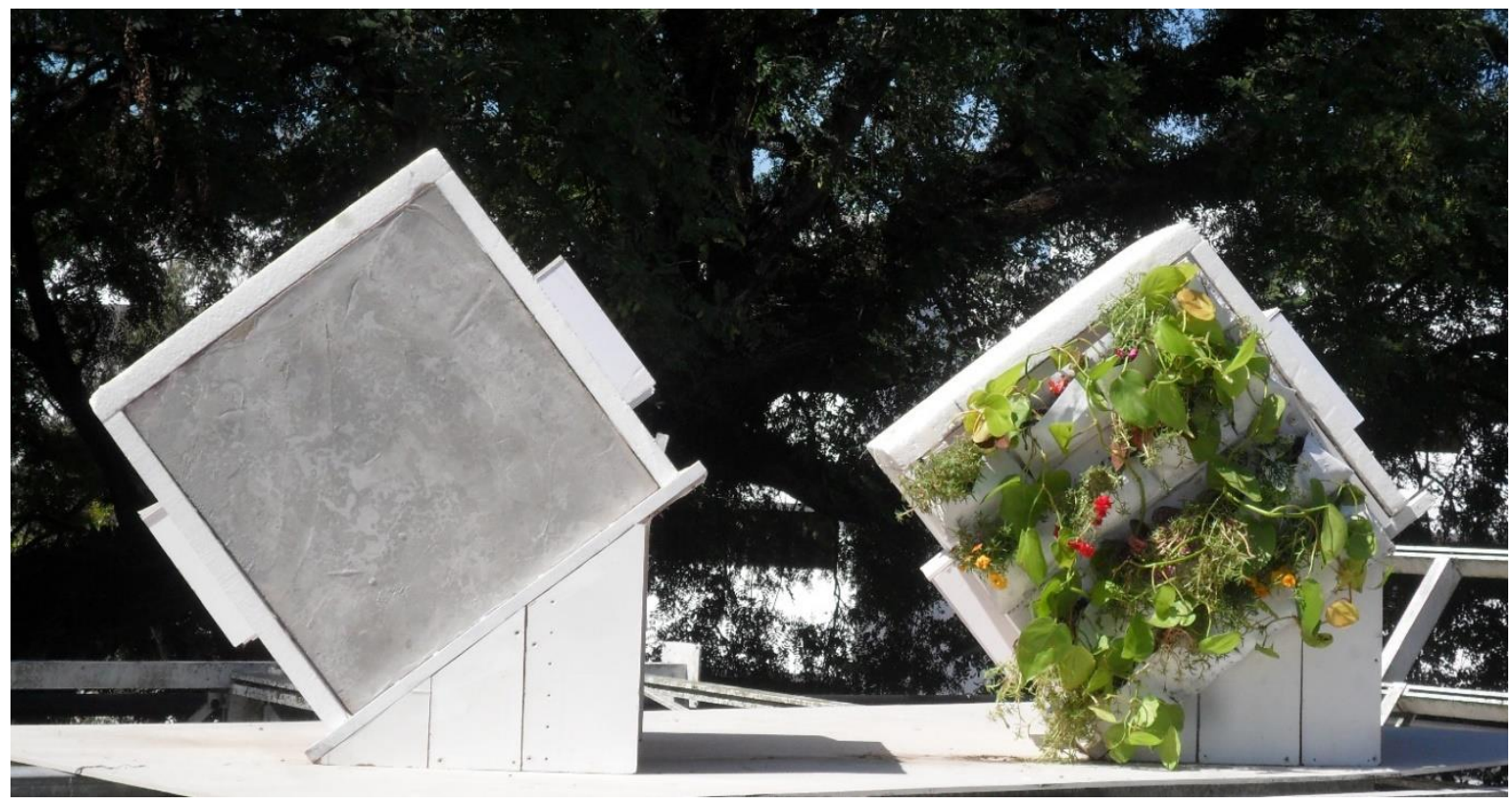

Figura 102. Configuración del aparato experimental para experimentación con la estrategia de muro vegetal. Fuente: Elaboración propia.

\section{Temperatura radiante}

Algunas de las termografías y fotografías adquiridas durante esta campaña experimental, se muestran en los collages elaborados para las 13:00, 15:30 y 18:00 del 15 de febrero de 2017. Estos collages corresponden a la Figura 103, Figura 104 y Figura 105 respectivamente. En esta secuencia, se observa y sintetiza la tendencia general de desempeño térmico de esta solución constructiva durante los tres días de experimentación.

Las imágenes de la Figura 103 muestran que a las 13:00 horas, la $T_{r}$ del $\mathrm{MI}$ se encontró $0,4^{\circ} \mathrm{C}$ por debajo del MT. Más adelante, en el collage de la Figura 104, correspondiente a las 15:30 horas, esta diferencia se acrecentó a $9,3^{\circ} \mathrm{C}$. Por último, en la Figura 105 correspondiente a las 18:00 horas, la diferencia de $T_{r}$ llegó a $2,4{ }^{\circ} \mathrm{C}$.

Las termografías mostraron una tendencia marcada y continua de que la $\mathrm{T}_{\mathrm{r}}$ del Ml se encontró siempre por debajo de la del MT, tanto desde el inicio como al final de la experimentación. 

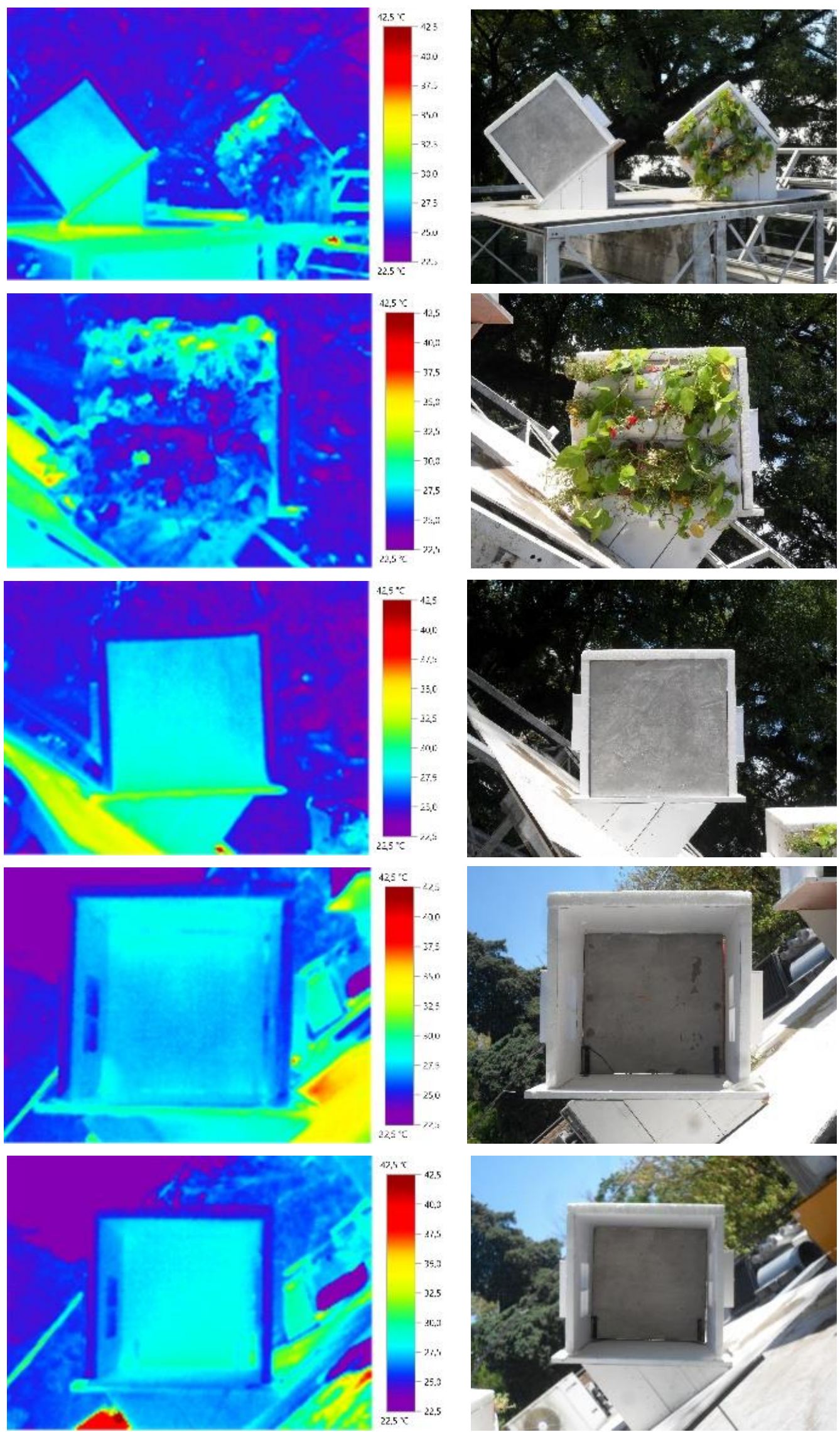

Figura 103. Collage de termografías y fotografías correspondientes al 15 de febrero de 2017 a las 12:30. Fuente: Elaboración propia. 

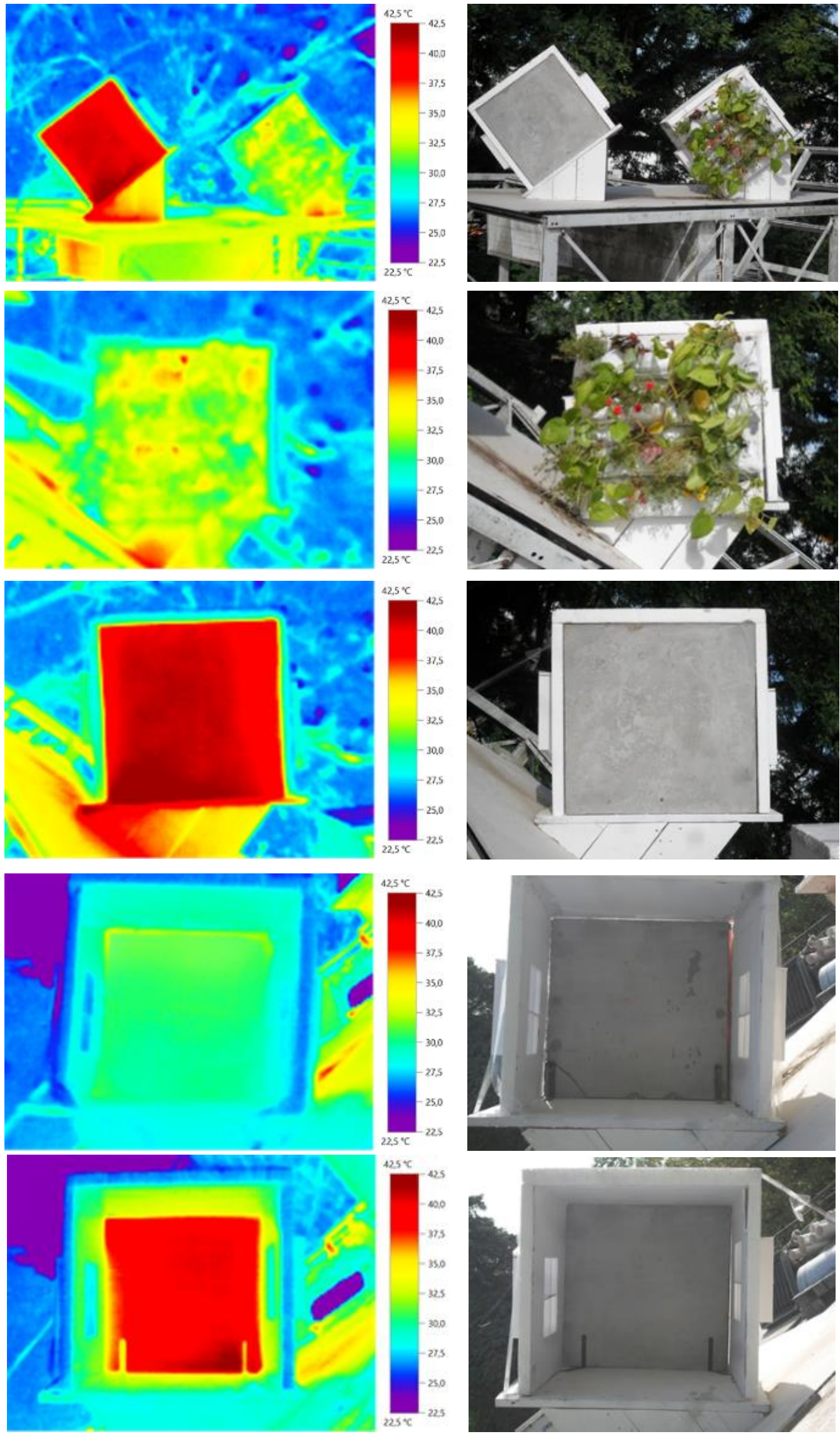

Figura 104. Collage de termografías y fotografías correspondientes al 15 de febrero de 2017 a las 15:30. Fuente: Elaboración propia. 

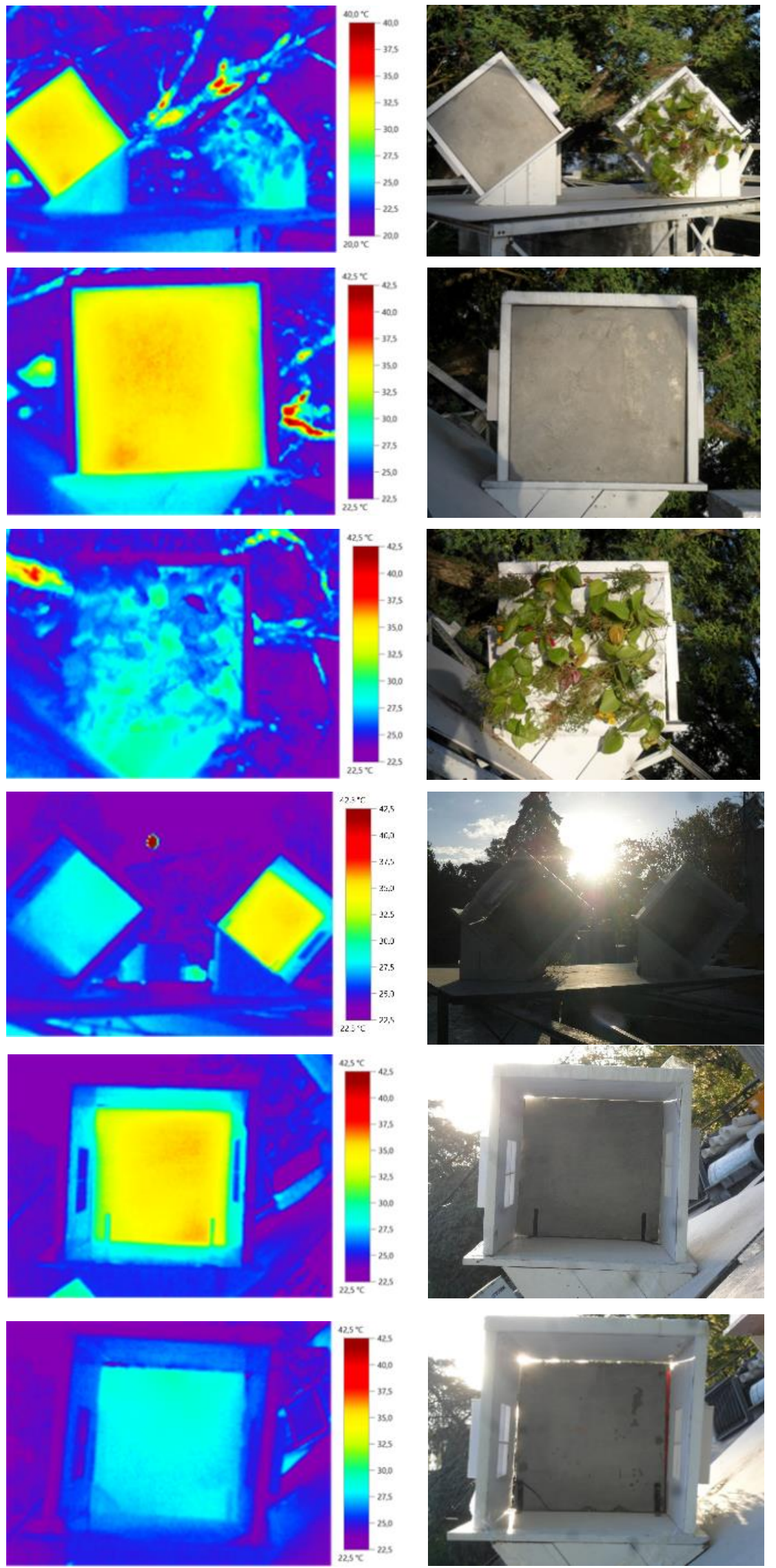

Figura 105. Collage de termografías y fotografías correspondientes al 15 de febrero de 2017 a las 18:00. Fuente: Elaboración propia. 
Los resultados de $T_{r}$ a lo largo de los tres días de experimentación, extraídos de las anteriores termografías se encuentran condensados en la gráfica de la Figura 106 . En esta gráfica puede observarse que la $\mathrm{T}_{\mathrm{r}}$ en el $\mathrm{Ml}$, representada con la línea discontinua es notoriamente menor que la del MT desde las primeras horas de la tarde hasta el final.

El porcentaje de reducción de $T_{r}$ logrado por esta alternativa fue bastante similar durante las tres tardes experimentadas, pues mediante las comparaciones de las áreas bajo las curvas se obtuvieron valores de $74,8 \%, 73,4 \%$ y $72,93 \%$, para un promedio de $73,7 \%$, lo cual es inferior en $17,03 \%$ si se compara con el porcentaje de 90,73\% calculado teóricamente.

Además, se encontró que la disminución media de $T_{\mathrm{r}}$ fue de $6,53^{\circ} \mathrm{C}$ y la máxima fue de 12,9 ${ }^{\circ} \mathrm{C}$ presentada durante las 15: 30 y 16 horas.

Nótese además que, aunque el ancho del muro de concreto solo posee $2 \mathrm{~cm}$ de espesor, durante el tiempo evaluado la estrategia pudo mantener la $T_{r}$ dentro del rango de confort durante el $71,8 \%$ del tiempo. En el tiempo restante se encontraron separaciones máximas solamente de $0,9^{\circ} \mathrm{C}$, teniendo como referencia el límite superior de $29,5{ }^{\circ} \mathrm{C}$.

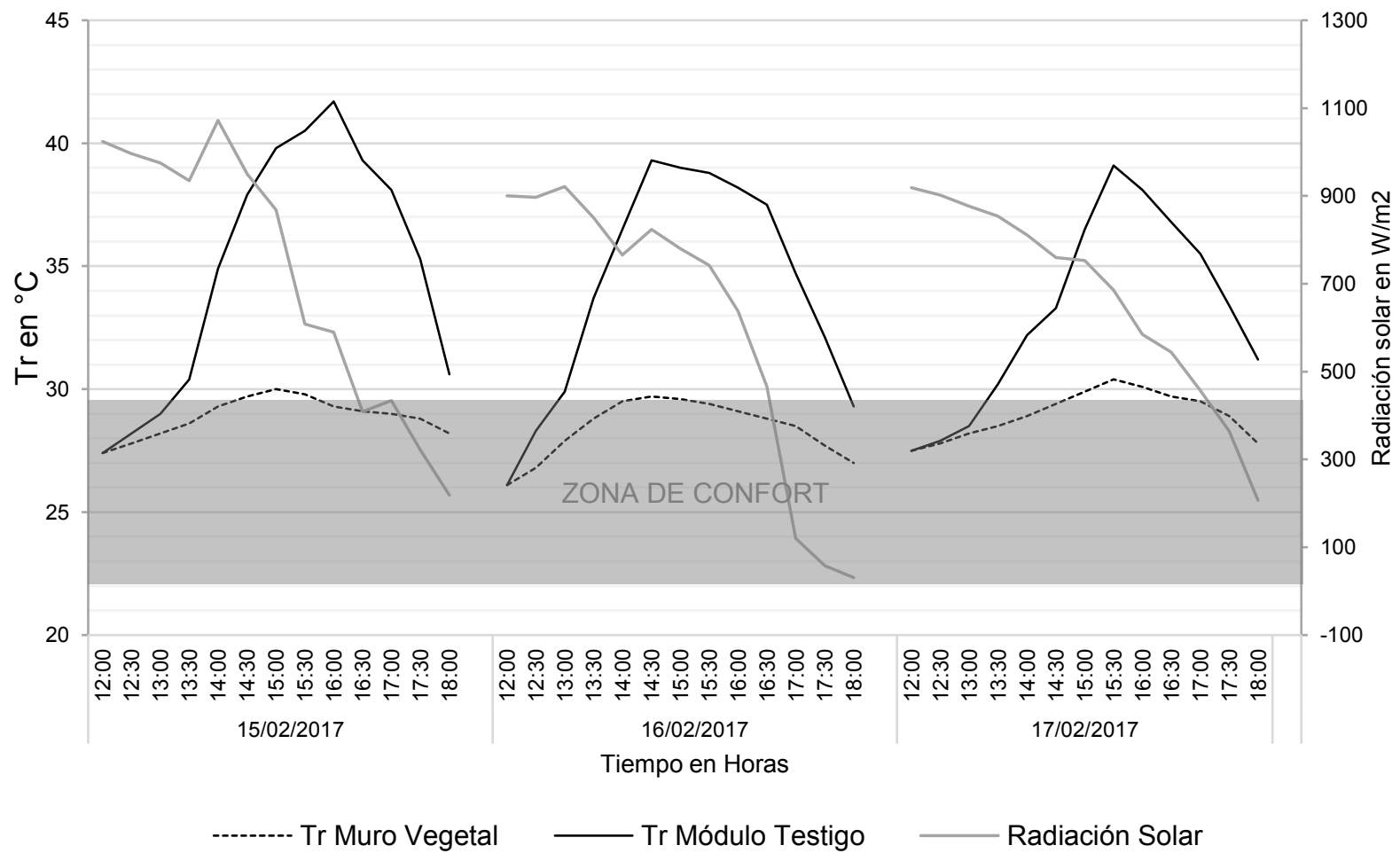

Figura 106. Gráfica comparativa de $\mathrm{T}_{\mathrm{r}}$ vs Tiempo entre el MI con la estrategia de muro vegetal y el MT. Fuente: Elaboración propia. 


\section{Temperatura del aire y humedad relativa}

Los valores de $T_{\text {air }}$ y HR registrados durante la experimentación con esta estrategia se muestran a continuación en la Figura 107, en la cual se distinguen las diferencias de estas variables entre el MT y el MI.

En todos los casos, la $\mathrm{T}_{\text {air }}$ en el MI fue menor que la del MT, el porcentaje medio de reducción fue del $28,26 \%$. Por otro lado, la HR permaneció en todos los casos más alta en el Ml que en el MT, en un porcentaje medio de $41,54 \%$.

En promedio la $\mathrm{T}_{\text {air }}$ del $\mathrm{Ml}$ estuvo $0,86{ }^{\circ} \mathrm{C}$ más baja que la del $\mathrm{MT}$ y el valor máximo de diferencia fue de $1,4{ }^{\circ} \mathrm{C}$. De la misma forma, en promedio la HR en el Ml estuvo $2,9 \%$ más alta que la del MT y el valor máximo de diferencia fue de 4,4\%.

Estas tendencias son continuas y los valores de diferencia superan los de imprecisión del instrumental y el aparato experimental, con lo cual esta estrategia demostró una influencia positiva en la $\mathrm{T}_{\text {air }}$ y HR.

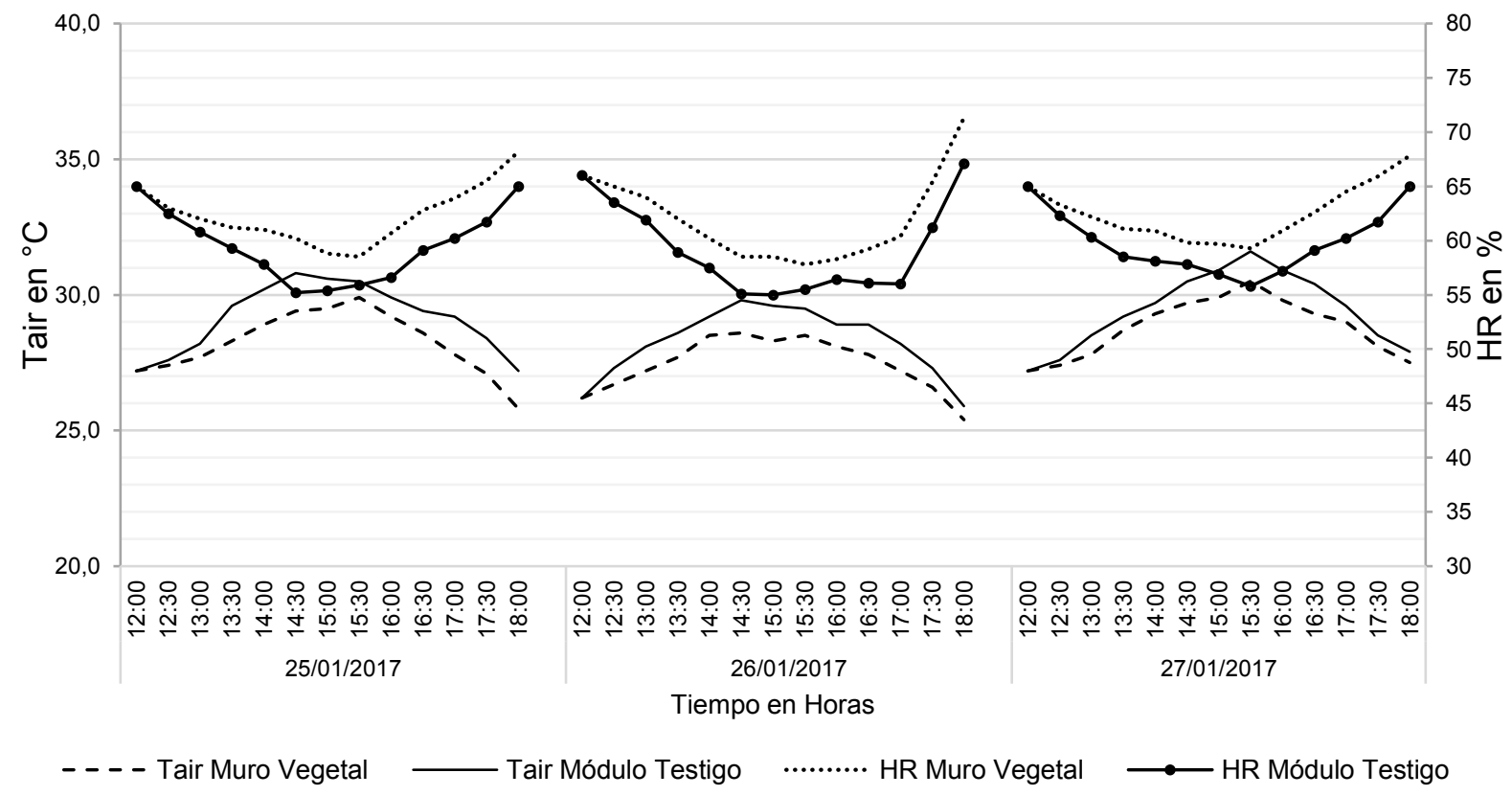

Figura 107. Gráfica comparativa de $\mathrm{T}_{\text {air }}$ y HR vs Tiempo entre el Ml con la estrategia de Muro Vegetal y el MT. Fuente: Elaboración propia. 


\subsubsection{Aislamiento reflectivo (AR)}

Más abajo en la Figura 108, se aprecian dos fotografías de esta alternativa, la imagen izquierda muestra el interior, en el cual se distingue la lámina corrugada de foil de aluminio con la cara brillante, mientras que la imagen derecha enseña la configuración totalmente acoplada.
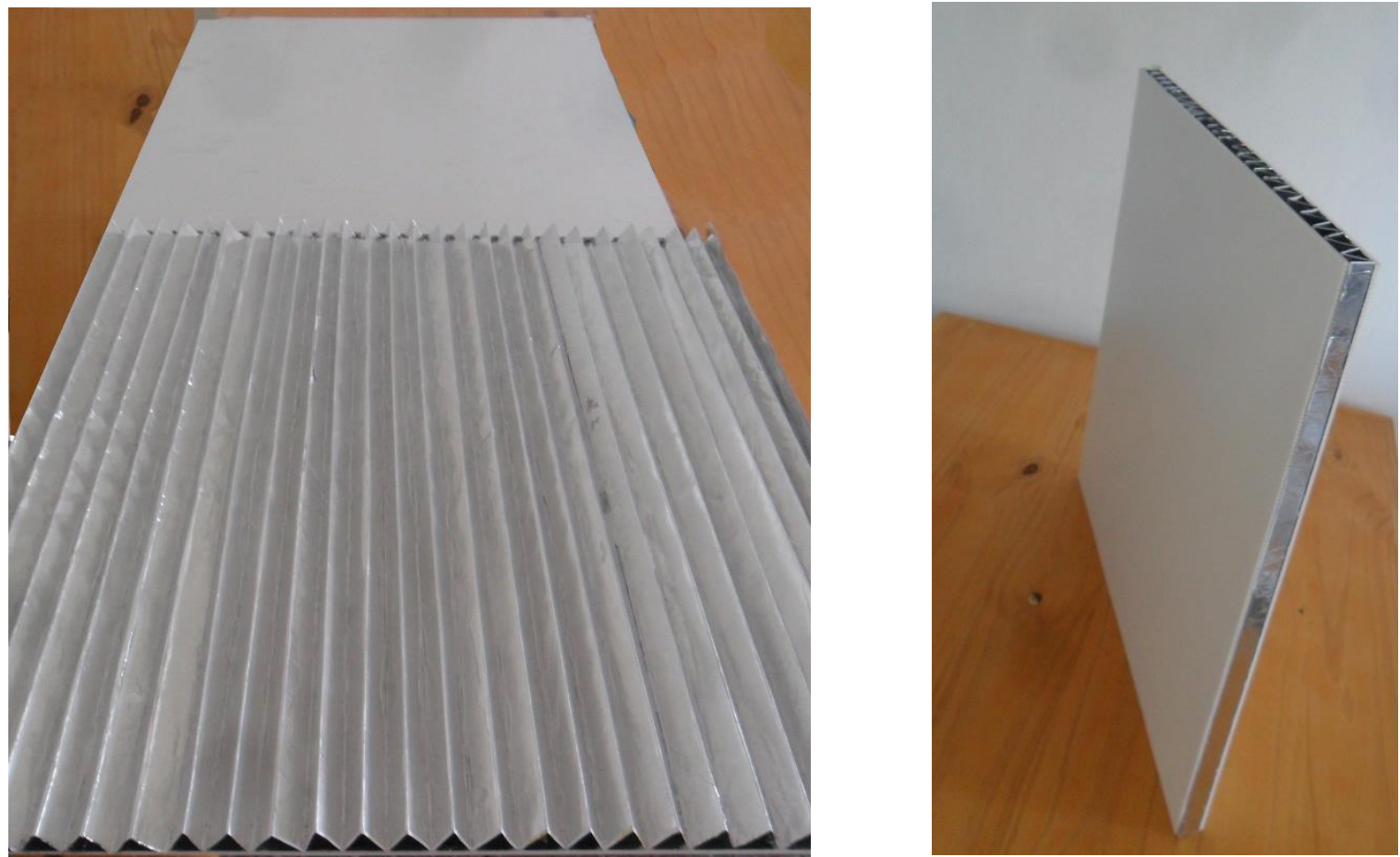

Figura 108. Fotografías del despiece de la solución constructiva, la imagen izquierda muestra el interior, en el cual se distingue la lámina corrugada de foil de aluminio con la cara brillante, mientras que la imagen derecha enseña la configuración totalmente acoplada. Fuente: Elaboración propia.

Luego de ser acoplado el panel fue anclado mediante chazos plásticos a la placa de concreto del módulo experimental, una fotografía del aparato experimental configurado con esta alternativa se aprecia en la Figura 109, en este escenario al lado derecho se ubicó el MI con el panel de aislamiento reflectivo, mientras que a la izquierda se ubicó el MT de concreto a la vista.

La campaña experimental con esta estrategia se realizó durante las tardes del 25,27 y 28 de febrero de 2017. 


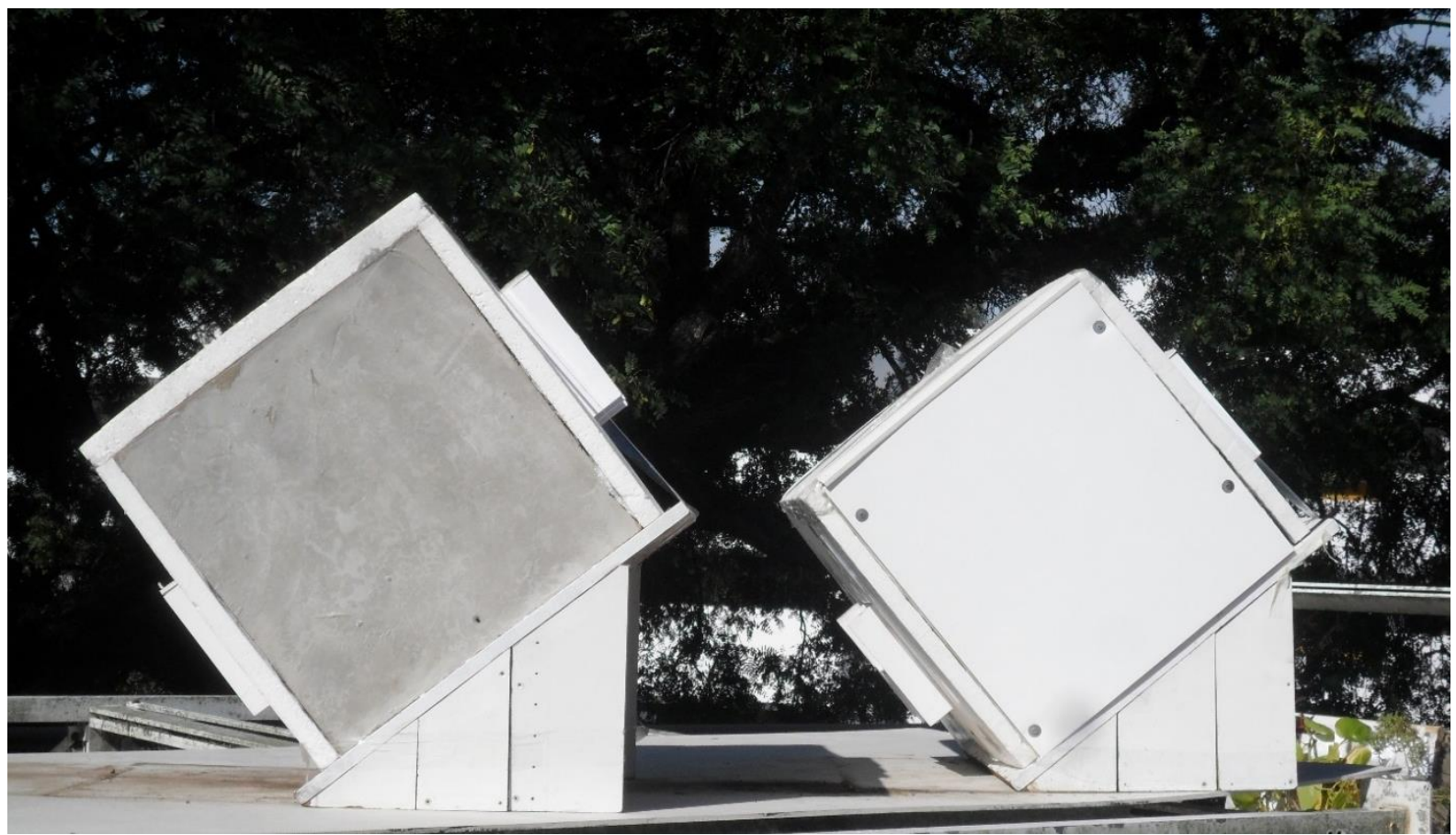

Figura 109. Configuración del aparato experimental para experimentación con la estrategia de aislamiento reflectivo + baja absortividad. Fuente: Elaboración propia.

\section{Temperatura radiante}

Algunas de las termografías y fotografías adquiridas durante esta campaña experimental, se muestran en los collages elaborados para las 13:00, 16:30 y 18:00 del 25 de febrero de 2017. Estos collages corresponden a la Figura 110, Figura 111 y Figura 112 respectivamente. En esta secuencia, se observa y sintetiza la tendencia general de desempeño térmico de esta solución constructiva durante los tres días de experimentación.

Las imágenes de la Figura 110 muestran que a las $13: 00$, la $\mathrm{T}_{\mathrm{r}}$ del $\mathrm{MI}$ se encontró $2,5^{\circ} \mathrm{C}$ por debajo del MT. Más adelante, en el collage de la Figura 111, correspondiente a las 16:30, esta diferencia se acrecentó a $14,9^{\circ} \mathrm{C}$. Por último, en la Figura 112, correspondiente a las 18:00, la diferencia de $\mathrm{T}_{\mathrm{r}}$ llega a $6,4^{\circ} \mathrm{C}$.

Las termografías muestran una tendencia marcada y continua de que la $T_{r}$ del Ml se encontró siempre por debajo de la del MT, tanto desde el inicio como al final de la experimentación. 

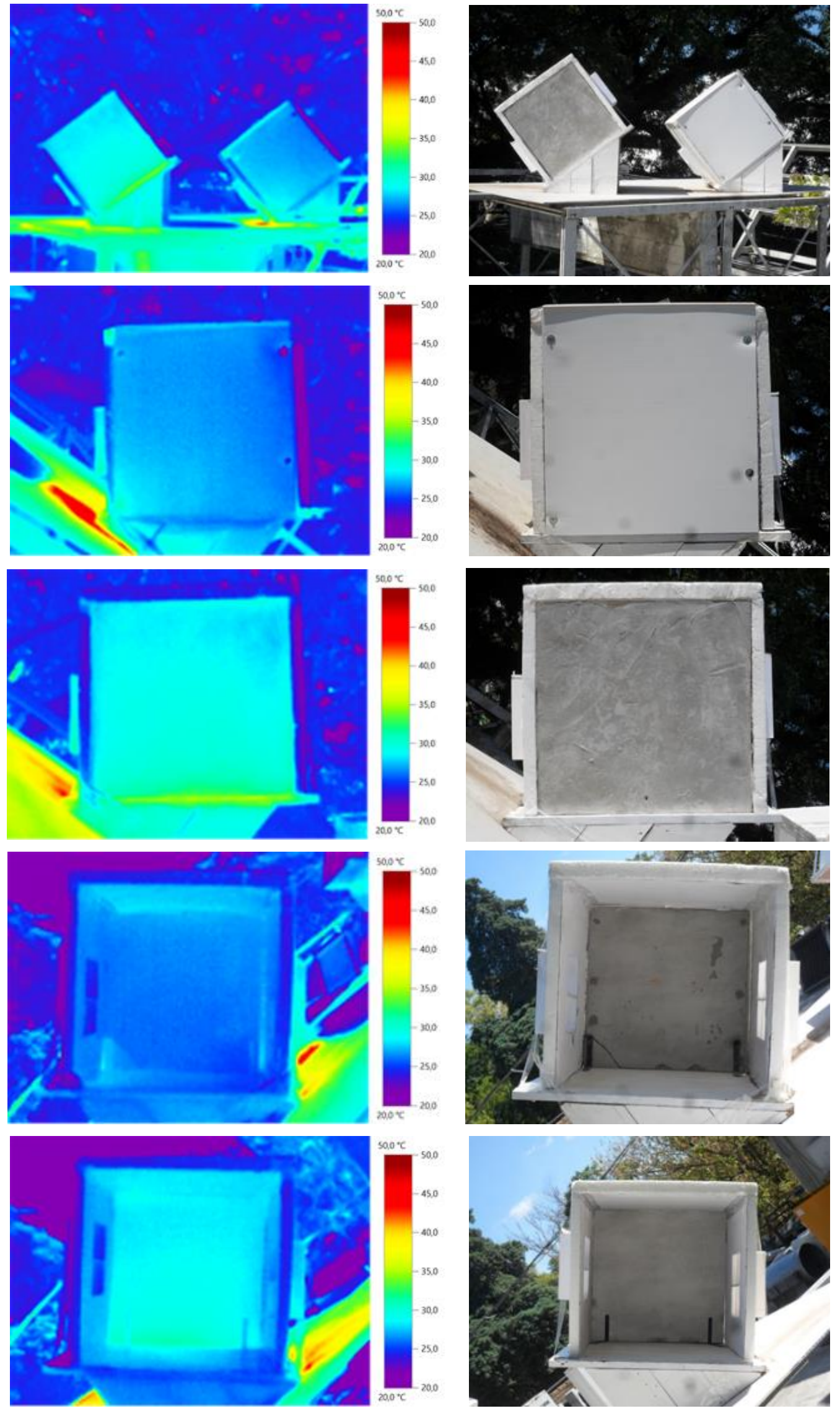

Figura 110. Collage de termografías y fotografías correspondientes al 25 de febrero de 2017 a las 13:00. Fuente: Elaboración propia. 

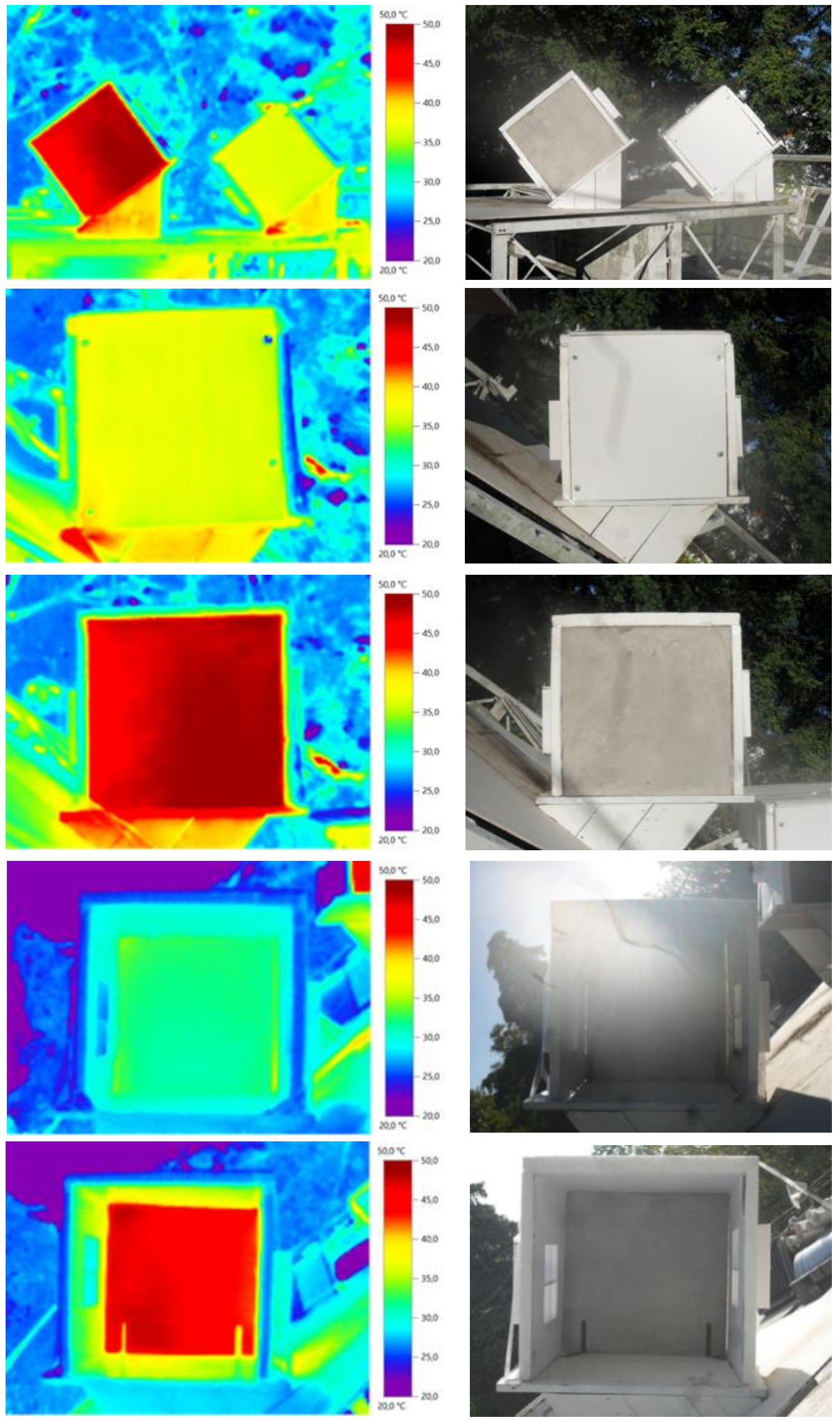

Figura 111. Collage de termografías y fotografías correspondientes al 25 de febrero de 2017 a las 15:30. Fuente: Elaboración propia. 

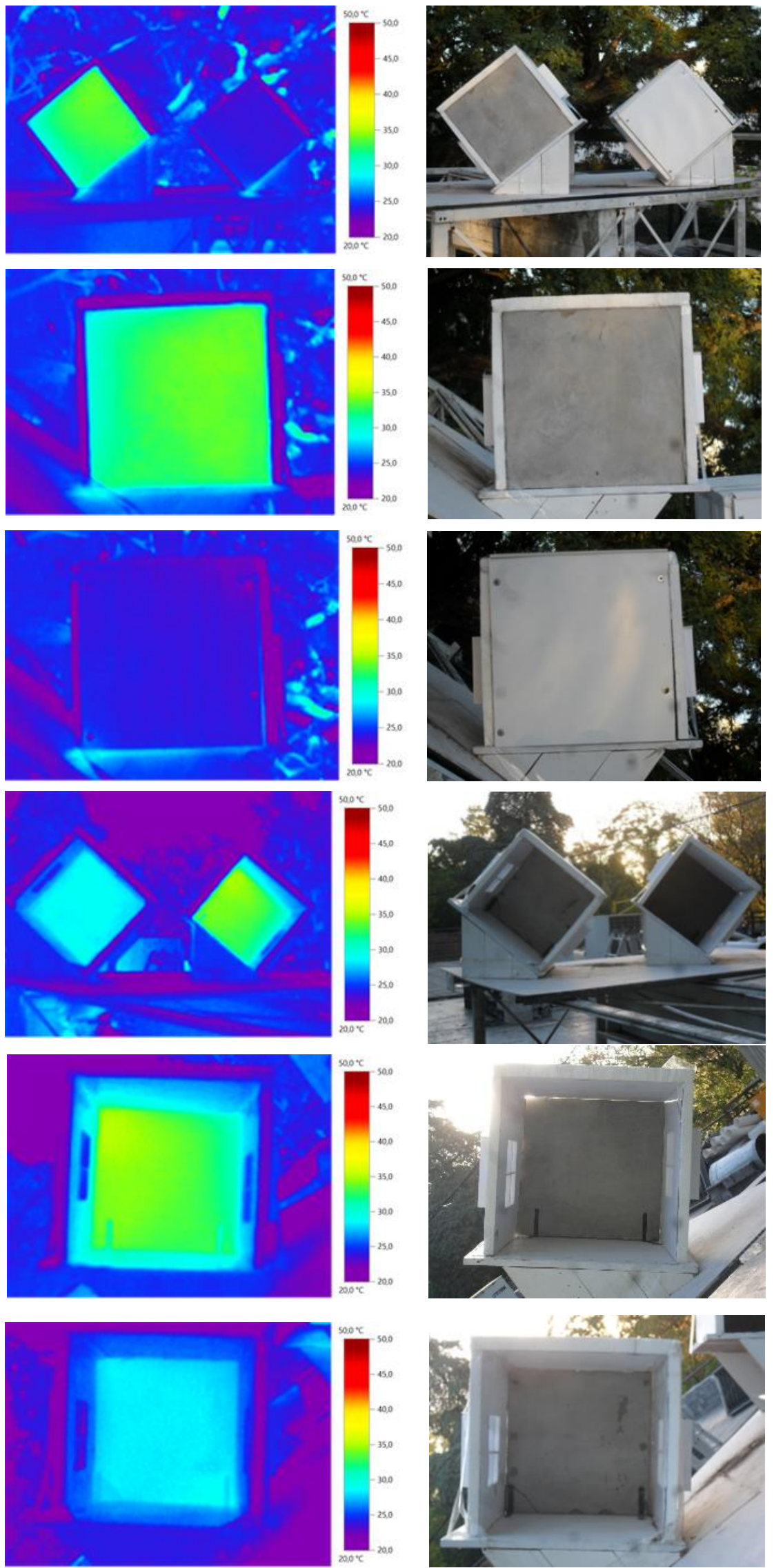

Figura 112. Collage de termografías y fotografías correspondientes al 25 de febrero de 2017 a las 18:00. Fuente: Elaboración propia. 
Los resultados de $T_{r}$ a lo largo de los tres días de experimentación, extraídos de las termografías se muestran a continuación en la gráfica de la Figura 113. Allí se observa que la $\mathrm{T}_{\mathrm{r}}$ en el MI, representada con la línea discontinua es notoriamente menor que la del MT desde las primeras horas de la tarde hasta el final.

El porcentaje de reducción de $T_{r}$ logrado por esta alternativa fue bastante similar durante las tres tardes experimentadas, pues mediante las comparaciones de las áreas bajo las curvas se obtuvieron valores de $73,21 \%, 73,25 \%$ y $76,21 \%$, para un promedio de $74,23 \%$, lo cual es $16,8 \%$ inferior respecto del porcentaje de $91,3 \%$ calculado teóricamente.

De otro lado, se encontró que la disminución media de $T_{r}$ fue de $9,4^{\circ} \mathrm{C}$ y la máxima fue de $15,6^{\circ} \mathrm{C}$ presentada durante a las $16: 30$ y $17: 00$ horas del 27/02/217.

Nótese además que, aunque el ancho del muro de concreto solo posee $2 \mathrm{~cm}$ de espesor, durante el tiempo evaluado la estrategia pudo mantener niveles aceptables de confort durante el $82,05 \%$ del tiempo. En el tiempo restante se encontraron separaciones máximas de $1,6{ }^{\circ} \mathrm{C}$, teniendo como referencia el límite superior del rango de confort.

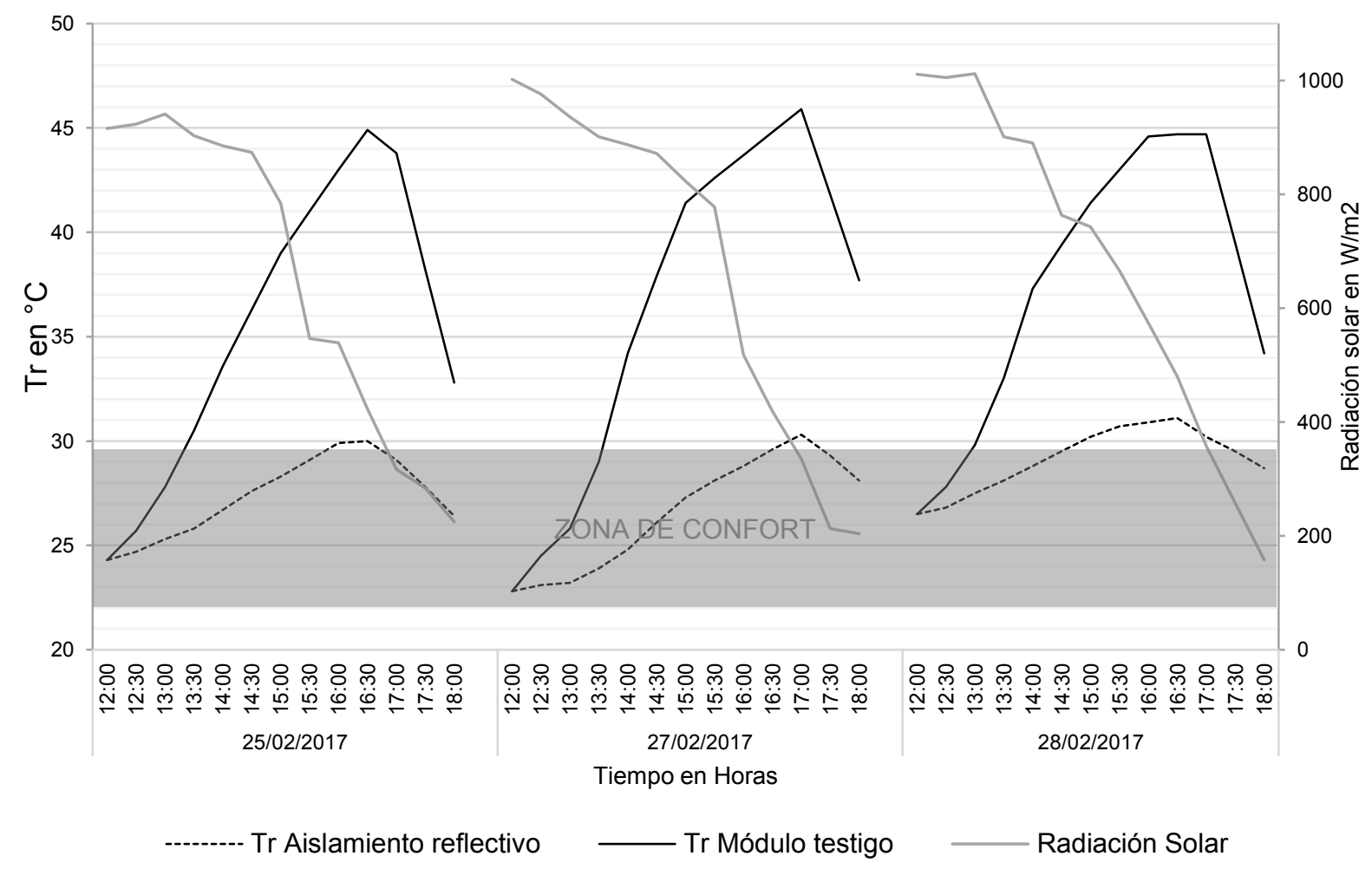

Figura 113. Gráfica comparativa de $\mathrm{Tr}$ vs Tiempo entre el MI con la estrategia de muro vegetal y el MT. Fuente: Elaboración propia. 


\section{Temperatura del aire y humedad relativa}

Los valores de $T_{\text {air }}$ y HR registrados durante la experimentación con esta estrategia se muestran a continuación en la Figura 114, en la cual se distinguen las diferencias de estas variables entre el MT y el MI.

En todos los casos, la $\mathrm{T}_{\text {air }}$ en el MI fue menor que la del MT, el porcentaje medio de reducción fue del $30,4 \%$. Por otro lado, la HR permaneció en todos los casos más alta en el MI que en el MT, en un porcentaje medio de $43,12 \%$.

En promedio la $\mathrm{T}_{\text {air }}$ del $\mathrm{Ml}$ estuvo $0,92{ }^{\circ} \mathrm{C}$ más baja que la del $\mathrm{MT}$ y el valor máximo de diferencia fue de $1,6{ }^{\circ} \mathrm{C}$. De la misma forma, en promedio la HR en el Ml estuvo $4,15 \%$ más alta que la del MT y el valor máximo de diferencia fue de 6,3\%.

Estas tendencias son continuas y los valores de diferencia superan los de imprecisión del instrumental y el aparato experimental, con lo cual esta estrategia demostró una influencia positiva en la $\mathrm{T}_{\text {air }} \mathrm{y} \mathrm{HR}$.

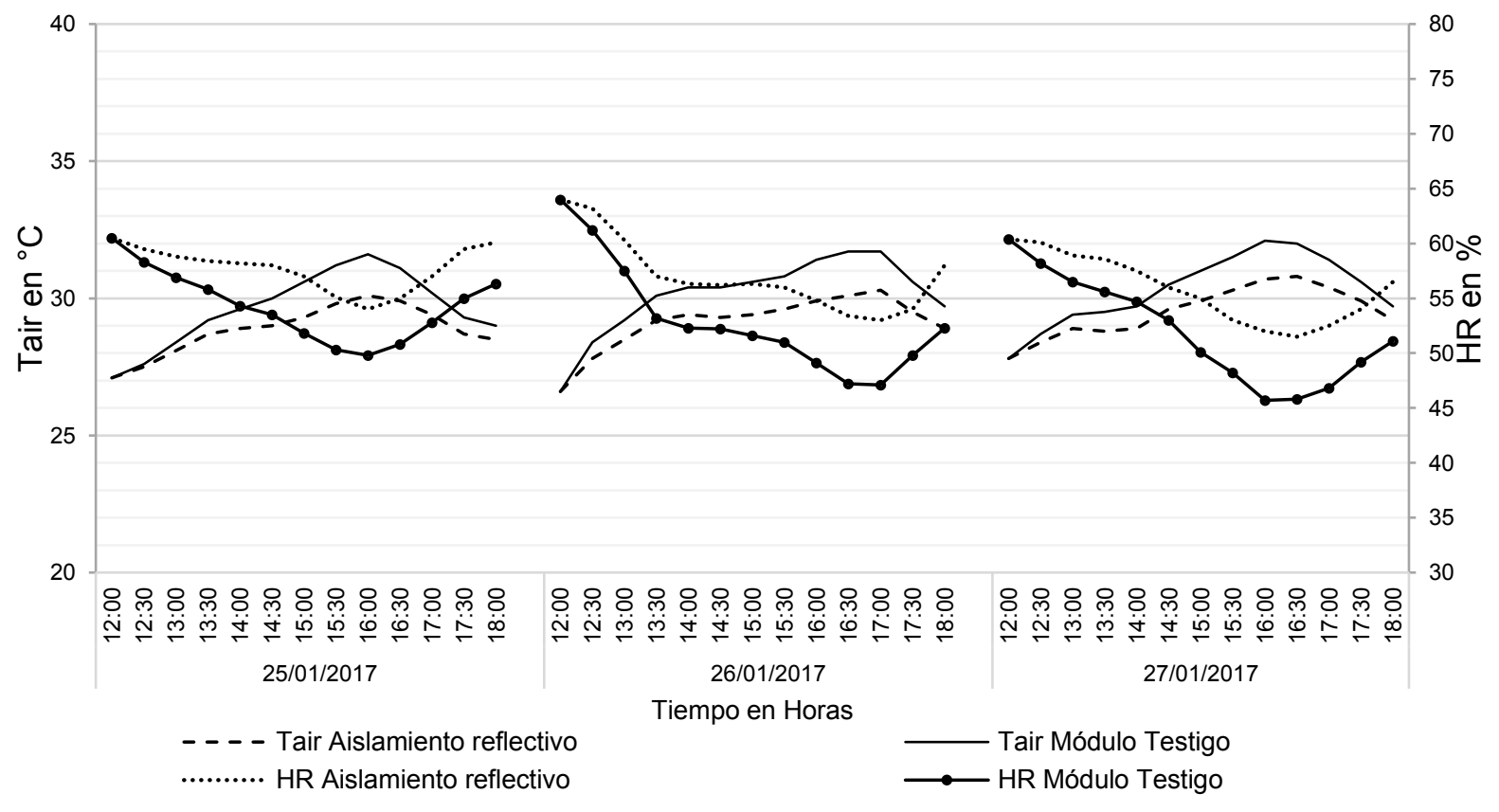

Figura 114. Gráfica comparativa de $\mathrm{T}_{\text {air }} \mathrm{y} \mathrm{HR}$ vs Tiempo entre el Ml con la estrategia de AR y el MT. Fuente: Elaboración propia. 


\subsection{Discusión sobre diferencias entre los cálculos teóricos en régimen estacionario vs datos experimentales en régimen transitorio}

Antes sintetizar y discutir acerca de los resultados experimentales de esta prueba, nos pareció necesario revisar la concordancia general de los cálculos teóricos con los datos empíricos de reducción de la $\mathrm{T}_{\mathrm{r}}$. Para esto se examinaron dos variables: una general y una puntual. La general es el porcentaje de reducción de la $T_{r}$ y la puntual equivale a la máxima reducción de $\mathrm{T}_{\mathrm{r}}$ en ${ }^{\circ} \mathrm{C}$.

Con estas dos variables se elaboró la

Tabla 26, que compara estos valores y servirá de herramienta para la interpretación. Como puede verse allí, las diferencias más notorias corresponden a la alternativa de RF, con $50 \%$ y $5,57^{\circ} \mathrm{C}$ respectivamente. Como se explicó anteriormente, a la hora de materializar esta alternativa no se logró la absortividad deseada y se estimó que la combinación del polvillo refractario con la resina acrílica también afectó negativamente el valor $R$.

Descartando la alternativa de RF por cuestiones de ejecución, se aprecia que en general los valores teóricos estiman un porcentaje de reducción mayor que el obtenido experimentalmente. Esta diferencia como mínimo es de 0,3\% y como máximo es de 17,07\%.

Por otra parte, y también exceptuando la alternativa RF, la variable de reducción máxima posee diferencias entre valores teóricos y empíricos que no superan el $( \pm) 7,4 \%$ de diferencia, porque en algunos casos el valor teórico suele ser mayor y en otros menor al medido experimentalmente.

\begin{tabular}{|c|c|c|c|c|c|c|}
\cline { 2 - 7 } \multicolumn{1}{c|}{} & \multicolumn{3}{c|}{$\%$ DE REDUCCIÓN DE Tr } & \multicolumn{2}{c|}{ REDUCCIÓN MÁXIMA DE Tr EN ${ }^{\circ}$ C } \\
\cline { 2 - 7 } & TEÓRICO & EXPERIMENTAL & DIFERENCIA & TEÓRICO & EXPERIMENTAL & DIFERENCIA \\
\hline AS & $18 \%$ & $17,70 \%$ & $0,30 \%$ & 3 & 5,4 & 2,40 \\
\hline BA & $62,20 \%$ & $49,40 \%$ & $12,80 \%$ & 8,8 & 8,4 & 0,40 \\
\hline RF & $81,80 \%$ & $31,50 \%$ & $50,30 \%$ & 11,99 & 6,42 & 5,57 \\
\hline MV & $90,73 \%$ & $73,70 \%$ & $17,03 \%$ & 13,93 & 9,9 & 4,03 \\
\hline AR & $91,30 \%$ & $74,23 \%$ & $17,07 \%$ & 14,56 & 15,6 & 1,04 \\
\hline
\end{tabular}

Tabla 26. Tabla comparativa de resultados teóricos y empíricos de desempeño térmico. Fuente: Elaboración propia. 


\subsection{Discusión acerca del porcentaje de reducción de la $T_{r}$ y los controles a la $\mathrm{T}_{\text {air }}$ y la HR}

Para sintetizar y contrastar el desempeño de las soluciones constructivas frente a estas tres variables, se elaboró la gráfica de la Figura 115 con los resultados obtenidos en el experimento bajo brillo solar.

En esta gráfica, el primer conjunto de barras de la izquierda, encerradas en línea discontinua, equivalen al Módulo Testigo de concreto a la vista, el cual representa el $100 \%$ de la $T_{r}$ y la $T_{\text {air, }}$, y el $0 \%$ de la HR. Después, se presentan cada una de las soluciones constructivas de menor a mejor desempeño.

Nótese que los controles realizados adicionalmente a la $T_{\text {air }}$ y la HR muestran coherencia, ya que al reducirse la $T_{r}$, simultáneamente se experimenta una reducción en el flujo de calor de la $T_{\text {air }} \mathrm{y}$ un aumento en la HR. Además, en general todas las alternativas demuestran haber tenido un desempeño positivo en las tres variables, es decir, todas redujeron la $T_{r}$ y la $T_{a i r} y$ aumentaron la HR.

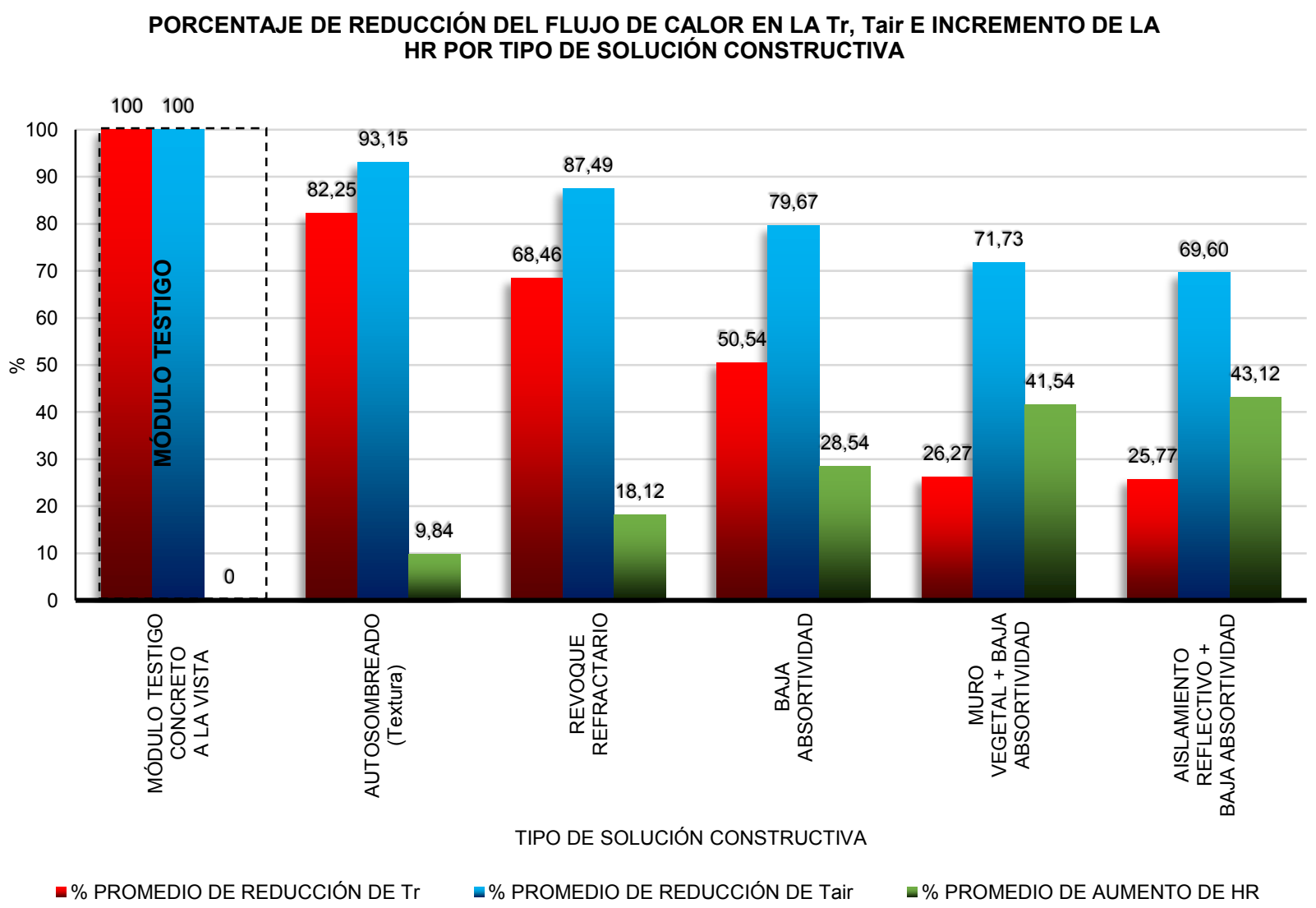

Figura 115. Gráfica de desempeño térmico según el tipo de solución constructiva. Porcentaje de reducción de $T_{\text {air }} \mathrm{y}$ $T_{r}$ y aumento de la HR. Fuente: Elaboración propia. 
Al comparar la $T_{r}$ del Módulo Testigo con la $T_{r}$ de las soluciones constructivas, la gráfica muestra que las soluciones que mejor se desempeñaron fueron en primer lugar el Aislamiento reflectivo + baja absortividad (AR), permitiendo disminuirla al 25,77\%; seguida del Muro vegetal + Baja absortividad (MV) con $26,77 \%$. En tercer lugar, se encuentra la alternativa de baja absortividad (BA), con la cual se reduce la $T_{r}$ al 50,54\%; en cuarto lugar, el Recubrimiento refractario (RF) con $68,46 \%$ y; en quinto lugar, con el resultado más bajo se encuentra la alternativa de autosombreado (AS) con $82,25 \%$.

Haciendo esta misma comparación con la variable $T_{\text {air, }}$ la gráfica muestra que las soluciones que menor flujo de calor dejaron pasar al aire corresponden al AR con 69,6\%; seguida del MV con $71,73 \%$. En tercer lugar, está la solución de BA con 79,67\%; en cuarto lugar, la alternativa de RF con 87,49\%; y por último, la opción de AS con $93,15 \%$.

Para el caso de la HR, es común que su comportamiento sea inversamente proporcional a la $\mathrm{T}_{\mathrm{air}}$, con lo cual, en este experimento es positivo que la HR de los Módulos Intervenidos sea superior a la del Módulo Testigo. En este sentido, la alternativa en la que menos se disminuyó la $\mathrm{HR}$ fue en el AR siendo acumulativamente superior en un $43,12 \%$; en segundo lugar, está el MV con 41,54\%; en tercer lugar, está la opción de BA con 28,54\%; en cuarto lugar, el RF con 18,12\%; y por último la alternativa de AS con solo $9,84 \%$.

De esta manera, existe una clara superioridad de desempeño térmico de las soluciones de AR y MV sobre las demás. Entre estas dos alternativas, el AR es ligeramente superior al MV. Sin embargo, los valores obtenidos con ambas soluciones son bastante cercanos y teniendo en cuenta que existen imprecisiones por parte de los equipos y leves diferencias en el aparato experimental, ambas alternativas pueden considerarse iguales.

Una prueba tardía, para corroborar este comportamiento fue llevada a cabo en los días 15 y 21 de abril de 2017, con el mismo procedimiento descrito en el título 6.6, pero, comparando solamente el AR y el MV. En esta campaña solo se registraron datos de $T_{r}$ mediante termografías como las mostradas en la Figura 116.

Al igual que las pruebas anteriores, los resultados de estas campañas mostraron una leve superioridad promedio del 5,13\% del módulo tratado con AR sobre el módulo tratado con MV, lo cual puede observarse en la gráfica de la Figura 117. 

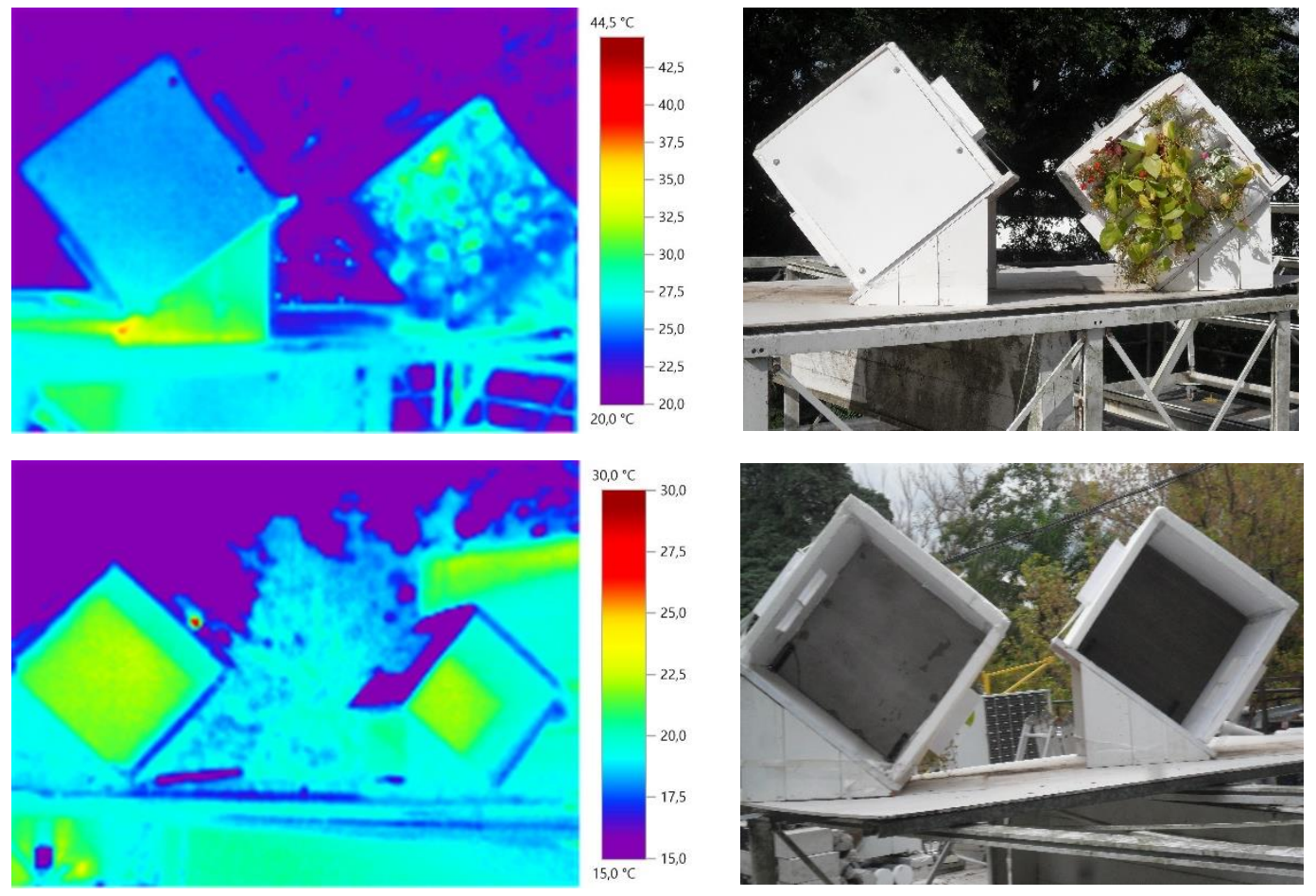

Figura 116. Termografías de experimentación de desempeño entre las soluciones constructivas de AR y MV. Fuente: Elaboración propia.

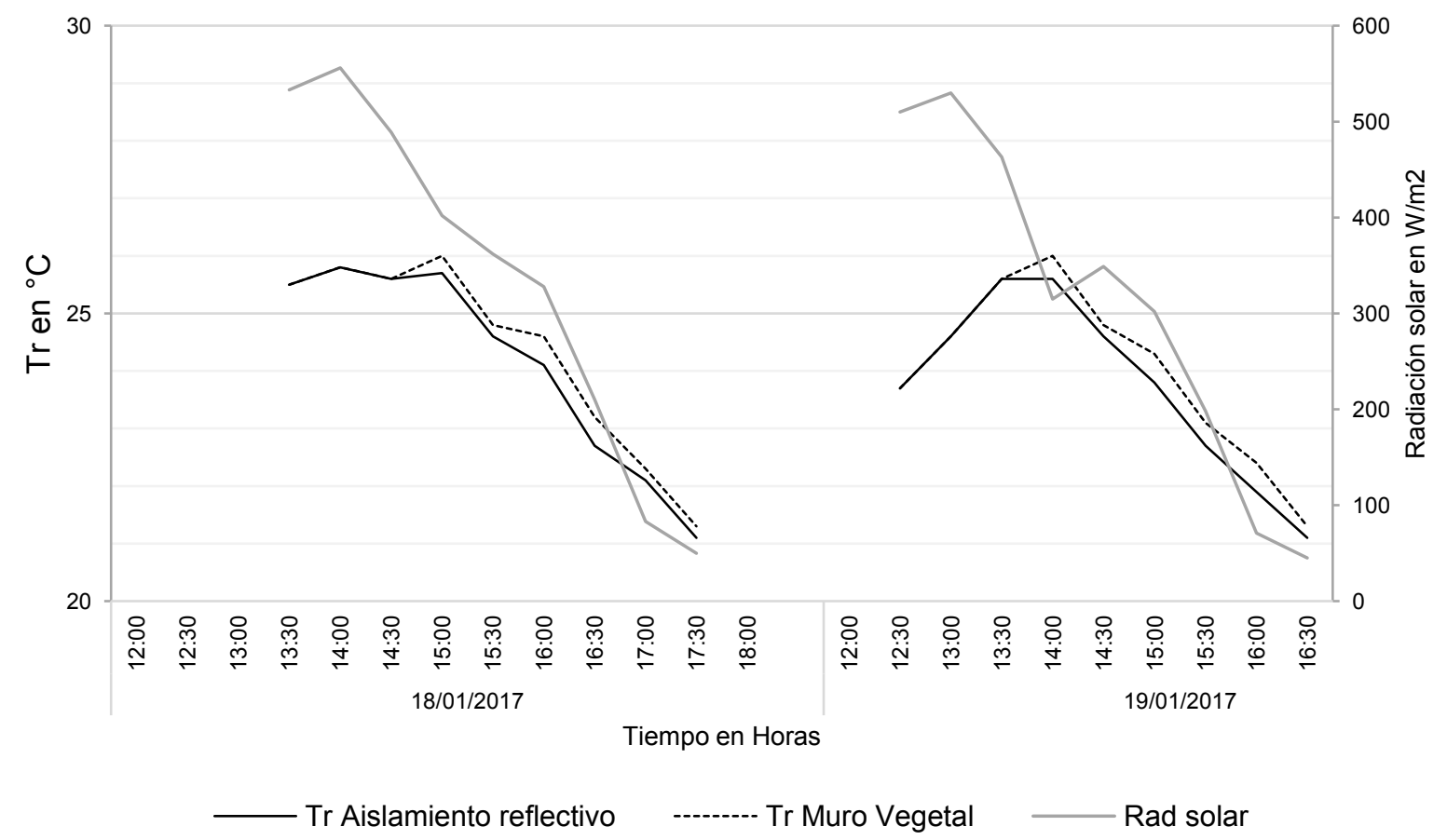

Figura 117. Gráfica comparativa de Tr vs Tiempo entre las soluciones constructivas de AR y MV. Fuente: Elaboración propia. 


\subsection{Conclusiones}

- El análisis climático comparativo entre Cali y La Plata (Apéndice 2) para seleccionar el periodo del año más semejante en el cual realizar las mediciones, al igual que el diseño, los controles y calibración del aparato experimental hicieron de esta una metodología confiable que permitió cumplir el objetivo de determinar el porcentaje de reducción de la $T_{r}$ de cada una de las soluciones constructivas diseñadas.

- Exceptuando lo acontecido con la solución RF, se encontró que los datos de porcentaje de reducción de la $T_{r}$ calculados en el Capítulo 5 fueron hasta 17,07\% superiores a los obtenidos experimentalmente aquí. Además, es visible que estos concuerdan en cuanto al orden de desempeño, es decir, con ambos métodos se pudo establecer cuales soluciones son mejores que otras, prueba de esto es que solamente las soluciones de Aislamiento reflectivo y Muro vegetal demostraron tanto teórica como experimentalmente reducir de manera sustancial la $T_{r}$, logrando reducirla respectivamente, al $25,77 \%$ y al $26,27 \%$. Al igual que fueron las únicas dos soluciones que se acercaron a los rangos de confort de $T_{r}$ y $T_{\text {air }}$.

- Las tecnologías de enfriamiento pasivo combinadas estratégicamente tienen un gran potencial de reducción de la $T_{r}$ ya que las soluciones independientes como el Autosombreado, Revoque refractario y Baja absortividad, tan solo obtuvieron reducciones de $17,75 \%, 31,54 \%$ y $49,46 \%$ respectivamente; mientras que aquellas donde se utilizan más de un tipo de tecnología como el Muro vegetal y el aislamiento reflectivo lograron $73,23 \%$ y $74,23 \%$ respectivamente.

- Registrar la $T_{\text {air }}$ y la HR, permitió demostrar la influencia positiva de reducir la $T_{r}$ en todo el ambiente térmico, pues se evidenció que a medida que la $T_{r}$ se redujo, también se redujo la $T_{\text {air }} \mathrm{y}$ aumentó la $\mathrm{HR}$.

- La alternativa de AR demostró desempeñarse térmicamente mejor en comparación a las demás opciones, aunque es seguida muy de cerca por el MV. Por esta razón, la siguiente experimentación va encaminada a conocer el valor $U$ de estas dos soluciones constructivas. 


\section{DETERMINACIÓN DE LA TRANSMITANCIA TÉRMICA (U)}

\subsection{Introducción}

El objetivo de este paso metodológico es conocer la transmitancia térmica de las soluciones constructivas que redujeron sustancialmente y se acercaron a los niveles confortables de la $\mathrm{T}_{\mathrm{r}}$ en la prueba anterior, las cuales fueron el AR y el MV.

Esta etapa experimental relaciona el punto anterior con el siguiente ya que se realizó con las opciones de mejor desempeño halladas en la prueba anterior y sirve como dato de entrada para la simulación computacional de mejoramiento de confort térmico del siguiente paso metodológico.

Obtener el valor $U$, además, posibilitó la comparación de estas soluciones constructivas con otras alternativas, como por ejemplo, el aislamiento con materiales de alta resistencia térmica como el poliestireno expandido, el poliuretano y el aerogel, que aunque no se trabajaron en el anterior experimento, sí se documentaron en el estado del arte.

Para determinar el valor $U$, se desarrolló un experimento basado en el método de la caja caliente calibrada descrito en la norma ISO 8990:1994 (International Organization for Standardization, 1997), para el cual se requiere alcanzar el régimen estacionario. A continuación, se describe técnicamente este experimento.

\subsection{Normas de Medición}

El método de la caja caliente calibrada y otros similares, que van dirigidos a obtener el valor $U$ de los materiales, se encuentran documentados en normas como la ISO 8990:1994 (International Organization for Standardization, 1997), la ASTM C-1363 (American Society for Testing and Materials, 1993) y en la norma argentina IRAM No. 11564 (Instituto Argentino de 
Normalización y Certificación). Los términos, procedimientos y dispositivos recomendados para hacer esta medición son explicados allí. En el presente trabajo se procuró seguir las recomendaciones de la primera norma mencionada.

El método de la caja caliente calibrada se basa en rodear la probeta de dos ambientes: uno frío y uno caliente como se enseña en la Figura 118. En ambos ambientes la $T_{\text {air }}$ es controlada y constante para lograr un régimen estacionario. Las diferencias de temperatura deben ser al menos $20^{\circ} \mathrm{C}$ o superior.

Las pérdidas de calor a través del cajón de medida se reducen al mínimo mediante materiales de alta resistencia térmica. La calibración se realiza mediante probetas patrón con transmitancia térmica conocida para corregir las pequeñas pérdidas de calor laterales y por las paredes.

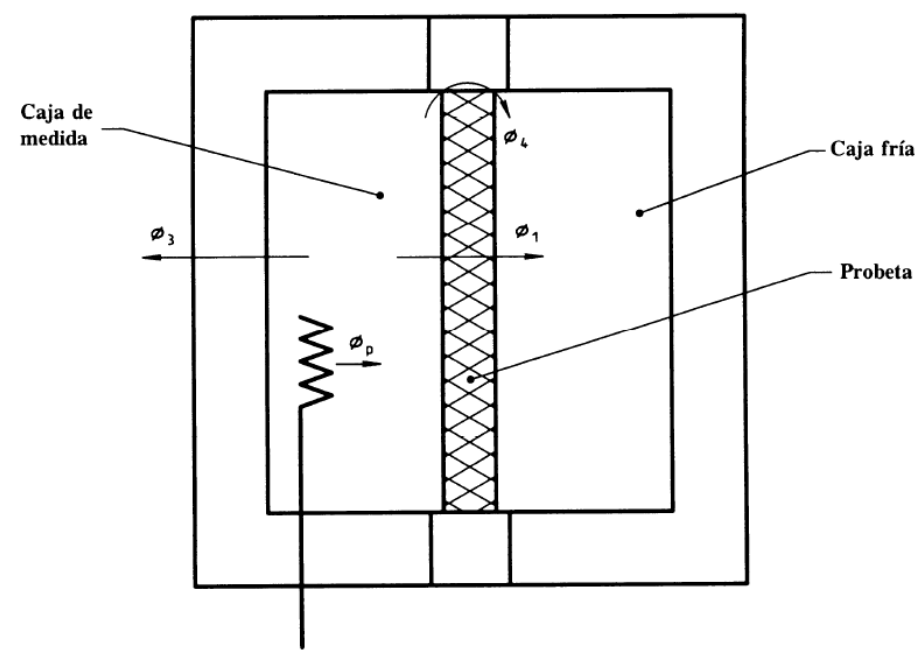

Figura 118. Explicación gráfica del método de la caja caliente. Fuente: Norma ISO 8990:1994 (International Organization for Standardization, 1997).

Este método requiere el registro simultaneo del flujo de calor de la cámara caliente a la cámara fría, la temperatura superficial del lado caliente y las temperaturas del aire en cada una de las cámaras para realizar el cálculo del valor $U$.

Con lo anterior, la fórmula matemática base para calcular el valor $U$ con esta norma es:

$$
\frac{Q}{A}=\bigcup(T \text { air }-T r)
$$

Donde:

$Q$ es el flujo de calor en W.

A es el área en $\mathrm{m}^{2}$ 
$\mathrm{U}$ es la transmitancia térmica en $\mathrm{W} / \mathrm{m}^{2 \circ} \mathrm{K}$

$\mathrm{T}_{\text {air }}$ es la temperatura del aire del ambiente en ${ }^{\circ} \mathrm{K}$ o en ${ }^{\circ} \mathrm{C}$

$\mathrm{T}_{\mathrm{r}}$ es la temperatura superficial de la probeta en ${ }^{\circ} \mathrm{K}$ o en ${ }^{\circ} \mathrm{C}$

En la actualidad, existen equipos adquisidores de datos a los que se conectan los diferentes sensores y mediante un cálculo en tiempo real arroja el valor $U$ en forma instantánea. Estos son: el medidor de flujo de calor y el medidor de valor $U$.

Ambos instrumentos son apropiados para medir el valor $U$ de construcciones existentes de las cuales se desconoce la composición de sus elementos, a la vez que tienen la versatilidad de utilizarse para determinar el valor $U$ de nuevos materiales o configuraciones innovadoras en laboratorio, como es el caso de esta investigación.

Para determinar la transmitancia, el medidor de flujo de calor es más tradicional porque como su nombre lo indica, se apoya en el flujo de calor y la diferencia de temperaturas ambiente y superficial; mientras que el medidor de $U$ utiliza solo el registro de tres temperaturas: la temperatura superficial en el lado caliente y la temperatura del aire en ambos ambientes.

El uso del medidor del flujo de calor ha sido utilizado en investigaciones como la de Evangelisti, Guattari, Gori, \& Asdrubali (2018), donde se compararon los resultados de transmitancia térmica obtenidos con simulaciones computarizadas y mediciones de campo.

Mientras que el medidor de U es utilizado por Buzatu, Stan Ivan, Mircea, \& Manescu (2017) en una investigación para determinar el valor $U$ de dos paredes y encontrar diferencias entre los datos medidos y calculados.

De acuerdo con las investigaciones anteriores, el uso de estos instrumentos es apropiado siempre y cuando se lleven las debidas calibraciones.

\subsection{Instrumental}

El instrumental utilizado en esta experimentación se relaciona a continuación en la Tabla 27 y puede consultarse una ampliación en el Apéndice 3, título 3.3. 


\begin{tabular}{|l|c|l|}
\hline \multicolumn{1}{|c|}{ INSTRUMENTO } & \multicolumn{1}{|c|}{ VARIABLE } & DESCRIPCIÓN \\
\hline $\begin{array}{l}\text { Instrumento multifunción marca } \\
\text { Testo, Ref: 435-2 }\end{array}$ & $\begin{array}{c}\text { - Cálculo y almacenamiento del } \\
\text { valor U }\end{array}$ & Consultar Apéndice 3, título 3.3. \\
\hline $\begin{array}{l}\text { Sonda termopar Marca Testo, } \\
\text { Ref: 06021793 }\end{array}$ & $\begin{array}{c}\text { - Temperatura del aire en el interior } \\
\text { de la cámara fría. }\end{array}$ & Consultar Apéndice 3, título 3.3. \\
\hline $\begin{array}{l}\text { Sonda valor U Marca Testo, Ref: } \\
06141635\end{array}$ & $\begin{array}{l}\text { Temperatura del aire en el interior } \\
\text { de la cámara caliente. } \\
\end{array}$ & Consultar Apéndice 3, título 3.3. \\
& Temperatura superficial de la & \\
\hline
\end{tabular}

Tabla 27. Instrumental utilizado en la determinación de la transmitancia térmica. Fuente: Elaboración propia.

Una vez que el equipo adquiere la $T_{r}$ de la probeta en el lado caliente y la $T_{\text {air }}$ al interior de ambas cámaras calcula el valor $U$ internamente y lo almacena. La fórmula con la que trabaja es:

$$
\mathrm{U}=\alpha^{*} \Delta \mathrm{T}_{1} / \Delta \mathrm{T}_{2}
$$

Donde:

$\alpha=$ Coeficiente de convección aparente normalizado $7,69 \mathrm{~W} / \mathrm{m}^{2} \mathrm{~K}$

$\Delta \mathrm{T}_{1}=\mathrm{T}_{\text {air }}$ de la cámara caliente $\left(\mathrm{T}_{\mathrm{i}}\right)$ - Temperatura superficial de la probeta en el lado caliente $\left(T_{r}\right)$

$\Delta T_{2}=$ Temperatura superficial de la probeta en el lado caliente $\left(T_{r}\right)-T_{\text {air }}$ de la cámara fría $\left(T_{0}\right)$

La diferencia de temperaturas entre cámaras para que el equipo medidor de $U$ funcione debe ser superior a $15{ }^{\circ} \mathrm{C}$, pero como se mencionó anteriormente, la norma ISO 8990:1994 establece que debe ser superior a $20^{\circ} \mathrm{C}$. En este caso, la diferencia se configuró a $40^{\circ} \mathrm{C}$ manteniendo la $\mathrm{T}_{\text {air }}$ del lado frío a $10^{\circ} \mathrm{C}$ y la del lado caliente a $50{ }^{\circ} \mathrm{C}$.

\subsection{Diseño y construcción}

El diseño del aparato experimental de esta prueba tomó como inspiración lo elaborado por Viegas, Walsh, \& Barros (2016). Al igual que estos autores, para la cámara del ambiente frío se utilizó una unidad enfriadora (heladera Sigma modelo S3100), a la cual se le desmontó la puerta principal para poder hacer el acople de los anillos y la cámara caliente. Las dimensiones internas de esta unidad son $0,5 \mathrm{~m}$ de ancho $\times 1,0 \mathrm{~m}$ de alto $\times 0,44 \mathrm{~m}$ de profundidad. 
Por su lado, la cámara caliente se fabricó con estas mismas dimensiones en poliestireno expandido y un recubrimiento vinílico transparente para mejorar la estanqueidad del aire en las paredes y juntas. Tanto la unidad enfriadora como la cámara caliente se muestran a continuación en la Figura 119.
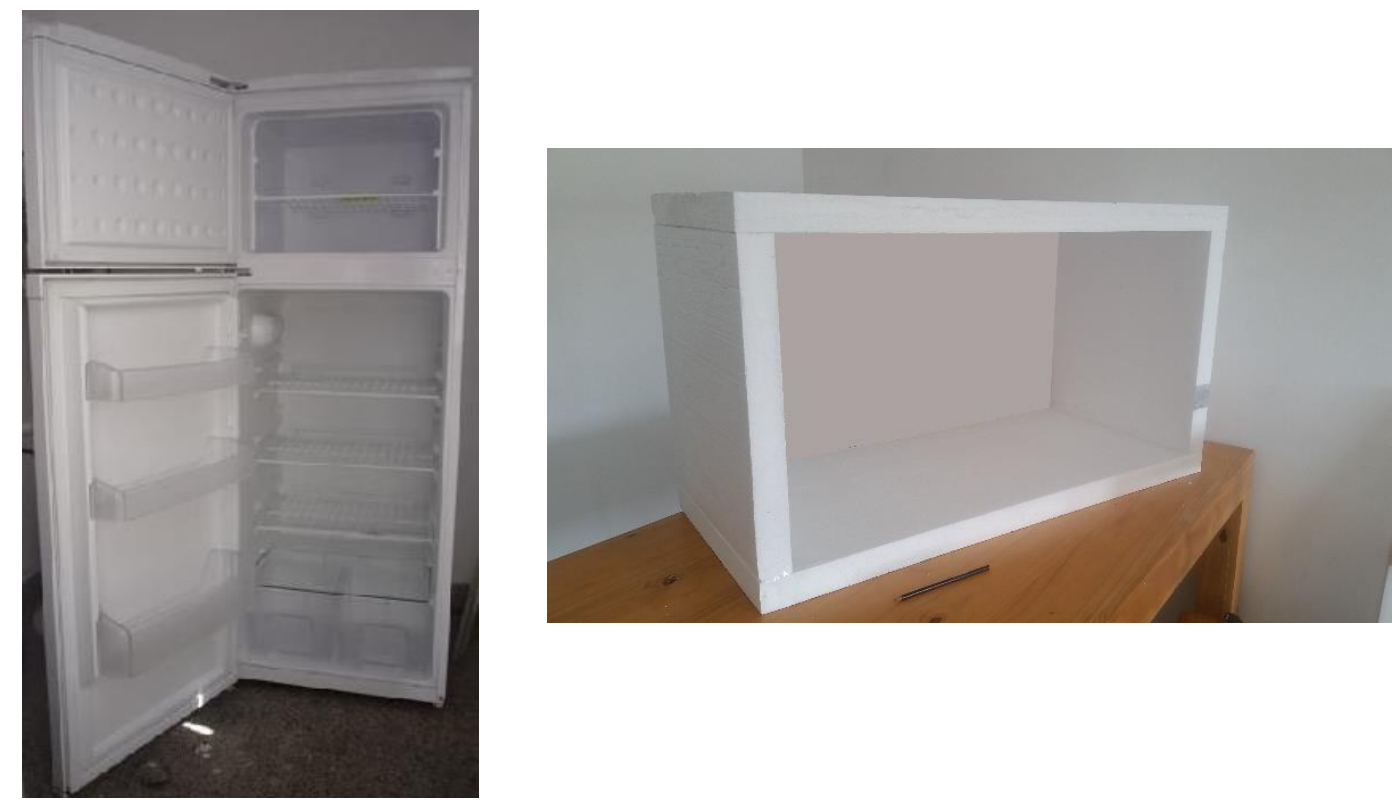

Figura 119. Lado izquierdo: unidad enfriadora (Heladera sigma modelo S3100), lado derecho cámara caliente. Fuente: Elaboración propia.

El calentamiento de la cámara caliente se realizó por medio de un calefactor con resistencia eléctrica de $2000 \mathrm{~W}$ de potencia controlada por termostato y ventilación forzada constante de $0,7 \mathrm{~m} / \mathrm{s}$ para homogeneizar la $\mathrm{T}_{\text {air }}$ al interior.

Un panel deflector para protección frente a la radiación y la ventilación hecho de foil de aluminio y celulosa fue dispuesto en frente del área de medición del lado caliente.

Los anillos de guarda se fabricaron también en poliestireno expandido con grosor de $100 \mathrm{~mm}$, de los cuales $50 \mathrm{~mm}$ estuvieron en el interior de la cámara fría y $50 \mathrm{~mm}$ en el interior de la cámara caliente. 
En la siguiente Figura 120 se observa una vista del interior de la cámara caliente, con y sin panel deflector.
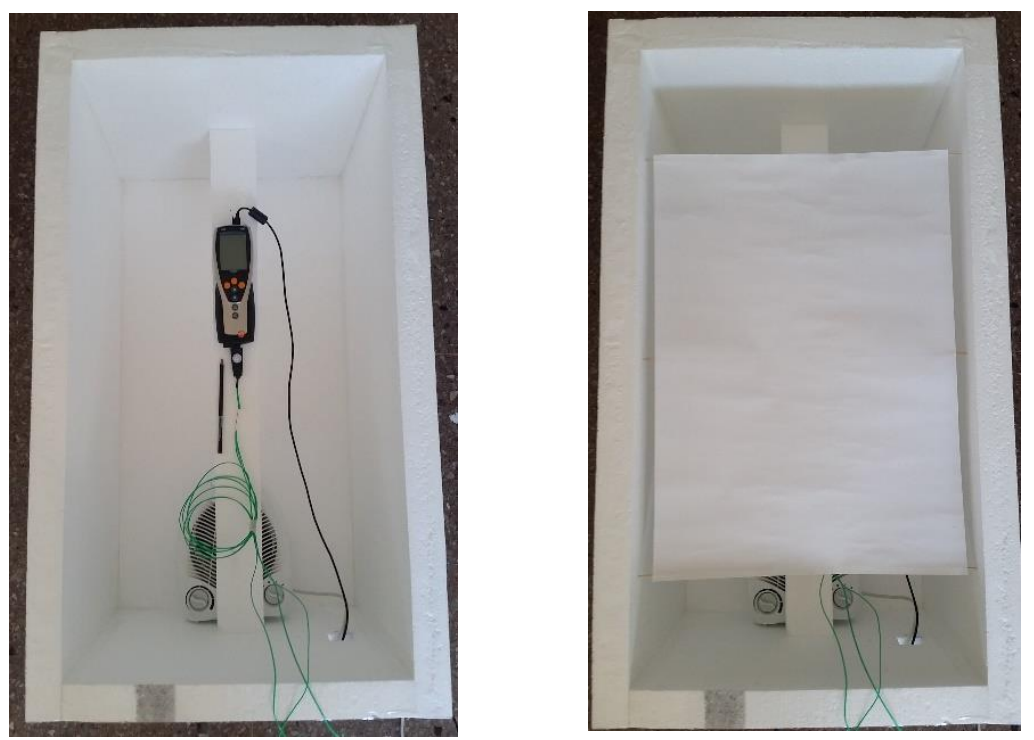

Figura 120. Configuración interna de la cámara caliente, izquierda sin panel deflector, derecha con panel deflector. Fuente: Elaboración propia.

\subsection{Verificación y Calibración}

Buzatu, Stan Ivan, Mircea, \& Manescu (2017), desarrollaron un estudio en el que se utilizó este equipo para determinar el valor $U$ de dos paredes, encontraron diferencias de $44,19 \%$ a $40,18 \%$ entre los datos medidos y los calculados, por lo cual es necesaria una calibración previa con materiales de transmitancia térmica conocida.

La verificación de funcionamiento consistió en probar que todos los sistemas trabajaran correctamente, que se cumplieran las diferencias de temperaturas entre el lado caliente y el lado frío y que en el lado caliente no existiesen estratificaciones de temperatura de acuerdo con lo estipulado en la norma ISO 8990:1994.

Luego de verificar el funcionamiento, se llevó a cabo la calibración, con el fin de corregir las imprecisiones del instrumental y las pérdidas de calor, comparando el valor $U$ de un panel conocido con el valor arrojado por el instrumental. En esta ocasión para calibrar el sistema se utilizaron dos materiales, un panel de vidrio incoloro común de $4 \mathrm{~mm}$ y un panel de poliestireno expandido de $50 \mathrm{~mm}$ cuyos valores de transmitancia térmica equivalente a $5,8 \mathrm{~W} / \mathrm{m}^{2 \circ} \mathrm{C}$ y 0,72 $\mathrm{W} / \mathrm{m}^{2 \circ} \mathrm{C}$ respectivamente. 
Estos paneles fueron dejados bajo las condiciones higrotérmicas interiores del laboratorio por una semana, logrando una condición equilibrada con el ambiente y luego se procedió con el montaje en el sistema de medición como se aprecia en las siguientes fotografías de la Figura 121.
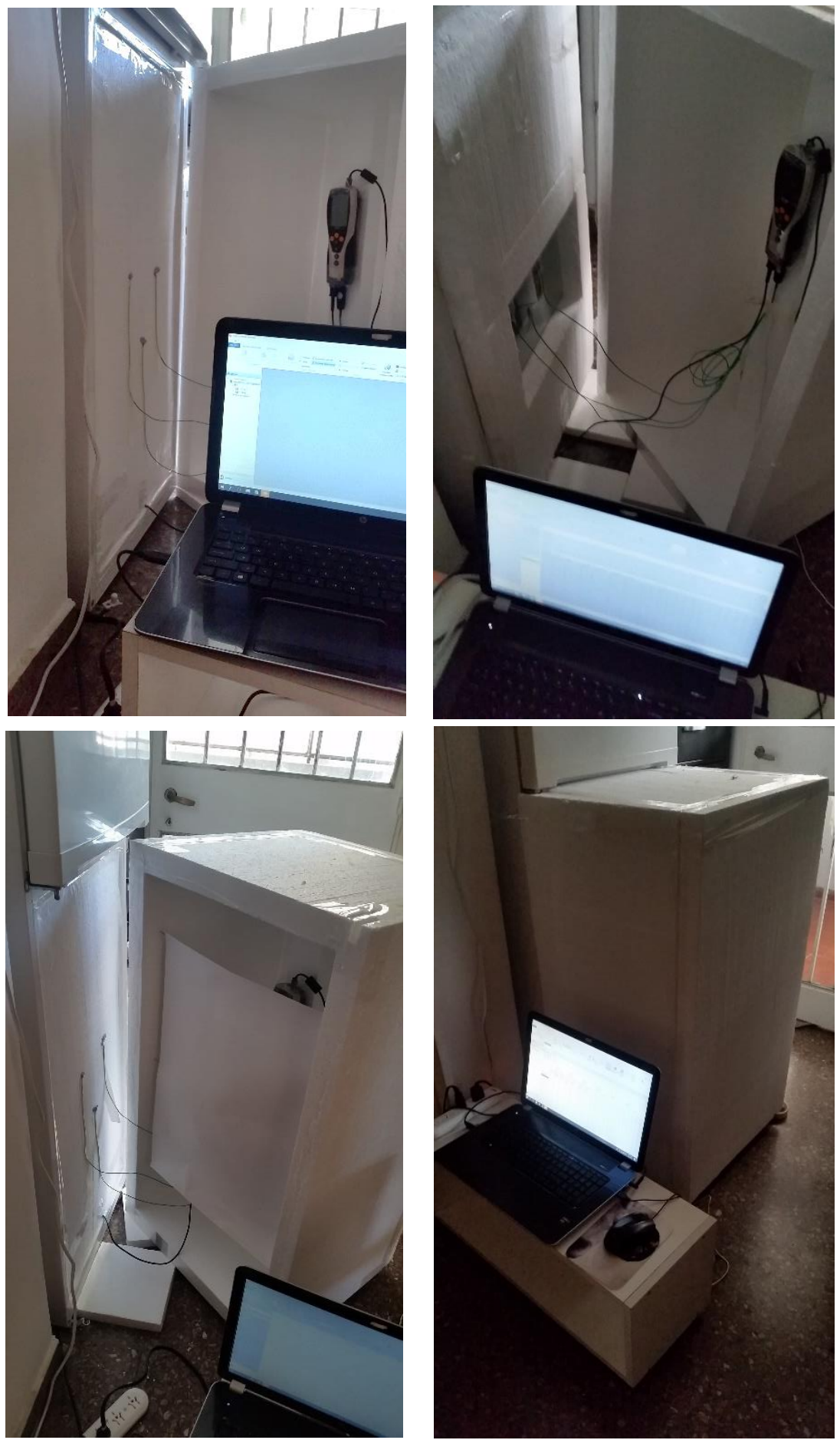

Figura 121. Fotografías de la configuración de la caja caliente, previo y durante el proceso de calibración. Fuente: Elaboración propia. 
El tiempo de registro de datos se realizó hasta que se encontró un periodo de estabilización de $T_{\text {air }}$ en ambos lados de la instalación y en la $T_{r}$ de la probeta, asegurando que los cálculos de la transmitancia se dieran en un régimen estacionario. De todos los datos de $U$ obtenidos durante el periodo de régimen estacionario, se tomó la media estadística con la ayuda del programa computacional Confort Software suministrado por el fabricante.

Los resultados de la calibración con poliestireno expandido mostrados en la gráfica de la Figura 122, revelan una estabilidad en la $T_{r}$ y las $T_{\text {air }}\left(T_{i}=T_{\text {air }}\right.$ de la cámara Caliente y $T_{0}=T_{\text {air }}$ de la cámara fría) con los cuales se alcanzó el régimen estacionario. También se nota la diferencia entre el valor $U$ conocido de $0,72 \mathrm{~W} / \mathrm{m}^{2 \circ} \mathrm{C}$, en línea discontinua de color azul, y el valor $\mathrm{U}$ medido promedio en línea continua de color azul con $0,50 \mathrm{~W} / \mathrm{m}^{2 \circ} \mathrm{C}$. Lo cual significa una diferencia del $30,55 \%$ entre el valor conocido y el valor medido.

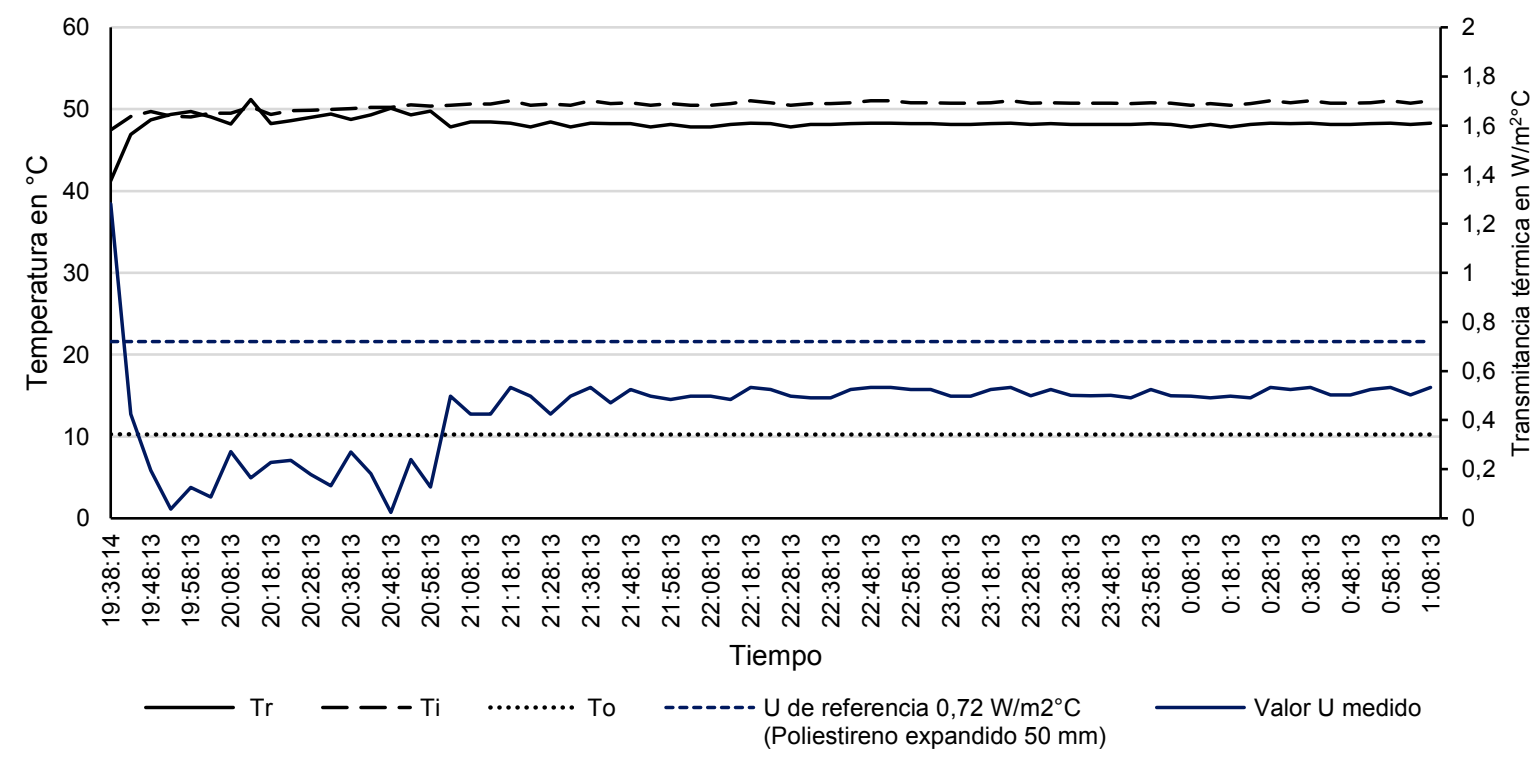

Figura 122. Gráfica de $U, T_{r}, T_{i}$ y $T_{0}$ vs tiempo para calibración con poliestireno expandido de valor $U$ conocido de $0.72 \mathrm{~W} / \mathrm{m}^{2 \circ} \mathrm{C}$. Fuente: Elaboración propia.

De otro lado, los resultados de la calibración realizada con el panel de vidrio incoloro de $4 \mathrm{~mm}$ se muestran en la gráfica de la Figura 123 , en la cual se nota también una estabilidad en la $T_{r}$ y las $T_{\text {air }}\left(T_{i}=T_{\text {air }}\right.$ de la cámara Caliente y $T_{0}=T_{\text {air }}$ de la cámara fría), característica de haber alcanzado el régimen estacionario.

En esta gráfica el valor U medido del vidrio, representado con la línea continua de color azul, tiene un promedio de $4,01 \mathrm{~W} / \mathrm{m}^{2 \circ} \mathrm{C}$; mientras que el valor conocido del material, representado con línea discontinua de color azul es de $5,8 \mathrm{~W} / \mathrm{m}^{2 \circ} \mathrm{C}$, con lo cual existe una imprecisión del $30,86 \%$. 


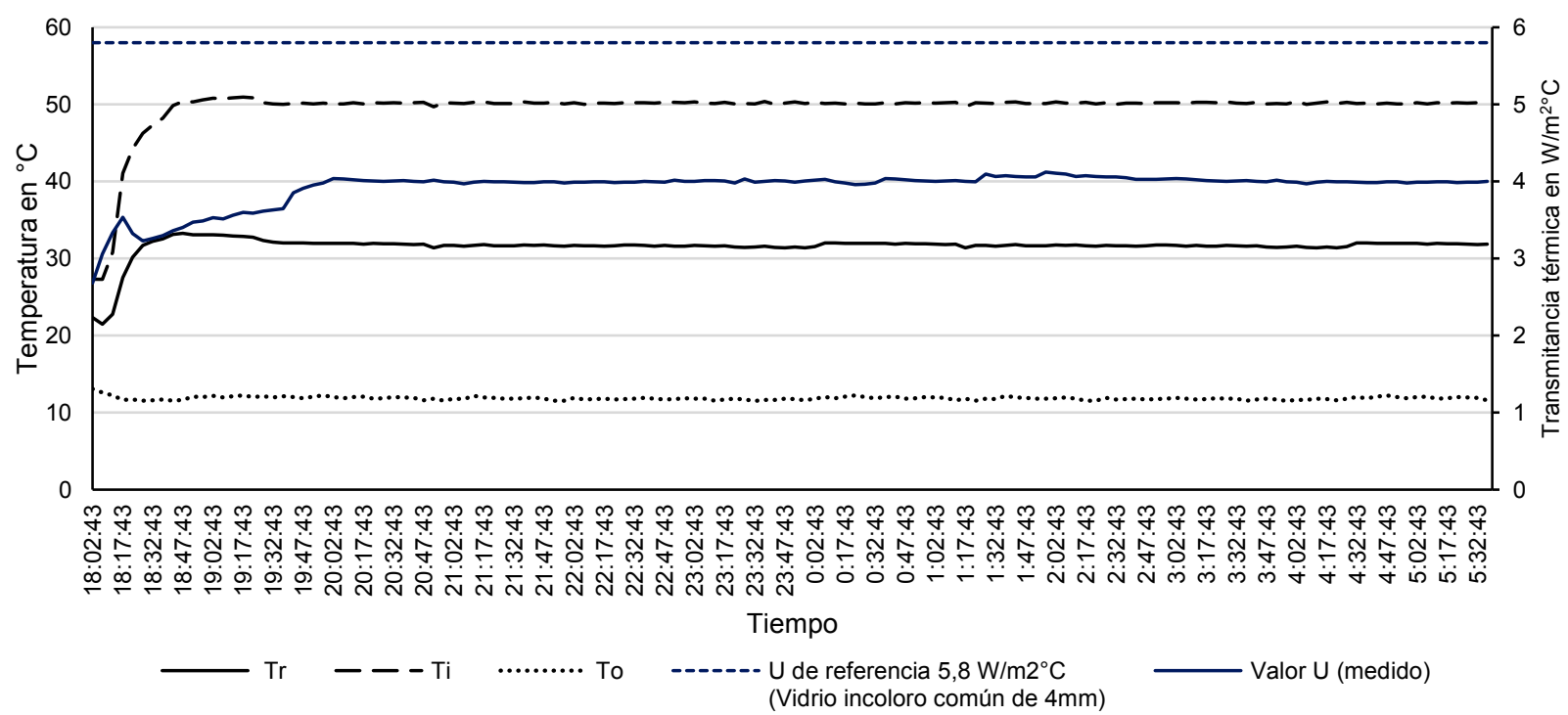

Figura 123. Gráfica de $U, T_{r}, T_{i}$ y $T_{0}$ vs tiempo para calibración con vidrio incoloro común de valor $U$ conocido de $5.8 \mathrm{~W} / \mathrm{m}^{2} \mathrm{C}$. Fuente: Elaboración propia.

Nótese que los porcentajes de imprecisión entre los valores $U$ conocidos y medidos son bastante altos, sin embargo, tanto para un material de baja y alta resistencia térmica como el vidrio y el poliestireno expandido, estos porcentajes se encuentran cercanos: $30,55 \%$ y $30,86 \%$ respectivamente. Estos porcentajes son parecidos también con los reportados por Buzatu et al Op. cit., quienes tuvieron diferencias de $44,19 \%$ y $40,18 \%$ entre valores calculados y medidos.

Tanto la repetición de esta rutina como la corrección de estas imprecisiones son tenidas en cuenta en las próximas mediciones. 


\subsection{Resultados}

\subsubsection{Aislamiento reflectivo (AR)}

El arreglo de la caja caliente calibrada, configurado con el panel de aislamiento reflectivo, se enseña a continuación en las fotografías de la Figura 124, la imagen de la izquierda enseña el panel AR ajustado a los anillos de guarda, la conexión de los sensores al equipo multifunción Testo 435-2 y el interior de la cámara caliente antes de instalar el panel difusor para radiación; mientras que, la imagen derecha muestra la cámara caliente calibrada completamente acoplada a la heladera y el ordenador recibiendo la adquisición de datos a través del programa computacional Confort Software de Testo.
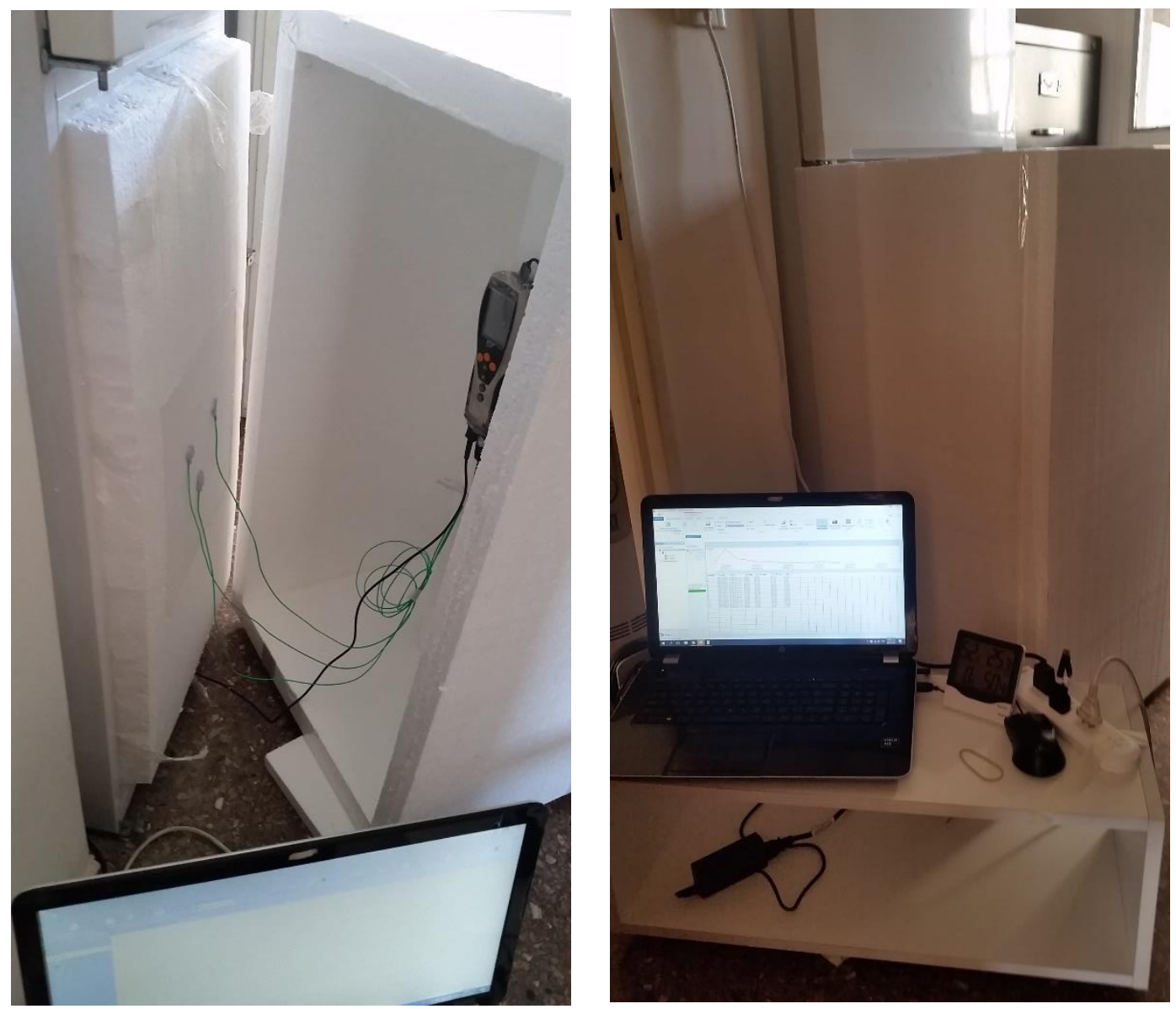

Figura 124. Configuración de la caja caliente calibrada con el panel de AR (Vista interna de la cámara caliente a la izquierda y vista exterior del arreglo cerrado a la derecha). Fuente: Elaboración propia.

La gráfica de la Figura 125 que se expone a continuación, contiene los datos obtenidos durante esta prueba. Inicialmente, se notan valores estables en la $\mathrm{T}_{\mathrm{r}}$ a partir de la cuarta hora de medición y también en la $T_{\text {air }}\left(T_{i}=T_{\text {air }}\right.$ de la cámara Caliente y $T_{0}=T_{\text {air }}$ de la cámara fría), lo cual es señal de haberse alcanzado el régimen estacionario. 
También, puede notarse esta misma estabilidad al final de la medición en la línea continua de color azul que representa el valor $\mathrm{U}$ obtenido directamente con el instrumental. Posteriormente este valor se corrige incrementándose en un 30,7\%, debido a la imprecisión encontrada en la calibración. Con este valor U corregido, indicado con línea continua de color rojo, se sacó la media de las últimas cuatro horas, obteniendo que el valor $U$ de la solución constructiva de AR es $0,49 \mathrm{~W} / \mathrm{m}^{2 \circ} \mathrm{C}$.

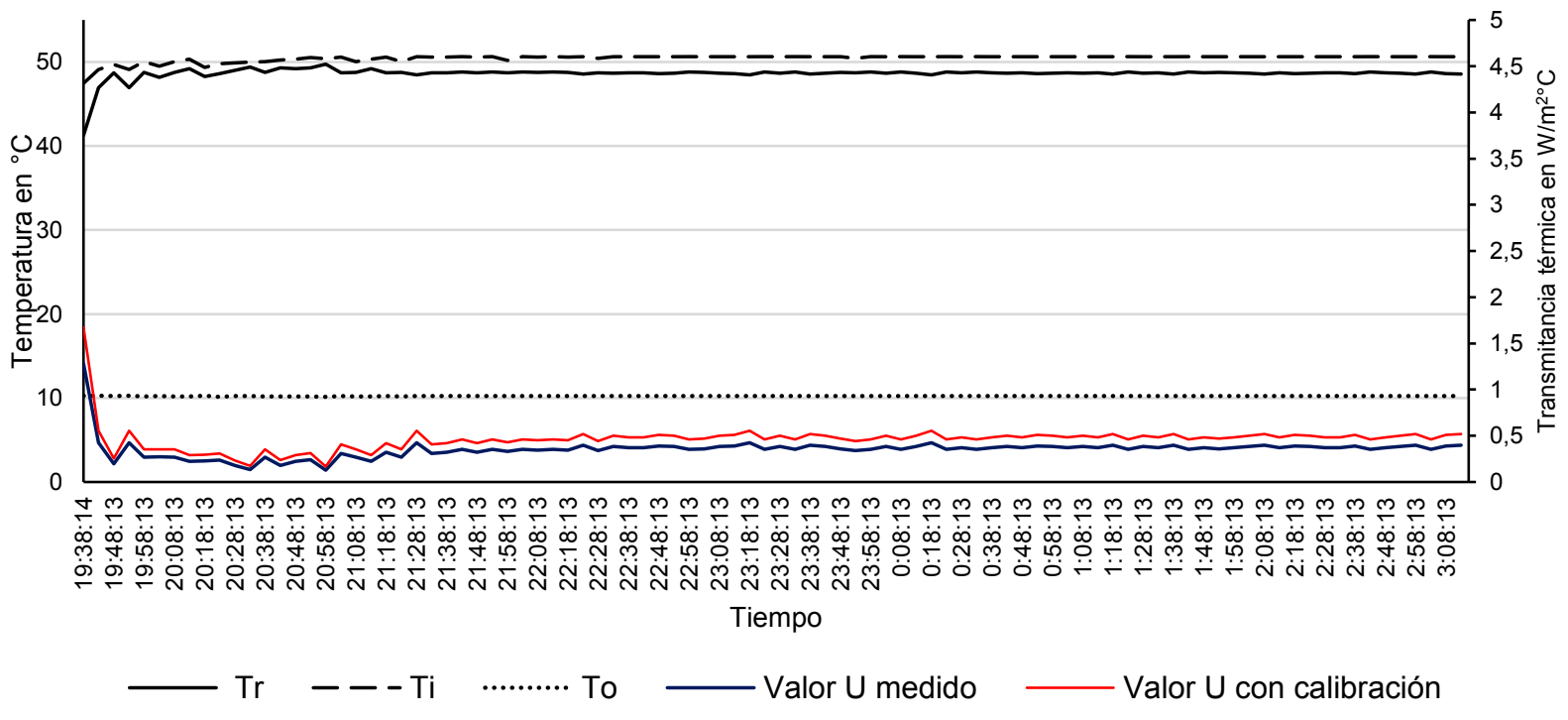

Figura 125. Gráfica de $U, T_{r}, T_{i}$ y $T_{0}$ vs tiempo, de la prueba con caja caliente calibrada realizada con la solución constructiva de Aislamiento Reflectivo (AR). Fuente: Elaboración propia. 


\subsubsection{Muro vegetal (MV)}

Aunque se intentó conocer la transmitancia térmica del Muro Vegetal (MV), tanto la parte tecnológica como la termodinámica imposibilitaron hacer una medición adecuada del MV.

En cuanto a lo tecnológico, el instrumental usado requirió fijar sensores verticalmente en el panel, lo cual no puede hacerse en la delicada estructura de las plantas; y por el lado de lo termodinámico, esta solución posee una alta heterogeneidad que no llevaría a adquirir datos coherentes y confiables, asunto también tratado en la norma ISO 8990, estudiada con anterioridad.

Así que, como se descubrió en el punto anterior un desempeño bastante parejo entre el AR y el MV se infiere que el valor U del AR puede ser muy similar al del MV. Aunque esto sea una estimación, todo el camino experimental recorrido, permitió hacer educadamente esta operación lógica.

Teniendo en cuenta la inferencia anterior, el MV puede tener un valor $\mathrm{U}$ levemente superior a $0,49 \mathrm{~W} / \mathrm{m}^{2 \circ} \mathrm{C}$, el cual puede ser, según las mediciones realizadas bajo brillo solar, entre el $1 \%$ y el $5 \%$. Considerando una media del $3 \%$, el valor $U$ del MV es de $0,50 \mathrm{~W} / \mathrm{m}^{2 \circ} \mathrm{C}$. 


\subsection{Discusión}

Al comparar los resultados experimentales de transmitancia térmica obtenidos en éste capítulo: $A R=0,49 \mathrm{~W} / \mathrm{m}^{2 \circ} \mathrm{K}$ y $\mathrm{MV}=0,50 \mathrm{~W} / \mathrm{m}^{2 \circ} \mathrm{K}$, con los calculados en los títulos 5.5 y 5.6 , se nota que los cálculos teóricos fueron conservativos sobre todo con la alternativa del MV, con la cual se proyectaba un valor $U$ de $1,754 \mathrm{~W} / \mathrm{m}^{2}{ }^{\circ} \mathrm{K}$, mientras que con el $A R$ se esperaban $0,704 \mathrm{~W} / \mathrm{m}^{2}{ }^{\circ} \mathrm{K}$. Esto significa una diferencia del $30 \%$ y $75 \%$ entre los datos teóricos y experimentales del AR y el MV respectivamente.

En relación con lo anterior, en el título 5.6, se mencionó que Juanicó \& González (2017), obtuvieron por otro método teórico un valor $U$ de $0,21 \mathrm{~W} / \mathrm{m}^{2}{ }^{\circ} \mathrm{K}$ para una solución constructiva de 4 cámaras reflectivas, lo cual permite extrapolar que una solución de 2 cámaras se acerque a los $0,42 \mathrm{~W} / \mathrm{m}^{2 \circ} \mathrm{K}$, lo cual es más coherente con los $0,49 \mathrm{~W} / \mathrm{m}^{2{ }^{\circ}} \mathrm{K}$ obtenidos experimentalmente aquí.

De otro lado, la premisa de diseño expuesta en la introducción del capítulo 5 que tuvo más hincapié fue la de crear soluciones con el mínimo espesor posible. Frente a este tema se realizó una comparación de la relación espesor-transmitancia térmica entre el AR, el MV y a otras alternativas convencionales y de punta en el estado del arte. Para esto, se elaboró la siguiente gráfica de la Figura 126, en la que se tomó como base los datos obtenidos en el presente capítulo, lo revisado en la bibliografía del Capítulo 3 y la norma Argentina IRAM 11601 (Instituto Argentino de Normalización IRAM, 2002).

De esta manera, la gráfica de la Figura 126, muestra cual es el espesor necesario en cm (con las barras), que cada material debe tener para alcanzar una transmitancia térmica igual a la lograda por el AR y el MV: $0,49 \mathrm{~W} / \mathrm{m}^{2 \circ} \mathrm{K}$ y $0,5 \mathrm{~W} / \mathrm{m}^{2 \circ} \mathrm{K}$ (con los puntos) respectivamente. Entre las opciones se incluye el Aerogel, uno de los mejores aislantes, ya mencionado en el título 3.5 y cuyo valor de conductividad térmica es $0,018 \mathrm{~W} / \mathrm{m}^{\circ} \mathrm{K}$.

En la gráfica, se aprecia que las dos cámaras de aire reflectivas formadas en la solución de AR poseen la más baja relación espesor-transmitancia, pues el AR con tan solo $2,4 \mathrm{~cm}$ de espesor logra lo que el Aerogel hace en $3,6 \mathrm{~cm}$; el Poliuretano (de densidad 30-60 Kg/m ${ }^{3}$ ) en $7,0 \mathrm{~cm}$; el Poliestireno (de densidad $13 \mathrm{Kg} / \mathrm{m}^{3}$ ) en $7,2 \mathrm{~cm}$ y el MV en $8,0 \mathrm{~cm}$. 


\section{ESPESOR EN cm POR TIPO DE SOLUCIÓN CONSTRUCTIVA CON IGUAL TRANSMITANCIA TÉRMICA $0,49-0,5 \mathrm{~W} / \mathrm{m}^{2 \circ} \mathrm{C}$}

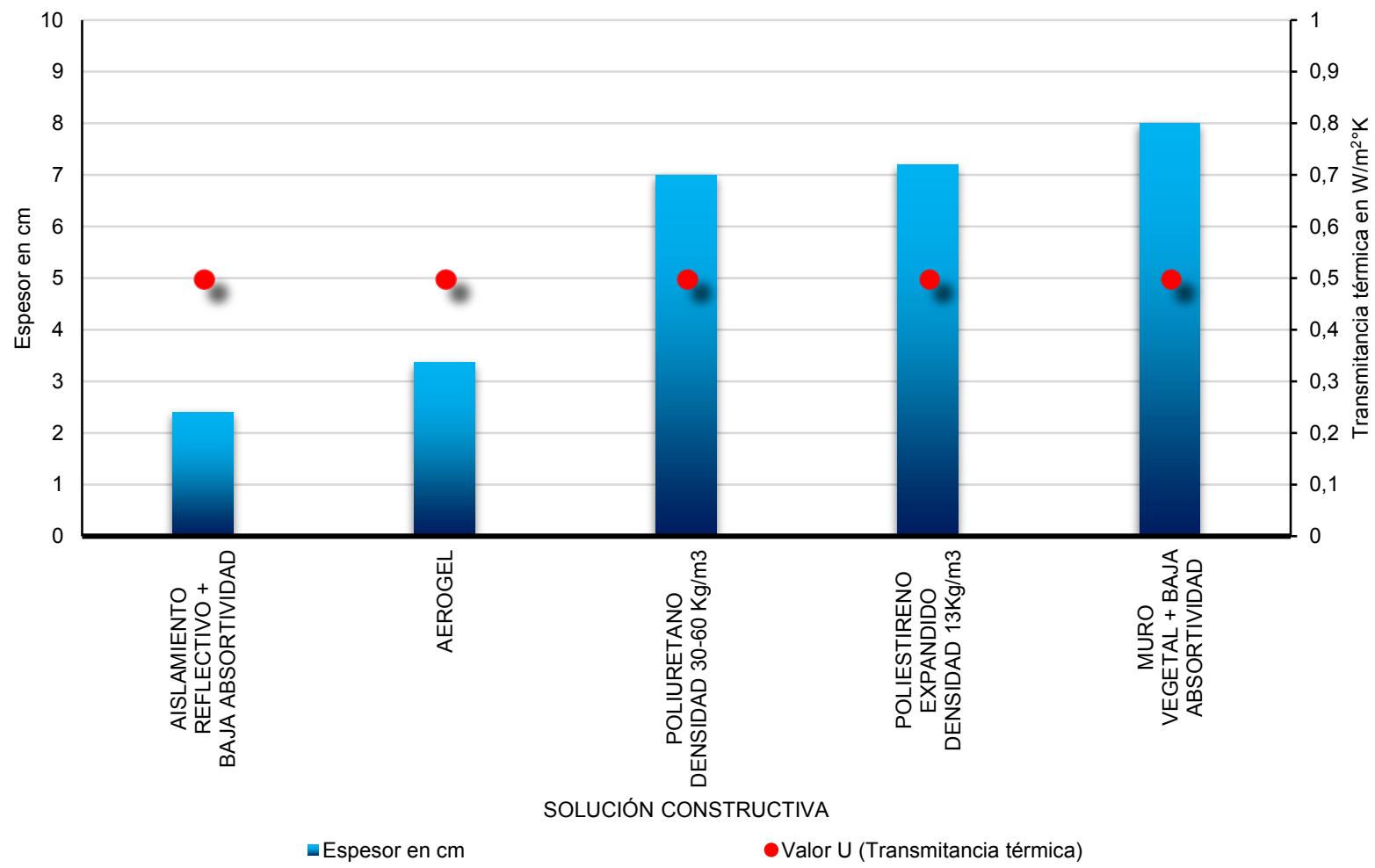

Figura 126. Gráfica comparativa de espesor por tipo de solución constructiva a igual transmitancia térmica $(0,5$ $\left.\mathrm{W} / \mathrm{m}^{2 \circ} \mathrm{C}\right)$. Fuente: Elaboración Propia.

Aunque el tema de emisiones de gases de efecto invernadero y energía incorporada en los materiales está fuera del objetivo de esta investigación, es evidente que hay un gran ahorro de material con la solución de AR, no solo porque su espesor es menor, sino porque el mayor porcentaje de esta solución está ocupada por aire.

Asimismo, a pesar de que la opción del MV posee el mayor espesor de todos con $8 \mathrm{~cm}$, cabe aclarar que se compone en su mayoría de aire, material orgánico y plantas vivas, las cuales producen oxígeno.

Haciendo salvedad, de que las soluciones AR y MV acá planteadas no están compuestas por un material homogéneo, se realizó el ejercicio consistente en encontrar la conductividad térmica de estas y compararla con las mismas soluciones anteriores, mediante la fórmula: $\mathrm{K}$ = Espesor del material/R, tratada en el título 1.3 del Glosario. Los datos obtenidos en este ejercicio se muestran a continuación en la gráfica de la Figura 127, la cual muestra que el mejor aislante entre estas opciones es el AR con un valor de $0,014 \mathrm{~W} / \mathrm{m}^{\circ} \mathrm{K}$; seguido por el Aerogel con $0,018 \mathrm{~W} / \mathrm{m}^{\circ} \mathrm{K}$; después el Poliuretano con $0,035 \mathrm{~W} / \mathrm{m}^{\circ} \mathrm{K}$; y por último, el Poliestireno expandido y el MV, ambos con 0,04 W/m $\mathrm{K}$. 


\section{CONDUCTIVIDAD TÉRMICA (K) POR TIPO DE SOLUCIÓN CONSTRUCTIVA}

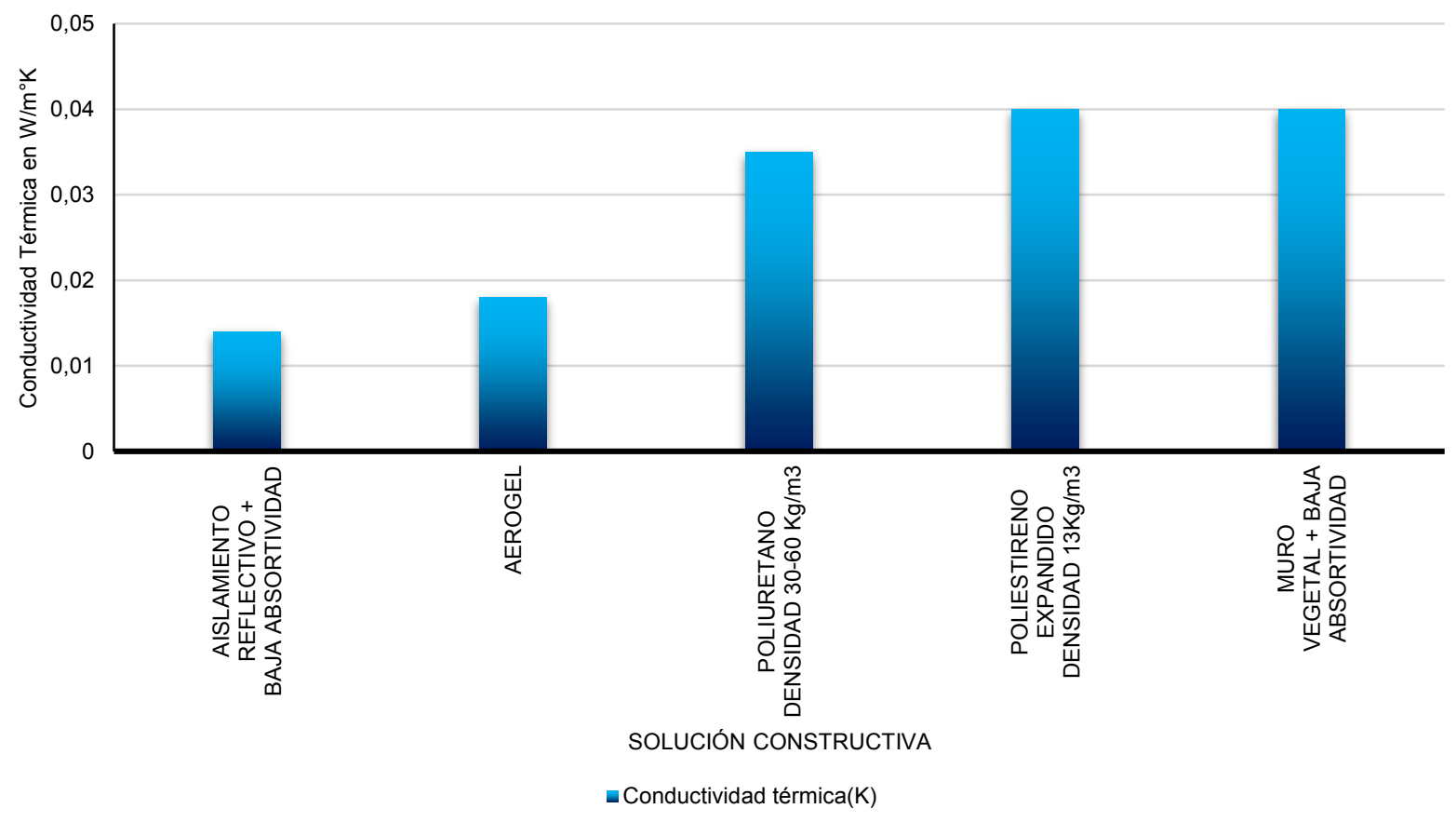

Figura 127. Gráfica comparativa de conductividad térmica por tipo de solución constructiva. Fuente: Elaboración propia. 


\subsection{Conclusiones}

- Mediante el procedimiento experimental seguido en este capítulo se cumplió con el objetivo de determinar el valor $U$ de la solución constructiva de aislamiento reflectivo (AR) y mediante inferencias basadas en los resultados empíricos del capítulo anterior determinar también el valor $\mathrm{U}$ del muro vegetal (MV).

- Los valores $\mathrm{U}$ experimentales de las alternativas MV y AR resultaron ser superiores a los calculados teóricamente en el Capítulo 5 en un $75 \%$ y un $30 \%$ respectivamente, con lo cual los cálculos resultaron ser bastante conservativos sobre todo con la opción MV. Sin embargo, el valor obtenido experimentalmente con el AR es coherente con cálculos encontrados en el estado del arte como los mostrados por Juanicó \& González (2017).

- El haber obtenido dichos resultados permitió hacer comparaciones con otras soluciones constructivas tanto tradicionales como de punta en el estado del arte, descubriendo que la relación espesor-transmitancia térmica de la solución AR es bastante competitiva e incluso superior a la de materiales tradicionales como el Poliuretano o materiales de punta como el Aerogel.

En detalle la solución $A R$ con un valor $U$ de $0,49 \mathrm{~W} / \mathrm{m}^{2 \circ} \mathrm{K}$ y un espesor de $2,5 \mathrm{~cm}$ y el del MV con un valor $U$ de $0,5 \mathrm{~W} / \mathrm{m}^{2 \circ} \mathrm{C}$ y un espesor de $8 \mathrm{~cm}$ pueden compararse con la capacidad de aislamiento que tienen $3,3 \mathrm{~cm}$ de Aerogel, $7 \mathrm{~cm}$ de Poliuretano (30-60 $\mathrm{Kg} / \mathrm{m}^{3}$ ) o $7,2 \mathrm{~cm}$ de Poliestireno expandido $\left(13 \mathrm{Kg} / \mathrm{m}^{3}\right)$. 


\section{EVALUACIÓN DE CONFORT TÉRMICO DEL MODELO VIS MEJORADO}

\subsection{Introducción}

La simulación energética computacional es un cálculo predictivo del comportamiento energético edilicio, que permite con bastante precisión, cuantificar y evaluar variables del comportamiento térmico como la $T_{\text {air, }}$ la $T_{m r}$, la $\mathrm{HR}$ e incluso el nivel de confort. Esto se hace por medio de programas que se encuentran configurados con las ecuaciones de comportamiento térmico, tratadas en capítulos anteriores.

Después de haber obtenido datos con las evaluaciones teóricas y empíricas de las soluciones constructivas, estos fueron utilizados como inputs en una simulación, que utiliza como línea base el apartamento VIS de tipología multifamiliar analizado en el título 4.4 del Capítulo 4. Esta simulación, está orientada especialmente a conocer el aporte en la optimización del confort térmico que se puede alcanzar con la solución constructiva que más se acercó a los niveles confortables de $T_{r}, T_{\text {air }}$ y HR en las experimentaciones anteriores.

Para lograr este objetivo, se empleó el método de Fanger con sus índices PMV y PPD, con la interfaz Openstudio y el motor de cálculo EnergyPlus creados por el Departamento de Energía (DoE) de Estados Unidos.

EnergyPlus, toma como datos de entrada para realizar los cálculos: los archivos climáticos del emplazamiento (que contienen la $T_{\text {air, }} \mathrm{HR}, \mathrm{V}_{\text {air }}$, radiación solar, etc.), el diseño de la edificación, los materiales para su construcción y las cargas térmicas internas y externas.

Para lograr una simulación acertada, se siguieron los siguientes pasos: modelado de la línea base, calibración y, por último, el modelado de intervenciones con su respectiva simulación. Cada paso se detalla a continuación: 


\subsection{Modelado de la línea base}

Esta fase consistió en el modelado del apartamento VIS monitoreado y definido anteriormente como línea base en el título 4.3.

Este modelado se realizó mediante el software Sketchup y la interfaz Openstudio. Para esto se usó el levantamiento arquitectónico y toda la documentación constructiva de la unidad de vivienda. Como se muestra en la siguiente vista de pantalla de la Figura 128, el modelo se simplificó acatando las recomendaciones de mejores prácticas consignadas en la documentación y tutoriales de la página web del NREL dedicada a Openstudio (National Renewable Energy Laboratory, 2018). En este archivo solamente se modeló el apartamento, configurando las paredes, techos y pisos conectados con otras unidades como adiabáticas. Se tuvo en cuenta también los planos adyacentes que arrojan sombra.

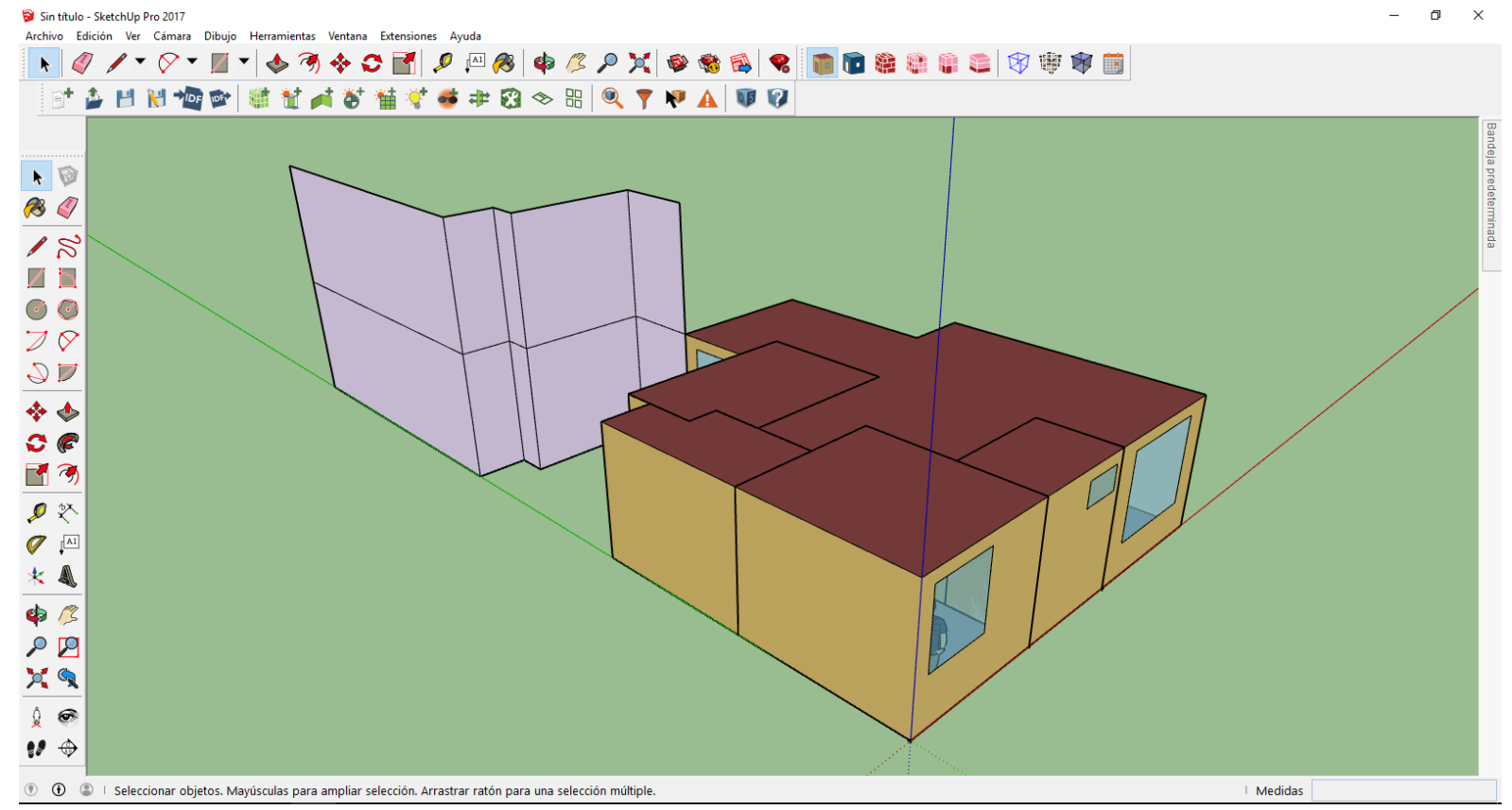

Figura 128. Vista de pantalla del modelado de la línea. Fuente: Elaboración propia a partir de SketchUp y Openstudio.

Cada superficie correspondiente a muros, pisos, cielos, ventanas o puertas fue configurada con sus respectivos materiales y valores de propiedades térmicas como: resistencia térmica, absortividad, emisividad, conductividad térmica, densidad y calor específico.

Para las ventanas se utilizó el material por defecto Clear $4 \mathrm{~mm}$ que viene con el programa, mientras que los demás materiales utilizados fueron creados. La siguiente Tabla 28 sintetiza los materiales constructivos con los valores dados a sus propiedades físicas y más abajo en la Tabla 29, se muestran los elementos constructivos utilizados en la simulación con su respectiva composición de materiales. 


\begin{tabular}{|c|c|c|c|c|c|c|c|c|c|}
\hline Material & Rugosidad & $\begin{array}{c}\text { Espesor } \\
\text { (m) }\end{array}$ & $\begin{array}{c}\text { Resistencia } \\
\text { Térmica } \\
\left(\mathrm{m} 2{ }^{\circ} \mathrm{C} / \mathrm{W}\right)\end{array}$ & $\begin{array}{c}\text { Conductividad } \\
\text { Térmica } \\
\text { (W/mK) }\end{array}$ & $\begin{array}{c}\text { Densidad } \\
(\mathrm{kg} / \mathrm{m} 3)\end{array}$ & $\begin{array}{c}\text { Calor } \\
\text { específico } \\
(\mathrm{J} / \mathrm{kgK})\end{array}$ & $\begin{array}{l}\text { Absortancia } \\
\text { térmica }(\%)\end{array}$ & $\begin{array}{c}\text { Absortancia } \\
\text { solar (\%) }\end{array}$ & $\begin{array}{c}\text { Absortancia } \\
\text { visible (\%) }\end{array}$ \\
\hline Estuco & $\begin{array}{l}\text { Medium } \\
\text { Smooth }\end{array}$ & 0,005 & & 0,6918 & 1858 & 837 & 0,9 & 0,92 & 0,92 \\
\hline $\begin{array}{c}\text { Losa } \\
\text { hormigón }\end{array}$ & Rough & 0,1 & & 1,4 & 2243 & 837 & 0,9 & 0,7 & 0,7 \\
\hline $\begin{array}{c}\text { Piso } \\
\text { Cerámico }\end{array}$ & $\begin{array}{l}\text { Medium } \\
\text { Smooth }\end{array}$ & 0,1 & & 0,9 & 1600 & 920 & 0,9 & 0,6 & 0,6 \\
\hline $\begin{array}{c}\text { Puerta } \\
\text { Madera }\end{array}$ & Smooth & 0,03 & & 0,15 & 614 & 2300 & 0,9 & 0,9 & 0,9 \\
\hline $\begin{array}{c}\text { Bloque } \\
\text { estructural de } \\
\text { arcilla }\end{array}$ & $\begin{array}{c}\text { Medium } \\
\text { Rough }\end{array}$ & 0,14 & 0,2 & & & & 0,9 & 0,7 & 0,7 \\
\hline $\begin{array}{l}\text { Estuco + } \\
\text { vinilo color } \\
\text { Blanco }\end{array}$ & $\begin{array}{c}\text { Medium } \\
\text { Rough }\end{array}$ & 0,05 & 0,011 & & & & 0,9 & 0,25 & 0,25 \\
\hline $\begin{array}{l}\text { Revoque de } \\
\text { cemento y } \\
\text { arena }\end{array}$ & $\begin{array}{l}\text { Medium } \\
\text { Smooth }\end{array}$ & 0,025 & 0,02 & & & & 0,9 & 0,7 & 0,7 \\
\hline
\end{tabular}

Tabla 28. Materiales utilizados en la simulación computacional con sus respectivos valores asignados a las propiedades físicas. Fuente: Elaboración propia.

\begin{tabular}{|c|c|c|c|c|c|}
\hline Cielo Falso & Entrepiso & Muros exteriores & Muros interiores & Puertas & Ventanas \\
\hline $\begin{array}{c}\text { Revoque de cemento } \\
\text { y arena }\end{array}$ & Piso Cerámico & $\begin{array}{c}\text { Bloque estructural de } \\
\text { arcilla }\end{array}$ & $\begin{array}{c}\text { Estuco + vinilo color } \\
\text { Blanco }\end{array}$ & Puerta Madera \\
\hline $\begin{array}{c}\text { Estuco + vinilo color } \\
\text { Blanco }\end{array}$ & $\begin{array}{c}\text { Revoque de cemento } \\
\text { y arena }\end{array}$ & $\begin{array}{c}\text { Revoque de cemento } \\
\text { y arena }\end{array}$ & $\begin{array}{c}\text { Revoque de cemento } \\
\text { y arena }\end{array}$ & \\
\hline & Losa hormigón & $\begin{array}{c}\text { Estuco + vinilo color } \\
\text { Blanco }\end{array}$ & $\begin{array}{c}\text { Bloque estructural de } \\
\text { arcilla }\end{array}$ & \\
\hline & & $\begin{array}{c}\text { Revoque de cemento } \\
\text { y arena }\end{array}$ & & \\
\hline & & $\begin{array}{c}\text { Estuco + vinilo color } \\
\text { Blanco }\end{array}$ & & \\
\hline
\end{tabular}

Tabla 29. Composición de materiales en los elementos constructivos modelados en la simulación. Fuente: Elaboración propia.

Asimismo, se asignaron cargas térmicas por ocupantes, equipos e iluminación con sus respectivos horarios de permanencia o utilización en cada espacio.

En este paso también se revisa la orientación del apartamento respecto de los puntos cardinales y se carga el archivo que contiene los datos climáticos con extensión EPW.

Una vez hecho esto, el modelo está listo para ser calibrado, proceso que será explicado en el siguiente punto. 


\subsection{Calibración del modelo}

Este proceso consistió en revisar y hacer que coincidieran los resultados de campo, derivados de la monitorización a la habitación tomada como línea base (revisar título 4.5 del Capítulo 4), con los obtenidos por el modelo virtual en la simulación. Esto se realizó con el objetivo de tener un modelo virtual más cercano a la realidad.

Para lograr esto, se realizaron varias iteraciones, modificando las variables de infiltración y cargas térmicas, de las cuales se tiene menor conocimiento, hasta que se logró conseguir resultados de $T_{\text {air, }} T_{\mathrm{mr}}, \mathrm{HR}$ y confort térmico (índices PMV y PPD) cercanos a los registrados en el trabajo de campo.

El periodo tomado para comparar los datos entre medición de campo y simulación fue el mismo en que se tomaron los registros de campo (enero 02 a enero 08), el promedio horario de estos valores se muestra a continuación en la Tabla 30. En esta tabla, el Clo y el Met, por ser variables independientes al modelo permanecieron iguales, al igual que el comportamiento de la $V_{\text {air. }}$

En la Tabla 30, los datos medidos en campo se encuentran bajo las columnas tituladas con la letra $\mathrm{M}$, mientras que, los pertenecientes a la simulación están bajo la letra $\mathrm{S}$. Allí se ve que, la $T_{\text {air }}$ y la $T_{m r}$ son siempre mayores en la simulación, pero, con diferencias medias de $0,2^{\circ} \mathrm{C}$ y $0,3^{\circ} \mathrm{C}$ respectivamente, lo cual no supera el $2 \%$.

De forma contraria sucede con la HR, la cual es siempre menor en los datos de la simulación con una diferencia media de $0,05 \%$. Por último, se revisó la columna PPD, en la cual se encontró una diferencia media de $2,5 \%$, la cual se considera baja si se tienen en cuenta toda la cantidad de variables de las cuales depende. 


\begin{tabular}{|c|c|c|c|c|c|c|c|c|c|c|c|c|c|c|}
\hline \multirow{2}{*}{ FECHA } & \multirow{2}{*}{ HORA } & \multicolumn{2}{|c|}{$\mathbf{T}_{\text {air }}$} & \multicolumn{2}{|c|}{$\mathrm{T}_{\mathrm{mr}}$} & \multirow{2}{*}{$\mathbf{V}_{\text {air }}$} & \multicolumn{2}{|c|}{ HR } & \multirow{2}{*}{ Met } & \multirow{2}{*}{ Clo } & \multicolumn{2}{|c|}{ PMV } & \multicolumn{2}{|c|}{ PPD } \\
\hline & & M & S & M & $S$ & & M & S & & & M & $S$ & M & S \\
\hline Ene 02 -Ene 08 & 0:00:00 & 24,7 & 24,9 & 27 & 27,4 & 0,05 & 71,01 & 71,01 & 0,8 & 1,2 & 0,4 & 0,5 & 8,3 & 10,2 \\
\hline Ene 02 -Ene 08 & 1:00:00 & 23,86 & 24,16 & 26,6 & 26,9 & 0,05 & 72,08 & 72,18 & 0,8 & 1,2 & 0,2 & 0,3 & 5,8 & 6,9 \\
\hline Ene 02 -Ene 08 & 2:00:00 & 23,47 & 23,57 & 25,9 & 26,4 & 0,05 & 73,10 & 73,40 & 0,8 & 1,2 & 0,1 & 0,1 & 5,2 & 5,2 \\
\hline Ene 02 -Ene 08 & 3:00:00 & 23,06 & 23,11 & 25,5 & 25,9 & 0,05 & 74,22 & 74,25 & 0,8 & 1,2 & $-0,1$ & 0 & 5,2 & 5 \\
\hline Ene 02 -Ene 08 & 4:00:00 & 22,3 & 22,7 & 24,94 & 25,54 & 0,05 & 75,42 & 75,44 & 0,8 & 1,2 & $-0,3$ & $-0,1$ & 6,9 & 5,2 \\
\hline Ene 02 -Ene 08 & 5:00:00 & 22,43 & 22,43 & 24,57 & 25,17 & 0,05 & 76,53 & 76,57 & 0,8 & 1,2 & $-0,3$ & $-0,2$ & 6,9 & 5,8 \\
\hline Ene 02 -Ene 08 & 6:00:00 & 22,52 & 22,52 & 25,19 & 25,39 & 0,05 & 76,25 & 76,28 & 0,8 & 1,2 & $-0,2$ & $-0,2$ & 5,8 & 5,8 \\
\hline Ene 02 -Ene 08 & 7:00:00 & 23,75 & 23,85 & 26,9 & 27 & 0,05 & 72,27 & 72,30 & 0,8 & 1,2 & 0,2 & 0,3 & 5,8 & 6,9 \\
\hline Ene 02 -Ene 08 & 8:00:00 & 25,2 & 25,5 & 28,55 & 28,55 & 0,1 & 67,95 & 68,00 & 1,2 & 0,6 & 0,9 & 1 & 22,1 & 26,1 \\
\hline Ene 02 -Ene 08 & 9:00:00 & 27,15 & 27,15 & 29,7 & 30 & 0,1 & 60,64 & 60,66 & 1,2 & 0,6 & 1,3 & 1,4 & 40,3 & 45,5 \\
\hline Ene 02 -Ene 08 & 10:00:00 & 28,5 & 28,8 & 30,75 & 31,25 & 0,1 & 54,07 & 54,12 & 1,2 & 0,6 & 1,6 & 1,7 & 56,3 & 61,8 \\
\hline Ene 02 -Ene 08 & 11:00:00 & 29,75 & 30,05 & 31,69 & 32,09 & 0,1 & 51,00 & 51,03 & 1,2 & 0,6 & 1,9 & 2 & 72,1 & 76,8 \\
\hline Ene 02 -Ene 08 & $12: 00: 00$ & 30,7 & 31,2 & 32,4 & 33 & 0,2 & 47,98 & 48,20 & 1,2 & 0,6 & 2 & 2,2 & 76,8 & 84,9 \\
\hline Ene 02 -Ene 08 & 13:00:00 & 31,5 & 32 & 33,4 & 33,9 & 0,2 & 47,56 & 47,60 & 1,2 & 0,6 & 2,3 & 2,5 & 88,3 & 93,4 \\
\hline Ene 02 -Ene 08 & $14: 00: 00$ & 32,02 & 32,12 & 34,4 & 34,4 & 0,2 & 48,24 & 48,25 & 1,2 & 0,6 & 2,5 & 2,6 & 93,4 & 95,3 \\
\hline Ene 02 -Ene 08 & $15: 00: 00$ & 31,8 & 32 & 34,6 & 34,6 & 0,2 & 48,40 & 48,40 & 1,2 & 0,6 & 2,5 & 2,6 & 93,4 & 95,3 \\
\hline Ene 02 -Ene 08 & $16: 00: 00$ & 31,32 & 31,52 & 34,2 & 34,3 & 0,2 & 49,00 & 49,00 & 1,2 & 0,6 & 2,4 & 2,4 & 91,1 & 91,1 \\
\hline Ene 02 -Ene 08 & $17: 00: 00$ & 29,83 & 30,13 & 32,7 & 32,8 & 0,2 & 52,17 & 52,20 & 1,2 & 0,6 & 1,9 & 2 & 72,1 & 76,8 \\
\hline Ene 02 -Ene 08 & 18:00:00 & 28,3 & 28,3 & 30 & 30 & 0,2 & 57,86 & 57,90 & 1,2 & 0,6 & 1,3 & 1,3 & 40,3 & 40,3 \\
\hline Ene 02 -Ene 08 & 19:00:00 & 27,5 & 27,7 & 29,1 & 29,5 & 0,2 & 61,54 & 61,60 & 1,2 & 0,6 & 1,1 & 1,2 & 30,5 & 35,2 \\
\hline Ene 02 -Ene 08 & 20:00:00 & 27,4 & 27,5 & 29 & 29,2 & 0,1 & 63,62 & 63,64 & 1,2 & 0,6 & 1,3 & 1,3 & 40,3 & 40,3 \\
\hline Ene 02 -Ene 08 & 21:00:00 & 26,94 & 27,04 & 28,3 & 28,8 & 0,1 & 64,78 & 64,80 & 1,2 & 0,6 & 1,1 & 1,2 & 30,5 & 35,2 \\
\hline Ene 02 -Ene 08 & $22: 00: 00$ & 26,17 & 26,47 & 27,8 & 28,4 & 0,1 & 66,86 & 66,90 & 0,8 & 1,2 & 0,7 & 0,9 & 15,3 & 22,1 \\
\hline Ene 02 -Ene 08 & 23:00:00 & 25 & 25,4 & 27,7 & 27,8 & 0,1 & 70,25 & 70,30 & 0,8 & 1,2 & 0,5 & 0,6 & 10,2 & 12,5 \\
\hline
\end{tabular}

Tabla 30. Tabla comparativa de valores medios medidos (M) y simulados (S) obtenidos con el modelo calibrado. Fuente: Elaboración propia.

Adicionalmente, los promedios horarios de la sensación térmica (PMV) y el porcentaje de personas insatisfechas (PPD) obtenidos en campo y en simulación, son comparados a continuación mediante las gráficas de la Figura 129 y la Figura 130, en estas se distingue un comportamiento muy similar de estos dos índices en las distintas horas del día, tanto en los picos calurosos del mediodía, como en los valles de la madrugada. Este análisis permite concluir que el modelo elaborado para la simulación arrojará resultados bastante cercanos a la realidad. 


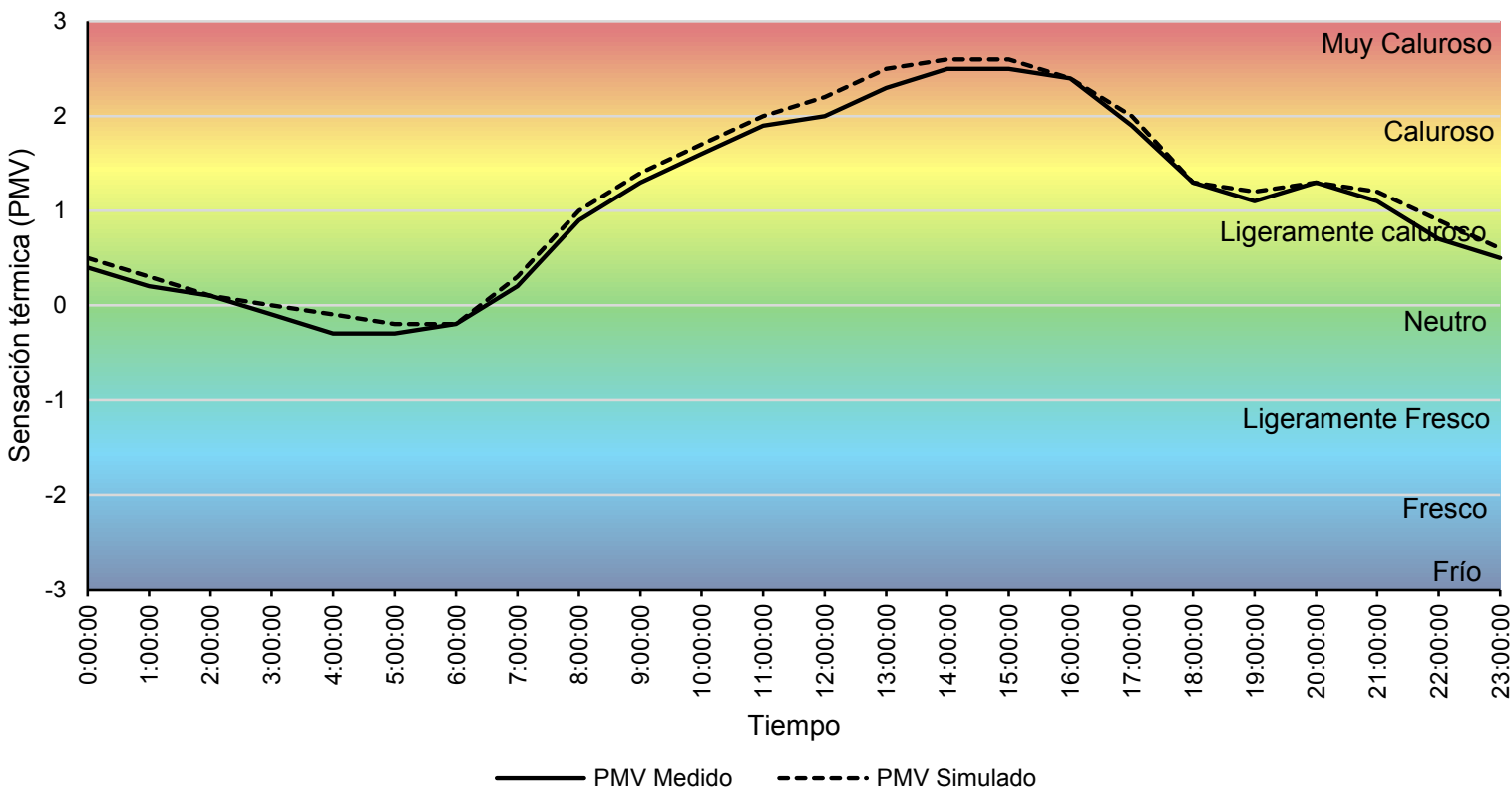

Figura 129. Gráfica comparativa de sensación térmica (PMV), de la línea base, entre los datos obtenidos en campo y mediante simulación, para fines de calibración. Fuente: Elaboración propia.

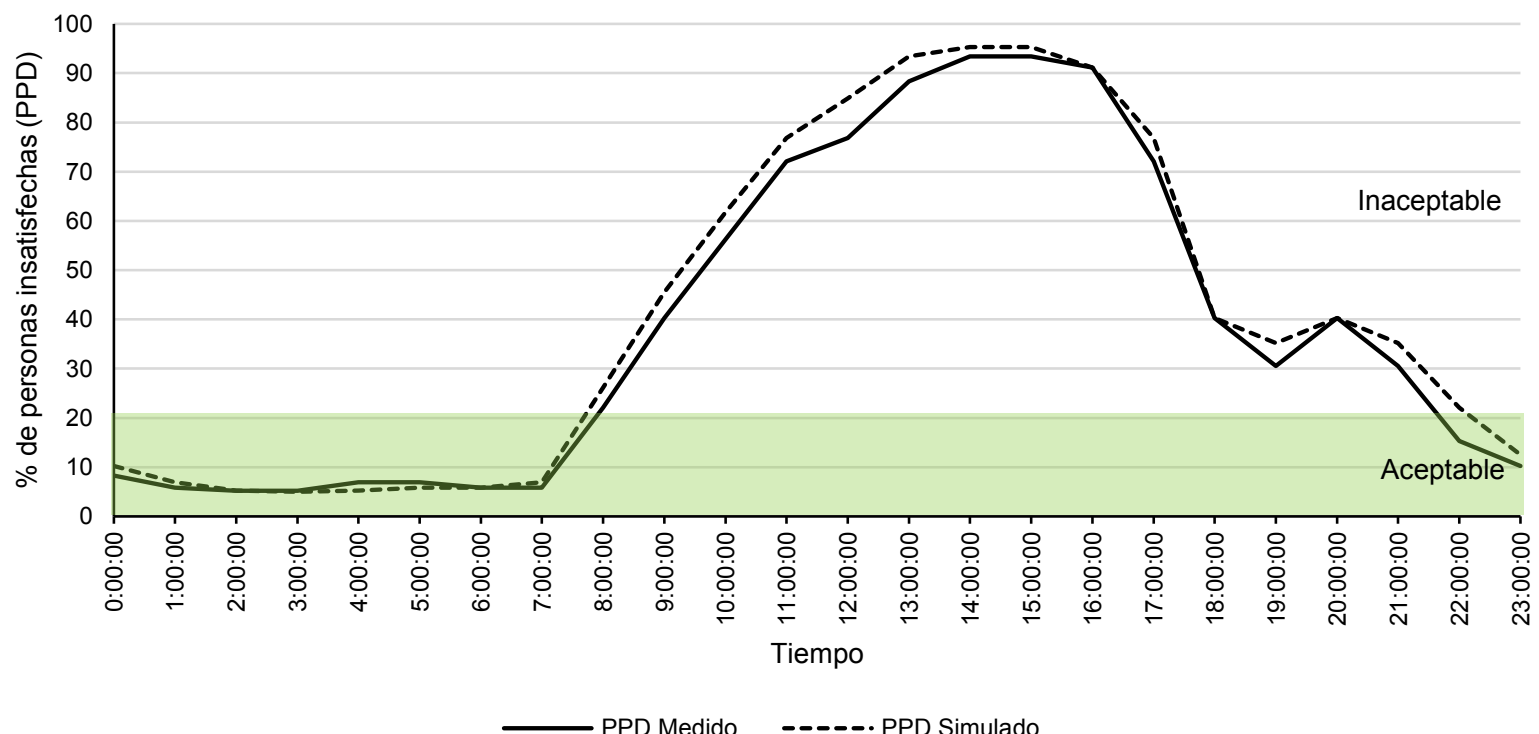

Figura 130. Gráfica comparativa de porcentaje de personas insatisfechas (PPD), de la línea base, entre los datos obtenidos en campo y mediante simulación, para fines de calibración. Fuente: Elaboración propia. 


\subsection{Modelo VIS mejorado y simulación final}

En este paso, a una copia del archivo calibrado en el punto anterior se le intervino la cara exterior de la envolvente agregando una capa adicional con las especificaciones de la solución constructiva de Aislamiento reflectivo obtenidas experimentalmente en el título 7.6.1 del Capítulo 7. Dichas especificaciones pueden consultarse más abajo en la

Tabla 31.

Tabla 31. Valores de las propiedades físicas correspondientes al panel AR ingresados en el programa para la

\begin{tabular}{|l|c|c|c|c|c|c|c|c|c|}
\hline Material & Rugosidad & $\begin{array}{c}\text { Espesor } \\
(\mathbf{m})\end{array}$ & $\begin{array}{c}\text { Resistencia } \\
\text { Térmica } \\
\left(\mathbf{m} \mathbf{2}^{\circ} \mathbf{C} / \mathbf{W}\right)\end{array}$ & $\begin{array}{c}\text { Conductividad } \\
\text { Térmica } \\
(\mathbf{W} / \mathbf{m K})\end{array}$ & $\begin{array}{c}\text { Densidad } \\
(\mathbf{k g} / \mathbf{m} 3)\end{array}$ & $\begin{array}{c}\text { Calor } \\
\text { específico } \\
(\mathbf{J} / \mathbf{k g K})\end{array}$ & $\begin{array}{c}\text { Absortancia } \\
\text { térmica (\%) }\end{array}$ & $\begin{array}{c}\text { Absortancia } \\
\text { solar (\%) }\end{array}$ & $\begin{array}{c}\text { Absortancia } \\
\text { visible (\%) }\end{array}$ \\
\hline $\begin{array}{l}\text { Panel de de } \\
\text { aislamiento } \\
\text { reflectivo } \\
\text { baja } \\
\text { absortividad }\end{array}$ & Smooth & 0,025 & 2.0 & & & & & & \\
\end{tabular}

simulación. Fuente: Elaboración propia.

Con este nuevo modelo virtual que representa el modelo VIS mejorado, se corrió otra simulación configurando el programa nuevamente en la semana crítica del 2 al 8 de enero, de la cual se extrajeron los datos para ser comparados con los de la línea base en la siguiente Tabla 32. 


\subsection{Resultados}

Los datos arrojados por la simulación del Modelo VIS mejorado con la solución constructiva de Aislamiento reflectivo (AR), al igual que los de la línea base (LB), se presentan a continuación en la Tabla 32, de la cual derivan todas las gráficas y análisis siguientes.

\begin{tabular}{|c|c|c|c|c|c|c|c|c|c|c|c|c|c|c|}
\hline \multirow{2}{*}{ FECHA } & \multirow{2}{*}{ HORA } & \multicolumn{2}{|c|}{$\mathbf{T}_{\text {air }}$} & \multicolumn{2}{|c|}{$\mathrm{T}_{\mathrm{mr}}$} & \multirow{2}{*}{$V_{\text {air }}$} & \multicolumn{2}{|c|}{ HR } & \multirow{2}{*}{ Met } & \multirow{2}{*}{ Clo } & \multicolumn{2}{|c|}{ PMV } & \multicolumn{2}{|c|}{ PPD } \\
\hline & & LB & AR & LB & AR & & LB & AR & & & LB & AR & LB & AR \\
\hline Ene 02 -Ene 08 & 0:00:00 & 24,9 & 22,24 & 27,4 & 24,62 & 0,05 & 71,01 & 79,00 & 0,8 & 1,2 & 0,5 & $-0,3$ & 10,2 & 6,9 \\
\hline Ene 02 -Ene 08 & 1:00:00 & 24,16 & 21,68 & 26,9 & 24,2 & 0,05 & 72,18 & 80,21 & 0,8 & 1,2 & 0,3 & $-0,5$ & 6,9 & 10,2 \\
\hline Ene 02 -Ene 08 & 2:00:00 & 23,57 & 21,16 & 26,4 & 23,8 & 0,05 & 73,40 & 81,44 & 0,8 & 1,2 & 0,1 & $-0,6$ & 5,2 & 12,5 \\
\hline Ene 02 -Ene 08 & 3:00:00 & 23,11 & 20,75 & 25,9 & 23,44 & 0,05 & 74,25 & 82,53 & 0,8 & 1,2 & 0 & $-0,8$ & 5 & 18,5 \\
\hline Ene 02 -Ene 08 & 4:00:00 & 22,7 & 20,46 & 25,54 & 23,14 & 0,05 & 75,44 & 83,40 & 0,8 & 1,2 & $-0,1$ & $-0,9$ & 5,2 & 22,1 \\
\hline Ene 02 -Ene 08 & $5: 00: 00$ & 22,43 & 20,23 & 25,17 & 22,86 & 0,05 & 76,57 & 84,31 & 0,8 & 1,2 & $-0,2$ & $-0,9$ & 5,8 & 22,1 \\
\hline Ene 02 -Ene 08 & 6:00:00 & 22,52 & 20,26 & 25,39 & 22,81 & 0,05 & 76,28 & 84,95 & 0,8 & 1,2 & $-0,2$ & $-0,9$ & 5,8 & 22,1 \\
\hline Ene 02 -Ene 08 & 7:00:00 & 23,85 & 21,13 & 27 & 23,44 & 0,05 & 72,30 & 83,04 & 0,8 & 1,2 & 0,3 & $-0,7$ & 6,9 & 15,3 \\
\hline Ene 02 -Ene 08 & 8:00:00 & 25,5 & 22,61 & 28,55 & 24,49 & 0,1 & 68,00 & 78,98 & 1,2 & 0,6 & 1 & 0 & 26,1 & 5 \\
\hline Ene 02 -Ene 08 & 9:00:00 & 27,15 & 24,06 & 30 & 25,58 & 0,1 & 60,66 & 72,76 & 1,2 & 0,6 & 1,4 & 0,3 & 45,5 & 6,9 \\
\hline Ene 02 -Ene 08 & $10: 00: 00$ & 28,8 & 25,6 & 31,25 & 26,61 & 0,1 & 54,12 & 66,08 & 1,2 & 0,6 & 1,7 & 0,7 & 61,8 & 15,3 \\
\hline Ene 02 -Ene 08 & 11:00:00 & 30,05 & 26,7 & 32,09 & 27,29 & 0,1 & 51,03 & 62,25 & 1,2 & 0,6 & 2 & 0,9 & 76,8 & 22,1 \\
\hline Ene 02 -Ene 08 & 12:00:00 & 31,2 & 27,61 & 33 & 27,9 & 0,2 & 48,20 & 59,52 & 1,2 & 0,6 & 2,2 & 1 & 84,9 & 26,1 \\
\hline Ene 02 -Ene 08 & 13:00:00 & 32 & 28,24 & 33,9 & 28,39 & 0,2 & 47,60 & 57,81 & 1,2 & 0,6 & 2,5 & 1,1 & 93,4 & 30,5 \\
\hline Ene 02 -Ene 08 & 14:00:00 & 32,12 & 28,22 & 34,4 & 28,49 & 0,2 & 48,25 & 58,27 & 1,2 & 0,6 & 2,6 & 1,1 & 95,3 & 30,5 \\
\hline Ene 02 -Ene 08 & 15:00:00 & 32 & 28,08 & 34,6 & 28,42 & 0,2 & 48,40 & 59,01 & 1,2 & 0,6 & 2,6 & 1,1 & 95,3 & 30,5 \\
\hline Ene 02 -Ene 08 & 16:00:00 & 31,52 & 27,57 & 34,3 & 28,09 & 0,2 & 49,00 & 60,35 & 1,2 & 0,6 & 2,4 & 1 & 91,1 & 26,1 \\
\hline Ene 02 -Ene 08 & 17:00:00 & 30,13 & 26,69 & 32,8 & 27,49 & 0,2 & 52,20 & 63,03 & 1,2 & 0,6 & 2 & 0,8 & 76,8 & 18,5 \\
\hline Ene 02 -Ene 08 & 18:00:00 & 28,3 & 25,81 & 30 & 26,76 & 0,2 & 57,90 & 65,68 & 1,2 & 0,6 & 1,3 & 0,5 & 40,3 & 10,2 \\
\hline Ene 02 -Ene 08 & 19:00:00 & 27,7 & 25,2 & 29,5 & 26,37 & 0,2 & 61,60 & 68,51 & 1,2 & 0,6 & 1,2 & 0,4 & 35,2 & 8,3 \\
\hline Ene 02 -Ene 08 & $20: 00: 00$ & 27,5 & 24,83 & 29,2 & 26,15 & 0,1 & 63,64 & 70,50 & 1,2 & 0,6 & 1,3 & 0,5 & 40,3 & 10,2 \\
\hline Ene 02 -Ene 08 & 21:00:00 & 27,04 & 24,22 & 28,8 & 25,79 & 0,1 & 64,80 & 72,33 & 1,2 & 0,6 & 1,2 & 0,4 & 35,2 & 8,3 \\
\hline Ene 02 -Ene 08 & 22:00:00 & 26,47 & 23,71 & 28,4 & 25,46 & 0,1 & 66,90 & 74,19 & 0,8 & 1,2 & 0,9 & 0 & 22,1 & 5 \\
\hline Ene 02 -Ene 08 & 23:00:00 & 25,4 & 22,87 & 27,8 & 25,03 & 0,1 & 70,30 & 77,09 & 0,8 & 1,2 & 0,6 & $-0,2$ & 12,5 & 5,8 \\
\hline
\end{tabular}

Tabla 32. Tabla comparativa de los datos de desempeño térmico obtenidos a través de la simulación computacional entre la LB y la implementación de la solución constructiva de AR. Fuente: Elaboración propia.

Temperatura del Aire: Un análisis individual de esta variable se muestra en la gráfica de la Figura 131, que compara la LB con el ambiente exterior y la implementación del Aislamiento reflectivo (AR). Aquí se encuentra que, en promedio la implementación del AR redujo en $2,92^{\circ} \mathrm{C}$ la $\mathrm{T}_{\text {air }}$ de la $\mathrm{LB}$, mientras que la diferencia máxima fue de $3,95^{\circ} \mathrm{C}$ a las $16: 00$ horas.

En relación con el ambiente exterior, la solución del $A R$ no solo logró enfriar en $1,82^{\circ} \mathrm{C}$ la $T_{\text {air }}$ en las horas más calientes alrededor del mediodía, sino que, logró conservar un poco más cálida la $\mathrm{T}_{\text {air }}$ en la madrugada cuando es necesario un poco de calor. 
Nótese que, dentro del rango de confort entre $22^{\circ} \mathrm{C}$ a $29,5^{\circ} \mathrm{C}$ (citado por Givoni, Olgyay y otros ${ }^{52}$ ) indicado con sombreado de color verde, esta solución logra estar 18 horas del día; mientras que, la LB logra 17 y el ambiente exterior 10.

Además, el horario de insatisfacción térmica de la LB se da en las horas del mediodía por exceso de calor; mientras que los horarios de insatisfacción del AR son en la madrugada por falta de calor, lo cual es fácilmente solucionable con algo de Clo.

Cabe mencionar que, en las horas más calurosas, la Tair de la LB está incluso más caliente que la del ambiente exterior.

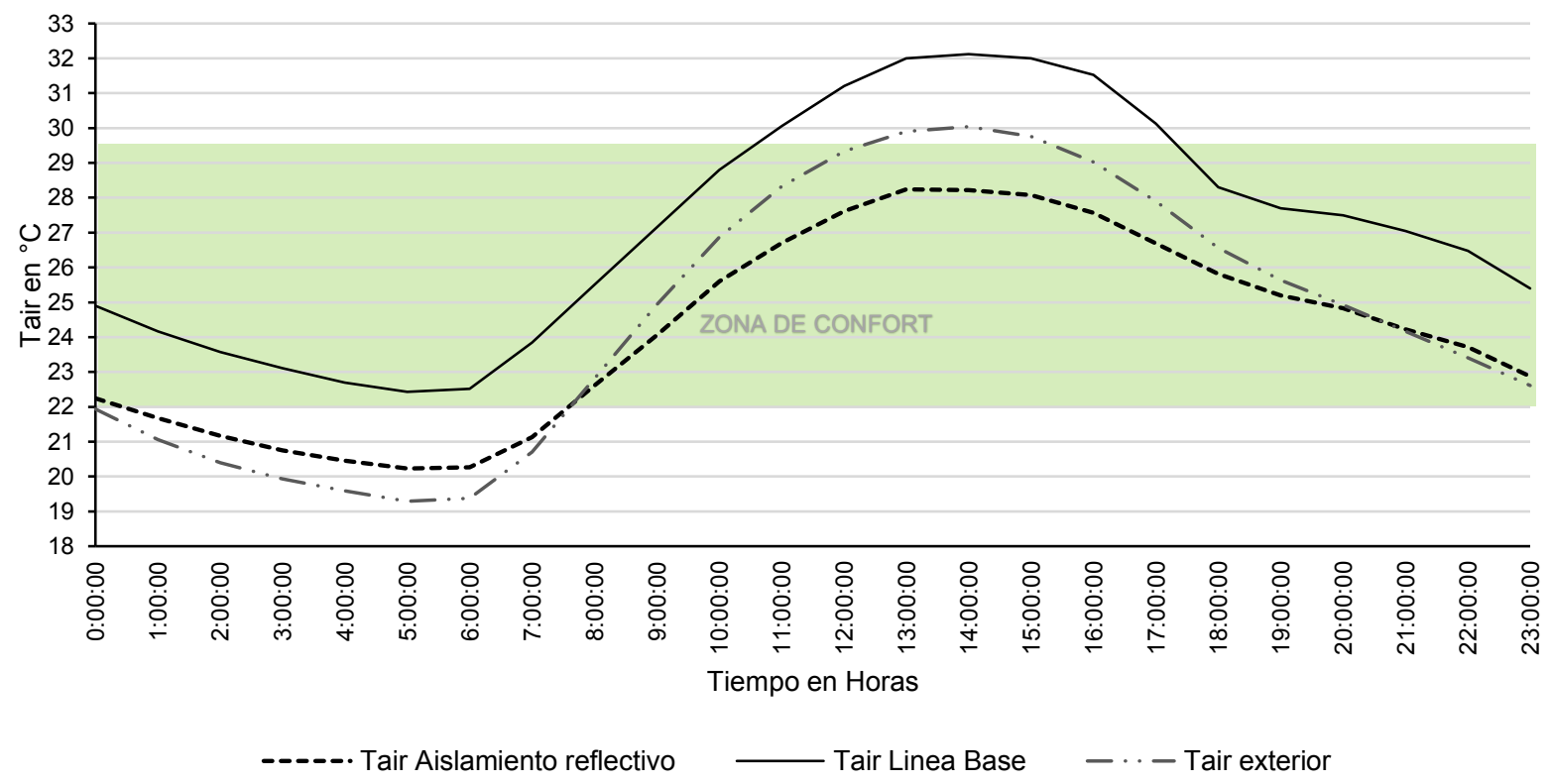

Figura 131. Gráfica comparativa de $T_{\text {air, }}$ entre la línea base, la implementación del AR y el ambiente exterior. Fuente: Elaboración propia.

Temperatura media radiante: Un análisis propio de esta variable se realiza mediante la gráfica de la Figura 132 que compara el comportamiento de esta variable entre la LB y la implementación del AR. De allí se extrae que, en promedio, la solución del AR fue capaz de reducir en $3,82^{\circ} \mathrm{C}$ la $T_{m r}$ de la LB; mientras que la diferencia máxima fue de $6,21^{\circ} \mathrm{C}$ y se obtuvo a las $16: 00$ al igual que con la $T_{\text {air. }}$.

52 El cual difiere un poco con el de Fanger o ASHRAE, como se dijo anteriormente, estos limitan la parte superior del rango en $28^{\circ} \mathrm{C}$, razón por la cual se tuvo en cuenta este último valor en la etapa teórica o de diseño. 
Nótese que, la alternativa AR representada con línea discontinua es capaz de permanecer el $100 \%$ del tiempo dentro del rango de confort citado por Givoni, Olgyay y otros ${ }^{53}$, el cual se señala con sombreado de color verde; mientras que, la LB solo logra permanecer 14 horas, lo cual equivale al $58,33 \%$ del tiempo.

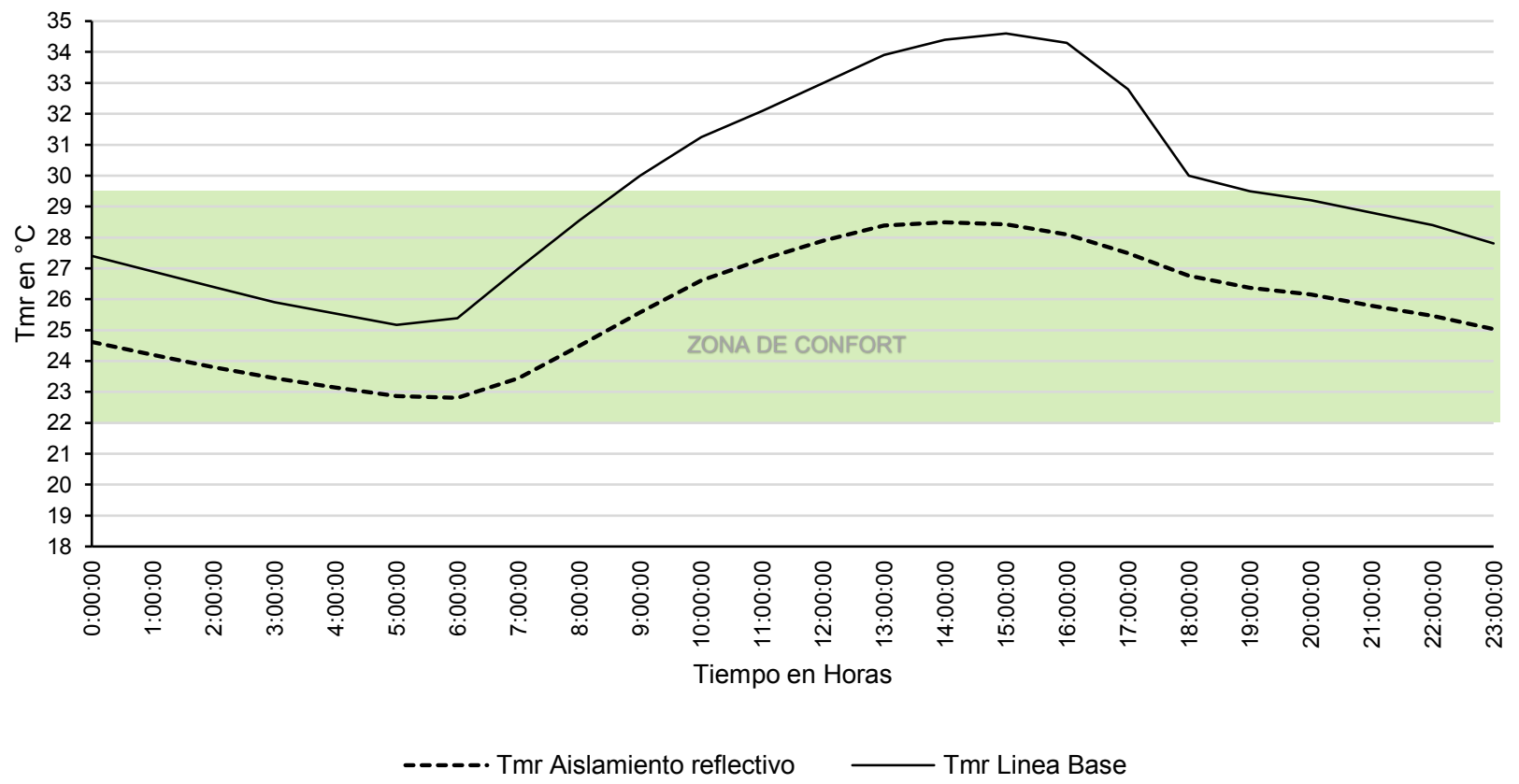

Figura 132. Gráfica comparativa de $T_{\mathrm{mr}}$, entre la línea base y la implementación del AR. Fuente: Elaboración propia.

Complementariamente a esta información, de la simulación se separaron los valores de las temperaturas superficiales interiores $\left(T_{r}\right)$ del muro Oeste, pertenecientes al día crítico ${ }^{54}$, cuya máxima radiación solar global fue de a $1080 \mathrm{~W} / \mathrm{m}^{2}$, la cual fue muy similar a la radiación medida durante los tres días de experimentación bajo brillo solar con la alternativa de AR (en el título 6.8.5), en los cuales se tuvieron máximas de $916 \mathrm{~W} / \mathrm{m}^{2}, 1002 \mathrm{~W} / \mathrm{m}^{2}$ y $1011 \mathrm{~W} / \mathrm{m}^{2}$. Esta selección de datos se efectuó con el objetivo de revisar que los valores y porcentajes de disminución de $T_{r}$ entre la LB y la implementación del AR coincidieran con los datos empíricos

\footnotetext{
${ }^{53}$ El cual difiere un poco con el de Fanger o ASHRAE, como se dijo anteriormente, estos limitan la parte superior del rango en $28^{\circ} \mathrm{C}$, razón por la cual se tuvo en cuenta este último valor en la etapa teórica o de diseño.

${ }^{54}$ El cual se trató en el punto 4.2.2.
} 
de la prueba bajo brillo solar, con lo cual se comprobó la precisión de la simulación computacional.

Estos datos se presentan en la gráfica de la Figura 133, de la cual se extrajo que hay una reducción máxima de $13,4^{\circ} \mathrm{C}$, muy semejante a la máxima de $14,7^{\circ} \mathrm{C}$ obtenida empíricamente.

También, se revisó el porcentaje de reducción del $T_{r}$ mediante el método del área bajo la curva, desde las 12:00 hasta las 18:00 (momentos en los cuales la fachada Oeste inicia y deja de recibir radiación solar respectivamente). El porcentaje de reducción obtenido de la simulación fue $76,7 \%$, mientras que el obtenido empíricamente en el título 6.8 .5 fue de $74,23 \%$, con lo cual se observan resultados muy semejantes. En consecuencia, se consideró que la simulación computacional es bastante cercana a los datos empíricos y por ende sus resultados son bastante ajustados a la realidad.

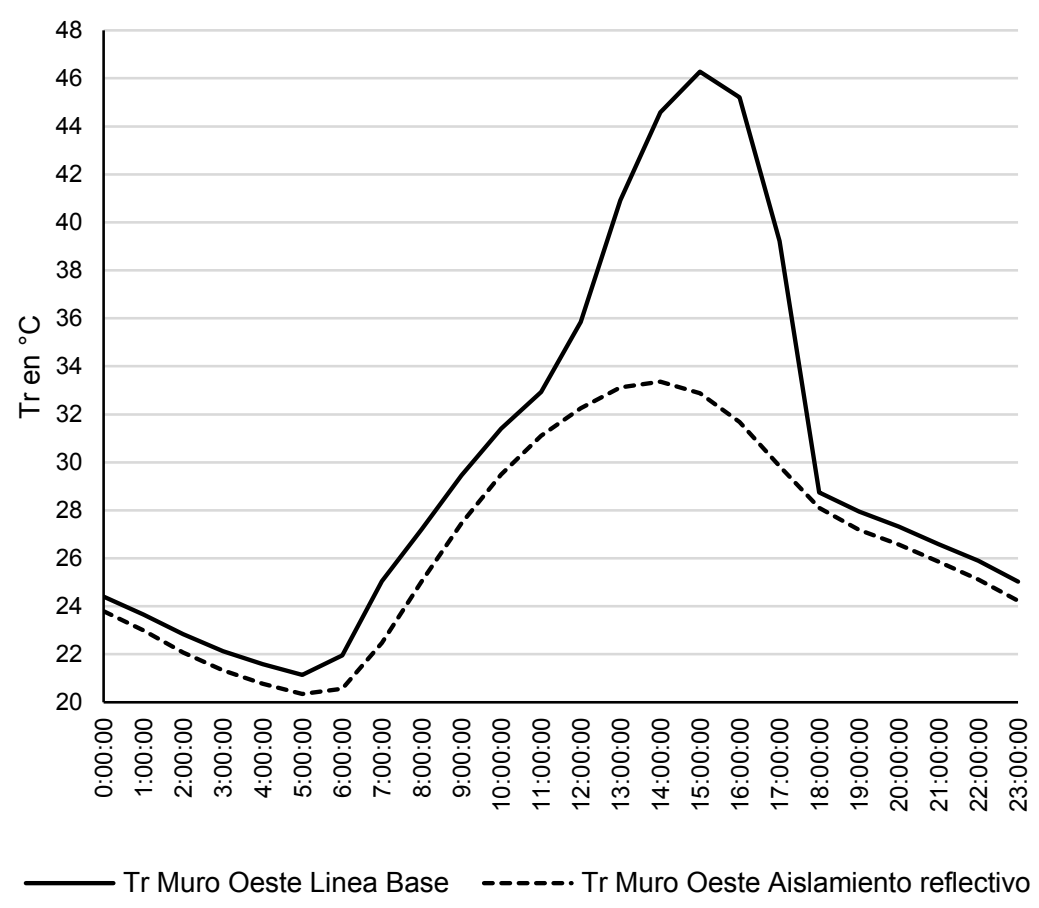

Figura 133. Gráfica comparativa de la $T_{r}$ del muro Oeste con los datos obtenidos en la simulación, entre la LB y la implementación del AR durante el día crítico. Fuente: Elaboración propia.

Ahora bien, en la anterior gráfica, la línea discontinua de color negro perteneciente al AR tuvo una $T_{r}$ máxima de $33,3^{\circ} \mathrm{C}$, con lo cual es claro que la aplicación del $A R$ no logró reducir la $T_{r}$ hasta los rangos de confort mencionados para la $T_{\mathrm{mr}}$, es decir a menos de $29,5^{\circ} \mathrm{C}$. No obstante, el haber disminuido la $T_{r}$ en $13,4^{\circ} \mathrm{C}$ fue muy influyente, pues debe recordarse que la $T_{m r}$ se promedia con la $T_{r}$ de las restantes superficies y el caso analizado fue el día más crítico del año. 
Humedad relativa: Un estudio por separado de esta variable se hace a continuación en la gráfica de la Figura 134, donde se compara el comportamiento entre la LB y la implementación del AR. Aquí se encuentra que la HR es en promedio $9,2 \%$ más alta con el AR que en la LB y la diferencia máxima fue de $11,35 \%$, presentada a las 16:00 horas al igual que con las variables anteriores $T_{\text {air }}$ y $T_{m r}$.

Recordando que el rango de confort y salubridad establecido para la HR según la ASHRAE está entre $50 \%$ y $70 \%$, el cual se señala con sombreado de color verde, se observa que ambos casos sobrepasan el límite superior en las horas de la madrugada cuando la $\mathrm{T}_{\text {air }}$ del ambiente exterior desciende. Esto podría resolverse fácilmente con ventilación natural, abriendo las ventanas o puertas. Sin embargo, la LB presenta también casos de insatisfacción por baja HR desde las 12:00 hasta las 16:00 horas, lo cual puede causar problemas de resequedad y alergias.

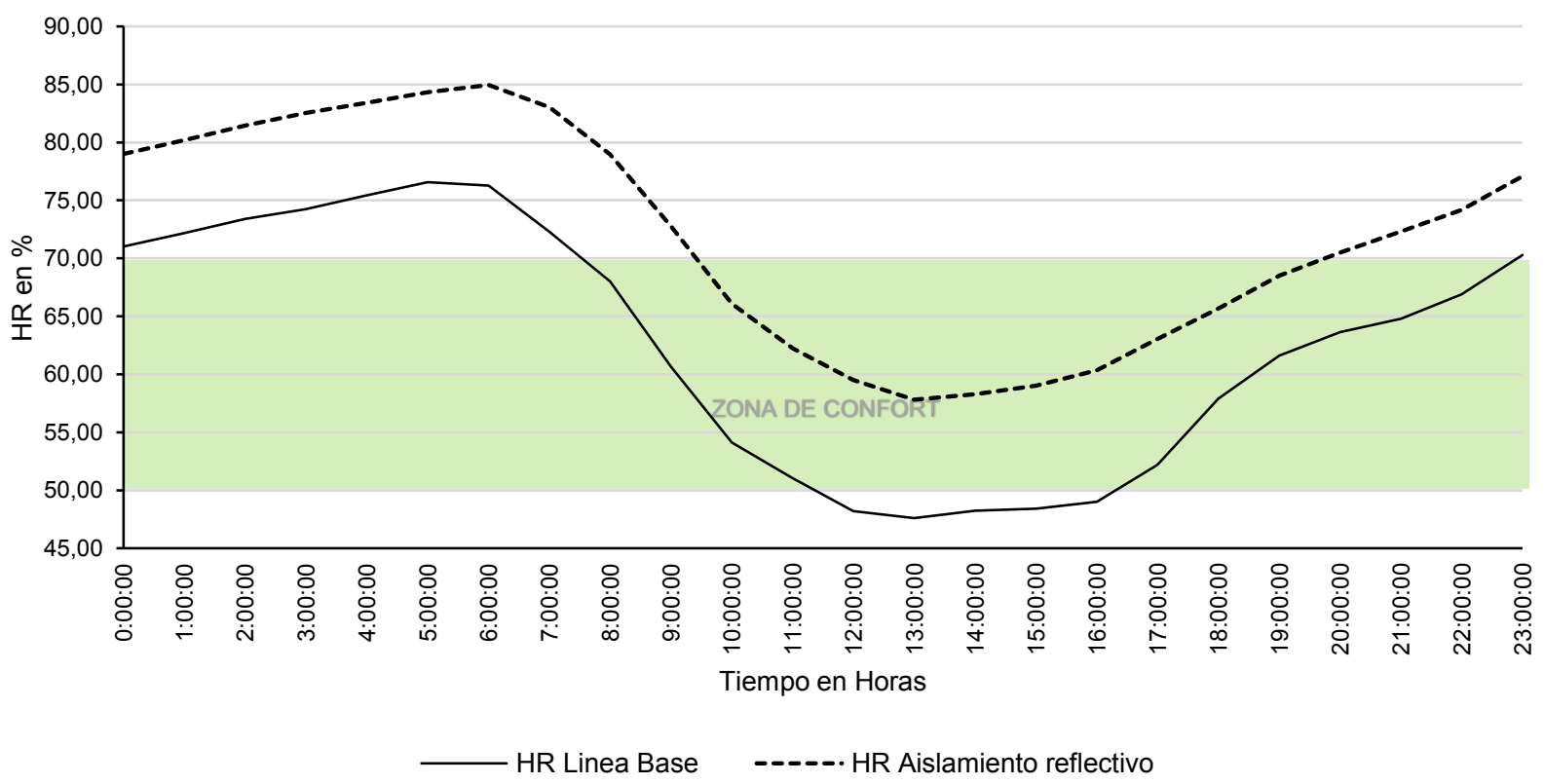

Figura 134. Gráfica comparativa de HR, entre la línea base, la implementación del AR. Fuente: Elaboración propia. 
Índice de sensación térmica (PMV) y porcentaje de personas insatisfechas (PPD): Ahora, para efectuar una evaluación holística del confort térmico obtenido en el modelo VIS mejorado mediante la implementación del AR, es necesario integrar todas las variables, en los índices PMV y PPD propuestos por Fanger.

Para esto, además de la Tabla 32 anterior, se han elaborado las gráficas de la Figura 135 y Figura 136, que contienen respectivamente el avance de la sensación térmica y el porcentaje de personas insatisfechas a lo largo del día.

De acuerdo con la Figura 135, en el interior de la habitación LB (representada con la línea continua de color negro), solamente se logra sensación térmica de "neutralidad" entre las 23:00 y las 7:00, mientras que desde las 8:00 hasta las $22: 00$ se sobrepasa el límite de lo "ligeramente caluroso", permaneciendo entre las sensaciones "calurosas" y "muy calurosas". La desventaja más notoria es sin duda que entre las 11:00 y las 17:00, la sensación térmica es "muy calurosa".

En contraste, en el Modelo VIS mejorado con la solución constructiva de AR (representada con la línea discontinua de color negro) se experimenta una sensación de "neutralidad" durante todo el día, exceptuando el periodo comprendido entre las 13:00 y las 15:00 cuando se llega muy levemente a la sensación "ligeramente calurosa".

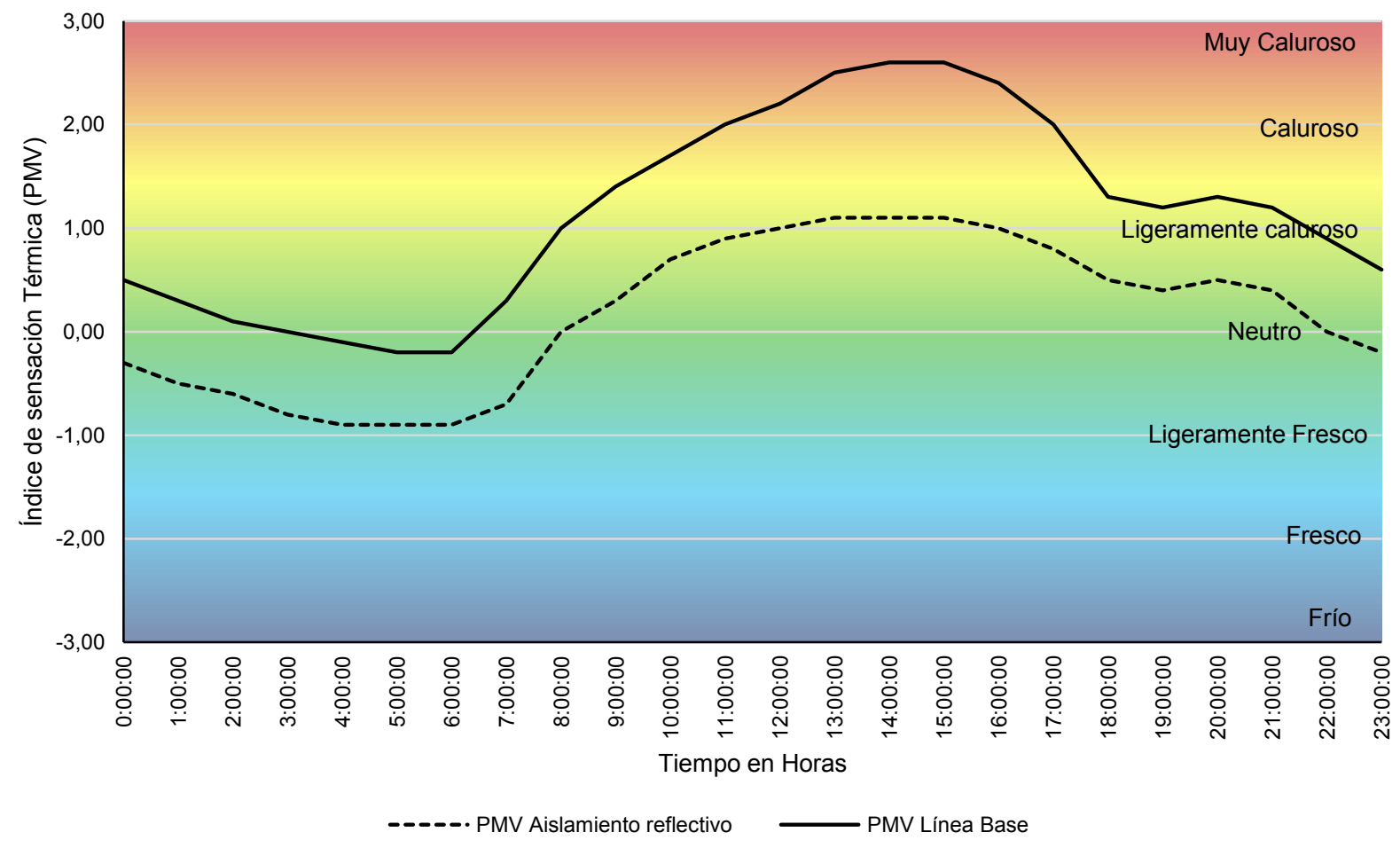

Figura 135. Gráfica comparativa del índice PMV, entre la línea base, la implementación del AR. Fuente: Elaboración propia. 
La evaluación de esta situación se complementa con el índice PPD que se muestra en la gráfica de la Figura 136. De allí se observa que la cantidad de personas insatisfechas con el ambiente térmico de la LB (representada en línea continua de color negro), sobrepasa el límite aceptable de $20 \%$ desde las 8:00 hasta las 22:00 horas, es decir, en 14 de las 24 horas del día, lo cual equivale al 58,33\%. Durante este periodo se destaca un pico comprendido entre las 13:00 y las 16:00, en el cual se llega al valor crítico de 95,30\% insatisfechos.

En contraste, como lo indica la línea discontinua de color negro que representa el Modelo VIS mejorado, la solución de AR redujo en $64,8 \%$ la cantidad de insatisfechos de la alcoba durante el periodo crítico de las 13:00 a las 16:00 horas. En general, esta alternativa tuvo 8 horas por fuera del rango aceptable de $20 \%$ de insatisfechos, lo cual equivale al $33,3 \%$ del tiempo. Dentro de esas 8 horas, 2 corresponden al 22,10\% de insatisfechos por la sensación térmica cercana a lo "ligeramente fresco" durante las 4:00 a las 6:00. Por su parte, las otras 6 horas de insatisfacción llegan como máximo al $30,50 \%$ de insatisfechos durante las 11:00 a las 17:00 cuando sutilmente se sobrepasó la sensación "Ligeramente calurosa".

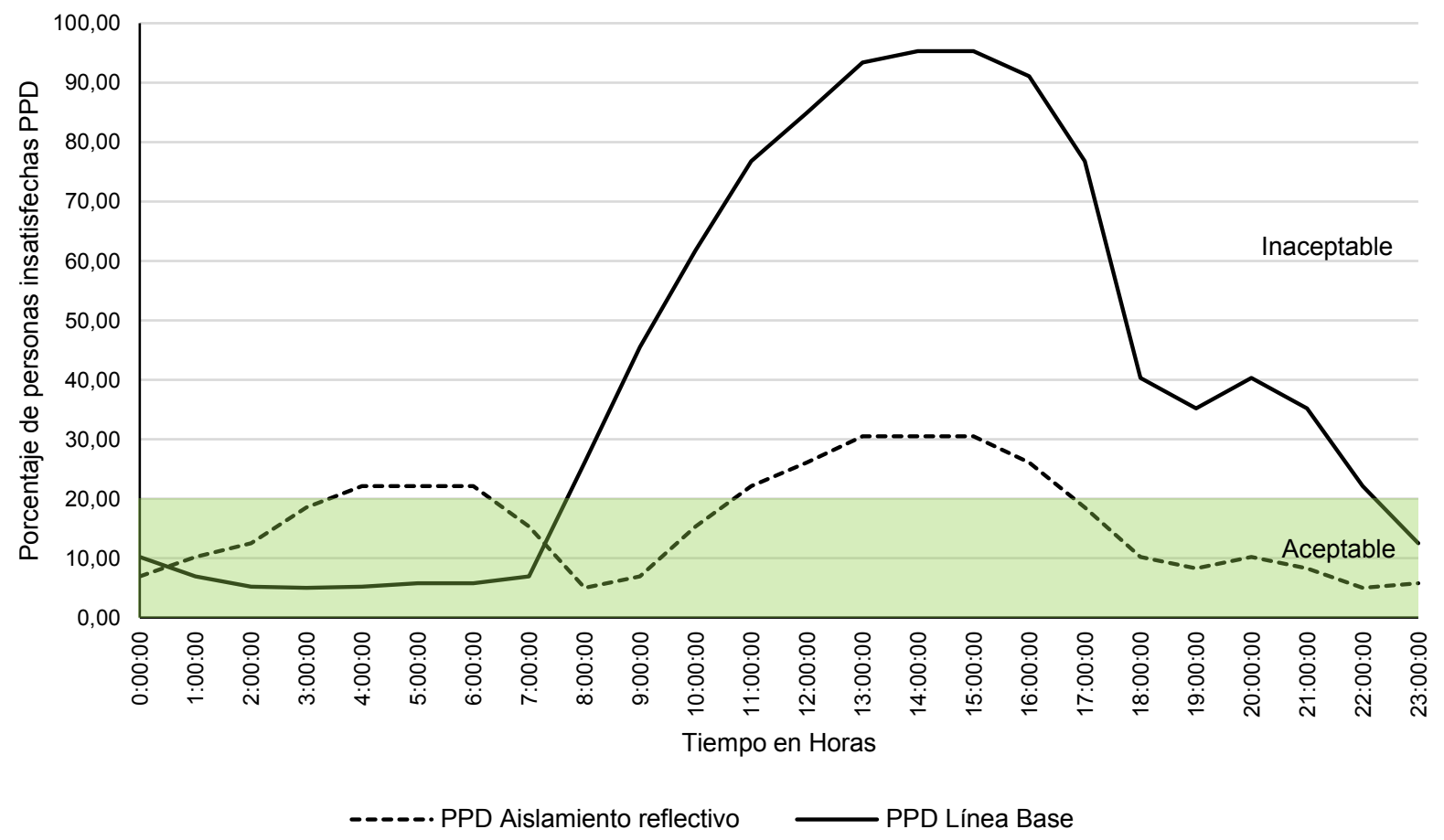

Figura 136. Gráfica comparativa del PPD, entre la línea base, la implementación del AR. Fuente: Elaboración propia. 


\subsection{Conclusiones}

- Mediante la metodología de simulación computacional seguida en este capítulo, en la cual se utilizaron como datos de entrada y control los resultados obtenidos en los capítulos anteriores (porcentaje de reducción de $T_{r}$, evaluación de confort del Modelo VIS, valor U, etc.) se cumplió con el objetivo de determinar el aporte que la solución constructiva de Aislamiento reflectivo puede alcanzar en la optimización del confort térmico de un ambiente VIS.

- Con la comparación de los índices de confort térmico logrados por la Línea Base (LB) y el Modelo VIS mejorado, se logró determinar que: con la implementación de tecnologías pasivas es factible proveer confort térmico a un ambiente VIS con rasgos críticos, ya que, durante la situación más desfavorable para esta habitación, la implementación del AR fue capaz de optimizar la sensación térmica "muy calurosa" con $95,3 \%$ de insatisfechos a una sensación "ligeramente calurosa" con tan solo $30,50 \%$ de insatisfechos, lo cual significa una mejora del $64,8 \%$.

Considerando que se investigó un ambiente VIS con características constructivas críticas, bajo condiciones y periodos climáticos críticos, (lo cual se explicó en el título 4), y se logró alcanzar adecuadas condiciones de confort térmico con la implementación del AR, se infiere que este espacio bajo las restantes condiciones del año (las cuales serán menos exigentes), también alcanzará condiciones óptimas de confort térmico.

- Como se utilizó una metodología basada en casos críticos, se entiende que esta tecnología es recomendable para optimizar el deficiente confort térmico que presentan las VIS tanto de tipología multifamiliar como unifamiliar.

- En caso tal, que se quiera reducir más este 30,5\% de insatisfechos de este espacio, existen otras mejoras de tipo pasivo fuera del alcance de esta investigación que pueden tener lugar, como por ejemplo dar protección solar a las ventanas y cambiar la ventilación unilateral por ventilación cruzada. Ninguna de estas alternativas complementarias se ve obstruida constructivamente por la implementación ya sea del AR o el MV.

- De la misma manera, es importante recordar que el desempeño obtenido por la solución constructiva de AR durante la prueba con brillo solar es muy similar al obtenido por el MV. Por lo tanto, se estima que los resultados logrados en el mejoramiento del confort térmico por el AR sean también similares a los del MV. 


\section{RELACIÓN COSTO-BENEFICIO}

\subsection{Introducción}

El costo es un tema muy relevante para todo tipo de edificación, pero, lo es más a este nivel socioeconómico debido a que, tanto los propietarios como el presupuesto constructivo de las VIS poseen recursos económicos limitados.

En este título se hace un reporte del costo total de la implementación de estas alternativas pasivas en la habitación del modelo VIS tratado en el Capítulo 4 para conocer la relación costo-beneficio de cada una de ellas, realizar comparaciones entre sí e incluso con otras alternativas revisadas en el estado del arte ( $y$ también disponibles en el mercado). Asimismo, se contrasta el costo de estas soluciones con el del suministro e instalación de un aparato de aire acondicionado, el cual ha sido la solución típica al problema de insatisfacción térmica en este tipo de vivienda. Los contrastes y discusiones mencionadas se realizan a la luz del desempeño térmico.

Para valorar el costo inicial se utilizó la metodología explicada por Casas Figueroa (2002), que inició con la realización del análisis de precios unitarios (APU) de cada solución constructiva tomando como base la información empírica del proceso de construcción del aparato experimental, los conocimientos del ejercicio profesional en construcción y la base de datos de precios oficiales para la construcción de la Gobernación del Valle del Cauca, disponible en internet $^{55}$ (Gobernación del Valle del Cauca, Colombia, 2017). Posteriormente, este precio

\footnotetext{
${ }^{55}$ http://www.valledelcauca.gov.co/vivienda/documentos.php?id=1018
} 
unitario se multiplicó por el área en la que se aplicó dicho tratamiento para la simulación computacional para tener un costo total de implementación.

\subsection{Análisis costo-beneficio}

Los análisis unitarios en detalle y el cálculo del costo total de implementar cada alternativa pueden consultarse en el Apéndice 4, de este apéndice se extrajo la información contenida en la siguiente Tabla 33, en ella se presentan tres variables de cada solución constructiva.

La primera corresponde al costo total de implementar cada alternativa en el exterior de la envolvente de la habitación VIS en ARS (\$18,65 ARS = \$1 USD = \$2.900 COP - TRM 16-012018). La segunda corresponde al porcentaje de $T_{r}$ transferido al interior de la habitación de cada solución. Y la tercera es el índice costo beneficio que relaciona el costo por cada unidad porcentual de $T_{r}$ reducida, dada en ARS/\%. Es decir, una buena relación costo-beneficio está dada por valores bajos en las dos primeras variables.

Como se ve en esta tabla, aparte de las cinco opciones constructivas pasivas trabajadas durante el corpus del trabajo, se adicionaron dos más. La primera es el Aislamiento con poliestireno expandido (EIFS), costeada con un valor $U$ igual al del AR; y la segunda es un equipo de Aire Acondicionado de 12000 Btu (AA) estimado para refrigerar esta habitación. Vale aclarar que la primera es otra solución pasiva, mientras que el AA es la única solución activa. 


\begin{tabular}{|c|c|c|c|c|}
\hline SOLUCIÓN CONSTRUCTIVA & & itación & $\begin{array}{c}\% \text { de } \mathrm{T}_{\mathrm{r}} \\
\text { transferido }\end{array}$ & $\begin{array}{l}\text { Índice costo- } \\
\text { beneficio }\end{array}$ \\
\hline Autosombreado (AS) & $\$$ & 474 & 82,25 & 26,69 \\
\hline Baja absortividad (BA) & $\$$ & 682 & 50,54 & 13,80 \\
\hline Revoque refractario (RF) & $\$$ & 2.791 & 68,46 & 88,50 \\
\hline $\begin{array}{c}\text { Aislamiento reflectivo + Baja } \\
\text { Absortividad (AR) }\end{array}$ & $\$$ & 3.648 & 25,77 & 49,14 \\
\hline Muro vegetal (MV) & $\$$ & 7.417 & 26,27 & 100,59 \\
\hline $\begin{array}{c}\text { Aislamiento con poliestireno } \\
\text { expandido (EIFS) }\end{array}$ & $\$$ & 8.830 & 25,77 & 118,95 \\
\hline Aire acondicionado (AA) & $\$$ & 21.087 & 0,00 & 210,87 \\
\hline
\end{tabular}

Tabla 33. Tabla comparativa de costo beneficio entre soluciones constructivas pasivas y el Aire acondicionado (solución activa). Fuente: Elaboración propia.

Esta tabla está organizada en orden ascendente con respecto al costo, y se tomó como base para elaborar la gráfica de la Figura 137. De ambas se extrajo que las opciones de AS, BA y RF ubicadas en los tres primeros lugares poseen costos económicos bajos, pero como se calculó en el Capítulo 5 y se corroboró con la experimentación del Capítulo 6, permiten el paso de la mitad de la $T_{r}$ y los aportes con relación al confort térmico son insuficientes. Sin embargo, dentro de este grupo se destaca la opción de BA, la cual redujo la $T_{r}$ a la mitad con \$ 682 ARS y cuyo índice costo beneficio de 13,80 es el más bajo de las siete alternativas comparadas.

Más adelante, entre las siguientes tres alternativas pasivas correspondientes al $A R, M V$ y EIFS, que poseen un porcentaje de calor transferido prácticamente igual, se destaca por su menor costo la solución de AR con $\$ 3.648$ ARS, seguida del MV con $\$ 7.417$ ARS y por último el EIFS con $\$ 8.830$ USD.

Por último, encontramos la opción del AA, de la cual no cabe duda de que posee la capacidad de evacuar toda la carga térmica de la habitación, pero su costo de $\$ 21.087$ ARS es muy superior al de las alternativas pasivas. Comparado con el AR, su costo es superior en un $82,7 \%$, mientras que en con el MV y el EIFS es superior en $64,82 \%$ y $58,12 \%$ respectivamente. 


\section{RELACIÓN COSTO - BENEFICIO}

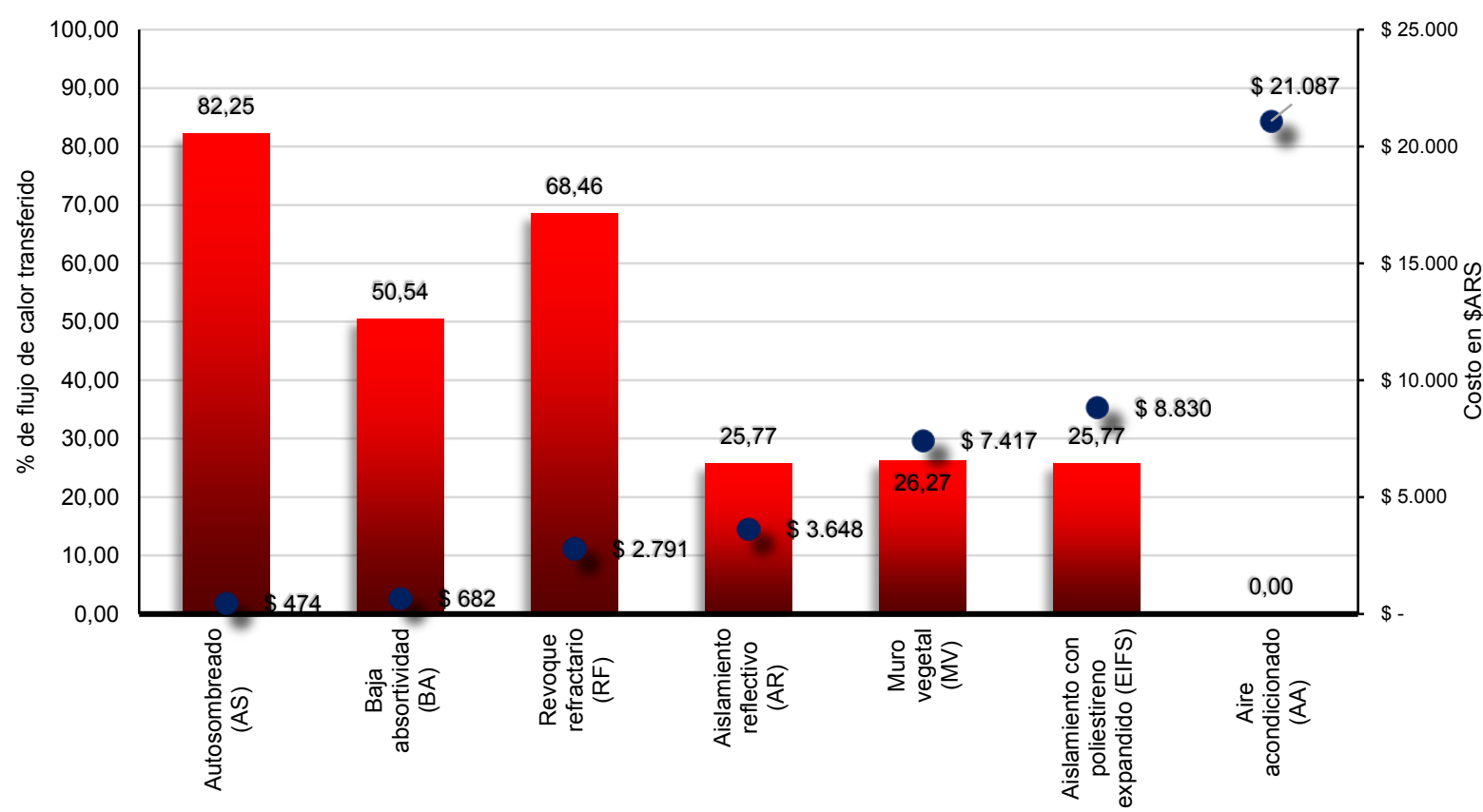

TIPO DE SOLUCIÓN CONSTRUCTIVA

- \% de $\operatorname{Tr}$ transferido

- Costo total por habitación en \$ARS

Figura 137. Gráfica comparativa de costo beneficio entre soluciones constructivas pasivas y el Aire acondicionado (solución activa). Fuente: Elaboración propia.

\subsection{Conclusiones}

- Mediante la metodología de análisis costo-beneficio seguida en este capítulo, en la cual se utilizaron como datos de trabajo los resultados de porcentaje de reducción de la $T_{r}$ y la experiencia constructiva del Capítulo 6 , se cumplió con el objetivo de determinar la relación costo-beneficio de las soluciones constructivas y compararlas con otras alternativas pasivas existentes en el estado del arte y la solución activa de implementar un aire acondicionado.

- Como se observó en la gráfica de la Figura 137, entre las soluciones constructivas pasivas que poseen el mejor e idéntico desempeño térmico tales como el $A R$, el MV y el EIFS, la que posee una mejor relación costo-beneficio es el AR. En esta solución constructiva se combinaron las estrategias de aislamiento reflectivo y baja absortividad. Con esta combinación se logró reducir la $T_{r}$ al $25,77 \%$ con un costo económico inicial de $\$ 3.648$ ARS. El costo del AR equivale al $41,3 \%$ del costo del EIFS y al $49,18 \%$ del MV. 
- De acuerdo con los cálculos realizados en el presente capítulo y en el Apéndice 4, para la habitación del modelo VIS evaluado, el costo de instalación de un equipo de aire acondicionado ( $\$ 21.087$ ARS) es $82,7 \%$ superior al costo de implementación de la solución constructiva de AR (\$3.648 ARS). Además, el aire acondicionado posee gastos de funcionamiento, mantenimiento, agrava la crisis ambiental y propicia el surgimiento de enfermedades de tipo respiratorio, en la piel o incluso la disminución en el rendimiento laboral como vimos que indica Hedge (2004) en el título 1.2.

- Aunque la alternativa de BA por sí sola no reduce la $T_{r}$ lo suficiente como para proporcionar niveles adecuados de confort térmico, sí tiene una la mejor relación costo-beneficio como lo indica la Tabla 33, incluso gran parte del éxito de las estrategias como el AR, MV e incluso en el EIFS ${ }^{56}$, radica en haberla incluido dentro de las estrategias que se combinaron. Esto amerita cavilar un poco más el lenguaje estético y la tecnología de acabados característica de este tipo de vivienda, pues con la aplicación de un acabado de baja absortividad como por ejemplo una pintura color blanco, el $50,54 \%$ de la $T_{r}$ es reducido.

${ }^{56}$ El APU del EIFS se calculó con una placa de poliestireno de valor U igual al obtenido por el AR, no obstante, para que llegue al mismo comportamiento térmico debe tener también el mismo valor de absortividad. 


\section{CONCLUSIONES}

\subsection{Introducción}

Este capítulo integra y sintetiza el conocimiento producido en los nueve capítulos anteriores, teniendo como guía los objetivos e interrogantes motivadores. En este también se compendian los hallazgos logrados en cuanto a lo tecnológico, lo metodológico y lo disciplinar.

En esta introducción se explica la estructura del apartado y se reelabora la conexión del objeto de estudio y el producto general de esta tesis con la teoría seguida en el marco teórico. En la segunda parte, se exponen las conclusiones relacionadas con los objetivos general y específicos. En la tercera y cuarta parte, se retoman las preguntas e hipótesis de investigación, dándoles respuesta y discutiendo acerca de su comprobación. En la quinta parte, se muestran los mayores aportes realizados a la disciplina y en la sexta y última se mencionan los futuros trabajos motivados por lo aquí realizado.

El objeto de estudio de esta tesis ha sido evaluar la influencia que tienen varios modelos de envolventes pasivas en el confort térmico de un modelo VIS de la ciudad de Cali, en la primera sección de este trabajo se expusieron los argumentos y las importantes relaciones de este objetivo con los aspectos: ambiental, energético, urbano, político, socioeconómico y tecnológico.

Específicamente en el segundo capítulo se analizó el impacto que tienen las VIS en el territorio de la ciudad de Cali, estableciendo que cubren una gran parte su suelo construido y que constituyen casi la mitad de las viviendas que se están construyendo.

En este capítulo también se revisaron estudios previos que señalaron que las VIS son inconfortables térmicamente, lo cual es corroborado por el monitoreo realizado a un ambiente en el Capítulo 4. Con lo anterior tiene sentido que los estudios globales de sustentabilidad mencionados en el capítulo introductorio sostengan que el consumo energético de las 
edificaciones representa casi la mitad de la energía utilizada a nivel global, y casi la mitad de esta sea dedicada a proporcionar confort térmico, lo cual hace que el funcionamiento de las edificaciones sea uno de los mayores responsables en el fenómeno de cambio climático.

El producto de este trabajo, en el cual se aplican las teorías y avances en arquitectura bioclimática, arquitectura sostenible, y eficiencia energética, confirma que es posible mitigar no solo el cambio climático, sino que también es factible impactar de manera positiva el ámbito socioeconómico de la comunidad al optimizarse el confort térmico y por ende la calidad de vida de los usuarios de las VIS de Cali.

La incorporación multidisciplinaria planteada por Olgyay desde 1968 entre tecnología, climatología, biología, y arquitectura sigue vigente en este trabajo, demostrando su utilidad, e incluso ampliándose y especializándose al abarcar otras áreas como la ingeniería de materiales, la computación y los aspectos sociales y económicos.

\subsection{En relación con los objetivos}

\subsubsection{Objetivo general:}

Evaluar la reducción de la $T_{r}$ en las envolventes verticales opacas y la optimización del confort térmico que pueden alcanzar en las VIS de Cali algunas soluciones constructivas, desarrolladas a partir de la combinación estratégica de tecnologías de enfriamiento pasivo tales como el sombreado, la baja absortividad, el aislamiento, los muros vegetales y la ventilación.

Dentro del contexto de las VIS de Cali se investigó por medio de un modelo teóricoexperimental el comportamiento térmico de varias soluciones constructivas aplicables a las fachadas que combinaron estratégicamente las tecnologías de enfriamiento pasivo. Mediante este modelo también se conoció el nivel de optimización que alcanza cada solución planteada en el confort térmico. En esta evaluación se tuvo en cuenta preponderantemente el desempeño térmico, pero también se discutió la relación costo-beneficio.

Las cinco alternativas acá diseñadas, han sido estudiadas y comparadas con el desempeño térmico y el costo de otras soluciones pasivas y activas. Tres de estas soluciones no alcanzaron una considerable reducción de la $T_{r}$ como para brindar confort térmico. Mientras que, las últimas dos en las que se combinaron las estrategias de baja absortividad, aislamiento reflectivo, muro vegetal y cámara de aire, lograron reducir la $T_{r}$ más del $70 \%$. Esto significó pasar de un índice de sensación térmica (PMV) "muy caluroso" a "ligeramente caluroso" y la disminución del porcentaje de insatisfechos (PPD) de 95,3\% a 30,50\% en un ambiente típico 
VIS. Se demostró, además, que el costo de la implementación de estas soluciones puede ser hasta 5 veces menor que instalar un equipo de aire acondicionado en el mejor de los casos.

\subsubsection{Objetivo específico 1:}

Evaluar el nivel de confort térmico de un ambiente de VIS de Cali y la relación con el comportamiento térmico de su envolvente vertical opaca.

En el Capítulo 4 se ha monitoreado y evaluado el confort térmico de un ambiente VIS perteneciente a la tipología multifamiliar mediante los índices PMV y PPD. Con este trabajo se encontró que la sensación térmica experimentada en este ambiente desde las 13:00 hasta las 17:00 horas oscila entre lo "caluroso" y "muy caluroso", con lo cual se alcanzan porcentajes de insatisfacción de hasta 93,4\%; y durante 14 de las 24 horas del día esta insatisfacción supera el $20 \%$ de los ocupantes

Temperaturas radiantes de hasta $47,27^{\circ} \mathrm{C}$ fueron registradas durante el monitoreo de la superficie interior de la fachada Oeste de este espacio, con lo cual, los valores de $R=0,42$ $\mathrm{m}^{2 \circ} \mathrm{C} / \mathrm{W}$, absortividad $=0,7$ y emisividad $=0,9$; que poseen las envolventes verticales opacas típicas de las VIS, tienen un desempeño térmico insuficiente que no logra brindar confort térmico a los ocupantes.

\subsubsection{Objetivo específico 2:}

Analizar teóricamente el comportamiento térmico de diferentes soluciones constructivas que puedan ser útiles en la reducción de la $T_{r}$ de las envolventes verticales opacas y la optimización del confort térmico, combinando las estrategias de enfriamiento pasivo.

En el Capítulo 5 de la tesis se da cumplimiento a este objetivo mediante un método teórico con el cual se calculó y comparó el desempeño térmico de cinco propuestas constructivas pasivas que se aplicaron a las envolventes verticales opacas de las VIS.

La gráfica de la Figura 70 de este mismo Capítulo 5 condensa los resultados de los cálculos de reducción de $\mathrm{T}_{\mathrm{r}}$ alcanzados con cada solución constructiva, de ella se extrae que de llegarse a implementar el Autosombreado (AS), la Baja absortividad (BA), el Revoque refractario (RF), el Muro vegetal + baja absortividad + cámara de aire (MV) y el Aislamiento reflectivo + baja absortividad (AR) se puede reducir respectivamente la $\mathrm{T}_{\mathrm{r}}$ al $82 \%, 37,8 \%$, $18,2 \%, 9,27 \%$ y $8,70 \%$. 
Entre las cinco opciones pasivas, se destacó el desempeño del MV y el AR, los cuales además tuvieron la capacidad de haber alcanzado la zona de confort al reducir la $\mathrm{T}_{\mathrm{r}}$ de $42,9^{\circ} \mathrm{C}$ a $28,97^{\circ} \mathrm{C}$ y $28,34^{\circ} \mathrm{C}$ respectivamente.

A pesar de que, estos datos fueron calculados teóricamente, considerando un estado estacionario sin contemplar otros aspectos termodinámicos como la acumulación de energía fueron útiles para realizar comparaciones posteriores con los datos experimentales.

\subsubsection{Objetivo específico 3:}

\section{Evaluar experimentalmente el comportamiento térmico de las soluciones constructivas desarrolladas y analizadas teóricamente.}

Para cumplir este objetivo se diseñaron dos experimentos, el primero se desarrolló en el Capítulo 6 con el fin de conocer el porcentaje de reducción de la $T_{r}$, el cual se llevó a cabo a cielo abierto bajo brillo solar. Y el segundo, explicado en el Capítulo 7, se elaboró con el objetivo de determinar el valor $U$ de las soluciones mediante el método de la caja caliente y utilizando un medidor de $U$.

La primera medición se sintetizó en la gráfica de la Figura 115 del Capítulo 6, con la cual se demostró que las tecnologías de enfriamiento pasivo combinadas estratégicamente tienen un gran potencial de reducción de la $T_{r}$, porque, aquellas soluciones que incluyeron dos o más estrategias como el Aislamiento reflectivo + Baja absortividad (AR) y el Muro vegetal + Baja Absortividad + Cámara de Air (MV) lograron reducir la $T_{r}$ un 74,23\% y 73,23\% respectivamente.

Mientras que aquellas soluciones en las que se incluyó solo una estrategia tales como la Baja absortividad (BA), el Revoque refractario (RF) y el Autosombreado (AS), lograron reducir un $49,46 \% ; 31,54 \% ; 17,75 \%$ respectivamente.

$Y$ en el mismo orden, estas soluciones constructivas fueron capaces de reducir la $T_{r}$ como máximo en $15,6^{\circ} \mathrm{C}, 12,9^{\circ} \mathrm{C}, 8,4^{\circ} \mathrm{C}, 6,42^{\circ} \mathrm{C}$ y $5,4^{\circ} \mathrm{C}$.

Con estos resultados se conoció y validó experimentalmente el comportamiento térmico de las alternativas que se habían evaluado de forma teórica en el Capítulo 5. Estos resultados revelaron que, a excepción del RF, el comportamiento calculado concuerda con el experimental. No obstante, los cálculos teóricos bajo régimen estacionario estimaron un 17\% de reducción mayor que los obtenidos de forma empírica. Y también, existe una incertidumbre máxima de $\pm 7,4 \%$ con los cálculos de reducción máxima de $\mathrm{T}_{\mathrm{r}}$ en ${ }^{\circ} \mathrm{C}$. 
En este experimento la alternativa de AR demostró desempeñarse térmicamente mejor en comparación a las demás opciones reduciendo la $T_{r}$ en un $74,23 \%$, aunque es seguida muy de cerca por el MV con 73,23\%. Solo estas dos soluciones se acercaron a los rangos de confort de la $T_{r}$, por esta razón, la siguiente experimentación se encaminó a conocer el valor $U$ de estas dos soluciones constructivas.

En el Capítulo 7 se llevó a cabo la segunda experimentación con la cual se encontró que el valor $U$ de la solución $A R$ es $0,49 \mathrm{~W} / \mathrm{m}^{2 \circ} \mathrm{C}$, la cual posee $2,5 \mathrm{~cm}$ de espesor; y mediante inferencias apoyadas en el primer experimento, se obtuvo que el valor $U$ del MV es 0,5 $\mathrm{W} / \mathrm{m}^{2 \circ} \mathrm{C}$, el cual tiene $8 \mathrm{~cm}$ de espesor.

Estos resultados se sintetizaron en la gráfica de la Figura 126 y se compararon otras tecnologías pasivas, estableciendo que la capacidad de aislamiento que tienen el AR y el MV equivalen a $3,3 \mathrm{~cm}$ de Aerogel, $7 \mathrm{~cm}$ de Poliuretano $\left(30-60 \mathrm{Kg} / \mathrm{m}^{3}\right) \circ 7,2 \mathrm{~cm}$ de EPS (13 $\mathrm{Kg} / \mathrm{m}^{3}$ ). Con lo anterior se entiende que la relación espesor-transmitancia térmica de la solución AR es bastante competitiva e incluso superior a la de materiales tradicionales como el Poliuretano o materiales de punta como el Aerogel.

\subsubsection{Objetivo específico 4:}

Estudiar la optimización del confort térmico que las soluciones constructivas con mejor comportamiento térmico pueden alcanzar en un ambiente típico de la VIS de Cali.

Este objetivo se desarrolló en el Capítulo 8, en el que se tuvo como recurso principal la simulación computacional. Un modelo virtual del dormitorio monitorizado y valorado en cuanto al confort térmico en el Capítulo 4 sirvió como línea base (LB).

El modelo virtual o LB se calibró con el comportamiento térmico registrado en campo y a una copia de este le fue implementada la solución constructiva de AR, configurando como datos de entrada y control los resultados obtenidos en el Capítulo 6 y 7. Con este Modelo VIS mejorado se llevó a cabo una simulación y evaluación de confort térmico, en la que se utilizaron los índices PMV y PPD, dando cumplimiento de este modo al objetivo.

Con este análisis que se sintetizó en la Tabla 32 y en las gráficas de la Figura 135 y Figura 136, se encontró que:

- La LB solamente logra sensación térmica de "neutralidad" entre las 23:00 y las 7:00; de 8:00 a 11:00 y de 17:00 a 22:00 se permanece entre las sensaciones "calurosas" y "muy calurosas" y entre las 11:00 y las 17:00, la sensación térmica es "muy calurosa". 
En contraste, en el Modelo VIS mejorado con la solución constructiva de AR se experimenta una sensación de "neutralidad" durante todo el día, exceptuando el periodo comprendido entre las 13:00 y las 15:00 cuando se llega muy levemente a la sensación "ligeramente calurosa".

- La cantidad de personas insatisfechas con el ambiente térmico de la LB sobrepasa el límite aceptable de $20 \%$ desde las 8:00 hasta las 22:00 horas, es decir, en 14 de las 24 horas del día, lo cual equivale al 58,33\%. Durante este periodo se destaca un pico comprendido entre las 13:00 y las 16:00, en el cual se llega al valor crítico de $95,30 \%$ insatisfechos. En contraste, el Modelo VIS mejorado con la solución de AR redujo en $64,8 \%$ la cantidad de insatisfechos durante el periodo crítico de las 13:00 a las 16:00. En general, esta alternativa tuvo 8 horas por fuera del rango aceptable de $20 \%$ de insatisfechos, lo cual equivale al 33,3\% del tiempo. Dentro de esas 8 horas, 2 horas corresponden al $22,10 \%$ de insatisfechos por la sensación térmica cercana a lo "ligeramente fresco" durante las 4:00 a las 6:00. Por su parte, las otras 6 horas de insatisfacción llegan como máximo al 30,50\% de insatisfechos durante las 11:00 a las 17:00 cuando sutilmente se sobrepasó la sensación "Ligeramente calurosa".

El desempeño obtenido por la solución constructiva de AR durante la prueba con brillo solar fue muy similar al obtenido por el MV. Por lo tanto, se estimó que los resultados logrados en el mejoramiento del confort térmico por el AR son similares a los del MV.

Con los logros alcanzados en este objetivo se demostró que, en Cali las tecnologías de enfriamiento pasivo combinadas estratégicamente en la envolvente de un ambiente VIS multifamiliar tienen la capacidad de brindar confort térmico, incluso en situaciones de alta insatisfacción.

\subsubsection{Objetivo específico 5:}

Evaluar la relación costo-beneficio de las soluciones pasivas propuestas, frente a otras similares en el estado del arte y frente a soluciones activas como la implementación de un equipo de aire acondicionado.

La evaluación costo-beneficio se llevó a cabo en el Capítulo 9 de la tesis, con esta evaluación que se sintetizó en la gráfica de la Figura 137 se halló que entre las opciones con desempeño superior y similar como el AR, MV y EIFS, la mejor relación costo-beneficio la obtuvo el AR, cuyo costo de implementación total por habitación es \$3.648 ARS, lo cual fue 2 veces menor que el MV (\$7.417 ARS), 2,4 veces menor que el EIFS ( $\$ 8.830$ ARS) y 5,78 veces menor que 
el costo de instalación de un equipo de aire acondicionado (\$21.087 ARS), que además, posee gastos de funcionamiento, mantenimiento, agrava la crisis ambiental y según Hedge (2004) propiciaría enfermedades.

Entre las tres alternativas que no lograron reducir la $T_{r}$ lo suficiente para proporcionar niveles adecuados de confort térmico como el AS, BA y RF, se destacó la alternativa de BA porque tiene la mejor relación costo-beneficio, incluso mejor que el AR. Gran parte del éxito de las soluciones como el AR, MV e incluso en el EIFS, radica en haberla incluido dentro de las estrategias que se combinaron.

Considerando todo lo anterior, en el Capítulo 9 se demostró que la implementación de soluciones de tipo pasivo con capacidad para brindar confort térmico en las VIS, tales como el AR, MV y EIFS, pueden llegar a costar hasta cinco veces menos que las soluciones activas como el aire acondicionado, esto considerando solamente los costos de instalación, los cuales no incluyen costos de funcionamiento, mantenimiento, reparación, etc.

\subsection{Respuestas a las preguntas de investigación}

¿Cuál es el desempeño térmico de algunas estrategias de enfriamiento pasivo o combinación de ellas si se implementan en las envolventes verticales opacas de las VIS de Cali en cuanto a reducción de la Tr?, ¿Cuál o cuáles poseen un mejor desempeño y que tanto influyen en la optimización del confort térmico?

Como se explicó más ampliamente en la anterior conclusión del objetivo específico 3 , mediante la experimentación, se obtuvo que el porcentaje de reducción de $T_{r}$ de las soluciones constructivas planteadas, en orden de mejor a menor desempeño, son: en primer lugar, el (AR) con 74,23\%; en segundo lugar, el MV con 73,23\%; en tercer lugar, la BA con $49,46 \%$; en cuarto lugar, el RF con $31,54 \%$ y; en quinto y último lugar, el AS con $17,75 \%$.

Igualmente, como se explicó detalladamente en la conclusión del objetivo específico 4, la simulación computacional indicó que durante la semana más calurosa del año experimentada en un dormitorio VIS, la implementación del AR logró reducir una sensación térmica "muy calurosa" a "ligeramente calurosa" y el porcentaje de insatisfechos de 95,3\% a 30,50\%.

Entendiendo que a este nivel socioeconómico el costo de la solución constructiva es muy importante ¿Cuál o cuáles estrategias de enfriamiento pasivo o combinación de ellas son más convenientes desde el punto de vista 
costo-beneficio?, ¿Cómo es este en comparación al costo de instalación de un aparato de aire acondicionado que ha sido la solución típica a este problema?

Mediante la evaluación costo-beneficio desarrollada en el Capítulo 9, se estableció que, entre las opciones analizadas, la mejor relación la obtuvo el AR, cuyo costo de implementación total por habitación fue $\$ 3.648$ ARS, lo cual equivale a 5,78 veces menos el costo de instalación de un equipo de aire acondicionado que llega a \$21.087ARS.

Incluso, otras soluciones pasivas evaluadas que tienen el mismo comportamiento térmico que el AR, tales como el MV o el EIFS que cuestan \$7.417 ARS y \$8.830 ARS respectivamente, tienen un costo menor al de un aire acondicionado.

\subsection{En relación con la hipótesis:}

Es posible optimizar el confort térmico de un ambiente típico de VIS de Cali mediante la implementación de estrategias de enfriamiento pasivo, ya sean individuales o unidas en soluciones constructivas, tales como: autosombreado (AS), baja absortividad (BA), revoque refractario + baja absortividad (RF), aislamiento reflectivo + baja absortividad (AR) y muro vegetal + baja absortividad + cámara de aire (MV); ya que tienen la capacidad de reducir la $T_{r}$ de las envolventes en más de un $\mathbf{6 0 \%}$. Con lo cual, se puede disminuir también en un $60 \%$ su PPD (porcentaje de personas insatisfechas). Adicionalmente, el costo inicial de implementar estas soluciones constructivas no es más costoso que la instalación de un equipo de aire acondicionado acorde con las necesidades de refrigeración.

El postulado general de la hipótesis se comprueba con dos de las soluciones constructivas estudiadas el: AR y el MV, cuya reducción de $T_{r}$ llegó a 74,23\% y 73,23\% respectivamente. Asimismo, los valores de reducción de PPD logrados por sendas alternativas llegó al 64,8\%. Además, se comprobó que el costo inicial de la implementación de estas dos soluciones el cual es de \$3.648 ARS y \$7.417 ARS respectivamente, no superan el valor de instalación de un equipo de aire acondicionado el cual es de \$21.087 ARS.

\subsection{Aportes realizados a la disciplina}

El presente trabajo realiza mayores contribuciones en los siguientes aspectos:

1. Provee un modelo teórico-experimental para diseñar, evaluar y comparar el desempeño térmico de tratamientos para envolventes verticales opacas, su impacto 
en la optimización del confort térmico de las edificaciones y su relación costo beneficio antes de llevar a cabo su construcción.

2. Proporciona datos experimentales de desempeño de las soluciones constructivas como porcentajes, promedios y máximas modificaciones en la $T_{r}, T_{a i r}$ y $H R$ e incluso la transmitancia térmica de los muros vegetales o del aislamiento reflectivo con varias capas, de los cuales poco se halla en la bibliografía. Esto simplifica y da seguridad al oficio de los arquitectos interesados en bioclimática y eficiencia energética, ya que pueden ser utilizados en simulaciones computacionales o cálculos numéricos de sus proyectos.

3. Propone soluciones constructivas innovadoras a bajo costo para reducir la insatisfacción térmica, lo cual es útil no solo a nivel local puntual con las VIS de Cali, sino en las edificaciones en general, pertenecientes a zonas geográficas de climas calurosos durante todo el año o parte de él.

4. Se encontró que las soluciones constructivas que integran los tres tipos de tecnologías de enfriamiento pasivo: de prevención, de modulación y de disipación del flujo de calor son más efectivas que las soluciones con un solo tipo. Esto se apoya en las comparaciones hechas en el Capítulo 6. Especialmente el caso del AR no solo logró ser más efectivo sino también más eficiente, ya que logró disminuir la $T_{\mathrm{r}}$ y optimizar el ambiente térmico a niveles confortables con menos espesor y con menos recursos económicos.

5. Se desarrolló la solución constructiva AR que combinó aislamiento reflectivo + baja absortividad, esta alternativa en 2,5 cm alcanzó la misma resistencia térmica que 3,3 $\mathrm{cm}$ de Aerogel, $7 \mathrm{~cm}$ de Poliuretano $\left(30-60 \mathrm{Kg} / \mathrm{m}^{3}\right) \circ 7,2 \mathrm{~cm}$ de EPS $\left(13 \mathrm{Kg} / \mathrm{m}^{3}\right)$, resultando también más económica.

6. En el Título 2.6.7 se mencionó que el Estado Colombiano tiene como compromiso con la COP 21 mitigar el cambio climático con políticas de eficiencia energética en las construcciones, para lo cual promulgó el Reglamento de construcción sostenible (Decreto 0549-2015).

Teniendo en cuenta lo anterior, esta investigación incentiva a que las VIS, que actualmente no están obligadas a cumplir con esta norma, sean incluidas en ella. Puesto que, en el Capítulo 2 se conoció que las VIS en Cali y en Colombia en general son casi la mitad de las viviendas que se están construyendo, pero al mismo tiempo son altamente inconfortables para los climas cálidos, (como se demostró en el Título 2.8 y el Capítulo 4) y por ende altas consumidoras de energía. De la misma manera en los Capítulos 6, 7 y 8 se demostró que existen las tecnologías a disposición para disminuir el consumo energético mediante la optimización del confort térmico. 
7. Los análisis, metodologías y hallazgos de esta investigación son de utilidad para el actual proceso de perfeccionamiento y complementación del Reglamento de Construcción Sostenible (Resolución 0549 de 2015) en el que avanza Colombia, en el cual se ordenó la reducción de consumo energético entre un $15 \%$ y $20 \%$ con relación a una Línea Base establecida con estadísticas de consumo (tema tratado en el apartado 2.6.7).

Sin embargo, la norma aún no especifica con cuales parámetros de consumo energético lograr dicho ahorro. De esta forma, lo aquí trabajado conforma los primeros pasos para cumplir dicho objetivo a través del confort térmico, con el cual pueden lograrse ahorros de hasta 59\% según lo revisado en el Capítulo 3. Con este enfoque, la metodología y las tecnologías pasivas acá estudiadas pueden formar parte de los procedimientos de cálculo y optimización de confort térmico o los anexos de propiedades térmicas de los elementos constructivos del reglamento.

\subsection{Trabajos futuros}

1. Potenciales investigaciones nacen de las variables que no fueron tenidas en cuenta para evaluar las soluciones constructivas como es el caso de la energía incorporada, el ciclo de vida y los costos económicos de mantenimiento y funcionamiento.

Asimismo, la durabilidad, la resistencia mecánica a impactos, la resistencia a las altas temperaturas e incluso al fuego no han sido evaluados y se recomienda que deben tratarse a profundidad.

2. Otro posible estudio es el de evaluar el ahorro de energía, emisiones GEl y recursos económicos proporcionados por estas tecnologías pasivas en comparación al funcionamiento de equipos de enfriamiento mecánico.

3. Frente a los buenos resultados de desempeño térmico obtenidos de la solución de aislamiento reflectivo, se espera realizar más estudios experimentales que incluyan más capas o diferentes materiales de soporte para el foil que aporten más resistencia térmica, e incluso que se elaboren desarrollos para producción de la tecnología a nivel industrial.

4. La investigación sobre la optimización del confort térmico en las VIS debería completarse con mejoras a las ventanas o a la ventilación natural, ya que aún queda un porcentaje de ocupantes por satisfacer térmicamente.

5. Este estudio debe completarse también con la evaluación de implementar las mismas soluciones constructivas, pero ubicándolas en el interior de los ambientes VIS, ya que en ocasiones es difícil el tratamiento en el exterior, e incluso en la otra tipología unifamiliar. 
6. Esta metodología podría replicarse para evaluar otras soluciones constructivas e incluso en edificaciones de otros usos.

7. Aunque el Reglamento de Construcción Sostenible (Resolución 0549 de 2015), vigente ya en Colombia no estipule como obligatorio el cumplimiento de este por parte de las VIS, una potencial investigación yace de revisar cual porcentaje de ahorro energético puede alcanzarse con estas soluciones constructivas y compararse con lo exigido en este documento.

8. De acuerdo con la revisión al Reglamento de Construcción Sostenible vigente en Colombia (Resolución 0549 de 2015) en el título 2.6.7, se notó la necesidad de complementarlo con un manual de aplicación, normalización de métodos de cálculo y anexos con las propiedades de los materiales utilizados en los sistemas constructivos colombianos. Dado que esta investigación ha tocado y debatido varios de estos temas, es deseable seguir aportando estudios para la optimización de dicha norma e incluso poder formar parte del grupo de trabajo que desarrolla estos apartados. 
APÉNDICES 


\section{GLOSARIO}

A lo largo de la revisión del estado del arte, se tratarán varios conceptos relacionados con el problema de la investigación. Es importante ahora definirlos puesto que serán conceptos determinantes de la presente investigación.

\subsection{Absortividad (as)}

De acuerdo con Santamouris \& Asimakopoulos (2001), la absortividad es la propiedad física de los materiales, que determina la cantidad de radiación solar incidente que estos pueden absorber. Para valorar esta propiedad se utiliza una escala de porcentaje con valores de 0,0 a 1,0

La absortividad depende fundamentalmente del color y el acabado de los materiales. En general, los colores claros y el blanco especialmente poseen los valores más bajos de absortividad. Así pues, la absortividad puede ser establecida en relación con radiaciones de diferentes longitudes de onda. Debido a ello, es común encontrar tres formas distintas de absortancia: la solar, la visible y la térmica.

La forma más común y la que se utilizará en esta investigación se refiere a la absortancia solar, la cual incluye el espectro visible, el infrarrojo y el ultravioleta. Se usará la absortividad para estimar la forma en que la radiación solar afecta el balance térmico de las superficies de los elementos constructivos. En la Tabla 34 se dan los valores de absortancia solar de algunos materiales utilizados en la construcción. 


\begin{tabular}{|c|c|c|}
\hline METALES & ESTADO SUPERFICIAL & ABSORTIVIDAD \\
\hline Aluminio & pulido & 0,1 \\
\hline Aluminio & anodizado & 0,14 \\
\hline Bronce & pulido & $0,3-0,5$ \\
\hline Cromo & Electroplateado & 0,41 \\
\hline Cobre & muy pulido & 0,18 \\
\hline Hierro galvanizado & pulido & 0,34 \\
\hline Hierro galvanizado & nuevo & 0,64 \\
\hline Hierro mate, & oxidado & 0,96 \\
\hline Níquel & muy pulido & 0,15 \\
\hline Acero inoxidable & pulido & 0,33 \\
\hline Zinc & pulido & 0,55 \\
\hline Asfalto pavimento & libre de polvo & 0,93 \\
\hline Asfalto pavimento & nuevo & 0,93 \\
\hline Ladrillo & rojo & 0,7 \\
\hline Ladrillo & rojo satinado oscuro & 0,77 \\
\hline Mármol & blanco & 0,44 \\
\hline Arena & & 0,76 \\
\hline Hormigón & descolorido & 0,65 \\
\hline Hormigón & sucio, oscuro & 0,71 \\
\hline Granito & & 0,45 \\
\hline Grava & & 0,29 \\
\hline Pintura aceite & blanco & $0,24-0,26$ \\
\hline Pintura aceite & crema clara & 0,3 \\
\hline Pintura aceite & verde claro & 0,5 \\
\hline Pintura aceite & gris claro & 0,75 \\
\hline Pintura aceite & negra sobre hierro galvanizado & 0,95 \\
\hline Pintura aluminio & & 0,55 \\
\hline
\end{tabular}

Tabla 34. Valor de absortividad de algunos materiales utilizados en la construcción. Fuente: Elaboración propia a partir de referencias, Incropera et al (Incropera, Dewitt, Bergman, \& Lavine, 2007).

\subsection{Actividad Física (Met).}

El cuerpo humano obtiene energía mediante la conversión química de los alimentos en el proceso metabólico, la cual disipa en forma de calor y en la elaboración de trabajos como el de caminar, comer o simplemente respirar. Esa liberación de energía depende del grado de actividad muscular y habitualmente se utiliza el Met como unidad de medida. Un 1 Met corresponde al metabolismo de una persona sentada sin hacer otra actividad. En otras unidades 1 Met equivaldría a: $58,15 \mathrm{~W} / \mathrm{m}^{2}=50 \mathrm{kcal} / \mathrm{h} \cdot \mathrm{m}^{2}$. O sea, que el Met es la relación entre la potencia térmica ( $\mathrm{W}$ o $\mathrm{kcal} / \mathrm{h}$ ) y la superficie corporal $\left(\mathrm{m}^{2}\right)$. Nótese entonces, que un adulto promedio tiene un área de $1,7 \mathrm{~m}^{2}$ y una pérdida de calor de $100 \mathrm{~W}$ al estar sentado y en confort.

El valor Met más bajo se alcanza cuando el ser humano duerme, el cual equivale a 0,8Met, mientras que los valores más altos se alcanzan desarrollando actividades deportivas con valores de 10Met o más.

La Tabla 35 tomada de Kvisgaard (1997), enseña algunos valores de Met según la actividad física. 


\begin{tabular}{|l|c|c|}
\hline Niveles Metabólicos (M) de las siguientes & W/m & Met \\
Actividades: & 46 & 0.8 \\
\hline Acostado & 58 & 1.0 \\
\hline Sentado relajado & 65 & 1.1 \\
\hline Trabajo de relojero & 70 & 1.2 \\
\hline De pié, relajado & 70 & 1.2 \\
\hline Actividad sedentaria: oficina, vivienda, escuela. & 80 & 1.4 \\
\hline Conduciendo un automóvil & 85 & 1.5 \\
\hline Profesión gráfica, encuadernador & 93 & 1.6 \\
\hline De pié, actividad ligera: comprando, industria ligera. & 95 & 1.6 \\
\hline Profesor & 100 & 1.7 \\
\hline Trabajo doméstico: afeitarse, lavarse, vestirse. & 110 & 1.9 \\
\hline Caminando horizontal 2 Km/h & 116 & 2.0 \\
\hline De pié, actividad media: vendedor, trabajo domestico. & 125 & 2.2 \\
\hline Construcción, colocando bloques de 15 Kg & 145 & 2,5 \\
\hline De pié, lavando platos & 170 & 2.9 \\
\hline Trabajo doméstico: rastrillando hojas sobre el cesped. & 170 & 2.9 \\
\hline Trabajo doméstico: lavando a mano y planchando. (120-220 W/m2) & 175 & 3.0 \\
\hline Construcción: hormigonando con un vibrador neumático & 180 & 3.1 \\
\hline Construcción: encofrando. & 200 & 3.4 \\
\hline Caminando en horizontal 5 Km/h & 205 & 3.5 \\
\hline Forestal: cortando monte con una sierra mecánica & 235 & 4.0 \\
\hline Agricultura: arando con un tiro de animales & 275 & 4.7 \\
\hline Construcción: cargando una carretilla con piedras & 360 & 6.2 \\
\hline Deporte: patinando sobre hielo 18 Km/h & 380 & 6.5 \\
\hline Agricultura: cavando con una pala (24 golpes/minuto) & 405 & 7.0 \\
\hline Deporte: esquiando en horizontal 9 Km/h & 500 & 8.6 \\
\hline Forestal: trabajando con un hacha de 2 Kg (33 golpes/minuto) & 550 & 9.5 \\
\hline Deporte: corriendo a 15 Km/h & & \\
\hline
\end{tabular}

Tabla 35. Valores Met según el tipo de actividad física. Fuente: (Kvisgaard, 1997).

\subsection{Conductividad térmica $(\mathrm{K})$}

La conductividad térmica es la cantidad de tiempo en que un flujo de calor en estado estacionario dado en $\mathrm{W}$ atraviesa un área unitaria de $1 \mathrm{~m}^{2}$ de material homogéneo de $1 \mathrm{~m}$ de espesor, en una dirección perpendicular al plano isotérmico, inducida por una diferencia de temperatura de $1^{\circ} \mathrm{K}$. La conductividad térmica, o valor $\mathrm{K}$, se expresa en $\mathrm{W} / \mathrm{m}-\mathrm{K}$ o Btu / h-ft-F o Btu-in / hrft 2-F. Cuando se tiene un valor conocido de resistencia térmica del material o la transmitancia, puede utilizarse la siguiente fórmula para encontrarla:

Conductividad térmica $=$ Espesor del material/Resistencia térmica .

Esta variable, se da en función de la temperatura media del material, la presión atmosférica y el contenido de humedad. Es la propiedad física de los materiales que mide la capacidad de transferir el calor por conducción. Por lo tanto, el conocimiento de los valores de conductividad 
térmica permite realizar comparaciones cuantitativas entre la eficacia de diferentes materiales aislantes térmicos.

Los valores de conductividad térmica de algunos materiales de construcción utilizados con frecuencia se presentan a continuación en la Tabla 36, tomados de Incropera, Dewitt, Bergman, \& Lavine (2007).

\begin{tabular}{|c|c|c|}
\hline \multicolumn{3}{|c|}{ PROPIEDADES TÉRMICAS DE ALGUNOS MATERIALES DE CONSTRUCCIÓN Y AISLANTES } \\
\hline Material & Densidad $\left(\mathrm{kg} / \mathrm{m}^{3}\right)$ & Conductividad térmica $(\mathrm{W} /(\mathrm{m} \cdot \mathrm{K}))$ \\
\hline Acero & 7850 & $47-58$ \\
\hline Agua & 1000 & 0,58 \\
\hline Aire & 1,2 & 0,026 \\
\hline Aluminio & 2700 & $209-232$ \\
\hline Arcilla refractaria & 2000 & 0,46 \\
\hline Asfalto & 2120 & $0,74-0,76$ \\
\hline Baldosas cerámicas & 1750 & 0,81 \\
\hline Bloques cerámicos & 730 & 0,37 \\
\hline Cartón & - & $0,14-0,35$ \\
\hline Cemento (duro) & - & 1,047 \\
\hline Cinc & 7140 & $106-140$ \\
\hline Corcho (tableros) & 120 & 0,042 \\
\hline Espuma de poliuretano & 40 & 0,029 \\
\hline Fibra de vidrio & 220 & 0,035 \\
\hline Hierro & 7870 & 72 \\
\hline Hormigón & 2200 & 1,4 \\
\hline Ladrillo común & 1800 & 0,8 \\
\hline Lana de vidrio & $100-200$ & $0,036-0,040$ \\
\hline Madera & 840 & 0,13 \\
\hline Mármol & 2400 & 2,09 \\
\hline Mortero de cemento & 2100 & 1,4 \\
\hline Placas de yeso & $600-1200$ & $0,29-0,58$ \\
\hline Plexiglás & 1180 & 0,195 \\
\hline Poliestireno & 1050 & 0,157 \\
\hline Porcelana & 2350 & 0,81 \\
\hline Tejas cerámicas & 1650 & 0,76 \\
\hline Vermiculita suelta & 150 & 0,08 \\
\hline Vidrio & 2700 & 0,81 \\
\hline Yeso & 1800 & 0,81 \\
\hline
\end{tabular}

Tabla 36. Valor de conductividad térmica de algunos materiales utilizados comúnmente en la construcción. Fuente: Incropera, Dewitt, Bergman, \& Lavine (2007).

\subsection{Confort Térmico}

El confort térmico es aquella condición de la mente en la cual se expresa satisfacción con el ambiente térmico. La insatisfacción puede ser causada por incomodidades de calor o frío presentadas en el cuerpo humano, ya sea total o parcialmente (International Organization for Standardization [ISO], 2005). Esta definición está basada en las investigaciones realizadas por Fanger (1970).

El autor propuso una metodología de valoración del confort térmico mediante un muestreo realizado sobre 1300 personas que calificaron el nivel de confort térmico de un ambiente 
interior, bajo diferentes combinaciones de variables. Esas variables fueron clasificadas en externas e internas. Las externas son aquellas que no dependen del individuo y están relacionadas con el clima, tales como la temperatura del aire, humedad relativa, velocidad del aire y temperatura media radiante. Por su lado, las variables internas dependen de cada persona y son la vestimenta (Clo) y la actividad física (Met). En este trabajo, se descubrió la imposibilidad de lograr un nivel satisfactorio del 100\% del grupo así se haya creado la mejor de las combinaciones. Así que, el mejor grado posible de satisfacción es del 95\%.

Para cuantificar el confort, Fanger propuso un índice denominado "Predicted Mean Vote" (PMV), o voto medio estimado, en el que toma en cuenta todos los factores vistos anteriormente y como resultado muestra la sensación térmica del recinto, esta es valorada en una escala de 7 niveles, que se explica en la Figura 138, que va desde lo Frío valorado como -3 hasta lo Muy Caluroso valorado como 3.

\begin{tabular}{ccccccc}
\hline-3 & -2 & -1 & 0 & 1 & 2 & 3 \\
Frio & Fresco & $\begin{array}{c}\text { Ligeramente } \\
\text { Fresco }\end{array}$ & Neutro & $\begin{array}{c}\text { Ligeramente } \\
\text { Caluroso }\end{array}$ & Caluroso & $\begin{array}{c}\text { Muy } \\
\text { Caluroso }\end{array}$
\end{tabular}

Figura 138. Escala de Valoración de la sensación Térmica de Fanger o PMV. Fuente http://www.ergonautas.upv.es/metodos/fanger/fanger-ayuda.php.

EI PMV se obtiene mediante la aplicación de la fórmula matemática explicada en la Tabla 37, mientras que en la Tabla 38 se explican cada uno de los términos incluidos en esta.

\begin{tabular}{|c|c|}
\hline Voto Medio Estimado & Valor \\
\hline PMV & ts $\bullet(M-W-E d-E-$ Eres - Cres $-\mathrm{R}-\mathrm{C})$ \\
\hline
\end{tabular}

Tabla 37. Formulación matemática para hallar el PMV. Fuente: (Fanger, 1970).

Donde: 


\begin{tabular}{|c|c|c|c|}
\hline Variable & Descripción & Valor & Unidades \\
\hline ts & $\begin{array}{c}\text { Coef. de transferencia de } \\
\text { sensación térmica }\end{array}$ & $0,303 \cdot \mathrm{e}^{-0,036 \mathrm{M}}+0,028$ & $\mathrm{~m} 2 / \mathrm{W}$ \\
\hline W & $\begin{array}{l}\text { Energía metabólica producida por } \\
\text { el organismo }\end{array}$ & 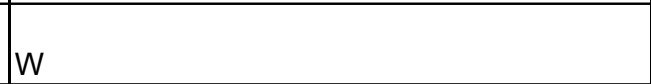 & $\mathrm{W} / \mathrm{m} 2$ \\
\hline $\mathrm{M}$ & Trabajo mecánico externo & $\mathrm{M}$ & $\mathrm{W} / \mathrm{m} 2$ \\
\hline Ed & $\begin{array}{l}\text { Pérdida de calor por difusión de } \\
\text { agua por la piel }\end{array}$ & $3,05 \cdot 10-^{3} \cdot[5733-6,99 \cdot(M-W)-p a]$ & $\mathrm{W} / \mathrm{m} 2$ \\
\hline $\mathrm{E}$ & $\begin{array}{c}\text { Pérdida de calor por } \\
\text { evaporación del sudor }\end{array}$ & $0,42 \cdot[(M-W)-58,15]$ & $\mathrm{W} / \mathrm{m} 2$ \\
\hline Eres & $\begin{array}{l}\text { Pérdida de calor latente por } \\
\text { respiración }\end{array}$ & $1,7 \cdot 10^{-5} \cdot M \cdot(5867-p a)$ & $\mathrm{W} / \mathrm{m} 2$ \\
\hline Cres & $\begin{array}{l}\text { Pérdida de calor sensible } \\
\text { por respiración }\end{array}$ & $0,0014 \cdot \mathrm{M} \cdot(34-\mathrm{ta})$ & $\mathrm{W} / \mathrm{m} 2$ \\
\hline $\mathrm{R}$ & $\begin{array}{l}\text { Pérdida de calor por } \\
\text { radiación }\end{array}$ & $3,96 \cdot 10^{-8} \cdot$ fclo $\cdot\left[(\text { tclo }+273)^{4}-(\text { TRM }+273)^{4}\right]$ & $\mathrm{W} / \mathrm{m} 2$ \\
\hline C & $\begin{array}{c}\text { Pérdida de calor por } \\
\text { convección }\end{array}$ & $\mathrm{fclo} \cdot \mathrm{hc} \cdot($ tclo $-\mathrm{ta})$ & $\mathrm{W} / \mathrm{m} 2$ \\
\hline
\end{tabular}

Tabla 38. Explicación matemática de los términos utilizados en la ecuación de PMV. Fuente: (Fanger, 1970).

Además, el autor desarrolló un índice para estimar el porcentaje de personas insatisfechas debido a la sensación térmica experimentada denominado Predicted Percentage of Dissatisfied (PPD) que va a la par con el índice PMV. EI PPD se da en porcentaje, y se puede obtener con la escala de la Tabla 39 o con la fórmula matemática de la Tabla 40.

\begin{tabular}{|c|c|c|}
\hline \multicolumn{3}{|c|}{ ESCALA DE SENSACIÓN TÉRMICA } \\
\hline PMV & PPD & SENSACIÓN \\
\hline+3 & $99 \%$ & Muy Caluroso \\
\hline+2 & $77 \%$ & Caluroso \\
\hline+1 & $26 \%$ & Ligeramente Caluroso \\
\hline+0 & $5 \%$ & Confort (Neutro) \\
\hline-1 & $26 \%$ & Ligeramente Frío \\
\hline-2 & $77 \%$ & Frío \\
\hline-3 & $99 \%$ & Muy Frío \\
\hline
\end{tabular}

Tabla 39. Escala de Sensación Térmica, PMV y PPD. Fuente: (Fanger, 1970).

\begin{tabular}{|c|cc|}
\hline Porcentaje de Insatisfechos & Valor (\%) \\
\hline PPD & $100-95 \cdot \mathrm{e}^{-\left(0,03353 \cdot \mathrm{PMV}^{\wedge} 4+0,2179 \bullet \mathrm{PMV}^{\wedge} 2\right)}$ \\
\hline
\end{tabular}

Tabla 40. Formulación matemática del índice PPD. Fuente: (Fanger, 1970). 


\subsection{Emisividad}

La emisividad es la proporción de radiación térmica emitida por una superficie o cuerpo debido a su calor. Se mide mediante un coeficiente adimensional que va de 0 a 1 , de esta manera se puede conocer la capacidad de un material para emitir energía en forma de radiación.

Para cuantificar la emisividad de los materiales se idealizó el concepto de cuerpo negro, que se basa en imaginar un cuerpo que absorbe toda la luz y toda la radiación que inciden sobre él. De esta manera el coeficiente de emisividad relaciona la habilidad de un objeto real para irradiar energía térmica, con la habilidad de irradiar si éste fuera un cuerpo negro.

$$
\varepsilon=\frac{\text { radiación emitida por una superficie }}{\text { radiación emitida si fuera cuerpo negro }}
$$

Por consiguiente, un cuerpo negro tiene un coeficiente $\varepsilon$ de 1 , mientras que un cuerpo real siempre tendrá coeficientes $\varepsilon$ menores a 1 . Algunos coeficientes de emisividad de algunos materiales ya estudiados pueden encontrarse en la siguiente Tabla 41, tomada de ASHRAE (2013).

\begin{tabular}{|c|c|}
\hline \multicolumn{2}{|c|}{ EMISIVIDADES DE ALGUNOS MATERIALES } \\
\hline MATERIAL & $\varepsilon$ \\
\hline Aluminio 98\% puro & 0.04 \\
\hline Aluminio comercial & 0.09 \\
\hline Aluminio oxidado & 0.2 \\
\hline Asbesto & 0.96 \\
\hline Asfalto & 0.93 \\
\hline Hormigón & 0.93 \\
\hline Hierro esmerilado & 0.24 \\
\hline Mármol blanco & 0.95 \\
\hline Pintura Negra mate & 0.97 \\
\hline Plásticos (PET, PVC) & 0.94 \\
\hline Pinturas no metálicas, no negras & 0.82 \\
\hline Yeso & 0.90 \\
\hline Vidrio & 0.94 \\
\hline
\end{tabular}

Tabla 41. Emisividad de algunos materiales. Fuente: (American Society of Heating Refrigerating and Airconditioning engineers [ASHRAE], 2001) 


\subsection{Geometría Solar}

La geometría solar es la forma de comprender los fenómenos astronómicos relacionados con el movimiento de la tierra alrededor del sol. Con estos conocimientos es posible calcular la posición del disco solar en la bóveda celeste y encontrar su ángulo de incidencia en las diferentes fachadas de los edificios.

La distribución de la radiación solar sobre la superficie de la tierra está determinada por los dos movimientos principales que realiza la tierra: el de traslación alrededor del sol y el de rotación en torno a su propio eje.

En el movimiento de traslación, la tierra se mueve en torno al Sol trazando una órbita elíptica, un ciclo de traslación completo en esta elipse tarda 365,25 días (un año).

El plano formado por la elipse, denominado eclíptica, es casi circular, ya que su excentricidad es tan solo del $3 \%$, el sentido de la traslación es contrario a las manecillas del reloj si se mira desde el Norte y el Sol se sitúa en uno de los focos de la elipse.

El segundo movimiento es la rotación de la Tierra en torno a su eje Norte-Sur, cuyo giro completo dura 24 horas. Si se mira nuevamente desde el Norte, el sentido del giro es también contrario al de las manecillas del reloj. Un resumen gráfico de lo expuesto anteriormente se observa en la Figura 139.

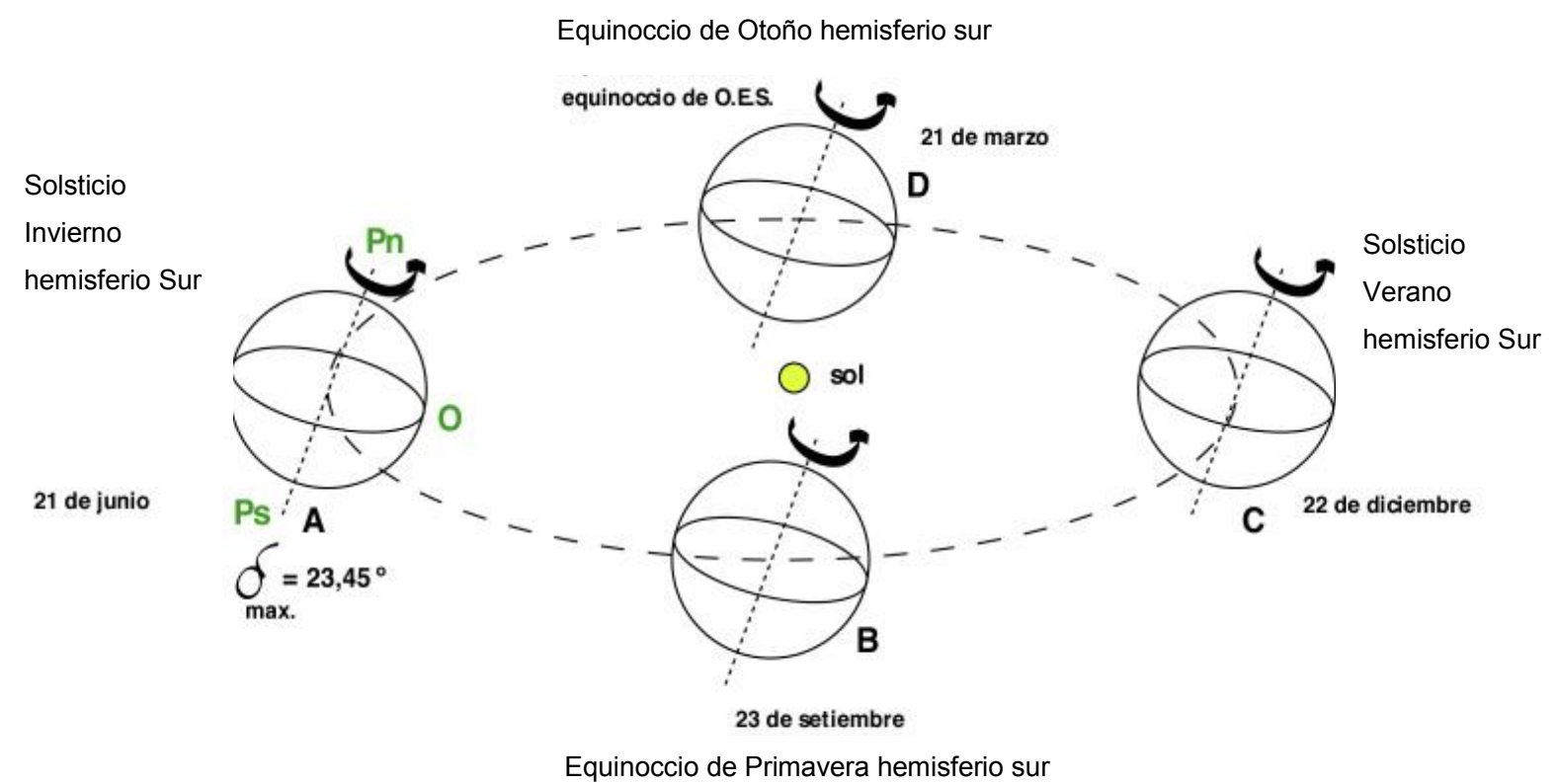

Figura 139. Movimientos principales de la Tierra: Traslación y Rotación. Fuente: (El rincón del vago, 2018) 
El eje Norte-Sur está inclinado $23.45^{\circ}$ en relación con el plano de la eclíptica, como consecuencia el plano Ecuatorial y el plano de la eclíptica difieren a lo largo del año ocasionando las estaciones y los periodos de día y noche. Este ángulo denominado declinación, es nulo en los Equinoccios (21 de marzo y 21 de septiembre), es positivo en el Solsticio de Verano, +23.45 (21 de junio) y negativo en el Solsticio de Invierno, -23.45 (21 de diciembre).

Al existir esta declinación, la radiación solar no es uniforme en el planeta a lo largo del año, las zonas cercanas a la línea ecuatorial cuya perpendicularidad con los rayos del sol es mayor suelen estar más irradiadas que el resto, ocasionando un gradiente de temperaturas que se extiende desde el Ecuador hacia los Polos.

El fenómeno explicado anteriormente visto por un observador sobre un punto de un plano horizontal tangente a la superficie terrestre se corrobora, ya que lo que percibe el observador es que el Sol, la Luna y todos los demás cuerpos celestes aparecen por el Este y desaparecen por el Oeste describiendo un arco en la bóveda celeste. A esta percepción se le denomina movimiento aparente del sol y se explica gráficamente en la Figura 140, que enseña el recorrido que hace el sol en una latitud del hemisferio norte en la estación de otoño.

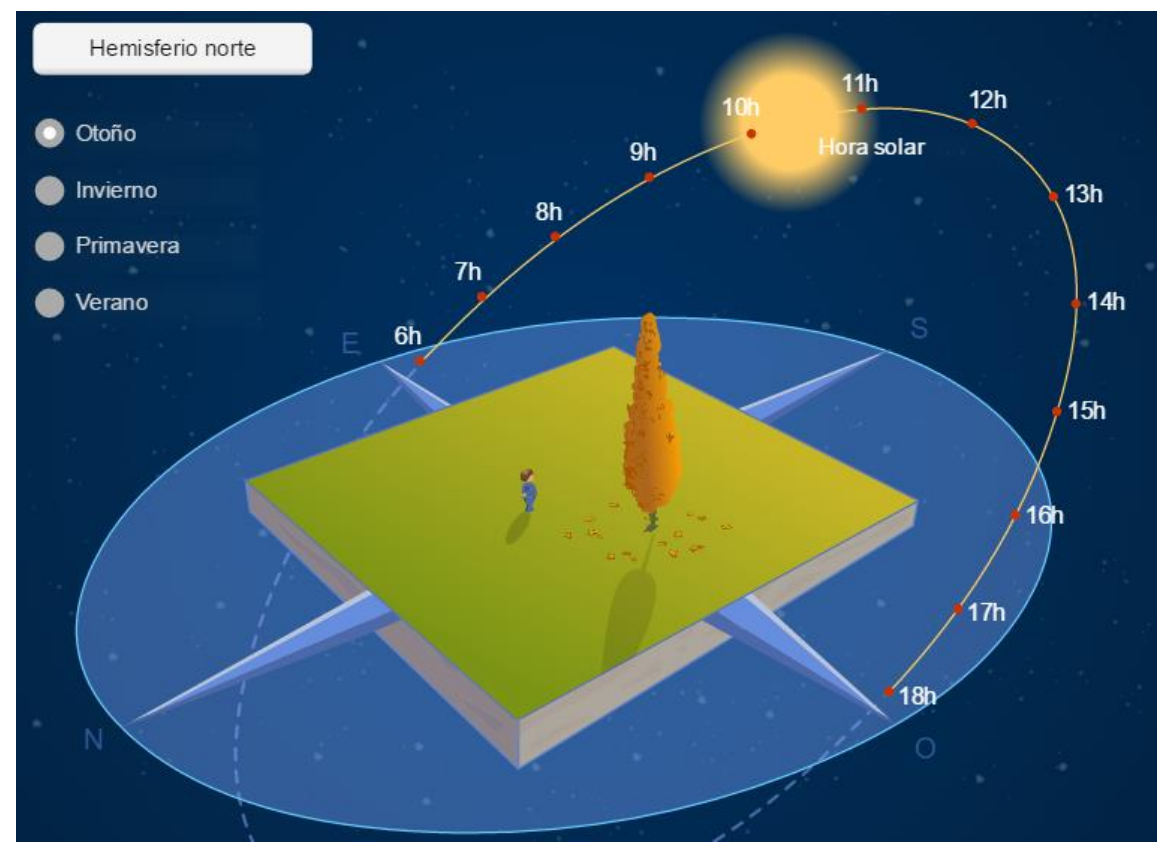

Figura 140. Descripción gráfica del arco descrito por el movimiento aparente del sol en el hemisferio norte en la estación de otoño. Fuente: (Edumedia, 2018) 
Posición Solar: En Arquitectura, al igual que en otros campos del conocimiento, conocer la ubicación del disco solar en la bóveda celeste es muy importante, bien sea para el aprovechamiento de la energía proveniente de él o por el contrario para impedir su incidencia. Para determinar la posición del Sol, se determina un plano de referencia tangente a la superficie terrestre en cualquier punto que se desee analizar, al cual se traslada el centro de la esfera celeste como lo indica la siguiente Figura 141.

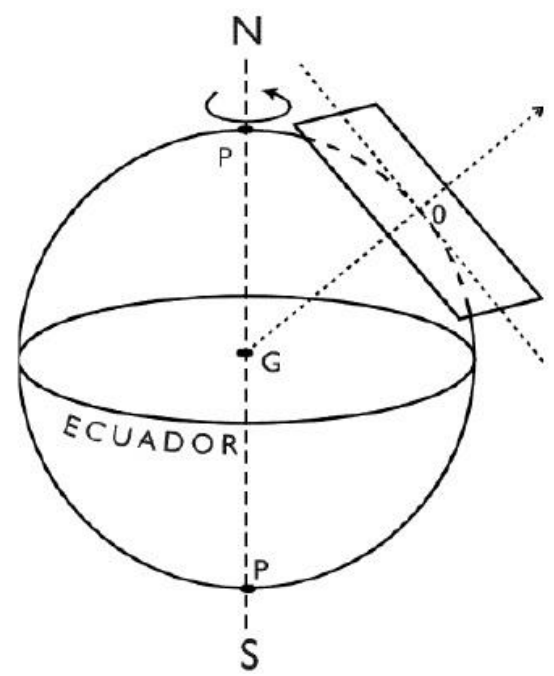

Figura 141. Plano horizontal tangente a la superficie terrestre. Fuente (Mercader, 2018)

Teniendo como referencia esta superficie horizontal, la posición solar se determinará por dos coordenadas o ángulos: el acimut y la altura solar.

El acimut $\alpha$ es el ángulo medido en el plano horizontal, formado entre el plano vertical que pasa por el Sol y la línea del meridiano del lugar (Línea Norte-Sur). El acimut se mide teniendo como origen dicho meridiano y se considera de magnitud positiva el sentido hacia el Este y negativo hacia el Oeste.

Por su parte la altura solar h, se mide sobre el plano vertical, es el ángulo formado por el rayo solar dirigido al centro de la bóveda celeste y el plano de referencia horizontal.

En la siguiente Figura 142, se pueden identificar cada uno de estos ángulos. 


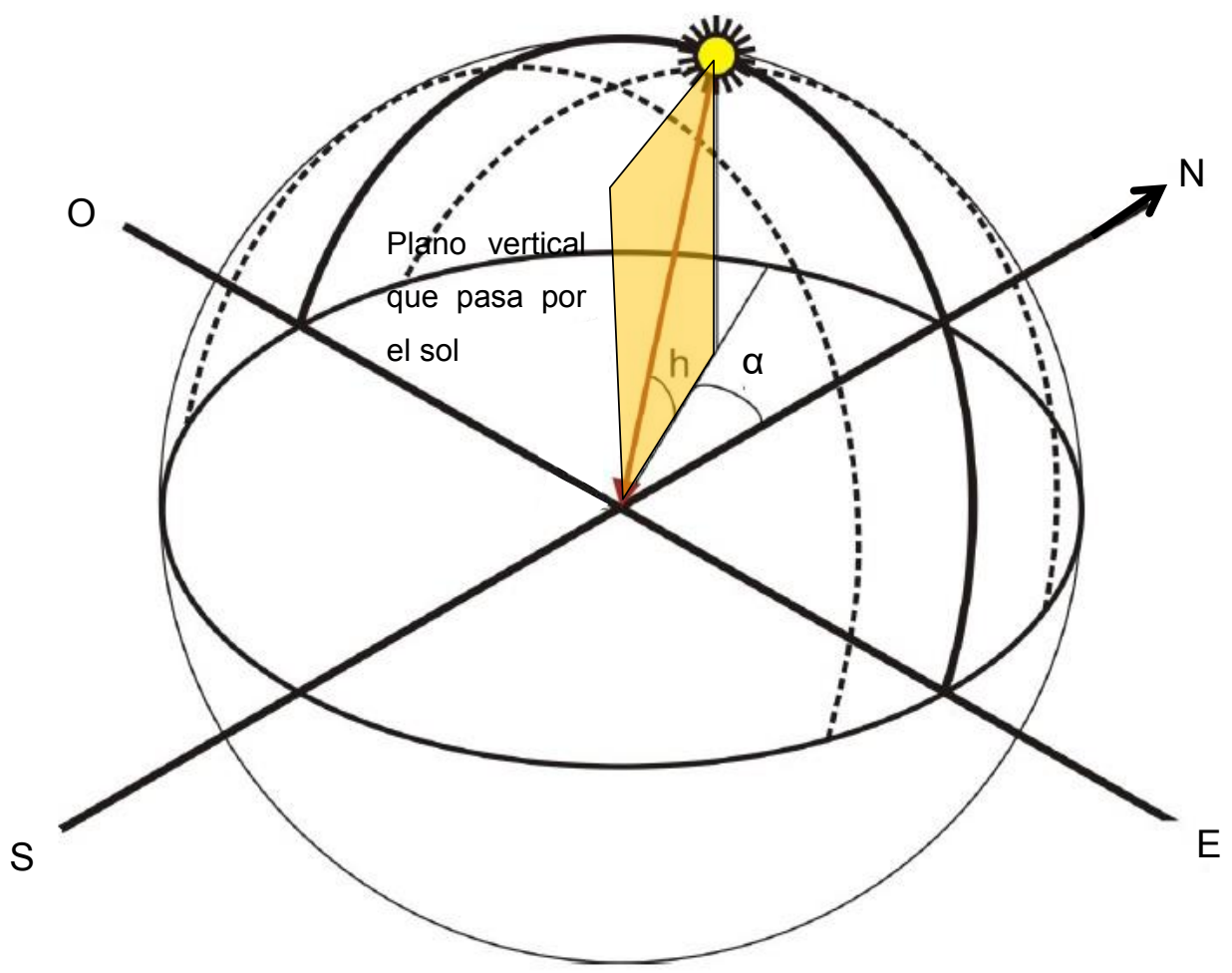

Figura 142. Coordenadas solares acimut $\alpha$ y altura solar h. Fuente: Elaboración propia.

Métodos para cálculo de la posición solar: Se conocen tres métodos para calcular la posición solar y analizar el comportamiento de este frente a la Arquitectura. El primero de ellos es el método matemático, el segundo es el método gráfico y el tercero es el método físico de simulación.

Método Matemático: Es el método que brinda información más precisa para determinar las coordenadas solares. Para ello se necesita la ubicación geográfica del sitio a analizar, su Latitud y Longitud. Igualmente es necesario definir el día (n) y la hora solar en la cual nos interesa conocer la posición solar.

Para efectos del cálculo, la hora solar deberá convertirse a grados. Esto se hace desde la posición del medio día a la del meridiano celeste. El ángulo horario $(\tau)$ a las $12: 00 \mathrm{~h}$ es $00.00^{\circ}$. $1^{\circ}$ equivale a 4 minutos y $15^{\circ}$ son 60 minutos.

Para el tiempo AM, el ángulo horario es positivo y PM negativo.

Así pues:

$\tau=(12$-hora $) 15$

El primer paso es calcular la declinación $(\partial)$, la cual puede obtenerse a partir de la Ecuación de Cooper:

$\partial=23.45^{\circ}$ sen $(360((284+n) / 365))$

Donde $\mathrm{n}$ es el número del día consecutivo del año.

Las coordenadas Altura Solar $(h)$ y Acimut $(\alpha)$ se obtienen con las siguientes ecuaciones: 
$\mathrm{h}=\operatorname{sen}^{-1}\left(\cos\right.$ Latitud $\left.^{*} \cos \partial * \cos \tau\right)+\left(\operatorname{sen}\right.$ Latitud $\left.^{*} \operatorname{sen} \partial\right)$

$\alpha=\cos ^{-1}\left(\operatorname{sen} h^{*} \operatorname{sen}\right.$ Latitud $\left.-\operatorname{sen} \partial\right) /\left(\cos h{ }^{*} \cos\right.$ Latitud $)$

Métodos gráficos: A pesar de no ser tan exactos como los métodos matemáticos, su utilización es confiable, rápida, clara y fácilmente aplicable para cuestiones de diseño arquitectónico. Los métodos más comunes son las cartas solares, que representan sobre un plano, las trayectorias aparentes del sol, vistas desde un punto de la superficie terrestre. La construcción de estas cartas solares se basa en la proyección cónica o cilíndrica de dichas trayectorias solares en la bóveda celeste sobre una superficie plana.

En las cartas se puede leer el día, la hora solar, la altura solar y el acimut del Sol durante todo el año. Los tipos de cartas más usadas son: la estereográfica, la ortográfica esférica y la ortográfica cilíndrica. Una carta solar estereográfica para la ciudad de Cali se muestra a continuación en la Figura 143.

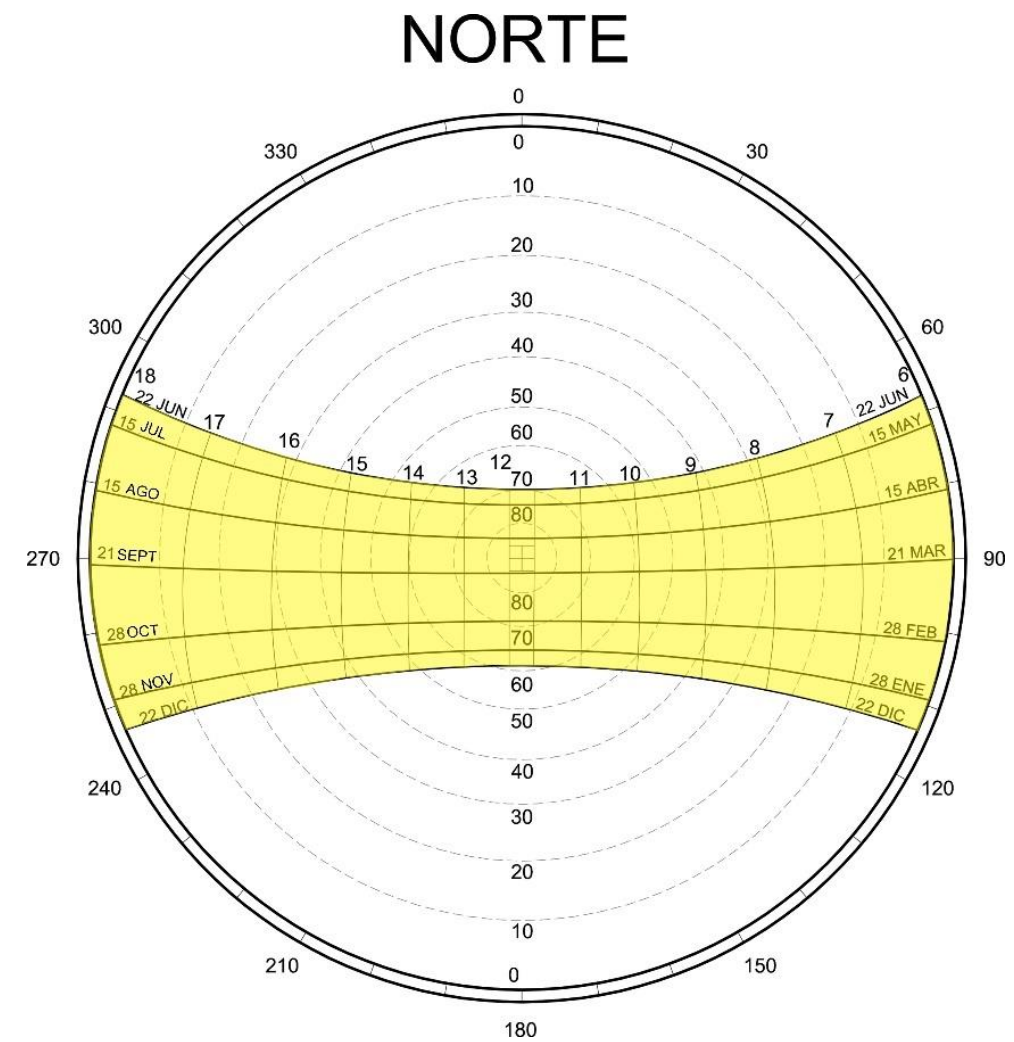

Figura 143. Carta solar estereográfica para Cali. Fuente: Elaboración propia. 
Métodos Físicos: Este tercer método de cálculo de la posición solar se vale de medios físicos, tales como maquetas, heliodones, gnómones y lámparas para únicamente dar una visión cualitativa del comportamiento del edificio u objeto analizado frente al asoleamiento. Entre los más conocidos están: La proyección gnomónica y los heliodones o máquinas solares.

\subsection{Humedad relativa (HR)}

Esta variable es una forma de medir la humedad ambiental, la cual se define como la cantidad de vapor de agua presente en el aire. Así mismo, la HR, es la relación porcentual entre la cantidad de vapor de agua real que contiene el aire y la que necesitaría contener para saturarse a idéntica temperatura y presión atmosférica.

Por ejemplo, una HR del $38 \%$ quiere decir que de la totalidad de vapor de agua (el 100\%) que podría tener el aire a determinada temperatura y presión atmosférica, tan solo tiene el $38 \%$.

La HR es importante porque "todos los animales precisan la conservación de la humedad para vivir, puesto que sus cuerpos están constituidos por cerca de un $85 \%$ de agua. Los cuerpos tienden a conservar humedad o perderla de acuerdo con la concentración de esta en el aire" (Harold Borrero, 1989).

Según la escala de sensación térmica del ASHRAE (ASHRAE, 2013), la HR en niveles del $50 \%$ al $70 \%$, permite la pérdida de calor fácilmente en climas cálidos mediante el intercambio de calor por sudoración, logrando un mayor grado de satisfacción entre las personas.

\subsection{Máscara de sombras}

El método de máscara de sombras se utiliza para representar los periodos de sombra que uno o varios dispositivos de protección solar son capaces de generar. Los periodos de sombra son representados mediante un sombreado en la carta solar.

En la siguiente Figura 144 tomada de De la Peña \& Quintero (2011), se presenta al lado izquierdo la carta solar para la ciudad de La Habana, Cuba. En esta carta solar se rellena la mitad de la cúpula celeste perteneciente al hemisferio Sur, esto indica que se desprecia dicha información ya que se va a analizar la fachada norte. En el esquema central se presenta la planta de un recinto al que se agregan dos elementos verticales de protección solar en su fachada Norte.

La representación a la derecha, indica los meses y horas en los que los dos elementos verticales pueden brindar sombra mediante el traslado del ángulo Beta a la carta solar. 


\section{Fachada Norte}

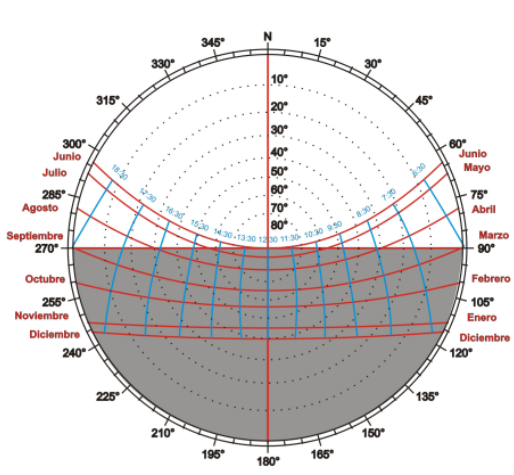

Horas y meses que recibe sol la fachada sin protección.

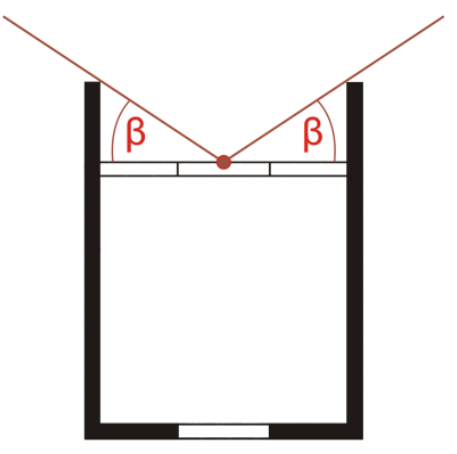

Esquema en planta de los elementos de protección sola verticales.

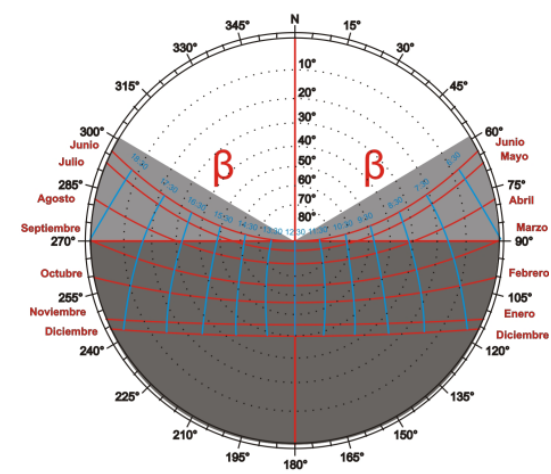

Protección solar de los elementos verticales de dimensiones aproximadas adosados a la fachada. según ángulo $\beta$

Figura 144. Procedimiento para calcular la sombra de elementos de protección solar (verticales en este caso) utilizando el método de la máscara de sombras en la carta solar. Fuente: (De la Peña González \& Quintero Díaz, 2011).

\subsection{Reflectancia solar o reflectividad}

La reflectancia solar es la fracción de la energía solar incidente que es reflejada por la superficie en cuestión, o sea que es una propiedad física de las superficies que indica la capacidad de reflejar o absorber la radiación solar.

En temas térmicos esta propiedad se mide mediante un índice llamado índice de reflectancia solar IRS (SRI en inglés) que se da en una escala de 0 a 100 o porcentaje, siendo $0(0.0)$ el valor que más absorbe e irradia calor y 100 (1.0) lo más reflectivo. De esta manera, un valor de 0 lo posee una superficie de color negro, mientras que el valor de 100 lo posee un techo tratado con pintura blanca reflectiva. En términos prácticos, bajo las mismas condiciones de brillo solar, la superficie negra se calienta mucho, mientras que la superficie blanca se calienta menos.

\subsection{Resistencia térmica $(R)$}

La resistencia térmica $(R)$ de un material es la capacidad que tiene dicho material de oponerse al flujo de calor como resultado de suprimir la transferencia por conducción, convección o radiación. Es el inverso de la conductividad térmica del material, en función de su espesor y densidad. El valor $\mathrm{R}$ se expresa en $\mathrm{m}^{2 \circ} \mathrm{K} / \mathrm{W}$ o h-ft2-F/Btu. 


\subsection{Temperatura del Aire $\left(T_{\text {air }}\right)$}

Según Ledesma (2011), la $T_{\text {air }}$ representa la cantidad de calor que lleva consigo el aire; para medirlo se utiliza el termómetro y la escala más utilizada es la Celsius expresada en grados $\left({ }^{\circ} \mathrm{C}\right)$. Aunque en el sistema internacional la unidad son los grados Kelvin, que asocia el valor $0^{\circ}$ al cero absoluto.

El ser humano puede tolerar temperaturas del aire entre los $0^{\circ} \mathrm{C}$ y los $50^{\circ} \mathrm{C}$, sin embargo, en estos límites ya puede producirse congelamiento o desmayos respectivamente. Los rangos de confort, más comunes internacionalmente están entre $22{ }^{\circ} \mathrm{C}$ a $28^{\circ} \mathrm{C}$ (American Society of Heating Refrigerating and Air Conditioned Engineers [ASHRAE], 2017). Sin embargo, según otros estudios desarrollados por Olgyay, Givoni y Serrá Op. cit., los rangos de confort de la $\mathrm{T}_{\text {air }}$ para verano o para climas cálidos se encuentra entre los $22^{\circ} \mathrm{C}$ y $29.5^{\circ} \mathrm{C}$.

\subsection{Temperatura media radiante $\left(T_{\mathrm{mr}}\right)$}

Según Kántor \& János (2011), este término se define como la temperatura uniforme de un recinto negro imaginario, que tuviera la misma transferencia de calor por radiación hacia la persona que el recinto real. También puede considerarse burdamente como el promedio de las temperaturas de los alrededores teniendo en cuenta el factor de vista y las emisividades $(\varepsilon)$ de cada superficie (Gamboa, Rosillo, Herrera Cáceres, López Bernal, \& Iglesias, 2011).

Para Dittmar (1995), la $T_{m r}$ ha sido bastante ignorada, aunque la influencia de la radiación en el confort térmico puede llegar a ser el valor más determinante. Paradójicamente, una persona puede tener una sensación de frío en un ambiente a $48^{\circ} \mathrm{C}$ si las temperaturas de las paredes que lo rodean son suficientemente bajas, mientras que en un ambiente a $10^{\circ} \mathrm{C}$ puede sentirse sofocada si las paredes alcanzan temperaturas altas.

Para Kántor \& János Op. cit., la $T_{m r}$ es la variable más difícil de calcular dentro de las requeridas para evaluar el confort térmico, pues depende de otros valores no constantes como el factor de forma y la emisividad de las superficies.

Aun así, expresa Walikewitz (2015) que la $\mathrm{T}_{\mathrm{mr}}$ es requerida para utilizar varios de los métodos de evaluación de confort térmico más utilizados, como por ejemplo el UTCI (Universal Thermal Climate Index), el PT (Percieved Temperature), el PMV (Predicted Mean Vote), y el PET (Physiologically Equivalent Temperature).

Factor de forma $(f p)$ : Se han desarrollado diversas ecuaciones para hallar el factor de forma (o de vista) como las propuestas por Duran Peralta \& Mesa (2006) y Dunkle (1963). Este factor 
es calculado en relación con la superficie del cuerpo humano. Dunkle propone dos ecuaciones que dependen del tipo de superficie (vertical u horizontal) y de la distancia al observador. Para superficies verticales:

$$
\mathrm{F}_{1-2}=0,07952 \tan ^{-1} \frac{Y Z}{A}+/-0,0130\left[\frac{Y}{B}-\frac{Y}{A C}\right]+/-0,005\left[\frac{Y}{B} \tan ^{-1} \frac{Z}{B}+\frac{Z}{C} \tan ^{-1} \frac{Y}{C}\right]
$$

Donde:

$Y=y / x$

$B=z / x$

$C=\left(1+Z^{2}\right)^{1 / 2}$

$A=\left(1+Y^{2}+Z^{2}\right)^{1 / 2}$

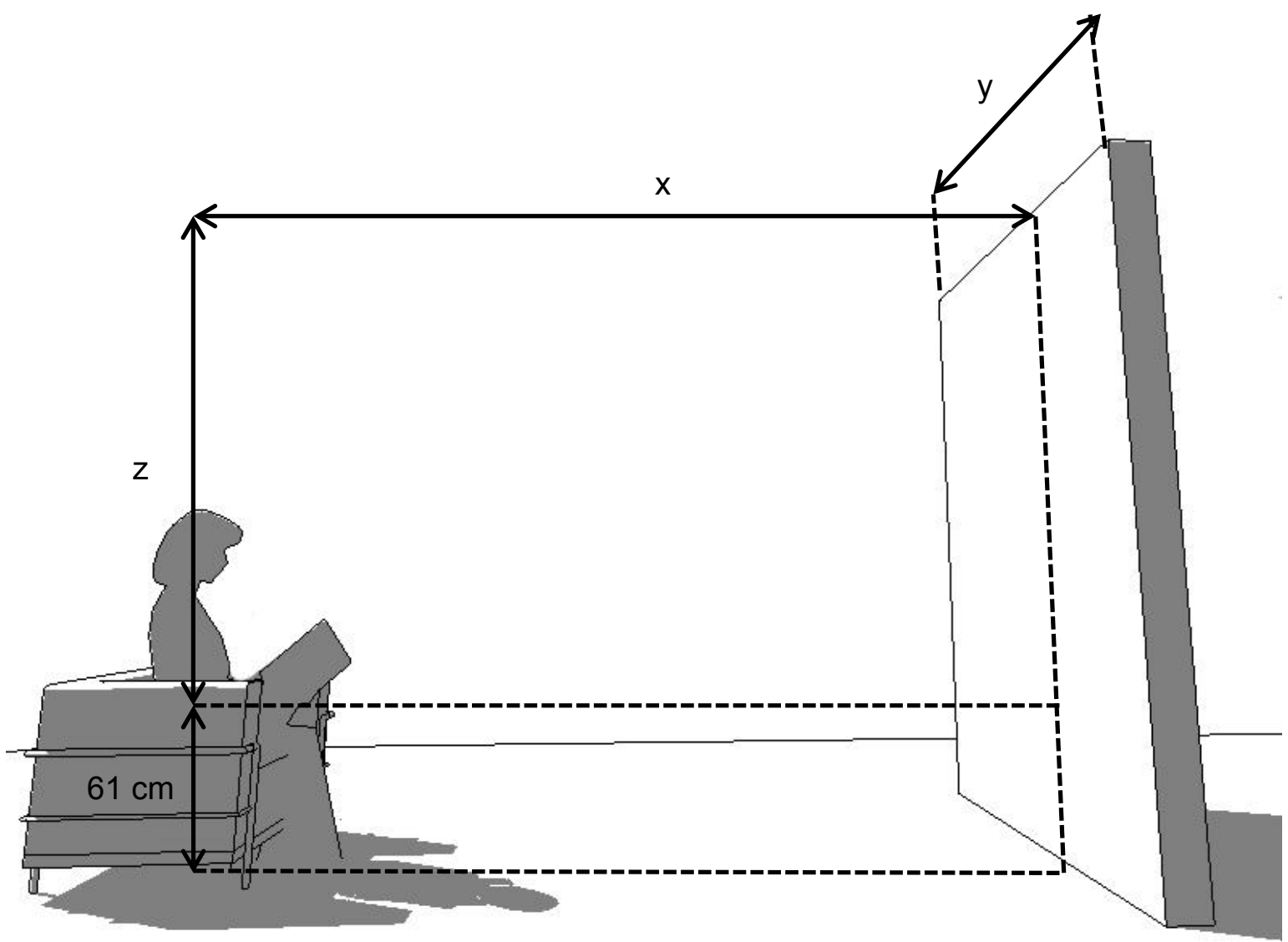

Figura 145. Gráfico de las diferentes distancias utilizadas en la ecuación de factor de forma para superficies verticales de Dunkle. Fuente: Creación propia a partir de referencias. (Dunkle R. V., 1963)

Y para superficies horizontales:

$$
\mathrm{F}_{1-2}=0,07952 \tan ^{-1} \frac{X Y}{A}+/-0,0130\left[\frac{Y}{\left(1+Y^{2}\right)^{1 / 2}}-\frac{Y}{A\left(1+X^{2}\right)}\right]+/-0,005\left[\tan ^{-1} Y-\frac{1}{X} \tan ^{-1} \frac{Y}{|X|}\right]
$$


Donde:

$X=x / z$

$\mathrm{Y}=\mathrm{y} / \mathrm{z}$

$A=\left(1+X^{2}+Y^{2}\right)^{2}$

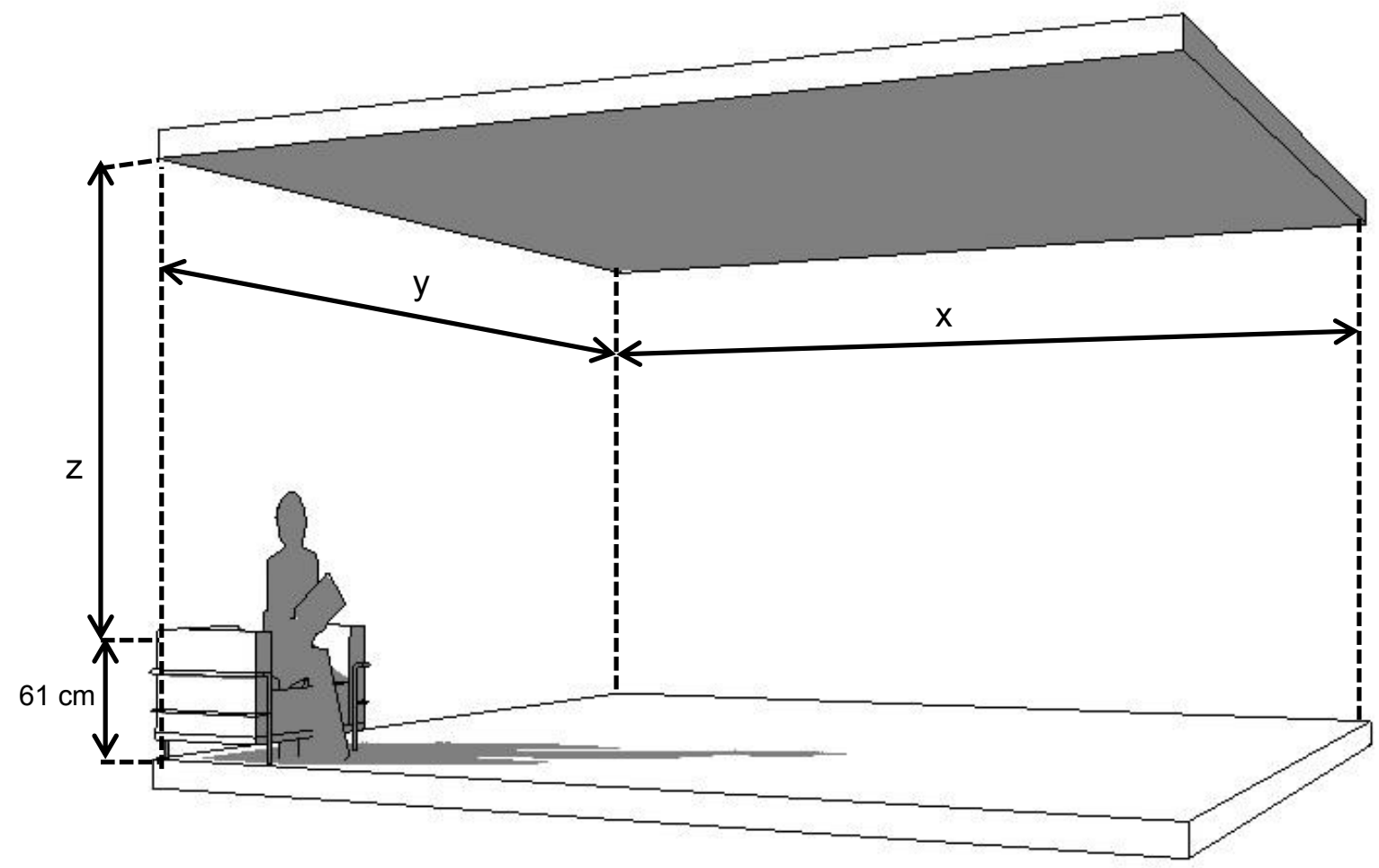

Figura 146. Gráfico de las diferentes distancias utilizadas en la ecuación de factor de forma para superficies horizontales de Dunkle. Fuente: Creación propia a partir de referencias (Dunkle R. , 1963).

Finalmente, teniendo calculado la $T_{r}$, el factor de forma y conocer la emisividad de las superficies, es posible reemplazar dichas variables en la siguiente fórmula para hallar $T_{\mathrm{mr}}$.

$$
\mathrm{T}_{\mathrm{mr}}=\left[\sqrt[4]{\sum_{n} f p \varepsilon(t i+273,15)^{4}}\right]-273,15
$$

Donde:

$t i=$ Temperatura de la superficie $i e n{ }^{\circ} \mathrm{C}$.

$f p=$ es el factor de vista entre la esfera y la superficie $i$

$\varepsilon=$ Emisividad del material. 
A pesar de que los niveles de bienestar óptimos para la $T_{m r}$ no están estrictamente definidos, Fanger y la ASHRAE Op. cit., recomiendan que no difieran de lo establecido para la $\mathrm{T}_{\text {air. }}$ Por lo tanto, para estos, el rango está entre $22^{\circ} \mathrm{C}$ y $28^{\circ} \mathrm{C}$. En contraste, para Olgyay, Givoni, Serrá y Blender Op. cit., el rango para condiciones de verano o climas cálidos se encuentra entre los $22^{\circ} \mathrm{C}$ y $29,5^{\circ} \mathrm{C}$. Esto también concuerda con el gráfico de la Figura 147 propuesto por Blender (2015), donde enmarca las zonas de confort térmico en función de la relación $\mathrm{T}_{\text {air }} \mathrm{Y}$ $\mathrm{T}_{\mathrm{mr}}$.

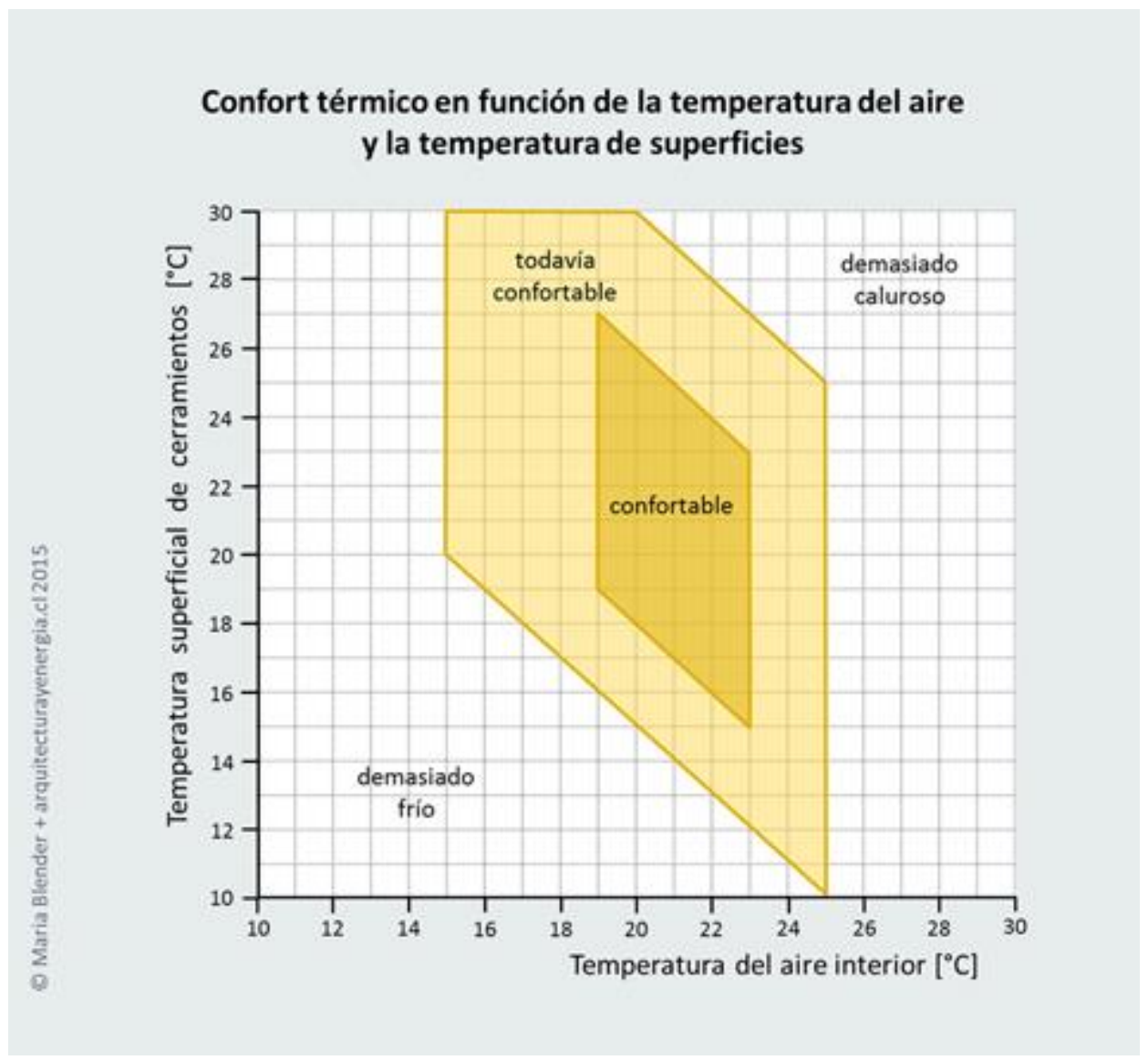

Figura 147. Gráfico de confort térmico en función de la $T_{\text {air }}$ y la $T_{m r}$. Fuente: (Blender, 2015).

\subsection{Temperatura radiante $\left(T_{r}\right)$}

Para el campo de estudio de la construcción, según Cengel (2003), la $T_{r}$ es la temperatura de la superficie interior de la envolvente de un edificio después de haber pasado el proceso de intercambio de calor por radiación, convección y conducción.

Asumiendo un estado estacionario y una pared expuesta al sol, la $T_{r}$ de dicha pared puede hallarse mediante el siguiente cálculo.

Inicialmente, el efecto de la radiación solar es tenido en cuenta al asignarle a la cara exterior de la pared una temperatura equivalente a la misma tasa de calor que podría transferirse por la combinación de la incidencia de la radiación solar, la convección del aire exterior y la 
radiación del cielo y los alrededores. A dicha temperatura se le denomina Temperatura SolAire ( $T_{\text {sol-air }}$. Así pues, el flujo de calor de la pared influenciada por la radiación solar puede expresarse como:

$Q_{\text {pared }}=Q_{\text {convección }}+$ Radiación $+Q_{\text {solar }}-Q_{\text {Corrección por radiación }}$

$Q_{\text {pared }}=h_{0} A\left(T_{\text {ambiente }}-T_{\text {superficie }}\right)+\alpha_{s} A q_{\text {solar }}-\varepsilon A \sigma\left(T_{\text {ambiente }}{ }^{4}-T_{\text {alrededores }}{ }^{4}\right)$

$Q_{\text {pared }}=h_{\circ} A\left(T_{\text {sol-aire }}-T_{\text {superficie }}\right)$

Donde:

$\mathrm{Q}_{\text {pared }}=$ Carga térmica de la pared en $\mathrm{W}$

$h_{0}=$ Coeficiente de transferencia de calor combinado de radiación y convección

$A=$ Área de la superficie

$q_{\text {solar }}=$ Radiación solar incidente sobre la superficie en $\mathrm{w} / \mathrm{m} 2$

$\alpha_{s}=$ Absortividad de la superficie.

$\varepsilon=$ Emisividad de la superficie.

$\sigma=$ Constante de Stefan Boltzmann

$\mathrm{T}_{\text {sol-aire }}=$ Tambiente $+\frac{\alpha \mathrm{s} * \mathrm{qsolar}}{\mathrm{ho}}-\frac{\varepsilon * \sigma\left(\text { Tambiente }^{4}-\text { Talrededores }^{4}\right)}{\text { ho }}$

El primer término de la ecuación anterior representa la transferencia de calor a la superficie cuando la temperatura ambiente y la temperatura de los alrededores es igual a la temperatura del aire: $T_{\text {ambiente }}=\mathrm{T}_{\text {alrededores }}$ Sin embargo, cuando estas difieren debe considerarse corregir la transferencia de calor por radiación con el último término de la ecuación. Este efecto de radiación tiene un rango que puede ir desde $0^{\circ} \mathrm{C}$ para superficies verticales como una pared o hasta $4^{\circ} \mathrm{C}$ para superficies totalmente horizontales. Esta diferencia se debe a la disminución de la temperatura efectiva del cielo.

Una vez que la temperatura sol-aire es hallada, solo resta encontrarla transferencia de calor por conducción a través de la pared, con la siguiente ecuación:

$$
Q_{\text {pared }}=U A\left(T_{\text {sol-aire }}-T_{\text {interior }}\right)
$$

Donde:

$\mathrm{U}=$ Coeficiente total de transferencia de calor de la pared

Una vez encontrada la carga térmica de la pared, la $T_{r}$ puede encontrarse con la siguiente ecuación:

$$
\mathrm{T}_{\mathrm{r}}=\frac{Q \text { pared } * R}{A}+\mathrm{T} \text { Aire interior }
$$




\subsection{Transferencia de Calor}

Yáñez (2008), explica que la parte de la física que se encarga de estudiar la transferencia de calor es la termodinámica, la cual considera el calor como energía. La termodinámica se fundamenta principalmente en dos leyes:

Primera Ley: La energía no se crea ni se destruye, únicamente se transforma.

Segunda Ley: La energía calorífica se transfiere espontáneamente solo en una dirección: del cuerpo más caliente al más frío.

La transferencia de calor estudia el desequilibrio térmico y el flujo de calor entre cuerpos, se entiende por flujo de calor (q) a la cantidad de calor, por unidad de tiempo que pasa a través de una superficie y se mide en Joules por segundo $(\mathrm{J} / \mathrm{s})$, que es igual a Watts $(\mathrm{W})$. Al conocer las dimensiones de dicha superficie es posible encontrar la densidad de flujo (q/Área) que se mide en $\mathrm{W} / \mathrm{m}^{2}$.

La transferencia de calor solamente sucede a través de tres formas: la conducción, la convección y la radiación. Además de la forma en que se transfiere, se debe distinguir si el proceso es estacionario o transitorio. Se dice que el régimen es estacionario cuando el flujo y la temperatura en cualquier punto son independientes del tiempo. Por el contrario, el régimen es transitorio cuando el flujo y la temperatura varían con el tiempo.

Conducción: Según la ley de Fourier, siempre que exista una diferencia de temperaturas entre dos regiones de un cuerpo sólido, el calor se transferirá por conducción desde la zona con mayor cantidad de calor a la de menor.

El flujo que se transmite en régimen estacionario es proporcional al gradiente por el área de la superficie a través de la cual se transfiere $\Delta T / \Delta x$. Así en un muro homogéneo de área $A$ y de espesor $\Delta \mathrm{x}$, siendo $\Delta \mathrm{T}$ la diferencia de temperaturas entre dos caras paralelas, el flujo de calor, $\mathrm{q}$, en $\mathrm{W} / \mathrm{m}^{2}$, perpendicular a dichas caras, de la más caliente a la más fría, es directamente proporcional al área $\mathrm{A}, \mathrm{y}$ a $\Delta \mathrm{T}$, e inversamente proporcional al espesor que las separa $\Delta x$, es decir:

$\mathrm{q}=\mathrm{kA} \Delta \mathrm{T} / \Delta \mathrm{x}$

Donde $\mathrm{k}$ es la conductividad o capacidad que tiene un material de transferir el calor. La conductividad mide la densidad del flujo de calor en $\mathrm{W} / \mathrm{m}^{2}$ en un metro de espesor cuando se produce una diferencia de $1 \mathrm{Kelvin}$ de temperatura entre caras, se da en $\mathrm{Wm} / \mathrm{m}^{2} \mathrm{~K}$ lo que es igual a $\mathrm{W} / \mathrm{m} \mathrm{K}$. 
Convección: El calor se transmite de esta manera cuando desde una superficie, que está a mayor temperatura, se transfiere calor a otra, a menor temperatura, mediante un fluido, que traslada el calor de un cuerpo a otro. En esta ocasión el flujo de calor depende de: el coeficiente de convección $\left(\mathrm{h}_{\mathrm{c}}\right.$ en $\mathrm{W} / \mathrm{m}^{2} \mathrm{~K}$ ), que a su vez depende de la orientación de la superficie, la velocidad del fluido, del tipo de régimen (laminar o turbulento) y de la viscosidad; la superficie de contacto entre el sólido y el fluido $\mathrm{A}\left(\mathrm{m}^{2}\right)$; y la diferencia de temperaturas entre la superficie de contacto del sólido y el fluido $\Delta T(K)$. La transferencia de calor por convección en $W\left(W / m^{2} K x m^{2} x K=W\right)$ es:

$\mathrm{q}_{\mathrm{v}}=\mathrm{h}_{\mathrm{c}} \times A \times \Delta \mathrm{T}$

Si la orientación de la superficie es vertical $h_{c}=3 \mathrm{~W} / \mathrm{m}^{2} \mathrm{~K}$, para horizontales con flujo vertical hacia arriba hc $=4.3 \mathrm{~W} / \mathrm{m}^{2} \mathrm{~K}$ y si es hacia abajo $\mathrm{h}_{\mathrm{c}}=1.5 \mathrm{~W} / \mathrm{m}^{2} \mathrm{~K}$. Cuando la superficie está expuesta al viento, el coeficiente de convección aumenta en función de su velocidad, adoptando la expresión $h_{c}=5.8+4.1 \mathrm{~V}$.

Radiación: La transmisión de calor por radiación no requiere un medio material para su propagación. Esta transferencia se produce entre dos superficies separadas en el espacio que tienen distintas temperaturas. Un ejemplo de este tipo de energía es la radiación emitida por el sol que alcanza la tierra a pesar de estar separado por $149.600 .000 \mathrm{~km}$ de distancia.

La energía irradiada se considera formada por ondas electromagnéticas o por corpúsculos llamados fotones, que se propagan a la velocidad de la luz.

Todo cuerpo con una temperatura mayor al cero absoluto irradia energía y cuanto más elevada es su temperatura, mayor es su energía emitida. Cuando la temperatura de un cuerpo no es muy elevada, emite radiación infrarroja, que es invisible al ojo humano, sin embargo, a partir de los $500-700^{\circ} \mathrm{C}$ las radiaciones de color rojo oscuro, empiezan a hacerse visibles, siendo estas de longitud de onda más corta que las anteriores.

\subsection{Transmitancia térmica (U)}

De acuerdo con Cengel (2003), es la relación entre la conductividad térmica y el espesor del elemento considerado. Es la tasa de flujo de calor a través de una unidad de superficie en $\mathrm{m}^{2}$, mientras existe una diferencia de temperaturas de $1^{\circ} \mathrm{K}$ entre las superficies de ambos lados del componente. Es el recíproco de la suma de las resistencias térmicas de todas las capas que componen la envolvente edilicia más la resistencia de las películas de aire interior y exterior. 
También es denominado comúnmente como el Coeficiente general de transferencia de calor o Valor U, y se expresa en $\mathrm{W} / \mathrm{m}^{2 \circ} \mathrm{K}$ o Btu/hft ${ }^{2} \mathrm{~F}$.

El método para calcular la transmitancia de una envolvente es explicado por Cengel \& Ghajar (2015), mediante el ejemplo de la Figura 148. En este ejemplo la envolvente está constituida por una estructura de madera, sistema liviano y aislamiento en fibra de vidrio, en el ejemplo se listan y se suman las resistencias térmicas de cada capa del muro obteniendo como resultado la transmitancia del muro. En el ejemplo la transmitancia corresponde a $0,449 \mathrm{~W} / \mathrm{m}^{2 \circ} \mathrm{C}$, lo cual puede entenderse como que, dicho muro pierde $0,449 \mathrm{~W}$ por cada metro cuadrado, por cada grado Celsius de diferencia que hay entre el interior y el exterior.

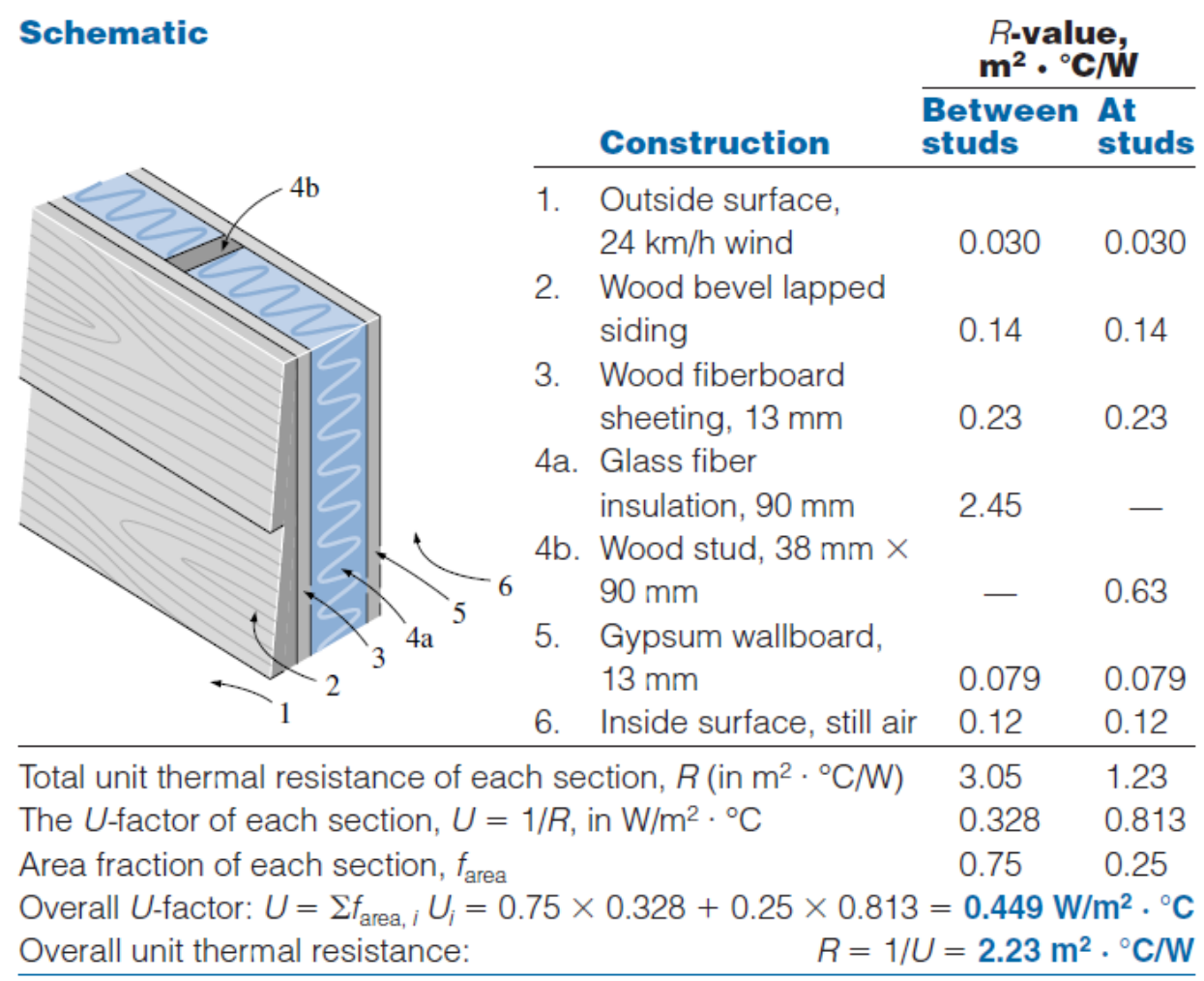

Figura 148. Ejemplo de cálculo de la transmitancia térmica. Fuente: (Cengel \& Ghajar, 2015).

\subsection{Velocidad del aire $\left(V_{\text {air }}\right)$}

En meteorología al movimiento del aire se le denomina viento. Se estudia como aire en movimiento tanto horizontal como verticalmente.

El viento es causado por las diferencias de temperatura existentes al producirse un calentamiento desigual de las zonas de la Tierra y de la atmósfera. Las masas de aire más calientes tienden a elevarse, y su lugar es ocupado por las masas de aire circundante más frías y, por tanto, más denso. Se denomina "viento" al flujo de aire que se mueve en sentido 
horizontal, mientras que "corriente de convección" suele utilizarse solamente para los movimientos de aire en sentido vertical.

Por lo tanto, la velocidad del aire es una relación entre la longitud recorrida por el viento y el tiempo (longitud por unidad de tiempo), usualmente se mide en $\mathrm{m} / \mathrm{s}$ (metros por segundo).

Para su uso en Urbanismo y Arquitectura, es común que esta medida se encuentre acompañada de un gráfico que señala la dirección o direcciones en que proviene el viento al que se le conoce como rosa de los vientos.

El movimiento del aire sobre la piel aumenta el confort ya que posibilita en mayor medida la pérdida de calor por convección, es decir el intercambio de calor entre el cuerpo humano y el aire.

Por último, Olgyay, define una escala de valoración para la velocidad del aire de la siguiente manera, Crítico entre 0 y $0,3 \mathrm{~m} / \mathrm{s}$ y > 17,2 m/s; Malo entre 0,4 y $3,4 \mathrm{~m} / \mathrm{s}$ y 10,8 a $17,7 \mathrm{~m} / \mathrm{s}$; Regular entre 3,5 a $5,4 \mathrm{~m} / \mathrm{s}$; Bueno entre 5,5 a $7,9 \mathrm{~m} / \mathrm{s}$ y Óptimo entre 8,0 a $10,7 \mathrm{~m} / \mathrm{s}$. 


\subsection{Vestimenta (Clo)}

El efecto que produce la indumentaria en el cuerpo humano es disminuir la pérdida de calor, por lo tanto, es considerada y clasificada como un aislamiento térmico. Las unidades en que se mide el aislamiento por la vestimenta son el "Clo" y " $\mathrm{m}^{2 \circ} \mathrm{C} / \mathrm{W}$ " donde $1 \mathrm{Clo}=0,155 \mathrm{~m}^{2 \circ} \mathrm{C} \mathrm{W}$. Una persona desnuda representa la usencia total de aislamiento y se valora como cero (0) Clo, mientras que un traje con chaqueta de algodón, camisa de algodón, ropa interior , calcetines y zapatos tiene un valor de un $1 \mathrm{Clo}$. Una vestimenta muy abrigada, puede ser un traje más gabardina de lana, sombrero, abrigo y bufanda que tendría valores de 3 y 4 Clo. $\mathrm{A}$ continuación, en la Tabla 42, tomada de Kvisgaard (1997), se encuentran varios valores de Clo para diferentes tipos de prendas que pueden ser sumadas para obtener un valor total.

\begin{tabular}{|c|c|c|c|}
\hline Prendas de vestir & & Clo & $\mathrm{m} \mathbf{2}^{\circ} \mathrm{C} / \mathrm{W}$ \\
\hline \multirow[t]{5}{*}{ Ropa interior inferior } & Medias & 0.02 & 0.003 \\
\hline & Panty & 0.03 & 0.005 \\
\hline & Bragas y calzoncillos & 0.04 & 0.006 \\
\hline & Calzoncillo $1 / 2$ pierna de lana & 0.06 & 0.009 \\
\hline & Calzoncillo pierna entera & 0.10 & 0.016 \\
\hline \multirow[t]{5}{*}{ Ropa interior superior } & Sujetador & 0.01 & 0.002 \\
\hline & Camiseta sin mangas & 0.06 & 0.009 \\
\hline & Camiseta manga corta & 0.09 & 0.014 \\
\hline & Camiseta manga larga & 0.12 & 0.019 \\
\hline & Camiseta térmica nylon & 0.14 & 0.022 \\
\hline \multirow[t]{7}{*}{ Camisas } & Top de tubo & 0.06 & 0.009 \\
\hline & Camisa manga corta & 0.09 & 0.029 \\
\hline & Blusa ligera, manga larga & 0.15 & 0.023 \\
\hline & Camisa ligera, manga larga & 0.20 & 0.031 \\
\hline & Camisa normal, manga larga & 0.25 & 0.039 \\
\hline & Camisa franela, manga larga & 0.30 & 0.047 \\
\hline & Blusa larga de cuello de cisne & 0.34 & 0.053 \\
\hline \multirow[t]{6}{*}{ Pantalones } & Pantalones cortos & 0.06 & 0.009 \\
\hline & Pantalones cortos de excursión & 0.11 & 0.017 \\
\hline & Pantalones ligeros & 0.20 & 0.031 \\
\hline & Pantalones normales & 0.25 & 0.039 \\
\hline & Pantalones de franela & 0.28 & 0.043 \\
\hline & Pantalones de chandal & 0.28 & 0.043 \\
\hline \multirow[t]{6}{*}{ Suéter } & Chaleco & 0.12 & 0.019 \\
\hline & Suéter fino & 0.2 & 0.031 \\
\hline & Suéter fino cuello de cisne & 0.26 & 0.040 \\
\hline & Suéter normal & 0.28 & 0.043 \\
\hline & Suéter grueso & 0.35 & 0.054 \\
\hline & Suéter grueso cuello de cisne & 0.37 & 0.057 \\
\hline \multirow[t]{4}{*}{ Chaqueta } & De vestido & 0.13 & 0.020 \\
\hline & Chaqueta ligera de verano & 0.25 & 0.039 \\
\hline & Chaqueta & 0.35 & 0.054 \\
\hline & Anorak & 0.30 & 0.047 \\
\hline \multirow[t]{4}{*}{ Abrigos } & Abrigo & 0.60 & 0.093 \\
\hline & Gabardina & 0.55 & 0.085 \\
\hline & Parka & 0.70 & 0.109 \\
\hline & Sobreabrigo multicomponente & 0.52 & 0.081 \\
\hline \multirow[t]{8}{*}{ calzado } & Calcetines & 0.02 & 0.003 \\
\hline & Calcetines gruesos tobillos & 0.05 & 0.008 \\
\hline & Calcetines gruesos largos & 0.10 & 0.016 \\
\hline & Zapatilla, rellena de peluche & 0.03 & 0.005 \\
\hline & Zapato suela fina & 0.02 & 0.003 \\
\hline & Zapato suela gruesa & 0.04 & 0.006 \\
\hline & Botas & 0.10 & 0.016 \\
\hline & Guantes & 0.05 & 0.008 \\
\hline \multirow[t]{5}{*}{ Falda, vestido } & Falda ligera, $15 \mathrm{~cm}$ sobre rodilla & 0.10 & 0.016 \\
\hline & Falda ligera, $15 \mathrm{~cm}$ bajo rodilla & 0.18 & 0.028 \\
\hline & Falda gruesa hasta la rodilla & 0.25 & 0.039 \\
\hline & Vestido ligero sin mangas & 0.25 & 0.039 \\
\hline & Vestido de invierno manga larga & 0.40 & 0.062 \\
\hline \multirow[t]{2}{*}{ Batas } & Bata larga acolchada de manga larga & 0.53 & 0.082 \\
\hline & Bata corta acolchada de manga larga & 0.41 & 0.064 \\
\hline
\end{tabular}

Tabla 42. Valores de Clo para diferentes tipos de prendas. Fuente: (Kvisgaard, 1997) 


\section{ANÁlisis CLIMATOLÓGICO COMPARATIVO ENTRE CALI Y LA PLATA. DEFINICIÓN DEL PERIODO DE MEDICIÓN}

Un análisis comparativo entre las condiciones climáticas de Cali y La Plata se elaboró para establecer el periodo en el cual, la ciudad de La Plata posee condiciones cercanas a las de Cali, y elaborar un cronograma de mediciones.

Para efectuar este análisis se utilizaron los datos climatológicos de los dos años inmediatamente anteriores, 2015 y 2016, de las estaciones meteorológicas de la Escuela de Arquitectura de la Universidad del Valle en Cali y del Observatorio de la ciudad de La Plata.

\subsection{Análisis comparativo de $\mathrm{T}_{\text {air }}$}

Con los datos climáticos de $T_{\text {air }}$ de cada ciudad se calcularon las medias mensuales y se construyó la gráfica comparativa de la Figura 149. En esta escala se identifica que los promedios pertenecientes a diciembre, enero y febrero son bastante similares. Al tener en cuenta las medias de ambos años, en el mes de diciembre la $T_{\text {air }}$ es superior en La Plata en $1.53 \%$, mientras que, en los meses de enero y febrero, la $\mathrm{T}_{\text {air }}$ es superior en Cali en $0.72 \%$ y $1.15 \%$ respectivamente. Por su parte hay unos meses transicionales como marzo y noviembre donde existen diferencias entre el $5 \%$ y el $8 \%$, mientras que en los meses restantes las diferencias superan el $10 \%$. 


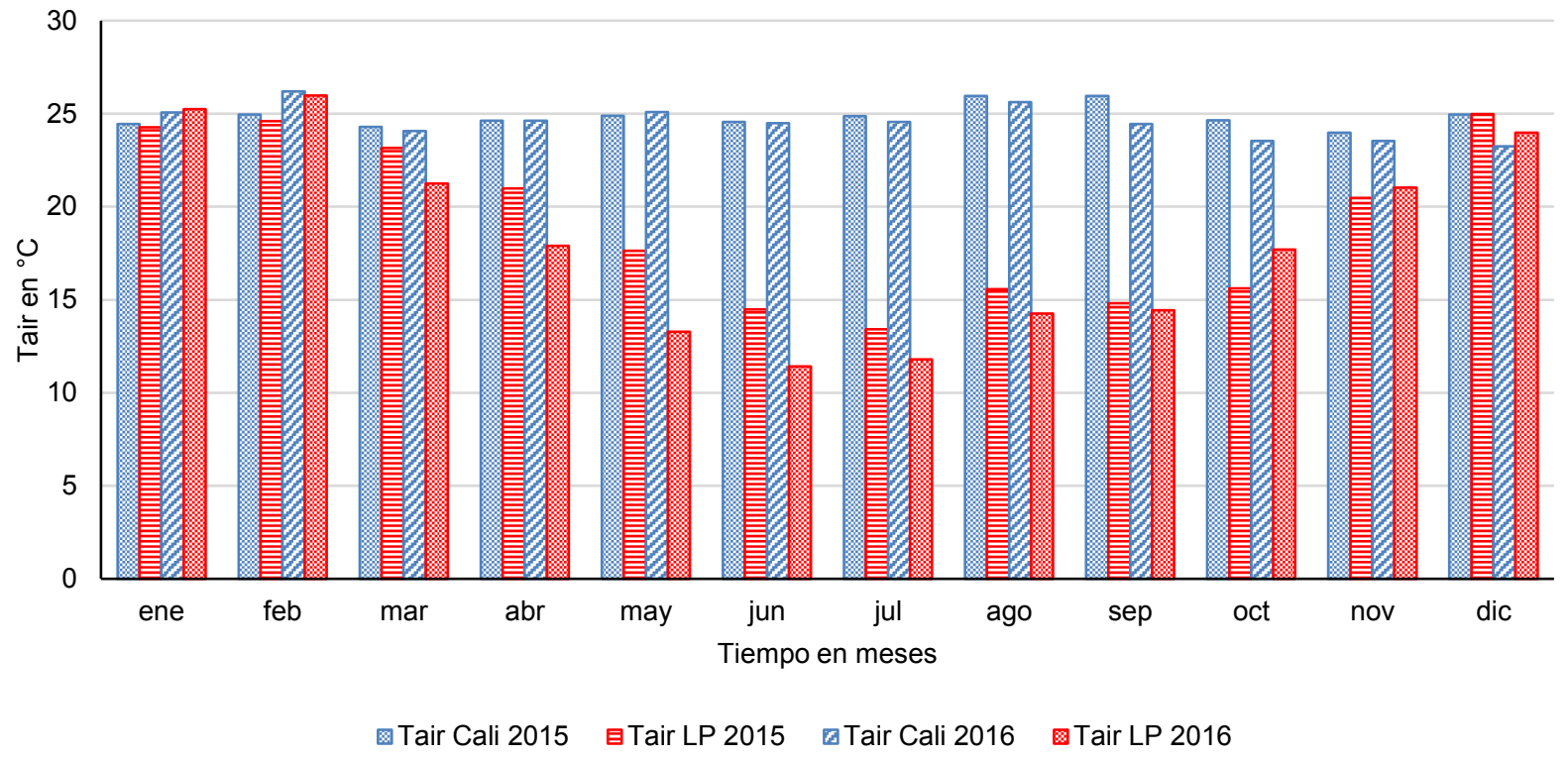

Figura 149. Gráfica comparativa de la media mensual de Tair entre Cali y La Plata durante los años 2015 y 2016. Fuente: Elaboración propia.

Con una escala más detallada y promediando los datos de 2015 y 2016 se elaboró la gráfica de la Figura 150, donde se aprecian las $\mathrm{T}_{\text {air }}$ medias horarias por mes, durante todo el año. En esta escala también es notorio que los meses con comportamiento más semejante son diciembre, enero y febrero.

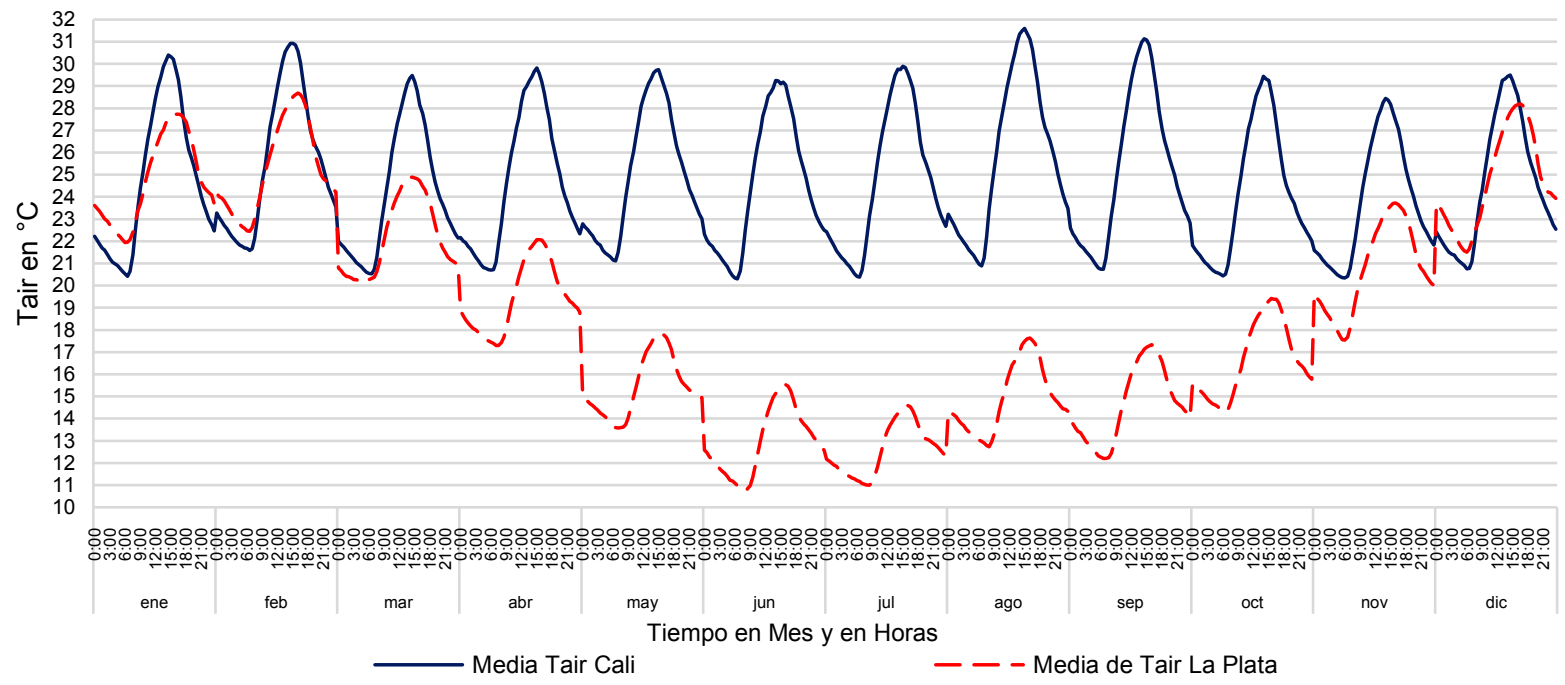

Figura 150. Grafica comparativa de las $T_{\text {air }}$ medias horarias mensuales durante todo el año entre Cali y La Plata. Fuente: Elaboración propia.

Por último, en la Figura 151 se compara un día típico de Cali (elaborado con los promedios horarios de 2015 y 2016) y un día típico en La Plata durante los meses de diciembre, enero y febrero (elaborado con los promedios horarios de estos meses durante 2015 y 2016). En esta 
gráfica se aprecia que hay una tendencia de que las $\mathrm{T}_{\text {air }}$ de Cali sean superiores entre las 11:00 y las $17: 30$ horas, sin embargo, esa diferencia no es superior a $1,47^{\circ} \mathrm{C}$.

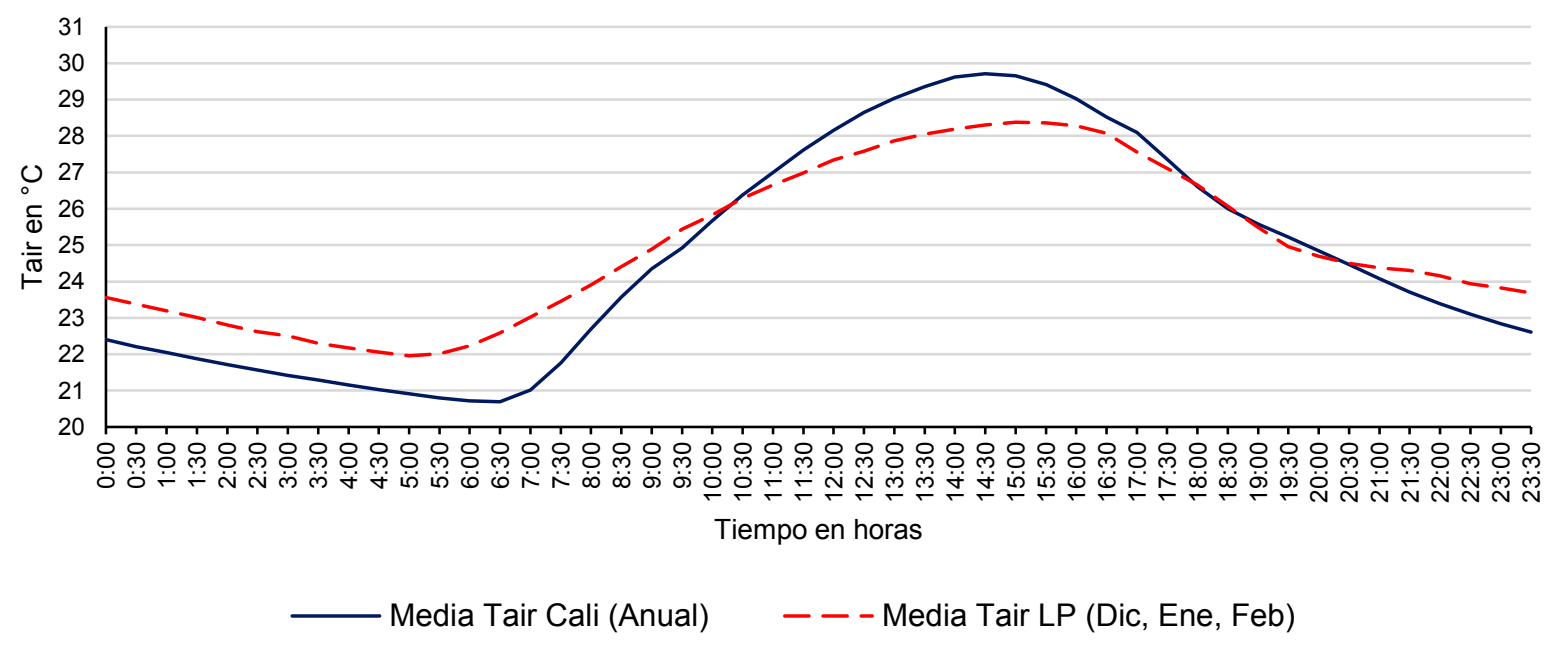

Figura 151. Grafica comparativa de Tair de un día típico durante los meses de diciembre, enero y febrero entre Cali y La Plata. Fuente: Elaboración propia.

Por otro lado, la $\mathrm{T}_{\text {air }}$ tiende a ser más alta en La Plata en las horas de la noche y la madrugada, pero esta diferencia no supera los $2,0^{\circ} \mathrm{C}$. Con este análisis vemos que las diferencias no son demasiado notorias y que durante estos tres meses la ciudad de La Plata tiene un comportamiento de $\mathrm{T}_{\text {air }}$ semejante al de un día típico de Cali. Es decir, que los meses de diciembre, enero y febrero son los más adecuados para realizar la experimentación desde la perspectiva de la $\mathrm{T}_{\text {air. }}$. 


\subsection{Análisis comparativo de radiación solar}

Con los datos de cada ciudad se calcularon las medias mensuales de radiación solar y se construyó la gráfica comparativa de la Figura 152. En esta gráfica se identifican varios meses que tienen medias de radiación similares, tales como enero, febrero, marzo, octubre y noviembre.

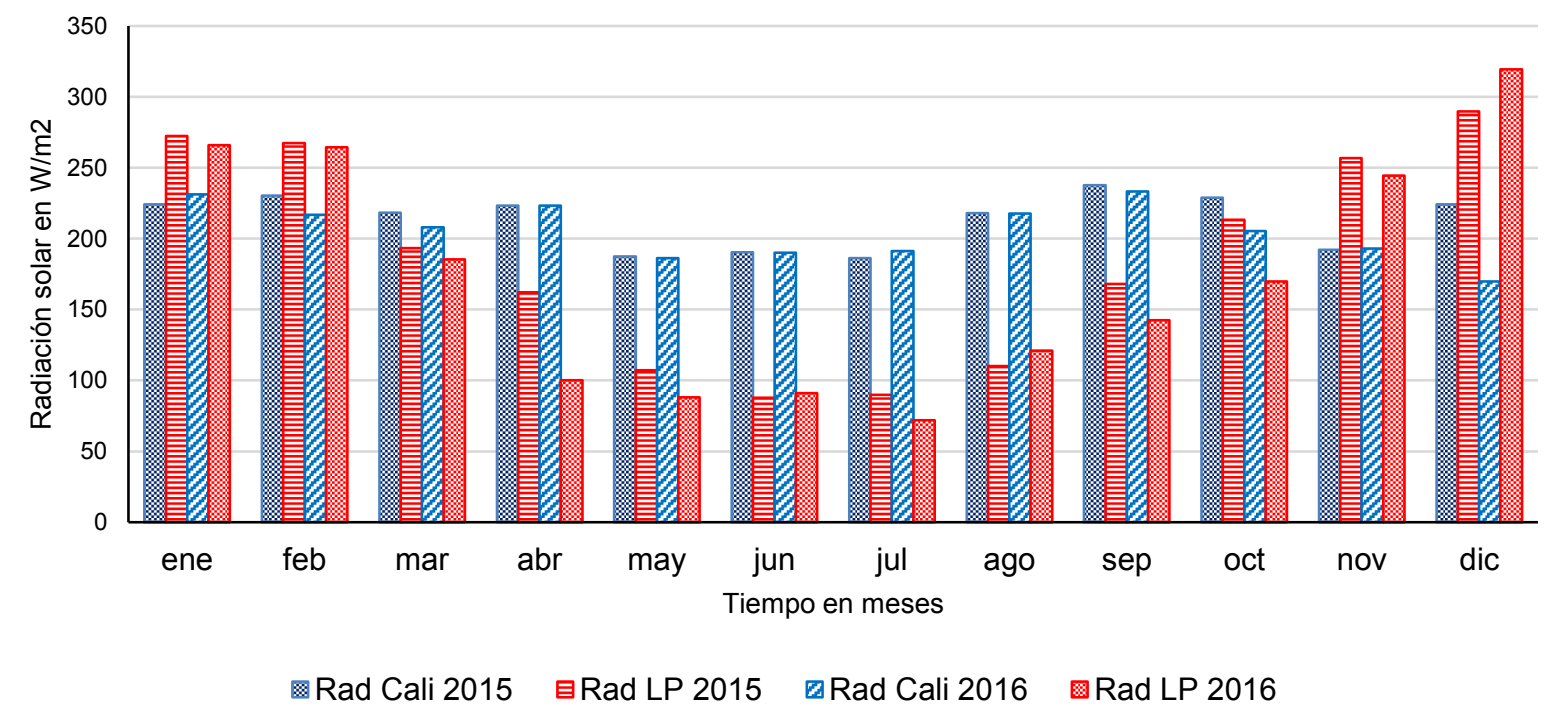

Figura 152. Gráfica comparativa de la media mensual de radiación solar entre Cali y La Plata durante los años 2015 y 2016. Fuente: Elaboración propia.

Sin embargo, en una escala más detallada y promediando los años 2015 y 2016 se elaboró la gráfica de la Figura 153, que contiene la radiación solar media por hora y por mes a lo largo del año. En esta escala se aprecia que los meses que presentan un comportamiento más semejante frente a esta variable son enero, febrero y marzo. 


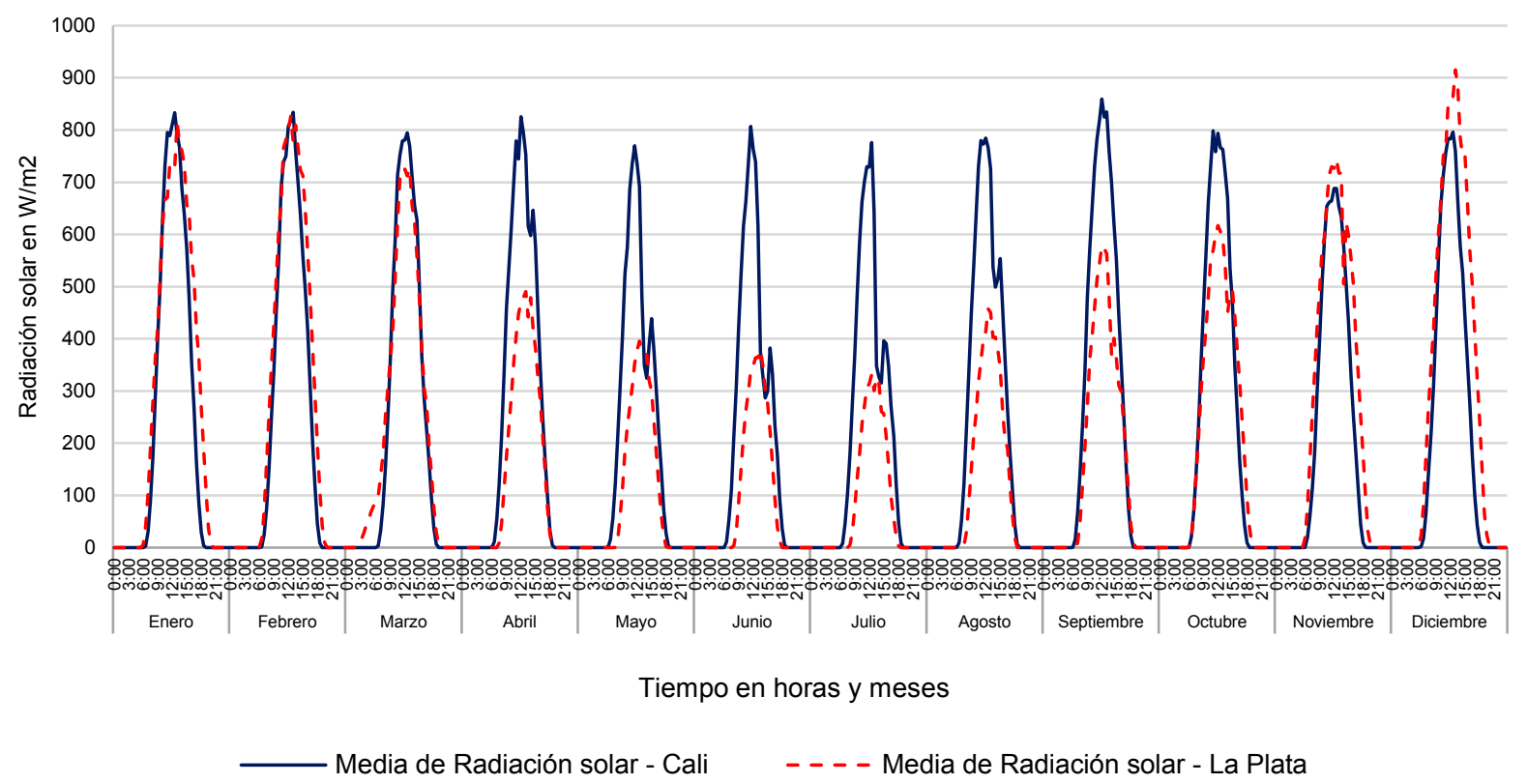

Figura 153. Grafica comparativa de radiación solar media por hora y por mes durante todo el año entre Cali y La Plata. Fuente: Elaboración propia.

Por último, en la Figura 154 se compara la radiación solar durante un día típico de Cali (elaborado con los promedios horarios de 2015 y 2016) y un día típico en La Plata durante los meses de enero, febrero y marzo (elaborado con los promedios horarios de estos meses durante 2015 y 2016). En esta gráfica se aprecia que, durante estos tres meses, la radiación solar en la ciudad de La Plata suele presentarse durante un periodo más prolongado y es más intensa que la de Cali.

Si se comparan las áreas bajo las curvas (valores acumulativos de radiación solar) de ambas ciudades se obtiene que Cali posee $10109,45 \mathrm{~W} / \mathrm{m}^{2}$ día, mientras que La Plata tiene 11591,39 $\mathrm{W} / \mathrm{m}^{2}$ día, lo cual significa que la radiación solar es un $14,65 \%$ mayor en La Plata que en Cali.

Como se ha visto, las diferencias en los meses restantes son superiores, por lo tanto, enero, febrero y marzo son los meses más recomendables desde el punto de vista de la radiación solar para realizar la experimentación. 


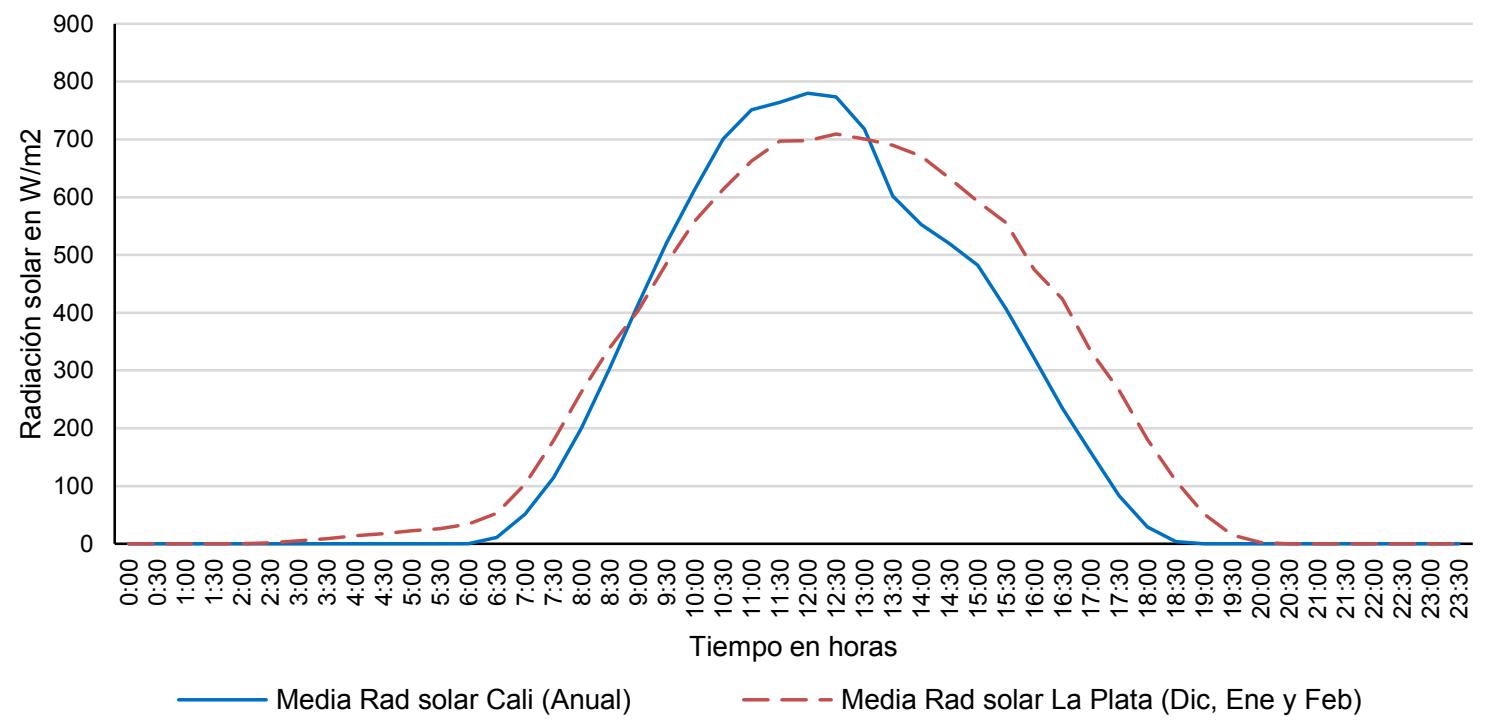

Figura 154. Grafica comparativa de Radiación solar de un día típico de Cali y un día típico de La Plata durante los meses de enero y febrero y marzo. Fuente: Elaboración propia.

\subsection{Análisis comparativo de humedad relativa}

Las medias mensuales de HR de Cali y La Plata en 2015 y 2016 pueden compararse en la gráfica de la Figura 155. En esta escala mensual se identifica que los promedios de esta variable son semejantes en la mayoría de los meses, sin embargo, enero, febrero y marzo se destacan.

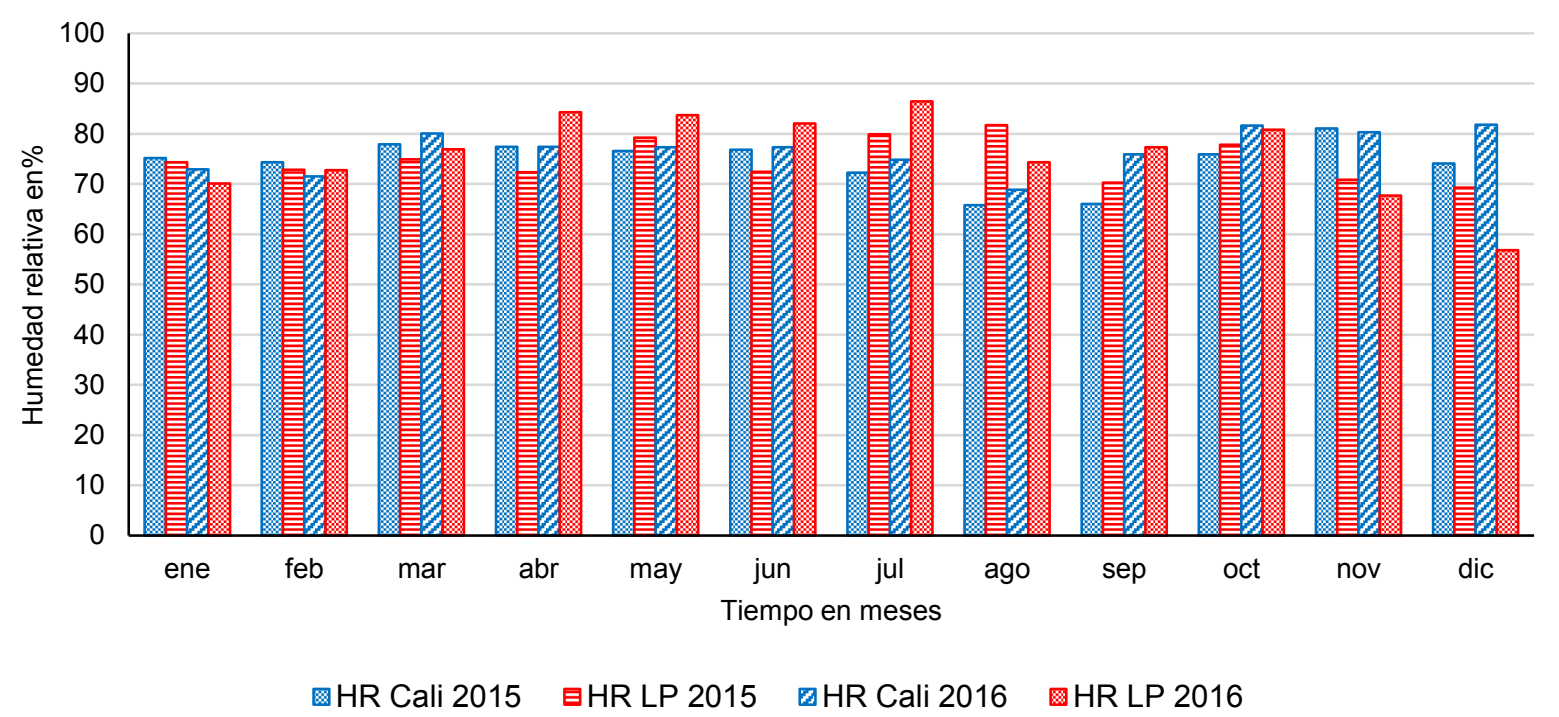

Figura 155. Gráfica comparativa de la media mensual de HR entre Cali y La Plata durante los años 2015 y 2016. Fuente: Elaboración propia. 
Posteriormente, se realizó la gráfica de la Figura 156, donde se promedian los valores anuales y se hace un acercamiento al comportamiento diario de la HR, en ella también es notorio que enero, febrero y marzo poseen una mayor semejanza que los meses restantes.

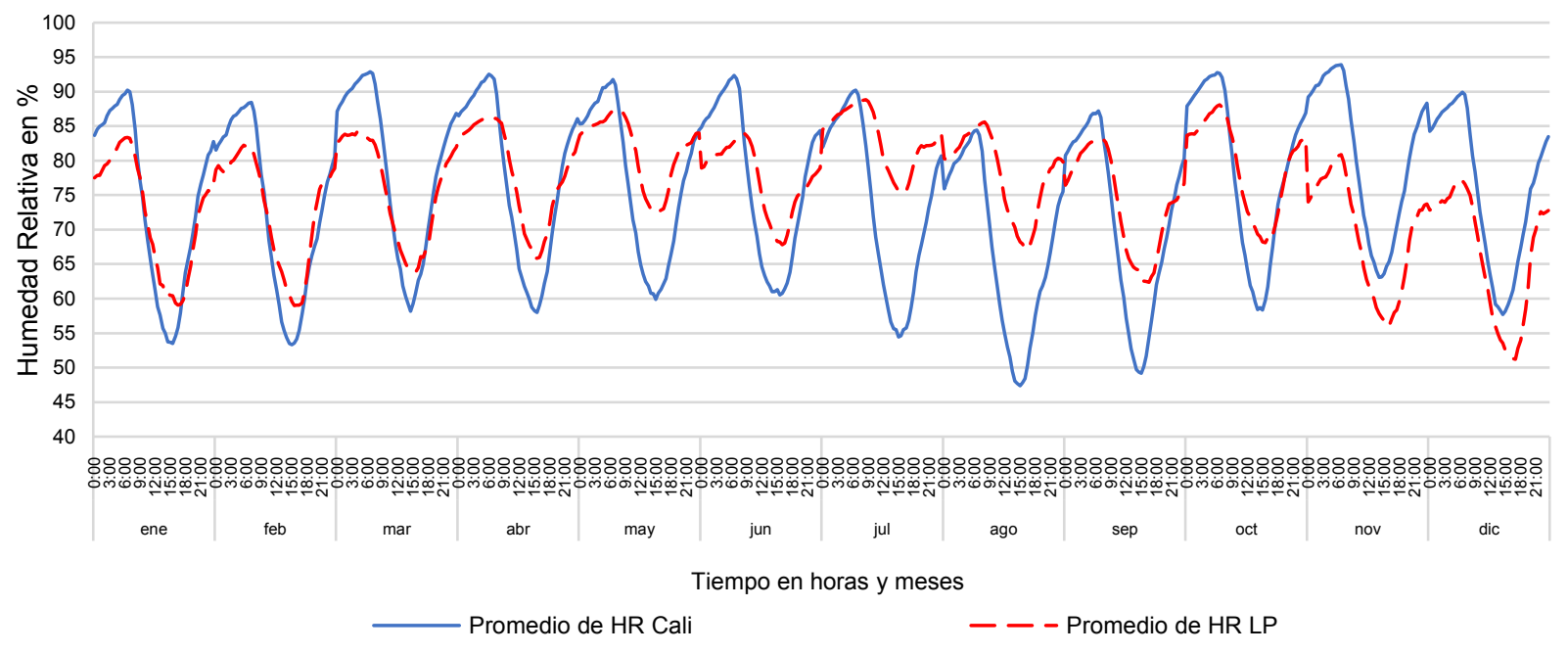

Figura 156. Grafica comparativa de HR media por hora y por mes durante todo el año entre Cali y La Plata. Fuente: Elaboración propia.

Por último, en la Figura 157 se compara la HR en un día típico de Cali (elaborado con los promedios horarios de 2015 y 2016) y un día típico en La Plata durante los meses de enero, febrero y marzo (elaborado con los promedios horarios de estos meses durante 2015 y 2016).

Si se comparan las áreas bajo las curvas correspondientes a ambas ciudades se obtiene que Cali es un 2,29\% más húmeda que La Plata durante estos tres meses. Sin embargo, se aprecia que, la HR en la ciudad de La Plata suele ser en promedio un 3,5\% más alta entre las 9:00 y las 17:00 horas, mientras que, en las horas de la mañana y la noche, Cali suele ser más húmeda en un promedio de $5 \%$.

Como se ha visto, desde el punto de vista de la HR, los meses de enero, febrero y marzo son los meses más recomendables para realizar la experimentación debido a que las diferencias son menores que en los meses restantes. 


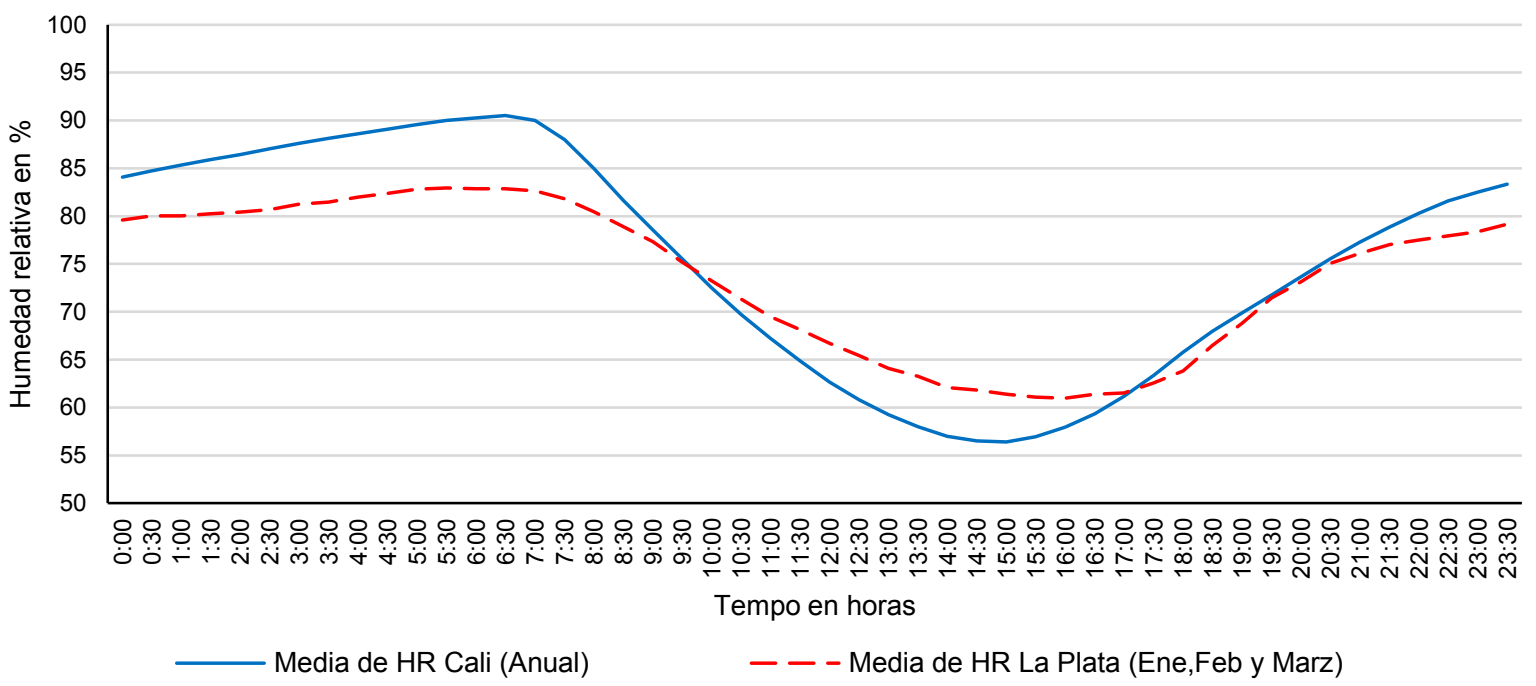

Figura 157. Grafica comparativa de HR de un día típico de Cali y un día típico de La Plata durante los meses de enero y febrero y marzo. Fuente: Elaboración propia.

Finalmente, con el objetivo de integrar y resumir estos análisis que se han efectuado de forma separada, se elaboró la

Tabla 43, acompañada de un gráfico de barras, cada uno de ellos indica el porcentaje de diferencia absoluto (positivo o negativo) de las variables $T_{\text {air, }}$, radiación solar y HR entre un día típico de Cali y el promedio de cada mes en La Plata. Aquí se distingue claramente que los menores porcentajes de diferencia se encuentran en enero, febrero y marzo. Por esta razón estos meses fueron escogidos como los más adecuados para realizar la campaña

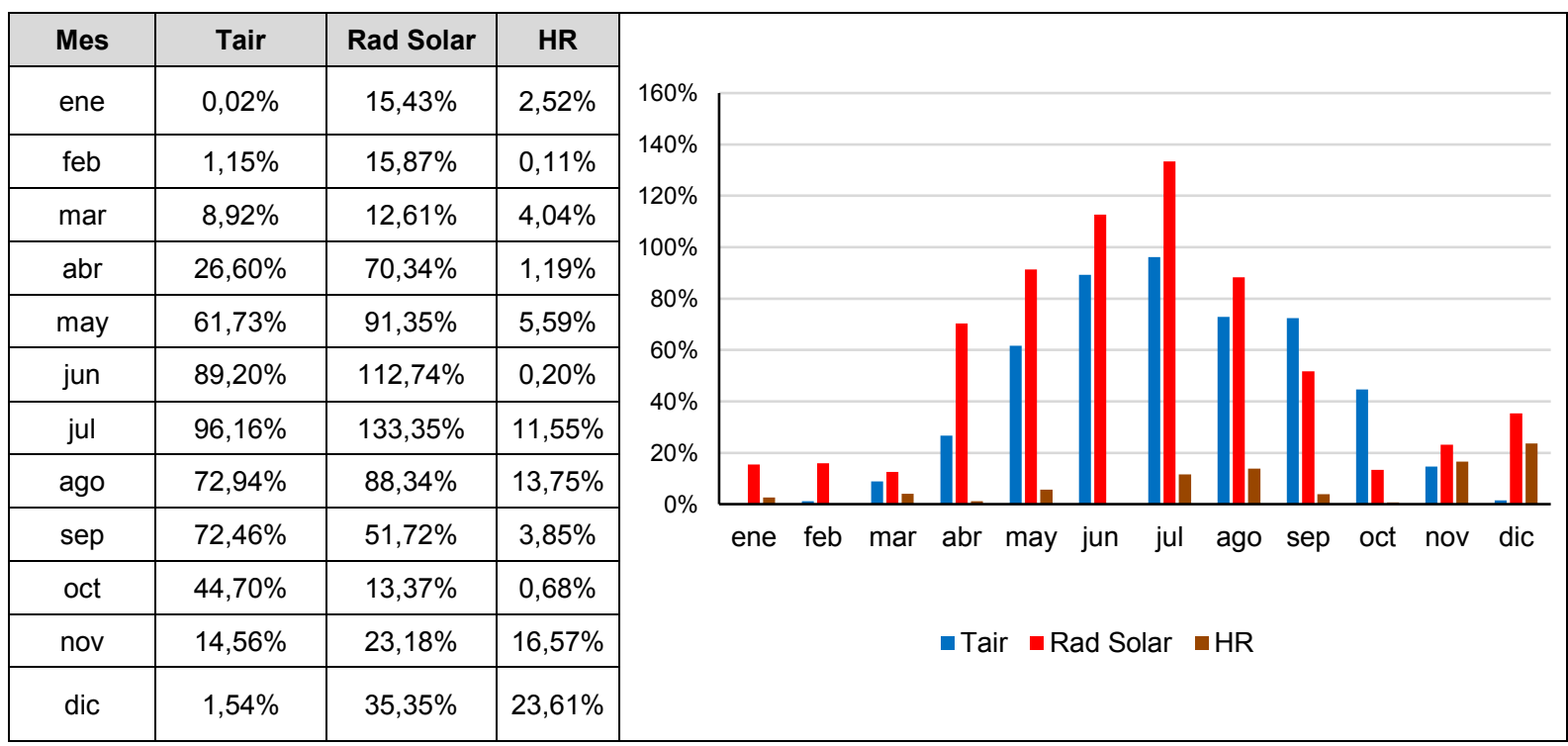

experimental.

Tabla 43. Integración de los porcentajes de diferencia de la Tair, radiación solar y HR en los distintos meses del año entre Cali y La Plata. Fuente: Elaboración propia. 


\section{INSTRUMENTAL}

Este pequeño apéndice compendia la descripción del instrumental utilizado durante las experimentaciones llevadas a cabo durante la tesis. La precisión los rangos, la calibración al igual que las normas que definen su utilización son temas de este apartado.

\subsection{Cámara termográfica testo $875 i$.}

De acuerdo con la norma ISO 7726-1998, la temperatura de una superficie dada o $T_{r}$, puede ser medida a través de sensores infrarrojos como las cámaras termográficas (CT) que miden el flujo de calor radiante de una superficie y lo convierten en temperatura.

En esta misma norma, se indica que, con motivos de evaluar el confort térmico, la $T_{r}$ debe medirse con instrumentos que tengan un rango de $0{ }^{\circ} \mathrm{C} \mathrm{a}+50{ }^{\circ} \mathrm{C}$. Asimismo, la exactitud requerida no debe ser menor que $\pm 1^{\circ} \mathrm{C}$ y deseable $\pm 0,5^{\circ} \mathrm{C}$.

Por su parte, la CT Testo $875 \mathrm{i}$, aquí utilizada posee un rango de medición de $-30^{\circ} \mathrm{C}$ a $350^{\circ} \mathrm{C}$ y su exactitud está en el $2 \%$, lo cual es aceptable hasta los $50^{\circ} \mathrm{C}$ del rango estipulado en la norma. 
Este equipo toma una imagen similar a la fotografía común, pero en este caso la imagen está conformada por colores que indican las temperaturas superficiales de los objetos abarcados en ella. Una vista exterior de este instrumento se presenta a continuación en la Figura 158.

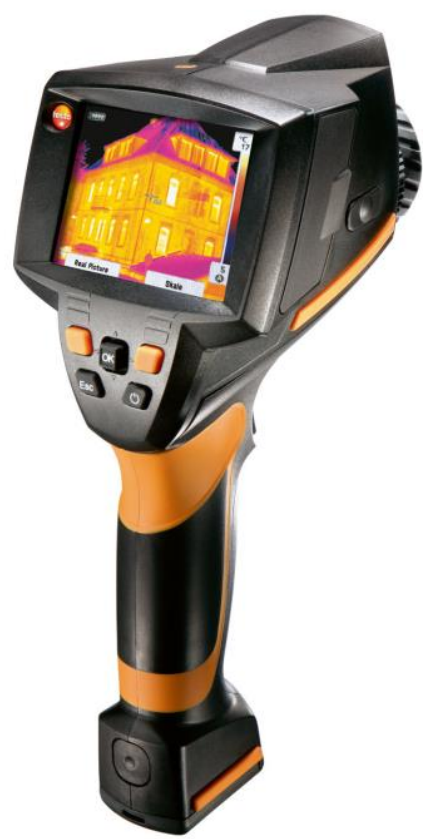

Figura 158. Vista exterior de la cámara termográfica testo 875i. Fuente: https://www.testo.com/es-AR/

\section{Calibración}

Aunque el equipo se encontraba debidamente calibrado, para mejorar la precisión de las mediciones se efectuaron algunos ajustes previos a razón de compensar la radiación aportada por el entorno y la atmósfera como se indica en las normas ASTM E1933-99a e ISO 184341:2008 (American Society for Testing and Materials. 2000; International Organization for Standardization. 2008). Para determinar el valor de la temperatura reflejada ${ }^{57}\left(T_{\text {refl }}\right)$ se manejó el método del film de aluminio arrugado (con el lado brillante hacia afuera) puesto sobre la superficie interior de la placa de concreto del aparato experimental y configurando la emisividad en 1 y la distancia en 0.

Durante cada tarde de campaña experimental, este procedimiento se realizó al inicio de las mediciones (12:30) y dos veces más en el intermedio de la tarde (14:00 y 16:00) debido a que

${ }^{57}$ Esta es definida como la temperatura que los otros objetos irradian hacia el objeto de interés. 
esta variable tiende a aumentar con el transcurso del tiempo debido a la radiación solar recibida sobre los módulos de prueba.

Otro ajuste importante que se indica en las mismas normas es el de la emisividad $(\varepsilon)$, para el cual se adhirió un trozo de cinta aislante negra con $\varepsilon$ conocida previamente de 0,95 sobre la cara interior de la placa de concreto. Con lo cual la cámara fue configurada con $\varepsilon=0,95$ y distancia en 1. Posteriormente, se tomó una medida de temperatura con la cámara sobre la cinta y se anotó el valor en una libreta. Luego se midió la temperatura directamente sobre la cara interior de la placa de concreto, obteniendo un dato distinto al escrito sobre la libreta. Finalmente, el valor de $\varepsilon$ se fue ajustando en la cámara hasta hacerla coincidir con el dato de temperatura apuntado.

El valor $\varepsilon$ de las placas de concreto fue 0,93 , el cual se configuró y permaneció así durante las mediciones.

Aunque estos dos métodos aparentemente son poco profesionales, fueron bastante efectivos, válidos y sencillos para una adecuada configuración de la cámara, lo anterior está apoyado por las mismas normas mencionadas con anterioridad y algunos manuales como el elaborado por la Fundación de la Energía de la Comunidad de Madrid (2011).

\subsection{Termohigrómetro digital Datalogger de $T_{\text {air }}$ y HR marca Extech (modelo RHT30)}

La norma ISO 7726-1998, aconseja que los instrumentos para la medición de la $\mathrm{T}_{\text {air }}$ con fines de evaluación de confort deben poseer al menos un rango de medición de $10^{\circ} \mathrm{C}$ a $40^{\circ} \mathrm{C}$, con una precisión requerida de $\pm 0,5^{\circ} \mathrm{C}$ y deseable de $\pm 0,2^{\circ} \mathrm{C}$. Este documento hace hincapié en proteger el sensor frente a la radiación solar directa y la radiación de otros objetos, artefactos de iluminación o calefacción que puedan alterar los datos de las mediciones.

En cuanto a la humedad relativa, esta misma norma recomienda que se puede medir mediante higrómetros capacitivos, y aunque la exactitud no se especifique en rangos de porcentaje sino en términos de presión parcial de vapor de agua, se entiende que las incertidumbres admitidas deben ser menores al $6 \%$. Una bibliografía de apoyo adicional que sí especifica el rango y la precisión en términos de HR es la Norma Brasilera de Confort Térmico (Associação Brasileira de Normas Técnicas (ABNT), 2016), allí se aconseja que los rangos sean de $25 \%$ a $95 \%$ y la precisión del 5\%.

Acogiendo estas recomendaciones, se emplearon registradores de datos inalámbricos o dataloggers de $\mathrm{T}_{\text {air }}$ y HR marca Extech de referencia RHT30, los cuales poseen sensores 
capacitivos que son sensibles a un rango de $\mathrm{T}_{\text {air }}$ entre $-30{ }^{\circ} \mathrm{C}$ y $70{ }^{\circ} \mathrm{C}$ con una resolución de $0,1^{\circ} \mathrm{C}$ y precisión de $\pm 0,5^{\circ} \mathrm{C}$. En Cuanto a la $\mathrm{HR}$, el equipo tiene un rango de medición entre $0,1 \%$ y $99,9 \%$, con resolución de $0,1 \%$ y precisión de $\pm 3 \%$.

\section{Calibración}

Para asegurar la precisión de los termohigrómetros, se realizó una prueba piloto en la que se contrastó un equipo debidamente calibrado frente a otros dos, de esta manera fue posible conocer si los equipos presentaban imprecisiones o si se encontraban calibrados. Los resultados de esta prueba piloto se muestran en la Figura 159, en la que se observa concordancia en los datos de $\mathrm{T}_{\text {air }}$ de los tres aparatos, mientras que los resultados de HR presentaron valores superiores de 0,3 puntos porcentuales en promedio, lo cual fue tomado en cuenta para ajustar los resultados.

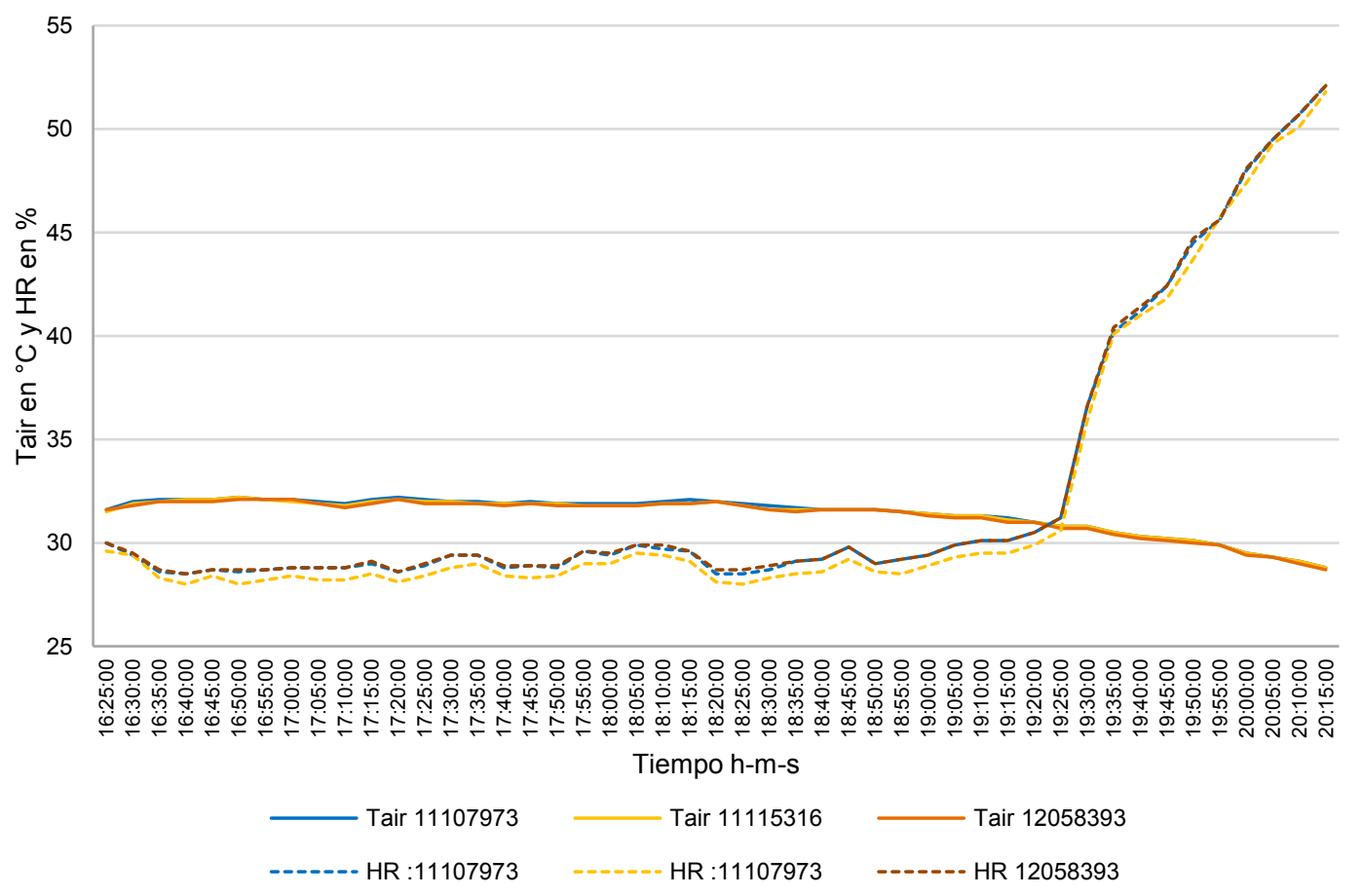

Figura 159. Prueba piloto de calibración de los termohigrómetros, gráfica de Tair y HR vs tiempo. Fuente: Elaboración propia.

Durante la anterior calibración y en todas las pruebas, los dataloggers fueron protegidos de la influencia de la radiación térmica circundante, ya que se alojaron en el interior de una cajilla de aluminio pulido con perforaciones que permiten el paso del aire, tanto el equipo como la cajilla se aprecian a continuación en la Figura 160. 

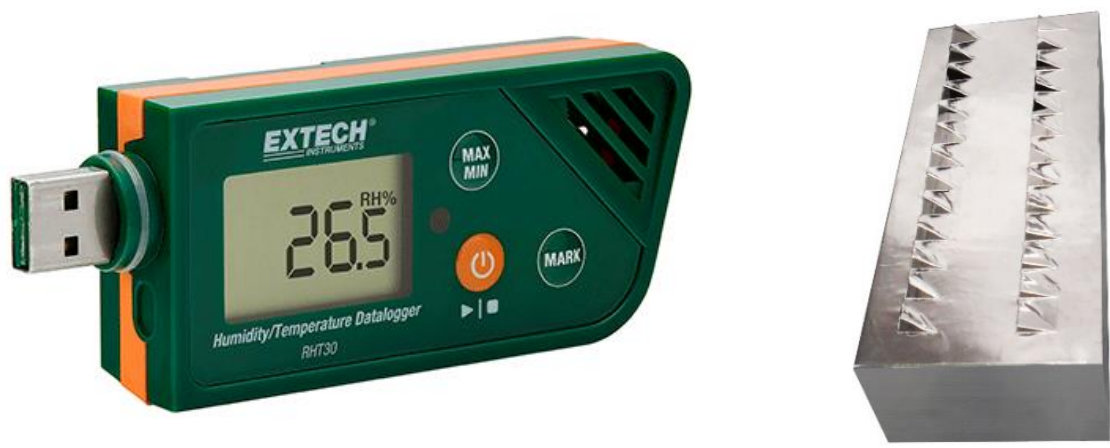

Figura 160. Datalogger Extech, modelo RHT30 y cajilla de protección contra radiación. Fuente: Elaboración propia.

\subsection{Instrumento multifunción Testo $435-2$ y sondas de $\mathrm{T}_{\text {air }}$ y $\mathrm{T}_{\mathrm{r}}$.}

El equipo utilizado para medir la transmitancia consta de un instrumento multifunción marca Testo 435-2 al cual se acoplaron 2 sondas. La primera es la sonda termopar (Testo 06021793) destinada a la medición de la $\mathrm{T}_{\text {air }}$ en el lado frío. La segunda es la sonda para medir la $\mathrm{T}_{\text {air }}$ del lado caliente y que además posee un sistema de triple sensor que se adhiere a la superficie de la probeta para medir su $\mathrm{T}_{\mathrm{r}}$ (Sonda valor $\mathrm{K}$ Testo 06141635).

El rango de medición de este instrumental está entre $-20^{\circ} \mathrm{C}$ y $70^{\circ} \mathrm{C}$ con una incertidumbre \pm $0,1^{\circ} \mathrm{C}$. Una vista de estos tres instrumentos se puede apreciar en la Figura 161.

Para asegurar el registro de los datos en simultaneidad, este sistema de medición posee el programa Confort Software suministrado por el fabricante, que debe ser instalado en un ordenador. Este programa permite ver en tiempo real los datos recopilados por el instrumental mediante tablas y gráficas. 

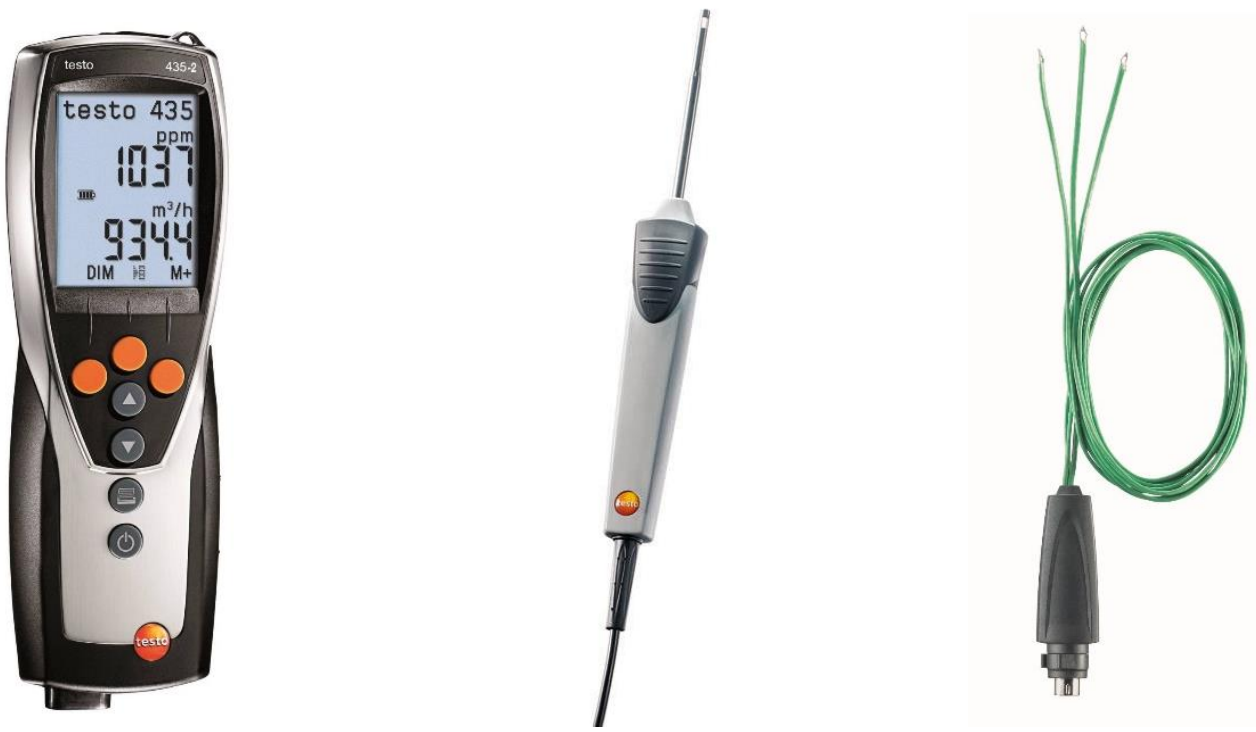

Figura 161. Instrumental de medición para obtener la transmitancia térmica: Izquierda: Registrador y procesador de datos Testo 435-2; Centro: Sonda de $T_{\text {air }}$ Testo 06021793 y Derecha: Sensor de $T_{\text {air }}$ y $\mathrm{T}_{\mathrm{r}}$ Testo 06141635. Fuente: Testo Argentina, https://www.testo.com/es-AR/

\subsection{Termoanemómetro digital de hilo caliente marca CEM (Modelo DT-8880)}

Para la medición de la velocidad del aire se utilizó un anemómetro digital de hilo caliente, cuyos datos se obtienen del enfriamiento producido por la corriente de aire que rodea un pequeño hilo metálico que funciona a modo de resistencia. Este dispositivo cuenta con una agudeza capaz de percibir movimientos de aire desde 0,1 hasta $25 \mathrm{~m} / \mathrm{s}$. Adicionalmente, cuenta con aplicaciones para medir la temperatura y el flujo de aire (volumen/tiempo) y sacar un promedio entre varias muestras. La imagen de la Figura 162 muestra las características exteriores de este dispositivo.

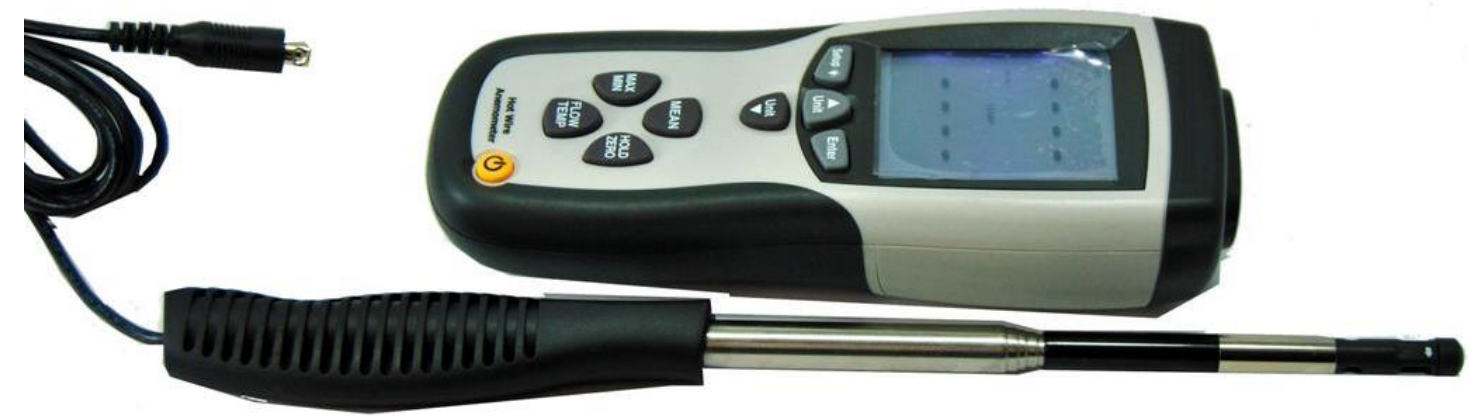

Figura 162. Termoanemómetro de hilo caliente CEM DT-8880. Fuente: Giraldo (2013). 


\subsection{Termómetro infrarrojo marca Extech modelo IR $\mathbf{4 2 5 0 0}$}

Este equipo obtiene la temperatura superficial o temperatura radiante de los elementos constructivos como pisos, paredes o techos. Este dispositivo está equipado con un láser que apunta donde se toma la temperatura y reconoce la cantidad de energía infrarroja emitida por el objeto y su emisividad. Posteriormente, procesa esa información en un sistema que traduce la energía captada en señal eléctrica, y la expresa en valores de temperatura en la pantalla del termómetro. El rango de medición va desde -20 a $260{ }^{\circ} \mathrm{C}$ con una precisión del $98 \%$ al 97\%. La apariencia exterior del instrumento puede verse en la Figura 163.

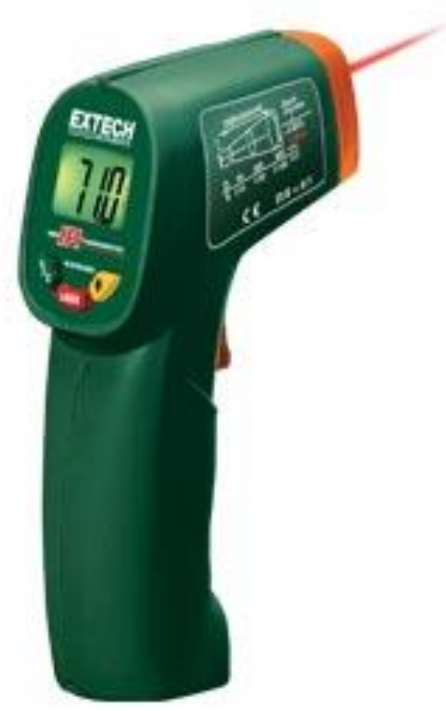

Figura 163. Termómetro infrarrojo marca Extech modelo IR42500. Fuente: Giraldo (2013). 


\section{ANÁLISIS DE PRECIOS UNITARIOS Y COSTO DE IMPLEMENTACIÓN TOTAL POR HABITACIÓN DE LAS SOLUCIONES CONSTRUCTIVAS}

Este apéndice contiene el análisis de precios unitarios (APU) y el cálculo del costo total por habitación de las soluciones constructivas planteadas durante el trabajo, también se realizaron estos mismos cálculos para la alternativa pasiva de EIFS y la alternativa activa de implementación de un equipo de aire acondicionado.

Los APU se realizaron en Pesos Argentinos (ARS), y el costo total se convirtió adicionalmente en otras dos monedas: Dólares Americanos (USD) y Pesos Colombianos (COP). La tasa representativa (TRM) es la siguiente: 18,65 ARS = 1USD = 2.900 COP (Fecha:16-01-2018). 


\begin{tabular}{|c|c|c|c|c|}
\hline \multicolumn{5}{|c|}{ SOLUCIÓN CONSTRUCTIVA DE AUTOSOMBREADO. FECHA: 16 ENERO-2018 } \\
\hline DESCRIPCIÓN & UNIDAD & CANTIDAD & $\begin{array}{c}\text { VALOR } \\
\text { UNITARIO EN } \\
\text { ARS \$ }\end{array}$ & $\begin{array}{c}\text { VALOR TOTAL EN } \\
\text { ARS \$ }\end{array}$ \\
\hline \multicolumn{5}{|l|}{ MATERIALES } \\
\hline Desmoldante & Gal & 0,250 & 4,24 & 1,06 \\
\hline Bastidor madera cepillada Otobo $3 \times 3 \times 300 \mathrm{~cm}$ & UN & 0,110 & 34,08 & 3,75 \\
\hline Puntilla de acero con cabeza 2" & Lb & 0,050 & 14,79 & 0,74 \\
\hline Concreto $1: 2: 3$ & m3 & 0,0033 & 1647,20 & 5,44 \\
\hline MANO DE OBRA & & & 0,00 & \\
\hline $\begin{array}{c}\text { Mano de obra Albañilería (1 Oficial + } 1 \\
\text { Ayudante) }\end{array}$ & $H / C$ & 0,2 & 116,50 & 23,30 \\
\hline EQUIPO & & & 0,00 & \\
\hline Herramienta menor & GL & 0,100 & 9,97 & 1,00 \\
\hline \multirow[t]{2}{*}{ COSTO POR m2 } & & & & 35,28 \\
\hline & LONGITUD & ALTO & (-) VENTANA & \\
\hline $\begin{array}{l}\text { ÁREA TOTAL ENVOLVENTE POR } \\
\text { HABITACIÓN }\end{array}$ & 6,27 & 2,400 & 1,62 & 13,43 \\
\hline COSTO TOTAL POR HABITACIÓN EN ARS & & & & 473,78 \\
\hline COSTO TOTAL POR HABITACIÓN EN USD & & & & 25,40 \\
\hline COSTO TOTAL POR HABITACIÓN EN COP & & & & $73.670,26$ \\
\hline
\end{tabular}

Tabla 44. APU y costo total por habitación para la solución constructiva de Autosombreado. Fuente: Elaboración propia.

\begin{tabular}{|c|c|c|c|c|}
\hline \multicolumn{5}{|c|}{ SOLUCIÓN CONSTRUCTIVA DE BAJA ABSORTIVIDAD. FECHA: 16 ENERO-2018 } \\
\hline DESCRIPCIÓN & UNIDAD & CANTIDAD & $\begin{array}{l}\text { VALOR } \\
\text { UNITARIO } \\
\text { EN ARS \$ }\end{array}$ & $\begin{array}{c}\text { VALOR TOTAL EN } \\
\text { ARS \$ }\end{array}$ \\
\hline \multicolumn{5}{|l|}{ MATERIALES } \\
\hline $\begin{array}{c}\text { Pintura a base de agua, fabricada con } \\
\text { polímeros acrílicos de color blanco y semi } \\
\text { mate. } 3 \text { manos }\end{array}$ & Gal & 0,070 & 331,19 & 23,18 \\
\hline Agua & L & 0,035 & 0,11 & 0,00 \\
\hline \multicolumn{5}{|l|}{ MANO DE OBRA } \\
\hline $\begin{array}{c}\text { Mano de obra Pintura (1 Oficial + } 1 \\
\text { Ayudante) }\end{array}$ & $\mathrm{H} / \mathrm{C}$ & 0,180 & 123,79 & 22,28 \\
\hline \multicolumn{5}{|l|}{ EQUIPO } \\
\hline Herramienta menor & GL & 0,020 & 9,97 & 0,20 \\
\hline Andamio & $\mathrm{U} / \mathrm{D}$ & 0,200 & 25,72 & 5,14 \\
\hline \multirow[t]{2}{*}{ COSTO POR m2 } & & & & 50,81 \\
\hline & LONGITUD & ALTO & (-) VENTANA & \\
\hline $\begin{array}{l}\text { ÁREA TOTAL ENVOLVENTE POR } \\
\text { HABITACIÓN }\end{array}$ & 6,27 & 2,400 & 1,62 & 13,43 \\
\hline COSTO TOTAL POR HABITACIÓN EN ARS & & & & 682,33 \\
\hline COSTO TOTAL POR HABITACIÓN EN USD & & & & 36,59 \\
\hline COSTO TOTAL POR HABITACIÓN EN COP & & & & $106.099,87$ \\
\hline
\end{tabular}

Tabla 45. APU y costo total por habitación para la solución constructiva de Baja absortividad. Fuente: Elaboración propia. 
SOLUCIÓN CONSTRUCTIVA DE REVOQUE REFRACTARIO. FECHA: 16 ENERO-2018

\begin{tabular}{|c|c|c|c|c|}
\hline DESCRIPCIÓN & UNIDAD & CANTIDAD & $\begin{array}{l}\text { VALOR } \\
\text { UNITARIO } \\
\text { EN ARS \$ }\end{array}$ & $\begin{array}{c}\text { VALOR TOTAL EN } \\
\text { ARS \$ }\end{array}$ \\
\hline \multicolumn{5}{|l|}{ MATERIALES } \\
\hline Polvo de ladrillo refractario & $\mathrm{Kg}$ & 5,6 & 14,02 & 78,51 \\
\hline Aglutinante acrílico color blanco & Gal & 0,2 & 327,33 & 65,47 \\
\hline \multicolumn{5}{|l|}{ MANO DE OBRA } \\
\hline $\begin{array}{c}\text { Mano de obra Albañilería (1 Oficial + } 1 \\
\text { Ayudante) }\end{array}$ & $\mathrm{H} / \mathrm{C}$ & 0,5 & 116,50 & 58,25 \\
\hline \multicolumn{5}{|l|}{ EQUIPO } \\
\hline Herramienta menor & GL & 0,1 & 9,97 & 0,50 \\
\hline Andamio & U/D & 0,2 & 25,72 & 5,14 \\
\hline \multirow[t]{2}{*}{ COSTO POR m2 } & & & & 207,87 \\
\hline & LONGITUD & ALTO & (-) VENTANA & \\
\hline $\begin{array}{c}\text { ÁREA TOTAL ENVOLVENTE POR } \\
\text { HABITACIÓN }\end{array}$ & 6,27 & 2,400 & 1,62 & 13,43 \\
\hline COSTO TOTAL POR HABITACIÓN EN ARS & & & & $2.791,25$ \\
\hline COSTO TOTAL POR HABITACIÓN EN USD & & & & 149,67 \\
\hline COSTO TOTAL POR HABITACIÓN EN COP & & & & $434.028,73$ \\
\hline
\end{tabular}

Tabla 46. APU y costo total por habitación para la solución constructiva de Revoque refractario. Fuente: Elaboración propia. 


\begin{tabular}{|c|c|c|c|c|c|}
\hline \multicolumn{6}{|c|}{ SOLUCIÓN CONSTRUCTIVA DE MURO VEGETAL FECHA: 16 ENERO-2018 } \\
\hline DESCRIPCIÓN & UNIDAD & CANTIDAD & $\begin{array}{c}\text { VALOR } \\
\text { UNITARIO } \\
\text { EN ARS \$ }\end{array}$ & & $\begin{array}{l}\text { R TOTAL EN } \\
\text { ARS \$ }\end{array}$ \\
\hline \multicolumn{6}{|l|}{ MATERIALES } \\
\hline Planta ornamental pequeña & UN & 32,000 & 3,22 & & 102,89 \\
\hline Sustrato (Tierra negra) & m3 & 0,050 & 160,77 & & 8,04 \\
\hline Lona reciclada & $\mathrm{m} 2$ & 2,400 & 0,00 & & 0,00 \\
\hline Hilo parafinado $1 \mathrm{~mm}$ & $\mathrm{~mL}$ & 11,000 & 0,79 & & 8,70 \\
\hline $\begin{array}{c}\text { Pintura a base de agua, fabricada con } \\
\text { polímeros acrílicos de color blanco y semi } \\
\text { mate. } 3 \text { manos }\end{array}$ & Gal & 0,050 & 331,19 & & 16,56 \\
\hline Perfil rectangular de PVC $3 \times 2 \mathrm{~cm}$ & UN & 1,000 & 99,42 & & 99,42 \\
\hline $\begin{array}{c}\text { Set de anclaje de nylon } 3 / 8 " \text {, chazo + tornillo + } \\
\text { arandela }\end{array}$ & UN & 18,000 & 3,34 & & 60,19 \\
\hline Agua & L & 1,800 & 0,11 & & 0,20 \\
\hline Sistema de riego (manguera 1/2") & $\mathrm{m}$ & 1,000 & 80,69 & & 80,69 \\
\hline \multicolumn{6}{|l|}{ MANO DE OBRA } \\
\hline Mano de obra fabricación muro verde & $\mathrm{H} / \mathrm{C}$ & 1,000 & 116,50 & & 116,50 \\
\hline $\begin{array}{c}\text { Mano de obra Instalación (1 Oficial + } 1 \\
\text { Ayudante) }\end{array}$ & $\mathrm{H} / \mathrm{C}$ & 0,400 & 116,50 & & 46,60 \\
\hline \multicolumn{6}{|l|}{ EQUIPO } \\
\hline Herramienta menor & GL & 1,000 & 9,97 & & 9,97 \\
\hline Andamio & U/D & 0,100 & 25,72 & & 2,57 \\
\hline \multirow[t]{2}{*}{ COSTO POR m2 } & & & & $\$$ & 552,34 \\
\hline & LONGITUD & ALTO & (-) VENTANA & & \\
\hline $\begin{array}{c}\text { ÁREA TOTAL ENVOLVENTE POR } \\
\text { HABITACIÓN }\end{array}$ & 6,27 & 2,400 & 1,62 & & 13,43 \\
\hline COSTO TOTAL POR HABITACIÓN EN ARS & & & & $\$$ & $7.416,83$ \\
\hline COSTO TOTAL POR HABITACIÓN EN USD & & & & $\$$ & 397,69 \\
\hline COSTO TOTAL POR HABITACIÓN EN COP & & & & $\$$ & $1.153 .287,67$ \\
\hline
\end{tabular}

Tabla 47. APU y costo total por habitación para la solución constructiva de Muro vegetal. Fuente: Elaboración propia. 


\begin{tabular}{|c|c|c|c|c|}
\hline \multicolumn{5}{|c|}{$\begin{array}{l}\text { SOLUCIÓN CONSTRUCTIVA DE AISLAMIENTO REFLECTIVO + BAJA ABSORTIVIDAD. FECHA: } 16 \\
\text { ENERO-2018 }\end{array}$} \\
\hline DESCRIPCIÓN & UNIDAD & CANTIDAD & $\begin{array}{c}\text { VALOR } \\
\text { UNITARIO } \\
\text { EN ARS \$ } \\
\end{array}$ & $\begin{array}{c}\text { VALOR TOTAL EN } \\
\text { ARS \$ }\end{array}$ \\
\hline \multicolumn{5}{|l|}{ MATERIALES } \\
\hline $\begin{array}{l}\text { Lámina opaca de plástico color blanco semi } \\
\text { mate. Espesor } 2 \mathrm{~mm}\end{array}$ & $\mathrm{~m} 2$ & 2,0 & 48,23 & 96,46 \\
\hline $\begin{array}{l}\text { Foil de aluminio natural industrial, espesor } \\
0,01 \mathrm{~mm}\end{array}$ & $\mathrm{~m} 2$ & 2,0 & 4,82 & 9,65 \\
\hline Lámina de PET reciclado. Espesor 0,5mm & $\mathrm{m} 2$ & 1,4 & 5,98 & 8,37 \\
\hline $\begin{array}{l}\text { Set de anclaje de nylon 3/8", chazo + tornillo + } \\
\text { arandela }\end{array}$ & UN & 6,0 & 3,34 & 20,06 \\
\hline \multicolumn{5}{|l|}{ MANO DE OBRA } \\
\hline Mano de obra fabricación panel & GL & 1,0 & 54,66 & 54,66 \\
\hline $\begin{array}{c}\text { Mano de obra panelería (1 Oficial + } 1 \\
\text { Ayudante) }\end{array}$ & $\mathrm{H} / \mathrm{C}$ & 0,6 & 116,50 & 69,90 \\
\hline \multicolumn{5}{|l|}{ EQUIPO } \\
\hline Herramienta menor & GL & 1,0 & 9,97 & 9,97 \\
\hline Andamio & $U / D$ & 0,1 & 25,72 & 2,57 \\
\hline \multirow[t]{2}{*}{ COSTO POR m2 } & & & & 271,65 \\
\hline & LONGITUD & ALTO & (-) VENTANA & \\
\hline $\begin{array}{l}\text { ÁREA TOTAL ENVOLVENTE POR } \\
\text { HABITACIÓN }\end{array}$ & 6,27 & 2,400 & 1,62 & 13,43 \\
\hline COSTO TOTAL POR HABITACIÓN EN ARS & & & & $3.647,72$ \\
\hline COSTO TOTAL POR HABITACIÓN EN USD & & & & 195,59 \\
\hline COSTO TOTAL POR HABITACIÓN EN COP & & & & $567.205,54$ \\
\hline
\end{tabular}

Tabla 48. APU y costo total por habitación para la solución constructiva de Aislamiento reflectivo + Baja absortividad. Fuente: Elaboración propia. 
SOLUCIÓN CONSTRUCTIVA DE EIFS (Exterior Insulation and Finish System) o POLIESTIRENO EXPANDIDO. FECHA: 16 ENERO-2018

\begin{tabular}{|c|c|c|c|c|}
\hline DESCRIPCIÓN & UNIDAD & CANTIDAD & $\begin{array}{l}\text { VALOR } \\
\text { UNITARIO } \\
\text { EN ARS \$ }\end{array}$ & $\begin{array}{c}\text { VALOR TOTAL EN } \\
\text { ARS \$ }\end{array}$ \\
\hline \multicolumn{5}{|l|}{ MATERIALES } \\
\hline $\begin{array}{l}\text { Revoque cementicio modificado con polímeros } \\
\text { acrílicos, utilizado como adhesivo y como base } \\
\text { niveladora. }\end{array}$ & m3 & 0,030 & 2054,78 & 61,64 \\
\hline $\begin{array}{l}\text { Placa de poliestireno expandido, espesor } 5 \mathrm{~cm} \text {, } \\
\qquad 13 \mathrm{~kg} / \mathrm{m} 3\end{array}$ & UN & 1,000 & 265,02 & 265,02 \\
\hline Malla de fibra de vidrio $0,5 \times 0,5 \mathrm{~cm}$ & $\mathrm{~m} 2$ & 1,010 & 80,64 & 81,45 \\
\hline Fijación mecánica & UN & 4,000 & 15,92 & 63,67 \\
\hline Estuco acrílico para exteriores & Gal & 0,250 & 80,39 & 20,10 \\
\hline Pintura acrílica para exteriores & Gal & 0,150 & 417,36 & 62,60 \\
\hline \multicolumn{5}{|l|}{ MANO DE OBRA } \\
\hline Mano de obra fabricación panel & GL & 1,000 & 20,65 & 20,65 \\
\hline $\begin{array}{c}\text { Mano de obra panelería (1 Oficial + } 1 \\
\text { Ayudante) }\end{array}$ & $\mathrm{H} / \mathrm{C}$ & 0,600 & 116,50 & 69,90 \\
\hline \multicolumn{5}{|l|}{ EQUIPO } \\
\hline Herramienta menor & GL & 1,000 & 9,97 & 9,97 \\
\hline Andamio & U/D & 0,100 & 25,72 & 2,57 \\
\hline \multirow[t]{2}{*}{ COSTO POR m2 } & & & & 657,57 \\
\hline & $\begin{array}{l}\text { LONGIT } \\
\text { UD }\end{array}$ & ALTO & $\begin{array}{c}(-) \\
\text { VENTANA }\end{array}$ & \\
\hline $\begin{array}{c}\text { ÁREA TOTAL ENVOLVENTE POR } \\
\text { HABITACIÓN }\end{array}$ & 6,27 & 2,400 & 1,62 & 13,43 \\
\hline COSTO TOTAL POR HABITACIÓN EN ARS & & & & $8.829,80$ \\
\hline COSTO TOTAL POR HABITACIÓN EN USD & & & & 473,45 \\
\hline COSTO TOTAL POR HABITACIÓN EN COP & & & & $1.372 .998,57$ \\
\hline
\end{tabular}

Tabla 49. APU y costo total por habitación para la solución constructiva de EIFS o Poliestireno expandido. Fuente: Elaboración propia. 


\begin{tabular}{|c|c|c|c|c|}
\hline \multicolumn{5}{|c|}{$\begin{array}{l}\begin{array}{l}\text { SUMINISTRO E INSTALACIÓN DE EQUIPO DE AIRE ACONDICIONADO } 12000 \text { Btu FECHA: } 16 \text { ENERO- } \\
2018\end{array} \\
\end{array}$} \\
\hline DESCRIPCIÓN & UNIDAD & CANTIDAD & $\begin{array}{c}\text { VALOR } \\
\text { UNITARIO } \\
\text { EN ARS \$ }\end{array}$ & $\begin{array}{l}\text { VALOR TOTAL EN } \\
\text { ARS \$ }\end{array}$ \\
\hline \multicolumn{5}{|l|}{ MATERIALES } \\
\hline $\begin{array}{l}\text { Suministro de unidad condensadora y salida } \\
\text { mini split } 12000 \text { Btu }\end{array}$ & UN & 1,000 & 8038,59 & 8038,59 \\
\hline Acometida eléctrica $110 \mathrm{~V}$ & UN & 1,000 & 3858,52 & 3858,52 \\
\hline Tubo PVC 3/4" & $\mathrm{m}$ & 6,000 & 20,69 & 124,17 \\
\hline Soldadura CPVC 1/4 galón & UN & 0,100 & 334,08 & 33,41 \\
\hline Limpiador PVC 1/4 galón & UN & 0,100 & 246,95 & 24,69 \\
\hline Unión presión PVC .3/4 & UN & 4,000 & 2,96 & 11,83 \\
\hline Codo presión PVC .3/4 & UN & 2,000 & 4,91 & 9,83 \\
\hline Tubo PVC 1"'" x 3 m & UN & 0,340 & 41,16 & 13,99 \\
\hline Estuco acrílico para exteriores & Gal & 1,630 & 80,39 & 131,03 \\
\hline Pintura acrílica para exteriores & Gal & 0,960 & 417,36 & 400,67 \\
\hline \multicolumn{5}{|l|}{ MANO DE OBRA } \\
\hline $\begin{array}{l}\text { Mano de obra instalación equipo Aire } \\
\text { acondicionado }\end{array}$ & GL & 1,000 & 2893,89 & 2893,89 \\
\hline Mano de obra eléctrica (1 Oficial + 1 Ayudante) & $\mathrm{H} / \mathrm{C}$ & 23,000 & 163,11 & 3751,44 \\
\hline $\begin{array}{l}\text { Mano de obra Hidrosanitaria (1 Oficial + } 1 \\
\text { Ayudante) }\end{array}$ & $\mathrm{H} / \mathrm{C}$ & 10,000 & 163,11 & 1631,06 \\
\hline \multicolumn{5}{|l|}{ EQUIPO } \\
\hline Herramienta menor & GL & 1,000 & 9,97 & 9,97 \\
\hline Andamio & U/D & 6,000 & 25,72 & 154,34 \\
\hline COSTO POR m2 & & & & $21.087,43$ \\
\hline EQUIPOS POR HABITACIÓN & & & & 1,00 \\
\hline COSTO TOTAL POR HABITACIÓN EN ARS & & & & $21.087,43$ \\
\hline COSTO TOTAL POR HABITACIÓN EN USD & & & & $1.130,69$ \\
\hline COSTO TOTAL POR HABITACIÓN EN COP & & & & $3.279 .010,20$ \\
\hline
\end{tabular}

Tabla 50. APU y costo total por habitación del suministro e instalación de un equipo de aire acondicionado 12000Btu. Fuente: Elaboración propia. 


\section{BIBLIOGRAFÍA}

(DOE), U. D. (2016). Passive Solar Home Design,. Recuperado el 7 de 6 de 2017, de http://energy.gov/energysaver/passive-solar-home-design).

Aditya, L., Mahlia, T. I., Rismanchi, B., Ng, H. M., Hasan, M. H., Metselaar, H. C., . . Aditiya, H. B. (2017). A review on insulation materials for energy conservation in buildings. Renewable and Sustainable Energy Reviews, 73, 1352-1365. doi:http://dx.doi.org/10.1016/j.rser.2017.02.034

Al-Anzi, A., \& Khattab, O. (2010). Solar conscious house design in Kuwait. Kuwait Journal of Science and Engineering, 37, 59-72.

Alcaldía de Santiago de Cali. (2014). Cali en cifras 2014. Cali.

Al-Homoud, M. S. (2005). Performance characteristics and practical applications of common building thermal insulation materials. Building and Environment, 40, 353-366. doi:10.1016/j.buildenv.2004.05.013

Al-Sanea, S., Zedan, M. F., \& Al-Hussain, S. N. (2013). Effect of masonry material and surface absorptivity on critical thermal mass in insulated building walls. Applied Energy, 102, $1063-1070$.

Alto Comisionado para los Derechos Humanos, Organización de las Naciones Unidas. (2009). Folleto Informativo N0. 21, El derecho a una vivienda digna.

American Society for Testing and Materials. (1993). Standard Test Method for Steady-State Thermal Performance of Building Assemblies by Means of a Guarded Hot Box.

American Society for Testing and Materials. (2000). ASTM E 1933 - 99a Standard Test Methods for Measuring and Compensating for Emissivity Using Infrared Imaging Radiometers. Filadelfia: American Society for Testing and Materials. 
American Society of Heating Refrigerating and Air Conditioned Engineers [ASHRAE]. (2017). ASHRAE STANDARD 55-2017 Thermal environmental conditions for human occupancy. Atlanta.

American Society of Heating Refrigerating and Air-conditioning engineers [ASHRAE]. (2001). Handbook Fundamentals. Atlanta, United States.

Aparicio-Fernández, C., Vivancos, J.-L., Ferrer-Gisbert, P., \& Royo-Pastor, R. (2014). Energy performance of a ventilated façade by simulation with experimental validation. Applied Thermal Engineering, 66, 563-570. doi:http://dx.doi.org/10.1016/j.applthermaleng

ASHRAE. (2013). Handbook of Fundamentals.

Asociación Colombiana de Ingeniería Sísmica. (2010). Norma Sismoresistente 2010. Bogotá, Colombia.

Associação Brasileira de Normas Técnicas (ABNT). (2016). Norma Brasileira de Conforto Térmico. São Paulo: Associação Brasileira de Normas Técnicas (ABNT).

Azraai, S. B., Ali, M. I., Salleh, S. S., \& Asaroon, O. (2012). Impact of Applying Radiant Barrier Fitted Beneath the Roof in Hot and Humid Climates. Proceedings of the International Conference on Science, Technology and Social Sciences (ICSTSS), 751-755. doi:10.1007/978-981-287-077-3_89

Baldinelli, G. (2010). A methodology for experimental evaluations of low-e barriers thermal properties: Field tests and comparison with theoretical models. Building and Environment, 45, 1016-1024. doi:doi:10.1016/j.buildenv.2009.10.009

Barona, J. (2016). Análisis y evaluación del comportamiento térmico de dos envolventes arquitectónicas utilizadas en la vivienda de interés social en santiago de Cali. (Tesis de Maestría). Santiago de Cali: Universidad del Valle.

Bekkouche, S. M., Benouaz, T., Yaiche, M. R., Cherier, M. K., Hamdani, M., \& Chellali, F. (2011). Introduction to Control of Solar gain and internal temperatures by thermal insulation, proper orientation and eaves. Energy and Buildings, 2414-2421. doi:10.1016/j.enbuild.2011.05.018

Bermúdez, M. (1987). Asoleamiento, Teoría General y Diagramas. Medellín.

Blanco, J. M. (2014). Investigating the thermal behavior of double-skin perforated sheet façades: Part A: Model characterization and validation procedure. Building and Environment(82), 50-62. 
Blender, M. (2015). Arquitectura y Energía. Recuperado el 21 de 08 de 2017, de http://www.arquitecturayenergia.cl/home/el-confort-termico/

Bolton, C., Rahman, M. A., Armson, D., \& Ennos, A. R. (2014). Effectiveness of an ivy covering at insulating a building against the cold in Manchester, U.K: A preliminary investigation. Building and Environment, 80, 32-35.

Buzatu, G. C., Stan Ivan, F. E., Mircea, P. M., \& Manescu, L. G. (2017). Thermal transmittance determination for different components of buildings. International Conference on Optimization of Electrical and Electronic Equipment (OPTIM) \& 2017 Intl Aegean Conference on Electrical Machines and Power Electronics (ACEMP). Brasov, Rumania.

Cameron, R. W., Taylor, J. E., \& Emmett, M. R. (2014). What's 'cool' in the world of green façades? How plant choice influences the cooling properties of green walls. Building and Environment, 73, 198-207. doi:https://doi.org/10.1016/j.buildenv.2013.12.005

Canales Gálvez, M. E. (2014). Efectos del uso de techos y fachadas vegetales en el comportamiento térmico de edificios. Santiago de Chile.

Capeluto, I. G. (2003). Energy performance of the self-shading building envelope. Energy and Buildings, 35, 327-336. doi:https://doi.org/10.1016/S0378-7788(02)00105-6

Casas Figueroa, M. L. (2002). Costos del proceso de edificación. Santiago de Cali: FAID Editores.

Ceballos, O., Saldarriaga, A., \& Tarcópulos, D. (2008). Vivienda Social en Colombia: Una mirada desde la Legislación 1918-2007. Bogotá: Pontificia Universidad Javeriana.

Cementos CEMEX. (5 de Marzo de 2018). Cementos CEMEX. Recuperado el 25 de 08 de 2017, de http://www.cemexmexico.com/Content/descargables/aplicaciones-manualconstruccion-general.pdf

Cengel, Y. A. (2003). Heat Transfer: A practical approach. McGraw-Hill.

Cengel, Y. A., \& Ghajar, A. J. (2015). Heat and Mass Transfer: Fundamentals and Applications. USA: McGraw-Hill.

Chan, A. L., \& Chow, T. T. (2014). Thermal performance of air-conditioned office buildings constructed with inclined walls in different climates in China. Applied Energy, 114, 4557. doi:https://doi.org/10.1016/j.apenergy.2013.09.048 
Chan, A. S. (2012). Effect of adjacent shading on the thermal performance ofresidential buildings in a subtropical region. Applied Energy, 92, 516-522.

Chávez, P., \& D., Q. (2008). Diseño y construcción de un medidor de conductividad térmica para materiales aislantes. Cali: Universidad del Valle.

Cheng, C. Y., Cheung, K. K., \& Chu, L. M. (2010). Thermal performance of a vegetated cladding system on facade walls. Building and Environment, 45, 1779-1787. doi:https://doi.org/10.1016/j.buildenv.2010.02.005

Cheng, V., Ng, E., \& Givoni, B. (2005). Effect of envelope colour and thermal mass on indoor temperatures in hot humid climate. Solar Energy, 78, 528-534.

Chirarattananon, S., Hien, V. D., \& Tummu, P. (2012). Thermal performance and cost effectiveness of wall insulation under Thai climate. Energy and Buildings, 45, 82-90. doi:10.1016/j.enbuild.2011.10.025

Cho, J., Yoo, C., \& Kim, Y. (2014). Viability of exterior shading devices for high-rise residential buildings: Case study for cooling energy saving and economic feasibility analysis. Energy and Buildings, 82, 771-785. doi:http://dx.doi.org/10.1016/j.enbuild.2014.07.092

Chui, E. B., \& Raithby, G. D. (1993). Chui, EComputation of radiant heat transfer on a nonorthogonal mesh using the finite-volume method. Heat Transfer(23), 269-288.

Coch Roura, H., \& Serrá Florensa, R. (1995). Arquitectura y Energía Natural. Barcelona: Ediciones UPC.

Coma, J., Pérez, G., de García, A., Burés, S., Urrestarazu, M., \& Cabeza, L. F. (2017). Vertical greenery systems for energy savings in buildings: A comparative study between green walls and green facades. Building and Environment, 111, 228-237.

Congreso de Colombia. (1991). Ley 3 de 1991 - Sistema Nacional de Vivienda de Interés Social. Colombia.

Obtenido de https://camacol.co/sites/default/files/base_datos_juridico/LEY_CONGRESO_NACION _0003_1991.pdf

Congreso de Colombia. (1997). Ley 388 de 1997. Bogotá. Obtenido de http://recursos.ccb.org.co/ccb/pot/PC/files/ley388.html

Congreso de Colombia. (2011). Ley 1450 de 2011. Bogotá, Colombia. Obtenido de https://www.procuraduria.gov.co/portal/media/file/docs/ddr/CompiladoNormativo_Part e3.pdf 
Czajkowski, J. D., \& Gómez, A. F. (1994). Diseño bioclimático y economía energética edilicia. Fundamentos y Métodos. La Plata, Argentina: UNLP.

De la Peña González, A. M., \& Quintero Díaz, G. (2011). Arquitectura y Medio Ambiente. Habana, Cuba: Efe Consultores.

Departamento Administrativo Nacional de Estadística - DANE. (24 de 02 de 2018). DANE. Recuperado el 09 de Mayo de 2017, de https://www.dane.gov.co/index.php/estadisticas-por-tema/pobreza-y-condiciones-devida/deficit-de-vivienda

Departamento de Sismología e Información Meteorológica. Estación Meteorológica Automática. La Plata Observatorio. (6 de Marzo de 2018). Estación Meteorológica Automática, La Plata Observatorio. (Universidad Nacional de La Plata.) Recuperado el Enero - Marzo de 2016, de http://meteo.fcaglp.unlp.edu.ar/

Departamento Nacional de Estadística DANE. (Febrero de 2017). DANE. Recuperado el 2017 de Mayo de 2017, de http://www.dane.gov.co

Department of Technology and Built Environment - Laboratory of Ventilation and Air Quality University of Gävle. (s.f.). PMV Calc v2. Gävle.

Dittmar, A. (1995). Le corps humain un systeme thermique complexe. Congrés Anuel de la Societé Francaise des Thermiciens. Elsevier, 29.

Duffie, J. A., \& Beckman, W. A. (2013). Solar Engineering of Thermal Processes. New Jersey: John Wiley \& Sons.

Dunkle, R. (1963). Configuration factors for radiant heat-transfer calculations involving people. Heat Transfer, 85(1), 71-76.

Dunkle, R. V. (1963). Configuration factors for radiant heat-transfer calculations involving people. Heat Transfer, 85(1), 71-76.

Duran Peralta, H. A., \& Mesa, L. A. (2006). Metodología para determinación de factores de forma de radiación aplicada a la configuración particular plano-esfera. Ingeniería e Investigación, 26(1).

Echeverry Campos, D., \& MetroVivienda. (2000). Vivienda de Interés Social: Inventario de Sistemas Constructivos. Bogotá: Universidad de los Andes,Departamento de Ingeniería Civil y Ambiental, Area de Ingeniería y Gerencia de la Construcción. 
Edumedia. (27 de Febrero de 2018). Recuperado el 20 de Junio de 2016, de https://www.edumedia-sciences.com/es/media/679-movimiento-aparente-del-solnorte

El rincón del vago. (27 de Febrero de 2018). Recuperado el 20 de Junio de 2016, de http://html.rincondelvago.com/movimientos-de-la-tierra-respecto-del-sol.html

Escallón G., C. (2011). La vivienda de interés social en Colombia, principios y retos. Revista de Ingeniería(35), 55-60.

Escudero, C., Martin, K., Erkoreka, A., Flores, I., \& Sala, J. M. (2013). Experimental thermal characterization of radiant barriers for building insulation. Energy and Buildings, 62-72. doi:http://dx.doi.org/10.1016/j.enbuild.2012.12.043

Esteves, A., De Rosa, C., Basso, M., Cortegosso, J., \& Atencio, M. (1988). Potencial solar de entornos urbanos en la ciudad de Mendoza - >Primeros resultados. ASADES (Asociación Argentina de Energía Solar(. Salta.

ETERNIT. (2017). VIVIENDAS ETERNIT. Recuperado el 18 de Mayo de 2017, de http://www.eternit.com.co/index.php?option=com_content\&view=article\&id=12:viviend as-y-cabinas-sanitarias\&catid=12:viviendas-y-cabinassanitarias\&Itemid=35\#descargas

Eumorfopoulou, E. A., \& Kontoleon, K. J. (2009). Experimental approach to the contribution of plant-covered walls to the thermal behaviour of building envelopes. Building and Environment, 44, 1024-1038. doi:https://doi.org/10.1016/j.buildenv.2008.07.004

Evangelisti, L., Guattari, C., Gori, P., \& Asdrubali, F. (2018). Assessment of equivalent thermal properties of multilayer building walls coupling simulations and experimental measurements. Building and Environment, 77-85. doi:http://dx.doi.org/10.1016/j.buildenv.2017.10.038

Fajardo Velasco, L. F. (2005). Desempeño costo-beneficio de dos sistemas pasivos de climatización en cubiertas para climas cálidos- subhúmedo (Tesis de maestría). Colima, México.

Obtenido de http://digeset.ucol.mx/tesis_posgrado/Pdf/Luis_Fajardo_Velasco.pdf

Fanger, P. O. (1970). Thermal Comfort. New York: Mc Graw Hill.

Fantucci, S., Marinosci, C., Serra, V., \& Carbonaro, C. (2017). Thermal performance assessment of an opaque ventilated façade in the summer period: calibration of a 
simulation model through in-field measurements. Energy Procedia, 111, $619-628$. doi:doi: 10.1016/j.egypro.2017.03.224

Franco, J. T. (25 de Junio de 2015). Plataforma Arquitectura. Recuperado el 11 de Enero de 2017, de http://www.plataformaarquitectura.cl/cl/769123/en-detalle-bloque-de-ladrillotermodisipador-desarrollado-en-colombia

Freewan, A. A. (2014). Impact of external shading devices on thermal and daylighting performance of offices in hot climate regions. Solar Energy, 102, 14-30. doi:http://dx.doi.org/10.1016/j.solener.2014.01.009

Fundación de la Energía de la Comunidad de Madrid. (2011). Guía de la termografía infrarroja, aplicaciones en ahorro y eficiencia energética. Madrid: Gráficas Arias Montano, S.A.

G, B. (2009). Double skin facades for warm climate regions: Analysis of a solution with an. Building and Environment, 44(6), 1107-1118.

Gagliano, A., Nocera, F., \& Aneli, S. (2016). Thermodynamic analysis of ventilated fac, ades under different wind conditions in summer period. Energy and Buildings, 122, 131-139. doi:http://dx.doi.org/10.1016/j.enbuild.2016.04.035

Gamboa, J., Rosillo, M. E., Herrera Cáceres, C. A., López Bernal, O., \& Iglesias, V. (2011). Confort Ambiental en Vivienda de Interés Social en Cali. Santiago de Cali: Universidad del Valle.

García López, J. D., Stand Villareal, F., Gómez Cabrera, A., \& Nuñez Moreno, F. A. (2016). Comparación de los principales sistemas constructivos de VIS en Colombia, desde una perspectiva de sostenibilidad, empleando BIM: caso estudio en Soacha. Bogotá: Pontificia Universidad Javeriana. Obtenido de https://repository.javeriana.edu.co/handle/10554/19639

Geetha, N. B., \& Velraj, R. (2012). Passive cooling methods for energy efficient buildingswith and without thermal energy storage -a review. energy education science and technology Part A(29), 913-946.

Giraldo, W. (2013). Diágnostico y Mejoramiento del Comportamiento Térmico y la Ventilación en Viviendas de Interés Social en Cali con Medios Pasivos. Cali.

Giraldo, W., \& Herrera, C. (2017). Ventilación pasiva y confort térmico en vivienda de interés social en clima ecuatorial. Ingeniería y desarrollo, 35(1), 77-101. doi:http://dx.doi.org/10.14482/inde.35.1.8944 
Givoni, B. (1976). Man, Climate and Architecture. London: Applied Science Publishers.

Givoni, B. (1992). Confort, climate analysis and building design guidelines. Energy and Buildings, 18, 11-23.

Givoni, B. (20 de Noviembre de 2002). Chile debe desarrollar estándares de confort locales. (U. y. Facultad de Arquitectura, Entrevistador)

Gobernación del Valle del Cauca. (7 de 3 de 2016). Gobernación del Valle del Cauca, Documentos Corporativos. Recuperado el 3 de 6 de 2017, de http://www.valledelcauca.gov.co/vivienda/documentos.php?id=1417

Gobernación del Valle del Cauca, Colombia. (27 de Junio de 2017). Gobernación del Valle del Cauca. Recuperado el 17 de Julio de 2017, de http://www.valledelcauca.gov.co/vivienda/documentos.php?id=1018

Gon, K., Hong Soo, L., Tae Sub, L., Schaefer, L., \& Jeong Tai, K. (2012). Comparative advantage of an exterior shading device in thermal performance for residential buildings. Energy and Buildings, 46, 105-111.

Guo, W., Qiao, X., Huang, Y., Fang, M., \& Han, X. (2012). Study on energy saving effect of heat-reflective insulation coating on envelopes in the hot summer and cold winter zone. Energy and Buildings, 50, 196-203. doi:10.1016/j.enbuild.2012.03.035

Haggag, M., Hassan, A., \& Elmasry, S. (2014). Experimental study on reduced heat gain through green façades in a high heat load climate. Energy and Buildings, 82, 668-674. doi:https://doi.org/10.1016/j.enbuild.2014.07.087

Hakim, C. (2005). Modelos de familia en las sociedades modernas. Ideales y realidades. Ed. Centro Investigaciones Sociológicas.

Han, K. C., R. E., \& E. W. (2012). Structured surfaces for enhanced pool boiling. Applied Physics Letters, 24, 100. doi:http://doi.org/10.1063/1.4724190

Han, K. C., R. E., \& E. W. (2012). Structured surfaces for enhanced pool boiling. Applied Physics Letters, 24, 100. doi:http://doi.org/10.1063/1.4724190

Harold Borrero, 1. (1989). Arquitectura y Clima referida a condiciones tropicales en Colombia. Cali, Colombia: Universidad del Valle, Facultad de Arquitectura, Departamento de Tecnología, Sección de Acondicionamiento Ambiental. 
Harvey, D. (2009). Reducing energy use in the buildings sector: measures, costs, and examples. Energy Efficiency(2), 139-163.

Hashemi, A., \& Khatami, N. (2017). Effects of solar shading on thermal comfort in low-income tropical housing. Energy Procedia(111), 235-244.

Hedge. (2004). CORNELL UNIVERSITY. Recuperado el 2012, de http://ergo.human.cornell.edu/studentdownloads/DEA350notes/Thermal/thcomnotes1 .html

Hedge, A. (2004). Linking Environmental Conditions toProductivity"2004. Recuperado el 16 de Enero de 2018, de http://ergo.human.cornell.edu/Conferences/EECE_IEQ\%20and\%20Productivity_ABB R.pdf

Hemenway, D., Sakura, H., \& Sampath, W. (s.f.). Thermal Modeling of PV Modules Using Computational Simulation. Recuperado el 29 de Septiembre de 2016, de http://ieeexplore.ieee.org/stamp.jsp?arnumber=6925166

Hernandez Sampieri, R., Fernández Collado, C., \& Baptista Lucio, P. (2006). Metodología de la Investigación. Ciudad de México: McGraw-Hill.

Hoyano, A. (1988). Climatological uses of plants for solar control and the effects on the thermal environment of a building. Energy and Buildings, 11, 181-199.

Ibañez-Puy, M., Vidaurre-Arbizu, M., Sacristán-Fernandez, J. A., \& Martín-Gómez, C. (2017). Opaque Ventilated Façades: Thermal and energy performance review. Renewable and Sustainable Energy Reviews, 180-191. doi:http://dx.doi.org/10.1016/j.rser.2017.05.059

IDEAM, Instituto de Hidrología, Meteorología y Estudios Ambientales, Tiempo y Clima en Colombia,. (16 de 05 de 2016). IDEAM. Recuperado el 16 de 05 de 2016, de http://www.ideam.gov.co/web/tiempo-y-clima/clima,2016.

IDEAM, P. d. (2015). Inventario nacional de gases de efecto invernadero (GEI) de Colombia. Tercera Comunicación Nacional de Cambio Climático de Colombia. Bogotá, Colombia. Incropera, F., Dewitt, D., Bergman, T., \& Lavine, A. (2007). Fundamentals of heat and Mass Transfer. Indiana, USA: John Wiley \& Sons.

Inicios del alcantarillado de Medellín 1920-1955. (21). Historelo, 251-284. doi:https://doi.org/10.15446/historelo.v7n14.47022 
Instituto Argentino de Normalización IRAM. (2002). Norma Argentina IRAM 11601: Aislamiento térmico de edificios - Métodos de Cálculo - Propiedades térmicas de los componentes en régimen estacionario. Buenos Aires: IRAM.

Instituto Argentino de Normalización y Certificación. (s.f.). Determinación de las propiedades de transmisión de calor en régimen estacionario de elementos de construcción. Método de la caja caliente con caja de guarda.

Instituto Colombiano de Normas Técnicas. (2000). NORMA NTC 4205, Ladrillos y bloques cerámicos.

Instituto Colombiano de Productores de Cemento. (1986). Fabricación de bloques de concreto. Medellín: CAMACOL.

Instituto Nacional de Vivienda de Interés Social y Reforma Urbana INURBE. (1996). Estado, Ciudad y Vivienda: Urbanismo y Arquitectura de la Vivienda en Colombia 1918-1990. Bogotá: Corporación Colegio de Villa de Leyva, CCEHAP Medellín, CITCE Cali. .

International Organization for Standardization [ISO]. (2005). Ergonomía del ambiente térmico. Determinación analítica e interpretación del bienestar térmico mediante el cálculo de los índices PMV y PPD y los criterios de bienestar térmico local (ISO 7730:2005). Génova: International Organization for Standardization.

International Organization for Standardization. (1997). ISO 8990:1994 Determinación de las propiedades de transmisión térmica en régimen estacionario. Métodos de la caja caliente guardada y calibrada. Madrid: AENOR Asociación Española de Normalización y Certificación.

International Organization for Standardization. (2002). ISO 7726: Ergonomics of the thermal environment - Instruments for measuring physical quantities. Génova, Suiza: International Organization for Standardization.

International Organization for Standardization. (2008). ISO 18434-1:2008: Condition monitoring and diagnostics of machines - Thermography- . Génova, Suiza.: International Organization for Standardization.

Iturre Campiño, A. (2013). Proyectar mejoras del confort térmico en la vivienda de interés social Buenaventura Caso: Barrio ciudadela Nueva Buenaventura. Cali.

Jim, C. Y. (2015). Thermal performance of climber greenwalls: effects of solar irradiance and orientation. Applied Energy, 15, 4631-4643. 
Juanicó, L. E., \& González, A. D. (2017). Thermal insulators with multiple air gaps: Performance, cost and embodied impacts. Journal of Building Engeniering, 12(Julio 2017), 188-195. doi:https://doi.org/10.1016/j.jobe.2017.06.005

Kang, P., \& Yang, H. (2013). Preparation of Aerogel-Modified Expanded Perlite and Its Application in Heat Insulation Coating. Advanced Materials Research, 668, 360-364. doi:10.4028/www.scientific.net/AMR.668.360

Kántor, N., \& János, U. (2011). The most problematic variable in the course of human biometereological comfort assesment, the mean radiant temperature. Central European Journal of Geoscience, 3(1), 90-100.

Khelifa, A., Touafek, K., Moussa, B., Tabet, I., Ben cheikh El hocine , H., \& Haloui, H. (2015). Analysis of a Hybrid Solar Collector Photovoltaic Thermal (PVT). Energy Procedia(74), $835-843$.

Köhler, M. (2008). Green façades e a view back and some visions, Urban Ecosyst. 11. Urban Ecosystems, 11, 423-436.

Koranteng, C., \& Abaitey, , E. G. (2009). Simulation based analysis on the effects oforientation on energy performance of residential buildings in Ghana. Journal of Science and Technology, 29, 86-101.

Koyama, T., Yoshinaga, M., Hayashi, H., Maeda, K.-i., \& Yamauchi, A. (2013). Identification of key plant traits contributing to the cooling effects of green façades using freestanding walls. Building and Environment, 66, 96-103.

Kuhn, T. E. (2006). Solar control: Comparsion of two new systems with the state of the art on the basis of a new general evaluation method for facades with venetian blinds or other solar control systems. Energy and Buildings, 38, 661-672.

Kvisgaard, B. (1997). “Thermal Comfort. Copenhague: Brüel\&Kjær.

L, C. (2012). Energy saving and environmental resources potentials: Toward new methods of building design. Building andEnvironment, 58, 199-207.

Labat, M., Woloszyn, M., Garnier, G., Rusaouen, G., \& Roux, J. (2012). Impact of direct solar irradiance on heat transfer behind an open-jointed ventilated cladding: experimental and numerical investigations. Solar Rnergy, 86, 2549-2560. doi:dx.doi.org/10.1016/j.solener.2012.05.030

Laboratório de Eficiência Energética em Edificações. (2016). SOL-AR 6.2. Florianópolis. 
Launder, B. E., \& Spalding, D. B. (1983). The numerical computation of turbulent flows. En Numerical Prediction of Flow, Heat Transfer, Turbulence and Combustion (págs. 96116). London, United Kingdom.

Ledesma Jimeno, M. (2011). Principios de Meteorología y Climatología. Madrid (España): Ediciones Paraninfo S.A.

Lee, W. S., Lim, H. C., \& Salleh, B. (2016). Reflective thermal insulation systems in building: A review on radiant barrier and reflective insulation. Renewable and Sustainable Energy Reviews, 65, 643-661. doi:http://dx.doi.org/10.1016/j.rser.2016.07.002

Lo, L. G.-R.-L. (2014). Passive shading strategies to reduce outdoor insolation and indoor cooling loads by using overhang devices on a building. Building Simulation, 7, 671-681. doi:10.1007/s12273-014-0182-7

Machado, M., Brito, C., \& Neila, J. (2000). La cubierta ecológica como material de construcción. Informes de la construcción, 52, 15-29.

Manso, M., \& Castro-gomes, J. (2015). Greenwallsystems :A review of their characteristics. Renewable and Sustainable Energy Reviews, 41, 863-871. doi:http://dx.doi.org/10.1016/j.rser.2014.07.203

Manso, M., \& Castro-Gomes, J. P. (2016). Thermal analysisofanewmodularsystemforgreenwalls. Journal ofBuildingEngineering, 7, 53-62. doi:http://dx.doi.org/10.1016/j.jobe.2016.03.006

Mazzali, U., Peron, F., Romagnoni, P., Pulselli, R. M., \& Bastianoni, S. (2013). Experimental investigation on the energy performance of Living Walls in a temperate climate. Building and Environment, 64, 66. doi:https://doi.org/10.1016/j.buildenv.2013.03.005

Mercader, M. (27 de Febrero de 2018). El blog de miguel mercader. Recuperado el 20 de Junio de 2016, de http://elblogdemiguelmercader.blogspot.com.ar/2015/05/5-laesfera-y-globo-terraqueo.html

Mingzhe, L., Wittchen, K. B., \& Heisel, P. K. (2015). Control strategies for intelligent glazed façade and their influence on energy and comfort performance of office buildings in Denmark. Applied Energy, 145, 43-51. 
Ministerio de Ambiente, Vivienda y Desarrollo Territorial, República de Colombia. (2011). Calidad en la Vivienda de Interés Social (Series Guías de Asistencia Técnica para Vivienda de Interés Social). Bogotá: Nuevas Ediciones S.A.

Ministerio de Minas y Energía. (2009). Reglamento Técnico de lluminación y Alumbrado Público. Bogotá, Colombia. Obtenido de https://www.minminas.gov.co/retilap

Ministerio de Minas y Energía. (2013). Reglamento Técnico de Instalaciones Eléctricas. Bogotá, Colombia. Obtenido de https://www.minminas.gov.co/retie

Ministerio de Vivienda, Ciudad y Territorio. (2015). Resolución nº 0549 - Parámetros y lineamientos de construcción sostenible - Guía para el ahorro de agua y energía en edificaciones. Reglamento del Capítulo 1 del Título 7 de la parte 2, del libro 2 del Decreto 1.077 de 2015. Bogotá.

Ministerio de Vivienda, Ciudad y Territorio de Colombia. (22 de Febrero de 2018). MINVIVIENDA. Recuperado el 18 de Noviembre de 2016, de http://www.minvivienda.gov.co/viceministerios/viceministerio-de-vivienda/vis-y-vip

MINVIVIENDA. (2000). Reglamento Técnico del Sector de Agua Potable y Saneamiento Básico (RAS). Bogotá, Colombia. Obtenido de http://www.minvivienda.gov.co/viceministerios/viceministerio-de-agua/reglamentotecnico-del-sector/reglamento-tecnico-del-sector-de-agua-potable

Moon, J. H., Woon Lee, J., Jeong, C. H., \& Lee, H. (2016). Thermal comfort analysis in a passenger compartment considering the solar radiation effect. International Journal of Thermal Sciences(107), 77-88.

Morales, M. P., \& Juárez, M. C. (2011). Study of the geometry of a voided clay brick using rectangular perforations to optimize its thermal properties. Applied Thermal Engineering, 31, 2063-2062.

National Renewable Energy Laboratory. (8 de Marzo de 2018). OpenStudio. (National Renewable Laboratory) Recuperado el 08 de Enero de 2018, de http://nrel.github.io/OpenStudio-user-documentation/getting_started/getting_started/

Nazarian, N., \& Kleissl, J. (2015). CFD simulation of an idealized urban environment: Thermal effects of geometrical characteristics and surface materials. Urban Climate(12), 141159. 
Nazarian, N., \& Kleissl, J. (2016). Realistic solar heating in urban areas: Air exchange and street-canyon ventilation. Building and Environment(95), 75-93.

Nikpour, M., Zin Kandar, M., Ghasemi, M., \& Ghomeshi, M. (2012). Heat transfer reduction using self shading strategy in energy comissionbuilding in Malaysia. Journal of Applied Sciences, 12, 897-901. doi:10.3923/jas.2012.897.901

Oak Ridge National Laboratory. (21 de 03 de 2018). Innovations in Buildings. Recuperado el 16 de 06 de 2017, de http://web.ornl.gov/sci/buildings/tools/radiant/

Odunfa, K. M., Odunfa, V. O., Ojo, T. O., \& Ohunakin, O. S. (2015). Energy efficiency in building: case of buildings at the University of Ibadan, Nigeria. Journal of Building Construction and Planning Research, 3, 18-26.

Olgyay, V. (1998.). Arquitectura y Clima: Manual de Diseño Bioclimático para Arquitectos y Urbanistas. Gustavo Gili.

Olivieri, F., Olivieri, L., \& Neila, J. (2014). Experimental study of the thermal-energy performance of an insulated vegetal façade under summer conditions in a continental mediterranean climate. Building and Environment, 77, 61-76. doi:https://doi.org/10.1016/j.buildenv.2014.03.019

Organización de las Naciones Unidas. (1987). Informe Brundtland.

Osuna Motta, I. (2017). Techo plantado como dispositivo de climatización pasiva en el trópico. Revista de Arquitectura, 42-55. doi:http://dx.doi.org/10.14718/RevArq.2017.19.1.1109

Parra, J., Guardo, A., Egusquiza, E., \& Alavedra, P. (2015). Thermal Performance of Ventilated Double Skin Façades with Venetian Blinds. Energies(8), 4882-4898. doi:10.3390/en8064882

Patania, F., Gagliano, A., Nocera, F., \& Galesi, A. (2010). Thermofluid-dynamic analysis of ventilated facades. Energy and buildings, 42, 1148-1155. doi:http://dx.doi.org/10.1016/j.enbuild.2010.02.006

Pavlou, D. G. (2015). Essentials of the Finite Element Method.

Pérez, G., Coma, J., Sol, S., \& Cabeza, L. F. (2017). Green facade for energy savings in buildings: The influence of leaf area index and facade orientation on the shadow effect. Applied Energy, 187, 424-437. doi:https://doi.org.bd.univalle.edu.co/10.1016/j.apenergy.2016.11.055 
Pérez, G., Rincón, L., González, J. M., \& Cabeza, L. F. (2011). Behaviour of green facades in Mediterranean Continental climate. Energy Conversion and Management, 52, 18611867. doi:https://doi.org/10.1016/j.enconman.2010.11.008

Perini, K., Ottelé, M., Fraaij, A. A., Haas, E. M., \& Rossana, R. (2011). Vertical greening systems and the effect on air flow and temperature on the building envelope. Building and Environment, 46, 2287-2294. doi:https://doi.org/10.1016/j.buildenv.2011.05.009

Perini, K., Ottelé, M., Fraaij, A., Haas, E. M., \& Raiteri, R. (2011). Vertical greening systems and the effect on air flow and temperature on the building envelope. Building and Environment, 46, 2287-2294. doi:doi:10.1016/j.buildenv.2011.05.009

Periódico El País. (24 de Marzo de 2015). El Pais.com.co. Recuperado el 16 de Mayo de 2017, de http://www.elpais.com.co/cali/el-60-de-esta-edificada-sin-licencia-deconstruccion.html

Periódico El Tiempo. (30 de Enero de 2013). EL TIEMPO. Recuperado el 16 de Mayo de 2016, de http://www.eltiempo.com/archivo/documento/CMS-12562830

Pino, A., Bustamante, W., \& Escobar, R. (2012). Thermal and lighting behavior of office buildings in Santiago of Chile. Energy and Buildings, 47, 441-449.

Pisello, A. L. (2017). State of the art on the development of cool coatings for buildings and cities. Solar Energy, 144, 660-680.

Pisello, A. L., Castaldo, V. L., Piselli, C., Fabiani, C., \& Cotana, F. (2017). Thermal performance of coupled cool roof and cool facade: Experimental monitoring and analytical optimization procedure. Energy and Buildings, Article in press.

Planeación Municipal, Alcaldía de Santiago de Cali. (2014). Plan de Ordenamiento Territorial de Cali. Recuperado el 27 de Mayo de 2017, de http://www.cali.gov.co/planeacion/publicaciones/106497/pot_2014_idesc/

R. Priyadarsini, e. a. (2004). Enhancement of natural ventilation in high-rise residential buildings using stack system. Energy and Buildings(36), 61-71.

Rehman, H. U. (2015). Steady state experimental analysis of various solar insulation materials and techniques for buildings in climatic condition of Ras Al Khaimah, UAE. Energy Procedia, 75, 1419 - 1424. doi:10.1016/j.egypro.2015.07.241

Rogers, L. (2013). Reflective-Insulation and Radiant-Barrier Systems. Home Energy. Obtenido de http://homeenergy.org/show/article/id/1933/viewFull/ 
Sanchez de la Flor, F. J., Ortiz Cebolla, R., Molina Félix, J. L., \& Álvarez Dominguez, S. (Noviembre de 2005). Solar radiation calculation methodology for building exterior surfaces. Solar Rnergy, 79, 513-522.

Sánchez Guzmán, L. H. (1993). Evaluación de un techo estanque como sistema de enfriamiento pasivo en un clima cálido subhúmedo (Tesis de Maestría). Colima. Obtenido de http://digeset.ucol.mx/tesis_posgrado/Pdf/Luis\%20Humberto\%20Sanchez\%20Guzma n.pdf

Sanjuan, C., Sánchez, M., Heras, R., \& Blanco, E. (2011). Experimental analysis of natural convection in open joint ventilated façades with 2D PIV. Building Environment, 46, 2314-2325. doi:http://dx.doi.org/10.1016/j.buildenv.2011.05.014

Santamouris, M., \& Asimakopoulos, D. (2001). Passive cooling of buildings,. Londres: James \& James.

Sarber, H. H. (2012). Investigation of thermal performance of reflective insulations for different applications. Building and Environment, 52, 32-44. doi:10.1016/j.buildenv.2011.12.010

Serra, R. (1998). Arquitectura y Climas. Gustavo Gili.

Shih, T. H., Liou, W. W., Shabbir, A., Yang, Z., \& Zhu, J. (1995). A new k- e eddy-viscosity model for high reynolds number turbulent flows - model development and validation. Comput Fluids(24), 227-238.

Sistema Intercomunicado Nacional. (22 de Febrero de 2018). Sistema Intercomunicado Nacional. Recuperado el 27 de 6 de 2017, de http://informesanuales.xm.com.co/2015/SitePages/operacion/2-4Generaci\%C3\%B3n-del-SIN.aspx

SL, P. I. (5 de Marzo de 2018). Plasticbages Industrial SL. Recuperado el 21 de 08 de 2017, de http://www.plasticbages.com/caracteristicaspvc.html

Stazi, F., Veglió, A., \& Di Perna, C. (2011). Experimental evaluation of ventilated walls with an external clay cladding. Renewable Energy, 36, 3373-3385. doi:http://dx.doi.org/10.1016/j.renene.2011.05.016

Stec, W. J., Van Passsen, A. C., \& Maziarz, A. (2005). Modelling the double skin façade with plants. Energy and Buildings, 37, 419-427. 
Sternberg, T., Viles, H., \& Cathersides, A. (2011). Evaluating the role of ivy (Hedera helix) in moderating wall surface microclimates and contributing to the bioprotection of historic buildings. Building and Environment, 46, 293-297. doi:https://doi.org/10.1016/j.buildenv.2010.07.017

Šuklje, T., Medved, S., \& Arkar, C. (2013). An Experimental Study on a Microclimatic Layer of a Bionic Façade Inspired by Vertical Greenery. Journal of Bionic Engineering, 10, 177185.

Susorova, I., Azimi, P., \& Stephens, B. (2014). The effects of climbing vegetation on the local microclimate, thermal performance, and air infiltration of four building facade

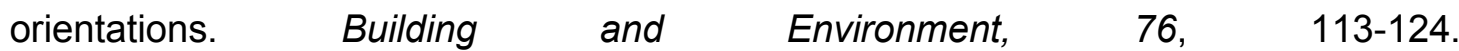
doi:https://doi.org/10.1016/j.buildenv.2014.03.011

Synnefa, A., \& Santamouris, M. (2007). Cool-colored coatings fight the urban heat-island effect. SPIE. doi:10.1117/2.1200706.0777

Synnefa, A., Santamouris, M., \& Akbari, H. (2007). Estimating the effect of using cool coatings on energy loads and thermal comfort in residential buildings in variousclimatic conditions. Energy Build, 39, 1167-1174.

Tectonica-online. (8 de Marzo de 2018). (CABOT NANOGEL GMBH) Recuperado el 07 de Enero de 2018, de http://www.tectonicaonline.com/productos/1143/aislante_translucido_aerogel_translucent_nanogel/

Terradosa, F., \& Morenoba, D. (2014). "Patio" and "Botijo": Energetic strategies' architectural integration in"Patio 2.12" prototype. Energy and Buildings(83), 70-88.

Toparlar, Y., Blocken, B., Vos, P., Van Heijst, G., Janssen, W., Van Hoof, T., . . Timmermans, H. (2015). CFD simulation and validation of urban microclimate: a case study for bergpolder zuid, rotterdam. Building and Environment(83), 79 - 90.

Unidad de Planeación Minero Energética, Ministerio de Minas y energía, República de Colombia. (2006). Caracterización energética de los sectores residencial, comercial y terciario. Bogotá.

United Nations Commission on Human Settlements, ONU. (2004). Indicadores sobre asentamientos humanos.

United Nations Commission on Human Settlements, ONU. (2011). INFORME MUNDIAL SOBRE ASENTAMIENTOS HUMANOS. 
University of Primorska. (2013). Optimization of passive solar design strategies: A review. Renewable and Sustainable Energy Reviews, 177-196.

Valladares-Rendón, L. G., Schmid, G., \& Lo, S.-L. (2017). Review on energy savings by solar control techniques and optimal building orientation for the strategic placement of fac, ade shading systems. Energy and Buildings, 140, 458-479.

Viegas, G. M., Walsh, C., \& Barros, M. V. (2016). Evaluación cuali-cuantitaviva de aislaciones térmicas alternativas para viviendas. El caso de la agricultura familiar. INVI, 31(86), 89 $-117$.

Vrachopoulos, M. G., Koukou, M. K., Stavlas, D. G., Stamatopoulos, V. N., Gonidis, A. F., \& Kravvaritis, E. D. (2011). Testing reflective insulation for improvement of buildings energy efficiency. Central European Journal of Engineering, 83-90. doi:10.2478/s13531-011-0036-3

Walikewitz, N. (2015). The difference between the mean radiant temperature and the air temperature within indoor environments: A case study during summer conditions. Building and Environment, 84, 151 - 161.

Wong, I., \& Baldwing, A. N. (2016). Investigating the potential of applying vertical green walls to high-rise residential buildings for energy-saving in sub-tropical region. Building and Environment, 97, 34-39.

Wong, N., Kwang Tan, A. Y., Yok Tan, P., Chiang, K., \& Chung Wong, N. (2010). Acoustics evaluation of vertical greenery systems for building walls. Building and Environment, 45, 411-420. doi:https://doi.org/10.1016/j.buildenv.2009.06.017

Yañez Pradera, G. (2008). Arquitectura Solar e iluminación natural. Madrid: Munilla-Lería.

Zinzi, M. (2016). Exploring the potentialities of cool facades to improve the thermal response of Mediterranean residential buildings. Solar Energy(135), 386-397. 


\section{ÍNDICE DE FIGURAS}

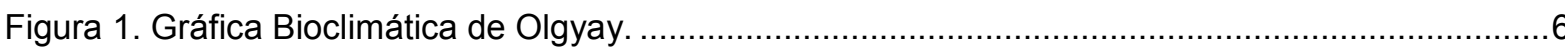

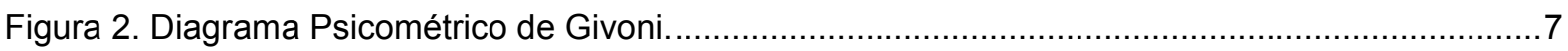

Figura 3. Fotografía vs Termografía de la fachada oeste del conjunto residencial Calicanto en Cali, hora $2 \mathrm{pm}$. .10

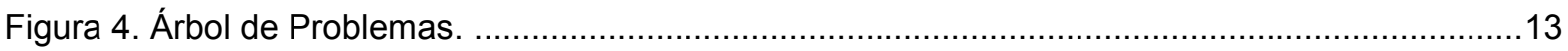

Figura 5. Árbol de Objetivos. ................................................................................................17

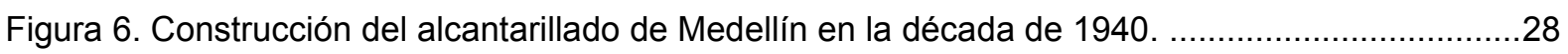

Figura 7. Vista del barrio Quinta Mutis en Bogotá, desarrollado por el Banco Central Hipotecario. ....29

Figura 8. Barrio Pablo VI, Bogotá Colombia 1966. Fuente: VIS en Bogotá: Lecciones de Gestión Estatal,

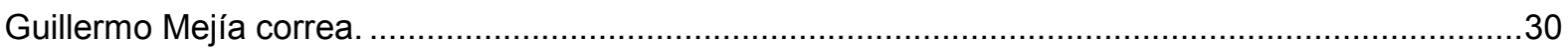

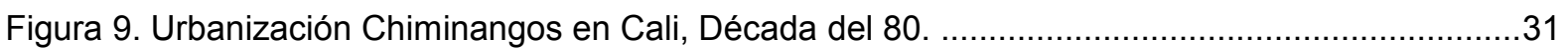

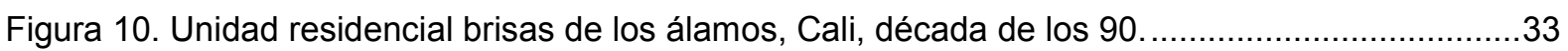

Figura 11. Gráfica comparativa de cantidades y porcentajes de viviendas culminadas VIS o No VIS durante 2013 y 2016.

Figura 12. Plano de Cali con indicación de desarrollos de VIS desde 1940 a la actualidad y proyección al futuro. .37

Figura 13. Gráfica comparativa de área por unidad de vivienda VIS tipo apartamento en $\mathrm{m} 2$. ..........39

Figura 14. Gráfica comparativa de área por unidad de vivienda VIS, tipología de casas en m2. .......39

Figura 15. Planimetrías y Fotografía de casas típicas del Conjunto Residencial Rosedales de Comfandi. Tipología de casas Individuales..

Figura 16. Vista exterior y planta tipo de uno de los apartamentos Sotorela de IC prefabricados.......40

Figura 17. Distribución de porcentaje de tipologías de VIS a nivel nacional.

Figura 18. Distribución de sistemas constructivos usados para VIS desde el segundo trimestre de 2012

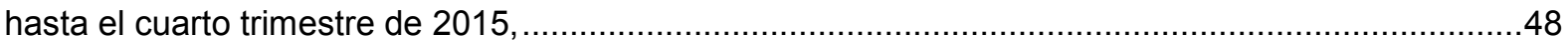

Figura 19. Muro de mampostería confinada con bloques de arcilla. …..........................................50

Figura 20. Conjunto habitacional VIS con mampostería reforzada en bloque de concreto. ...............52

Figura 21. Urbanización desarrollada con el sistema constructivo Vivienda Celular Eternit. ...............55

Figura 22. Vista exterior de una VIS con sistema constructivo Plycem 1000 ...................................56

Figura 23. Detalle constructivo del sistema Royalco. Fuente: http://royaluruguay.com ......................57 
Figura 24. Proceso constructivo de una vivienda utilizando el sistema constructivo 3D panel.

Figura 25. Detalle de las láminas Thermowall (izquierda) y proceso constructivo de las viviendas con sistema constructivo Speedco (centro y derecha).

Figura 26. Sistema constructivo Colditec (Drywall). Proceso constructivo de muros.

Figura 27. Aspecto exterior de una VIS construida con el sistema constructivo Servivienda.

Figura 28. Soluciones de VIS de $36 \mathrm{~m}^{2}$ y $56 \mathrm{~m}^{2}$ desarrolladas con el sistema constructivo Metecno. ..63

Figura 29. Proceso constructivo con el sistema de grandes paneles.

Figura 30.Detalle y vista exterior de la formaleta armada de un apartamento tipo VIS utilizando el sistema constructivo Con-tech.

Figura 31. Proyecto VIS materializado con el sistema constructivo Outinord en Bogotá Colombia. ...69

Figura 32. Conjunto de VIS desarrolladas con el sistema constructivo Corpacasa en la ciudad de Barranquilla.

Figura 33. Temperaturas superficiales del interior de una cubierta perteneciente a una VIS de tipología unifamiliar. .72

Figura 34. Esquema de intervención a cubierta hecho por Gamboa et al. .....................................73

Figura 35. Termografías de la intervención a la cubierta de la VIS unifamiliar. . .73

Figura 36. Disposición constructiva de las mejoras de los módulos de prueba y las estrategias pasivas implementadas por Giraldo \& Herrera (2017) ......................................................................... 74

Figura 37. Experimentación con techos plantados en Cali..............................................................75

Figura 38. Termografías interiores de una VIS con envolvente de bloques de arcilla.) ......................76

Figura 39. Termografías interiores de una VIS con envolvente de concreto reforzado.......................77

Figura 40. Evaluación de PMV y PPD de una VIS con envolvente de ladrillo de arcilla.......................77

Figura 41. Evaluación de PMV y PPD de una VIS con envolvente de concreto reforzado.................78

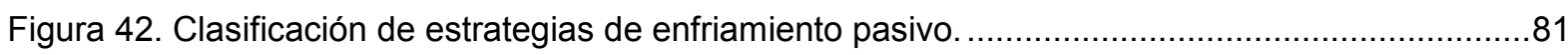

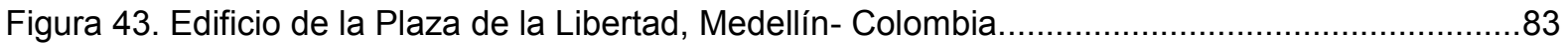

Figura 44. Secciones esquemáticas en 2D y 3D de diseños simples $(a-f)$ y complejos $(g-I)$ de fachadas auto-sombreadas.

Figura 45. Secciones esquemáticas en 2D y 3D de diseños simples $(a-f)$ y complejos $(g-I)$ de fachadas dispositivos de sombreado.

Figura 46. Esquema tridimensional de proporción de ventanas en fachada exterior en relación con la visibilidad y la iluminación natural.

Figura 47. Grafica comparativa de resistencia térmica de algunos materiales de aislamiento térmico utilizados en la construcción, elaborada con muestras de $5 \mathrm{~cm}$ de espesor.

Figura 48. Corte transversal explicativo de los componentes de una barrera radiante y el proceso de transferencia de calor a través de ella..

Figura 49. Radiación Solar Total (Directa + Difusa) acumulada en un año en $\mathrm{Wh} / \mathrm{m}^{2}$ de 8:00 a 18:00 h, en Fachadas y Cubierta.

Figura 50. Gráfica de radiación solar total anual sobre la fachada oeste.

Figura 51. Gráfica de radiación solar (incidente, directa y difusa) en la fachada oeste perteneciente al día crítico en la ciudad de Cali. 
Figura 52. Gráfica comparativa de $T_{r}$ vs Tiempo entre las tipologías más comunes de envolventes VIS durante la tarde del caso crítico. ........................................................................................118

Figura 53. Localización conjunto residencial Calicanto. ..............................................................119

Figura 54. Fachada oeste del conjunto residencial Calicanto. ..................................................120

Figura 55. Distribución arquitectónica del apartamento establecido como línea base. ....................121

Figura 56. Gráfica de $T_{r}$ vs tiempo de la fachada oeste, durante el monitoreo de campo en la habitación modelo.

Figura 57. Gráfica de PMV (índice de sensación térmica) en la alcoba seleccionada como línea base.

Figura 58. Gráfica de PPD (Porcentaje de personas insatisfechas) en la alcoba seleccionada como línea base.

Figura 59. Máscaras de sombra logradas sobre la fachada oeste con elementos horizontales al lado izquierdo y elementos verticales al lado derecho.

Figura 60. Carta Solar correspondiente a la ciudad de Cali indicando el periodo con mayor radiación solar (9:00 a 15:30 horas).

Figura 61. Sección transversal con dimensiones del diseño de lamas horizontales para generar el autosombreado.

Figura 62. Sombreado producido el diseño de las lamas horizontales en la fachada oeste de 12:30 a 17:30, con su respectivo coeficiente de sombra.

Figura 63. Gráfica comparativa de $\operatorname{Tr}$ vs Tiempo entre un muro típico de VIS y con tratamiento de sombreado.

Figura 64. Gráfica comparativa de $T_{r}$ vs Tiempo entre un muro de concreto macizo sin y con tratamiento

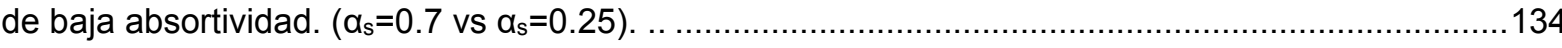

Figura 65. Polvillo de ladrillo refractario.

Figura 66. Gráfica comparativa de $T_{r}$ vs Tiempo entre un muro de concreto macizo con y sin revoque refractario.

Figura 67. Gráfica comparativa de $T_{r}$ vs Tiempo del muro de concreto macizo con y sin la implementación del muro vegetal.

Figura 68. Planta de la solución constructiva de aislamiento reflectivo + baja absortividad. 142

Figura 69. Gráfica comparativa de $T_{r}$ vs Tiempo del muro de concreto macizo con y sin implementación del aislamiento reflectivo.

Figura 70. Gráfica comparativa de reducción de $\mathrm{T}_{\mathrm{r}}$ en $\%$ y máxima reducción de $\mathrm{T}_{\mathrm{r}}$ en ${ }^{\circ} \mathrm{C}$ entre un muro típico VIS y las soluciones constructivas.

Figura 71. Planimetría de un módulo experimental: planta y alzados con especificaciones y dimensiones en metros.

Figura 72. Análisis para determinar la inclinación de la plataforma de los módulos del aparato experimental,

Figura 73. Disposición final del aparato experimental que consta de dos módulos idénticos de poliestireno expandido y concreto sobre una base inclinada $38.35^{\circ}$ hacia el norte. ......................152

Figura 74. Desencofrado y resultado final de las placas de concreto. 
Figura 75. Verificación de condiciones similares de $T_{r}$ en el sitio de acopio. 158

Figura 76. Posicionamiento de los dataloggers

Figura 77. Posicionamiento y alineación del aparato experimental en la plataforma de medición. .. 160

Figura 78. Captura de termografías. 161

Figura 79. Vista de pantalla del procesamiento de las termografías para hallar la $T_{r}$ 162

Figura 80. Lugar y condiciones de acopio del aparato experimental. 163

Figura 81. Gráfica comparativa de $T_{\text {air, }}, H R$ y $T_{r}$ vs tiempo, entre los dos módulos del aparato experimental. Datos obtenidos durante la calibración.

Figura 82. Configuración del aparato experimental para experimentación con la estrategia de autosombreado.

Figura 83. Collage de termografías y fotografías correspondientes al 14 de enero de 2017 a las 13:00.

Figura 84. Collage de termografías y fotografías correspondientes al 14 de enero de 2017 a las 15:30.

Figura 85. Collage de termografías y fotografías correspondientes al 14 de enero de 2017 a las 18:00.

Figura 86. Gráfica comparativa de $T_{r}$ vs Tiempo entre el módulo experimental modificado con la estrategia de autosombreado y el módulo testigo.

Figura 87. Gráfica comparativa de $T_{\text {air }}$ y HR vs Tiempo entre el módulo experimental modificado con la estrategia de autosombreado y el módulo testigo. 172

Figura 88. Configuración del aparato experimental con la estrategia de baja absortividad. 173

Figura 89. Collage de termografías y fotografías correspondientes al 17 de enero de 2017 a las 13:00.

Figura 90. Collage de termografías y fotografías correspondientes al 17 de enero de 2017 a las 15:30.

Figura 91. Collage de termografías y fotografías correspondientes al 17 de enero de 2017 a las 18:00.

Figura 92. Gráfica comparativa de $\mathrm{T}_{\mathrm{r}}$ vs Tiempo entre el MI con la estrategia de baja absortividad y el MT.

Figura 93. Gráfica comparativa de $\mathrm{T}_{\text {air }}$ y HR vs Tiempo entre el MI con la estrategia de baja absortividad y el MT.

Figura 94. Configuración del aparato experimental para experimentación con la estrategia de revoque refractario.

Figura 95. Collage de termografías y fotografías correspondientes al 25 de enero de 2017 a las 12:30.

Figura 96. Collage de termografías y fotografías correspondientes al 25 de enero de 2017 a las 15:30.

Figura 97. Collage de termografías y fotografías correspondientes al 25 de enero de 2017 a las 18:00. 
Figura 98. Gráfica comparativa de $T_{r}$ vs Tiempo entre el MI con la estrategia de revoque refractario y el MT.

Figura 99. Gráfica comparativa de $\mathrm{T}_{\text {air }}$ y HR vs Tiempo entre el MI con la estrategia de revoque de polvo de ladrillo refractario y el MT. 184

Figura 100. Configuración de la lona antes de recibir el sustrato y las especies vegetales (izquierda) y la estructura de perfiles de PVC (derecha). 185

Figura 101. Fotografía de la configuración del muro vegetal al cuarto mes de ser plantado. 186

Figura 102. Configuración del aparato experimental para experimentación con la estrategia de muro vegetal.

Figura 103. Collage de termografías y fotografías correspondientes al 15 de febrero de 2017 a las 12:30.

Figura 104. Collage de termografías y fotografías correspondientes al 15 de febrero de 2017 a las 15:30.

Figura 105. Collage de termografías y fotografías correspondientes al 15 de febrero de 2017 a las 18:00. 190

Figura 106. Gráfica comparativa de $\mathrm{T}_{\mathrm{r}}$ vs Tiempo entre el MI con la estrategia de muro vegetal y el MT. 191

Figura 107. Gráfica comparativa de $\mathrm{T}_{\text {air }}$ y HR vs Tiempo entre el MI con la estrategia de Muro Vegetal y el MT.

Figura 108. Fotografías del despiece de la solución constructiva, la imagen izquierda muestra el interior, en el cual se distingue la lámina corrugada de foil de aluminio con la cara brillante, mientras que la imagen derecha enseña la configuración totalmente acoplada. 193

Figura 109. Configuración del aparato experimental para experimentación con la estrategia de aislamiento reflectivo + baja absortividad. 194

Figura 110. Collage de termografías y fotografías correspondientes al 25 de febrero de 2017 a las 13:00. 195

Figura 111. Collage de termografías y fotografías correspondientes al 25 de febrero de 2017 a las 15:30. 196

Figura 112. Collage de termografías y fotografías correspondientes al 25 de febrero de 2017 a las 18:00. 197

Figura 113. Gráfica comparativa de $\mathrm{T}_{\mathrm{r}}$ vs Tiempo entre el $\mathrm{MI}$ con la estrategia de muro vegetal y el MT. 198

Figura 114. Gráfica comparativa de $\mathrm{T}_{\text {air }}$ y HR vs Tiempo entre el MI con la estrategia de AR y el MT. .. 199

Figura 115. Gráfica de desempeño térmico según el tipo de solución constructiva. Porcentaje de reducción de $T_{\text {air }} \mathrm{y} \mathrm{T}_{\mathrm{r}} \mathrm{y}$ aumento de la $\mathrm{HR}$.

Figura 116. Termografías de experimentación de desempeño entre las soluciones constructivas de AR y MV. 203

Figura 117. Gráfica comparativa de $T_{r}$ vs Tiempo entre las soluciones constructivas de AR y MV. ..203 
Figura 118. Explicación gráfica del método de la caja caliente. Fuente: Norma ISO 8990:1994 (International Organization for Standardization, 1997). ........................................................206

Figura 119. Lado izquierdo: unidad enfriadora (Heladera sigma modelo S3100), lado derecho cámara caliente.

Figura 120. Configuración interna de la cámara caliente, izquierda sin panel deflector, derecha con panel deflector. 210

Figura 121. Fotografías de la configuración de la caja caliente, previo y durante el proceso de calibración.

Figura 122. Gráfica de $U, T_{r}, T_{i}$ y $T_{0}$ vs tiempo para calibración con poliestireno expandido de valor $U$ conocido de $0.72 \mathrm{~W} / \mathrm{m}^{2 \circ} \mathrm{C}$.

Figura 123. Gráfica de $U, T_{r}, T_{i}$ y $T_{o}$ vs tiempo para calibración con vidrio incoloro común de valor $U$ conocido de $5.8 \mathrm{~W} / \mathrm{m}^{2 \circ} \mathrm{C}$

Figura 124. Configuración de la caja caliente calibrada con el panel de AR (Vista interna de la cámara caliente a la izquierda y vista exterior del arreglo cerrado a la derecha). 214

Figura 125. Gráfica de $U, T_{r}, T_{i}$ y $T_{0}$ vs tiempo, de la prueba con caja caliente calibrada realizada con la solución constructiva de Aislamiento Reflectivo (AR). 215

Figura 126. Gráfica comparativa de espesor por tipo de solución constructiva a igual transmitancia

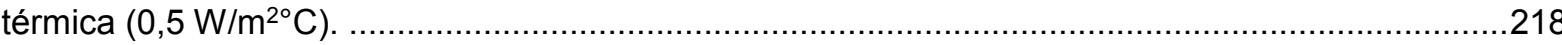

Figura 127. Gráfica comparativa de conductividad térmica por tipo de solución constructiva. .........219 Figura 128. Vista de pantalla del modelado de la línea. . a partir de SketchUp y Openstudio...........222 Figura 129. Gráfica comparativa de sensación térmica (PMV), de la línea base, entre los datos obtenidos en campo y mediante simulación, para fines de calibración. 226

Figura 130. Gráfica comparativa de porcentaje de personas insatisfechas (PPD), de la línea base, entre los datos obtenidos en campo y mediante simulación, para fines de calibración. 226 Figura 131. Gráfica comparativa de $T_{\text {air, }}$ entre la línea base, la implementación del AR y el ambiente exterior 229

Figura 132. Gráfica comparativa de $T_{m r}$, entre la línea base y la implementación del $A R$. 230

Figura 133. Gráfica comparativa de la $T_{r}$ del muro Oeste con los datos obtenidos en la simulación, entre

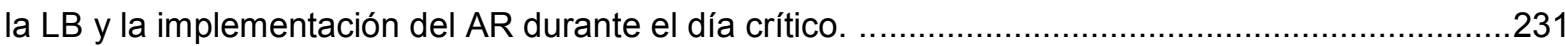

Figura 134. Gráfica comparativa de HR, entre la línea base, la implementación del AR. ................232

Figura 135. Gráfica comparativa del índice PMV, entre la línea base, la implementación del AR. ...233

Figura 136. Gráfica comparativa del PPD, entre la línea base, la implementación del AR. 234

Figura 137. Gráfica comparativa de costo beneficio entre soluciones constructivas pasivas y el Aire

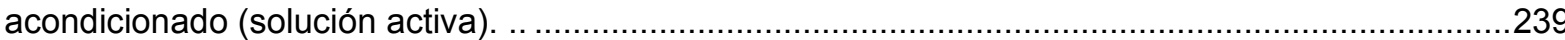

Figura 138. Escala de Valoración de la sensación Térmica de Fanger o PMV ...........................257

Figura 139. Movimientos principales de la Tierra: Traslación y Rotación.......................................260

Figura 140. Descripción gráfica del arco descrito por el movimiento aparente del sol en el hemisferio norte en la estación de otoño. 261

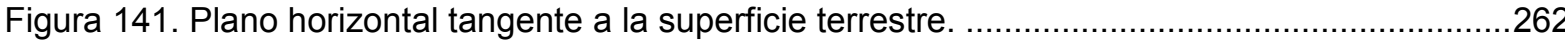

Figura 142. Coordenadas solares acimut $\alpha$ y altura solar $h$ 263 
Figura 143. Carta solar estereográfica para Cali. 264

Figura 144. Procedimiento para calcular la sombra de elementos de protección solar.

Figura 145. Gráfico de las diferentes distancias utilizadas en la ecuación de factor de forma para superficies verticales de Dunkle. 268

Figura 146. Gráfico de las diferentes distancias utilizadas en la ecuación de factor de forma para superficies horizontales de Dunkle. 269

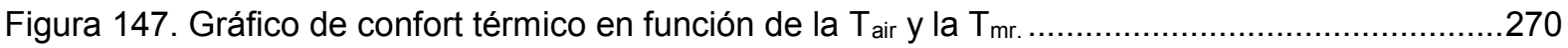

Figura 148. Ejemplo de cálculo de la transmitancia térmica. 274

Figura 149. Gráfica comparativa de la media mensual de $T_{\text {air }}$ entre Cali y La Plata durante los años 2015 y 2016. 278

Figura 150. Grafica comparativa de las $T_{\text {air }}$ medias horarias mensuales durante todo el año entre Cali y La Plata. 278

Figura 151. Grafica comparativa de $T_{\text {air }}$ de un día típico durante los meses de diciembre, enero y febrero entre Cali y La Plata. 279 Figura 152. Gráfica comparativa de la media mensual de radiación solar entre Cali y La Plata durante los años 2015 y 2016. 280

Figura 153. Grafica comparativa de radiación solar media por hora y por mes durante todo el año entre Cali y La Plata. 281

Figura 154. Grafica comparativa de Radiación solar de un día típico de Cali y un día típico de La Plata durante los meses de enero y febrero y marzo. 282

Figura 155. Gráfica comparativa de la media mensual de HR entre Cali y La Plata durante los años 2015 y 2016. 282

Figura 156. Grafica comparativa de HR media por hora y por mes durante todo el año entre Cali y La Plata.

Figura 157. Grafica comparativa de HR de un día típico de Cali y un día típico de La Plata durante los

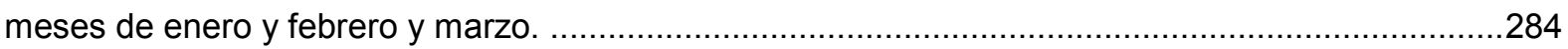

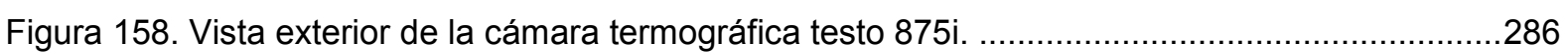

Figura 159. Prueba piloto de calibración de termohigrómetros, gráfica de Tair y HR vs tiempo. ....288

Figura 160. Datalogger Extech, modelo RHT30 y cajilla de protección contra radiación. 289

Figura 161. Instrumental de medición para obtener la transmitancia térmica: Izquierda: Registrador y procesador de datos Testo 435-2; Centro: Sonda de $T_{\text {air }}$ Testo 06021793 y Derecha: Sensor de $T_{\text {air }}$ y $T_{r}$ Testo 06141635 .

Figura 162. Termoanemómetro de hilo caliente CEM DT-8880. 290

Figura 163. Termómetro infrarrojo marca Extech modelo IR42500 291 


\section{ÍNDICE DE TABLAS}

Tabla 1. Resumen esquemático de la estructura metodológica.

Tabla 2. Resumen esquemático de las relaciones entre Objetivos - Metodología - Resultados y

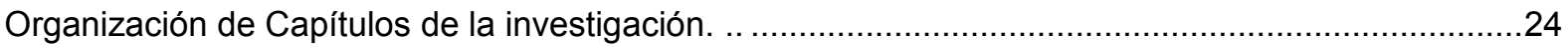

Tabla 3. Compilación de Normativas para la VIS en Colombia. ....................................................42

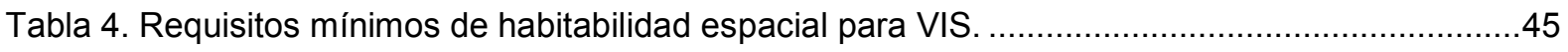

Tabla 5. Características generales de los sistemas constructivos de mampostería. ...........................49

Tabla 6.Características generales de los sistemas constructivos livianos o en seco............................54

Tabla 7. Características generales de los sistemas constructivos de Concreto..................................65

Tabla 8. Características generales de los sistemas constructivos combinados. ..................................70

Tabla 9. Cuadro comparativo de VIS de Buenaventura sin intervenir vs Modelo mejorado. ...............75

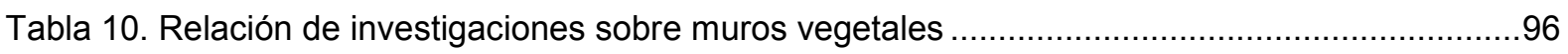

Tabla 11. Tabla de valores $\mathrm{R}$ para barreras radiantes con diferentes configuraciones de emisividad, dirección del flujo de calor, posición y ancho de la cámara de aire. 105

Tabla 12. Síntesis y comparación del desempeño térmico máximo logrado por las estrategias de enfriamiento pasivo mediante los indicadores de reducción del flujo de calor, reducción de $T_{\text {air, }}$ ahorro de energía anual en enfriamiento y reducción de $T_{r}$ exterior de la envolvente. 108 Tabla 13. Cálculo del valor U para un muro de concreto macizo típico de los sistemas Outinord o Contech de VIS de Cali. 114

Tabla 14. Cálculo del valor U para un muro de concreto macizo típico de los sistemas de mampostería estructural de VIS de Cali. 115

Tabla 15. Valores asignados para cálculo de $\mathrm{T}_{\text {sol-air. }}$ 116

Tabla 16. Instrumental utilizado en el monitoreo al ambiente VIS.

Tabla 17. Resultados medios horarios de las mediciones de campo en la alcoba elegida como línea base. 123

Tabla 18. Cálculo del valor U para la solución constructiva de autosombreado. 133

Tabla 19. Cálculo del valor $U$ de la solución constructiva que incorpora revoque refractario. 137

Tabla 20. Cálculo del valor U para la solución constructiva que incorpora muro vegetal.

Tabla 21. Cálculo del valor U para la solución constructiva que incorpora aislamiento reflectivo. ...143 
Tabla 22. Valores de luminancia e iluminancia registrados en la cara exterior de cada muestra y su respectivo cálculo de reflectancia para el espectro visible.

Tabla 23. Valores de peso y volumen y densidad registrados y calculados para cada placa de concreto construida.

Tabla 24. Valores de transmitancia térmica registrados mediante el método de la caja caliente para las placas de concreto No. 1, 2 y 4 . 156

Tabla 25. Instrumental utilizado en la experimentación de porcentaje de reducción de la $T_{r}$ y control de la Tair y la HR. 157

Tabla 26. Tabla comparativa de resultados teóricos y empíricos de desempeño térmico. 200

Tabla 27. Instrumental utilizado en la determinación de la transmitancia térmica. 208

Tabla 28. Materiales utilizados en la simulación computacional con sus respectivos valores asignados a las propiedades físicas.

Tabla 29. Composición de materiales en los elementos constructivos modelados en la simulación. ..

Tabla 30. Tabla comparativa de valores medios medidos (M) y simulados (S) obtenidos con el modelo calibrado.

Tabla 31. Valores de las propiedades físicas correspondientes al panel AR ingresados en el programa para la simulación.

Tabla 32. Tabla comparativa de los datos de desempeño térmico obtenidos a través de la simulación computacional entre la LB y la implementación de la solución constructiva de AR. 228

Tabla 33. Tabla comparativa de costo beneficio entre soluciones constructivas pasivas y el Aire acondicionado (solución activa). 238

Tabla 34. Valor de absortividad de algunos materiales utilizados en la construcción. 254

Tabla 35. Valores Met según el tipo de actividad física. 255

Tabla 36. Valor de conductividad térmica de algunos materiales utilizados comúnmente en la construcción. 256

Tabla 37. Formulación matemática para hallar el PMV. 257

Tabla 38. Explicación matemática de los términos utilizados en la ecuación de PMV. 258

Tabla 39. Escala de Sensación Térmica, PMV y PPD. 258

Tabla 40. Formulación matemática del índice PPD. .258

Tabla 41. Emisividad de algunos materiales 259

Tabla 42. Valores de Clo para diferentes tipos de prendas. 276

Tabla 43. Integración de los porcentajes de diferencia de la Tair, radiación solar y HR en los distintos

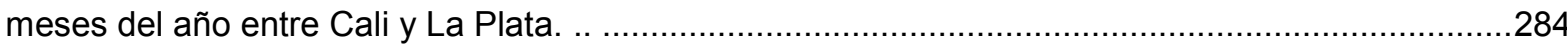

Tabla 44. APU y costo total por habitación para la solución constructiva de Autosombreado. .........293

Tabla 45. APU y costo total por habitación para la solución constructiva de Baja absortividad. ......293

Tabla 46. APU y costo total por habitación para la solución constructiva de Revoque refractario. .. 294

Tabla 47. APU y costo total por habitación para la solución constructiva de Muro vegetal. 295

Tabla 48. APU y costo total por habitación para la solución constructiva de Aislamiento reflectivo + Baja absortividad. 
Tabla 49. APU y costo total por habitación para la solución constructiva de EIFS o Poliestireno expandido

Tabla 50. APU y costo total por habitación del suministro e instalación de un equipo de aire acondicionado 12000Btu. 